\title{
Abyssal Archives: Unravelling the Late Neogene evolution of the Pacific Deep Western Boundary Current from the New Zealand sector of the Southern Ocean
}

by

Amy Alexandra Plant

\author{
A THESIS \\ Submitted in partial fulfilment \\ of the requirements \\ for the degree of \\ Masters in Science \\ in \\ Geochemistry
}

School of Geography, Environment and Earth Sciences

Victoria University of Wellington, New Zealand

February

2015 



\section{Abstract}

Abyssal ocean currents develop unique physical and chemical properties, based on their geographic location of formation, circulation pathways, and the biogeochemical cycling of elements and their isotopes between different water masses. These distinct physiochemical properties enable water fingerprinting, the ability to identify and trace water masses as they circulate the globe, in their relentless attempt to redistribute the Earths heat, salt and biogeochemical agents. Over geological time, the chemical fingerprint of water masses has evolved in response to changing climatic regimes and tectonic events. Hydrogenous FMNs incorporate a record of these chemical fingerprints from the abyssal water masses in which they grow, as they accrete each successive growth layer from the elements and compounds available within ambient deep waters. Due to the exceptionally slow growth rate of these abyssal archives, FMNs provide insights on the chemical history of the deep ocean over millions of years. Such changes in FMN geochemistry have been previously linked to the development and demise of polar ice sheets and the opening and closing of ocean gateways.

Here an attempt is made to recover the paleoenvironments recorded in the accretion of a large hydrogenous FMN recovered from the New Zealand Oceanic Gateway, where the conjoined flow of the Antarctic Circumpolar Current and Pacific Deep Western Boundary Current enter the Southwest Pacific from the Southern Ocean. This region of the deep ocean is of great interest, as it is the least explored ocean basin in terms of its elemental and radiogenic isotope composition and paleoceanographic evolution. The chemical and physical characteristics of these currents respond to environmental changes in their source area, Antarctica, as well as to global climatic and oceanographic events due to the effective mixing of all of the world's major currents within the ACC. From a revision and assessment of beryllium cosmochronometry, analysis of macro- and micro- growth structures, authigenic and detrital nodule components and growth rates, analysis of major, minor and trace element chemistry via ICP-MS and Pb isotopic analysis via MC-ICPMS, in addition to the application of multiple paleosource, paleocirculation proxies and novel application of paleoproductivity and redox, five major accretion periods and corresponding paleoenvironments can be ascertained for the late Neogene evolution of the PDWBC:

Phase 1: The late mid-Miocene PDWBC - The first period of nodule growth is a faster accretionary period, distinguished by its calcareous shell fragment at the core, surrounded by dark red-brown Fe-Mn precipitates, and white-grey aluminosilicates and characterised by mottled microstructures due to high detrital incorporation. The physical and chemical archives of U1365B-M indicate that the PDWBC, during this phase of globally depressed atmospheric and 
oceanic temperatures, was characterised by the corrosive, vigorous, well-ventilated currents characterised by a shallow CCD. Paleocirculation proxies suggest the PDWBC transmits a strong NADW signal throughout this interval or, in the case of trends exhibited by $\mathrm{Pb}$ isotopic compositions, an increase in ice-sheet activity. Phase 2: The late Miocene PDWBC - The paleoceanographic conditions of the PDWBC established during the late mid-Miocene are strengthened over this second phase of accretion, distinguished by the lighter zone textures, in association with highest detrital incorporation percentages. The excursion toward radiogenic $\mathrm{Pb}$ values has been associated with further restriction of the Indonesian seaway to bottom and deep water circulation between the Pacific and Indian Oceans in addition to a phase of shoaling of the Panama Isthmus, leading to the increased divergence of warm tropic waters into the North Atlantic and strengthening of the 'NADW' fingerprint being exported to the Southern Ocean and incorporated into the PDWBC through effective mixing within the greatly sped-up ACC at this time. Additionally, the shift in $\mathrm{Pb}$ isotopic compositions in $\mathrm{Pb}-\mathrm{Pb}$ space, indicate the PDWBC receives an increased aeolian flux in association with the colder, drier climate and shallow glacial ocean. Phase 3: The terminal late Miocene PDWBC - This phase of FMN growth is a slowing accretionary period, displaying reductions in detrital components and as such, microstructures grade from mottled to cuspate, as $\mathrm{Mn}$ and mangophile elements increase in concentration and the chemical evolution of PDWBC occurs in three main stages: 1) From [10 to $8.4 \mathrm{Ma}$ ] the PDWBC is in a transitional state, bottom water temperatures are reported to be higher and ocean oxygen (redox proxies) is significantly reduced as surface water productivity increases (productivity proxies). The large excursion to more radiogenic $\mathrm{Pb}$ is systematically and gradually reduced to those characteristic of the PDWBC before the excursion occurred, potentially in response to: (a) closure of the Indonesian gateway and the resulting re-organisation and strengthening of Pacific circulation, strongly indicated by paleocirculation proxies which record an increasing 'equatorial Pacific' like signal from $10 \mathrm{Ma}$ onward; (b) reduced spin up of the ACC during this period of relatively warmer conditions and thus a reduced NADW signal, indicated by the lack of regional hiatuses and declining detrital incorporation; (c) reduction of Antarctic ice-sheet activity after reaching a critical threshold at $10 \mathrm{Ma}$; (2) From [8 to $7 \mathrm{Ma}$ ] the CCD deepens, indicated by an increase in the $\mathrm{Mn} / \mathrm{Fe}$ value as Fe delivery to the deep ocean is reduced due to decreased carbonate dissolution, and; (3) [7 - $6 \mathrm{Ma}$ ] when both detrital proportions and authigenic element concentrations increase potentially in response to a fresh influx of young AABW into the PDWBC as sheets are proposed to have increased once more, maintaining stable Ocean oxygen levels. Phase 4: The Miocene-Pliocene PDWBC - This fourth phase of growth is a slower accretionary period, marking the transition from previously higher accretion rates to those that are greatly reduced and the previously mottled and cuspate microstructures of the previous zones become continuously laminated and structured from this point forward. This phase of growth signifies a 
change in PDWBC chemistry, associated with the onset of modern thermohaline circulation, recorded in U1365B-M by transition from Atlantic to Pacific like $\mathrm{Zr}-\mathrm{Hf}$ values, declining ocean oxygen as bottom waters become progressively frigid, and a biological boom in surface water productivity in response to: expansion of the west Antarctic ice sheet cooler, drier climates and enhanced AABW production. Phase 5: The Pliocene-Pleistocene PDWBC - The final phase of growth is the slowest accretionary period over which with microstructures become progressively more laminated on a finer micro-millimetre scale, indicative of strong PDWBC currents facilitating the accretion of a more compact and pure ferromanganese zone, displaying high concentrations of $\mathrm{Mn}$ (and associated elements, including group 3- $\mathrm{Cu} \& \mathrm{Zn}$ ) and reductions in $\mathrm{Fe}$ (and associated elements). During the warm Pliocene [4.7 Ma to $3 \mathrm{Ma}$ ], a slight return of cuspate microstructures, reduction of detrital grains, and increase in the redox proxies over this interval, indicate a slower, warmer an increasingly ventilated Pliocene PDWBC. Significant reversals in long-term chemical trends occur at c. $4 \mathrm{Ma}$, most noticeable in the group 3 and HREE/LREE profiles, potentially recording the chemical response of the PDWBC to final closure of the Central American Seaway, and(or) the coeval shift and weakening of Indonesian Throughflow from a more southerly position to its more northern position of present, accompanied by a weakening of this flow. The transition from a warm Pliocene to a cold Pleistocene PDWBC is marked by cyclical spurts of increased Fe-Mn scavenging of tracer elements to greater levels of enrichment, which generally rise to their highest concentrations at 3 $\mathrm{Ma}$ (especially groups 4-6) and $1 \mathrm{Ma}$ (especially groups 1-3), the latter of which is associated with the final shift in $\mathrm{Mn} / \mathrm{Fe}$ values to double that of the terminal Miocene, indicating a further deepening of the CCD and thus decrease in PDWBC corrosivity. Productivity proxies are not in agreement over this period except for the decline in values to c. 1.5 Ma. Paleoredox proxies display a continued decrease in ocean oxygen as the oceans continued to cool and Paleocirculation proxies show a decrease from $3 \mathrm{Ma}$ onwards to less radiogenic $\mathrm{Pb}$ values consistent with a reduced export of NADW during the Pleistocene as the AMOC is reduced to its shallow glacial mode of circulation

In addition to reconstructing the paleoceanography in the Southwest Pacific, this thesis aims to improve our current knowledge about general sources and input mechanisms of elements to this region of the ocean and to broaden the range of possible applications of using the physiochemical archives of ferromanganese nodules in ocean and climate research in addition to providing a new technique. 


\section{Acknowledgements}

Firstly, I would like to thank my supervisors Monica Handler and Lionel Carter, for not only giving me the opportunity to study such a fascinating topic, but also, and perhaps most importantly, for providing unwavering support and guidance. Secondly, without the help, support and continued encouragement of Shona DeSain and more recently Kate King, this thesis would not have been possible. Words cannot express my many thanks for their continued support and commitment. Thirdly, I would like to thank Ian Graham and Bob Ditchburn for their help and guidance, especially regarding dating of the nodule, and also for playing a significant role in laying the ground work for such a fascinating study. Additionally, thanks go out to Professor Friedhelm von Blanckenburg who never failed to respond to any of my numerous questions regarding his and my research. Lastly, I would like to thank my friends and family, who I love and adore and couldn't have done any of this without. My mum, who has always been there for me through thick and thin, encouraging me to keep on striving forward 'keep my chin up' and telling me that I can do anything I set my mind to, I love you, forever and always. To my closest, Katie Allen, Tamsin Coutts and Georgia Grant, for always being there, for the numerous cups of tea, the late nights, the talks on the front porch, everything. And of course, a huge thanks to my rock, my partner, the love of my life. I thank you for keeping me sane and smiling, always looking after me, making me laugh, keeping me supplied with food, love and copious amounts of coffee, you are my world. And on a final note a big thanks to the other men in my life, my flatties, for putting up with me and not complaining once. 


\section{Contents}

Abstract iv

Acknowledgements vii

List of Tables $\quad x$

List of Figures $\quad$ xi

1 Introduction: Thesis aim, objectives and structure

1.1 Motivation 1

1.2 Aim \& Objectives 4

1.3 Thesis outline 6

2 Study Area: Oceanographic Setting \& the Campbell Nodule Field

2.1 The Southern Ocean $\quad 7$

2.2 The New Zealand Oceanic Gateway $\mathbf{1 2}$

$\begin{array}{ll}2.3 & \text { The Campbell Nodule Field } \\ \end{array}$

3 Ferromanganese Nodules: Abyssal archives of past ocean chemistry

3.1 Abyssal Archives 20

3.2 Formation \& Classification $\quad 24$

$\begin{array}{ll}\text { 3.3 Physical Archives } & \mathbf{2 7}\end{array}$

3.4 Chemical Archives

4 Methods: Retrieving the seawater record

4.1 Samples \& Sampling $\quad \mathbf{4 2}$

4.2 Isolating the Seawater Record 45

4.3 Chronologies \& Growth Rates $\quad 47$

4.4 Multi-Element Chemistry $\mathbf{5 0}$

4.5 Lead Isotope Chemistry $\mathbf{5 6}$

5 Results: Physiochemical Archives of U1365B-M

5.1 Chronologies \& Growth Rates $\quad \mathbf{6 3}$

$\begin{array}{ll}\text { 5.2 Macroscopic Physical Archives } & \mathbf{7 0}\end{array}$

5.3 Microscopic Physical Archives $\quad 75$

$\begin{array}{ll}\text { 5.4 Chemical Archive Overview } & 79\end{array}$

5.5 Major Element Chemistry $\quad 85$

$\begin{array}{lll}5.6 & \text { Minor \& Trace Element Chemistry } & 89\end{array}$ 
6 Discussion: Unravelling 13 million years of deep ocean chemistry

$\begin{array}{lll}\text { 6.1 Introduction } & 96\end{array}$

6.2 Isolating the Seawater Record 98

6.3 Revising \& Utilising the Chronological Framework 101

$\begin{array}{ll}\text { 6.4 Unravelling the Physical Archives } & 109\end{array}$

$\begin{array}{ll}\text { 6.5 Unravelling the Chemical Archives } & 116\end{array}$

6.6 Unravelling the late Neogene evolution of the PDWBC $\mathbf{1 6 0}$

7 Conclusions: Key findings \& future challenges

$\begin{array}{llr}7.1 & \text { Key Findings } & 171\end{array}$

$\begin{array}{lll}7.2 & \text { Future Challenges } & 181\end{array}$

$\begin{array}{lr}\text { References } & 183\end{array}$

$\begin{array}{ll}\text { Appendices } & \text { CD-ROM }\end{array}$

A Late Neogene Evolution of the Deep Ocean

B Technique Development

C Beryllium \& Cobalt Chronologies \& Growth Rates

D Lead Isotope Chemistry

E Multi-Element Chemistry

F The Physical \& Chemical Archives of FMN U1365B-M 


\section{List of Tables}

Ch.1 Introduction: Thesis aim, objectives and structure

1.1 Key climatic and oceanographic events in the late Neogene evolution of the deep ocean

1.2 Thesis Outline

Ch.3 Ferromanganese Nodules: Abyssal archives of past ocean chemistry

3.1 Cobalt chronometers of Manheim (1986), Halbach, et al. (1983) and Frank, et al (1998)

3.2 Speciation, residence times, average concentration and vertical distribution of studied elements in seawater

3.3 Proxies of past ocean conditions

Ch.4 Methods: Retrieving the seawater record

4.1 Location and depth of ferromanganese nodules collected from the Campbell Nodule Field for further investigation

4.2 Multi-element data for USGS Nod-P-1

4.3 ICP-MS parameters for multi-element analyses of FMN samples

4.4 MC-ICP-MS parameters for analysis of $\mathrm{Pb}$ isotope compositions from FMN samples

Ch.5 Results: Physiochemical Archives of U1365B-M

5.1 Key differences between original and revised chronologies.

5.2 Growth model segments and time zones

C.1 Beryllium growth rates: total, authigenic and detrital. (Appendix C)

CD-

C.2 Cobalt chronometry (Appendix C)

ROM

Chemical Archives of U1365B-M: Major, minor, trace element concentrations and

CDROM

F.1 Pb isotopic compositions (Appendix F)

$\mathrm{CD}-$ ROM

F.2 Long-term trends in element concentration and $\mathrm{Pb}$ composition (Appendix $\mathrm{F}$ )

$\begin{array}{llr}\text { F.3 Inter-element associations from cluster correlation analyses (Appendix F) } & \text { CD- } \\ \text { ROM }\end{array}$

Ch.6 Discussion: Unravelling 13 million years of deep ocean chemistry

6.1 Assumptions of the growth model for beryllium dating 103

$\begin{array}{lll}6.2 & \text { Assumptions of cobalt chronometry } & 106\end{array}$

6.3 Global time markers recorded in FMNs of the global ocean \& U1365B-M 110 


\section{List of Figures}

\section{Ch.1 Introduction: Thesis aim, objectives and structure}

1.1 The Physiochemical Archives of U1365B-M

Ch.2 Study Area: Oceanographic Setting \& the Campbell Nodule Field

$2.1 \quad$ Schematic of the structure \& flow of the Southern Ocean 8

2.2 A schematic of circumpolar fronts \& water masses of the Southern Ocean 10

Oceanic gateway events of the Late Neogene and the Southwest Pacific gateway of the Pacific DWBC

2.4 Ocean circulation and seafloor sediments of the New Zealand Oceanic Gateway

2.5 Structure of water masses from the Antarctic continent to the Campbell Plateau

2.6 Seafloor substrates and nodule facies of the Campbell Plateau

Ch.3 Ferromanganese Nodules: Abyssal archives of past ocean chemistry

3.1 Global distribution of FMN fields and ocean circulation 24

3.2 Mechanisms of hydrogenous ferromanganese nodule formation 26

3.3 Hydrogenous and diagenetic modes of nodule formation 27

3.4 Morphological parameters for characterising FMNs 29

$\begin{array}{lll}3.5 & \text { Macroscopic nodule architecture } & 30\end{array}$

3.6 Microstructures and their paleoceanographic significance 31

3.7 Source, transport and sink of elements to the deep ocean 33

$\begin{array}{lll}3.8 & \text { Chemical archives and their paleoceanographic significance } & 38\end{array}$

Ch.4 Methods: Retrieving the seawater record

4.1 Ferromanganese nodules collected from the north-eastern sector of the CNF 42

4.2 New sampling strategy for FMN U1365B-M 44

4.3 New analytical technique for isolating the seawater component of FMNs 46

4.4 Original and repeat 10Be/9Be dating of U1365B-M 48

4.5 Multi-element analyses performed using ICP-MS 51

4.6 Accuracy and precision of multi-element analytical procedure 55

$\begin{array}{lll}4.7 & \text { Lead column chemistry } & 58\end{array}$

4.8 MC-ICP-MS accuracy and precision of authigenic $\mathrm{Pb}$ isotope ratio measurements. 62

Ch.5 Results: Physiochemical Archives of U1365B-M

5.1 10Be/9Be-depth and age-depth plots of U1365B-M 64

5.2 Growth rates of U1365B-M derived by beryllium dating 68

$\begin{array}{lll}5.3 & \text { Major textural zones of U1365B-M } & 71\end{array}$ 
5.4 Major textural zones and subzones of U1365B-M

$\begin{array}{lll}5.5 & \text { Microstructures of U1365B-M }\end{array}$

$\begin{array}{lll}5.5 & \text { Microstructures of U1365B-M } & 77\end{array}$

5.6 Depth-time series of macrotextures, microscopic structures and authigenic-... $\quad 78$

5.7 Authigenic chemistry of U1365B-M and bulk chemistry of Campbell Nodules 80

$5.8 \quad$ Hierarchal cluster of geochemically similar elements and correlation matrix 84

5.9 Major element chemistry of U1365B-M 86

5.10 Major element, authigenic \& detrital compositions of Campbell Nodules 88

5.11 Minor element depth-time series for U1365B-M 90

5.12 Paleo-seawater $\mathrm{Pb}$ isotopic compositions for 13 Ma growth history of U1365... 92

5.13 Paleo-seawater Pb isotopic compositions for U1365B-2 and U1365B-M 94

$\begin{array}{lll}5.14 & \mathrm{~Pb}-\mathrm{Pb} \text { mixing plots of U1365B-M } & 95\end{array}$

Ch.6 Discussion: Unravelling 13 million years of deep ocean chemistry

6.1 Testing the key assumptions of 10Be/9Be dating 104

$\begin{array}{lll}6.2 & \text { Testing the assumptions of cobalt chronometers } & 108\end{array}$

6.3 Physical archives of FMN U1365B-M and key climatic-oceanic-tectonic events... 113

6.4 Detrital incorporation and microstructures of FMN U1365B-M with key climatic... 115

6.5 Hierarchal cluster analysis and element speciation in seawater 118

6.6 Geochemically similar element groups of U1365B-M 121

6.7 $\mathrm{Pb}-\mathrm{Pb}$ mixing plots of U1365B-M and regional, riverine, aeolian, sources of $\mathrm{Pb} \ldots \quad 126$

6.8 $\mathrm{Pb}-\mathrm{Pb}$ mixing plots of U1365B-M and local or advected volcanic sources 128

$6.9 \quad \mathrm{~Pb}-\mathrm{Pb}$ mixing plots of U1365B-M and global provenance 130

6.10 $\mathrm{Pb}-\mathrm{Pb}$ mixing plots of U1365B-M and surface scrapings of Circum-Antarctic FMNs 132

6.11 Mode of FMN U1365B-M formation 133

6.12 Contributions from Oxic and Suboxic Diagenesis 135

6.13 Paleoproductivity proxies of U1365B-M record of relative changes in biological... 138

6.14 Shale normalised YREE profile of U1365B-M 142

6.15 Paleoredox proxies of U1365B-M : V/(V+Ni), Ni/Co and U/Th 143

6.16 Time-series of paleoredox proxies of $\mathrm{U} 1365 \mathrm{~B}-\mathrm{M}$ as a record of relative ocean $\mathrm{O}_{2} \ldots \quad 145$

6.17 Tracing the PDWBC from the Southern Ocean into the Equatorial Pacific over the... 150

6.17 Tracing the PDWBC from the Southern Ocean into the Equatorial Pacific over the... 151

6.18 Depth-time-series of HFSE paleocirculation proxies of U1365B-M as a record of... 153

6.19 HFSE paleocirculation proxies of U1365B-M as a record of water mass mixing... 155

6.20 Time-series of paleocirculation proxies of U1365B-M as a record of water mass... 158

6.21 Application of YREEs in tracing water mass mixing - Er/Lu (Er/Yb) 159 


\section{Chapter}

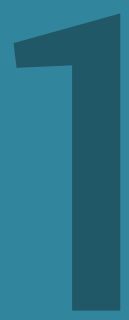

States the motivation, aim, objectives and structure of the thesis

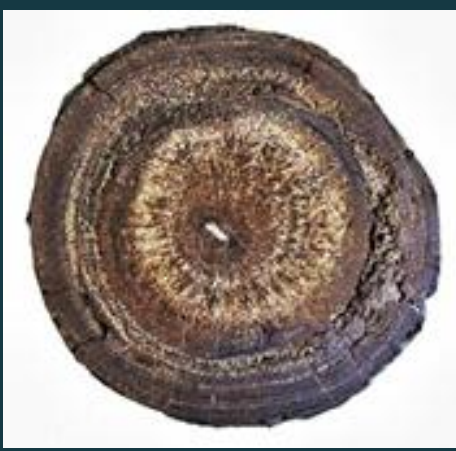

$1.1 \quad$ Motivation

1.2 Aim \& Objectives

1.3 Thesis Outline 


\subsection{Motivation}

The Southern Ocean is home to the largest and longest ocean current system on Earth, the Antarctic Circumpolar Current (ACC), which connects and mixes water masses of the Atlantic, Indian and Pacific Oceans. Consequently, the ACC plays an essential role in the redistribution of heat, salt, gases and the biogeochemical cycling of elements throughout the global ocean (Carter, et al., 2009; Bostock, et al., 2012). Additionally, since the increased glaciation of Antarctica c. 14 -12 Ma, deep water masses formed in the Southern Ocean have served to ventilate the intermediate and abyssal depths of much of the world's oceans, through an intricate network of northward flowing deep western boundary currents (Rintoul, et al., 2001). Presently, 40\% of these deep oxygenated waters are transported into the greater Pacific Ocean (cf. McCave, et al., 2008), via the Pacific Deep Western Boundary Current (PDWBC). On transit from the Southern Ocean into the Southwest Pacific, the PDWBC is effectively steered along the submerged extensions of the New Zealand continent, which also serves to constrain the eastward flowing ACC along the Subantarctic Front (SAF). Thus, both of these globally significant currents are transported from the Southern Ocean into the Southwest Pacific in concert, through the New Zealand oceanic gateway (Manighetti, 2001; McCave, et al., 2004; Carter, 2008).

Constriction of the ACC-PDWBC system enhances high energy eddy systems associated with the SAF, resulting in the propagation of energy down through the ACC to the underlying PDWBC, promoting fast abyssal currents and water mass mixing (Carter \& McCave, 1997; Carter, et al., 2009). As such, the PDWBC is comprised of deep waters formed along the Antarctic coastline in addition to circumpolar deep waters mixed within the ACC, and thus has the potential to carry chemical signals from Antarctica, and the Atlantic, Indian and Pacific Oceans. In terms of paleoceanography, the physiochemical properties of the PDWBC are likely to have changed in response to the Late Neogene evolution of Earth's climate, cryosphere and oceans (e.g., Hall, et al., 2003; L. Carter, et al., 2004; R. Carter, et al., 2004; Naish, et al., 2009), as summarised in Table 1.1.

The fast flowing, well-oxygenated currents of the ACC-PDWBC system provide ideal conditions for the formation of deep sea ferromanganese nodules (FMNs), and have resulted in the formation of the Campbell Nodule Field since c. $13 \mathrm{Ma}$ (Graham \& Wright, 


\begin{tabular}{|c|c|c|c|}
\hline $\begin{array}{l}\text { Age } \\
\text { (Ma) }\end{array}$ & $\begin{array}{l}\text { Climatic } \\
\text { Event }\end{array}$ & $\begin{array}{l}\text { Oceanographic } \\
\text { Event }\end{array}$ & $\begin{array}{l}\text { Biogeochemical Evolution of the Deep } \\
\text { Ocean }\end{array}$ \\
\hline $0-2$ & $\begin{array}{l}\text { Pleistocene to } \\
\text { Present G-I } \\
\text { cycles }\end{array}$ & $\begin{array}{l}\text { Glacial closure of Arctic } \\
\text { Seaways, namely Bering } \\
\text { Strait and CAA via ice } \\
\text { land bridges }\end{array}$ & $\begin{array}{l}\text { Present system of waxing and waning ice-sheets, } \\
\text { eustatic sea-level changes and alternating } \\
\text { dominance of Atlantic Meridional Overturning } \\
\text { Circulation (MOC) and Southern Ocean MOC }\end{array}$ \\
\hline $3-2$ & $\begin{array}{l}\text { Late Pliocene } \\
\text { Climate } \\
\text { Transition } \\
\text { (LPCT) }\end{array}$ & $\begin{array}{l}\text { Formation of Canadian } \\
\text { Arctic Archipelago (CAA) } \\
\text { Gateways } \\
\text { Major expansion of Ross } \\
\text { Ice Shelf ( } 3.3 \text { to } 2.5 \mathrm{Ma})\end{array}$ & $\begin{array}{l}\text { Northern Hemisphere Glaciation } \\
\text { Intensification of Antarctic cooling, expansion } \\
\text { of sea ice, enhanced deep water production } \\
\text { (McKay, et al., 2012) }\end{array}$ \\
\hline $4-3$ & $\begin{array}{l}\text { Mid - Pliocene } \\
\text { Climate } \\
\text { Optimum } \\
\text { (MPCO) }\end{array}$ & $\begin{array}{l}\text { Emergence of Panama } \\
\text { Isthmus ( } 5-3 \mathrm{Ma}) \\
\text { Shift of Indonesian } \\
\text { Throughflow north }(5-3 \\
\mathrm{Ma})\end{array}$ & $\begin{array}{l}\text { Northward deflection of warm equatorial } \\
\text { currents to N. Atlantic } \\
\text { Decreased atmospheric heat transport toward } \\
\text { c. } 3 \mathrm{Ma} \text { (Cane \& Molnar, 2001) }\end{array}$ \\
\hline $5-4$ & $\begin{array}{l}\text { Early Pliocene } \\
\text { relative } \\
\text { warmth }\end{array}$ & $\begin{array}{l}\text { Opening of Bering Strait } \\
(5-3 \mathrm{Ma}) \\
\text { Shift of Indonesian } \\
\text { Throughflow north }(5-3 \\
\text { Ma) }\end{array}$ & $\begin{array}{l}\text { Freshwater supply from N. Pacific to N. Atlantic } \\
\text { via the Arctic } \\
\text { Reduced strength of Indonesian Throughflow, } \\
\text { and termination of permanent El Niño state in } \\
\text { Pacific Ocean (Molnar \& Cane, 2002) }\end{array}$ \\
\hline $6-5$ & $\begin{array}{l}\text { Late Miocene } \\
\text { climate } \\
\text { variability }\end{array}$ & $\begin{array}{l}\text { Opening of Gibraltar } \\
\text { Strait } \\
(5.3 \mathrm{Ma})\end{array}$ & $\begin{array}{l}\text { Formation of Mediterranean Overflow Water } \\
\text { (MOW), increased North Atlantic Deep Water } \\
\text { (NADW) production, density gradients } \\
\text { favouring AMOC. Increased ice volume of West } \\
\text { Antarctic Ice Sheet and enhanced deep water } \\
\text { production }\end{array}$ \\
\hline $7-6$ & $\begin{array}{l}\text { Late Miocene } \\
\text { cooling }\end{array}$ & $\begin{array}{l}\text { Shallow glacial ocean } \\
\text { (c. } 6.2 \mathrm{Ma}) \\
\text { Isolation of Mediterranean } \\
\text { Sea }(7-5 \mathrm{Ma})\end{array}$ & $\begin{array}{l}\text { Marine regression, development of Antarctic ice- } \\
\text { sheet and bottom water production, deeper } \\
\text { calcium compensation depth (CCD), global } \\
\text { decrease in FMN growth rates (Segl, et al., 1989) }\end{array}$ \\
\hline $6-13$ & $\begin{array}{l}\text { Mid - Late } \\
\text { Miocene } \\
\text { cooling }\end{array}$ & $\begin{array}{l}\text { Restriction of Indonesian } \\
\text { Gateway (14-10 Ma) } \\
\text { Opening \& deepening of } \\
\text { Arctic Seaways (c. } 10 \mathrm{Ma})\end{array}$ & $\begin{array}{l}\text { Blocking equatorial transport of deep water from } \\
\text { the Pacific to Indian Ocean } \\
\text { Formation of proto- NADW }\end{array}$ \\
\hline \multirow[t]{2}{*}{$13-14$} & \multirow{2}{*}{$\begin{array}{l}\text { Mid-Miocene } \\
\text { Climate } \\
\text { Transition } \\
\text { (MMCT) }\end{array}$} & $\begin{array}{l}\text { Expansion of East } \\
\text { Antarctic ice sheet }\end{array}$ & $\begin{array}{l}\text { Reduction of Tethys Warm Saline Deep Water } \\
\text { (WSDW) to Southern Ocean }(15-13 \mathrm{Ma})\end{array}$ \\
\hline & & $\begin{array}{l}\text { Deepening of Drake } \\
\text { Passage and Tasman } \\
\text { Gateway (c. } 35-15 \mathrm{Ma})\end{array}$ & $\begin{array}{l}\text { Development of ACC, thermal isolation of } \\
\text { Antarctica and initiation of Antarctic Bottom } \\
\text { Water (AABW) production }\end{array}$ \\
\hline
\end{tabular}

Table 1.1 Key climatic and oceanographic events in the late Neogene evolution of the global ocean summarised from references cited in addition to Kennett \& von der Borch, (1986) and Cronin, (2010). 
2008). These nodular deposits form at the sediment-water interface from the precipitation of iron-manganese (Fe-Mn) oxyhydroxide minerals directly from seawater. These minerals effectively scavenge tracer elements from the water column as they descend to the seafloor, where they accrete around nuclei of volcanic, biogenic or older nodule fragments (Halbach \& Fellerer, 1980; Segl, et al., 1984; Glasby, 2000). FMNs continue to grow by addition of concentric layers about the nucleus, at rates of millimetres per millions of years or about a layer of atoms per year (Goldberg, 1974), episodically trapping fine-grained land-derived aluminosilicates during layer formation (Glasby, 2000; Banakar, 2010). The resulting internal structure is analogous to the growth rings of trees and similarly, each nodule growth ring can be dated and analysed to retrieve its chemical composition.

In general, the seawater-derived component (Fe-Mn minerals, also referred to as hydrogenous or authigenic), records the chemical evolution of the paleo-ocean from which they originated (e.g., Frank, 2002; van de Flierdt, et al., 2003, 2004; Xu, et al., 2006), whereas the land-derived component (entrapped detrital minerals) reflect erosional trends of the surrounding landmass (e.g., Banakar, et al., 2003) and (or) phases of strong current activity (e.g., Mangini, et al., 1990). As such, FMNs are abyssal archives that store a record of the environmental conditions governing deposition within each concentric layer (Hein, et al., 1992; Hein \& Koschinsky, 2013), with environmental conditions referring to the physical, chemical, biological, climatic and geographic controls that inevitably determine or modify the physiochemical properties of each layer (Levin, 2013). Thus, the physical and chemical archives of FMNs are the key to unravelling past changes in the deep-sea environment. Due to their propensity to form within regions of non-deposition and erosion, FMNs present a powerful tool for reconstructing the history of abyssal currents.

Unravelling the abyssal archives of FMNs in order to reconstruct the Late Neogene evolution of the PDWBC, is the prime motivation for this thesis

A suite of FMNs were collected from the Campbell Nodule Field (Chang, et al., 2003; Graham, et al., 2003a; Graham, et al., 2003b), the largest of which provided an opportunity to reconstruct the Late Neogene evolution of the PDWBC through the New Zealand oceanic gateway, exploiting the unique circumstances of the combined ACC-PDWBC flow enforced by the gateway. 


\subsection{Aim \& Objectives}

In this study, the physical and chemical archives of mega nodule U1365B-M are investigated across the crust to core depth-profile illustrated in Figure 1.1. This depthprofile is a 'condensed stratigraphic section' representing c. 13 million years of deep ocean history. Comparisons are made between the results obtained for U1365B-M and those previously derived for nine FMNs selected from the Campbell Nodule Field, and a variety of other sedimentary archives. Results are discussed in terms of their implications for nodule genesis and the paleoceanographic evolution of the PDWBC, from the New Zealand sector of the Southern Ocean. Thus, the main aim of this thesis was to determine:

How the oceanographic properties of the deep ocean have changed in response to the Late Neogene evolution of the oceans, climate and cryosphere, as recorded within a large hydrogenous FMN at the New Zealand oceanic gateway.

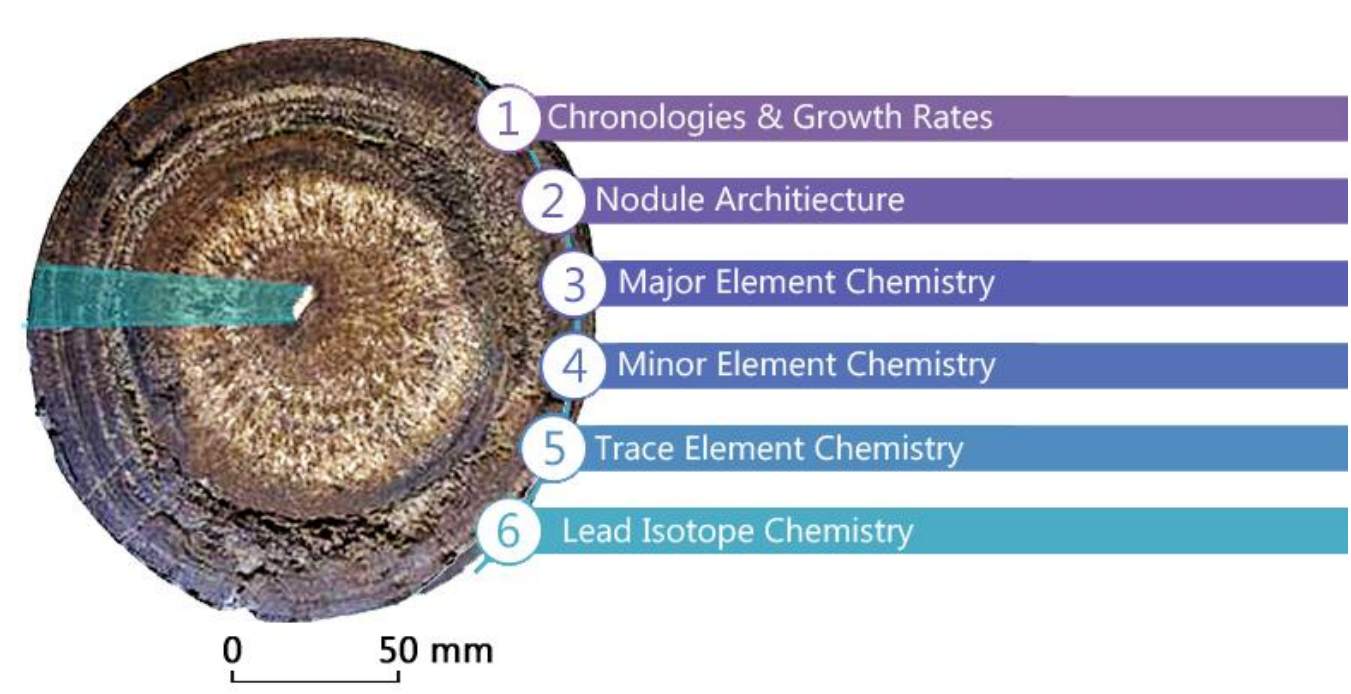

Figure 1.1 | The physiochemical archives of U1365B-M. FMNs are complex, heterogeneous objects which are studied here in a systematic manner from the macroscopic (physical) to sub-microscopic (chemical) (Sorem \& Fewkes, 1977): (1) knowledge of absolute ages and growth rates (derived from beryllium isotope dating) provide the timeframe upon which the history of a deep-water mass can be developed; (2) physical components, summarised here as 'Nodule Architecture' refer to (a) macroscopic features - visible with the naked eye and include; (i) external morphology, (ii) physical distribution of authigenic (dark) and detrital material (light), (iii) nodule nucleus, (iv) textural features of concentric layers and; (b) microscopic features that include; (v) Fe-Mn minerals and (vi) internal growth structures (architectural images can be used as "maps" to link physical and chemical archives); the sub-microscopic or chemical archives (3)-(6) are derived from samples collected across the highlighted $95 \mathrm{~mm}$ radius, image from unpublished document regarding U1365B-M re-sampling, Ditchburn \& Graham (2006a). 
Supporting the main aim of the thesis is a series of objectives:

1 Isolate the seawater component of U1365B-M, through development of a wet chemistry technique that separates the seawater component (containing Fe-Mn oxyhydroxides and their associated trace elements) from the detrital component (residual material containing land derived sediments). Through a selection of analytical procedures and data processing, retrieve and quantify the elemental and lead $(\mathrm{Pb})$ isotopic seawater record and calculate the amount of detrital material trapped within each sample.

2| Revise \& utilise the chronological framework by revising the results of beryllium dating performed on each of the ten selected FMNs (Graham, et al., 2003b; Ditchburn \& Graham, 2006b), to the new half-life of 1.39 Ma (Korschinek, et al., 2010; Chmeleff, et al., 2010), followed by the determination of new growth rates (Figure 1.1 (1)), and an assessment of cobalt chronometers as reliable tools for dating FMNs $>10-15$ Myrs old.

3| Unravel the physical archives by identifying macroscopic \& microscopic changes in texture and assessing the variable proportions of detrital material. Describe where changes occur along the depth-profile (mm) of U1365B-M and associated chronological framework (Figure $1.1(2)$ ). Determine if there are common time-intervals characterised by a change in accretion for the nine other FMNs selected from the Campbell Nodule Field.

4| Unravel the chemical archives through descriptions on the paleogeochemistry of U1365B-M using timeseries, inter-elemental and inter-archival correlations. Present data based on detailed evaluations of: (a) major element chemistry (>10,000 ppm), (b) minor element chemistry (>1000 ppm), (c) trace element chemistry $(<1000 \mathrm{ppm})$ and (d) lead isotope stratigraphy (Figure 1.1 (3-6)).

\section{5 | Reconstruct the Late Neogene evolution of the PCDW from the New Zealand sector} of the Southern Ocean using the physiochemical archives of U1365B-M and associated FMNs from the Campbell Nodule Field and discuss how the abyssal environment has evolved in response to local and global changes in climate, cryosphere, ocean structure and circulation, through inter-correlations with other paleoclimate archives. 


\subsection{Thesis Outline}

This thesis is written in the standard format of: (1) Introduction, (2)-(3) Literature review, (4) Methods, (5) Results, (6) Discussion and (7) Conclusions. An outline of the thesis is presented in Table 1.2.

\section{Chapter}

1 Introduction:

Thesis Aim, Objectives \& Structure

2 Study Area:

Oceanographic Setting and the Campbell Nodule Field

3 Ferromanganese Nodules: Abyssal Archives of Past Ocean Chemistry

4 Methods:

Retrieving the Seawater Record

\section{Description}

States the motivation aim and objectives of the thesis and outlines the thesis structure through a brief account of chapter content.

Describes the physical \& chemical oceanography of the study area, focusing on the major currents of the New Zealand sector of the Southern Ocean: the ACC and PDWBC, together with a description of the Campbell Nodule Field. Details the theoretical context behind the genesis of FMNs, their use as abyssal archives of ancient seawater chemistry and application in reconstructing past changes in the deepsea environment.

Details FMN samples collected from the Campbell Nodule Field (Chang, et al., 2003) and methods used in revising their chronologies (Graham, et al., 2003b), high resolution sampling and dating of U1365B-M (Ditchburn \& Graham, 2006a,b) in addition to methods employed in extracting the information outlined in Figure 1.1, including an account of the new separation technique developed.

5 Results:

Physiochemical Archives of U1365B-M

Describes the updated chronology and growth rates, micro \& macro nodule architecture and the geochemical behaviour of elements and $\mathrm{Pb}$ isotopes in U1365B-M as depth-timeseries and inter-element correlations, following the outline of Figure 1.1.

\section{Discussion:}

Unravelling 13 Myrs of Deep Ocean Chemistry

\section{Conclusions:}

Key Findings and Future Challenges
Discusses the links between physical and geochemical signals recorded within U1365B-M with, global and local, oceanic and climatic events that have occurred over the last 13 Myrs in order to address the aim of the thesis

A synthesis of the key findings of the thesis and suggestions for future research

Table 1.2 Thesis Outline. Details the structure of the thesis with a brief account of chapter content 


\section{Chapter}

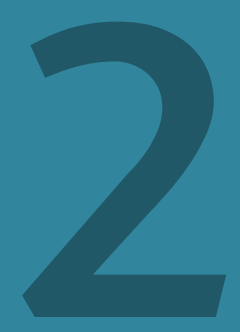

Describes the physiochemical oceanography of the study area with a description of the Campbell Nodule Field

\section{Study Area}

Oceanographic Setting \& the Campbell

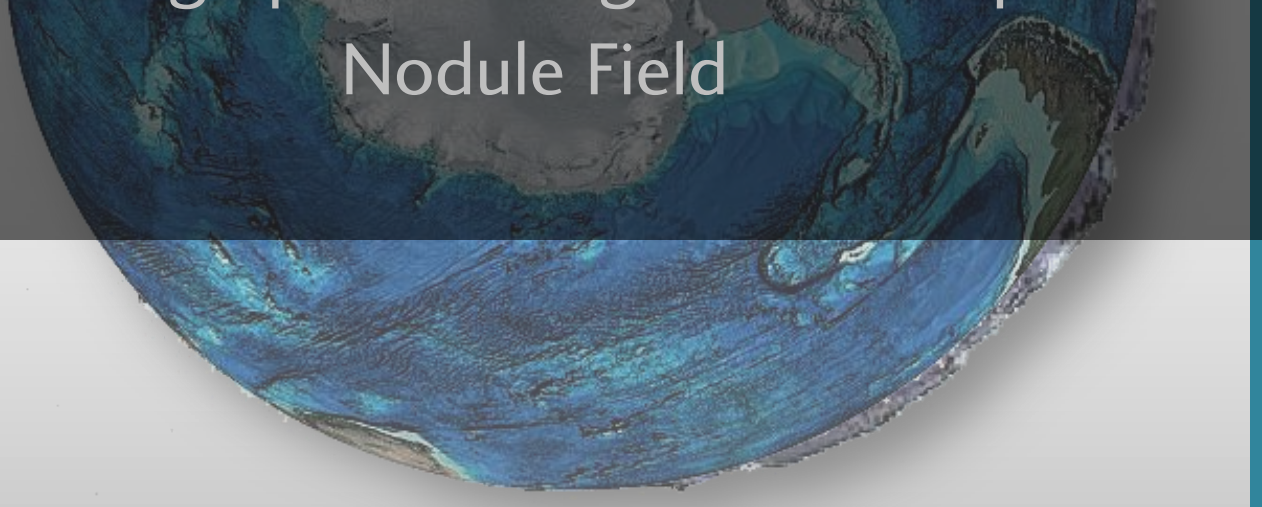

$2.1 \quad$ The Southern Ocean

2.2 The New Zealand Oceanic Gateway

2.3 The Campbell Nodule Field 


\subsection{The Southern Ocean}

The Southern Ocean, defined here as extending from the Antarctic coastline ( $\left.\sim 70^{\circ} \mathrm{S}\right)$ to the Subtropical Front $\left(\sim 40^{\circ} \mathrm{S}\right)$ (Figure 2.1(a)), was established during the early Oligocene, through opening of the Tasman Gateway and Drake Passage (Lawver \& Gahagan, 2003; see Figure 2.3(a)), coinciding with the largest climatic cooling event of the Cenozoic (EoceneOligocene Climate Transition c. $34 \mathrm{Ma}$ ) and the first undisputable evidence for the presence of ice-sheets on Antarctica (Zachos, et al., 2001; Miller, et al., 2009; see Appendix A). However, permanent ice-sheets did not develop until the Middle Miocene Climate Transition (MMCT) c. 14-13 Ma, by which time, the northward drift of Australia and South America had further expanded the Southern Ocean, whilst restricting and closing oceanic gateways of the low latitudes (Exon, et al., 2004; Cronin, 2010).

Closure of tropical seaways and opening of Antarctic gateways has been associated with the termination of Warm Saline Deep Water (WSDW) production in the tropics and increased Antarctic Bottom Water (AABW) production and export in the Southern Ocean. Reduction of WSDWs, in addition to the development of the Antarctic Circumpolar Current (ACC), has been proposed to have aided in the thermal isolation of the Antarctic continent and initiation of permanent ice sheets by c. 14 - 13 Ma (e.g., Hall, et al., 2003; Verducci, et al., 2009; Anderson \& Wellner, 2011). Additionally, from c. 18 to $10 \mathrm{Ma}$ Arctic gateways progressively opened leading to the production of proto-North Atlantic Deep Water (NADW), aiding in the transition from greenhouse climates of the Early Cenozoic, characterised by latitudinal halothermal circulation, to the icehouse climate of present, characterised by a meridional thermohaline circulation (Wright, et al., 1991; Flower \& Kennett, 1993; Exon, et al 2004; O’Reagan, et al., 2011).

Since its establishment, the Southern Ocean has provided a connection between the Antarctic continent and the Atlantic, Indian and Pacific Oceans via the ACC and through a global network of northward bound Deep Western Boundary Currents (DWBC) permitting the existence of a meridional overturning circulation (Schmittner, et al., 2007; Marshall \& Speer, 2012), and inter-ocean communication routes, for the exchange of heat, salt, freshwater, biogeochemical substances and gases (e.g., $\mathrm{CO}_{2}, \mathrm{O}_{2}, \mathrm{CH}_{4}$ ) that influence the global climate (Ganachaud \& Wunsch, 2000; Weijer, et al., 2012; Bostock, et al., 2013). 
(a) Circumpolar Fronts and Surface Water Masses

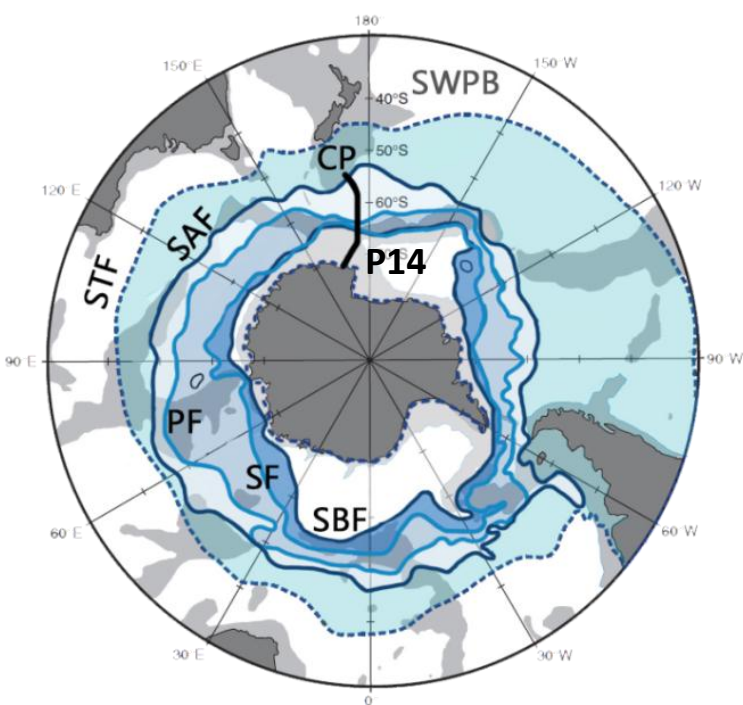

(b) Wind-driven Surface Currents

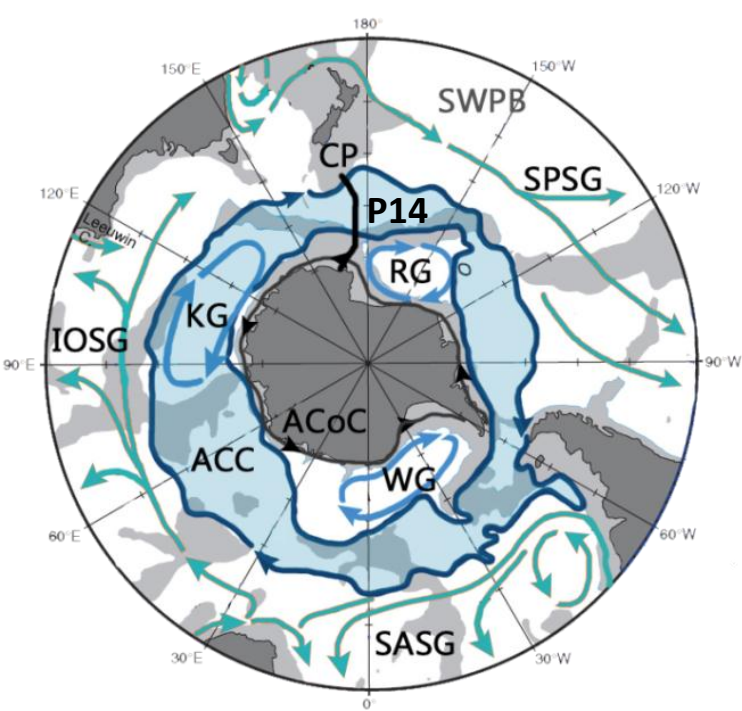

Figure 2.1 | Schematic of the structure \& flow of the Southern Ocean. (a) Circumpolar Fronts: Subtropical Front (STF), Subantarctic Front (SAF), Polar Front (PF), Southern Front (SF) and Southern Boundary Front (SBF). Surface Waters: Subantarctic Water (SAW; turquoise), Circumpolar Surface Water (CSW; light blue), Antarctic Surface Water (AASW; mid to dark blue). (b) Surface Currents: Antarctic Circumpolar Current (ACC), poleward limbs of the Subtropical Gyres in the South Pacific (SPSG), South Atlantic (SASG) and Indian Ocean (IOSG), the subpolar gyres of the Ross (RG), Weddell (WG) and Kerguelen (KG) basins and westward flowing Antarctic Coastal Current (ACoC). The Campbell Plateau (CP), Southwest Pacific Basin (SWPB) and transect line P14 of the World Ocean Circulation Experiment (WOCE; see also Figure 2.5) are labelled in both (a) and (b), modified from Carter, et al., (2009) and Rintoul, et al. $(2001,2012)$

The Southern Ocean is dominated by the Antarctic Circumpolar Current (ACC) (Russell, et al., 2006; Sokolov \& Rintoul, 2009). Extending to 2000 kilometers in width, with depths of up to $4000 \mathrm{~m}$, the cross-sectional area of the ACC allows for the current to transport and mix more water than any other current on Earth (Barker \& Thomas, 2004; Rintoul, 2009). As the ACC extends from the sea surface to the sea floor it is largely steered by seafloor topography (Gille, et al., 2004). For much of its passage, the ACC flows along flanks of mid-ocean ridges and either widens (e.g., Kerguelen Plateau) or becomes constrained (e.g. Drake Passage, Campbell Plateau) when passing over, or around, oceanic plateaux, and shifts poleward where gaps exists in the mid-ocean ridge systems (Whitworth \& Peterson, 1985; Morris, et al., 2001; Carter, et al., 2009; Figure 2.1(b)). In part, this bathymetric steering has resulted in the braided flow structure of the ACC, which 
consists of embedded regions of deep reaching, high speed currents, which outcrop at the sea surface as a series of circumpolar fronts (Orsi, et al., 1995). The northern boundary of the ACC is defined by the Subantarctic Front (SAF), succeeded to the south by the Polar Front (PF), Southern Front (SF) and Southern Boundary Front (SBF) (Carter, et al., 2009) (Figure 2.1(a)). South of the SBF the west and easterly wind belts form three deep reaching gyres; (1) the Weddell Gyre, (2) the Ross Gyre and (3) an unnamed gyre, termed by some authors as the Kerguelen Gyre (Fahrbach, 2013) (Figure 2.1(b)). These gyres extend from the ACC to the Antarctic continental margin and occupy the ridge-bound sectors of the Weddell, Ross and Australian-Antarctic basins (Orsi, et al., 1993; Jacobs, et al., 2002; Carter, et al., 2009). They transfer nutrients and what little heat has reached this latitude, from the ACC to the Antarctic margin (Barker \& Thomas, 2004) (Figure 2.1(b)).

Circumpolar front's partition water masses of the Southern Ocean that are characterised by different physiochemical properties (Rintoul, et al., 2001). The STF marks the boundary where cool, low salinity Subantarctic Waters (SAW) to the south, converge with warm, highly saline Subtropical Waters (STW) to the north (Figures 2.1(a) \& Figure 2.2). SAW sinks at the STF and mixes with denser water masses below forming Subantarctic Mode Water (SAMW) (Figure 2.2(i)). Well-oxygenated SAMW descends northward to c. $500 \mathrm{~m}$ depths and effectively ventilates the deep ocean. Further mixing of SAMW on decent contributes to the formation of Antarctic Intermediate Water (AAIW), a denser water mass that descends north under SAMW to depths of c. $1500 \mathrm{~m}$ (Figure 2.2 (ii)). AAIW also forms along the PF where near freezing, relatively fresh Antarctic Surface Water (AASW) sinks under the more buoyant Circumpolar Surface Water (CSW) (Figure 2.2(iii)). AAIW and SAMW circulate through the subtropical gyres of the Atlantic, Indian and Pacific, before returning to the Southern Ocean as 'old' AAIW/SAMW (Orsi, et al., 1995; Carter, et al., 2009; Weijer, et al., 2012).

The main water mass of the ACC is Circumpolar Deep Water (CDW), which is subdivided into three types based on salinity, nutrient and oxygen content (L. Carter, et al., 2004; McCave, et al., 2008). Upper Circumpolar Deep Water (UCDW) is enriched in nutrients and depleted of oxygen (Figure 2.2(iv)). On return to the Southern Ocean 'old' AAIW and SAMW are converted through mixing with denser layers to form UCDW. 


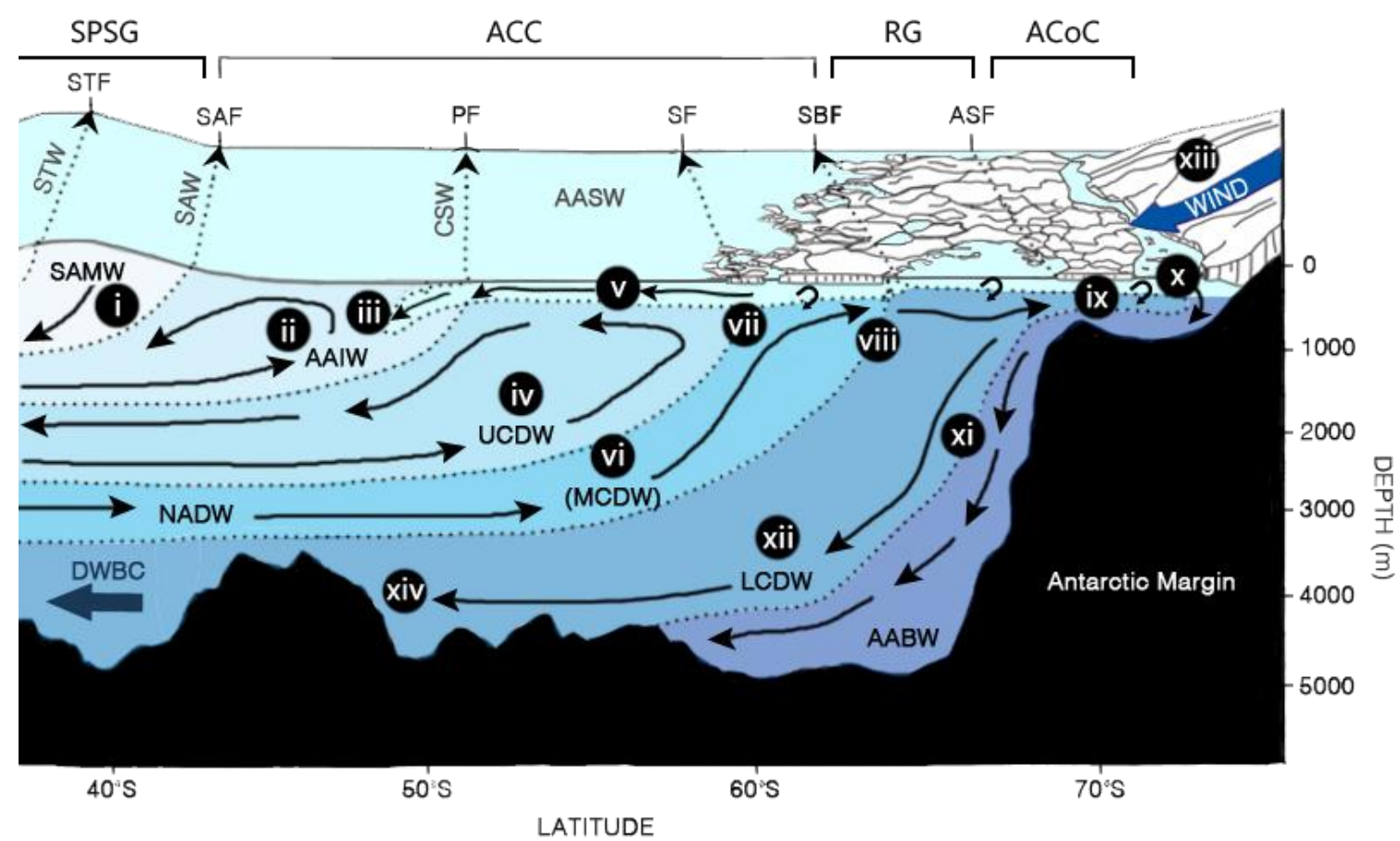

Figure 2.2 A schematic of circumpolar fronts \& water masses of the Southern Ocean. (i) SAMW=Subantarctic Mode Water, formed from SAW sinking below STW, (ii) AAIW=Antarctic Intermediate Water, (iii) AASW sinking below CSW, (iv) UCDW=Upper Circumpolar Deep Water, (v) UCDW mixes with AASW at the PF, (vi) MCDW=Middle Circumpolar Deep Water, (vii) MCDW contributes toward the formation of (viii) LCDW= Lower Circumpolar Deep Water, (ix) LCDW mixes with AASW and, (x) HSSW \& ISW=Highly Saline Shelf Water \& Ice Shelf Water, (xi) dense LCDW sinks, (xii) forming a mixed LCDW-AABW=Antarctic Bottom Water, (xiii) AABW formation via coastal polynyas, (xiv) LCDW-AABW distributed through ocean basins as DWBC=Deep Western Boundary Currents. SPGS, ACC, RG and ACoC are labelled as an example to illustrate surface and deep water circulation, modified from Carter, et al. (2009).

Additionally, UCDW forms when nutrient rich deep waters are upwelled to the surface and are subsequently depleted of oxygen through biogenic processes. The core of UCDW flows north at depths of c. 2,000 m and shoals south of the PF where it mixes with AASW (Figure 2.2(v)) (Carter, et al., 2004, 2009). Middle (or Modified) Circumpolar Deep is highly saline (c. 34.9-35.0 psu), reflecting the input of North Atlantic Deep Water (NADW) (Figure 2.2(vi)). Upon meeting the ACC, NADW is entrained and exported eastward around the Antarctic continent, and mixes with waters from the Indian and Pacific Oceans. Despite vigorous mixing, the high salinity signature of NADW is retained (Tally, et al., 2011; Lozier, 2012). MCDW rises from depths of c. $3000 \mathrm{~m}$ to shoal near the SF where it mixes with deeper waters contributing to the formation of Lower Circumpolar 
Deep Water (LCDW) (Figure 2.2(vii)) (Carter, et al., 2009; Weijer, et al., 2012). As such, LCDW has high oxygen (4-6 $\mu$ moles / kg seawater) and salinity signatures inherited from NADW (Toggweiler \& Samuels, 1995). At several locations around Antarctica, LCDW rises to the surface along the SBF (Figure 2.2(viii)). Upon reaching the sea surface LCDW mixes with cold AASW (Figure 2.2(ix)), in addition to Highly Saline Shelf Waters (HSSWFoster \& Carmack, 1976) and cold Ice Shelf Waters (ISW- Baines \& Condie, 1985; Figure 2.2(x)). A proportion of LCDW becomes denser than ambient waters and sinks below the more buoyant upwelled LCDW (uLCDW), renewing deep ocean circulation (Figure 2.2(xi)) (Ganachaud \& Wunsch, 2000; Jacobs, 2004; Carter, et al., 2009).

At depths below c. $4000 \mathrm{~m}$, LCDW mixes with extremely cold and dense Antarctic Bottom Water (AABW), forming an admixture of the two masses (LCDW-AABW or eLCDW; Figure 2.2(xii)) (McCave, et al., 2008; Carter, et al., 2009). AABW forms at certain locations along the Antarctic coastline, namely within the subpolar gyres, where intense cooling and salinification of surface waters occurs through ocean-atmosphere-ice interactions (Rintoul, 2011). Several mechanisms are proposed for AABW formation; (1) coastal polynyas - where katabatic winds (Figure 2.2(xiii)) push sea-ice seaward exposing surface waters to the intense cold of the Antarctic atmosphere; (2) formation of ISW and HSSW - through freezing and melting at the base of ice-shelves (ISW), which together with brine rejection forms HSSW(Figure 2.2(x)); (3) intrusions of saline NADW bearing LCDW beneath ice shelves (Figure 2.2(viii)) and; (4) mixtures of the above (Orsi, et al., 1999; Carter, et al., 2009; Padro, et al., 2012).

Except for the deepest basins around the Antarctic margin (where AABW resides), $\mathrm{LCDW}$ fills the abyssal realms of the major oceans and is carried equatorward in a global network of Deep Western Boundary Currents (DWBC) (Figure 2.2(xiv)) travelling at c. 3500 - $5000 \mathrm{~m}$ below the ocean surface (Figure 2.2(c)) (Weijer, et al., 2012). The Pacific DWBC (PDWBC) is the largest in the world (Whitworth et al., 1985, 1999), providing the main source of deep water to the greater Pacific Ocean (Warren, 1971, 1973). The flow of LCDW into the deep Pacific is modulated by the ACC, which entrains and mixes all water masses with ambient waters of the current, before they continue north as DWBCs (Fukamachi, et al., 2010; Meinen, et al., 2012; van Sebille, et al., 2013). Late Neogene (c. 13 to $0 \mathrm{Ma}$ ) changes in deep water circulation and thus, the chemical evolution of LLCDWs 
of the PDWBC, are thought to have been associated with: (a) Southern Ocean processes, in regions of deep water formation in relation to the changing glacial state of Antarctica (e.g. Carter, et al., 1996; Barker \& Thomas, 2004; Florindo \& Siegert, 2009; Holbourn, et al., 2013); (b) NADW export to the Southern Ocean, which has changed in response to the opening and closing of major Northern Hemisphere seaways (Figure 2.3(a); e.g., Rutberg, et al., 2000; Frank, et al., 2002; Robinson \& van de Flierdt, 2009); (c) Indian Ocean Deep Water (IODW) export, which has been influenced by weathering and erosion of the Himalayan ranges and constriction of the Western Tethys Seaway and Indonesian Gateway (e.g., Hotinski \& Toggweiler, 2003; Khunt, et al., 2004; Frank, et al., 2006; Figure 2.3(a)) and; (d) North Pacific Deep Water (NPDW) export, which has responded to changes in Arctic (e.g., Thompson, et al., 2012), Central (e.g., Christiansen, et al., 1997) and Pacific seaways (e.g., van de Flierdt et al., 2004; Figure 2.3(a)). Thus, the chemical oceanography of the ACC and PDWBC are likely to have changed in response to the late Neogene evolution of the oceans, climate and cryosphere (Table 1.1). The ACC-PDWBC is presently (and over the course of the late Neogene) transported from the Southern Ocean into the Southwest Pacific along the prominent western boundary of the New Zealand continent and thus, the chemical evolution of the current is also likely to be influenced by local sources in addition to global chemical signals derived from water mass mixing within the ACC.

\subsection{The New Zealand Oceanic Gateway}

The Campbell Plateau and Macquarie Ridge form the southern submerged extensions of the New Zealand microcontinent (Shuur, et al., 1998; Campbell \& Hutching, 2007) and strongly influence the nature and flow of the ACC and underlying (>3500 m) Pacific DWBC (Figure 2.3 (b \& c)) (Carter, et al., 2009). Fracture zones and topographic lows of Macquarie Ridge provide deep water passageways, whereas topographic highs obstruct flow. Thus, at the approach to the Pacific Ocean, a small portion of the ACC-PDWBC enters the Pacific through deep seated gaps in the ridge, north and south of Macquarie Island, which allow current filaments to spill into the adjacent Emerald Basin (Gordon, 1972, 1975), where sediments from the Macquarie Ridge and Solander Trough are presently injected into the current system (Carter \& Mitchell, 1987; Carter, et al., 1996). 


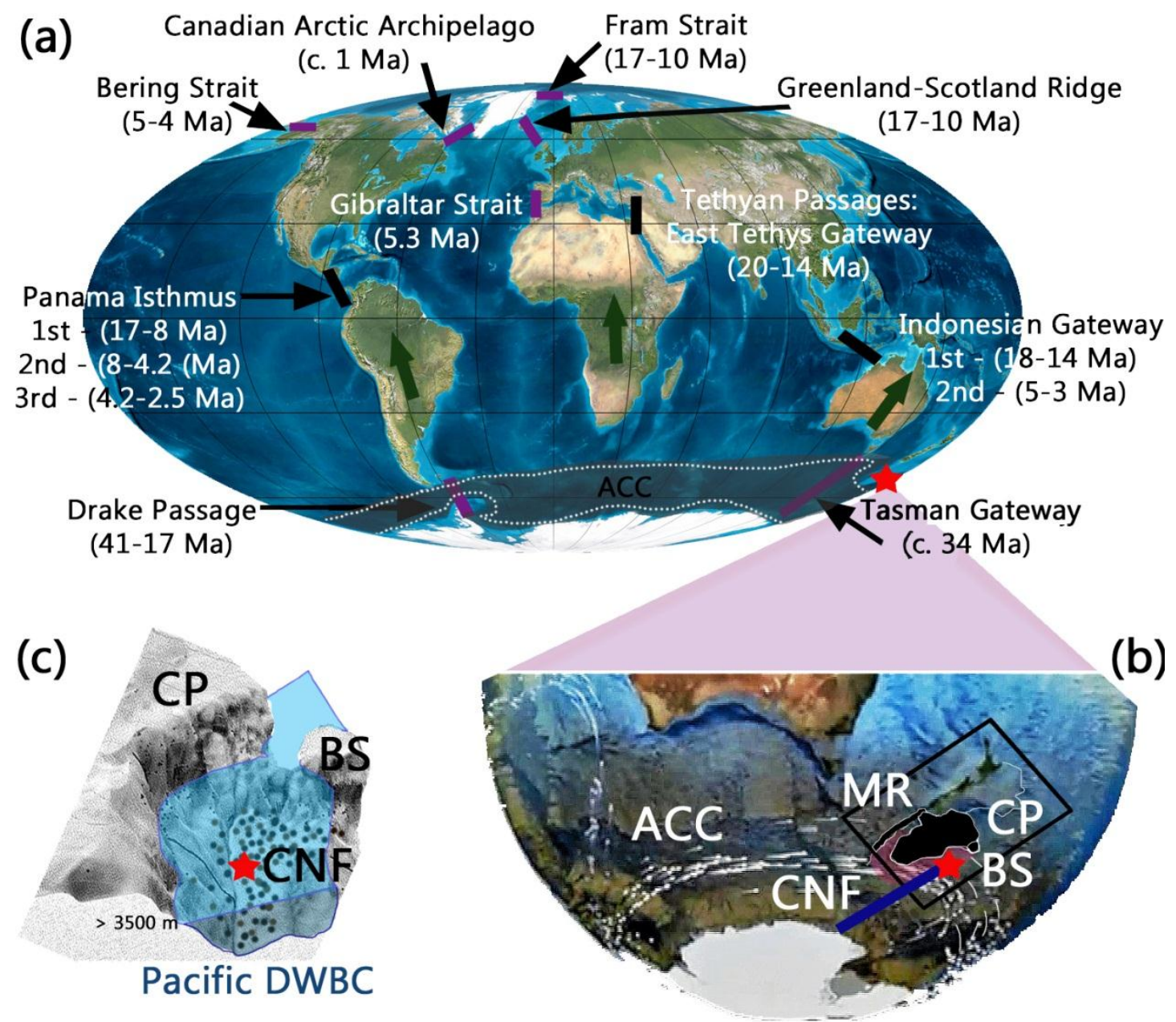

Figure 2.3 | Oceanic gateway events of the Late Neogene and the Southwest Pacific gateway of the Pacific DWBC. (a) Major ocean 'gateway' events since formation of the ACC. Continental arrows indicate the direction of continental drift with Antarctic and Arctic Seaways opening (purple 'gates') as equatorial, Tethyan Passages, have closed (black 'gates'), modified from Frank (2002). (b) Key bathymetric elements of the New Zealand sector of the Southern Ocean displaying the CP=Campbell Plateau, $\mathrm{MR}=$ Macquarie Ridge and BS= Bollons Seamount in black (insert box= Figure 2.4). The CNF= Campbell Nodule Field (pink area), north-eastern sector of the field - study area (red star) and ACC (white arrows) are also shown. Image modified from Shirah, et al. (2009). (c) The Pacific DWBC carrying chemical signals to the CNF, to be sequestered and archived by the underlying FMNs (brown dots), modified from (Chang, et al., 2003; see also Damuth, 1980).

The main body of the ACC-DWBC passes around the southern tip of Macquarie Ridge before entering the Emerald Basin as a series of meanders and deep reaching mesoscale eddies, reaching depths $>3000$ m (Boyer \& Guala, 1978; Morrow, et al., 1992; Hollister and Nowell, 1991). The Campbell Plateau on the other hand, serves as a solid barrier, forming part of the western margin of the Southwest Pacific Basin. The surface of the Plateau lies 
mainly at water depths between $400-1000$ m, apart from a series of volcanic Subantarctic Islands (Figure 2.4). Upper layers of the ocean, above and to the east of the Campbell Plateau, contain two major frontal systems; the SAF, associated with the northern boundary of ACC, separating cold polar waters to the south from subtropical waters to the north, and the STF, associated with the poleward limbs of the South Pacific Gyre. SAMW and AAIW bathe the top and eastern flank of the Campbell Plateau at depths of $400-1500$ m (Morris, et al., 2001; Figure $2.4 \& 2.5$ ). To the east, the Plateau descends steeply to the seafloor of the Southwest Pacific Basin at depths of c. 4000 - $5000 \mathrm{~m}$ (Nelson \& Cooke, 2001; Wright, et al., 2005).

On intercepting the Campbell Plateau the ACC-PDWBC is steered to the north, impinged along the c. $4000 \mathrm{~m}$ high scarp of the Subantarctic Slope (Figure 2.4). Interaction of the current system with the plateau enhances high energy eddy systems associated with the SAF, which impart kinetic energy to the underlying Pacific DWBC and seabed (Bryden \& Heath, 1985; Hughes \& Ash, 2001). The momentum creates fast flowing bottom currents up to $29 \mathrm{~cm} / \mathrm{s}$ along the south-eastern margins of the Plateau (Carter \& McCave, 1997; Carter \& Wilkin, 1999), beneath which the Campbell Nodule Field is distributed (Wright, et al., 2005). On meeting Bollons Seamount the ACC-PDWBC system separates, marking the northern extent of the nodule field about the flanks of the seamount (Figure 2.3(b, c); Wright, et al., 2005). The ACC continues its circum-antarctic circuit across the southern Pacific Ocean while the $1000 \mathrm{~km}$-wide DWBC continues north along the Campbell Plateau, across the Bounty Fan, around the eastern edge of Chatham Rise, to pass through the Valerie Passage and on to the Tonga-Kermadec Ridge, where it continues into the Greater Pacific Ocean (Figure 2.4; Carter \& McCave, 1994; Carter et al., 1999).

The ACC-PDWBC system is thus strongly influenced by oceanographic and continental processes of eastern New Zealand. Carter et al., $(1996,2004)$ proposed the Eastern New Zealand Sedimentary System (ENZOSS) to connect the climatic, oceanographic, sedimentary and tectonic processes controlling the sedimentary regime beneath the PDWBC. ENZOSS sediment supply to the study area is presently dominated by terrigenous sediments from the rising mountains of the South Island (Figure 2.4). Land derived sediments are introduced to the ACC-PDWBC via extensive submarine 


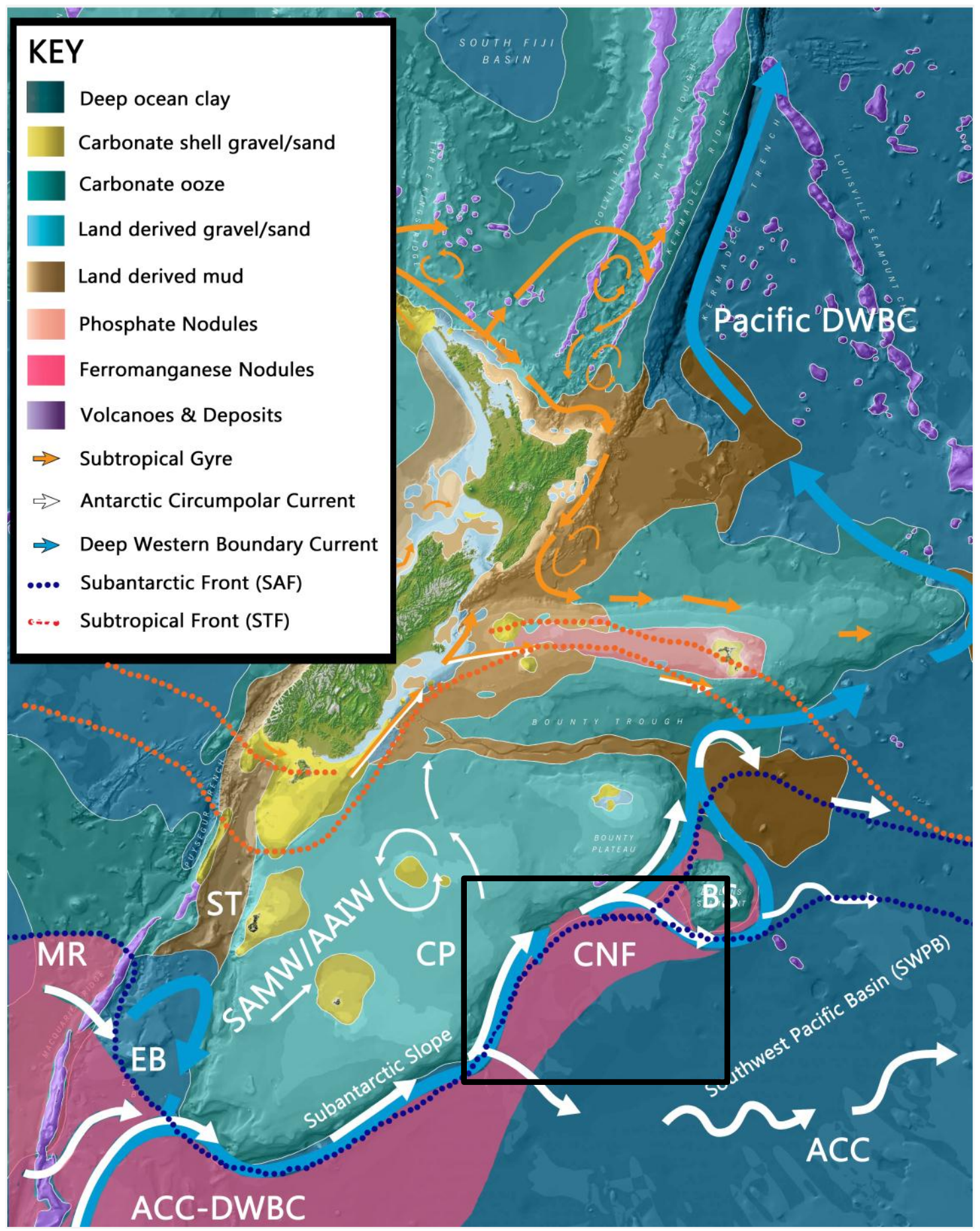

Figure 2.4 | Ocean circulation and seafloor sediments of the New Zealand Oceanic Gateway. Ocean circulation patterns are represented by arrows of varying width and colour. Deep water circulation patterns are represented by wider arrows and shallower circulation by narrower arrows. Colour codes for the arrows are listed in the key. Seafloor sediments are also colour coded and listed within the accompanying key. Annotated features of the gateway are; Macquarie Ridge (MR), Solander Trough (ST), Emerald Basin (EB), Campbell Plateau (CP), Campbell Nodule Field (CNF), Bollons Seamount (BS). The study area is denoted by the black outline and illustrated in detail in Figure 2.6. Image modified from Orpin, et al. (2008). 


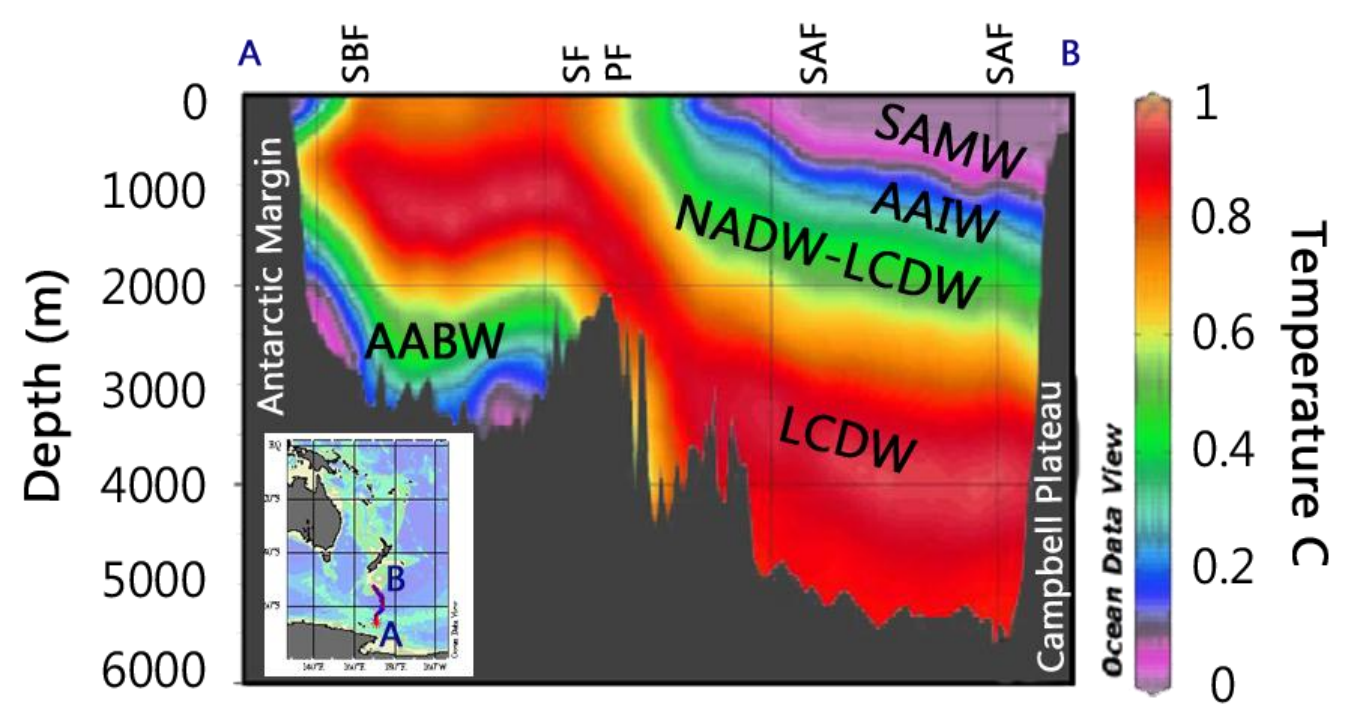

Figure 2.5 Structure of water masses from the Antarctic continent to the Campbell Plateau. Antarctic Bottom Water (AABW), Lower Circumpolar Deep Water (LDCW), North Atlantic Deep Water (NADW), Antarctic Intermediate Water (AAIW), Subantarctic Mode Water (SAMW). Image derived using data from 'P14 south' the World Ocean Circulation Experiment (see also Daly, et al., 2001), using Ocean Data View (see also Schlitzer, 2002).

channels and their prograding fan complexes. South of the study area (Figure $2.4 \& 2.6$ ), the Solander Trough has intercepted the path of the ACC-PDWBC system since c. $3 \mathrm{Ma}$, injecting a source of land-derived sediments into the current (Figure 2.4), which is most apparent during shallow glacial conditions (Carter \& McCave, 1997). An alternative local source of sediments to the ACC-PDWBC is derived from accumulations of calcareous and siliceous shells deposited above the carbonate compensation depth (CCD, < 4500m; Thuman \& Trujillo, 2004), illustrated by the presence of carbonate ooze in Figure 2.4. Additionally, dissolution of shells and tests below the CCD provide a source of dissolved and organically complexed chemicals to the current system. Furthermore, intermittent volcanic sources of chemicals and sediments have been evidenced in the region, derived from the Subantarctic Islands (e.g. Timm et al., 2010) and further afield, including the Taupo Volcanic Zone (e.g. R. Carter, et al., 2004; Figure 2.4). However, for the most part, intensified current activity of the ACC-PDWBC prevents the accumulation of detrital and biogenic sediments providing ideal conditions for the precipitation of Fe-Mn minerals, and thus the formation of the Campbell Nodule Field (Graham et al., 2004; Figure 2.6). 


\subsection{The Campbell Nodule Field}

The Campbell Nodule Field (CNF) extends $1700 \mathrm{~km}$ along the southern and south eastern margin of the Campbell Plateau at water depths of 4000 - $5200 \mathrm{~m}$ (Wright, et al., 2005) and is part of a much larger field, a few hundred kilometers wide, that encircles much of the Antarctic continent (Fakes \& Moreton, 1990). Knowledge regarding the timing of nodule formation, mechanisms of growth, and the relationship between the nature of the ferromanganese nodule (FMN) deposits and the overlying PDWBC, was unknown until a RV Tangaroa cruise to the north-eastern sector of the field was undertaken in 1991. Seafloor mapping, photography and dredging along two transects were used to determine nodule characteristics and to map their distribution beneath the Pacific DWBC (Figure 2.6; Chang, et al., 2003; Graham, et al., 2003; Graham, et al., 2003b; Wright, et al., 2005). Previous studies on FMNs from the study area (and region) describe the occurrence and chemistry of FMNs with limited discussion on the mechanisms of nodule formation and the paleoceanographic evolution of the ACC-PDWBC from within this region (e.g. Summerhayes, 1967; Margolis, 1973, 1975; Meylan, et al., 1975; Glasby \& Summerhayes, 1975; Glasby, 1976; Watkins \& Kennet, 1977; Glasby, et al., 1980; Carter, 1989; Glasby \& Wright 1990; Glasby, et al., 1991; Usui, et al., 1993; Usui \& Someya, 1997).

Across the study area from west to east, FMN shape, size, seafloor density and the underlying seafloor sediments, were found to vary with distance away from the Subantarctic Slope and five distinct nodule facies were identified (Wright, et al., 2005; Figure 2.6). The Upper Subantarctic Slope is covered by a thin layer of sediment, the 'Campbell Skin Drift' (Carter \& McCave, 1997; Chang, et al., 2003; Wright, et al., 2005), which is littered with ice rafted boulders and occasional whale bones coated in ferromanganese (Figure 2.6 see also Figure 3.4). At Ocean Drilling Program (ODP) Site 1121 (Leg181), the Campbell Skin Drift contains buried nodules at several stratigraphic horizons, entrapped by periods of faster sedimentation (R. Carter, et al., 2004; Graham, et al., 2004). South-east of Antipodes Islands, sediments grade into a mixed nodule-sediment, composed of abundant hydrogenous (derived from seawater) FMNs of uniform size and density (SHH facies; Figure 2.6(e)). The Lower Subantarctic Slope is composed of a mobile sediment belt characterised by well-developed sand ripples (Figure 2.6(a)), which 

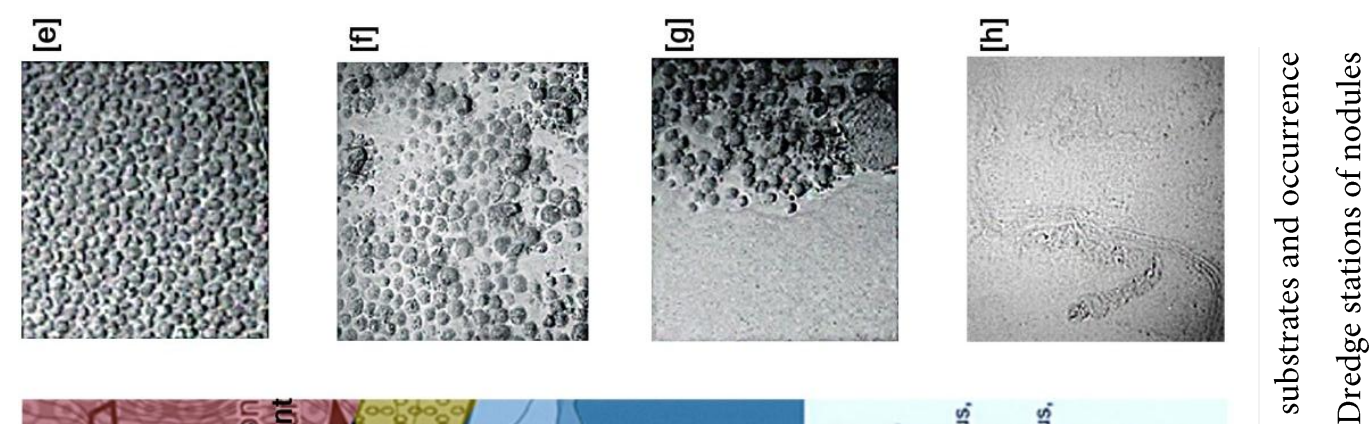

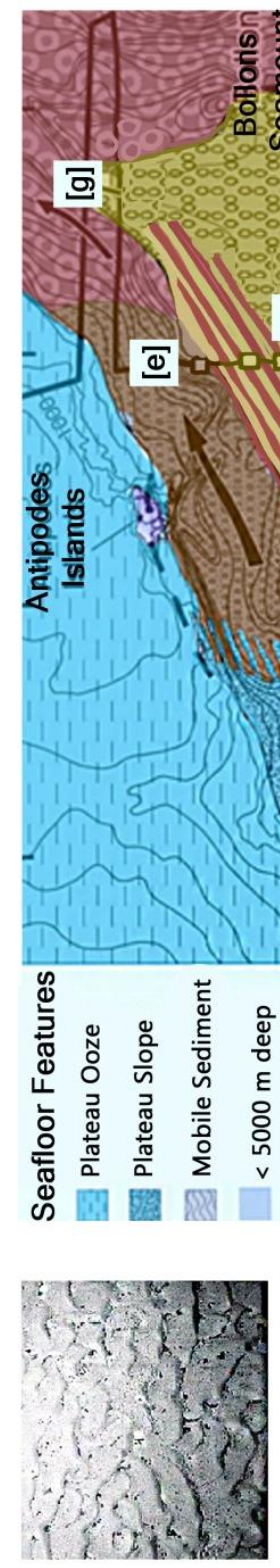

匹

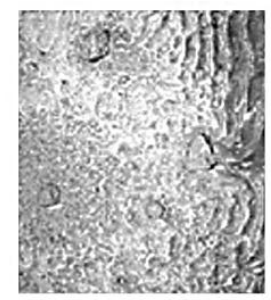

$\overline{\underline{a}}$

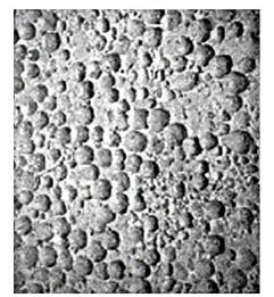

$\bar{\Xi}$

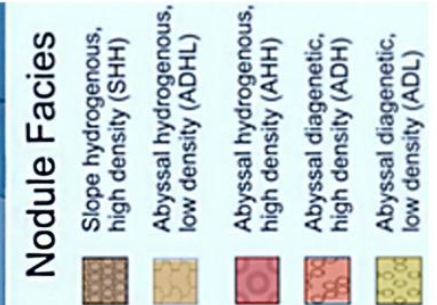

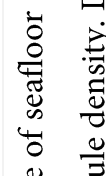

范

:ี

ㅇ․
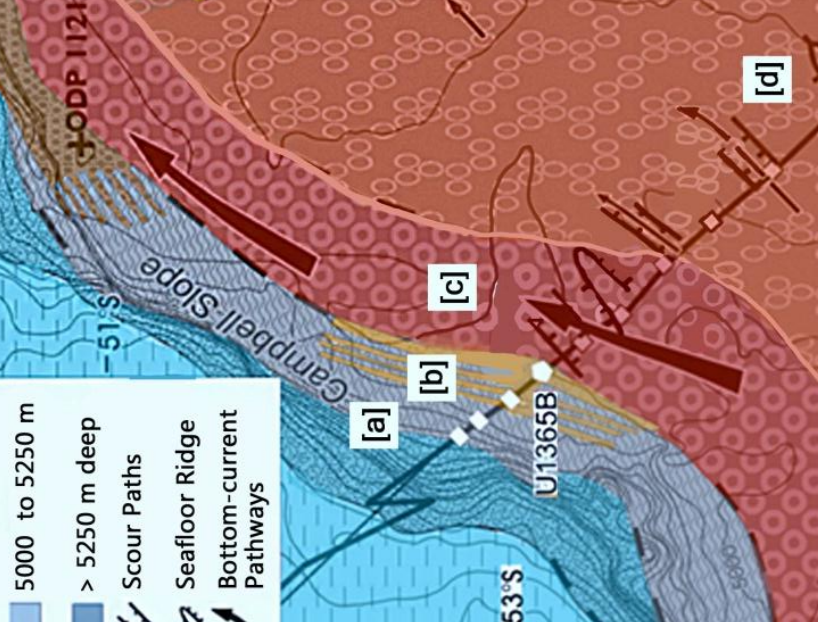

ㅎ

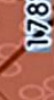

च

氙

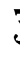

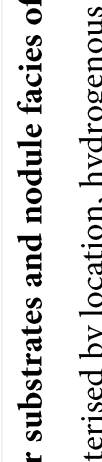

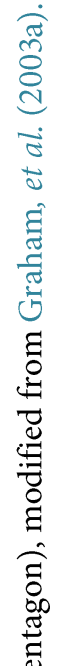

崩

竞

敛

ह

,

금

:

¿

ङ

$\frac{\omega}{0}$.

i

壳

므 
in regions, is overlain by hydrogenous and diagenetic (derived from pore waters) FMNs of low density (ADHL facies; Figure 2.6(b)). East of the sediment belt, the main nodule field abuts the base of the Subantarctic Slope at water depths of 4000-5200 m. The field forms a c. $300 \mathrm{~km}$ wide belt at $55-53.5^{\circ} \mathrm{S}$, narrowing to c. $100 \mathrm{~km}$ at $51^{\circ} \mathrm{S}$, where the field divides around Bollons Seamount (Carter, 1989; Wright, et al., 2005). The main nodule field is locally eroded into 2 - $3 \mathrm{~km}$ wide active scour paths incised by faster flow filaments of the ACC-PDWBC (Figure 2.6). Beneath the fast flowing currents abyssal hydrogenous FMNs grow in high abundance (AHH facies; Figure 2.6(c)) grading from hydrogenous to diagenetic eastward, as currents weaken and sediment cover increases (ADH facies; Figure 2.6(d); ADL facies; Figure 2.6(f)). Additionally, nodule density diminishes laterally, grading from high to low density facies over c. 50 - $100 \mathrm{~km}$, into abyssal seafloor sediments of the Southwest Pacific Basin. These sediments are composed of bioturbated clays and are completely devoid of FMNs (Figure 2.6(h)). In contrast, to the north-west the nodule field terminates abruptly along the flanks of Bollons Seamount (Chang, et al., 2003; Wright, et al., 2005; Figure 2.6(g)).

A representative selection of FMNs from various facies were studied to determine; distribution and morphology (Chang, et al., (2003), petrography and chemistry (Graham et al., 2003a) and deposit ages (Graham, et al., 2003b). The key conclusions were that FeMn precipitation began at c. $14 \mathrm{Ma}$, with the oldest and largest hydrogenous FMNs generally forming beneath the strongest ACC-PDWBC pathways, impinged along the Subantarctic Slope. Internally, FMNs illustrated a wide variety of macro- and microscopic growth textures with growth rates and chemical contents generally decreasing from core to rim (see Graham, et al., 2003a for more details). Changes in nodule architecture and chemistry were interpreted to reflect changes in the physical and chemical characteristics of the PDWBC in response to local, regional and global environmental changes (Wright, et al., 2005; Graham \& Wright, 2006). Thus, research into the changing elemental and lead isotopic compositions of the largest nodule (U1365B-M) recovered from the field, will cast new light on the history of the PDWBC, which has played an essential role in controlling Southern Hemisphere and global climate over the nodules 14 - 13 Myr growth history. 


\section{Chapter}

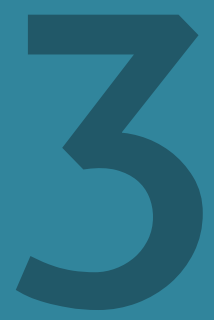

Details the theoretical context behind the genesis of FMNs and their use as abyssal archives of ancient seawater chemistry

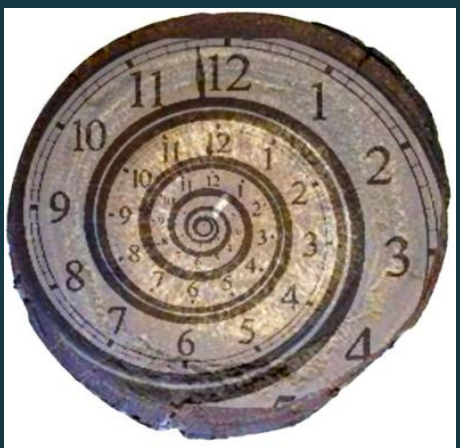

\section{Ferromanganese Nodules} Abyssal Archives of Past Ocean Chemistry

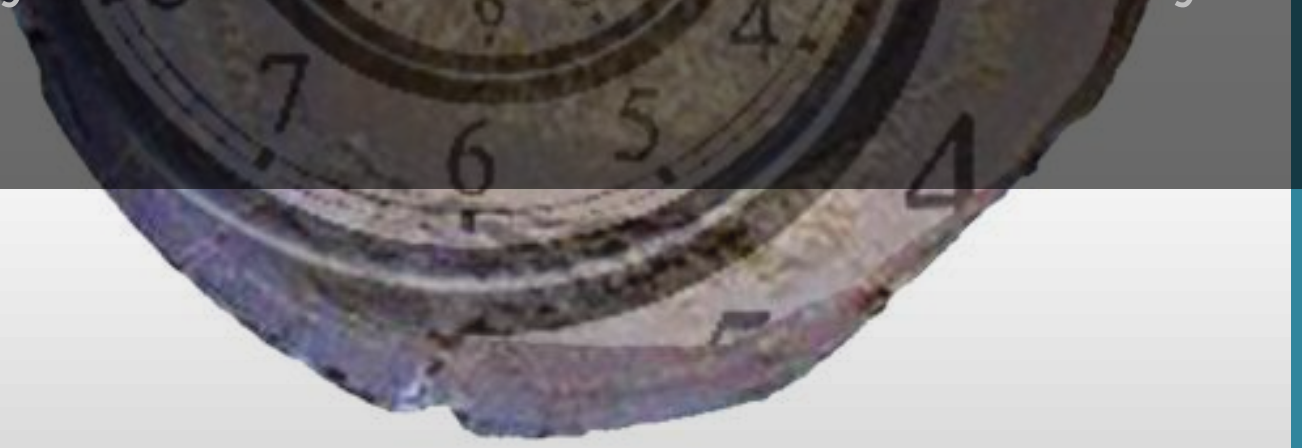

3.1 Abyssal Archives

3.2 Formation \& Classification

3.3 Physical Archives

3.4 Chemical Archives 


\subsection{Abyssal Archives}

FMNs are composed of intricate mixtures of Fe-Mn minerals and detrital grains. The former are precipitated directly from seawater over several millions of years, forming a series of concentric layers that each hold a record of the chemical composition of the deep ocean at the time of deposition (Hein, et al., 1992; Frank, et al., 2002). In contrast, detrital grains, entrapped during growth, are derived from the surrounding landmass and(or) reworked seafloor sediments, providing a record of continental erosion and(or) phases of strong bottom water activity (Banakar, et al., 1993, 2003; Banakar, 2010). The proportion of entrapped detrital minerals, and the elemental and isotopic composition of Fe-Mn minerals, thus provide a wide range of information on: sediment (element) sources, the mode and nature of sediment (element) transport, past climate changes, ocean circulation patterns, current speeds, organic fluxes, deep sea ventilation (redox), and changes in the mechanism of nodule formation (Glasby, 2000; Goldstein \& Hemming, 2003; Calvert \& Pedersen, 2007). Additionally, the internal structure of FMNs can be used to discern major changes in the depositional environment through variations in texture, microscopic growth structures and growth rates (Segl, et al., 1989; Mangini, et al., 1990). As such, the physical and chemical archives of FMNs can be used to reconstruct the paleoenvironment of deposition, providing a record of the major paleoceanographic events over the nodules growth history (Calvert \& Pedersen, 2007).

A pre-requisite for paleoceanographic interpretation is an accurate chronological framework, upon which the history of the deep ocean can be constructed. Attempts to date FMNs have employed various approaches including strontium $\left({ }^{87} \mathrm{Sr} /{ }^{86} \mathrm{Sr}\right.$ ) ratios (Hein, et al., 1993; Burton, et al., 1997), magnetostratigraphy (Joshima \& Usui, 1998; Oda, et al., 2011) and recently, osmium $\left({ }^{187} \mathrm{Os} /{ }^{188} \mathrm{Os}\right)$ ratios (Nielsen, et al., 2011). The most precise age and growth rate estimates have been obtained using thorium $\left({ }^{230} \mathrm{Th} /{ }^{232} \mathrm{Th}\right)$ ratios, however, such chronologies are restricted to the last $\sim 400 \mathrm{kyrs}$ (Segl, et al., 1984; Abouchami, et al., 1997; Han, et al., 2009). The application of cosmogenic beryllium $\left({ }^{10} \mathrm{Be}\right)$, normalised to its stable isotope $\left({ }^{9} \mathrm{Be}\right)$, have been shown to give reliable results on chronologies back to c. 10 $15 \mathrm{Ma}$ (Ling, et al., 1996; Frank, et al., 1998; Ding, et al., 2009; Zhang, et al., 2013) and are supported by recently developed Os isotope stratigraphy (Klemm, et al., 2005, 2008). 
The two isotopes of beryllium have distinctly different origins. Dissolved ${ }^{9} \mathrm{Be}$ is sourced from continental material and ${ }^{10} \mathrm{Be}$ from the interaction of cosmic rays with oxygen and nitrogen atoms in the upper atmosphere (Bourles, et al., 1989). Spallation of these atoms produces particle-reactive ${ }^{10} \mathrm{Be}$ that absorbs onto aerosols and is rapidly transferred to the Earth's surface via precipitation (Raisbeck, et al., 1981). If deposited in a continental setting, ${ }^{10} \mathrm{Be}$ interacts with the nuclei of atoms on surface sediments where it decays with a half-life of $\sim 1.4 \mathrm{Ma}$ (Korschinek, et al., 2010; Chmeleff, et al., 2010) and thus can be used to date sediments to c. 10 - $15 \mathrm{Ma}$ (Glasby, 2000; Frank, et al., 1999, 2009). If deposited in the ocean, ${ }^{10} \mathrm{Be}$ is effectively removed from the water column on settling particles and accumulates in deep sea sediments. FMNs acquire ${ }^{10} \mathrm{Be}$ as they grow by accretion of the settling particles directly from seawater (Turekian \& Bacon, 2003; Willenbring \& von Blanckenburg, 2010). Once in the ocean, ${ }^{10} \mathrm{Be}$ and land derived ${ }^{9} \mathrm{Be}$ have oceanic residence times of c. 500 years and thus concentrations are effectively homogenised by advection and water mass mixing, making it effectively independent of its locus of delivery (Turekain \& Cochran, 1979).

The beryllium isotope dating method, used for this thesis (see Graham, et al., 2003b, Graham \& Ditchburn, 2006 unpublished), employs the isotopic ratio of ${ }^{10} \mathrm{Be} /{ }^{9} \mathrm{Be}$, as isotopic concentrations are affected by variable scavenging on settling particles and the exposed surface of FMNs (Somayajulu, 2000). As differential scavenging and ocean homogenisation affect both ${ }^{10} \mathrm{Be}$ and ${ }^{9} \mathrm{Be}$ isotopes equally, so that, any variations in the above processes, do not change the ${ }^{10} \mathrm{Be} /{ }^{9} \mathrm{Be}$ value, ${ }^{10} \mathrm{Be}$ is normalised with respect to ${ }^{9} \mathrm{Be}$ (Willenbring \& von Blanckenburg, 2010). Given the fundamentally different input sources of Be isotopes, the method applies only to the dissolved fraction, associated with the hydrogenous component of FMNs (Bourles, et al., 1989). Sequential leaching techniques have thus been developed to selectively extract the authigenic phase in order to measure its ${ }^{10} \mathrm{Be} /{ }^{9} \mathrm{Be}$ (Bourles, et al., 1989; Graham, et al., 2003b). The resulting authigenic ${ }^{10} \mathrm{Be} /{ }^{9} \mathrm{Be}$ thus represents soluble beryllium present at the time of deposition and can be used to develop a chronological framework. Beyond 10 - $15 \mathrm{Ma}$ Be isotope dating becomes inaccurate, as ${ }^{10} \mathrm{Be}$ concentrations fall below accelerator mass spectrometry (AMS) detection limits. The only other geochemical tool available for estimating age and growth rates beyond this age are cobalt (Co) chronometers and flux models (Frank, et al., 1999). 
Cobalt chronometry relies on the assumption that Co has a short residence time in the oceans, as it is effectively scavenged by the authigenic mineral vernadite $\left(\delta \mathrm{MnO}_{2}\right)$ thus, the Co-flux to the deep ocean, on temporal and regional scales, is thought to be constant. Changes in the concentration of Co are interpreted to reflect a change in growth rate with high concentrations resulting from low accretion rates, allowing more time for the scavenging of Co from ambient seawaters (vice versa for low concentrations). A series of cobalt chronometers have been developed to derive growth rates from Co concentrations (Halbach, et al., 1983; Manheim, 1986; Puteanus \& Halbach, 1988; Manheim \& LaneBostwick, 1988; Frank, et al., 1999; Table 3.1). Additionally, Co-flux models can be applied, when growth rates are calculated from the logarithmic fit of beryllium derived growth rates and Co concentrations (in wt\%). The age is then determined from the calculated Co growth rates and extrapolated beyond samples dated by beryllium cosmochronometry, to derive older chronologies and accretion rates.

The equation of Manheim (1986) is considered the most applicable chronometer, used on a wide variety of ferromanganese deposits with $\left[\mathrm{Co}_{\mathrm{w}}\right]$ referring to the concentration of Co (wt\%). The chronometer of Halbach, et al. (1983) is more specifically designed for Corich deposits and that of Frank, et al. (1999) for Co-poor deposits. The use of Co chronometers to date FMNs and crusts in excess of $10 \mathrm{Ma}$ has been applied extensively (e.g. Frank, et al., 1999; van der Flierdt, et al., 2004; Banerjee, et al., 2010), however their application has recently been brought into question (see Nielsen, et al., 2011).
Type
Equation
Author

All FMN deposits

$\mathrm{G}(\mathrm{mm} / \mathrm{Ma})=0.68 /\left[\mathrm{Co}_{\mathrm{w}}\right]^{1.67}$

Manheim (1986)

Co-rich crusts

$(0.2-2$ wt $\%)$

$\mathrm{G}(\mathrm{mm} / \mathrm{Ma})=1.28 /\left[\mathrm{Co}_{\mathrm{w}}\right]-0.24$

Halbach et al. (1983)

Co-poor deposits

$(<0.3$ wt $\%)$

$\mathrm{G}(\mathrm{mm} / \mathrm{Ma})=0.25 /\left[\mathrm{Co}_{\mathrm{w}}\right]^{2.69}$

Frank et al. (1998)

Table 3.1 | Cobalt chronometers of Manheim (1986), Halbach, et al. (1983) and Frank, et al. (1998) 
An important consideration before using Co chronometers is to assess whether older FMN (\& crusts) sections have been altered by phosphatisation. This occurs when older FeMn minerals are impregnated with carbonate fluorapatite, which effectively 'dilutes' the chemical composition of these zones and thus the efficiency of the Co-chronometer (Puteanus \& Halbach, 1988; Koschinsky, et al., 1997). Phosphatisation is a common feature of Fe-Mn crusts from the Central and South Pacific Ocean. Within the New Zealand region an episode of phosphatisation occurred during the Middle Miocene Climate Optimum resulting in widespread phosphate deposits across the Chatham Rise and Campbell Plateau (Figure 2.4). During the Middle Miocene Climate Transition into colder more oxygenated conditions, phosphate deposits were superseded by $\mathrm{Fe}-\mathrm{Mn}$ precipitation, to form the Campbell Nodule Field (Glasby \& Summerhayes 1975; Graham, et al., 2004). On assessing FMNs collected from the field, Summerhayes (1967) and Glasby (1970) found nodules to contain carbonate fluorapatite with up to $3 \% \mathrm{P}_{2} \mathrm{O}_{5}$. Additionally, Glasby \& Summerhayes (1975) found that some FMNs had grown around older phosphorite nodules. Concerns as to whether U1365B-M had grown around an older phosphate deposit or developed an older nodule zone altered by phosphatisation, can be rejected as Graham, et al. $\left(2003_{\mathrm{a}}\right)$ report $0.6 \% \mathrm{P}_{2} \mathrm{O}_{5}$ for the oldest sections of nodule U1365B-M.

An additional concern when using either ${ }^{10} \mathrm{Be} /{ }^{9} \mathrm{Be}$ dating or Co-chronometry is that they fail to identify hiatuses of erosion or non-deposition, which are generally visible from macroscopic and microscopic changes in the structure of ferromanganese precipitates (Banakar, et al., 1993; Banerjee, et al., 1999; Pulyaeva \& Hein, 2010). Hiatuses may result from: (1) a cessation in ferromanganese oxyhydroxide precipitation due to changes in ambient chemical conditions; (2) submarine weathering via chemical dissolution; (3) physical erosion by abyssal currents and; (4) periodic burial under a layer of sediment preventing oxyhydroxide precipitation, which is later removed by erosive bottom currents to re-establish precipitation. Unconformities can be identified in back-scattered electron images (BSE) as sharp boundaries that truncate pre-existing growth structures and reflect local, regional or basin-wide changes to the physical and chemical properties of the ocean (e.g. Segl, et al., 1989; Banakar, et al., 1993). 


\subsection{Formation \& Classification}

The formation, distribution and composition of FMNs vary from ocean to ocean, basin to basin and within basins (Zhang, et al., 2013) reflecting: (i) availability of nucleating seeds for nodule growth; (ii) local, regional and global fluxes of elements and their proximity to nodule fields; (iii) seafloor topography, with major fault zones, seamounts, abyssal slopes and hills, forming preferred locations for nodule formation, and; (iv) the circulation pathways of vigorous abyssal currents, typically dominating water depths of $4000-6500$ $\mathrm{m}$. These abyssal currents restrict sediment deposition to rates generally below $10 \mathrm{~mm} \mathrm{ky}^{-1}$ (Mero, 1965; Glasby, 2000; Hein \& Koschinsky, 2013). Over millions of years, vigorous abyssal currents have provided an oxygenated environment, enabling the precipitation of elements from these waters to form Fe-Mn minerals, and kinetic energy to maintain nodules at the sediment-water interface (in addition to bioturbation) (Usui, et al., 1993; Koschinsky \& Hein, 2003; Mukhopadhyay, et al., 2008; Figure 3.1).

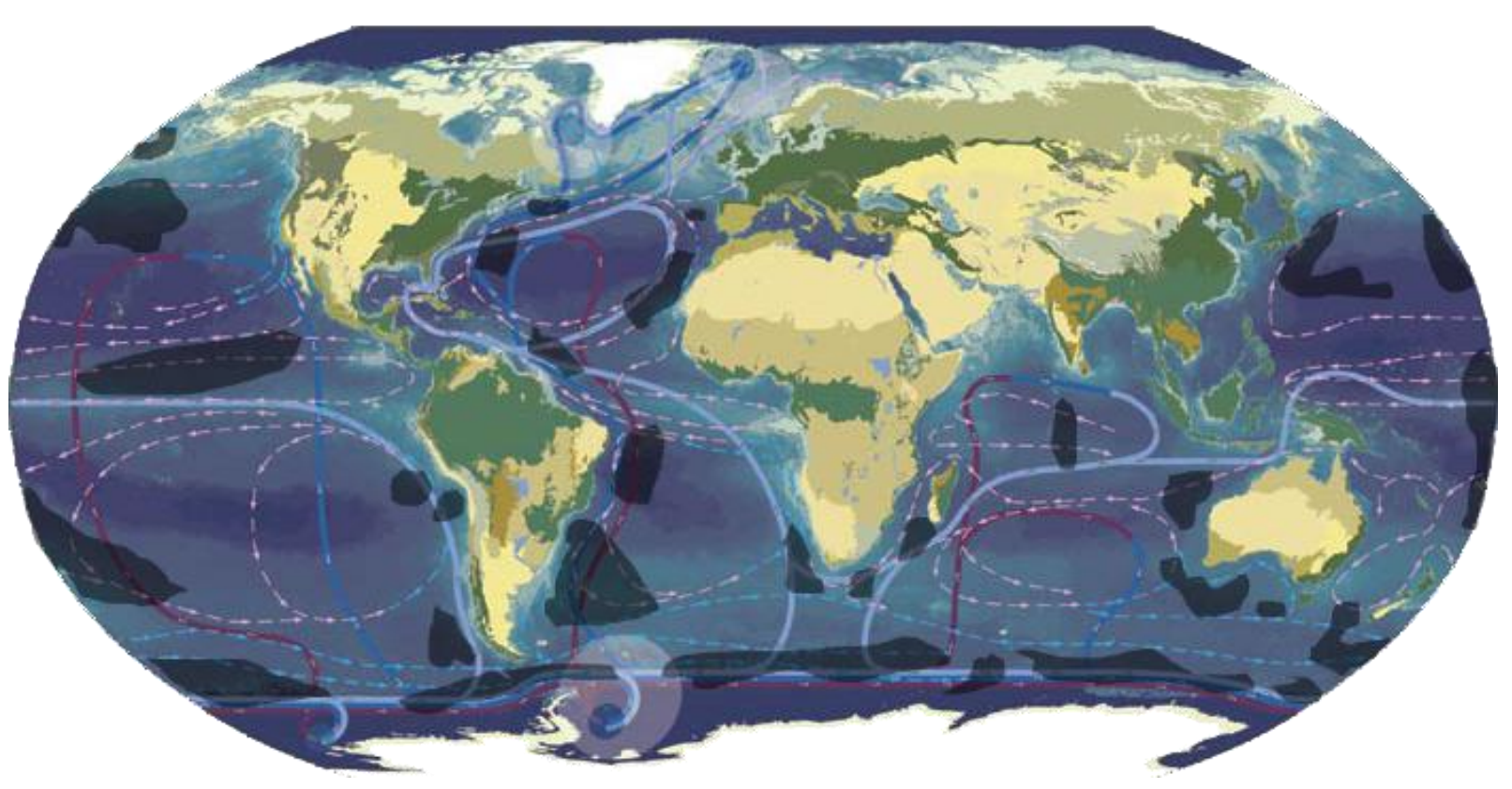

Figure 3.1 | Global distribution of FMN fields and ocean circulation. Map of main nodule fields (dark blue) in relation to ocean circulation patterns: (i) deep to bottom waters $>3500 \mathrm{~m}$ (dark purple); (ii) intermediate to deep waters (light purple); (iii) intermediate waters of 2000 - $3500 \mathrm{~m}$ (dark blue); (iv) surface to intermediate waters (green blue) and; (v) surface waters of $0-2000 \mathrm{~m}$ (light blue). The distribution of nodule fields were assembled from: Rawson \& Ryan (1978); Piper, et al. (1985); Fakes \& Moreton (1990), and; Glasby, (1977a, 1984, 2000). Image modified from Hein, et al. (2013). 
The formation of extensive nodule fields reflects the abundance of $\mathrm{Mn}$ and Fe in the Earth's crust and their ability to migrate under the influence of redox gradients from low to oxygen-rich environments (Glasby, 2000). With increasing distance below the oxygen minimum zone (OMZ; a region of low ocean oxygen due to organic decomposition and limited vertical mixing), and within areas where AAIW and NADW sink to ventilate the mid to deep ocean, seawater becomes saturated in dissolved Mn and Fe (Mero, 1965; Glasby, 2000; Figure 3.1). Further addition of Fe and Mn below the OMZ zone, under optimum redox conditions ( $\mathrm{Eh}, \mathrm{pH}$, high $\mathrm{O}_{2}$ concentration) leads to supersaturation of these elements, forcing their precipitation into a solid authigenic phase (Goldberg, 1954; Hein, et al., 2013; Zhang, et al., 2013). The authigenic precipitates are small (10-10,000 $)$ and finely dispersed so that their descent through the water column is relatively slow ( 100 years; Hein, et al., 1997). These colloidal particles are electrically charged. Mn exists predominantly as $\mathrm{MnO}_{2}$ with a negative surface charge and $\mathrm{Fe}$ as $\mathrm{Fe}$-oxyhydroxides with a slightly positive surface charge (Mero, 1965; Hein et al., 2013; Figure 3.2). As the charged colloids slowly descend through the water column, they attract dissolved elements and compounds of opposite charge. Generally, dissolved cations such as $\mathrm{Co}^{2+}, \mathrm{Cu}^{2+}$, and $\mathrm{Ni}^{2+}$ are attracted to the negatively charged Mn oxides, whereas elements bound to carbonate ions (e.g. $\left.\mathrm{Pb}\left(\mathrm{CO}_{3}\right)_{2}{ }^{2-}\right)$, hydroxide ions (e.g. $\mathrm{Hf}(\mathrm{OH})_{5}{ }^{-}$) and other large complexes (e.g. $\mathrm{MoO}_{4}{ }^{2-}$ ) are attracted to the positive charge of Fe oxyhydroxides (Hein, et al., 1997; Figure 3.2). Thus, the ionic charge of an element or ionic compounds, influences how elements are eventually incorporated into different mineral phases (Koschinsky \& Hein, 2003). Further down the water column, as Fe and Mn become increasingly saturated and $\mathrm{O}_{2}$ concentrations rise, particles can combine to form larger $\mathrm{Fe}, \mathrm{Mn}$ and mixed $\mathrm{Fe}-\mathrm{Mn}$ colloids, which effectively "scavenge" trace elements from ambient seawater (Figure 3.2).

FMNs are classified based on the dominant source of elements as: (1) hydrogenous, derived from elements dissolved in seawater; (2) hydrothermal, sourced directly from hydrothermal solutions, and; (3) diagenetic, originating from interstitial pore waters of sediments (Glasby, 2000; Hein \& Koschinsky, 2013; Figure 3.3). Diagenetically sourced elements increase FMN growth rates by up to 2 - 50 times faster than hydrogenous counterparts, whose rates are on average $1 \mathrm{~mm} / 10^{6}$ years (von Stackelberg, 2000). Hydrothermal FMNs are the fastest growing of the three end-members due to their 


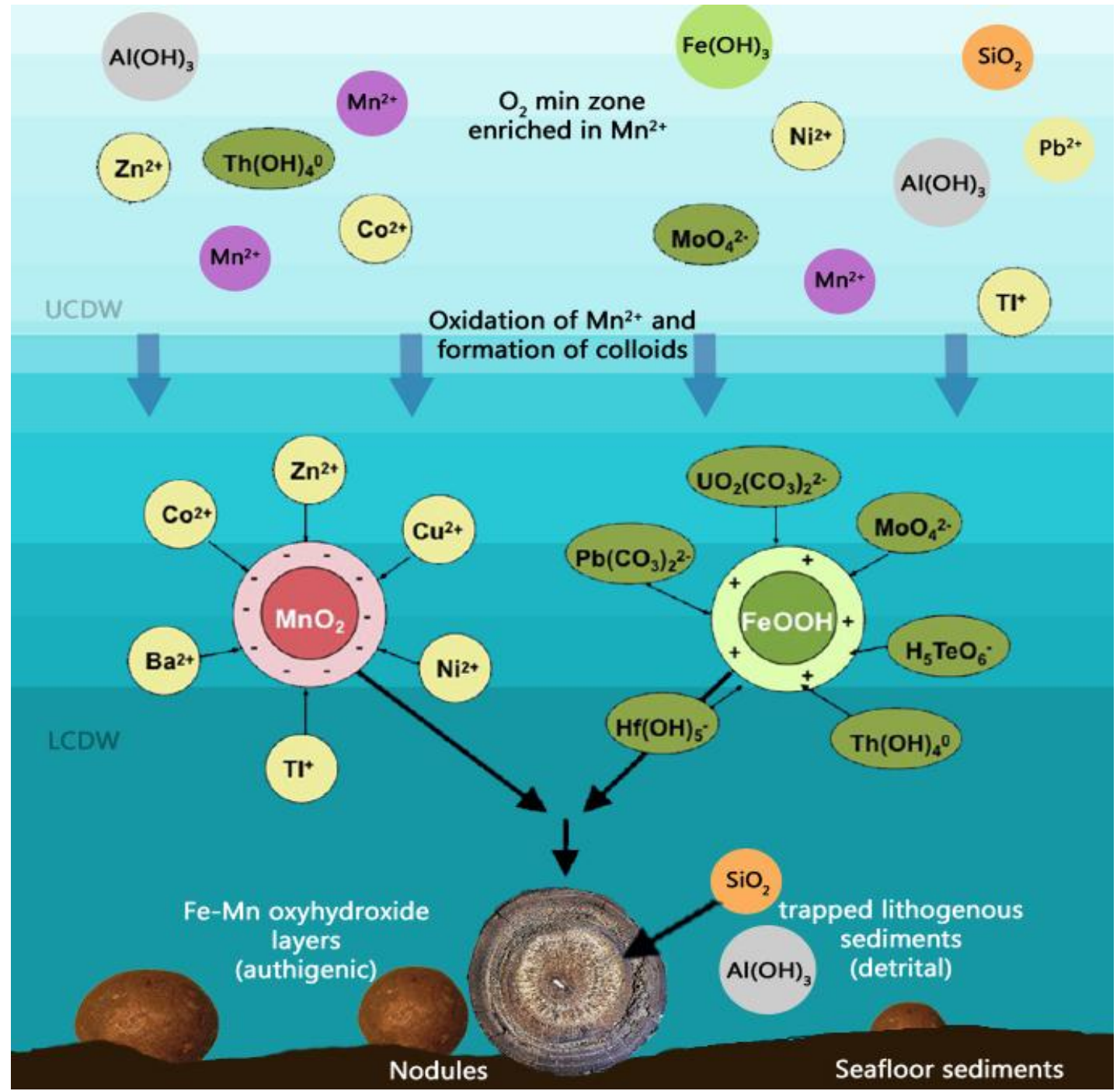

Figure 3.2 | Mechanisms of hydrogenous ferromanganese nodule formation. Simplified colloidalchemistry model of FMN formation illustrating the presence of dissolved elements above the $\mathrm{O}_{2} \min$ zone [UCDW (Southern Ocean)] and the precipitation of Fe and Mn below this zone, leading to the formation of $\mathrm{Mn}$ and $\mathrm{Fe}$ minerals, which effectively scavenge tracer elements of opposing charge from seawater. Fe-Mn minerals descend through the water column to the seafloor where they adhere to a nucleus and grow by addition of concentric layers, occasionally entrapping aluminosilicate minerals. Image modified from Hein, et al. (2013).

proximity to hydrothermal vents and voluminous supply of elements, and form crusts and pavements rather than FMNs (Hein, et al., 2013). Concentrations of scavenged elements can vary in response to: (1) changing environmental conditions in the source region; (2) changes in ocean circulation patterns and structure, in addition to other oceanographic parameters such as; (3) Eh-pH relationships; (4) primary productivity of surface waters; (5) depth of the OMZ, and; (6) carbonate compensation depth (Verlaan, et al., 2004). 


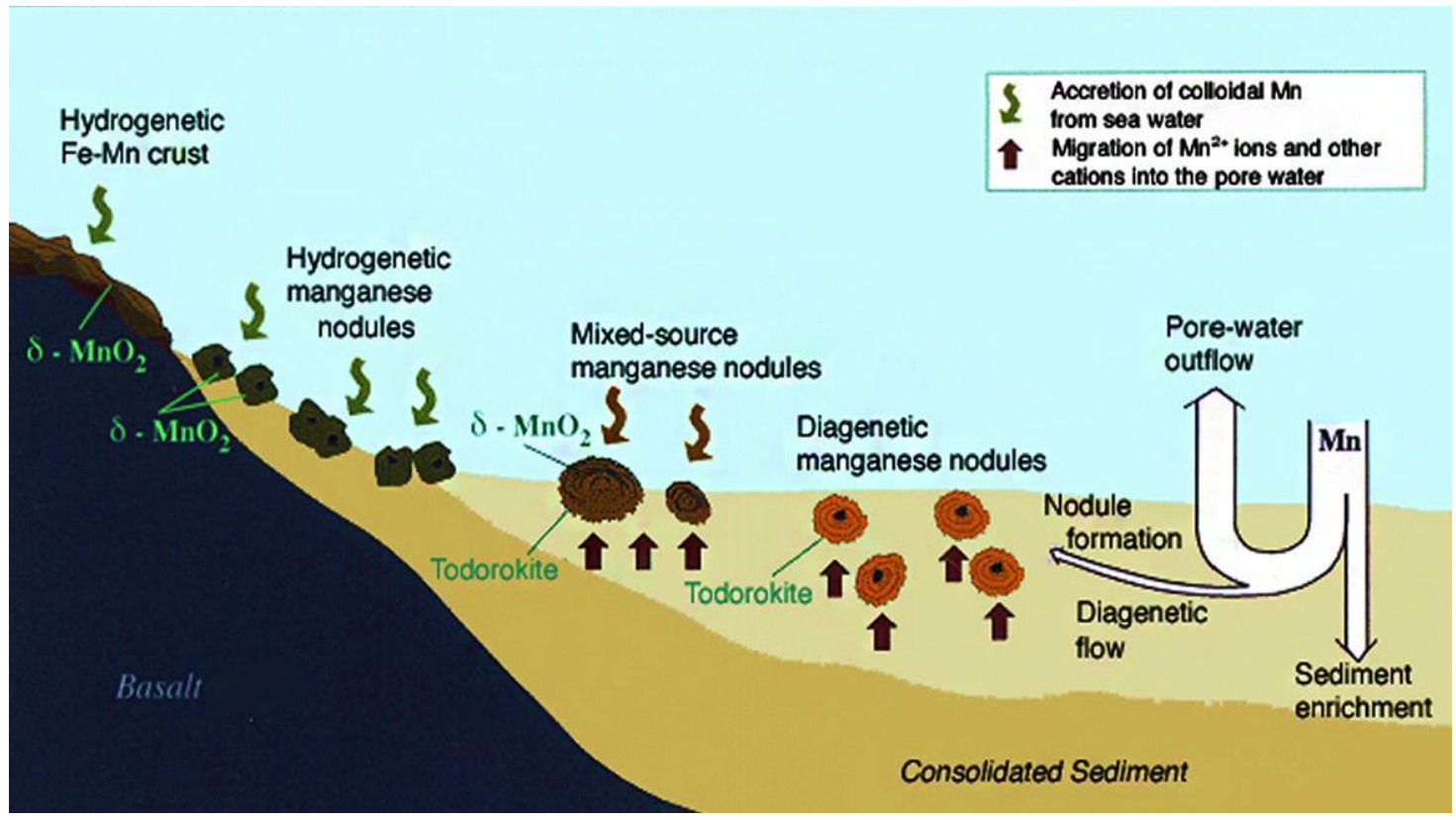

Figure 3.3 | Hydrogenous and diagenetic modes of nodule formation. The diagram illustrates hydrogenetic, diagenetic and mixed-source FMN formation. With increasing distance from abyssal slopes and seamounts FMNs generally become less hydrogenous in nature, commonly in association with decreased bottom current activity and increased sedimentation rates (Graham \& Wright, 2006). Thus FMNs general grade from a hydrogenous end-member composed of the Fe-Mn mineral vernadite $\left(\delta \mathrm{MnO}_{2}\right)$, through to a mixed-sourced nodule, followed by diagenetic FMNs, largely composed of the mineral todorokite. Diagenetic precipitation (upward facing arrows) involves elements derived from sediment pore fluids that consist of ocean water modified by chemical reactions within the sediment column. Hydrogenetic precipitation (downward facing arrows) occurs when FMNs grow directly from ambient seawaters. Mixed origin FMNs are more common than either of the end-member types (Glasby, 2000; Hein \& Koschinsky, 2013). Image modified from Hein et al. (2013).

\subsection{Physical Archives}

On reaching the deep ocean, colloids of Fe and $\mathrm{Mn}$ are transported by abyssal currents until they come into contact with a charged object, capable of adhering precipitates to its surface. Objects such as shark teeth, calcareous shells, bones, rock fragments and bacterial communities (coating seafloor substrates), act as electrical conductors, attracting the charged colloidal particles to the surface of the nuclei where they are 'fixed' by strong covalent bonds (Mero, 1965; Glasby, 2000). The initial layer of precipitates consists of mineralised and biomineralised Fe-oxyhydroxides, which act as a catalyst for the precipitation of Mn-minerals. Following the build-up of initial Fe-Mn mineral layers, the 
reaction becomes autocatalytic, whereby nodule material itself scavenges colloidal particles, dissolved elements and compounds from seawater (Koschinsky \& Halbach, 1995; Wang \& Müller, 2009; Wang, et al., 2010, 2012; Figure 3.2). Fine-grained lithogenous sediments are occasionally incorporated into the Fe-Mn mineral structures as they grow (Figure 3.2). The process continues indefinitely, provided the external adsorption surface remains exposed to surrounding seawater and biogeochemical conditions are optimal for growth (Hein, et al., 2007, 2013). Bacterial communities that grow within the matrix of Fe-Mn minerals attract feeding organisms and consequently, in an almost symbiotic relationship, the nodules are kept in a constant state of motion. This 'biogenic lifting', in addition to movement by strong bottom currents, maintains their location at the seafloor (von Stackelberg, 1984, 1997; Weber, et al., 2000; Yli-Hemminki, et al., 2014).

Over thousands to millions of years, FMNs develop concentric layers, composed of intricate mixtures of Fe-oxyhydroxides (reddish-brown), Mn-oxides (blue-black) and finegrained aluminosilicate grains (grey-white). Accreting colloidal particles naturally form spherically-shaped concretions, hence, generally, the more spherical the deposits, the greater the seawater component. However, there are other influences operating to modify the spherical shape such as: (i) the shape of nodule nuclei; (ii) predominance of hydrogenous, diagenetic, or hydrothermally sourced elements; (iii) proportion and size of trapped detrital grains; (iv) the degree of bioturbation and strength of bottom water currents and (v) density of neighbouring nodules and free space for growth (Mero, 1965; Koschinsky \& Halbach, 1995). Consequently, FMNs are found in a variety of forms (Figure 3.4). Furthermore, FMNs can be characterised by the nature of their internal structure, as revealed in whole-nodule cross-sections (Figure 3.5). Cross-sectional images form 'maps' with which to control analytical work and link physical and chemical data (Sorem \& Fewkes, 1972). Physical properties such as: (i) layer thickness; (ii) distribution of authigenic, Fe-oxyhydroxides and Mn-oxides, deduced from; (iii) colour; (iv) lustre; (v) hardness, and; (vi) porosity, are used to divide growth bands into a series of zones, characterised by similar properties, e.g. core, inner layers, central layers, outer layers and crust (Figure 3.5). Using this cross sectional approach it is possible to determine (i) the nature of the nodule nucleus, (ii) the thickness and continuity of layers, (iii) the number of major zones, (iv) textural features relating to porosity and massiveness, (v) distribution of 


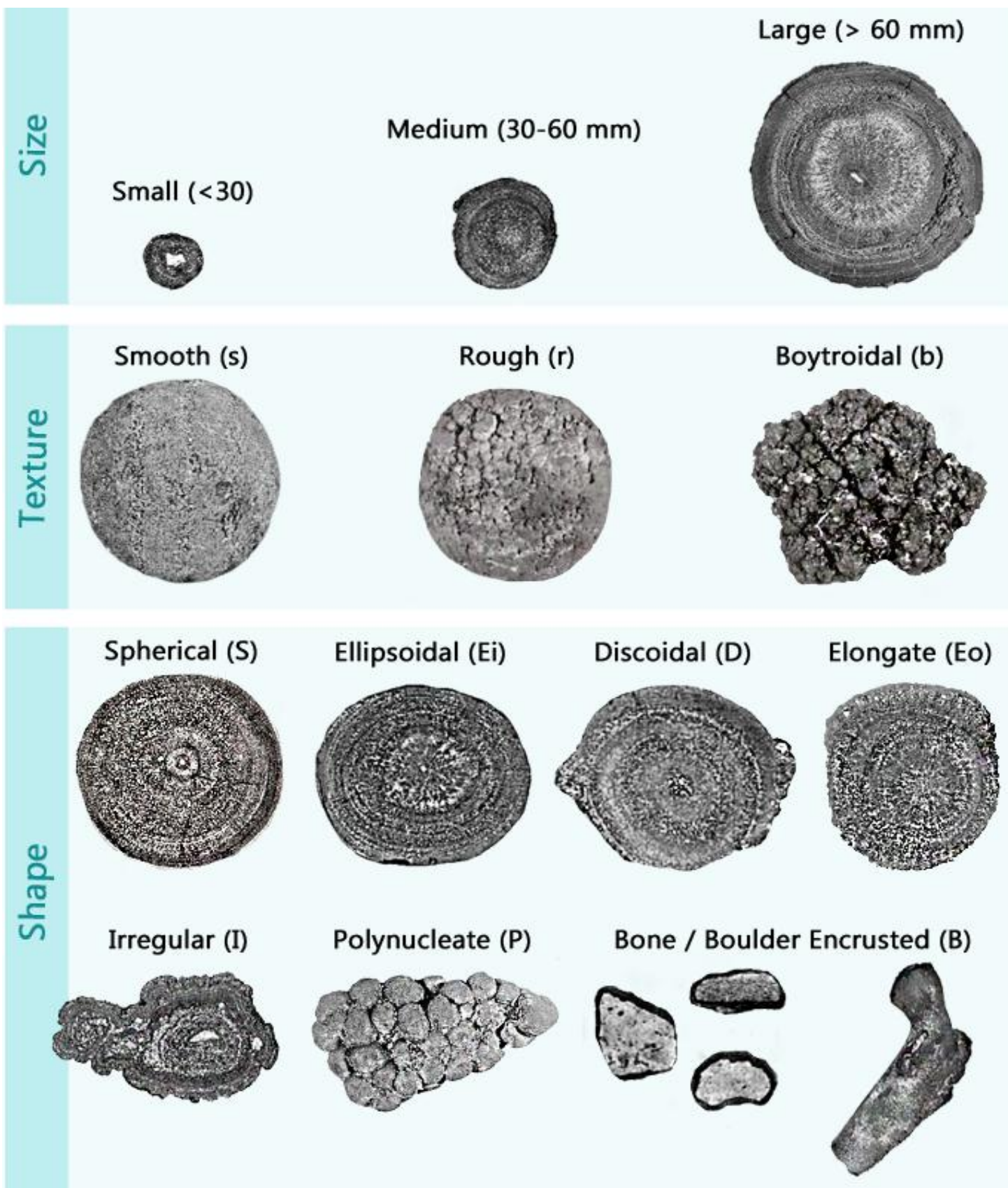

Figure 3.4 | Morphological parameters for characterising FMNs. Using images of FMNs collected from the Campbell Nodule Field (Chang, et al., 2003), morphological parameters of size, surface texture and shape are illustrated. The descriptive classification of Glasby, et al. (1980) is shown were: (1) a prefix of s, m, l denotes size, (2) capitals denote shape e.g. S, D, P and; (3) a suffix of s, r, b denotes textures e.g. U1365B-M is a large spherical FMN with a smooth surface texture, summarised as $1[\mathrm{~S}]^{\mathrm{S}}$.

Fe-Mn phases and detrital material, (vi) regular repetition or cyclic deposition and, (vii) fractures and unconformities (facies changes) (Glasby, 1977a; Segl, et al., 1989). The boundaries or horizons between different facies (zones) generally represent hiatuses of unknown duration $\left({ }^{10} \mathrm{Be} /{ }^{9} \mathrm{Be}\right.$ dating can be used to give an idea of the timeframe spanning 
a hiatus), during which the environment of deposition changed (Pichoki \& Hoffert, 1986; $\mathrm{Xu}$, et al., 2006). The complex growth histories of FMNs can thus be revealed by the textures of FMN interiors and correlated with chemical compositions and accretion rates (Glasby, 1977a; DeCarlo, 1987, 1991; McMurtry, et al., 1994; Koschinsky, et al., 1996).

Nodule Zones

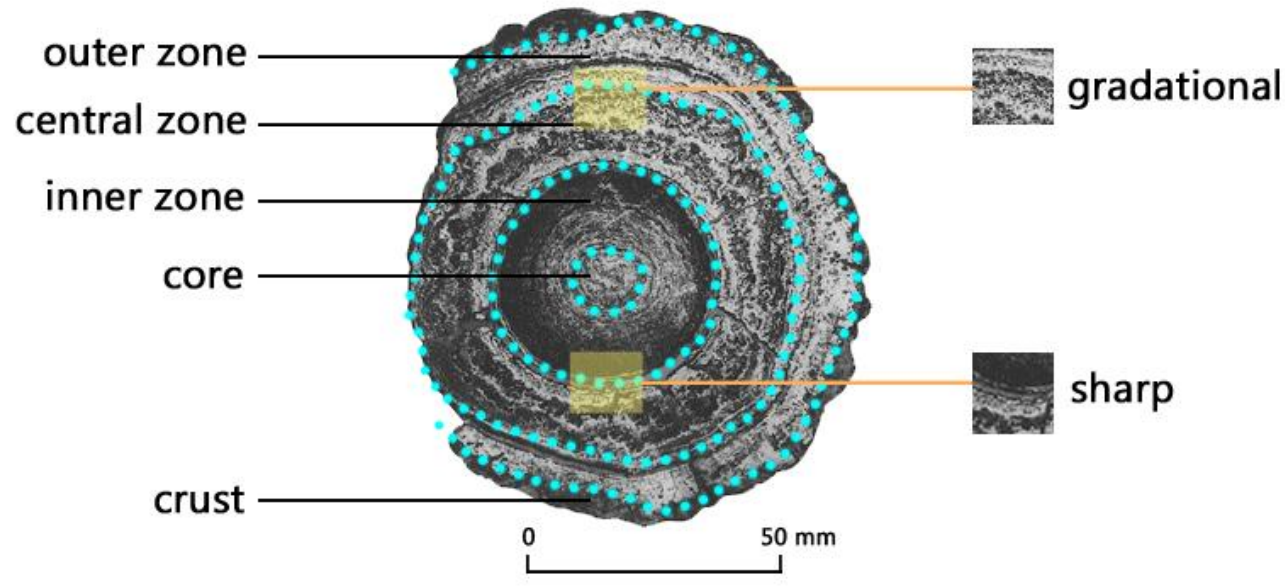

Figure 3.5 | Macroscopic nodule architecture. Cross-sectional approach for further characterising the growth history of FMNs. Five zones are distinguishable based on visible texture changes from the core to crust. Boundaries or 'horizons' between these zones of relatively homogenous growth can be gradational or sharp, and reflect changes in the mechanism of nodule accretion. Image modified from Trefil (2001).

Although each concentric zone has a certain degree of homogeneity, on a microscopic level homogenous layers are rarely thicker than $0.1 \mathrm{~mm}$ (Glasby, 1977a). The fundamental structural units of FMNs are built of complex, but distinct internal microstructures, reflecting the depositional environment and growth history (Sorem \& Foster, 1972). Internal microstructures are classified into five groups: (1) massive; (2) mottled (chaotic, globular); (3) compact; (4) columnar (dendritic, cuspate), and; (5) laminated. Their descriptions and paleoceanographic significance are summarised in Figure 3.6 (Glasby, 1977a; Sorem \& Foster, 1972; Banakar, et al., 1993; Banakar \& Tarakian, 1991). Analysis of internal growth structures are important for determining and refining compositional boundaries of $\mathrm{Fe}-\mathrm{Mn}$ precipitates and for correlating chemical and physical archives, in order to improve inferences of past changes in seawater composition and bottom water conditions (Hein, et al., 1992). Microstructural unconformities (diffuse, sharp and 
Microstructure
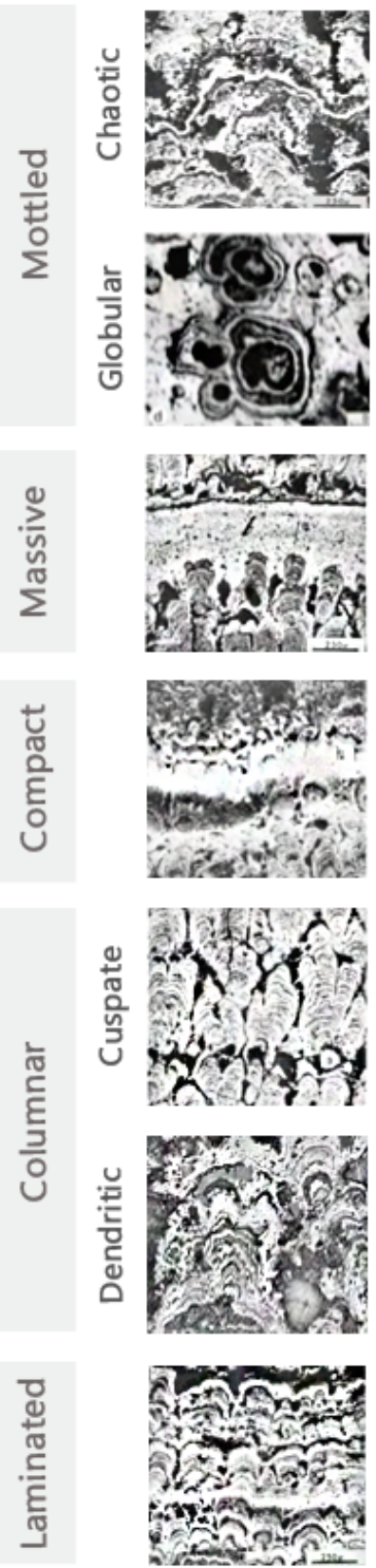

\section{Description}

Laminea show discontinous patterns of non-directional growth and are either (i) chaotic inter-laminations of Fe (light grey) and $\mathrm{Mn}$ (dark grey) minerals or (ii) sporadic globular growths about a micronucleus. These structures contain the largest proportions of detrital and biogenic material and are enriched in $\mathrm{Mn}, \mathrm{Ni}$ and $\mathrm{Cu}$ ( $21 \% \mathrm{Mn}, 12 \% \mathrm{Fe}, 1 \% \mathrm{Ni}, 0.5 \% \mathrm{Cu}$ ).

A dense unit composed of diffuse laminea of microcrystalline $\mathrm{Fe}-\mathrm{Mn}$ minerals, with minor amounts of detrital material. These zones are also enriched in $\mathrm{Mn}, \mathrm{Ni}$ and $\mathrm{Cu}$ ( $32 \% \mathrm{Mn}, 4 \% \mathrm{Fe}, 2 \% \mathrm{Ni}, 0.8 \% \mathrm{Cu}$ ).

Texturally similar to the massive zone compact structures contain the most highly reflective laminae found in nodules and are generally composed of $19 \% \mathrm{Mn}, 17 \% \mathrm{Fe}, 0.6 \%$ $\mathrm{Ni}$ and $0.2 \% \mathrm{Cu}$.

Consists of radially orientated columns of laminated Fe-Mn minerals. Laminea composing the columns display: (i) cuspate and (ii) dentritic textures with each column showing a delicate branching pattern. Columns can be short medium or long and vary from densley to sparsely packed with clay filling the space between columns. The zones are composed of $16 \% \mathrm{Fe}$ and $\mathrm{Mn}, 0.4 \% \mathrm{Ni}, 0.25 \% \mathrm{Cu}$.

Laminated zones occur when columnar structures are short, densley packed and relatively uniform laterally, giving a concentrically layered appearence.

\section{Paleoenvironment}

Chaotic and globular structures are most commonly found at the centre of nodules, marking the early stage of growth, where charged nuclei attract elements from a range of sources and grow rapidly, trapping detrital grains. Faster growth rates are ascribed to increased velocities of abyssal currents.

The microcrystalline nature of massive and compact zones generally indicate a quiescent water column and/or reduced ventilation. Lower oxygen contents and reduced current speeds limit collidal particle interaction and growth resulting in the precipitation of micocrystalline Fe-Mn colloids.

The occurence of massive and compact zones are relatively rare.

Dentritic and cuspate structures are the most common microstructures. Generally, cuspate growth indicates the precipitation of elements almost exclusively from seawater with structures becoming shorter and more densley packed as bottom current velocities increase. Dendritic structures indicate growth from both seawater and pore water derived elements and develop a rough surface texture.

Laminated zones are characteristic of the outer c. $6 \mathrm{~mm}$ of large FMNs and are generally indicative of G-I cycles of the Pleistocene. These structures result in smooth external surfaces.

Figure 3.6 Microstructures and their paleoceanographic significance. Descriptions and paleoenvironmental interpretations of microlaminations were compiled from: Mero (1965), Sorem \& Fewkes, (1972, 1977), Goldberg (1974), Segl, et al. (1984, 1989), Mangini, et al. (1990), Hein, et al. (1992), Banakar, et al. (1993) and Vineesh, et al. (2009). Images modified from Sorem \& Fewkes, (1977).

truncated) suggest changes in the style of deposition and periods of erosion or nondeposition. Specific sequences of microlaminations (and macro changes in texture) that have been dated, have been shown to be repeated in nodules from different oceanic regions 
(Segl, et al, 1989) suggesting that conditions of deep sea deposition have been relatively uniform over a wide area for long periods of time, (Glasby, 1985). Correlations of these textural changes with the timings of significant oceanic changes in circulation, have led to the suggestion that a change in nodule texture reflects important past changes to the structure and flow of the deep ocean (Segl, et al., 1989; Mangini, et al., 1990; Banakar, et al., 1993, 1997). Such changes in nodule architecture are largely governed by changes on the atomic level, as the underlying chemistry (and incorporation of detrital minerals) determines the emergent properties of the physical archives.

\subsection{Chemical Archives}

The chemical composition of nodule growth rings is determined by the physical (e.g., Eh, $\mathrm{pH}$, temperature), chemical (e.g., salinity, available ions, elements \& compounds), biological (organic fluxes), climatic (G-I cycles, deep water production) and geographic (e.g., configuration of ocean gateways) controls on the depositional environment (Levin, 2010). These parameters serve to modify the source, transport and sink of elements delivered to the deep oceans (Table 3.2). Elements can be sourced from: the weathering, erosion and mass wasting of surrounding continents, and subsequent transport to the oceans via riverine, aeolian and glacial processes; volcanic eruptions (aerial, submarine \& marine) and venting of hydrothermal fluids; precipitation of cosmogenic particles; gaseous exchanges between the ocean surface and overlying atmosphere; primary productivity of surface layers, the settling of dead organic debris and activity of benthic organisms; in addition to submarine weathering; remobilisation of elements from deep-sea sediments; and through the translation of chemical signals via mixing and circulation of ocean currents (Chester, 2003; Thurman \& Trujillo, 2004; Figure 3.7).

Seafloor topography, bottom current speeds and sedimentation rates also influence the rate, type, structure and chemistry of Fe-Mn oxyhydroxide precipitates (and nodules) that form (Figure 3.3). Moreover, element sources and transport pathways are transient over geological time. In general terms, cryospheric development and demise have caused fluctuations in sea level and deep water production, and tectonic forcings have resulted in the opening and closing of oceanic gateways (Exon, et al., 2004). Past changes in climate- 

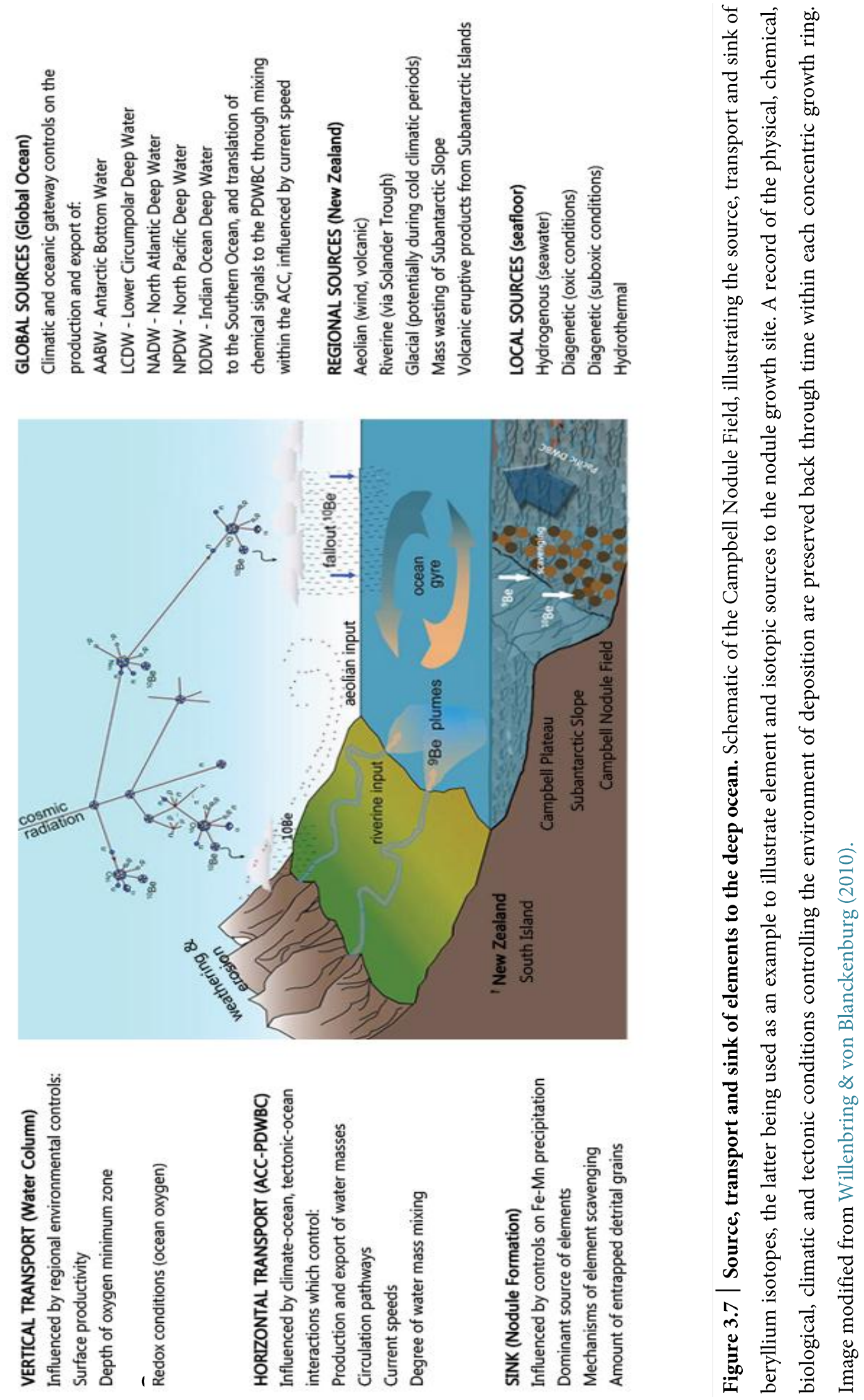
ocean and tectonic-ocean interactions have caused the complete reorganisation of the oceans, provenance of source material, style and intensity of continental weathering and erosion, and subsequent alterations to the biogeochemical cycling of seawater constituents (Glasby, 2000; Frank, 2002; Hein \& Koschinsky, 2013; Appendix A).

On an atomic level, dissolved and particulate elements are present in a variety of ionic species or oxidation states. The state of oxidation, amount of time for which the species resides in the reservoir (residence time) and the relative abundance of an element, is in part, governed by their subatomic anatomy and the physiochemical properties of seawater (Millero, 2010; Chester \& Jickells, 2012). In general terms, atomic properties determine the 'reactivity' of an element or ion in any given system, controlling the type, rate and frequency of chemical reactions, which in turn determines how elements are biogeochemically cycled. In the marine environment, the least reactive or conservative elements (e.g., $\mathrm{Na}, \mathrm{Cl}, \mathrm{Mg}, \mathrm{K}$ and $\mathrm{Ca}$ ) tend to be more soluble in sea water with longer residence times ( $10^{6}$ years) and are more evenly mixed throughout the oceans. Relatively reactive elements (e.g., $\mathrm{Fe}, \mathrm{Mn}, \mathrm{Zn}, \mathrm{Cu}$ and $\mathrm{Pb}$ ) tend to be less soluble in seawater and are easily removed via scavenging processes, such as in the formation of FMNs. As a consequence, these elements have shorter residence times (days to years) and are unevenly distributed in seawater (Chester, 2003; Thurman \& Trujillo, 2004). In case of the latter, water masses develop distinct elemental and isotopic signals. As a result, elements (and their isotopes) with oceanic residence times on the order of, or shorter than, the mixing time of the oceans (c. 1500 years e.g., Broecker \& Peng, 1982) can be used as tracers of source provenance, weathering style and ocean circulation (e.g., Hf, Nd, Pb) (Frank, 2002; Goldstein \& Hemming, 2003). Table 3.2 presents a list of the elements studied in this thesis with their oceanic residence times, average concentration in seawater, speciation, and commonly precipitated compounds (minerals) as well as their vertical profile (conservative, nutrient, scavenged).

In order to use these elements in reconstructing past deep sea environments, requires the use of proxies. A proxy is defined here as an element (concentration, ratio, group) or isotope that can be measured, and is controlled to some degree by a physical, chemical, biological, climatic or tectonic variable of interest (Calvert \& Pederson, 2007; Sarmiento \& Gruber, 2006). Multiple proxies for each studied variable allow for increased confidence in 


\begin{tabular}{|c|c|c|c|c|c|}
\hline Element & Species & Compound & $\begin{array}{l}\text { Residence } \\
\text { Time } \\
\text { (yrs) }\end{array}$ & $\begin{array}{c}\text { Av. Conc. } \\
\text { in the ocean } \\
(\ldots / \mathrm{kg})\end{array}$ & Type \\
\hline Iron & $\mathrm{Fe}^{3+}$ & $\mathrm{Fe}(\mathrm{OH})_{2}^{-}$ & $200-500$ & $540 \mathrm{pmol}$ & $\mathrm{N}$ \\
\hline Manganese & $\mathrm{Mn}^{4+}$ & $\mathrm{MnO}_{2}$ & 60 & $360 \mathrm{pmol}$ & S \\
\hline Cobalt & $\mathrm{Co}^{2+}$ & $\mathrm{Co}^{2+}$ & 340 & $20 \mathrm{pmol}$ & $\mathrm{N} / \mathrm{S}$ \\
\hline Cerium & $\mathrm{Ce}^{3+} \mathrm{Ce}^{4+}$ & $\mathrm{CeCO}_{3}{ }^{+}$ & $50-130$ & $5 \mathrm{pmol}$ & S \\
\hline Nickel & $\mathrm{Ni}^{2+}$ & $\mathrm{Ni}^{2+}$ & 6000 & $8.2 \mathrm{nmol}$ & $\mathrm{N}$ \\
\hline Barium & $\mathrm{Ba}^{2+}$ & $\mathrm{Ba}^{2+}$ & 10,000 & $109 \mathrm{nmol}$ & $\mathrm{N}$ \\
\hline Lead & $\mathrm{Pb}^{2+}$ & $\mathrm{PbCO}_{3}$ & $50-100$ & $13 p m o l$ & S \\
\hline Copper & $\mathrm{Cu}^{2+}$ & $\mathrm{Cu}^{2+}$ & 5000 & $2.4 \mathrm{nmol}$ & $\mathrm{N}$ \\
\hline Zirconium & $\mathrm{Zr}^{4+}$ & $\mathrm{Zr}(\mathrm{OH})^{-}$ & 5600 & $160 \mathrm{pmol}$ & $\mathrm{N}$ \\
\hline Vanadium & $\mathrm{V}^{5+}$ & $\mathrm{H}_{2} \mathrm{VO}_{4}^{-}$ & 50,000 & $39 \mathrm{nmol}$ & C \\
\hline Zinc & $\mathrm{Zn}^{2+}$ & $\mathrm{Zn}^{2+}$ & 51,000 & $5.4 \mathrm{nmol}$ & $\mathrm{N}$ \\
\hline Molybdenum & $\mathrm{Mo}^{6+}$ & $\mathrm{MoO}_{4}{ }^{2-}$ & 760,000 & $100 \mathrm{nmol}$ & C \\
\hline Lanthanum & $\mathrm{La}^{3+}$ & $\mathrm{LaCO}_{3}^{+}$ & $650-1600$ & $40 \mathrm{pmol}$ & $\mathrm{N}$ \\
\hline Neodymium & $\mathrm{Nd}^{3+}$ & $\mathrm{NdCO}_{3}{ }^{+}$ & $400-950$ & $23 \mathrm{pmol}$ & $\mathrm{N}$ \\
\hline Arsenic & $\mathrm{As}^{5+}$ & $\mathrm{HAsO}_{4}{ }^{2-}$ & 39,000 & $20 \mathrm{nmol}$ & $\mathrm{N}$ \\
\hline Yttrium & $\mathrm{Y}^{3+}$ & $\mathrm{YCO}_{3}^{+}$ & 51,000 & $190 \mathrm{pmol}$ & $\mathrm{N}$ \\
\hline Niobium & $\mathrm{Nb}^{5+}$ & $\begin{array}{l}\mathrm{Nb}(\mathrm{OH})_{5} \\
\mathrm{Nb}(\mathrm{OH})_{6}^{-}\end{array}$ & Unknown & $3.8 \mathrm{pmol}$ & $\mathrm{N}$-like \\
\hline Tungsten & $w^{6+}$ & $\mathrm{WO}_{4}{ }^{2-}$ & 61,000 & $54 \mathrm{pmol}$ & C \\
\hline Thorium & $\mathrm{Th}^{4+}$ & $\mathrm{Th}(\mathrm{OH})_{4}$ & 45 & $90 \mathrm{fmol}$ & S \\
\hline Gadolinium & $\mathrm{Gd}^{3+}$ & $\mathrm{GdCO}_{3}^{+}$ & $450-1100$ & $5.7 \mathrm{pmol}$ & $\mathrm{N}$-like \\
\hline Thallium & $\mathrm{Tl}^{+}$ & $\mathrm{TICl}$ & Unknown & $64 \mathrm{pmol}$ & C \\
\hline Samarium & $\mathrm{Sm}^{3+}$ & $\mathrm{SmCO}_{3}{ }^{+}$ & $400-1000$ & $3.8 \mathrm{pmol}$ & $\mathrm{N}$-like \\
\hline Dysprosium & $\mathrm{Dy}^{3+}$ & $\mathrm{DyCO}_{3}^{+}$ & $600-1500$ & $6.8 \mathrm{pmol}$ & $\mathrm{N}$-like \\
\hline Antimony & $\mathrm{Sb}^{5+}$ & $\mathrm{Sb}(\mathrm{OH})_{6}^{-}$ & 5,700 & $1.6 \mathrm{nmol}$ & $\mathrm{C}$ \\
\hline Erbium & $\mathrm{Er}^{3+}$ & $\mathrm{ErCO}_{3}^{+}$ & $2700-6800$ & $7.2 \mathrm{pmol}$ & $\mathrm{N}$-like \\
\hline Ytterbium & $\mathrm{Yb}^{3+}$ & $\mathrm{YbCO}_{3}^{+}$ & 2200 & $6.9 \mathrm{pmol}$ & $\mathrm{N}$-like \\
\hline Hafnium & $\mathrm{Hf}^{4+}$ & $\mathrm{Hf}(\mathrm{OH})_{5}^{-}$ & 1300 & $710 \mathrm{fmol}$ & N-like \\
\hline Europium & $\mathrm{Eu}^{3+}$ & $\begin{array}{c}\mathrm{EuCO}_{3}{ }^{+} \\
\mathrm{BiO}^{+},\end{array}$ & $300-800$ & $1.1 \mathrm{pmol}$ & $\mathrm{N}$-like \\
\hline Bismuth & $\mathrm{Bi}^{3+}$ & $\begin{array}{l}\mathrm{Bi}(\mathrm{OH})_{2}{ }^{+}, \\
\mathrm{Bi}(\mathrm{OH})_{3}\end{array}$ & Unknown & $140 \mathrm{fmol}$ & S \\
\hline Uranium & $u^{4+}$ & $\mathrm{UO}_{2}\left(\mathrm{CO}_{3}\right)^{4-}$ & 400,000 & $13.4 \mathrm{nmol}$ & C \\
\hline Lutetium & $\mathrm{Lu}^{3+}$ & $\mathrm{LaCO}_{3}{ }^{+}$ & 6200 & $1.3 \mathrm{pmol}$ & $\mathrm{N}$-like \\
\hline Cadmium & $\mathrm{Cd}^{2+}$ & $\mathrm{CdCl}^{+}$ & 50,000 & $620 \mathrm{pmol}$ & $\mathrm{N}$-like \\
\hline Tantalum & $\mathrm{Ta}^{5+}$ & $\mathrm{Ta}(\mathrm{OH})_{5}$ & Unknown & $200 \mathrm{fmol}$ & N-like \\
\hline
\end{tabular}

Table 3.2 | Speciation, residence times, average concentration and vertical distribution of studied elements in seawater. Type refers to element distribution profiles as either $\mathrm{N}=$ nutrient, $\mathrm{S}=$ scavenged, $\mathrm{C}=$ conservative. Coloured bars refer to the type of compounds formed; purple $=$ hydroxides, green $=$ chlorides; turquoise $=$ carbonates, orange $=$ oxides; grey $=$ oxyanions, white $=$ free cations. Compiled from: Bruland (1980, 1994); Broecker \& Peng, (1982); Flegal \& Patterson (1985); Greaves, et al., (1991); Rue \& Bruland (1995); Johnson, et al., (1996, 1997); Sohrin, et al., (1998); Alibo \& Nozaki, (1999), see also 'Periodic Table of Elements in the Ocean' http://www.mbari.org/chemsensor/pteo.htm). 
paleoenvironmental reconstructions. However, of the many publications regarding FMNs (e.g., Burns \& Burns, 1977, 1979; Baturin, 1988; Cronan, 1992; Hein, et al., 1997; Glasby, 2000; Frank, et al., 2002), a limited number of paleoceanographic proxies have been developed and applied (Table 3.3). The majority of these publications have dealt with distribution, composition and other general characteristics, focusing on major and minor elements of economic interest (e.g., $\mathrm{Mn}, \mathrm{Fe}, \mathrm{Co}$, and $\mathrm{Ni}$ ) and implications for nodule genesis, rather than elements of paleoceanographic significance. None-the-less, previous studies have used these elements, their ratios and associations, as proxies for: paleosource (at the sediment-water interface; Table 3.3; Figure 3.8 (a)) and thus mechanisms of nodule formation (e.g. Ohta, et al., 1999; Chandnani, et al., 2012); for discerning changes in the vertical transport of elements, i.e., through changes in organic fluxes, the carbonate compensation depth and depth of the OMZ (e.g. Halbach \& Puteanus, 1984; Verlaan, et al., 2004; Figure 3.8 (h)), and; changes in ocean circulation (e.g. Mangini, et al., 1990; Eisenhauer, et al., 1992; McMurtry, et al., 1994). Wen, et al. (1997) suggested that major and minor elements are more strongly controlled by local environmental conditions rather than global basin-wide processes, which were suggested to be recorded by isotopic compositions and trace element ratios. The latter was demonstrated recently by Lutfi, et al. (2011), who illustrated the potential of high field strength element (HFSE) ratios (Zr/Hf and $\mathrm{Nb} / \mathrm{Ta}$ ) for tracing water masses (Table 3.3; Figure $3.8(\mathrm{f})$ ).

The majority of paleoceanographic studies have been largely conducted based on isotopic variations (e.g., $\mathrm{Hf}, \mathrm{Nd}$ and $\mathrm{Pb}$ ). This reflects the assumption that element concentrations in seawater are influenced by a multitude of processes that can complicate paleoceanographic interpretations. On the other hand, heavy radiogenic isotopes (such as ${ }^{208} \mathrm{~Pb},{ }^{207} \mathrm{~Pb}$ and ${ }^{206} \mathrm{~Pb}$ ) are independent of biological or thermodynamic modifications and hence their archives are generally easier to unravel, with changes in composition only occurring by addition from a source region and subsequent mixing via ocean circulation (Frank, et al., 2002). FMNs and crusts have been shown to preserve a record of past variations of seawater $\mathrm{Pb}$ isotope composition, including; the timing and oceanographic consequences of the opening of the Drake Passage and closure of the Indonesian gateway (van de Flierdt, et al., 2004); closure of the Panama gateway (Burton, et al., 1997; 
Oceanographic Conditions

SOURCE

Local (sediment-water interface)

Regional (New Zealand sediment supply)

Global (the Southern \& Global Ocean)

TRANSPORT

Horizontal (ACC-PDWBC)

Water mass mixing, export, circulation

Current speed

Vertical (water column)

Biological productivity

Carbonate compensation depth

Redox (ocean oxygen)

SINK

Change in mechanism of formation

Scavenging mechanisms

\section{Examples of Paleoproxies}

Ternary plot $\left[\mathrm{Mn} / \mathrm{Fe}, \mathrm{Ni}-\mathrm{Co}-\mathrm{Cu}^{\star} 10\right]$

$\mathrm{Pb}$ isotope compositions

$\mathrm{Pb}$ isotope compositions

$\mathrm{Pb}$ isotope compositions, HFSE

Amount of detritals, microtexture changes

$\mathrm{Ba}, \mathrm{Cu}, \mathrm{Zn}$

$\mathrm{Mn}, \mathrm{Fe}, \mathrm{Mn} / \mathrm{Fe}$

Mn, Mo, V, Ni, U, EREE, Ce $e^{\star}, \mathrm{U} / \mathrm{Th}$,

$\mathrm{V} /(\mathrm{V}+\mathrm{Ni}), \mathrm{Ni} / \mathrm{Co}$

Macrotexture changes

Inter-element associations

Table 3.3 | Proxies of Past Ocean Conditions within FMN archives and their implications for nodule genesis and paleoceanography, sourced from (Halbach \& Puteanus, 1984; Glasby, 2000; Frank, 2002; Koschinsky \& Hein, 2003; van de Flierdt, et al., 2004; Soua, 2011; Hein, et al., 2013)

Frank, et al., 1999), and; varying export of deep water masses to the Southern Ocean (Frank, et al., 2002; van de Flierdt, et al., 2004), as well as geographical variations at the present time (e.g., Abouchami \& Goldstein, 1995; Vlastélic, et al., 2001).

The fundamental theory behind the application of lead isotopes is that they are reactive in the marine environment and are easily removed via scavenging processes, such as in the formation of FMNs. As a consequence, $\mathrm{Pb}$ has a relatively short residence time of 50-100 years (Schaule \& Patterson, 1981; von Blanckenburg \& Igel, 1999) resulting in measurable differences between ocean basins, basin regions, and water masses (Figure $3.8(\mathrm{e}-\mathrm{f})$ ). Thus, $\mathrm{Pb}$ isotopic compositions have been successfully applied as proxies in reconstruct past circulation patterns. Moreover, despite its very short oceanic residence time, the behaviour 
(a)

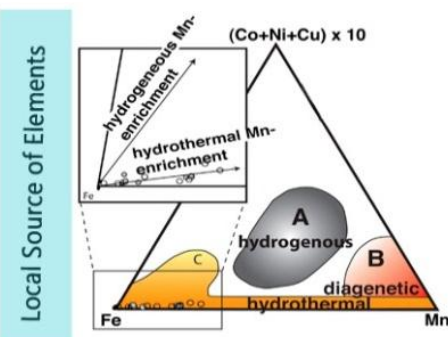

(c)

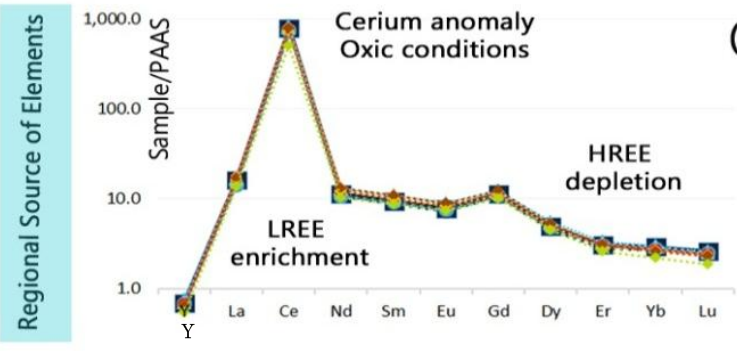

(e)

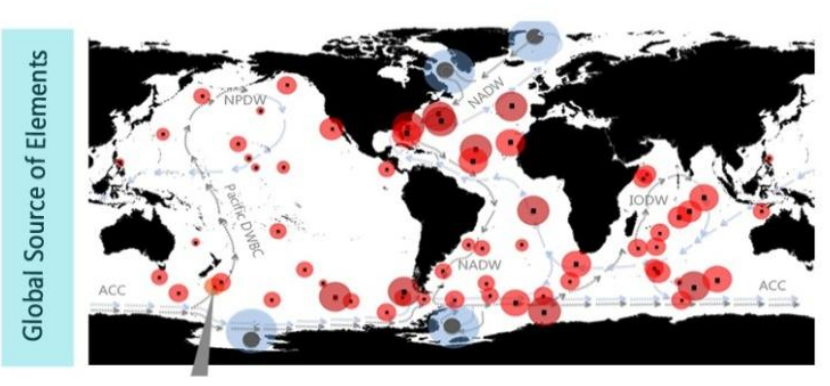

(f)
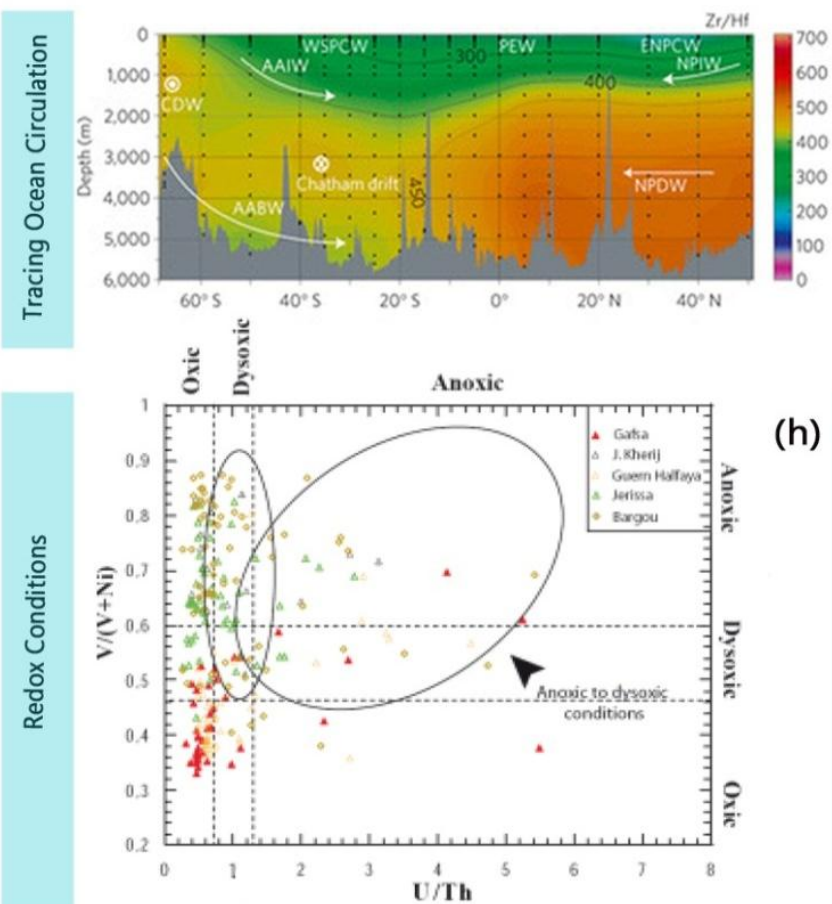

(g)

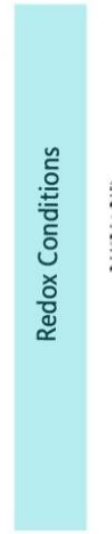

(b)
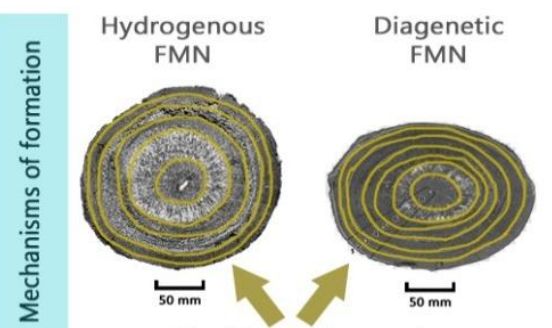

Hydrothermal

crust

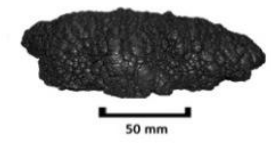

ignificant changes in

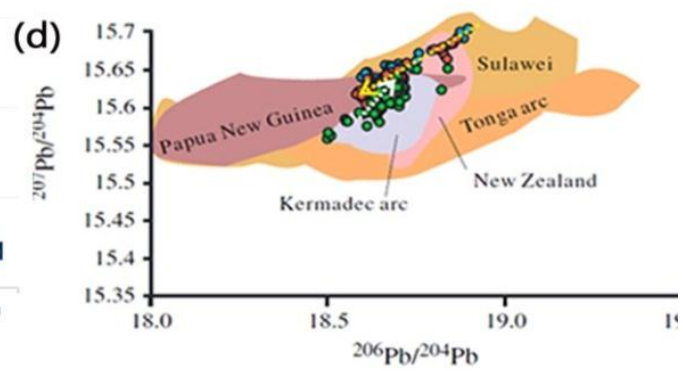

Natural ${ }^{206} \mathrm{~Pb} /{ }^{204} \mathrm{~Pb}$ of Abyssal Currents

$\begin{array}{ll}\text { - } & <18.6 \\ \text { - } 18.6-18.7 \\ \text { - } 18.7-18.8\end{array}$

18.8-18.9

- 18.9-19.0

(-) $>19.0$

IODW/CDW

NADW
$\mathrm{Pb}$ isotopes \& HFSE can be used

to trace water mass mixing and thus global sources of elements

Figure 3.8 | Chemical archives and their paleoceanographic significance. Examples of chemical proxies and their uses in reconstructing the paleoenvironment; (a) ternary plot used to discern local paleosource (Edwards, et al., 2011), (b) mode of FMN formation derived from (a) and evidence from physical archives (Chang, et al., 2003), (c) regional paleosource and redox conditions using REE, 
(this thesis), (d) discerning potential source rocks (prior to ocean mixing) from $\mathrm{Pb}-\mathrm{Pb}$ compositions (Chen, et al., 2013), (e) global sources of elements derived from water mass mixing, using $\mathrm{Pb}-\mathrm{Pb}$ compositions (modified from Frank, 2002) and (f) HFSE (Lutfi, et al., 2011), (g) regional environmental conditions such as redox (Soua, 2011) and (h) carbonate compensation depth (Halbach \& Puteanus, 1984).

of oceanic $\mathrm{Pb}$ somewhat resembles $\mathrm{Sr}$ in resulting from competing continental and hydrothermal fluxes and can therefore also be used to interpret continental-hydrothermal source provenance (e.g., Abouchami \& Goldstein, 1995; Abouchami \& Galer, 1998; Goldstein \& Hemming, 2003; Chen, et al., 2013; Figure 3.8 (d)). Furthermore, the weathering regime characteristic at the time of $\mathrm{Pb}$ erosion and deposition plays a major role in determining $\mathrm{Pb}$ compositions. In short, radioactive decay of ${ }^{238} \mathrm{U},{ }^{235} \mathrm{U}$, and ${ }^{232} \mathrm{Th}$ yields the three radiogenic isotopes of lead: ${ }^{206} \mathrm{~Pb},{ }^{207} \mathrm{~Pb}$, and ${ }^{208} \mathrm{~Pb}$, respectively. In contrast, ${ }^{204} \mathrm{~Pb}$ is a stable isotope and used as a reference when calculating isotopic ratios (Faure, 1977). U, Th, and $\mathrm{Pb}$ are all incompatible elements, meaning they preferentially concentrate in early stages of melt processes and as such are generally more enriched in continental crusts relative to bulk earth. Due to the heterogeneity of crustal rocks and the different decay rates of $U$ and $T h$, parent rock compositions of weathered material reflect distinct isotopic ratios of $\mathrm{Pb}$. Thus, $\mathrm{Pb}$ isotopes have the potential to record information on incongruent weathering as they are fractionated during weathering and erosion of continental rocks (von Blanckenburg \& Nägler, 2001; Fenn, et al., 2013).

The link between seawater $\mathrm{Pb}$ isotope compositions (preserved in Fe-Mn crusts) and inputs of eroded continental material due to global climate change was first noted by Christensen et al. (1997) through correlation of $\mathrm{Pb}$ compositions with benthic foraminifera $\delta^{18} \mathrm{O}$ records. This was followed by the recognition that glaciation of continental landmasses had a fundamental effect on the $\mathrm{Pb}$ isotope composition of seawater through the incongruent weathering of silicate rocks preferentially releasing the more labile, radiogenic $\mathrm{Pb}$ fraction as the crystalline structure of a mineral becomes damaged during radioactive decay, leaving radiogenic daughter isotopes loosely bound and susceptible to weathering (von Blanckenburg \& Nägler, 2001; Frank, 2002). This is clearly demonstrated by the rise in the radiogenic $\mathrm{Pb}$ isotope composition of $\mathrm{Fe}-\mathrm{Mn}$ crust records from the North Atlantic over the last 2 Ma (Burton, et al., 1997; Reynolds, et al., 1999). 
Conversely, knowledge on tracer elements, their relationships (ratios), and paleoceanographic significance is still limited (Hein \& Koschinsky, 2013). This largely reflects the assumption that element concentrations in seawater are influenced by a multitude of processes that can complicate paleoceanographic interpretations. Those studies utilising tracer elements have predominantly used Rare Earth Elements (REE), in particular cerium-lanthanum ratios (Ce/La) and Ce anomalies (e.g. Glasby, 1974; Glasby, et al., 1987; Karsten, et al., 1998; Garcia-Solsona, et al., 2013). Although the REE are a chemically coherent set of elements, several processes (e.g. adsorption, scavenging etc.) cause fractionations within this group, which are revealed by shale-normalised REE patterns and REE ratio timeseries. REE patterns of hydrogenous FMNs, typically display light REE (LREE; lanthanum to samarium) enrichment relative to heavy REE (HREE; from europium to lutetium), with a significant positive Ce anomaly (Elderfield, 1988; Byrne \& Kim, 1990; McLennan, 1989; Figure 3.8 (c)). Changes to this 'ideal' REE pattern in addition to REE ratio profiles, can be used as a proxy for paleosource (HREE/LREE; e.g. Bayon, et al., 2004), water mass mixing (Ce/La; e.g. Karsten, et al., 1998) and paleoredox (Ce*; e.g. German \& Elderfield, 1990; Nakada, et al., 2013; Figure 3.8 (c)). The use of other trace elements as proxies of past ocean conditions, have largely been adapted from their use in other sedimentary archives (see Pattan, et al., 2005; Tribovillard, et al., 2006; Calvert \& Pederson, 2007) and pedology (see Sheldon \& Tabor, 2009). For example, redoxsensitive elements, such as uranium, vanadium and molybdenum, have been used to characterise the paleoenvironment as oxic (high $\mathrm{O}_{2}$ ), suboxic or anoxic (low to no $\mathrm{O}_{2}$, respectively) (Galarraga, et al., 2008; Soua, 2011; Boiteau, et al., 2012; Figure 3.8 (g)), and barium, copper and zinc have been used as paleoproductivity proxies (e.g. Calvert \& Pederson, 2007). Additionally, information regarding paleoprecipitation, scavenging mechanisms and modes of nodule formation (sink; Figure 3.7), can be derived from element associations, by grouping elements of similar geochemical behaviour (e.g. Koschinsky \& Hein, 2003; Table 3.2).

The latter typically requires the application of sequential leaching techniques in order to analyse different mineral phases (e.g. Koschinsky \& Hein, 2003). Additionally, acidreductive leaching of FMNs, crusts and bulk sediment have been considered a reliable way to extract deep water isotopic composition (e.g., $\mathrm{Be}, \mathrm{Hf}, \mathrm{Nd}, \mathrm{Pb}$ ) from the authigenic 
component (e.g. Rutberg, et al., 2000; van de Flierdt, et al., 2004). However, the majority of paleoceanographic studies concerning the major, minor and trace element chemistry of these archives, present discussions based on bulk chemistry (e.g. Karsten, et al., 1998; Frank, et al., 1999). Bulk chemical methods concomitantly analyse seawater (authigenic) and land (detrital) derived FMN components, effectively combining different histories. Furthermore, the detrital component, although not dominant, has the ability to mask chemical signals of the authigenic fraction (Chandnani, et al., 2012). In regards to elemental rather than isotopic studies of these archives, few studies perform the necessary separation techniques in order to reliably extract the pristine seawater signal (e.g. Chandnani, et al., 2012). In this thesis, geochemical analyses of this seawater component are essential for reconstructing the chemical evolution of the PDWBC. 


\section{Chapter}

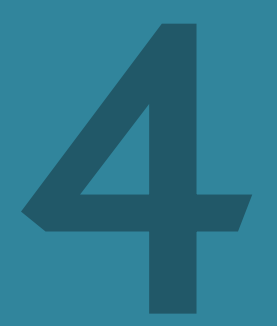

Details methods used in dating FMNs, revising chronologies, \& methods used to retrieve \& quantify the authigenic elemental and $\mathrm{Pb}$ isotope chemistry of U1365B-M

\section{Methods}

\section{Retrieving the Seawater Record}

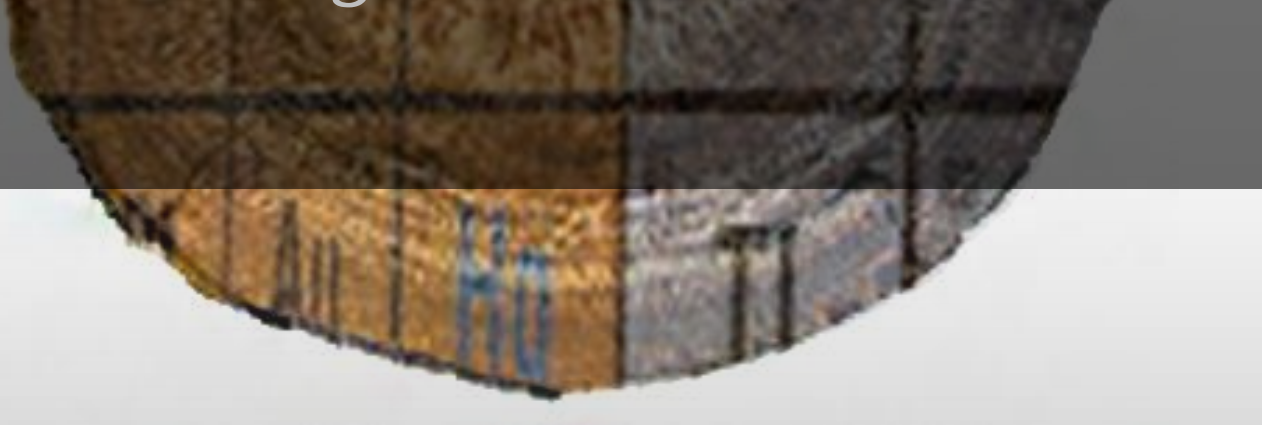

4.3 Chronologies \&

Growth rates

$4.4 \quad$ Multi-Element

Chemistry

4.5 Lead Isotope

Chemistry 


\subsection{Samples \& Sampling}

Ten nodule specimens, including U1365B-M, were selected, beryllium isotope dated $\left({ }^{10} \mathrm{Be} /{ }^{9} \mathrm{Be}\right.$ dating) and chemically analysed continuing the RV Tangaroa cruise to the northeastern sector of the Campbell Nodule Field (CNF) in 1999 (Chang, et al., 2003; Graham, et al., 2003a; Graham, et al., 2003b; Figure 4.1; Table 4.1). Nodules were bisected at GNS Science with a wet circular diamond-encrusted saw and the cross-sectional area sanded flat. The two hemispheres of each nodule were cleaned with ultra-pure water (Milli-Q water) until all loose debris had been removed (Ditchburn \& Graham, 2003). One nodule hemisphere remained at GNS Science for sampling and ${ }^{10} \mathrm{Be} /{ }^{9} \mathrm{Be}$ dating (Graham et al., 2003b; Ditchburn \& Graham, 2003), whereas the other hemisphere was sent to the Korea

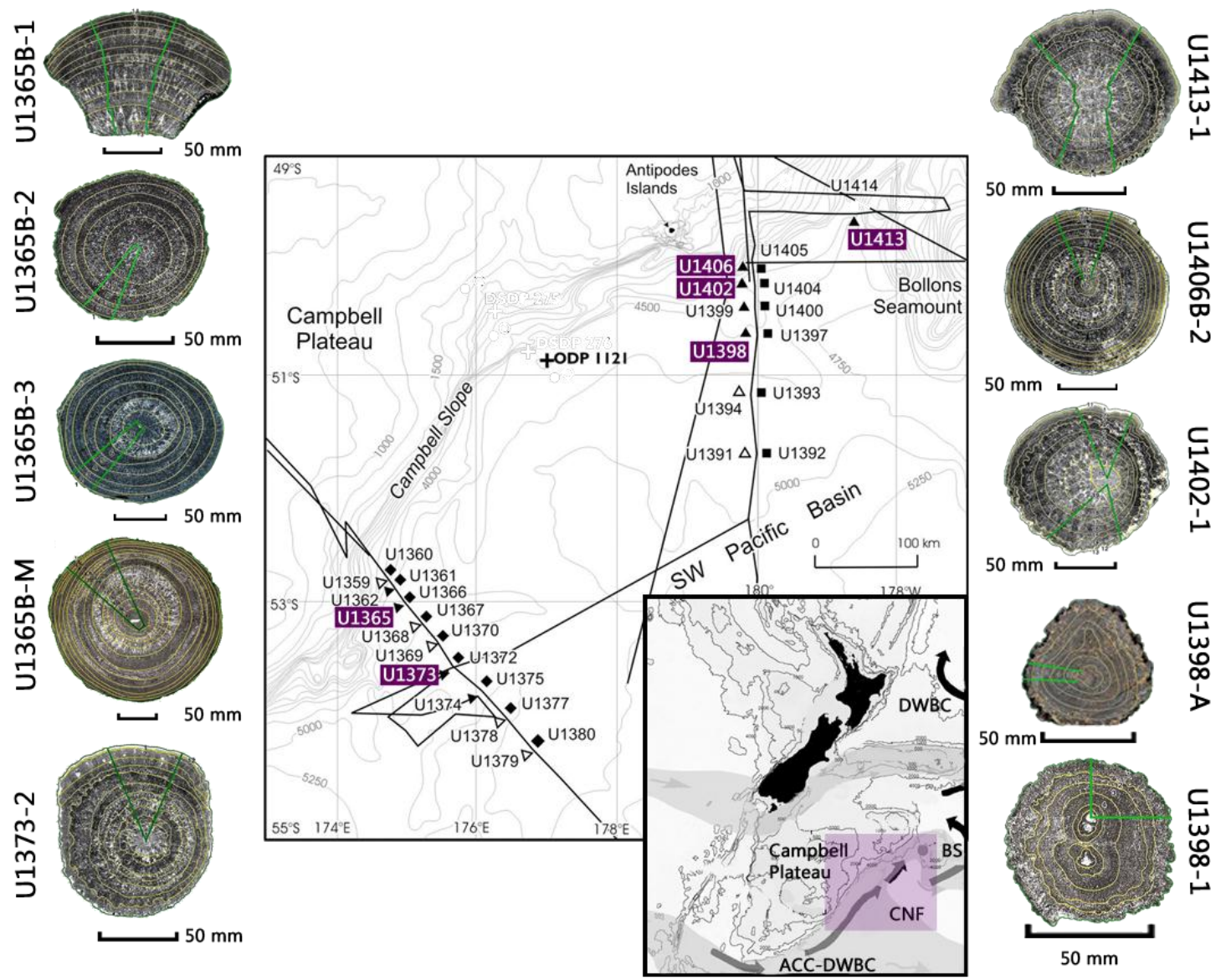

Figure 4.1 | Ferromanganese nodules collected from the north-eastern sector of the Campbell Nodule Field. FMNs are named according the dredge station (purple box) they were collected from. FMNs collected from the same station are differentiated by a number or alphabet. The location and water depth of each dredge station are presented in Table 4.1. 


\begin{tabular}{|c|c|c|c|c|c|}
\hline \multirow[t]{2}{*}{ Nodule Sample } & \multicolumn{2}{|c|}{ Latitude } & \multicolumn{2}{|c|}{ Longitude } & \multirow{2}{*}{$\begin{array}{c}\text { Depth } \\
(\mathrm{m})\end{array}$} \\
\hline & start & finish & start & finish & \\
\hline \multicolumn{6}{|l|}{ Northern transect } \\
\hline U1413 & $49^{\circ} 31.110^{\prime} \mathrm{S}$ & $49^{\circ} 32.061^{\prime} \mathrm{S}$ & $178^{\circ} 39.230^{\prime} \mathrm{E}$ & $178^{\circ} 39.590^{\prime} \mathrm{E}$ & $4375-4314$ \\
\hline U1406B & $50^{\circ} 00.554^{\prime} \mathrm{S}$ & $50^{\circ} 01.964^{\prime} \mathrm{S}$ & $179^{\circ} 56.125^{\prime} \mathrm{E}$ & $179^{\circ} 56.582^{\prime} \mathrm{E}$ & $4520-4475$ \\
\hline U1402 & $50^{\circ} 12.091^{\prime} \mathrm{S}$ & $50^{\circ} 13.204^{\prime} \mathrm{S}$ & $179^{\circ} 54.960^{\prime} \mathrm{E}$ & $179^{\circ} 56.086^{\prime} \mathrm{E}$ & 4400 \\
\hline U1398 & $50^{\circ} 37.860^{\prime} \mathrm{S}$ & $50^{\circ} 37.491^{\prime} \mathrm{S}$ & $179^{\circ} 59.155^{\prime} \mathrm{E}$ & $179^{\circ} 56.986^{\prime} \mathrm{E}$ & 4495 \\
\hline \multicolumn{6}{|l|}{ Southern transect } \\
\hline U1365B & $52^{\circ} 59.656^{\prime} \mathrm{S}$ & $52^{\circ} 56.734^{\prime} \mathrm{S}$ & $174^{\circ} 56.872^{\prime} \mathrm{E}$ & $174^{\circ} 54.276^{\prime} \mathrm{E}$ & $4619-4560$ \\
\hline U1373 & $53^{\circ} 35.008^{\prime} \mathrm{S}$ & $53^{\circ} 35.366^{\prime} \mathrm{S}$ & $174^{\circ} 41.677^{\prime} \mathrm{E}$ & $174^{\circ} 42.277^{\prime} \mathrm{E}$ & $4943-4942$ \\
\hline
\end{tabular}

Table 4.1 | Location and depth of ferromanganese nodules collected from the Campbell Nodule Field for further investigation. Samples selected for further analysis Chang, et al., (2003).

Institute of Geology, Mining and Materials (KIGAM) for petrographic and geochemical studies (Graham et al., 2003a). FMN hemispheres were sampled based on macroscopic changes in texture ( 4 to $10 \mathrm{~cm}$ sample intervals), confirmed using back-scattered electron (BSE) images (Graham, et al., 2003a, Graham, et al., 2003b). Low resolution bulk chemical analyses were performed on the KIGAM nodule hemisphere using a variety of analytical techniques (Graham, et al., 2003a) and ${ }^{10} \mathrm{Be} /{ }^{9} \mathrm{Be}$ dating of the seawater component was performed on the GNS hemisphere, using accelerator mass spectrometry (AMS) and inductively coupled plasma optical emission spectrometry (ICP-OES) (Graham, et al., 2003b; Ditchburn \& Graham, 2003). The ${ }^{10}$ Be chronology could not be accurately matched with the associated geochemical data. As such, U1365B-M was re-sampled at GNS Science along a new high resolution ( 1-2 mm) depth profile (Ditchburn \& Graham, 2006a). Splits of the same sample material were used for ${ }^{10} \mathrm{Be} /{ }^{9} \mathrm{Be}$ dating at GNS Science (Ditchburn \& Graham, 2006b) and for multi-element and lead (Pb) isotope analyses (this thesis). A radius line was drawn from the centre of the nucleus (identified by a visible shell fragment) to the crust of U1365B-M (Figure 4.2 (a)-(e)). A tapered symmetrical segment was outlined either side of the radius line, using a dremel mini diamond saw. Along this segment, $5 \mathrm{~mm}$ wide and $18 \mathrm{~mm}$ deep channels were drilled (Figure 4.2 (b)). Compressed air was continually blown from the centre toward the rim to minimise dust entering 
crevices and pores. Low pressure settings ensured limited erosion of the softer layers. The dremel saw was then used to undercut the layer to be removed for sampling, working from the crust to core, using $1 \mathrm{~mm}$ deep rebates to collect sample material (Figure $4.2(\mathrm{c})$ ). Due to the variable physical nature of U1365B-M, the dremel saw was only practical for the outermost part of the nodule. A sharp wood-working chisel replaced the saw to sample the inner sections (Figure 4.2 (d)). Both methods followed the natural contours of U1365B-M and where practicable, $1 \mathrm{~mm}$ layers were progressively removed along the radius line (from which all distance measurements were made). Each sample scraping was collected in a fresh folded paper tray, cut to suit the section being sampled and held in place with PVC tape (Figure 4.2 (d)). The shell nucleus, surrounded by a dark layer of Fe-Mn oxide minerals, was not removed in order to maintain a reference point for future re-sampling (Ditchburn \& Graham, 2006a; Figure 4.2 (e)).

(a)

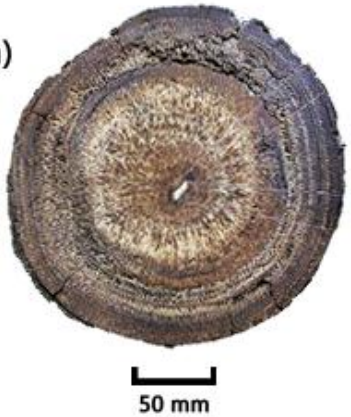

(d)

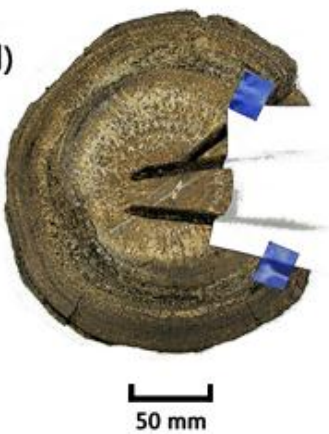

(b)
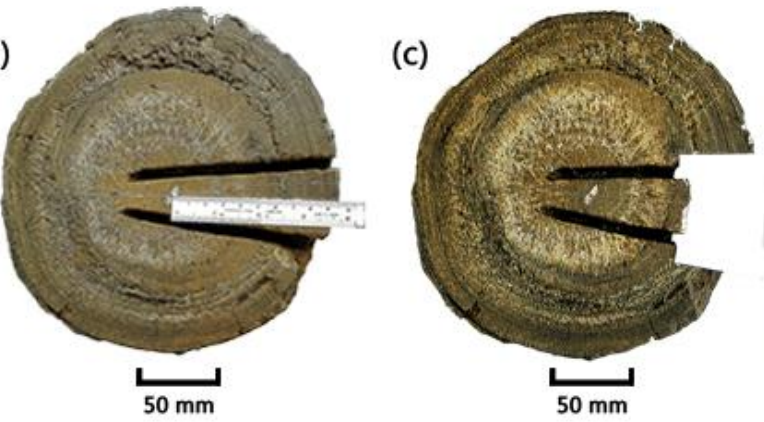

(e)
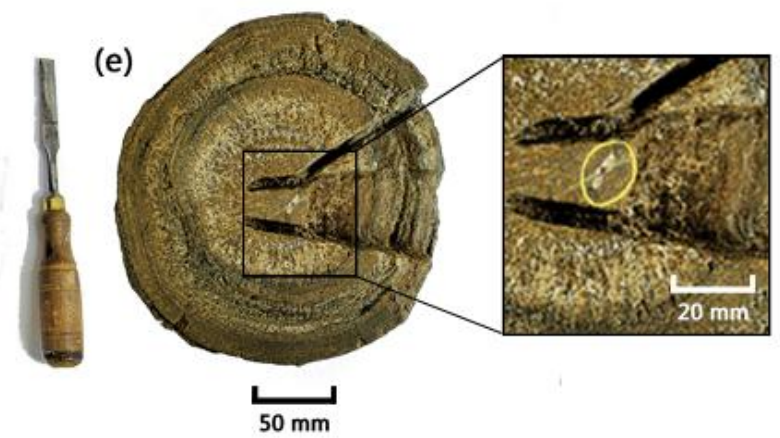

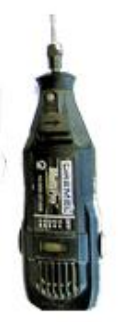

Figure 4.2 | New sampling strategy for FMN U1365B-M. (a) a cross-section through U1365B-M shows concentric growth rings around the nodule nucleus (white shell fragment) and concentrations of lighter coloured trapped silica material. Individual growth rings of c. $1 \mathrm{~mm}$ were sampled from the (b) tapered segment of the nodule radius by (c) under-cutting layers with a Dremel saw followed by (d) a wood-working chisel. The nodule core (e) was left intact as a reference for future sampling. Sampling was conducted by Ditchburn \& Graham (2006a) at GNS Science. 


\subsection{Isolating the Seawater Component}

A number of different digestion procedures, for determining element concentrations and isotopic compositions in FMNs, have been reported in the literature (e.g. Axelsson, et al., 2002; Frank, et al., 2002; van de Flierdt, et al., 2006). In relation to the measurement of multiple element concentrations, the majority rely on traditional hot-plate bulk digestions of nodules, dissolving both authigenic and detrital components. The lack of literature available detailing a simple procedure for the successful separation of authigenic (seawater) and detrital nodule components and exclusive analysis of the elemental seawater fraction, required the development of a new separation technique. To establish the most effective approach, published methods available were examined in detail (e.g., Chester \& Hughes, 1967; Tessier, et al., 1979; Aplin \& Cronan, 1985; Koschinsky \& Halbach, 1995; Axelsson, et al., 2002; Ditchburn \& Graham, 2006b; Gutjahr, et al., 2007; Basak, et al., 2011). Using Pacific FMN standard, USGS Nod-P-1, acid leaching procedures were modified and optimised with respect to: solid/solution ratios, type and concentration of leaching reagent, reaction time, temperature, and use of an ultra-sonic bath for sample agitation (Appendix B). The developed technique is illustrated for minor and trace element chemistry in Figure 4.3 and detailed below for all elemental and $\mathrm{Pb}$ isotope chemistry.

All ferromanganese material (sample and standard) was dried for $24 \mathrm{hr}$ at $110^{\circ} \mathrm{C}$ in an ultra-clean oven (Figure 4.3 (a)). Once cooled to room temperature $\sim 50 \mathrm{mg}$ of FMN material was weighed into pre-cleaned $23 \mathrm{~mL}$ Savillex vials, for minor and trace element chemistry (Figure 4.3 (b)). [For major and $\mathrm{Pb}$ isotope chemistry $\sim 10 \mathrm{mg}$ of material was weighed into pre-cleaned $1.5 \mathrm{~mL}$ micro-centrifuge tubes.] Weighed material was digested in $5 \mathrm{~mL} 6 \mathrm{M} \mathrm{HCl}$ for $60 \mathrm{~min}$ (Figure 4.3 (c)) at room temperature, and then agitated in an ultra-sonic bath for $90 \mathrm{~min}$ (Figure 4.3 (d)), requiring a total digestion time of $150 \mathrm{~min}$. [For major and $\mathrm{Pb}$ isotope chemistry, weighed samples were digestion for a total of $60 \mathrm{~min}$ in $1.5 \mathrm{~mL} 11 \mathrm{M} \mathrm{HCl}$ at room temperature.] Once the seawater component had completely dissolved within the supernatant (aqueous solution) the mixture was quantitatively diluted by weighing $\sim 13 \mathrm{~g}$ of ultra-pure water $(>18.2 \mathrm{M} \Omega$ ) (Figure $4.3(\mathrm{e})$ ). [This step was not required for major and lead chemistry analysis.] For both multi-element and $\mathrm{Pb}$ isotope chemistry, the supernatant (authigenic, seawater component) and suspended ultra-fine lithogenous fraction (detrital component) were separated by centrifuge for $5 \mathrm{~min}$ at 5000 rps (revolutions per second) (Figure 4.3 (f-g)). 
For minor and trace elements, a $1 \mathrm{~mL}$ aliquot of the supernatant was transferred into pre-cleaned, $10 \mathrm{~mL}$ centrifuge tubes, and a measured aliquot of the supernatant was then quantitatively diluted (1:100) with $0.1 \mathrm{M} \mathrm{HCl}$, ready for ICP-MS analysis. The remaining supernatant was discarded and the residue cleaned by adding $\sim 5 \mathrm{~mL}$ ultra-pure water, gently stirring, centrifuging for $3 \mathrm{~min}$ at $5000 \mathrm{rps}$, discarding $\sim 4.5 \mathrm{~mL}$ of the solution and

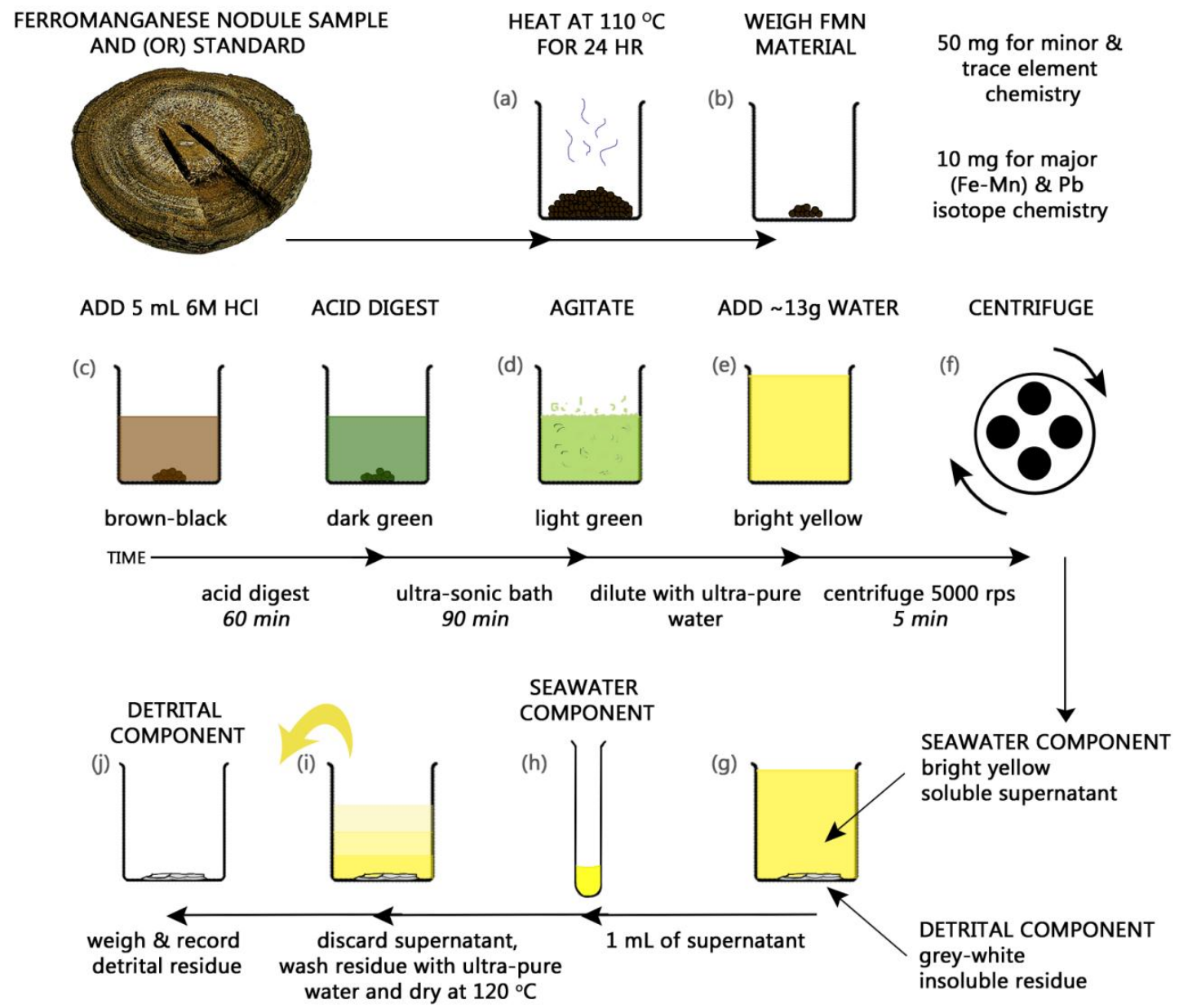

Figure 4.3 New analytical technique for isolating the seawater component of FMNs. FMNs can absorb up to $10 \%$ of their weight in water(Smith, 1995), thus samples must be dried (a) before processing. Once cooled to room temperature FMN samples were weighed (b) followed by sample digestion in hydrochloric acid $(\mathrm{HCl})(\mathrm{c})$ and ultra-sonic agitation (d). Following a colour change from brown-black to light green, samples are diluted, turning bright yellow in colour (e), and centrifuged (f) to physically separate elements liberated from the Fe-Mn sample matrix (in the supernatant) from the insoluble detrital residue (g). An aliquot of the supernatant is isolated for ICP-MS analysis (preceding further dilution) whilst the remaining supernatant is discarded (i) and the detrital component separated and weighed (j). 
repeating three times. The beaker was then placed on a hotplate $\left(120^{\circ} \mathrm{C}\right)$ until any remaining water had completely evaporated (Figure 4.3 (i)). The remaining residue was then weighed and recorded to later be used in calculating the weight of the Fe-Mn component of each sample and standard (Figure $4.3(\mathrm{j})$ ). For Pb isotope chemistry a $1 \mathrm{~mL}$ aliquot of the supernatant was transferred into pre-cleaned $3 \mathrm{~mL}$ Savillex beakers and for major chemistry, $0.005 \mu \mathrm{L}$ of solution was transferred into pre-cleaned $30 \mathrm{~mL}$ polypropylene vials and quantitatively diluted $(1: 100)$ in $30 \mathrm{~mL}$ of $1 \% \mathrm{HNO}_{3}$, ready for ICP-MS analysis. Well characterised reference materials and synthetic standards were required to monitor the overall accuracy and precision of the analytical procedures developed and are detailed within Appendix B, and the results discussed in Section 4.4.

\subsection{Chronologies \& Growth Rates}

Beryllium dating was performed at the National Isotope Centre GNS Science in 2006 for U1365B-M as part of this thesis, and initially in 2003 for selected FMNs (Ditchburn \& Graham, 2003, 2006b; Figure 4.4). A chronological framework was established for the authigenic fraction using cosmogenic ${ }^{10} \mathrm{Be}$ normalised to the dissolved fraction of its stable isotope ${ }^{9} \mathrm{Be}\left({ }^{10} \mathrm{Be} /{ }^{9} \mathrm{Be}\right) .{ }^{10} \mathrm{Be}$ measurements $\left(\right.$ at $\left.\mathrm{g}^{-1}[10]^{9}\right)$ were made by AMS and stable ${ }^{9} \mathrm{Be}$ (at $\mu \mathrm{g} \mathrm{g}^{-1}$ ) by ICP-OES (Ditchburn \& Graham, 2006b). Details of sample preparation are described in Ditchburn \& Graham (2003) and are summarised as follows: (1) 50 mg aliquots of FMN samples were oven dried at $110^{\circ} \mathrm{C}$ for 24 hours; (2) samples were crushed into a fine powder using an agate pestle and mortar; (3) $5 \mathrm{~mL} 6 \mathrm{M} \mathrm{HCl}$ was heated to $65^{\circ} \mathrm{C}$ and transferred onto powdered samples; (4) samples were left to stand for 30 minutes to dissolve the authigenic fraction; (5) a $2 \mathrm{~mL}$ aliquot of this supernatant was removed for ${ }^{9} \mathrm{Be}$ measurements by ICP-OES; (6) the remaining leachate was spiked with $\sim 1 \mathrm{mg}$ of ${ }^{9} \mathrm{Be}$ carrier and purified using hydroxide precipitation of $\mathrm{Be}(\mathrm{OH})$ and cation chromatography, prior to ${ }^{10} \mathrm{Be}$ measurements by AMS; (7) the remaining acid-insoluble detrital material was washed, dried, weighed and reported as \% residue (Appendix C). The mixed ${ }^{9} \mathrm{Be}$ carrier and ${ }^{10} \mathrm{Be}$ from U1365B-M samples were measured as a ${ }^{10} \mathrm{Be} /{ }^{9} \mathrm{Be}$. All ${ }^{10} \mathrm{Be}$ measurements were normalised using ${ }^{10} \mathrm{Be} /{ }^{9} \mathrm{Be}$ SRM 4325 NIST (National Institute of Standards and Technology) with an assigned ${ }^{10} \mathrm{Be} /{ }^{9} \mathrm{Be}$ of $3.06 \pm 0.14 \times 10^{-11}$ and half-life 
(a)

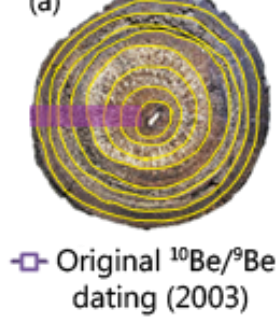

(b)

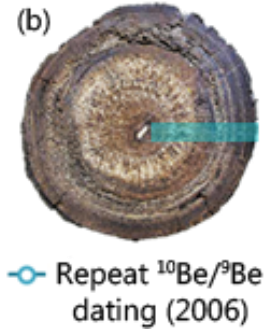

(c)

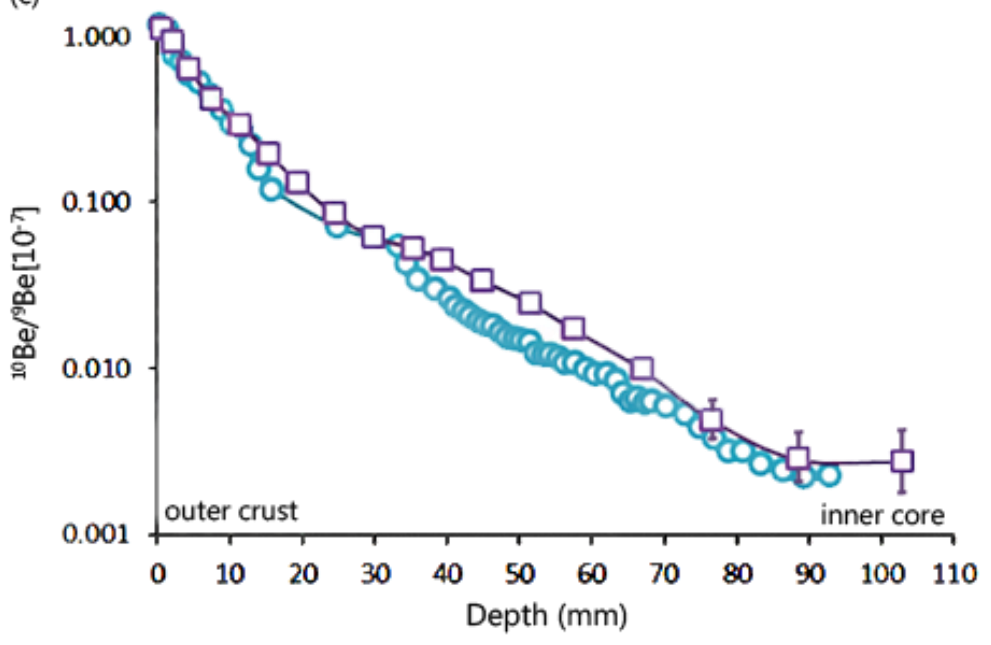

Figure 4.4 | Original and repeat ${ }^{10} \mathrm{Be} /{ }^{9} \mathrm{Be}$ dating of U1365B-M. A cross-sectional view of U1365B-M displaying: (a) initial sampling and ${ }^{10} \mathrm{Be} /{ }^{9} \mathrm{Be}$ dating (yellow rings) across a $108 \mathrm{~mm}$ depth-profile (purple area; Graham, et al., 2003b) and (b) repeat sampling at a higher sample resolution of $\sim 1-2 \mathrm{~mm}$ along a new $95 \mathrm{~mm}$ profile (blue area; Ditchburn \& Graham, 2006b). Updated ${ }^{10} \mathrm{Be} /{ }^{9} \mathrm{Be}$ values derived for each profile are presented in (c) as a function of depth from crust to core (this thesis). Error bars $(2 \delta)$ are shown when larger than marker.

of $1.51 \pm 0.1 \mathrm{Ma}$ (Middleton et al., 1993; Bhat et al., 1973). As a known quantity of ${ }^{9} \mathrm{Be}$ carrier was added to each sample aliquot this value was multiplied by the measured ratio to obtain the number of ${ }^{10} \mathrm{Be}$ atoms present in the sample. The $2 \mathrm{~mL}$ aliquot of the supernatant, removed for ${ }^{9} \mathrm{Be}$ measurements, was then converted to ${ }^{9} \mathrm{Be}$ atoms and the natural ${ }^{10} \mathrm{Be} /{ }^{9} \mathrm{Be}$ ratio of the sample calculated. However, since these measurements were made, new concordant publications have re-determined the ratio of the primary standard $\left({ }^{10} \mathrm{Be} /{ }^{9} \mathrm{Be}\right.$ of $2.79 \pm 0.03 \times 10^{-11}$; Nishiizumi, et al., 2007) and half-life of ${ }^{10} \mathrm{Be}$ from $1.51 \pm 0.1$ Ma (Bhat et al., 1973) to $1.387 \pm 0.012 \mathrm{Ma}$ (Korschinek, et al., 2010; Chmeleff, et al., 2010). AMS measurements of ${ }^{10} \mathrm{Be} /{ }^{9} \mathrm{Be}$ were updated through dividing values by the original NIST SRM $4325\left({ }^{10} \mathrm{Be} /{ }^{9} \mathrm{Be} ; 3.06 \pm 0.14 \times 10^{-11}\right)$ and multiplying by the new NIST SRM 4325 $\left({ }^{10} \mathrm{Be} /{ }^{9} \mathrm{Be} ; 2.79 \pm 0.03 \times 10^{-11}\right)$. From these re-calculations, the difference between old and updated measurements can be used as a scaling factor to convert between AMS measurements derived by old and new means, i.e. old measurements can be updated by multiplying by the scaling factor of 0.91176 . This was applied in updating the Southwest Pacific Ocean (SWPO) ${ }^{10} \mathrm{Be} /{ }^{9} \mathrm{Be}$, from $1.34 \pm 0.03\left[10^{-7}\right]$ (Graham, et al., 2003b) to a 
new ${ }^{10} \mathrm{Be} /{ }^{9} \mathrm{Be}$ of $1.22 \pm 0.03\left[10^{-7}\right]$, and for updating the chronologies and growth rates of the ten selected FMNs (Figure 4.1), including the original low resolution dating of U1365B-M (Figure 4.4; Appendix C). Age models were determined for the authigenic fraction of selected FMNs by using the following age equation:

$$
\text { Age }(\mathrm{Ma})=\ln \left({ }^{10} \mathrm{Be} /{ }^{9} \mathrm{Be} \text { MeAsured } /{ }^{10} \mathrm{Be} /{ }^{9} \mathrm{Be} \text { swpo }\right) *{ }^{10} \mathrm{Be} \mathrm{t}^{1 / 2} / \ln (2)
$$

where ${ }^{10} \mathrm{Be} /{ }^{9} \mathrm{Be}$ MEASURED is the revised ratios of each sample, ${ }^{10} \mathrm{Be} /{ }^{9} \mathrm{Be}$ swPo is the re-calculated 'initial' ${ }^{10} \mathrm{Be} /{ }^{9} \mathrm{Be}$ for the SWPO $\left(1.22 \pm 0.05\left[10^{-7}\right]\right)$ and ${ }^{10} \mathrm{Be} \mathrm{t}^{1 / 2}$ is the new half-life of 1.378 Ma (Korschinek, et al., 2010; Chmeleff, et al., 2010). A record of the insoluble residue, remaining after acid digestion, was used to calculate relative proportions of authigenic (acid-soluble) and detrital (acid-insoluble) material, which were used to determine total, authigenic and detrital growth rates using:

$$
\text { Growth rate }(\mathrm{mm} / \mathrm{Ma})=\text { sample depth }(\mathrm{mm}) / \text { age }(\mathrm{Ma})
$$

where sample depth $(\mathrm{mm})$ and age $(\mathrm{Ma})$ represents the subtracted values obtained from the start and end of each sampled shell. Conventional representation of growth rates also uses sampling mid-points and the associated calculated age. Using the established agedepth relationships of FMNs, specifically U1365B-M, an age model was assigned to the macro- and microscopic images. Visible changes in texture were categorised into zones and correlated to the age model, which were then further investigated using BSE images (Graham, et al., 2003a). Both macro- and microscopic images were then used as 'maps' to link key findings of the physical and chemical archives of U1365B-M. Uncertainties $(2 \sigma)$ associated with the age model range from $\pm 0.15 \mathrm{Ma}$ at the core (due to lower concentrations of ${ }^{10} \mathrm{Be}$ ) to $\pm 0.10 \mathrm{Ma}$ at the outer rim, with an average $2 \sigma$ precision of \pm 0.12 . This value incorporates analytical uncertainties associated with measurements of ${ }^{10} \mathrm{Be},{ }^{9} \mathrm{Be}$ and uncertainties associated with the ${ }^{10} \mathrm{Be}$ half-life $( \pm 0.01)$, and the SWPO ${ }^{10} \mathrm{Be} /{ }^{9} \mathrm{Be}( \pm$ 0.03). Reproducibility was evaluated by comparing initial ${ }^{10} \mathrm{Be} /{ }^{9} \mathrm{Be}$, determined in 2003 (Ditchburn \& Graham, 2003), with those determined in 2006 (Ditchburn \& Graham, 2006b), along opposing depth-profiles (Figure 4.4). From the outermost crust to a depth of c. $11 \mathrm{~mm}$ old and new ${ }^{10} \mathrm{Be} /{ }^{9} \mathrm{Be}$ ratios yield a percentage difference of $<10 \%$ and overlap one another in log space. For the remainder of the nodule the deviation of the repeat 
${ }^{10} \mathrm{Be} /{ }^{9} \mathrm{Be}$ from the original values ranges from 10 to $40 \%$ difference, most likely a consequence of sampling along two different nodule radii (Figure 4.4 (a) \& (b)). Concentric growth rings of U1365B-M are of variable width and hence do not cross nodule radii at the same depth. Overall, the new data is reliable to within $\pm 12 \%$ standard error ( $2 \sigma$ precision) and reproducible to within $\sim 20 \%$ of the original data.

Beryllium isotope dating of FMNs can only be successfully applied on nodules younger than 10-15 Ma. Beyond this range Co-chronometers provide one of the only other means of dating. As such, they are strongly relied upon in the literature (e.g. Frank, et al., 1999). However, recent studies have raised concerns as to the reliability of this method (e.g. Nielson, et al., 2011). In order to test the assumptions of Co chronometry, a selection of Co-chronometers were applied, and a Co-flux model developed, for U1365B-M (see also Section 3.1). Co age-depth relationships were derived using total, detrital and authigenic depth-profile data, and the Co flux rate was calculated over the growth history of U1365BM. The equation of Halbach, et al. (1983) was used to calculate the flux (F) of Co:

$$
F=C_{e} \cdot G \cdot D\left(\mu \mathrm{g} \mathrm{cm}{ }^{2} \mathrm{ky}\right)
$$

where $C_{e}$ is the element concentration in wt $\%$; $G$, the growth rate $(\mathrm{mm} / \mathrm{Ma})$ and; $D$ the in situ density $\left(\mathrm{g} \mathrm{cm}^{-3}\right)$ of U1365B-M. The in situ density being derived from:

$$
D=\gamma \operatorname{solid}(1-\varepsilon)
$$

where $\gamma$ solid is the average authigenic bulk density of U1365B-M $\left(3.54 \mathrm{~g} \mathrm{~cm}^{3}\right)$ with bulk density = mass $(6900 \mathrm{~g}) /$ volume $\left(975 \mathrm{~cm}^{3}\right)$ and volume $\left.=3 / 4 \pi \mathrm{r}^{3}\right)$ and; $\varepsilon$ the average $\mathrm{e}$ porosity of FMNs (0.51; Halbach, et al, 1975).

\subsection{Multi-Element Chemistry}

Multi-element analyses were performed at the Geochemistry Laboratory, School for Geography, Environment and Earth Sciences, VUW. Sample and standard dilutions were analysed for: major elements (>10, $000 \mathrm{ppm})$; minor elements ( $>1000 \mathrm{ppm})$, and trace elements (<1000 ppm) using an Agilent 7500CS ICP-MS (Figure 4.5). 

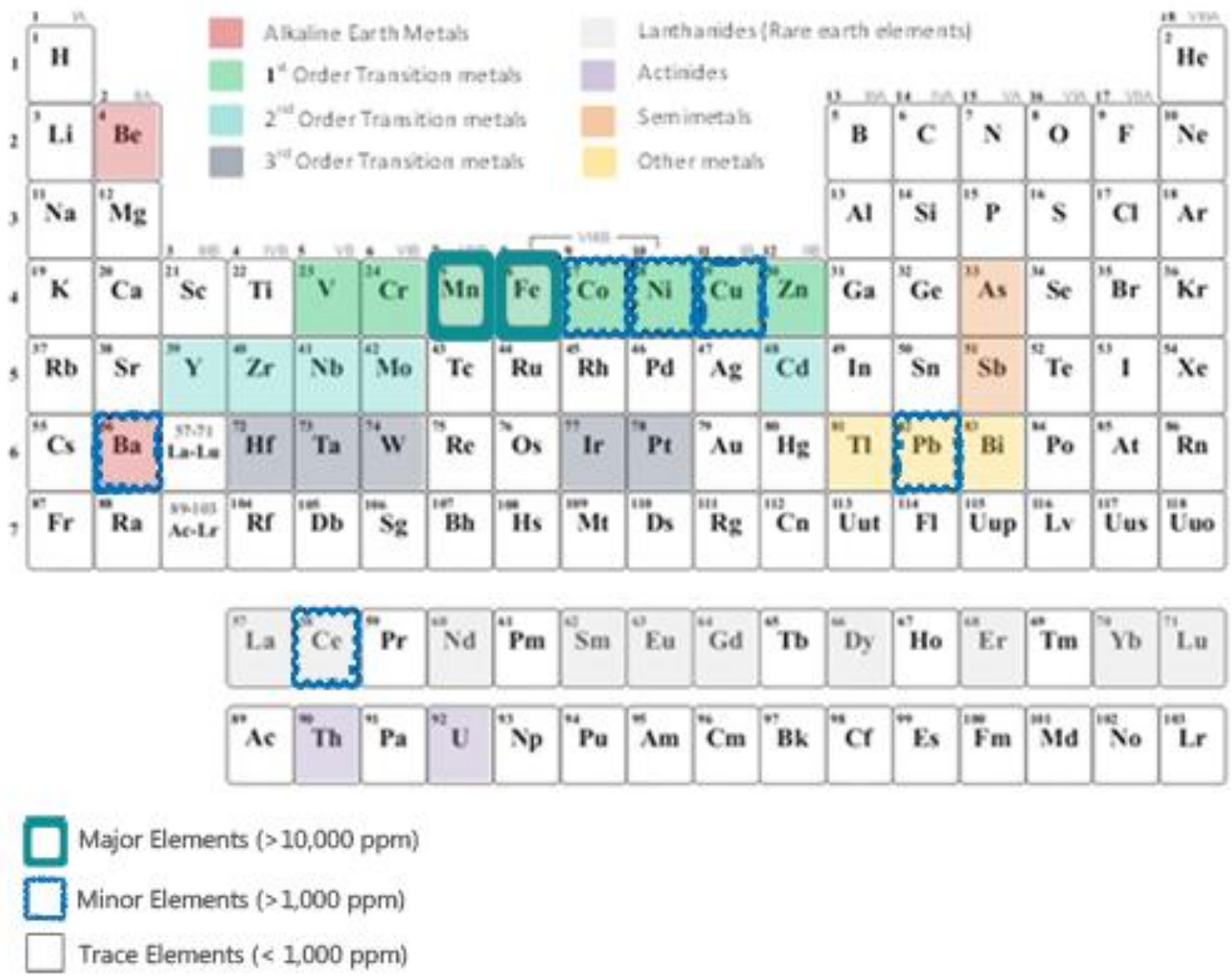

Figure 4.5 | Multi-element analyses performed using ICP-MS. Elements analysed in order of highest to lowest concentration in U1365-M include; (1) major elements: iron (Fe) and manganese (Mn); (2) minor elements: cobalt $(\mathrm{Co})$, cerium $(\mathrm{Ce})$, nickel $(\mathrm{Ni})$, barium $(\mathrm{Ba})$, lead $(\mathrm{Pb})$, copper $(\mathrm{Cu}) ;(3)$ trace elements: zirconium (Zr), vanadium (V), zinc (Zn), molybdenum (Mo), lanthanum (La), neodymium, $(\mathrm{Nd})$, arsenic $(\mathrm{As})$, yttrium $(\mathrm{Y})$, niobium $(\mathrm{Nb})$, tungsten $(\mathrm{W})$, thorium $(\mathrm{Th})$, gadolinium $(\mathrm{Gd})$, thallium (Tl), samarium ( $\mathrm{Sm}$ ), dysprosium (Dy), antimony (Sb), erbium (Er), ytterbium (Yb), hafnium (Hf), bismuth $(\mathrm{Bi})$, europium $(\mathrm{Eu})$, uranium $(\mathrm{U})$, lutetium $(\mathrm{Lu})$, cadmium $(\mathrm{Cd})$ and tantalum $(\mathrm{Ta})$, including chromium (Cr), iridium ( $\mathrm{Ir}$ ) and platinum $(\mathrm{Pt})$ which were discarded during development of the analytical procedure (see Appendix B; see also Table 3.2).

Typical analytical conditions are summarised in Table 4.2. To remove interfering ions the ICP-MS was operated in 'reaction cell mode' using He gas. On introduction into the ICP-MS via a peristaltic pump, samples 'collide' with the He collision gas which effectively removes unknown matrix interferences without compromising the multi-element capacity, requiring matrix- or element-specific optimisation, or requiring interference correction equations. Prior to sample analysis, the ICP-MS was tuned using an Agilent multi-element ( $\mathrm{Li}, \mathrm{Y}, \mathrm{Ce}, \mathrm{Tl}, \mathrm{Ca})$ calibration standard $(10 \mathrm{ppb})$ to achieve low relative standard deviation 


\begin{tabular}{|c|c|c|}
\hline ICP-MS & $\begin{array}{c}\text { Minor \& Trace Element } \\
\text { Chemistry }\end{array}$ & $\begin{array}{l}\text { Major Element } \\
\text { Chemistry }\end{array}$ \\
\hline ICP-MS system & Agilent 7500CS & Agilent 7500CS \\
\hline Acquisition mode & Peak hopping & Peak hopping \\
\hline Detection mode & Pulse and analog (mainly pulse) & Pulse and analog (mainly pulse) \\
\hline \multicolumn{3}{|l|}{ Standards } \\
\hline Primary standard & USGS Nod-P1 & USGS Nod-P1 \\
\hline Calibration/bracketing & Nod-P1-Trace & Fe-Mn Nod-P1 \\
\hline standard & Procedural blank $(0.1 \mathrm{M} \mathrm{HCl})$ & Procedural blank $\left(1 \% \mathrm{HNO}_{3}\right)$ \\
\hline \multicolumn{3}{|l|}{ Blank standard } \\
\hline \multicolumn{3}{|l|}{ Analysis method } \\
\hline Background acquisition & $60 s$ & $60 s$ \\
\hline Sample/standard acquisition & $90 \mathrm{~s}$ & $90 s$ \\
\hline Washout times & $1^{\text {st }}$ washout $120 \mathrm{~s}(0.1 \mathrm{M} \mathrm{HCl})$ & $1^{\text {st }}$ washout $120 \mathrm{~s}\left(1 \% \mathrm{HNO}_{3}\right)$ \\
\hline & $2^{\text {nd }}$ washout $60 \mathrm{~s}(0.1 \mathrm{M} \mathrm{HCl})$ & $2^{\text {nd }}$ washout $60 \mathrm{~s}\left(0.5 \% \mathrm{HNO}_{3}\right)$ \\
\hline $\begin{array}{l}\text { Measured isotopes and } \\
\text { integration times: }\end{array}$ & 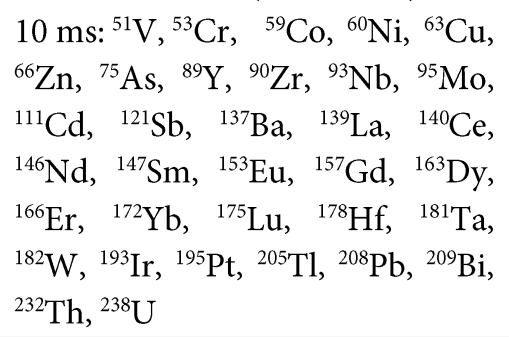 & $10 \mathrm{~ms}:{ }^{55} \mathrm{Mn},{ }^{56} \mathrm{Fe},{ }^{60} \mathrm{Ni}$ \\
\hline \multicolumn{3}{|c|}{ 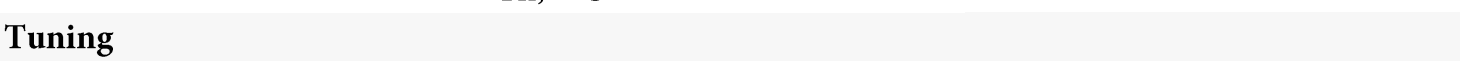 } \\
\hline Tuning standards & $\begin{array}{l}\text { Agilent } 10 \text { ppb standard (Li, Co, } \\
\mathrm{Y}, \mathrm{Ce}, \mathrm{Tl})\end{array}$ & $\begin{array}{l}\text { Agilent } 10 \text { ppb standard ( } \mathrm{Li}, \mathrm{Co} \text {, } \\
\mathrm{Y}, \mathrm{Ce}, \mathrm{Tl})\end{array}$ \\
\hline $\begin{array}{l}\text { Monitored isotopes and } \\
\text { oxides during tuning }\end{array}$ & $\begin{array}{l}{ }^{7} \mathrm{Li}, \quad{ }^{59} \mathrm{Co}, \quad{ }^{89} \mathrm{Y}, \quad{ }^{140} \mathrm{Ce}, \quad{ }^{205} \mathrm{Tl}, \\
{ }^{156} \mathrm{CeO}^{+} /{ }^{140} \mathrm{Ce}(\mathrm{RSD}<5 \%)\end{array}$ & $\begin{array}{l}{ }^{7} \mathrm{Li}, \quad{ }^{59} \mathrm{Co}, \quad{ }^{89} \mathrm{Y}, \quad{ }^{140} \mathrm{Ce}, \quad{ }^{205} \mathrm{Tl}, \\
{ }^{156} \mathrm{CeO}^{+} /{ }^{140} \mathrm{Ce}(\mathrm{RSD}<5 \%)\end{array}$ \\
\hline $\begin{array}{l}\text { Calibration standard } \\
\text { Monitored isotopes during } \\
\text { calibration }\end{array}$ & $\begin{array}{l}\text { Synthetic Nod-P1-Trace standard } \\
{ }^{51} \mathrm{~V},{ }^{59} \mathrm{Co},{ }^{60} \mathrm{Ni},{ }^{63} \mathrm{Cu},{ }^{66} \mathrm{Zn},{ }^{75} \mathrm{As}, \\
{ }^{89} \mathrm{Y},{ }^{90} \mathrm{Zr},{ }^{93} \mathrm{Nb},{ }^{95} \mathrm{Mo},{ }^{111} \mathrm{Cd},{ }^{121} \mathrm{Sb}, \\
{ }^{139} \mathrm{La},{ }^{140} \mathrm{Ce},{ }^{208} \mathrm{~Pb}(\mathrm{RSD}<5 \%)\end{array}$ & $\begin{array}{l}\text { Synthetic Nod-P1-Trace standard } \\
{ }^{51} \mathrm{~V},{ }^{59} \mathrm{Co},{ }^{60} \mathrm{Ni},{ }^{63} \mathrm{Cu},{ }^{66} \mathrm{Zn},{ }^{75} \mathrm{As}, \\
{ }^{89} \mathrm{Y},{ }^{90} \mathrm{Zr},{ }^{93} \mathrm{Nb},{ }^{95} \mathrm{Mo},{ }^{111} \mathrm{Cd},{ }^{121} \mathrm{Sb}, \\
{ }^{139} \mathrm{La},{ }^{140} \mathrm{Ce},{ }^{208} \mathrm{~Pb}(\mathrm{RSD}<5 \%)\end{array}$ \\
\hline Oxides & $\mathrm{CeO}^{+} / \mathrm{Ce}^{+} 10 \mathrm{ppb}$ solution $<5 \%$ & $\mathrm{CeO}^{+} / \mathrm{Ce}^{+} 10 \mathrm{ppb}$ solution $<5 \%$ \\
\hline Carrier gas (Ar) & $1.07-1.13 \mathrm{~L} / \mathrm{min}$ & $1.07-1.13 \mathrm{~L} / \mathrm{min}$ \\
\hline Reaction cell mode & $\mathrm{He}$ gas, $4 \mathrm{~mL} / \mathrm{min}$ & He gas, $4 \mathrm{~mL} / \mathrm{min}$ \\
\hline RF power & $1500 \mathrm{~W}$ & $1500 \mathrm{~W}$ \\
\hline RF matching & $1.68-1.78 \mathrm{~V}$ & $1.68-1.78 \mathrm{~V}$ \\
\hline Sample depth & $7 \mathrm{~mm}$ & $7 \mathrm{~mm}$ \\
\hline
\end{tabular}

Table 4.2 ICP-MS parameters for multi-element analyses of FMN samples. Conditions required for ICP-MS analysis of major, minor and trace elements, listing parameters selected for the Agilent 7500CS ICP-MS, standards used, the analysis method and tuning parameters. 
(RSD) and optimize sensitivity (Table 4.2). Oxide generation was monitored using $\mathrm{CeO}+/ \mathrm{Ce}+$ ratios $(<2 \%)$. This step was then repeated using synthetic standard Nod-P1_Trace, for minor and trace element chemistry and Nod-P-1_Major, for major element chemistry, in order to calibrate ICP-MS response and monitor drift in measurements (see Appendix B). Synthetic calibration standards were analysed at the start of each analytical run and re-measured after every five samples. During minor and trace chemistry, variations in isotopic abundance and degree of ionisation varied from element to element and so different concentrations were needed for all elements to fall within the required range of counts per second (cps), between 100,000 and 1,000,000. For this reason pulse/analog (P/A) factor was assessed for elements that exceeded $1 \times 10^{6} \mathrm{cps}$ (e.g. Ni, Co, $\mathrm{Cu}, \mathrm{Pb})$.

For minor and trace element analysis (major element analysis in brackets) samples were then run using a sample-standard bracketing technique analysing: (1) Nod-P1-Trace (Nod-P1-Major); (2) five (ten) nodule samples; (3) Nod-P1-Trace (Nod-P1-Major). Between each sample and standard the ICP-MS was washed out for 120 s in $0.1 \mathrm{M} \mathrm{HCl}(1 \%$ $\left.\mathrm{HNO}_{3}\right)$, followed by $60 \mathrm{~s}$ in a separate solution of $0.1 \mathrm{M} \mathrm{HCl}\left(0.5 \% \mathrm{HNO}_{3}\right)$, used to measure background cps. For each batch of samples processed, two procedural blanks, two USGS Nod-P1 samples and three repeat analyses of samples were also measured.

\section{Data Processing}

At the end of an ICP-MS run, the data results were exported in a csv file to Microsoft Excel. Measurements were reported for each trace metal in counts per second (cps) for every $0.754 \mathrm{~s}$ of solution analysis. In order to convert cps data into concentration values in parts per million (ppm) the data was processed as follows (see also Appendix B \& E):

Major element data were background corrected using $60 \mathrm{~s}$ of $1 \% \mathrm{HNO}_{3}$ wash. From creating the synthetic standards using ratios to Ni (Appendix B \& E), a similar method was applied here, using the known $\mathrm{Ni}$ concentrations and $\mathrm{Fe} / \mathrm{Ni}$ and $\mathrm{Mn} / \mathrm{Ni}$ ratios as an internal standard to determine concentration data for Fe and $\mathrm{Mn}$. Firstly, following background corrections, $\mathrm{Fe} / \mathrm{Ni}$ and $\mathrm{Mn} / \mathrm{Ni}$ ratios were calculated from the raw cps data. 
Data were then normalised to Ni by multiplying the ratios by the sum of: $a / b$ where $a=100$ (on average $\mathrm{Ni}$ is 100 times lower in concentration compared to $\mathrm{Fe}$ and $\mathrm{Mn}$ ) and $\mathrm{b}=$ the isotopic abundance of either ${ }^{56} \mathrm{Fe}=91.754 \%$ or $\mathrm{Mn}=100 \%$ (as $\mathrm{Mn}$ is monoisotopic the abundance for ${ }^{60} \mathrm{Ni}=26.223 \%$ was used). Standard corrections were then conducted by multiplying the $\mathrm{Fe} / \mathrm{Ni}$ and $\mathrm{Mn} / \mathrm{Ni}$ ratios by the average of the two bracketing Nod-P1FeMn2 calibration standards. The Fe/Ni and $\mathrm{Mn} / \mathrm{Ni}$ ratios and previously determined $\mathrm{Ni}$ concentration for each sample of U1365B-M and Nod-P-1 reference standard, where then used to calculate $\mathrm{Fe}$ and $\mathrm{Mn}$ concentrations in ppm by multiplying the $\mathrm{Fe} / \mathrm{Ni}$ and $\mathrm{Mn} / \mathrm{Ni}$ ratios by $\mathrm{Ni}$ concentration. The final $\mathrm{ppm}$ of $\mathrm{Fe}$ and $\mathrm{Mn}$ were then derived by dilution correcting by multiplying by 10,0000 .

Minor and trace element data were background corrected by subtracting the average value for the $60 \mathrm{~s}$ of analysis prior to sample introduction (when the ICP-MS is being rinsed with $0.1 \mathrm{~m} \mathrm{HCl}$ ) from the average value of the last 90s of sample analysis. Standard corrections were then conducted by multiplying the background corrected value of ferromanganese material by the concentration value ( $\mathrm{ppm}$ ) of the analyte in the calibrating standard of Nod-P1-Trace (Appendix E). This value was then divided by the average of the two bracketing standards. Digestion and dilution corrections were then made on the standard corrected values by multiplying: (1) the overall dilution factor, determined by multiplying the first dilution of $5 \mathrm{~mL} 11 \mathrm{M} \mathrm{HCl}$ with c. $13 \mathrm{~g}$ of Milli-Q water $(5+13)$ by the second dilution (1:100), which is then divided by (2) the mass of the Fe-Mn fraction, calculated from the \% residue.

\section{Accuracy \& Precision}

Once the experimental procedure had been established $>30$ duplicate analyses were performed on USGS Nod-P-1 to determine accuracy (reliability) and precision (reproducibility) for the analytical method (Figure 4.6). Generally, measurements were reliable to within $5-10 \%$ of reference values (Axelsson, et al., 2002) and precise to within $\pm 10 \%$ of two standard deviations (95\% confidence limits) of the mean (Appendix B). Excellent agreement, to within 5\% of values reported in Axelsson et al. were found for 15 elements: As, Y, Mo, Cd, Ba, La, Nd, Sm, Eu, Dy, Er, Yb, Tl, Pb and U (out of 29), colour 
coded in Figure 4.6 (blue). An additional seven elements were within $10 \%$ of reported values: $\mathrm{Co}, \mathrm{Ni}, \mathrm{Cu}, \mathrm{Zr}, \mathrm{Gd}, \mathrm{Lu}$ and $\mathrm{Th}$ (Figure 4.6; green). Slightly poorer accuracy (results generally within $\pm 20 \%$ except for Fe at $25 \%$ ) was found for: V, Mn, Fe, Zn, Ce, Hf and Bi. Axelsson et al. (2002) made a note of poor accuracy between their results and those of the published ranges for elements Th, Y, Zn, B and As, which may be a consequence of sample matrix heterogeneity or of the different techniques applied i.e., values higher than would be expected based on values reported in Axelsson et al, are likely a result of bulk digestion.

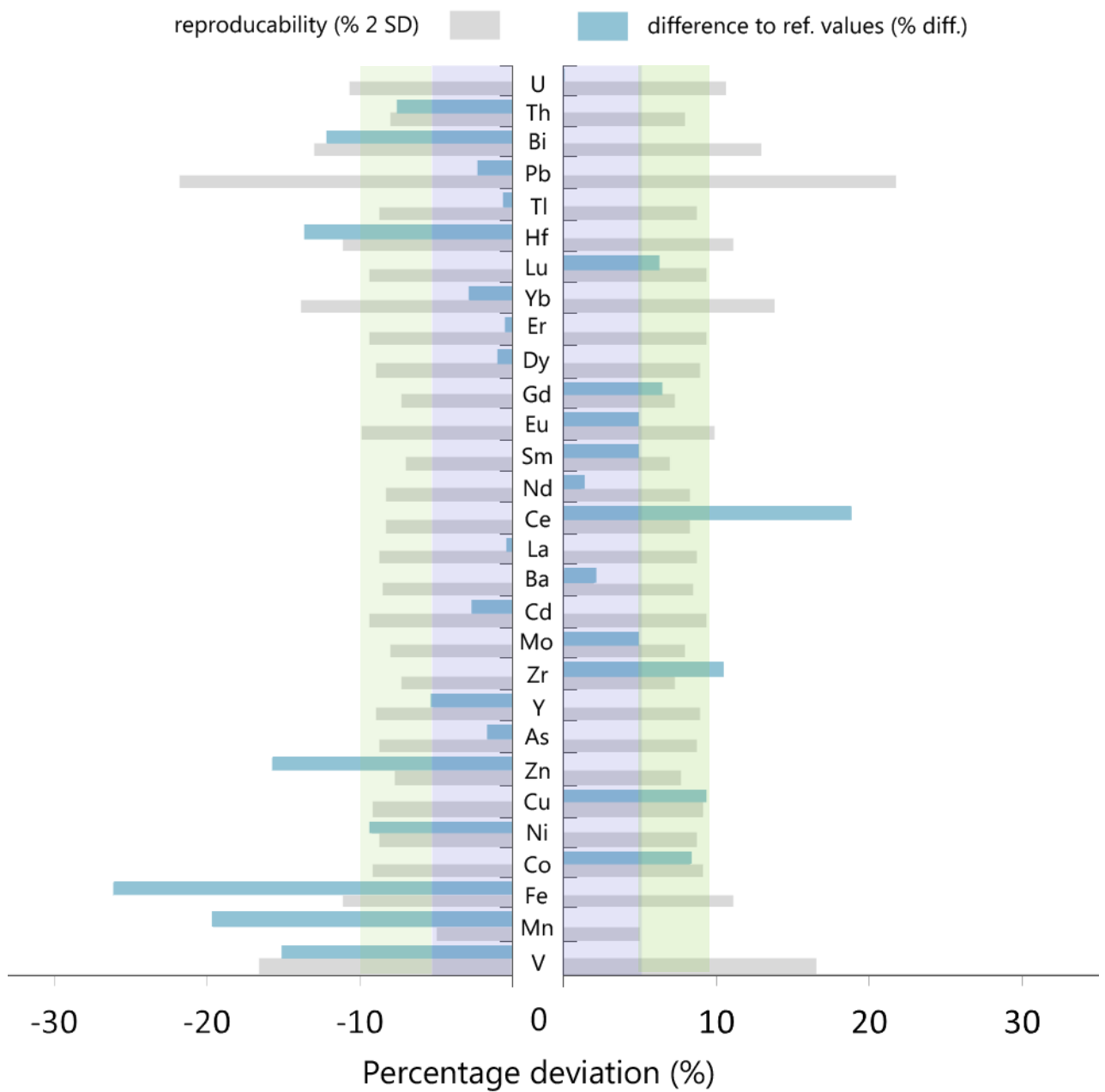

Figure 4.6 Accuracy and precision of multi-element analytical procedure. The reliability of the technique for each element assessed is illustrated by grey bars and signifies the percentage value of two standard deviation (\%2 SD) based on more than 30 repeated analyses of Nod-P-1 and generally derived data that was $< \pm 10 \%$. The accuracy of the technique was assessed through calculations of the percentage difference between those measured for Nod-P-1 and values reported in Axelsson, et al. (2002), illustrated by the blue bars, which are generally within $5-10 \%$. Data within $5 \%$ accuracy and precision fall within the blue field and data within $10 \%$ the green field. 
The presence of aluminosilicates can mask the chemical signals of certain elements such as Ce. As for the lower than expected Fe and Mn concentrations, Axelsson et al. also make a point of commenting upon 'numerous interferences' when measuring complex matrices such as FMNs using ICP-SFMS. Additionally, Flanagan \& Gottfried (1980) describe a certain degree of sample heterogeneity for NOD-P-1 (see Appendix B for further information).

\subsection{Lead Isotope Chemistry}

During major element and $\mathrm{Pb}$ isotope sample preparation for analysis, $1 \mathrm{~mL}$ of the acid supernatant was extracted and transferred into pre-cleaned $3 \mathrm{~mL}$ Savillex beakers. The solutions were then evaporated to dryness on a hotplate $\left(\right.$ c. $\left.120^{\circ} \mathrm{C}\right)$, before being converted to bromide salts by addition and evaporation of $0.5 \mathrm{~mL} 0.8 \mathrm{M} \mathrm{HBr}$. The solid was then dissolved in $1 \mathrm{~mL} 0.8 \mathrm{M} \mathrm{HBr}$, forming negatively charged bromide complexes $\left(\mathrm{PbBr}^{3-}\right.$ and $\mathrm{PbBr}_{4}{ }^{2-}$ ). The solution was fluxed for $24 \mathrm{hr}$ at $120^{\circ} \mathrm{C}$ on a hotplate before being set aside to re-equilibrate to room temperature prior to loading on anion exchange columns.

\section{Column Chemistry}

Columns where created by converting $1 \mathrm{~mL}$ pipette tips into columns. The lower $8 \mathrm{~mm}$ of the pipette tip was cut off and porous polypropylene frits were inserted into the base of the cut pipette (Figure 4.7 (a)). The columns were then soaked in $6-7 \mathrm{M} \mathrm{HCl}$ for approximately one week before use. Prior to loading with resin, columns were washed through three times with alternating loads of ultra-pure water and $11 \mathrm{M} \mathrm{HCl}$ (Figure 4.7 (b)). Analytical grade BioRad AG 1-X8 anion exchange resin, a quaternary amine anion exchanger resin on a polystyrene base with a 100 - 200 mesh size, was used to effectively separate $\mathrm{Pb}$ from the FeMn matrix of nodule samples in a single column pass. The AG 1-X8 resin was transferred into a $125 \mathrm{~mL}$ wash bottle. Once the re-suspended resin had settled excess ultra-pure water was decanted. The resin was then converted to chloride form by soaking in $11 \mathrm{M} \mathrm{HCl}$ for 2 $\mathrm{hr}$ and then rinsed through three times with ultra-pure water prior to use. The pre-cleaned $\mathrm{Pb}$ columns were loaded with $0.5-1 \mathrm{~cm}($ c. $0.2 \mathrm{~mL})$ of resin and cleaned 3 times with alternating volumes of $6 \mathrm{M} \mathrm{HCl}$ and $1 \mathrm{~mL}$ of ultra-pure water (Figure 4.7 (c \& d). The resin was stored in ultra-pure water to avoid potential degradation in concentrated $\mathrm{HCl}$. 
In preparation for column chemistry the resin was pre-treated with two reservoirs of 0.8 M HBr (Figure 4.7 (e)). Samples and standards dissolved in $0.8 \mathrm{M} \mathrm{HBr}$ were then loaded onto the columns and the bromide complexes bonded to the AG 1-X8 resin (Figure 4.7 (f)). One full and two half column loads of $0.8 \mathrm{M} \mathrm{HBr}$ were eluted to remove the matrix of the sample (Figure $4.7(\mathrm{~g})$ ). Pb was collected off the column through substitution of the bromide complexes with chloride complexes in $3 \mathrm{~mL}, 7 \mathrm{M} \mathrm{HCl}$ (Figure 4.7 (h)). The $\mathrm{Pb}$ separate was then evaporated on a hotplate at $120{ }^{\circ} \mathrm{C}$ for $24 \mathrm{hr}$. One $\mathrm{mL}$ of $16 \mathrm{M} \mathrm{HNO}_{3}$ was then added to convert the $\mathrm{Pb}$ bromide salts to nitrates, liberating bromide as $\mathrm{Br}_{2}$ gas. The $\mathrm{Pb}$ nitrates were then dissolved in $1 \mathrm{~mL} 0.5 \% \mathrm{HNO}_{3}$ and c. $0.003 \mathrm{~mL}$ aliquot transferred to an acid cleaned $1.5 \mathrm{~mL}$ micro centrifuge tube. Finally, $1.5 \mathrm{~mL} 0.5 \% \mathrm{HNO}_{3}$ was delivered to the micro centrifuge tube to dilute the $\mathrm{Pb}$ samples ready for MC-ICP-MS analysis.

\section{MC-ICP-MS analysis \& data processing}

MC-ICP-MS analyses of $\mathrm{Pb}$ are associated with a series of analytical challenges. Unlike other radioactive decay systems (e.g. $\mathrm{Sr}, \mathrm{Nd}, \mathrm{Os}), \mathrm{Pb}$ only has one non-radioactive isotope $\left({ }^{204} \mathrm{~Pb}\right)$, so there is no invariant ratio available to correct for instrument mass bias. Thus, accuracy and precision of $\mathrm{Pb}$ measurements are dependent upon the use of different methods to correct for mass fractionation during MC-ICP-MS analysis. Several different methods exist: (1) double-spiking; (2) external element doping, and; (3) sample-standard bracketing. A sample-standard bracketing approach was adopted in this study. The method involved correcting for isotopic fractionation by bracketing the measurement of a ferromanganese sample with analyses of a well characterised standard solution, in this case, SRM 981 Natural Lead (Appendix D). This approach continuously monitors for mass discrimination for each individual sample and corrects for mass fractionation by interpolating the mass bias factors of the standards to the sample following the formula (Albarède et al., 2004):

$$
\left(\mathrm{R}_{\mathrm{t}}\right)_{\text {smp }}=\left(\mathrm{R}_{\mathrm{t}}\right)_{\mathrm{std}} *\left[\left(\mathrm{R}_{\mathrm{m}}\right)_{\mathrm{smp}} /\left(\mathrm{R}_{\mathrm{m}}\right)_{\mathrm{std} 1} *\left(\mathrm{R}_{\mathrm{m}}\right)_{\mathrm{std} 2}\right.
$$

where $\mathrm{Rt}$ and $\mathrm{Rm}$ are true and measured isotopic ratios respectively and the subscripts smp and std refer to the sample and standard respectively. (Rt)std refers to $\mathrm{Pb}$ isotopic ratios reported for NIST SRM981 by Baker et al. (2004); (1) ${ }^{208} \mathrm{~Pb} /{ }^{204} \mathrm{~Pb}=36.7258$, (2) ${ }^{207} \mathrm{~Pb} /{ }^{204} \mathrm{~Pb}=$ 15.499 and $(3){ }^{206} \mathrm{~Pb} /{ }^{204} \mathrm{~Pb}=16.9416$. (Rt)std 1 and $(\mathrm{Rt}) \mathrm{std} 2$ are $\mathrm{Pb}$ isotopic ratio 
(a) Make column

(b) Clean column
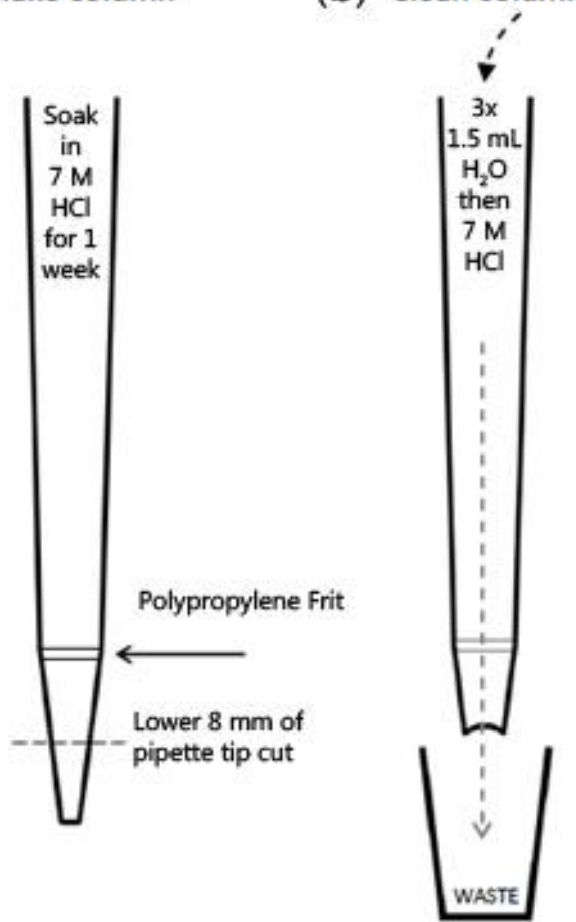

(e) Pre-treat resin

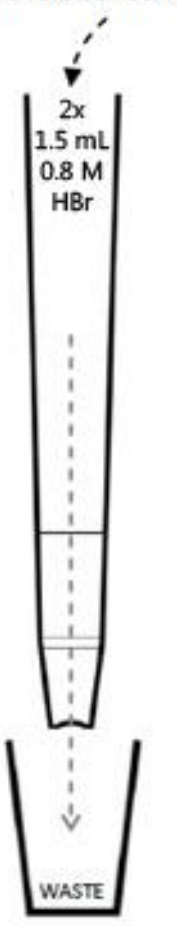

(f) Load sample

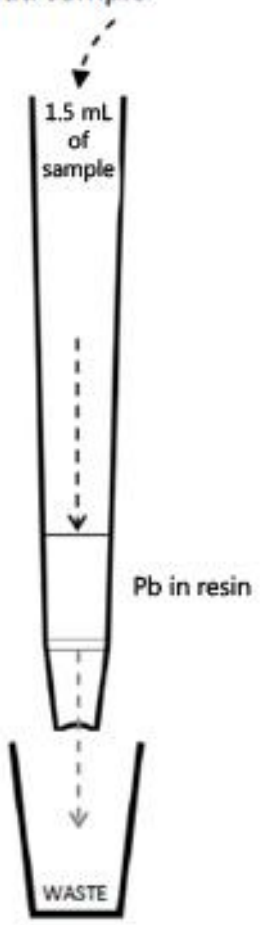

(c)

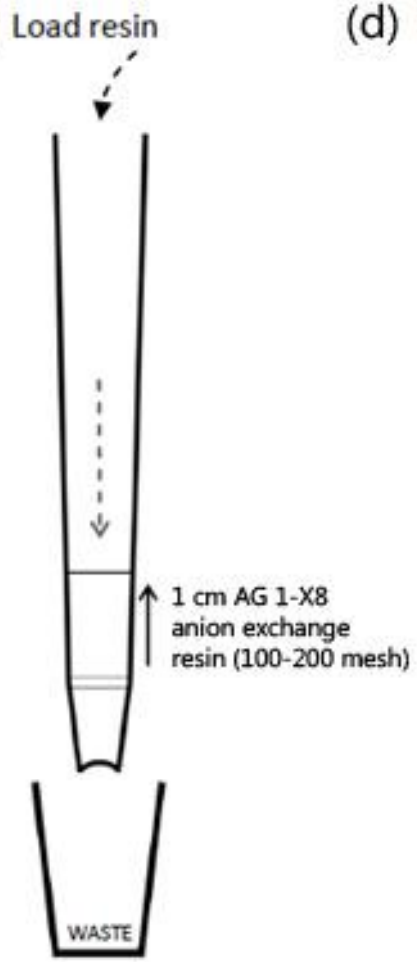

(d) Clean resin

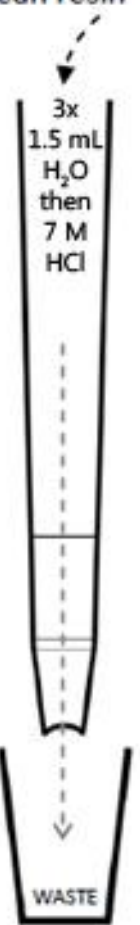

(g) Elute matrix

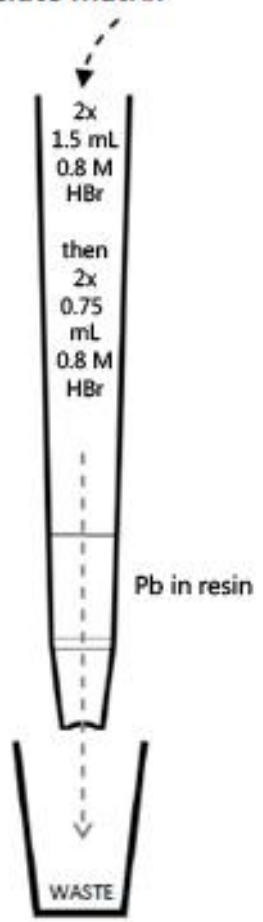

(h) Collect $\mathrm{Pb}$

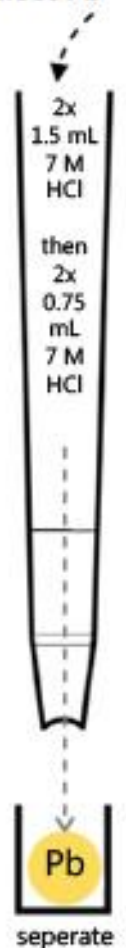

Figure 4.7 | Lead column chemistry. Systematic separation procedure for isolating $\mathrm{Pb}$ from the Fe-Mn sample matrix. 
measurements for the two bracketing NIST SRM981 standards. FMN samples and standards were analysed for $\mathrm{Pb}$ isotope compositions ${ }^{208} \mathrm{~Pb},{ }^{207} \mathrm{~Pb},{ }^{206} \mathrm{~Pb}$ and ${ }^{204} \mathrm{~Pb}$ using a Nu-Plasma MC-ICP-MS at VUW. The typical instrument operating conditions are shown in Table 4.3, however method parameters were systematically varied and tested in order to obtain the most accurate and precise $\mathrm{Pb}$ isotope ratios. The $\mathrm{Nu}$ Plasma MC-ICP-MS was coupled to a DSN-100 Desolvating Nebuliser System for solution mode analysis. Sample solutions were introduced to the DSN-100 by a $200 \mu \mathrm{L} / \mathrm{min}$ flow glass nebuliser in free aspiration mode. The nebulised aerosol was sprayed into a heated $\left(110^{\circ} \mathrm{C}\right)$ PFA chamber and maintained in its gaseous state. The sample vapour then entered a PTFE membrane desolvator module where a counter current argon sweep gas removed any solvent vapours that permeated the porous membrane. Non-volatile sample components remained within the membrane walls and continued into the MC-ICP-MS instrument. Although the DSN-100 was useful for enhancing sensitivity, longer washout times of $c .15 \mathrm{~min}$ and the use of isopropyl alcohol (IPA) solution were necessary due to the large memory effect. The machine was tuned using a $15 \mathrm{ppb}$ solution of NIST SRM 981 by adjusting operating conditions of the instrument to optimize analytical sensitivity to $7-8 \mathrm{~V}$ for ${ }^{208} \mathrm{~Pb}$.

Isotopes were measured simultaneously in static mode using a multi-faraday cup array. The Faraday collectors were set to detect the following isotopes of $\mathrm{Pb}$ simultaneously: ${ }^{208} \mathrm{~Pb}$ $(\mathrm{H} 4),{ }^{207} \mathrm{~Pb}(\mathrm{H} 3),{ }^{206} \mathrm{~Pb}(\mathrm{H} 2)$ and ${ }^{204} \mathrm{~Pb}(\mathrm{Ax})$. The ion current detected at each collector was converted to voltages through a $1011 \Omega$ resister and the difference in the voltage detected at each of the collectors was calibrated against the central Faraday by passing a constant electric current. Data collection consisted of 50 cycles with $4 \mathrm{~s}$ integrations per cycle. Sequences consisted of alternate analyses of standard NIST SRM981 with; (1) USGS Nod-P-1, (2) U1365B-M nodule samples and (3) procedural blanks. All samples and standards were introduced in $1 \% \mathrm{HNO}_{3}$ and two blank measurements of this reagent were performed for every 20th measurement. All blank measurements displayed insignificant voltages for ${ }^{208} \mathrm{~Pb}$ and as a result produced no deviation to the true sample composition.

Prior to the measurement of each block the introduction system was cleaned with: (1) $0.5 \% \mathrm{HNO}_{3}$; (2) PVA solution and; (3) $1 \% \mathrm{HNO}_{3}$, each running for 5 min until background levels of ${ }^{208} \mathrm{~Pb}$ were $<5 \mathrm{mV}$. In addition, baseline data was collected for $60 \mathrm{~s}$ during the $5 \mathrm{~min}$ 


$\begin{array}{ll}\begin{array}{l}\text { Instrument configuration \& settings } \\ \text { Instrument }\end{array} & \text { NU Plasma ICP-MS } \\ \text { Resolution } & \text { Low }-300(\mathrm{~m} / \Delta \mathrm{m}) \\ \text { Rf power } & \text { Counting } \\ \text { Nebulizer } & \text { Standard } 6 \mathrm{~mm} \text { glass nebulizer } \\ \text { Sample introduction accessory } & \text { DSN-100 } \\ \text { Spray chamber } & \text { Cyclonic } \\ \text { Coolant argon flow rate } & \sim 12.5 \mathrm{~L} \mathrm{~min}^{-1} \\ \text { Auxiliary argon flow rate } & 1.1 \mathrm{~L} \mathrm{~min}^{-1} \\ \text { Nebulizer argon flow rate } & 1.1 \mathrm{~L} \mathrm{~min}^{-1} \\ \text { Instrument tuning } & \text { Performed using; (1) } 10 \text { ppb multi-element } \\ & \text { standard }(2) \mathrm{NIST} \text { SRM981 } \\ \text { Ion transmission } & \text { Typically } 5-7 \mathrm{x} 10^{5} \text { counts } \mathrm{s}^{-1} \text { for } 15 \text { ppb }{ }^{208} \mathrm{~Pb} \\ \text { Scan type } & \text { Fixed magnet with electric scan over small mass } \\ & \text { range } \\ \text { Ion sampling depth } & \text { Adjusted daily to obtain max signal intensity } \\ \text { Ion lens setting } & \text { Adjusted daily to obtain max signal intensity and }\end{array}$

\section{Standards}

Primary standard

USGS Nod-P1

Calibration/bracketing standard NIST SRM981

Blank standard

Procedural blank $\left(1 \% \mathrm{HNO}_{3}\right)$

\section{Method parameters}

Isotopes considered

Scan type

${ }^{201} \mathrm{Hg},{ }^{204} \mathrm{~Pb},{ }^{206} \mathrm{~Pb},{ }^{207} \mathrm{~Pb},{ }^{208} \mathrm{~Pb}$

Magnet fixed at ${ }^{208} \mathrm{~Pb}$, electric scans over other mass ranges

Mass scanning window

$3 \%$

Magnet settle time

$0.1 \mathrm{~s}$

Dwell time per measurement

$0.001 \mathrm{~s}$

Scan duration per sweep

$5 \times 0.025 \mathrm{~s}$

Number of sweeps

2000

Detector mode

Integration type

Counting

Data Collection

Sample uptake and equilibration time

Average

$50 \times 4$ s integrations

$5-10 \mathrm{~min}$

$1^{\text {st }}$ washout $3-5 \min \left(0.5 \% \mathrm{HNO}_{3}\right)$

$2^{\text {nd }}$ washout $3-5 \min (\mathrm{PVA})$

$3^{\text {rd }}$ washout $3-5 \min \left(1 \% \mathrm{HNO}_{3}\right)$

Total time per sample

$15-30 \mathrm{~min}$

Table 4.3 MC-ICP-MS parameters for analysis of $\mathrm{Pb}$ isotope compositions from FMN sample.

Conditions required for MC-ICP-MS analysis of $\mathrm{Pb}$ isotopic compositions, listing the instrument configuration and settings selected, standards used, and the analysis method and tuning parameters. 
wash in $1 \% \mathrm{HNO}_{3}$. The baseline response of the machine was deducted from sample measurements. The concentration of standards and samples were closely matched at 15 ppb which resulted in ${ }^{208} \mathrm{~Pb}$ signals between $5-9 \mathrm{~V}$. The standard NIST SRM981 was measured at the start, middle and end of each sequence and used to monitor quality control (accuracy and precision) of the sample-standard bracketing approach. In addition to the isotopes of $\mathrm{Pb},{ }^{202} \mathrm{Hg}$ was measured to allow for correction of the isobaric interference of ${ }^{204} \mathrm{Hg}$ on ${ }^{204} \mathrm{~Pb}$. The contribution of ${ }^{204} \mathrm{Hg}$ to the total ${ }^{204} \mathrm{~Pb}$ ion beam was negligible for all measurements (Table 4.3). During MC-ICP-MS data collection (1 block of 50 cycles) measurements; ${ }^{208} \mathrm{~Pb} /{ }^{204} \mathrm{~Pb},{ }^{207} \mathrm{~Pb} /{ }^{204} \mathrm{~Pb},{ }^{206} \mathrm{~Pb} /{ }^{204} \mathrm{~Pb}$ and the associated standard errors, were manually entered in to a Microsoft Excel spreadsheet. Instrumental mass bias was corrected by external normalisation of sample data to the bracketing NIST SRM 981 standard using the double spike values of Baker et al. $(2004):{ }^{208} \mathrm{~Pb} /{ }^{204} \mathrm{~Pb}=36.726$, ${ }^{207} \mathrm{~Pb} /{ }^{204} \mathrm{~Pb}=15.499$ and ${ }^{206} \mathrm{~Pb} /{ }^{204} \mathrm{~Pb}=16.942$, in the above equation.

\section{Accuracy \& Precision}

In order to assess data quality of the sample-standard bracketing technique, a batch of 14 USGS Nod-P-1 samples were processed and analysed on the MC-ICP-MS for ${ }^{208} \mathrm{~Pb},{ }^{207} \mathrm{~Pb}$, ${ }^{206} \mathrm{~Pb}$ and ${ }^{204} \mathrm{~Pb}$ isotopes. The results are presented in Figure 4.8 and tabulated in Appendix D. Accuracy of analytical measurements recorded for USGS Nod-P-1 were calculated as a percentage difference by comparing the mean $\mathrm{Pb}$ isotopic ratio measurements with the $\mathrm{Pb}$ isotopic values for Nod-P-1 reported by Baker et al. (2004): (i) ${ }^{208} \mathrm{~Pb} /{ }^{204} \mathrm{~Pb}=38.697 \pm 0.008$; (ii) ${ }^{207} \mathrm{~Pb} /{ }^{204} \mathrm{~Pb}=15.638 \pm 0.003$ and; (iii) ${ }^{206} \mathrm{~Pb} /{ }^{204} \mathrm{~Pb}=18.700 \pm 0.006$. Mean $\mathrm{Pb}$ isotopic ratio measurements (this thesis) are displayed in Figure 4.8 (orange line and circular marker) in addition to the reference values of Baker et al. (2004) (Figure 4.8; grey squares). On average, measured isotope ratios are within $\pm 0.0003, \pm 0.002$ and \pm 0.004 of reference values at $(1){ }^{208} \mathrm{~Pb} /{ }^{204} \mathrm{~Pb}=36.7258,(2){ }^{207} \mathrm{~Pb} /{ }^{204} \mathrm{~Pb}=15.499$ and $(3){ }^{206} \mathrm{~Pb} /{ }^{204} \mathrm{~Pb}=16.9416$, with percentage differences of $0.001 \%, 0.012 \%$ and $0.026 \%$, respectively (Figure 4.8 ). Reliability of the data (\% $2 \mathrm{SD}$ ) ranged from $(1)^{208} \mathrm{~Pb} /{ }^{204} \mathrm{~Pb}=0.032 \%,(2){ }^{207} \mathrm{~Pb} /{ }^{204} \mathrm{~Pb}=0.052 \%$ and (3) ${ }^{206} \mathrm{~Pb} /{ }^{204} \mathrm{~Pb}=0.061 \%$. The upper calculated (UCL) and lower calculated limits (LCL) of precision are illustrated in Figure 4.8 by the shaded boxes. Thus, this method generated reliable (to within $0.012 \%$ published values) and reproducible ( $\pm 0.05 \%$ repeat values) data. 


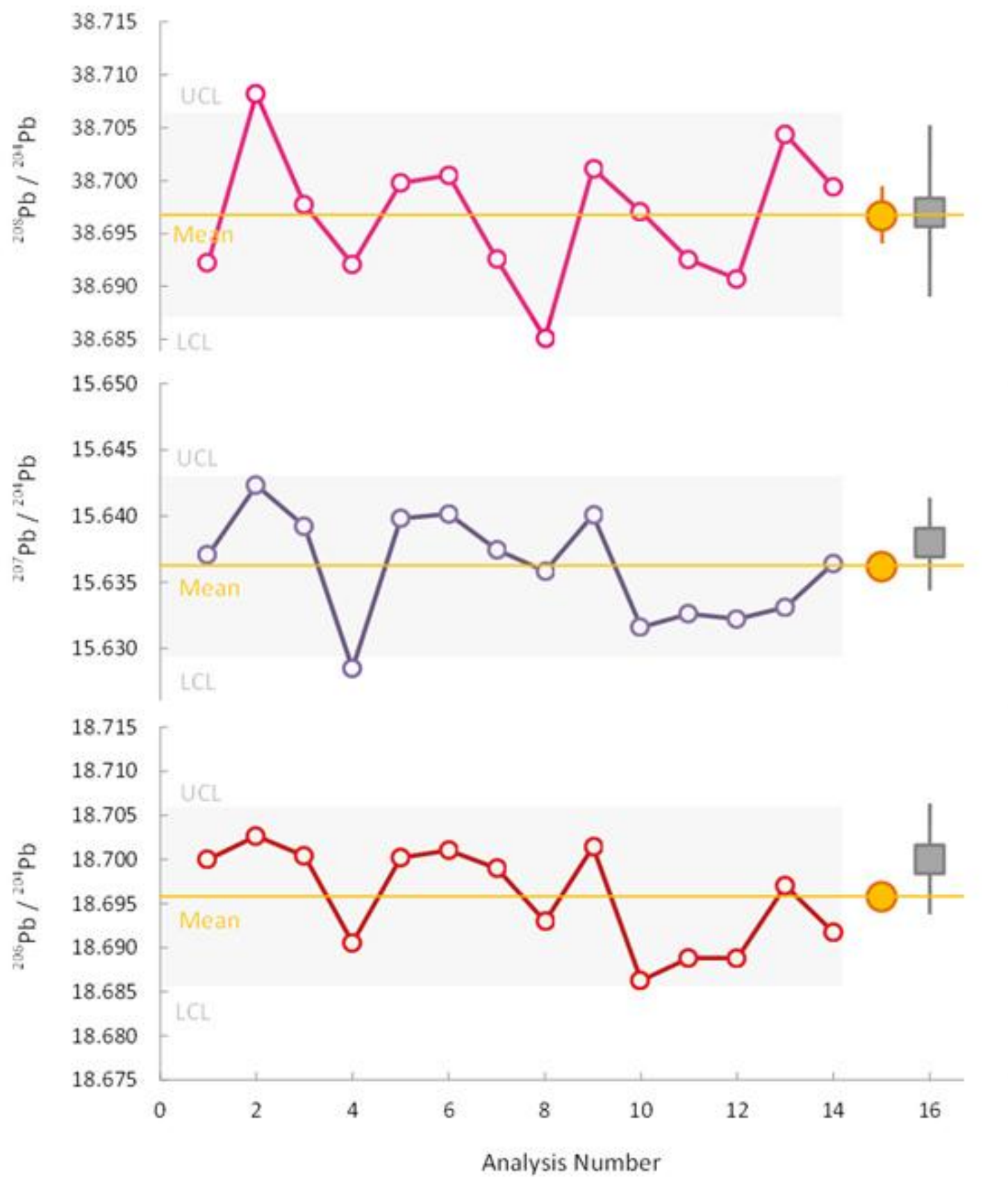

Figure 4.8 $\mathrm{MC}$-ICP-MS accuracy and precision of authigenic $\mathrm{Pb}$ isotope ratio measurements. Determined for USGS geochemical reference material Nod-P1. Calculations to determine data accuracy (\% diff.) used $\mathrm{Pb}$ isotope compositional data reported in Baker et al. (2004), illustrated by grey markers. Precision was calculated by determining $\% 2$ s.d. from 14 replica analyses of USGS Nod-P1. The upper and lower control limits of precision are shown $( \pm 2$ s.d.) by the shaded boxes that are centred about the mean value for each $\mathrm{Pb}-\mathrm{Pb}$ composition, the measured mean, displayed by an orange line and circular marker. 


\section{Chapter}

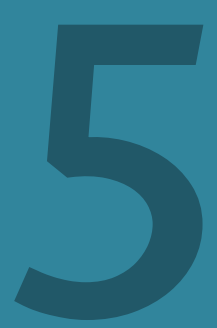

Describes chronologies \& growth rates, micro \& macro nodule architecture and the geochemical behaviour of elements and $\mathrm{Pb}$ isotopes as time-series and interelement correlations

\section{Results}

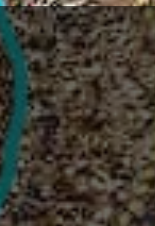

Physiochemical Archives of $11365 \mathrm{~B}-\mathrm{M}$
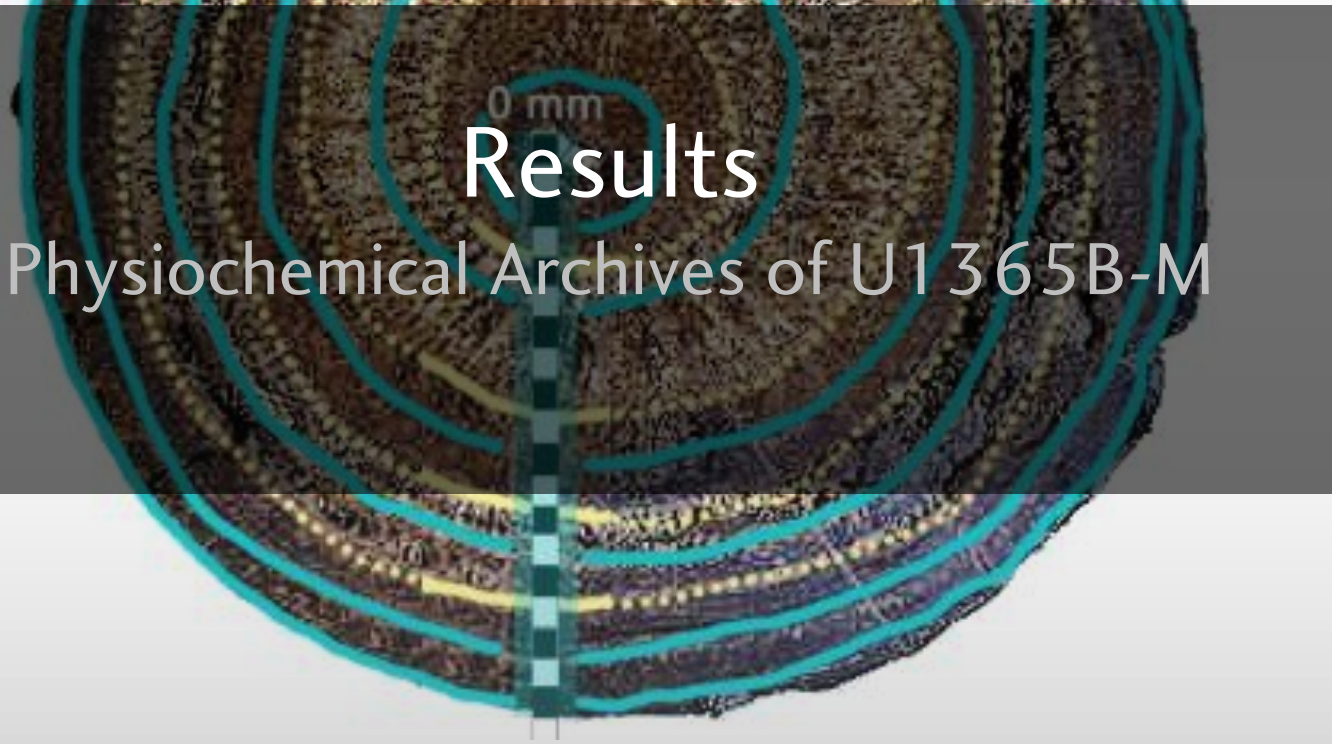

.

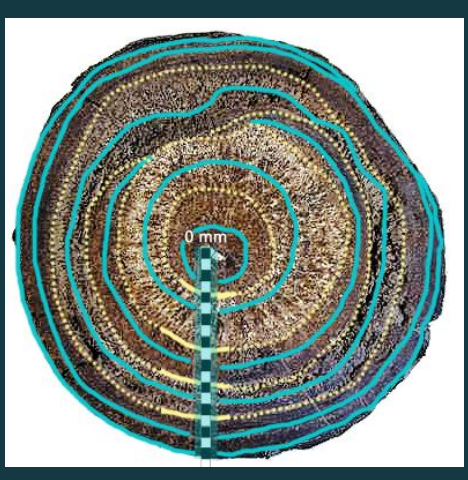

5.1 Chronologies \& Growth Rates

5.2 Macroscopic Physical Archives

5.3 Microscopic Physical Archives

5.4 Chemical Archive Overview

5.5 Major Element Chemistry

5.6 Minor \& Trace Element Chemistry

5.7 Lead Isotope Chemistry 


\subsection{Chronologies \& Growth Rates}

The unpublished age-model and growth rates established for U1365B-M by Graham \& Ditchburn (2006b), for this thesis, are presented in Table C.1 (Appendix C). ${ }^{10} \mathrm{Be} /{ }^{9} \mathrm{Be}$ ratios (Figure 5.1(b)), calculated ages (Figure 5.1(c)) and the time-frame over which each sample was accreted (Figure 5.1(d)), are plotted as a function of depth in Figure 5.1. ${ }^{10} \mathrm{Be} /{ }^{9} \mathrm{Be}$ measurements decrease across the 'crust to core' profile (Figure 5.1(a)) from 1.15 \pm 0.05 to $0.0022 \pm 0.0002$ (Figure $5.1(\mathrm{~b})$ ). Using the age equation, these ${ }^{10} \mathrm{Be} /{ }^{9} \mathrm{Be}$ ratios equate to ages of $0.11 \pm 0.10 \mathrm{Ma}$ for the outer crust and $12.7 \pm 0.15 \mathrm{Ma}$ for Fe-Mn precipitates surrounding the nodule core (Figure 5.1(c)). This provides a late mid Miocene through recent chronology for U1365B-M. The updated chronology has ages that are c. 8 \% lower than the original chronology (Table C.1 and 5.1). In the youngest part of the nodule, this translates to a very small difference between calculated ages. However, toward the older sections differences amount to around one million years, as summarised in Table 5.1.

\begin{tabular}{|c|c|c|c|c|c|}
\hline $\begin{array}{l}\text { Sections of } \\
\text { U1365B-M }\end{array}$ & $\begin{array}{l}\text { Depth } \\
\text { Profile } \\
(\mathbf{m m})\end{array}$ & $\begin{array}{c}\text { Original Chronology } \\
{ }^{10} \mathrm{Be} t^{1} / 2=1.51 \mathrm{Ma} \\
\text { (Bhat, et al., 1978) }\end{array}$ & $\begin{array}{c}\text { Revised Chronology } \\
{ }^{10} \mathrm{Be} t^{1 / 2}=1.39 \mathrm{Ma} \\
\text { (Korschinek, et al., 2010) }\end{array}$ & $\begin{array}{l}\text { Difference } \\
\text { (old - new) }\end{array}$ & $\begin{array}{l}\text { Percentage } \\
\text { difference } \\
\text { (\% diff.) }\end{array}$ \\
\hline \multirow[t]{2}{*}{ Young } & $0.00-1.00$ & $0.12 \mathrm{Ma}$ & $0.11 \mathrm{Ma}$ & 0.01 & 8.15 \\
\hline & $13.5-15.0$ & $4.46 \mathrm{Ma}$ & $4.09 \mathrm{Ma}$ & 0.36 & 8.15 \\
\hline \multirow[t]{2}{*}{ Middle } & $45.0-46.0$ & $9.17 \mathrm{Ma}$ & $8.42 \mathrm{Ma}$ & 0.75 & 8.14 \\
\hline & $72.0-74.0$ & $11.9 \mathrm{Ma}$ & $10.9 \mathrm{Ma}$ & 0.97 & 8.14 \\
\hline Old & $91.0-95.0$ & $13.8 \mathrm{Ma}$ & $12.7 \mathrm{Ma}$ & 1.10 & 8.13 \\
\hline
\end{tabular}

Table 5.1 | Key differences between original and revised chronologies. Illustrating the differences between ages calculated for original and revised chronologies, for the young, middle and older segments of U1365B-M.

The timeframe over which each sample was deposited ranges from 6000 to 700,000 years with an average of $\sim 230,000$ years (Figure 5.1(d)). Between 17 - $33 \mathrm{~mm}$, U1365B-M exhibits an extremely friable texture preventing micro-sampling. As such this sample spans $16 \mathrm{~mm}$ of the depth profile and represents a summary of one million years of ocean chemistry. Except for between $33-17 \mathrm{~mm}$, nodule material was mostly collected at a 
A 1210

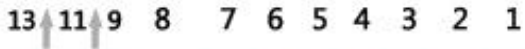
(b)
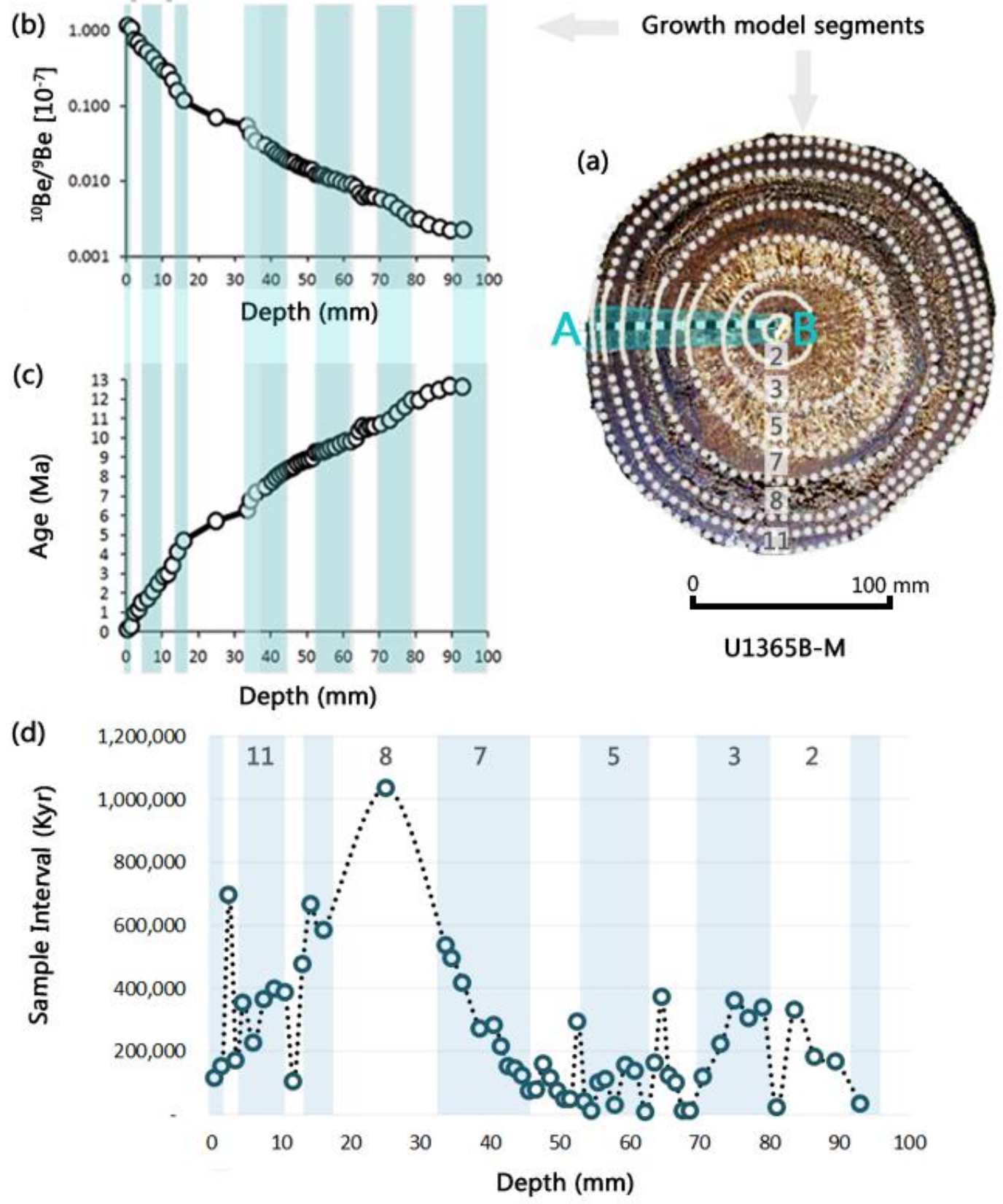

Figure 5.1 ${ }^{10} \mathrm{Be} /{ }^{9} \mathrm{Be}-d e p t h$ and age-depth plots of U1365B-M. (a) cross-section cut of U1365B-M, the depth profile from crust to core (A-B) is scaled with black and white bars each representing $5 \mathrm{~mm}$ of material, (b) is a log-linear plot of ${ }^{10} \mathrm{Be} /{ }^{9} \mathrm{Be}$ ratios vs depth, (c) an age-depth plot. Traversing the two graphs are 13 coloured bars that closely correspond to breaks in the logarithmic line and appear to be associated with major changes in texture, illustrated by grey perforated lines in (a) and numbered accordingly. The 13 bars are referred to as 'growth model segments,' as according to the applied growth model (see Somayajulu, 2000), the disjointed profile of (a) and (b) are a direct result of a change in growth rate or hiatus in nodule accretion. (d) Illustrates the time taken for each sample to be deposited (the sample interval) with an average of c. 230, $000 \mathrm{kyrs}$, in addition to the growth model segments. 
resolution of 1-2 mm. Thus, variations in the time-span represented by each sample do not appear to be controlled by sample resolution. As a 'growth model' was applied in the application of beryllium isotope dating (see Somayajulu, 2000; Graham, et al., 2003b), it is assumed that variable time-frames are a reflection of the episodic growth of U1365B-M. In plots of ${ }^{10} \mathrm{Be} /{ }^{9} \mathrm{Be}$ ratios and age versus depth, both parameters display stepped-profiles, with thirteen segments of equal slope separated by abrupt changes in slope angle and are numbered 1-13 from the core to crust (Figure $5.1(\mathrm{~b}-\mathrm{c})$ ). This disjointed profile is a common feature of FMNs and according to the growth model, are attributed to changes in FMN growth rate or hiatus's in accretion (Glasby, 1978; Somayajulu, 2000). Each of the thirteen segments of equal slope is therefore assumed to represent different phases of nodule growth and the boundaries between segments, a change in the depositional environment. As such they are referred to as 'growth model segments' in Figure 5.1.

Boundaries of growth model segments appear to correlate with spikes in sample intervals (Figure 5.1(d)) at: (i) $81 \mathrm{~mm}$, (ii) $65 \mathrm{~mm}$, (iii) $53 \mathrm{~mm}$, (iv) $11.8 \mathrm{~mm}$ and (v) 2.5 $\mathrm{mm}$ (see also Section 5.2) and with changes in the internal structure of U1365B-M. Growth model segments 1-2, 3-5, 6-7, 8 and 9-13 are associated with five distinct changes in texture, visible with the unaided eye (Figure 5.1(a)), and individual growth segments with less strongly defined textural changes, confirmed with microscopic texture changes (see also Section 5.2).

As a means for linking physical \& chemical archives, the age model is subdivided based on the occurrence of growth model segments and textural changes, into a series of time zones, summarised in Table 5.2. For Zones 1 and 4, disparities exist between observable changes in texture (physical archive) and the retrievable samples (chemical archive). In the case of Zone $4,16 \mathrm{~mm}$ of the depth profile is represented by only one sample. Distinguishable changes in texture occur across these $16 \mathrm{~mm}$ of material, but, cannot be further investigated with chemical compositions due to sampling restrictions. Thus, in order to provide a reference for both physical and chemical archives Zones 1 and Zone 4 are not subdivided when investigating chemical data, despite their being distinct changes in texture (Table 5.2; potential physical divisions based on texture are presented in purple text). 


\begin{tabular}{|c|c|c|c|c|c|c|c|}
\hline \multirow{2}{*}{$\begin{array}{c}\text { GNS } \\
\text { Sample } \\
\text { Number }\end{array}$} & \multicolumn{2}{|c|}{ mm from crust } & \multirow{2}{*}{$\begin{array}{l}\text { Mid } \\
\text { Point } \\
(\mathrm{mm})\end{array}$} & \multirow{2}{*}{$\begin{array}{c}\text { Age Model } \\
\text { Be } t^{1 / 2}=1.4 \mathrm{Ma} \\
(\mathrm{Ma})\end{array}$} & \multirow{2}{*}{$\begin{array}{c}\text { Growth Model } \\
\text { Segments }\end{array}$} & \multicolumn{2}{|c|}{ Time Zones } \\
\hline & $\begin{array}{l}\text { Inner } \\
(\mathrm{mm})\end{array}$ & $\begin{array}{l}\text { Outer } \\
(\mathrm{mm})\end{array}$ & & & & $\begin{array}{l}\text { Major Zones } \\
\text { (Zone Name) }\end{array}$ & $\begin{array}{c}\text { Subzones } \\
\text { (Zone Name) }\end{array}$ \\
\hline 27855 & 0.0 & 1.0 & 0.50 & 0.11 & \multirow{2}{*}{13} & \multirow{13}{*}{$\begin{array}{c}\text { Zone } 5 \\
\text { (Banded Zone) }\end{array}$} & \multirow{2}{*}{$\begin{array}{c}\text { Zone 5iv } \\
\text { (Outer Rind and Gum) }\end{array}$} \\
\hline 27856 & 1.0 & 2.0 & 1.50 & 0.26 & & & \\
\hline 27857 & 2.0 & 3.0 & 2.50 & 0.96 & \multirow{2}{*}{12} & & \multirow{7}{*}{$\begin{array}{c}\text { Zone 5iii } \\
\text { (Outer Banded Zone) }\end{array}$} \\
\hline 27858 & 3.0 & 4.0 & 3.50 & 1.13 & & & \\
\hline 27859 & 4.0 & 5.0 & 4.50 & 1.48 & \multirow{5}{*}{11} & & \\
\hline 27860 & 5.0 & 7.0 & 6.00 & 1.70 & & & \\
\hline 27861 & 7.0 & 8.0 & 7.50 & 2.07 & & & \\
\hline 27862 & 8.0 & 10.0 & 9.00 & 2.46 & & & \\
\hline 27863 & 10.0 & 11.0 & 10.50 & 2.85 & & & \\
\hline 27864 & 11.0 & 12.5 & 11.75 & 2.95 & \multirow{2}{*}{10} & & \multirow{2}{*}{$\begin{array}{c}\text { Zone 5ii } \\
\text { (Central Banded Zone) }\end{array}$} \\
\hline 27865 & 12.5 & 13.5 & 13.00 & 3.43 & & & \\
\hline 27866 & 13.5 & 15.0 & 14.25 & 4.09 & \multirow{2}{*}{9} & & Zone $\mathbf{5 i}$ \\
\hline 27867 & 15.0 & 17.0 & 16.00 & 4.68 & & & (Inner Banded Zone) \\
\hline 27868 & 17.0 & 33.0 & 25.00 & 5.72 & 8 & & \\
\hline & 21.0 & 17.0 & & & & Zone 4 & Banded Zone \\
\hline & 27.0 & 21.0 & & & & (Crumbly Zone) & Outer Rough Zone \\
\hline & 33.0 & 27.0 & & & & & Inner Rough Zone \\
\hline 27869 & 33.0 & 34.0 & 33.50 & 6.25 & & & \\
\hline 27870 & 34.0 & 35.0 & 34.50 & 6.75 & & & \\
\hline 27871 & 35.0 & 37.0 & 36.00 & 7.17 & & & \\
\hline 27872 & 37.0 & 40.0 & 38.50 & 7.44 & & & Zone 3ii \\
\hline 27873 & 40.0 & 41.0 & 40.50 & 7.72 & 7 & & (Outer Compact Zone) \\
\hline 27874 & 41.0 & 42.0 & 41.50 & 7.93 & & & \\
\hline 27875 & 42.0 & 43.0 & 42.50 & 8.08 & & Zone 3 & \\
\hline 27876 & 43.0 & 44.0 & 43.50 & 8.23 & & (Compact Zone) & \\
\hline 27877 & 44.0 & 45.0 & 44.50 & 8.35 & & & \\
\hline 27878 & 45.0 & 46.0 & 45.50 & 8.42 & & & \\
\hline 27879 & 46.0 & 47.0 & 46.50 & 8.49 & & & \\
\hline 27880 & 47.0 & 48.0 & 47.50 & 8.66 & & & Zone $3 \mathbf{i}$ \\
\hline 27881 & 48.0 & 49.0 & 48.50 & 8.77 & 6 & & (Inner Compact Zone) \\
\hline 27882 & 49.0 & 50.0 & 49.50 & 8.84 & & & \\
\hline 27883 & 50.0 & 51.0 & 50.50 & 8.89 & & & \\
\hline 27884 & 51.0 & 52.0 & 51.50 & 8.94 & & & \\
\hline 27885 & 52.0 & 53.0 & 52.50 & 9.23 & & & \\
\hline 27886 & 53.0 & 54.0 & 53.50 & 9.27 & & & \\
\hline 27887 & 54.0 & 55.0 & 54.50 & 9.28 & & & \\
\hline 27888 & 55.0 & 56.0 & 55.50 & 9.38 & & & Zone $2 \mathrm{iii}$ \\
\hline 27889 & 56.0 & 57.0 & 56.50 & 9.49 & 5 & & (Outer Iris Zone) \\
\hline 27890 & 57.0 & 58.5 & 57.75 & 9.52 & & & \\
\hline 27891 & 58.5 & 60.0 & 59.25 & 9.67 & & & \\
\hline 27892 & 60.0 & 61.5 & 60.75 & 9.81 & & & \\
\hline 27893 & 61.5 & 63.0 & 62.25 & 9.81 & & Zone 2 & \\
\hline 27894 & 63.0 & 64.0 & 63.50 & 9.98 & & (Iris Zone) & \\
\hline 27895 & 64.0 & 65.0 & 64.50 & 10.35 & & & \\
\hline 27896 & 65.0 & 66.0 & 65.50 & 10.47 & 4 & & Zone 2ii \\
\hline 27897 & 66.0 & 67.0 & 66.50 & 10.57 & & & (Central Iris Zone) \\
\hline 27898 & 67.0 & 68.0 & 67.50 & 10.58 & & & \\
\hline 27899 & 68.0 & 69.0 & 68.50 & 10.59 & & & \\
\hline 27900 & 69.0 & 72.0 & 70.50 & 10.71 & & & Zone $2 \mathrm{i}$ \\
\hline 27901 & 72.0 & 74.0 & 73.00 & 10.93 & 3 & & (Inner Iris Zone) \\
\hline 27902 & 74.0 & 76.0 & 75.00 & 11.29 & & & \\
\hline 27903 & 76.0 & 78.0 & 77.00 & 11.59 & & & \\
\hline 27904 & 78.0 & 80.0 & 79.00 & 11.93 & & & Outer Core \\
\hline 27905 & 80.0 & 82.0 & 81.00 & 11.95 & & & \\
\hline 27906 & 82.0 & 85.0 & 83.50 & 12.28 & 2 & Zone 1 & Inner Core \\
\hline 27907 & 85.0 & 88.0 & 86.50 & 12.46 & & (Core Zone) & finet Core \\
\hline 27908 & 88.0 & 91.0 & 89.50 & 12.63 & & & \\
\hline 27909 & 91.0 & 95.0 & 93.00 & 12.66 & 1 & & Nucleus \\
\hline
\end{tabular}

Table 5.2 | Growth model segments and time zones. Growth model segments defined from 'steps' in the ${ }^{10} \mathrm{Be} /{ }^{9} \mathrm{Be}$ profile are correlated with distinct changes in nodule texture (see Section 5.2). 


\section{Beryllium Growth Rates}

The growth history of U1365B-M, including individual rates for the authigenic and detrital components, is presented in Table C.1 (Appendix C) and Figure 5.2. Growth rates can be expressed as the rate of accretion for individual samples (Figure 5.2(a)), or more conventionally, as a quasi-cumulative growth rate (Figure 5.2(b); calculated following the methodology of Ditchburn \& Graham (2006b)). The latter represents the overall growth rate of the nodule at a specified depth, whereas the former represents the time taken to deposit each sample. Both authigenic and detrital growth rates decrease from core to rim (13 Ma to present) becoming less variable with time. A major shift in the rate of accretion occurs at c. $6 \mathrm{Ma}$, occurring at the termination of Zone 3 and start of Zone 4, after which point growth rates are significantly, reduced Figure 5.2(a). The cumulative growth of U1365B-M is also illustrated in Figure 5.2(a) (green) and clearly differentiates the two distinct growth regimes: (1) 13 to $6 \mathrm{Ma}$ - whereby U1365B-M accreted over half its total mass (c. $60 \%$ ) during a period characterised by variable and high rates of authigenic and detrital accretion and, (2) $6 \mathrm{Ma}$ to present - characterised by slower, less variable rates of authigenic accretion and greatly diminished detrital growth rates Figure 5.2(a).

The overall growth rate of U1365B-M is extremely slow at $7.4 \mathrm{~mm} / \mathrm{Ma}$. From c. 13 to 1 Ma the total growth rate decreases from 7.4 to $2.6 \mathrm{~mm} / \mathrm{Ma}$ and increases significantly from c. $1 \mathrm{Ma}$ to present, near doubling in speed from 2.6 to $5.7 \mathrm{~mm} / \mathrm{Ma}$ at $0.3 \mathrm{Ma}$ before decreasing to $4.4 \mathrm{~mm} / \mathrm{Ma}$ at $0.1 \mathrm{Ma}$, approaching the average total growth rate of 5.4 $\mathrm{mm} / \mathrm{Ma}$. The time marker at c. $6 \mathrm{Ma}$ is identifiable as marking the initiation of reduced rates of growth, which are maintained at lower values (c. $4 \mathrm{~mm} / \mathrm{Ma}$ ) for c. 5 Myrs. An additional marker at c. $1 \mathrm{Ma}$, between Zone 5iii and Zone 5iv, marks a return to relatively rapid growth rates (Figure 5.2(b)). Similarly, detrital growth rates decrease from c. 13 to 1 $\mathrm{Ma}(3$ to $0.5 \mathrm{~mm} / \mathrm{Ma}$ ) and double at $0.3 \mathrm{Ma}$ from 0.5 to $1 \mathrm{~mm} / \mathrm{Ma}$. The oldest section of the nodule (Zone 1 to Zone 2ii), displays the highest rates of detrital incorporation (2.5 to $3 \mathrm{~mm} / \mathrm{Ma}$ ) equivalent to $34-45 \%$ aluminosilicates. These rates were maintained for c. 3 Myrs from c. 13 to 10 Ma. After c. $10 \mathrm{Ma}$ the incorporation of aluminosilicates progressively decreases by $\sim 0.1 \mathrm{~mm} / \mathrm{Ma}$ until c. $4 \mathrm{Ma}$. This trend is interrupted by a pulse of sedimentation between 7.4 and $6.3 \mathrm{Ma}$ when rates increase from 1.3 to $1.5 \mathrm{~mm} / \mathrm{Ma}, 21$ to 


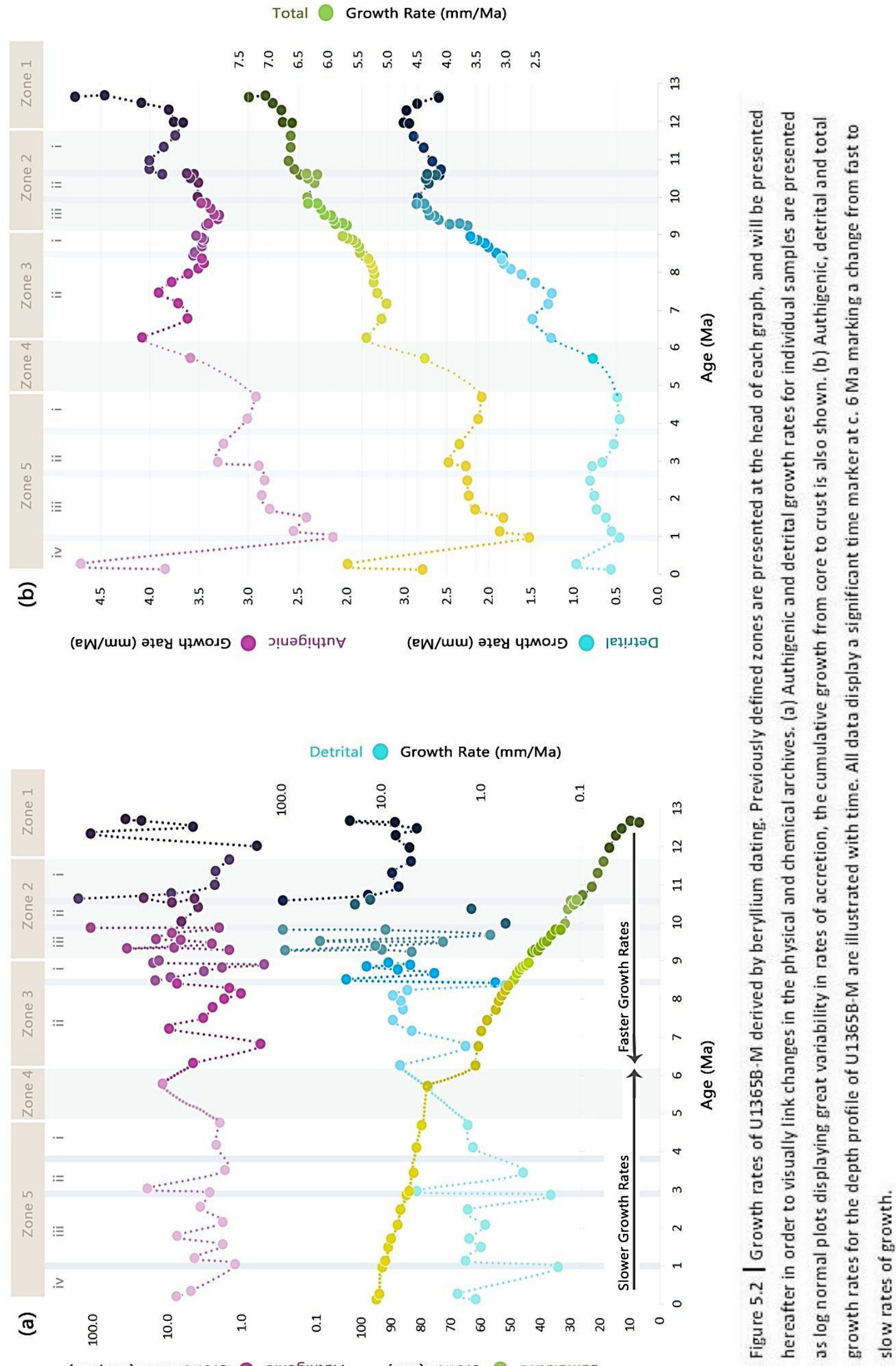


$29 \%$ aluminosilicates. Between 4 and $1 \mathrm{Ma}$ a small increase in detrital growth rates of $\sim 0.3$ $\mathrm{mm} / \mathrm{Ma}$ occurs (Figure 5.2 (b)). Authigenic growth rates also decrease between c. 13 to 1 $\mathrm{Ma}(4.8$ to $2.2 \mathrm{~mm} / \mathrm{Ma}$ ) and increase at $0.3 \mathrm{Ma}$ (from 2.2 to $4.7 \mathrm{~mm} / \mathrm{Ma}$ ). Additionally, four major trends can be identified: (1) decreasing rates throughout Zone 1 from 4.7 to 3.7 $\mathrm{mm} / \mathrm{Ma}$; (2) relatively consistent growth rates of $\sim 3.7 \mathrm{~mm} / \mathrm{Ma}$ between Zone $2 \mathrm{i}$ and Zone 3, with pulses in authigenic accretion to rates of c. $4 \mathrm{~mm} / \mathrm{Ma}$ occurring between c. 11 to 10.5 Ma, 8 to $7.4 \mathrm{Ma}$ and 6.8 to $6.3 \mathrm{Ma}$; (3) decreasing accretion rates from Zone 3 to Zone 5iv (6.3 to $1 \mathrm{Ma}$ ) from 4 to $2.2 \mathrm{~mm} / \mathrm{Ma}$, with slightly increased rates of growth from 4.7 to $3 \mathrm{Ma}$ and; (4) rapid increase in authigenic rates of accretion in the youngest section of the nodule (Zone 5iv) (Figure 5.2(b)).

\section{Cobalt Chronometry}

Data are presented in Table C.2 (Appendix C) as (1) sample data, growth rates and cobalt concentration profiles; (2) Co flux rates and the results for the published chronometers of Halbach, et al. (1983) and Manheim (1986); (3) the Co chronometer of Frank, et al. (1999) and that developed for $\mathrm{U} 1365 \mathrm{~B}-\mathrm{M}$, in addition to the percentage difference between ages and growth rates derived from beryllium cosmochronometry and Co chronometry, as a means of assessing the accuracy of the data derived by using Co. The chronometer of Halbach et al (1983) yields the most comparable ages and growth rates that are on average within $20 \%$ of those derived by beryllium cosmochronology with: (i) Co-derived growth rates yielding an average of $6.2 \mathrm{~mm} / \mathrm{Ma}$ comparable to $7.8 \mathrm{~mm} / \mathrm{Ma}$ and (ii) a total age for U1365B-M at $12.9 \mathrm{Ma}$, within $0.2 \mathrm{Ma}$ of the ${ }^{10} \mathrm{Be} /{ }^{9} \mathrm{Be}$ age of $12.7 \mathrm{Ma}$ (Appendix $\mathrm{C}$ ). In contrast, the equation of Manheim (1986) and Frank, et al. (1999) generate growth rates that are lower than the beryllium calculated rates by $50 \%$ and $60 \%$, respectively. This results in age models that are far in excess of the Be-age model with core ages for U1365B$\mathrm{M}$ dated at 31.8 and $35.5 \mathrm{Ma}$.

In applying the Co-flux model to U1365B-M, ${ }^{10} \mathrm{Be} /{ }^{9} \mathrm{Be}$ derived total growth rates were reversed and plotted with the corresponding Co-concentration profiles in weight percent (wt\%). The logarithmic fit to the data produced ages and growth rates that were comparable for deriving overall age and growth rates of $13.3 \mathrm{Ma}$ and $7 \mathrm{~mm} / \mathrm{Ma}$ 
respectively (Appendix C; Table C.2). Thus the results of Co-chronometers are variable depending on the type of published chronometer used (Halbach, et al., 1983; Manheim, 1986; Frank, et al., 1999) and (or) the use of Co-flux modelling for individual FMNs (e.g. the cobalt chronometer developed for U1365B-M) (Appendix C; Table C.2), illustrating that none of the Co chronometers are able to reproduce the Be-age model and fluctuate with changes in the Co-flux rate, deriving variable ages for U1365B-M.

\subsection{Macroscopic Physical Archives}

The physical archives of U1365B-M are the macro- and microscopic changes in internal structure of the nodule, in addition to changes in the relative proportions of authigenic and detrital minerals. Macroscopic structures were determined through assessment of the cross-sectional cut through U1365B-M (Figure 5.3) and original interpretations of microstructures were determined from the back-scattered electron (BSE) images published in Graham, et al. (2003a). Detrital and authigenic proportions were determined from the detrital residue (\% residue) remaining after sample digestion (Appendix C; Table C.2).

U1365B-M is the largest nodule recovered from the Campbell Nodule Field (Chang, et al., 2003; Graham, et al., 2003a) measuring $24 \mathrm{~cm}$ in long diameter, and has a spherical shape with a smooth surface texture (Figure 5.3). As eluded to when defining zones and subzones in Section 5.1, U1365B-M displays distinct changes in its internal structure. Five major concentric zones can be distinguished with the naked eye and are named according to their textural appearance as: core, iris, compact, crumbly and banded, including what appears to be a discontinuous erosional unconformity between compact and crumbly zones (Figure 5.3). Each zone can be further subdivided by subtle texture and colour changes into a total of eleven time zones illustrated in Figure 5.4 (see also Table 5.2).

\section{Core Zone [12.7 - 11.9 Ma]}

The core zone (zone 1) is $18 \mathrm{~mm}$ thick, extending from $95-77 \mathrm{~mm}$ (core to crust) and forms the base of the depth-profile. The zone comprises of six samples of 2-3 $\mathrm{mm}$ thickness except for the first sample (4 mm thick) surrounding the core. These initial 
layers of Fe-Mn precipitates were deposited over $0.69 \mathrm{Ma}$ and are characterised by the fastest rates of accretion for the nodule (c. $7 \mathrm{~mm} / \mathrm{Ma}$ ) and have high detrital entrapment of c. $40 \%$. The zone is generally lustreless, red-brown in colour and fairly homogenous in texture exhibiting variable layer thickness $(3-10 \mathrm{~mm}$ thick). There are three distinguishable physical/textural changes within the zone dividing it into: nucleus, inner core and outer core, with the boundaries between layers appearing gradational (Figure 5.3 \& 5.4).

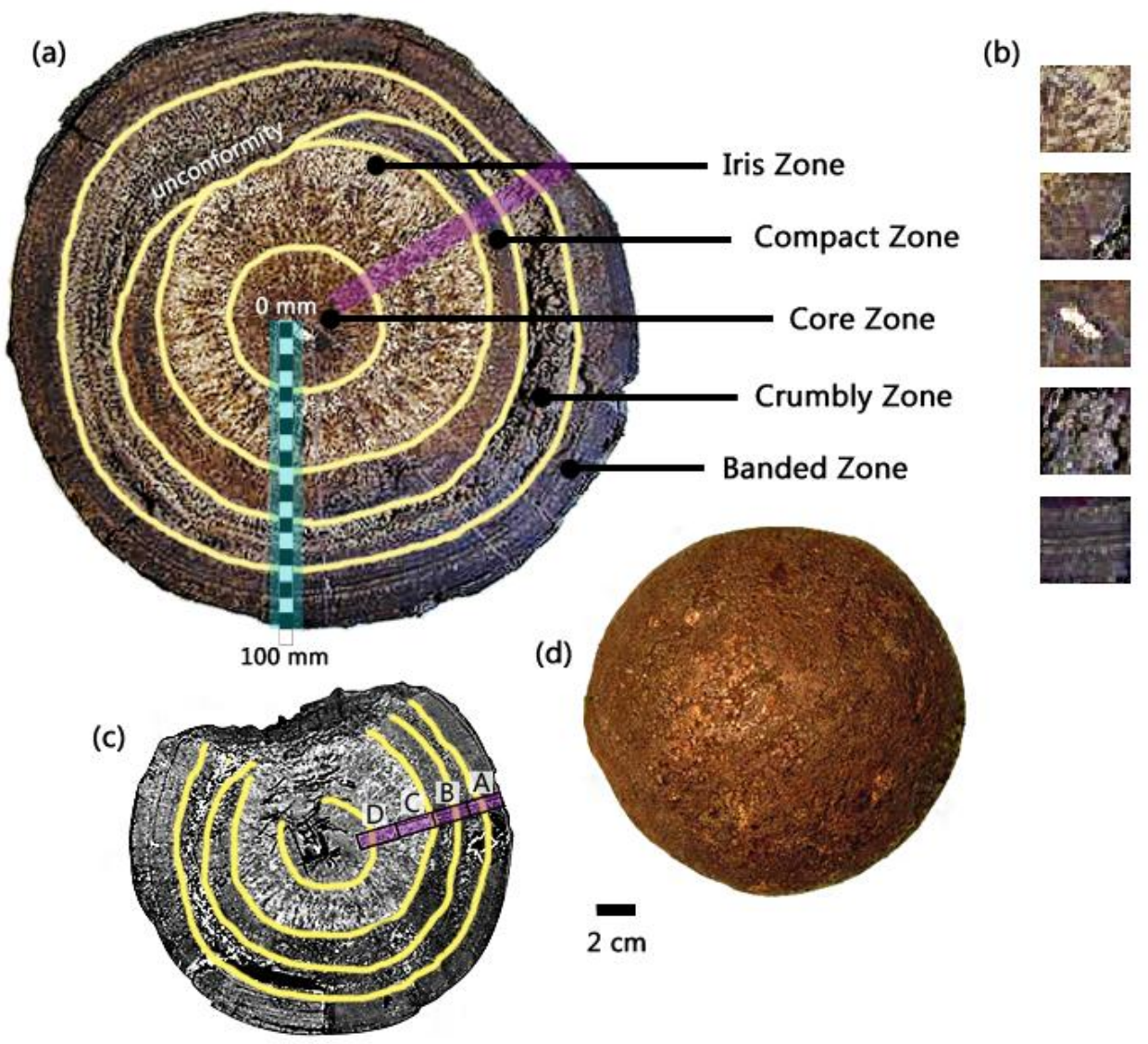

Figure 5.3 | Major textural zones of U1365B-M. Physical properties such as colour, lustre, texture, hardness and porosity, were used to divide U1365B-M into five major zones (yellow lines). (a) GNS segment of U1365B-M, the nodule radii sampled for chemical analyses is highlighted in blue and the depth profile presented in $5 \mathrm{~mm}$ black-white segments for the $95 \mathrm{~mm}$ profile. Each of the major zones has been assigned a descriptive term that summarises the overall texture of the layer, (b) each texture is magnified in the stacked boxes in order of zone labels: iris, compact, core, crumbly and banded. (c) Korean half of U1365B-M, displays the profile (pink, labelled A to D) along which back-scattered electron images were taken (Graham, et al., 2003a), allowing the assessment of microscopic structure. (d) External morphology and texture of U1365B-M at a smaller scale, displaying a spherical shape and smooth external surface characteristic of hydrogenous nodules (Glasby, 2000) (see also Section 3.2). 


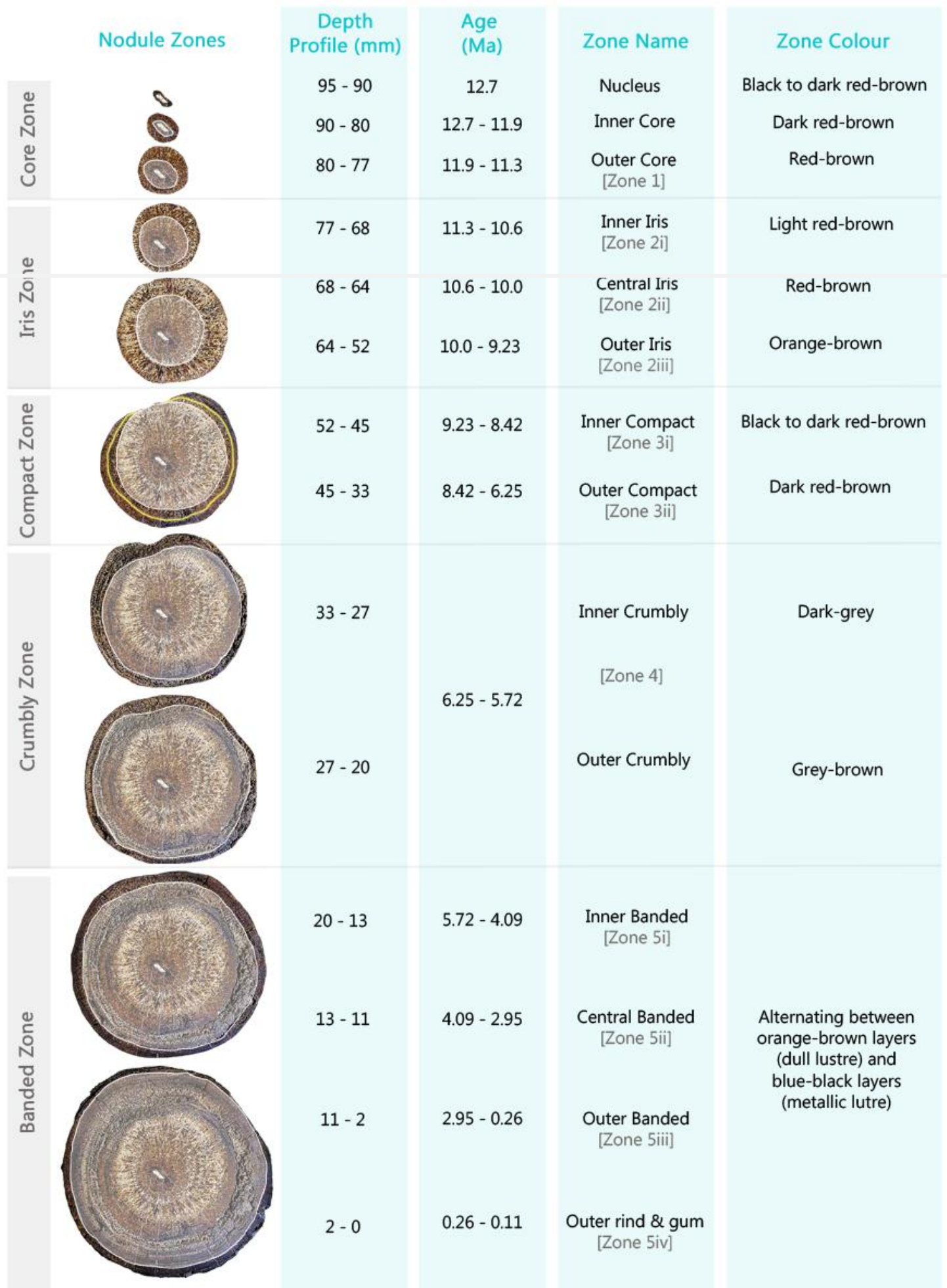

Figure 5.4 | Major textural zones and subzones of U1365B-M. A visual presentation of the growth history of the U1365B-M, with the five major zones defined and the progressive development of these zones illustrated in sequence from core to crust (95 to $0 \mathrm{~mm}$ ), with the preceding layer shaded white. Occurrence of subzones along the depth profile, corresponding ages, zone names and colour are also displayed (see also Table 5.2). 
The nucleus is made up of a white calcareous shell fragment (c. $3 \mathrm{~mm}$ thick and $10 \mathrm{~mm}$ in length) that is surrounded by a black rim (c. $4 \mathrm{~mm}$ thick) of Mn-oxide minerals. This layer is coated by inner core deposits (c. $9 \mathrm{~mm}$ thick), which are dark red-brown and surrounded by the outer core which grades to a lighter red-brown. From nucleus to outer core the progressive lightening of layer colour reflects the increased incorporation of detrital grains from 35 to $45 \%$. As the first and last sample points of this zone represent the nucleus and outer core, respectively, this zone was not subdivided (Table 5.2).

\section{Iris Zone $[11.9-9.23 \mathrm{Ma}]$}

Surrounding the core zone is the $25 \mathrm{~mm}$ thick iris zone (zone 2) that took c. $2 \mathrm{Ma}$ to deposit with an average growth rate of $6.3 \mathrm{~mm} / \mathrm{Ma}$. This layer is orange-brown in colour, displaying a series of radial spokes that propagate from the surface of the core zone and radiate outward toward the crust, a textural pattern similar to that of an iris. The 'spokes' are darker in colour (blue-black) with a dull-moderate metallic lustre, whereas the surrounding material is much lighter (yellow-brown), fairly indurated and contains the largest proportions of detrital material (c. $45 \%$ ). The zone is subdivided into an inner (zone 2i), central (zone 2ii) and outer layer (zone 2iii), based on the concentric rim of dark-red brown material forming the central iris zone, with gradational boundaries between subzones (Figure $5.3 \&$ 5.4). The inner iris is generally darker in colour with more closely spaced radial 'spokes' of what appears to be concentrated regions of Fe-Mn minerals. The subzone mirrors variations in layer thickness seen in the outer core, with the widest segment (c. $15 \mathrm{~mm}$ ) occurring above the nucleus and narrowing to c. $10 \mathrm{~mm}$ beneath the shell fragment. The outer iris is lighter in colour (orange-brown) and forms a continuous layer c. $15 \mathrm{~mm}$ thick, surrounding the inner iris, with greater proportions of yellow-brown detritals which peak within this zone to c. $45 \%$. The boundary between the outer iris zone and compact zone is relatively sharp, diffuse over $<1 \mathrm{~mm}$.

\section{Compact Zone $[9.23-6.25 \mathrm{Ma}]$}

The compact zone (zone 3) forms a c. $20 \mathrm{~mm}$ thick red-brown layer that was accreted over the following c. $2 \mathrm{Ma}$ at a reduced rate of $5.4 \mathrm{~mm} / \mathrm{Ma}$. The darker colour is most likely associated with a reduction in detrital contents, from $45 \%$ in the previous zone to an 
average of $30 \%$ within this zone. The zone is weakly banded, with thin concentric (c. 1 $\mathrm{mm}$ ) seems of blue-black material of metallic lustre. The compact zone is a continuous layer and is sub-divided into an inner (zone 3i) and outer layer (zone 3ii) based a visible band of darker material that separates the zone into two equal segments of c. $10 \mathrm{~mm}$ thickness. The boundary between compact and crumby zones at around $35 \mathrm{~mm}$ depth (Figure 5.3 \& Figure 5.4) is sharp and forms the most distinctive boundary of the major nodule zones. In Figure 5.3 (a) and (c), this boundary appears to be an erosional unconformity and truncates both the compact zone and underlying iris zone.

\section{Crumbly Zone $[6.25-4.68 \mathrm{Ma}]$}

The crumbly zone is a highly friable $16 \mathrm{~mm}$ thick layer that is analysed by only one sample and represents c. $2 \mathrm{Ma}$ of nodule accretion at a rate of $4.4 \mathrm{~mm} / \mathrm{Ma}$. As the layer is represented by only one sample the age range given for the zone is derived from the ages of the layers below and above. The layer is characterised by reduced growth and significantly lower detrital contributions (c. $20 \%$ ). The layer forms a fairly continuous zone in regards to thickness (c. $15 \mathrm{~mm}$ ) except for above the unconformity where it is, disproportionately thicker $($ c. $30 \mathrm{~mm})$. In regards to texture, the zone is highly porous, dull in lustre and discontinuous, displaying alternating, white-grey detrital and red-brown Fe-Mn banding (c. $1 \mathrm{~mm}$ ) to the left of the nucleus, weak banding to a massive texture above the unconformity and an extremely rough texture to the right of the nucleus. The zone can be divided into inner and outer zones of roughly equal thickness (c. $10 \mathrm{~mm}$ ) based on a weak but definable colour change from dark-grey to grey-brown (Figure 5.3 \& Figure 5.4).

\section{Banded Zone [4.68 - $0.11 \mathrm{Ma}]$}

The banded zone is $17 \mathrm{~mm}$ thick with the lowest growth rates of c. $3 \mathrm{~mm} / \mathrm{Ma}$, except for the outer rind and gum (crust; $5 \mathrm{~mm} / \mathrm{Ma}$ ). The zone consists of a series of banded structures with continuous texture, metallic lustre and blue-black colour, which become progressively narrower toward the crust. The zone contains noticeable radial fractures (c. 1 $\mathrm{mm}$ thick) that propagate from the outer crust to the upper boundary of the outer crumbly zone. The zone is divided into an inner banded zone (zone 5i), central banded zone (zone 5ii), outer banded zone (zone 5iii) and outer rind and gum zone, or crust (zone 5iv) based on the occurrence of these banded structures (see also Figure 5.4 and Table 5.2). 


\subsection{Microscopic Physical Archives}

The acumen used for defining the five-zone morphology was confirmed by observations using BSE images, described in Figure 5.5. As nodule layering does not develop at an equal thickness about the nucleus, BSE images derived from a different depth-profile along a separate hemisphere of U1365B-M (Figure 5.3 (c)) could not be directly matched to the depth-profile sampled for this thesis (Figure 5.3 (a)). As such, microstructures were correlated with the time zones of U1365B-M by applying a depth-profile to the BSE images, matching the occurrence of major textural boundaries, identified by Graham, et al. (2003a) and utilising photographic evidence of both cross-sectional cuts of U1365B-M (Figure 5.3 (a) \& (c)), in order to trace the occurrence of time zone boundaries through the nodule. In this way, an assessment of the underlying microstructures comprising each of the major texture zones could be made.

In general, microstructures grade from mottled to cuspate to columnar to laminated from core to crust, as the ratio of authigenic to detrital material increases (Figure 5.6). Detrital components were determined by X-ray Diffractrometry (XRF) (see Graham, et al., 2003a) to largely consist of quartz, feldspar, pyroxene, amphibole and mica whilst authigenic components were dominated by the mineral vernadite $\left(\delta \mathrm{MnO}_{2}\right)$. The large presence of these aluminosilicates through zones 1 and 2 results in a chaotic mottled structure with Fe-Mn precipitates showing no direction in precipitation as large angular detrital grains disrupt their formation. As the presence of these detrital grains decreases across the outer compact zone (zone 3ii), authigenic to detrital ratios transition to higher values and grade from cuspate to columnar structure (Figure 5.6). This trend is interrupted by a pulse in detritus at c. $34 \mathrm{~mm}$, between 6.8 and $6.3 \mathrm{Ma}$ whereby microstructures briefly return to a chaotic mottled structure. In contrast, periods characterised by the highest authigenic/detrital ratios: $7.2(37 \mathrm{~mm}), 4.1(15 \mathrm{~mm})$ and $0 . \mathrm{Ma}$ $(1 \mathrm{~mm})$, show well-developed Fe-Mn oxyhydroxide precipitates. From 4.1 to $3 \mathrm{Ma}(12$ $\mathrm{mm}$ ) authigenic/detrital ratios decline rapidly as aluminosilicate incorporation increases to c. $20 \%$ and is roughly maintained from c. $3 \mathrm{Ma}$ to present (Figure 5.6). Columnar structures become progressively smaller and closer packed, until they merge into the finely laminated layers of the outer crust. 


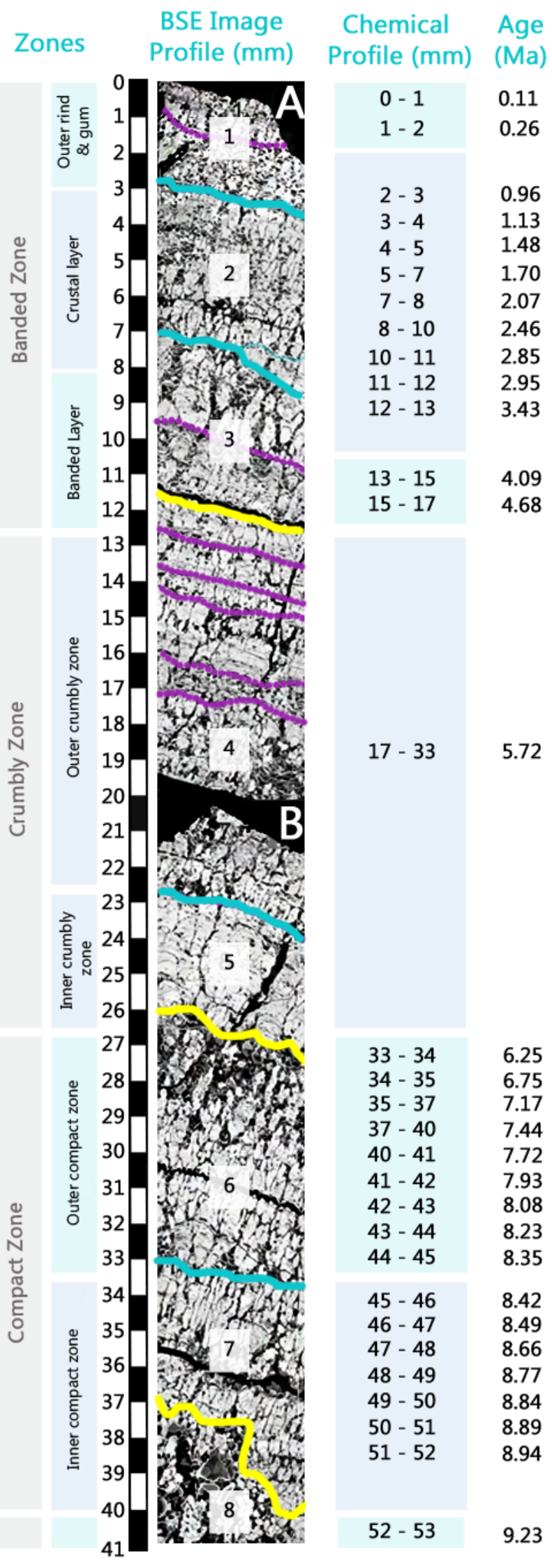

\section{Description}

Finely laminated, micro-columns consists of densley packed crenulated cuspate structures $<0.2 \mathrm{~mm}$.

Columnar with cusps c. $1 \mathrm{~mm}$ length and $0.5 \mathrm{~mm}$ wide with the space between columns filled with mico-laminations of Fe-Mn minerals and interstitial detritals. Colmnar structures get smaller toward the outer rind grading into laminated structures.

Laminated Fe-Mn minerals at the base of the banded layer, grade into large cuspate columns of c. 1-2 $\mathrm{mm}$ in length with colmn spaces filled with detrital grains.

From the base of the outer rough zone small (c. $0.5 \mathrm{~mm}$ ) densley packed cuspate columns grade into a laminated zone ( c. $1 \mathrm{~mm}$ wide) followed by a columnar to massive zone (c. $2 \mathrm{~mm}$ wide) which is suceeded by a series of $0.5-1 \mathrm{~mm}$ layers of small densley packed cuspate columnar structures. Interstital detrital grains occur throughout the zone. The boundary between the banded layer and outer rough zone is marked by a concentric fracture filled with resin, radial fractures are also visible throughout the crumbly zone.

The inner rough zone is composed of cuspate columnar structures so densley packed that they merge into a semi-massive structure.

The upper an lower boundary of the outer compact zone is marked by an increase in column space, in-filled with detrital grains. The zone is composed of cuspate columns of c. $0.5-1 \mathrm{~mm}$ height by 0.5 width which become thinner (c. $0.3 \mathrm{~mm}$ ) and longer (1-1.5 $\mathrm{mm}$ ) toward the upper boundary. A concentric fracture segregates the zone

The inner compact zone consists of thin (c. $0.1 \mathrm{~mm}$ ) densely packed cuspate columnar structures ( $<0.5 \mathrm{~mm}$ ) which become longer (c. $1 \mathrm{~mm}$ ) after the concentric fracture. The lower boundary between the inner compact and outer iris zones is marked by a sharp irregular unconformity 


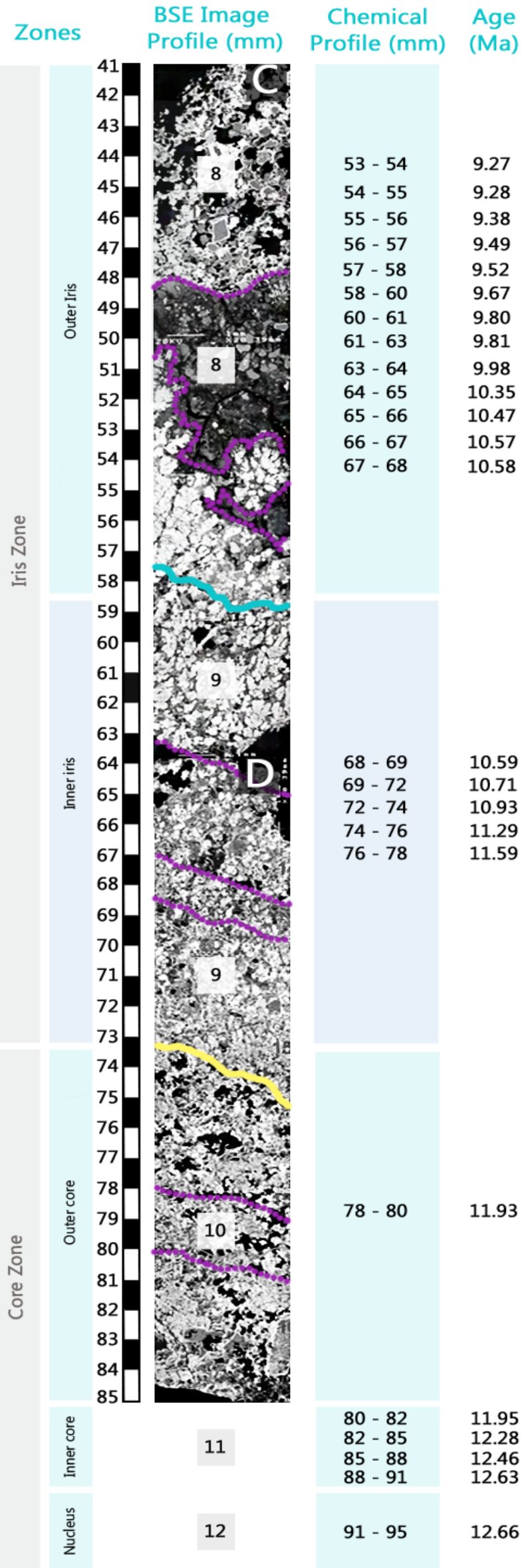

\section{Description}

The outer iris zone contains high concentrations of detrital grains some of which have been coated by a thin layer $(<0.1 \mathrm{~mm})$ of Fe-Mn minerals. From c. $40 \mathrm{~mm}-48 \mathrm{~mm}$ microstructures are mottled illustrating a choatic growth pattern around detrital grains $(<1-1 \mathrm{~mm}$ ) with large, roughly spherical, pore spaces (c. $0.5 \mathrm{~mm}$ ) present.

From 48 - $58 \mathrm{~mm}$, material composing the lighter and darker 'radial spokes' of the iris zone are visible. Lighter material visible in Figure 5.1 is composed of clay and detrital grains (dark grey) whilst darker material in $\mathbf{5 . 1}$ is composed of Fe-Mn minerals visible by its high reflectance. The Fe-Mn minerlas display columnar- cuspate structures that grade into dendritic structures as clay contnet increases toward the upper boundary of the zone

The inner iris zone contains mottled microstructures that grade from $(73-58 \mathrm{~mm})$ a chaotic aggregate of: non-directional, densley inter-grown Fe-Mn minerals, with fine-grained $(<0.1 \mathrm{~mm})$ interstitial detritus into a globular aggregate of: semi-directional, dispersed Fe-Mn growths of small (c. $0.3 \mathrm{~mm}$ ) cuspate column structures.

The outer core zone displays mottled microstructures of a chaotic nature. Fe-Mn minerals show multiple growth directions, with smallmedium (c. $0.5 \mathrm{~mm}$ ) cuspate columns densley packed and displaying a larger $\mathrm{mm}$ scale dendtritic pattern. Large and multiple pore spaces $(0.5-1 \mathrm{~mm})$ are present with almost even percentages of extremely fine-grained detrital material (dark grey) and authigenic Fe-Mn precipitates 
Figure 5.5 Microstructures of U1365B-M. The microstructures of Fe-Mn precipitates are illustrated for the selected radii along which BSE imaging was performed (Graham, et al., 2003a) illustrated in Figure 5.1 (c). Zones A-D are defined and divided into the five major zones (yellow), eleven (or twelve) subzones including the subdivision of the nucleus (blue) and further significant changes in structure (purple). The subzones have been labelled from crust to core for ease of reference as not all subzones were easily traceable and thus have been simplified. Such as the iris zone, which has been divided into an inner and outer section and the banded zone has been simplified by combining the inner and central banded zones (banded) and to differentiate the outer banded zone has been referred to as crustal.

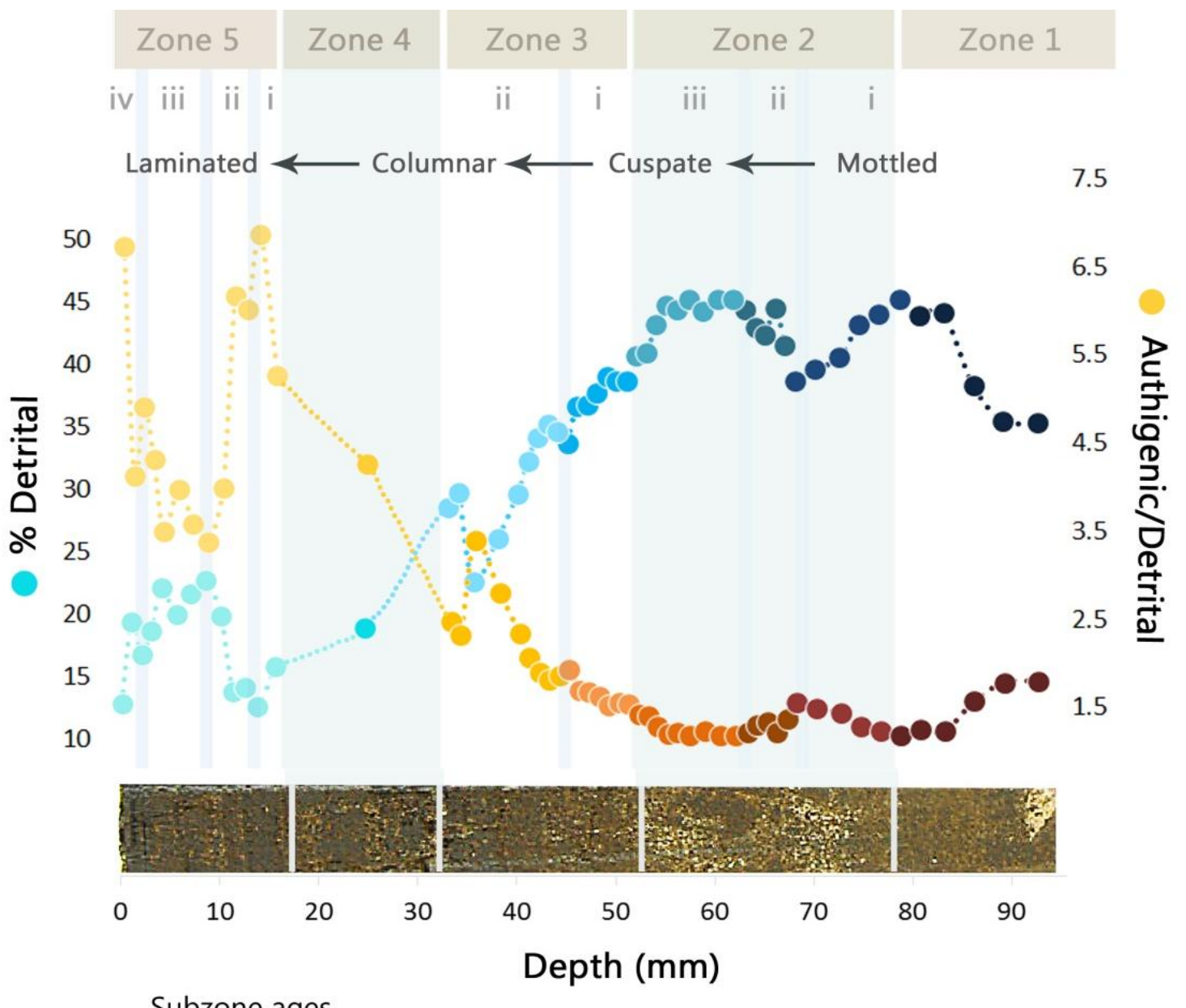

Subzone ages

$12.7-11.9 \mathrm{Ma}$

$11.9-10.6 \mathrm{Ma}$

$10.6-10.0 \mathrm{Ma}$

$10.0-9.23 \mathrm{Ma}$

$9.23-8.42 \mathrm{Ma}$

$8.42-6.25 \mathrm{Ma}$

$6.25-4.68 \mathrm{Ma}$

$4.68-0.00 \mathrm{Ma}$
Figure 5.6 | Depth-time series of macrotextures, microscopic structures and authigenic-detrital components. Macrotextures of U1365B-M are illustrated along the $\mathrm{X}$-axis and the percentage detrital and authigenic/detrital ratios are plotted verses depth. The general trends exhibited by microstructures from core to crust are annotated. Each of the major and subzones are displayed and the data points colour coded according to their associated zones and the age ranges are provided. 


\subsection{Chemical Archive Overview}

Major element chemistry was gathered to derive concentration data on Fe and $\mathrm{Mn}$, as they form the fundamental building-blocks of ferromanganese minerals, comprising the authigenic fraction of U1365B-M (Figure 5.5 \& 5.6). Tracer elements are enriched within these authigenic precipitates at varying concentrations. The principal elements scavenged to concentrations of 10,000 to $1000 \mathrm{ppm}$, are classified here as minor elements, and include: cobalt $[\mathrm{Co}]$, cerium $[\mathrm{Ce}]$, nickel $[\mathrm{Ni}]$, barium $[\mathrm{Ba}]$, lead $[\mathrm{Pb}]$ and copper $[\mathrm{Cu}]$. Elements at concentrations below $1000 \mathrm{ppm}$ have been classified as trace elements and include:

- Yttrium and Rare Earth Elements (YREE); yttrium [Y], lanthanum [La], neodymium $[\mathrm{Nd}]$, samarium $[\mathrm{Sm}]$, europium $[\mathrm{Eu}]$, gadolinium $[\mathrm{Gd}]$, dysprosium [Dy], erbium [Er], ytterbium [Yb], lutetium [Lu],

- High Field Strength Elements (HFSE); zirconium [Zr], niobium [Nb], hafnium [Hf], tantalum $[\mathrm{Ta}]$

- uranium decay series elements; uranium [U], thorium [Th]

- semi-metals; arsenic [As], antimony [Sb], bismuth [Bi] and

- and the remaining transition elements; vanadium $[\mathrm{V}]$, zinc $[\mathrm{Zn}]$, molybdenum $[\mathrm{Mo}]$, tungsten $[\mathrm{W}]$, thallium [Tl], and cadmium [Cd] (see also Figure 4.6).

A composite of all elemental and $\mathrm{Pb}$ isotopic data are presented in Table F.1 (Appendix F) and Table F.2 has been modified to illustrate the general trends of element and $\mathrm{Pb}$ isotopic compositions throughout the history of U1365B-M by assigning colours to highlight: rising, falling, minima and maximum in element concentrations and $\mathrm{Pb}$ isotopic compositions. Apparent from these general trends is that each time zone of U1365B-M exhibits characteristic changes in its overall chemical content and that certain elements appear to display similar geochemical behaviour. Additionally, chemical archives are presented as: (i) depth-time series, to highlight trends throughout the growth history of U1365B-M whilst linking these changes to physical archives; and as (binary (and ternary) plots, and time series within the body of the discussion. 
Average element concentrations measured for U1365B-M are compared to chemical data from the preliminary, low resolution, analyses of Campbell nodules (Graham, et al., 2003a) in Figure 5.7 and Figure E.1 (Appendix E). These data are highly comparable however, chemical data derived for this thesis are generally higher than those derived by the bulk digestion methods of Graham et al. (2003a). There are five noticeable differences between the chemical data: $\mathrm{Co}, \mathrm{Ce}$ and $\mathrm{Pb}$ are reported at higher values for this thesis (2395 - 6171 ppm, 1140 - 2084 ppm, 1203 - 1883 ppm respectively) than for Campbell nodules (1215 - 2726 ppm, 746 -1302 ppm, 376 - 578 ppm, respectively); whereas Mn and $\mathrm{Ni}$ are reported at lower values for this thesis (Mn $7.5-21.7 \mathrm{wt} \%$ and Ni $878-6683 \mathrm{ppm}$ ) than for Campbell nodules (Mn $16-57 \mathrm{wt} \%$ and Ni 1303 - 5029 ppm). These differences may be related to the methods of sample digestion, however the average Campbell nodule compositions include those of diagenetic nodules which are known to contain higher concentrations of Mn and Ni (e.g., Glasby, 2000).

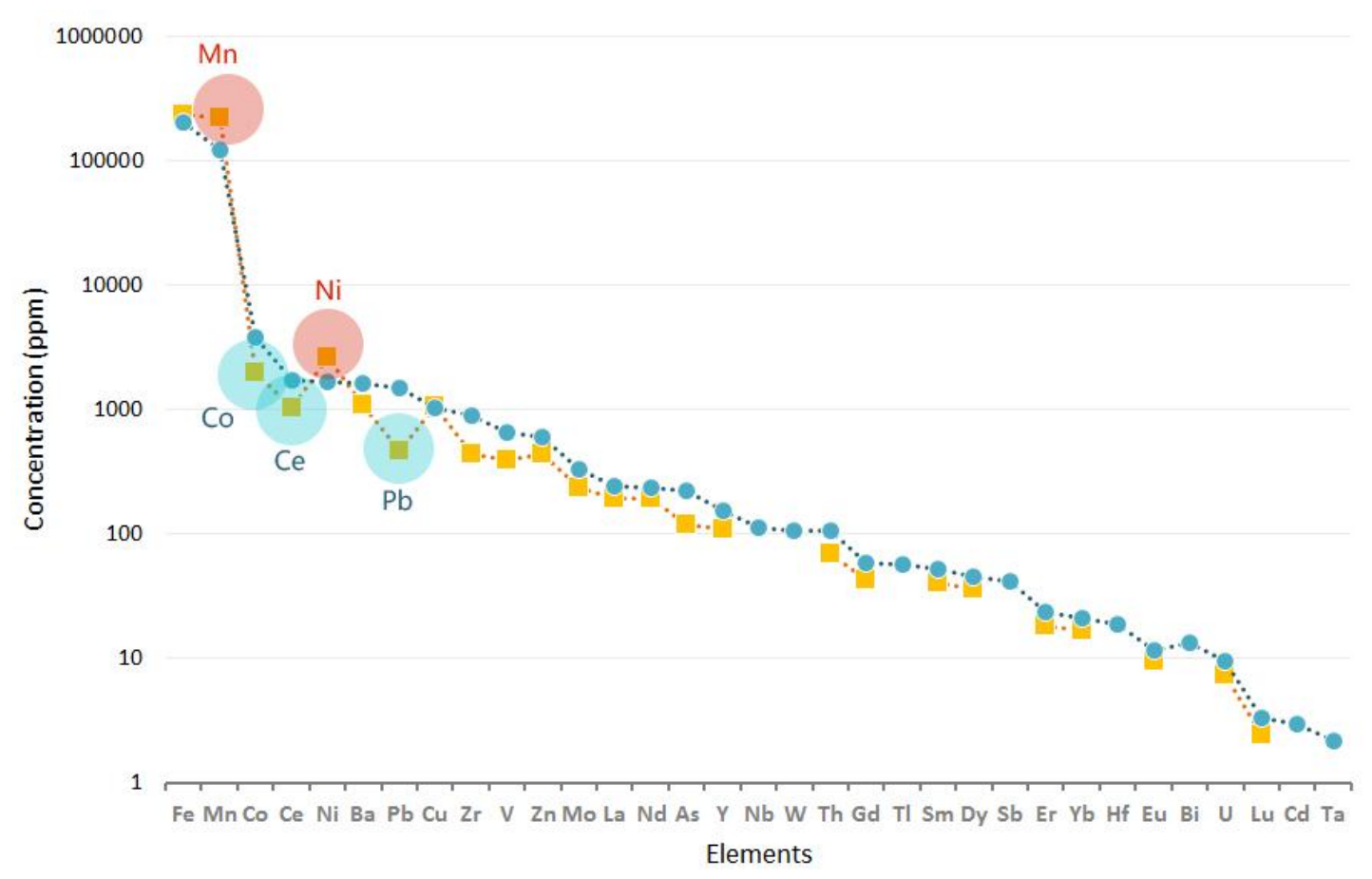

Figure 5.7 | Authigenic chemistry of U1365B-M and bulk chemistry of Campbell Nodules Average multi-element concentration data measured for U1365B-M are plotted with the average concentration of elements reported for chemical analyses performed on selected FMNs from the Campbell Plateau (see Graham, et al. (2003a). 


\section{General Trends in Element and Lead Isotope Chemistry}

From 12.7 to $11.9 \mathrm{Ma}$, across the core zone, the majority of elements studied increase in concentration peaking at the boundary between the inner and outer core (at $12.3 \mathrm{Ma}$ ), in association with decreasing growth rates and increasing aluminosilicate incorporation (Table F.1; Appendix F). Certain elements reach their highest concentrations for U1365B$\mathrm{M}$ growth history at this boundary: $\mathrm{Ba}(2316$ ppm), $\mathrm{Pb}$ (1896 ppm), Zr (1168 ppm), Zn (791 ppm), Th (135 ppm), Hf (23.6 ppm), Bi (16.7 ppm) and Lu (3.95 ppm). Elements that differ are Mo, which mimics the trends of Fe and Mn (displaying small fluctuations in ppm with a low (Mo $300 \mathrm{ppm}$ ) at the outer core boundary), and Ni, $\mathrm{Tl}$ and $\mathrm{Cd}$ which have their lowest concentrations at $12.6 \mathrm{Ma}(881,15.02 .08 \mathrm{ppm}$, respectively). Additionally, Th, Hf and $\mathrm{Bi}$ differ from the trends of other elements, displaying a characteristic peak-troughpeak in ppm (see Table F.2). Through the outer core (11.95 Ma) all elements decrease or display a low in concentration in association with a peak in total and authigenic growth rates and high detrital contributions (44\%).

From 11.9 to $10.6 \mathrm{Ma}$, across the inner iris zone (zone $2 \mathrm{i}$ ), elements display a much wider range in their general trends. The physical archives reveal that microstructures grade into less chaotic mottled structures as the amount of detrital entrapment decreases from a peak at $11.9 \mathrm{Ma}(45 \%)$ to a low at the termination of the zone (39\%), still remaining within a high detritus zone (Figure 5.6). Additionally, authigenic growth rates increase from 3.7 to $4.0 \mathrm{~mm} / \mathrm{Ma}$. Elements displaying similar trends to authigenic growth rates (increasing) are: $\mathrm{Fe}, \mathrm{Mn}, \mathrm{Ni}, \mathrm{Nb}, \mathrm{Th}, \mathrm{Tl}$, and $\mathrm{Pb}$ isotopic compositions, and elements comparable to detritus (decreasing) are: $\mathrm{Co}, \mathrm{Ce}, \mathrm{Ba}, \mathrm{Pb}, \mathrm{Cu}, \mathrm{Zr}, \mathrm{V}$ and $\mathrm{Zn}$. A number of

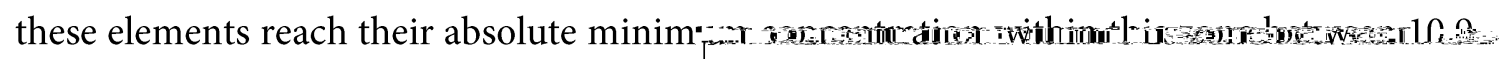
and 11.3 Ma: Pb, V, As, Nd, Sm, Dy, Er, Yb, Eu and U. Succeeding these chemical lows, most elements show consistent trends, increasing in concentration at $10.7 \mathrm{Ma}$ (except for: $\mathrm{Cu}, \mathrm{Sb}$ and $\mathrm{Ta}$ ), accompanying a rise in authigenic growth rate and low in ${ }^{207} \mathrm{~Pb} /{ }^{204} \mathrm{~Pb}$ and ${ }^{208} \mathrm{~Pb} /{ }^{204} \mathrm{~Pb}$ compositions. At the end of the zone (10.6 Ma) most elements decrease (except for $\mathrm{Mn}, \mathrm{Co}, \mathrm{Ce}, \mathrm{Ni}, \mathrm{Sb}$ and $\mathrm{Ta}$ ), consistent with a decrease in total, authigenic and detrital growth rates (Table F.2). 
From 10.6 to $10 \mathrm{Ma}$, across the central iris zone (zone 2 ii), Fe-Mn precipitates are governed by decreasing growth rates and grade from a mottled to a more cuspate like structure but remain non-directional as the amount of detritus remains high at c. $43 \%$ (Figure 5.6). The chemical contents of these precipitates display a great deal of coherency, rising in content to peak at $10.57 \mathrm{Ma}$, succeeded by a low at $10.5 \mathrm{Ma}$ (Co and Mo record their lowest values), and return to higher values at $10.0 \mathrm{Ma}$, where $\mathrm{Pb}$ isotopes are at their most radiogenic. The peak and low in contents correlate with a pulse in detritus, (from 41 and $45 \%$ ). Exceptions are: (i) Fe and $\mathrm{Mn}$, which decrease to the end of the zone (with a Mn minima at $10 \mathrm{Ma}$ ); (ii) Co and $\mathrm{Ni}$, which decrease to a low at $10.5 \mathrm{Ma}$, and; (iii) $\mathrm{Ba}, \mathrm{Pb}$, $\mathrm{W}, \mathrm{Th}, \mathrm{Sb}, \mathrm{Hf}, \mathrm{Bi}, \mathrm{U}$ and $\mathrm{Ta}$, which decrease from a peak at $10.5 \mathrm{Ma}$ to the end of the zone.

From 10 to $9.23 \mathrm{Ma}$, the outer iris zone (zone 2 iii) appears to be a zone of transition, with almost all elements displaying a unified trend, with contents decreasing to a low between 9.67 and $9.80 \mathrm{Ma}$ before continuing to increase throughout the zone to 9.23 Ma. Co, Ce, V, Mo, As, Tl and Cd, increase throughout the zone, whilst; Fe, Mn and Ta show greater variability, $\mathrm{Ni}$ and $\mathrm{Cu}$ show a reversed trend, and Th decreases throughout the zone. High detrital contents are reported between 10.0 and $9.38 \mathrm{Ma}$ (c. $45 \%$ ), results in the lowest authigenic/detrital ratio, at 9.8 Ma, and low authigenic growth rates until 9.38 Ma when detritals decrease, eliminating interrupts to Fe-Mn microstructures, which have returned to a chaotic mottled structure in this high detrital zone (Figure 5.5 \& 5.6).

From 9.23 to 8.42 Ma, the inner compact zone (zone $3 \mathrm{i}$ ) continues the trends exhibited in the previous zone with the majority of elements increasing to a peak at $8.6 \mathrm{Ma}$ and decreasing thereafter. Nd, As, Y, Sm, Dy, Sb, Er, Yb, Hf, Eu, U and Ta all show their highest contents between 8.6 and $8.7 \mathrm{Ma}$. Fe, $\mathrm{Mn}, \mathrm{Ba}$ (minimum value), $\mathrm{Pb}$, Th and $\mathrm{Bi}$ display lows in concentration at $8.5 \mathrm{Ma}$. Conversely, $\mathrm{Pb}$ compositions are variable throughout this period, generally displaying low values with peaks at 8.8 and $8.5 \mathrm{Ma}$ and the lowest ${ }^{208} \mathrm{~Pb} /{ }^{204} \mathrm{~Pb}$ at the end of the zone c. $8.4 \mathrm{Ma}$. Detrital contents continue to decrease from c. $9.3 \mathrm{Ma}$ to the next zone (43 to $34 \%$ ). Conversely, authigenic growth rates increase from 3.4 to $3.6 \mathrm{~mm} / \mathrm{Ma}$, reflected in rising authigenic/detrital ratios and the development of cuspate columnar structures.

Over the outer compact zone (zone 3ii: 8.4 to 6.3 Ma) elements generally display three trends: (1) decreasing concentrations; $\mathrm{Ce}, \mathrm{Cu}, \mathrm{Zr}, \mathrm{Zn}$, Hf, with the latter three elements 
displaying the same behaviour, (2) decreasing concentrations of a cyclical nature, with peaks at 7.9, 8.4, 7.2 and 6.3 Ma; V, La, Nd, Y, Gd, Sm, Dy, Er, Yb, Lu, (3) increasing concentrations, Mn, Mo, W (highest at 7.2 Ma), (4) increasing contents of a cyclical nature, displaying peaks in concentration as those aforementioned; $\mathrm{Ba}, \mathrm{Bi},{ }^{207} \mathrm{~Pb} /{ }^{204} \mathrm{~Pb}$ and ${ }^{208} \mathrm{~Pb} /{ }^{204} \mathrm{~Pb}$ and, (5) variable changes in concentration, with certain groups of elements displaying comparable trends: $\mathrm{Co}-\mathrm{Ni}$ (highest Co contents at $6.8 \mathrm{Ma}$ ), $\mathrm{Tl}-\mathrm{Cd}$ (lowest values at $8.2 \mathrm{Ma}$ ). Additionally, from c. $8.5 \mathrm{Ma}$ of Zone 3ii (inner compact zone) Fe and $\mathrm{Mn}$ contents vary anti-synchronously. The cyclical nature of element variability (mostly $\mathrm{V}$ and REY), began at around c. 8.7 Ma and appears to correlate with a change from cuspate to columnar structures across the compact zone, as detrital contributions continue to decrease and the authigenic component becomes more dominant. Additionally, macrostructures reveal the development of weak banding within this zone.

After the decrease in chemical content associated with Zone 4 between 6.3 and $4.7 \mathrm{Ma}$, the cyclical variability of chemical content becomes more apparent for a greater number of elements throughout the banded zone (zone 5: 4.7 to $0.1 \mathrm{Ma}$ ). With almost all elements increasing at c. $4.7 \mathrm{Ma}$ (except for $\mathrm{Co}, \mathrm{Ni}, \mathrm{Cu}, \mathrm{Nb}, \mathrm{Hf}, \mathrm{Bi}$ ), decreasing at c. $4 \mathrm{Ma}$ (except for $\mathrm{Pb}, \mathrm{Zn}$ and $\mathrm{Bi}$ ) and peaking in concentration at c. $3 \mathrm{Ma}$ (except for $\mathrm{Fe}$ and $\mathrm{Mn}$ ) with $\mathrm{Ce}, \mathrm{La}$, $\mathrm{Nd}$, As and Gd reaching their highest concentrations. Maximum contents for Fe and Mn are reached at $2.5 \mathrm{Ma}$. The majority of elements then tend to decrease in concentration at 2 $\mathrm{Ma}$, before rising to a peak again at $1.5 \mathrm{Ma}$ (where $\mathrm{U}$ reaches its highest concentrations) and at c. $1 \mathrm{Ma}$, where $\mathrm{Ni}, \mathrm{Cu}, \mathrm{Mo}, \mathrm{Tl}$, and $\mathrm{Cd}$ reach their highest values and ${ }^{206} \mathrm{~Pb} /{ }^{204} \mathrm{~Pb}$ and ${ }^{207} \mathrm{~Pb} /{ }^{204} \mathrm{~Pb}$ their most unradiogenic compositions. From c. $0.3 \mathrm{Ma}$ to present element concentrations tend to decrease with Fe, Ce, Ba, Zr, La, Y, Nb, W Gd, Sm, Er, Yb, Hf, Bi and $\mathrm{Lu}$ reaching their lowest concentrations.

\section{Inter-element Associations}

Evident from the trends in chemical content is that certain groups of elements behave similarly. To establish inter-element relationships, calculations of Pearson's productmoment correlation coefficients for all potential element pairs, and hierarchal cluster analyses of these coefficients were performed. The resulting correlation matrix and cluster hierarchy are presented in Figure 5.8 and an enlarged version of the correlation matrix in Table F.3 (Appendix F). 


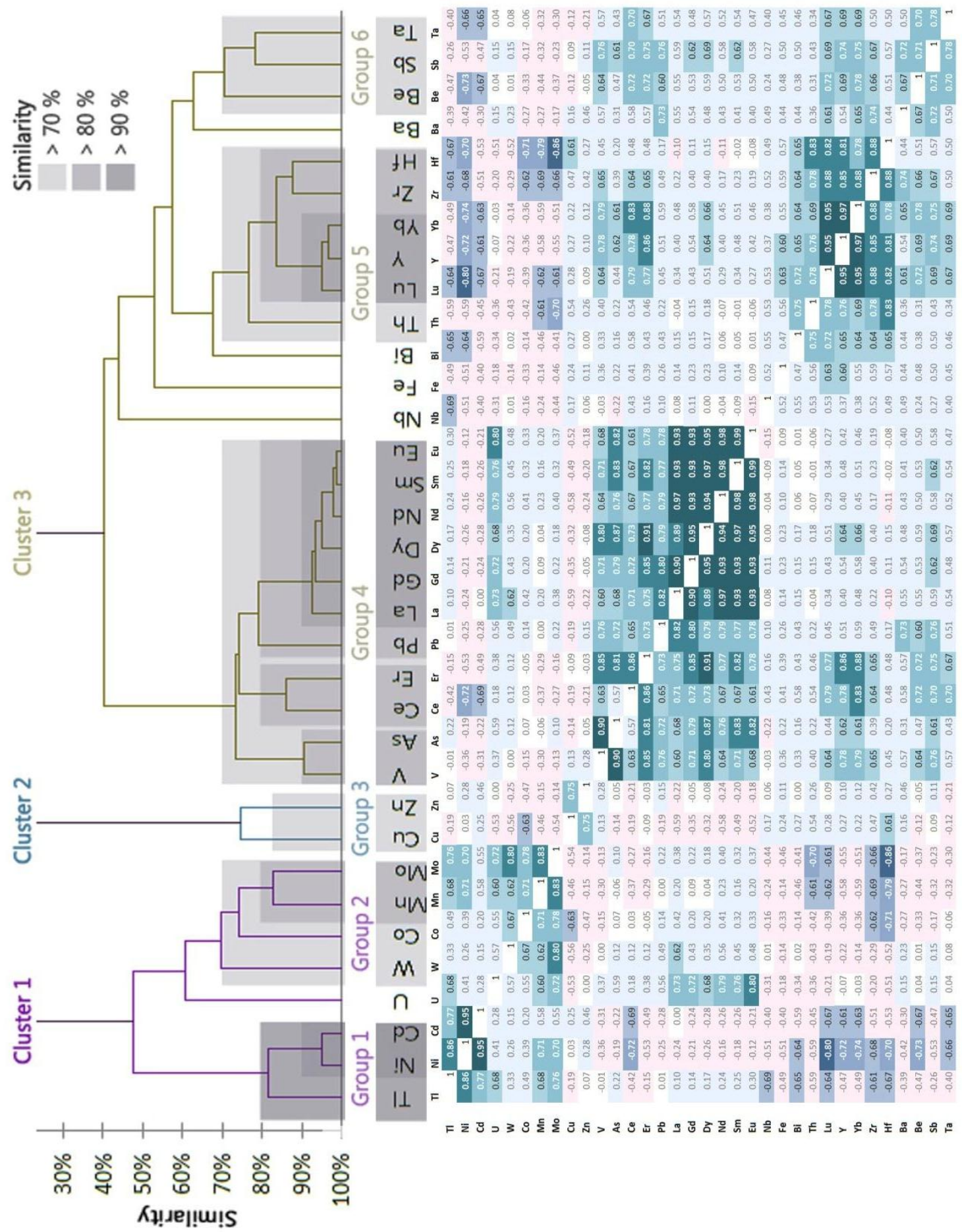

Figure 5.8 Hierarchal cluster of geochemically similar elements and correlation matrix. The closer element clusters are to the $\mathrm{x}$-axis, the more similar in geochemical behaviour. Three main clusters are identified, and six groups of elements determined that show $>70 \%$ similarity. Elements displaying greater than 80 and $90 \%$ similarity are also highlighted with progressively darker shades of grey, respectively. For the correlation matrix, elements displaying significant $( \pm 0.6$; c. $60 \%$ similarity) positive relationships are progressively darker shades of turquoise and significant negative relationships in progressively darker shades of navy blue. Correl coefficients less than 0.6 are faded blue (+) and red (-). 
In addition to the 34 elements analysed, data for ${ }^{9} \mathrm{Be}$ (Ditchburn \& Graham, 2006b), was included as an indication of authigenic contributions from terrigenous sediments. According to Figure 5.8, elements in U1365B-M can be grossly split into three major clusters of elements. Within each cluster elements that have greater than $70 \%$ similarity have been grouped together, illustrated by the six groups of elements. Furthermore, within each group there are pairs and suites of elements that show $>80 \%$ and $>90 \%$ similarity in their chemical profiles e.g. $\mathrm{Pb}, \mathrm{La}-\mathrm{Gd}-\mathrm{Dy}-\mathrm{Nd}-\mathrm{Sm}-\mathrm{Eu}$ as a suite and $\mathrm{Ni}-\mathrm{Cd}$ as a pair. Elements with $<70 \%$ similarity with other elements are $\mathrm{U}, \mathrm{Nd}, \mathrm{Fe}, \mathrm{Bi}$ and $\mathrm{Ba}$. In addition to clearly illustrating the cluster of elements, the correlation matrix also identifies elements that behave anti-synchronously (-ve Pearson's r), such as Ce with Ni-Cd and group 3 elements with group 5-6 elements. Based on these geochemical associations and the degree of element enrichment within U1365B-M the chemical archives are further discussed in terms of: (a) major element chemistry; (b) minor \& trace element chemistry, whereby the most enriched elements of each group 1- 5 are taken as being representative and their profiles described, and; (c) Lead isotope chemistry.

\subsection{Major Element Chemistry}

Figure 5.9 illustrates variations in Fe-Mn contents and $\mathrm{Mn} / \mathrm{Fe}$ ratios throughout U1365BM's growth history. Overall, Mn contents rise from the core to the crust $(7,500$ to 21,700 $\mathrm{ppm})$ and $\mathrm{Fe}$ contents decline (31,700 to $16,900 \mathrm{ppm})$. This is reflected in the overall increase of the $\mathrm{Mn} / \mathrm{Fe}$ ratio (0.4 to 1.2 ).

\section{Fe-Mn Chemistry}

The Mn-profile displays two major trends. The first, from $95-64 \mathrm{~mm}$ (zones 1 through 2ii; 12.7 to $10 \mathrm{Ma}$ ) and the second, $64 \mathrm{~mm}-0.0 \mathrm{~mm}(10 \mathrm{Ma}$ to $0.1 \mathrm{Ma})$. The first trend shows highly variable $\mathrm{Mn}$ contents that oscillate by $\sim 50,000 \mathrm{ppm}$ every c. $1.3 \mathrm{Ma}$. Over zone 2ii concentrations level-off and then drop steeply down to the lowest concentration recorded (64 mm; $7490 \mathrm{ppm}$ ). The $\mathrm{Mn}$ minimum, at $10 \mathrm{Ma}$, is a time marker of change. Past this point Mn contents are characterised by the second trend, a progressive increase in Mn contents to a maxima at $2.5 \mathrm{Ma}$ (Zone 5iii; 21,700 ppm). Superimposed on this longterm trend are four additional micro-trends roughly corresponding with zone boundaries: 


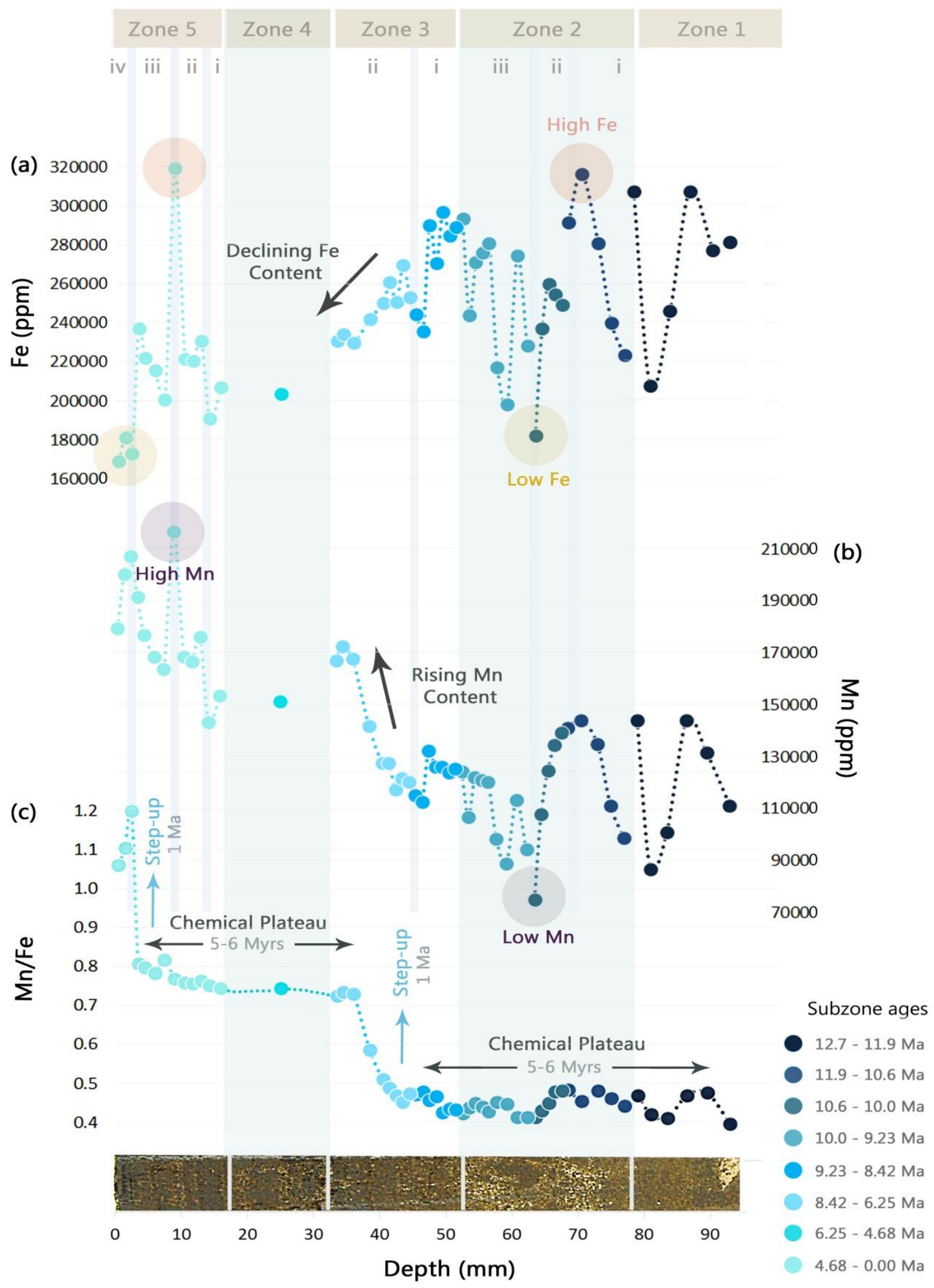

Figure 5.9 | Major element chemistry of U1365B-M. Concentrations of Fe and Mn across the depth profile of U1365B-M are shown in addition to the colour coded time-series for each of the samples representing key subzones with zones 1-5 forming the graph header. The highest and lowest concentrations are encircled in purple for $\mathrm{Mn}$ and orange for Fe. The $\mathrm{Mn} / \mathrm{Fe}$ ratio is also displayed and its unique profile annotated. 
(1) zones 2 iii \& $3 \mathrm{i}$ (9.8 to $8.5 \mathrm{Ma}$ ) consist of a series of gently slanted plateaux of sustained concentration (vary by $\sim 300 \mathrm{ppm}$ ), separated by sudden changes in concentration of $\sim 1000$ ppm which display a crudely rhythmic cyclicity of $\sim 300,000$ kyrs; (2) zones 3i \& 3ii (8.5 to $6.3 \mathrm{Ma}$ ) show a gradual $\sim 5000 \mathrm{ppm}$ rise in $\mathrm{Mn}$-content to a peak at $6.8 \mathrm{Ma}(34.5$ $\mathrm{mm} ; 17,200 \mathrm{ppm})$; (3) zones $3 \mathrm{ii} \& 5 \mathrm{i}(6.8$ to $4.1 \mathrm{Ma})$ display a sustained decline in concentrations of $3000 \mathrm{ppm}$ over c. $3 \mathrm{Ma}$, and; (4) zone 5 (4.7 Ma to present), exhibits a rise in concentrations to $\sim 21,000 \mathrm{ppm}$ at $1 \mathrm{Ma}$, with the Mn maximum occurring as an abrupt spike in the record.

On the other hand, the Fe-profile displays three major trends. The first, from $95-64$ $\mathrm{mm}$ (Zones 1 to $2 \mathrm{ii} ; 12.7$ to $10 \mathrm{Ma}$ ), the second, from $64-46.5 \mathrm{~mm}$ (Zones 2ii to 3i; $10 \mathrm{Ma}$ to $8.5 \mathrm{Ma}$ ) and the third from 46.5 to $0.0 \mathrm{~mm}$ (Zone 3i through Zone 5; 8.5 Ma to 0.1 Ma). The first trend shows variations that are synchronous to changes in $\mathrm{Mn}$, but at higher concentrations of $\mathrm{Fe}(20,660 \mathrm{ppm}$ to $31,660 \mathrm{ppm})$. The zone also shows greater variability, oscillating by $\sim 10,000 \mathrm{ppm}$ between adjacent peaks and troughs of $\sim 0.3 \mathrm{Ma}$ duration. This period (in addition to Zone 5iv) contains both the highest and lowest concentrations of the record. One of two Fe maxima, occur at $70.5 \mathrm{~mm}(10.7 \mathrm{Ma} ; 31,700 \mathrm{ppm})$ and of Fe minima (63.5 mm; 18,200 ppm) at the $10 \mathrm{Ma}$ time marker, coincident with the Mn-minima. The second trend appears to display a magnification of those explained for Mn contents except at higher concentrations and variability. The third trend is a long-term decrease in Fe content, from $\sim 27,000 \mathrm{ppm}$ at $43.5 \mathrm{~mm}(8.4 \mathrm{Ma} ; 16,900 \mathrm{ppm})$ to the second Fe minima of $16,900 \mathrm{ppm}$, within the outer $10 \mathrm{~mm}$ of crust (Zone $5 \mathrm{iv} ; 2.5$ to $0.1 \mathrm{Ma}$ ). As seen in the $\mathrm{Mn}$ profile, a sudden pulse in Fe content also occurs at $2.5 \mathrm{Ma}(29 \mathrm{~mm} ; 31,900 \mathrm{ppm})$, disrupting the long term trends.

\section{The Mn/Fe Value}

$\mathrm{Mn} / \mathrm{Fe}$ are lowest at the nodule core $(\mathrm{Mn} / \mathrm{Fe}=0.2)$ and highest between zone 5iii and zone 5iv at $1 \mathrm{Ma}(\mathrm{Mn} / \mathrm{Fe}=1.2)$. The increase in $\mathrm{Mn} / \mathrm{Fe}$ from core to crust occurs through a series of stages, consisting of abrupt and relatively rapid transitions (zone 3 and zone 5iv) with intervening periods of longer chemical stability (zones $1 \& 2$ and zones $4 \&$ 5i-iii). Evolution of the $\mathrm{Mn} / \mathrm{Fe}$ is periodic, with chemical plateaux being sustained for 5-6 Ma 
and characterised by a restricted range in $\mathrm{Mn} / \mathrm{Fe}$ ratios, whereas transitions take c. $1 \mathrm{Ma}$ to establish a 'new' elevated $\mathrm{Mn} / \mathrm{Fe}$ ratio, increasing by c. 0.3 (Figure 5.9). Mn-Fe chemistry of the plateaux, show simultaneous variations in concentrations of comparable magnitude. In contrast, during transitional stages, variations in $\mathrm{Mn}$ and $\mathrm{Fe} \mathrm{ppm}$ are asynchronous, with pulses in Mn content coincident with a decrease in Fe.

The results of major element chemistry are consistent with FMNs of the Campbell Nodule Field. Average values of $\mathrm{Fe}, \mathrm{Mn}, \mathrm{Mn} / \mathrm{Fe}$, in addition to a summary of the authigenic and detrital chemistry are illustrated in Figure 5.10. Nodule U1365B-M falls within average values generated from the field, despite the bulk chemical data used for comparison (Graham, et al., 2003a), with the larger nodules (U1406B-2, U1402-1 and U1365B-M) generally displaying lower Mn/Fe. Furthermore, Fe-Mn data are within ranges previously reported for the FMNs of the Southwest Pacific with Mn contents ranging from 8,000 to $22,000 \mathrm{ppm}$, Fe from 10,000 to $30,000 \mathrm{ppm}$ and $\mathrm{Mn} / \mathrm{Fe}$ ratios of unity (Summerhayes, 1977; Glasby \& Summerhayes, 1979; Mangini, et al., 1990; Glasby, 2000).

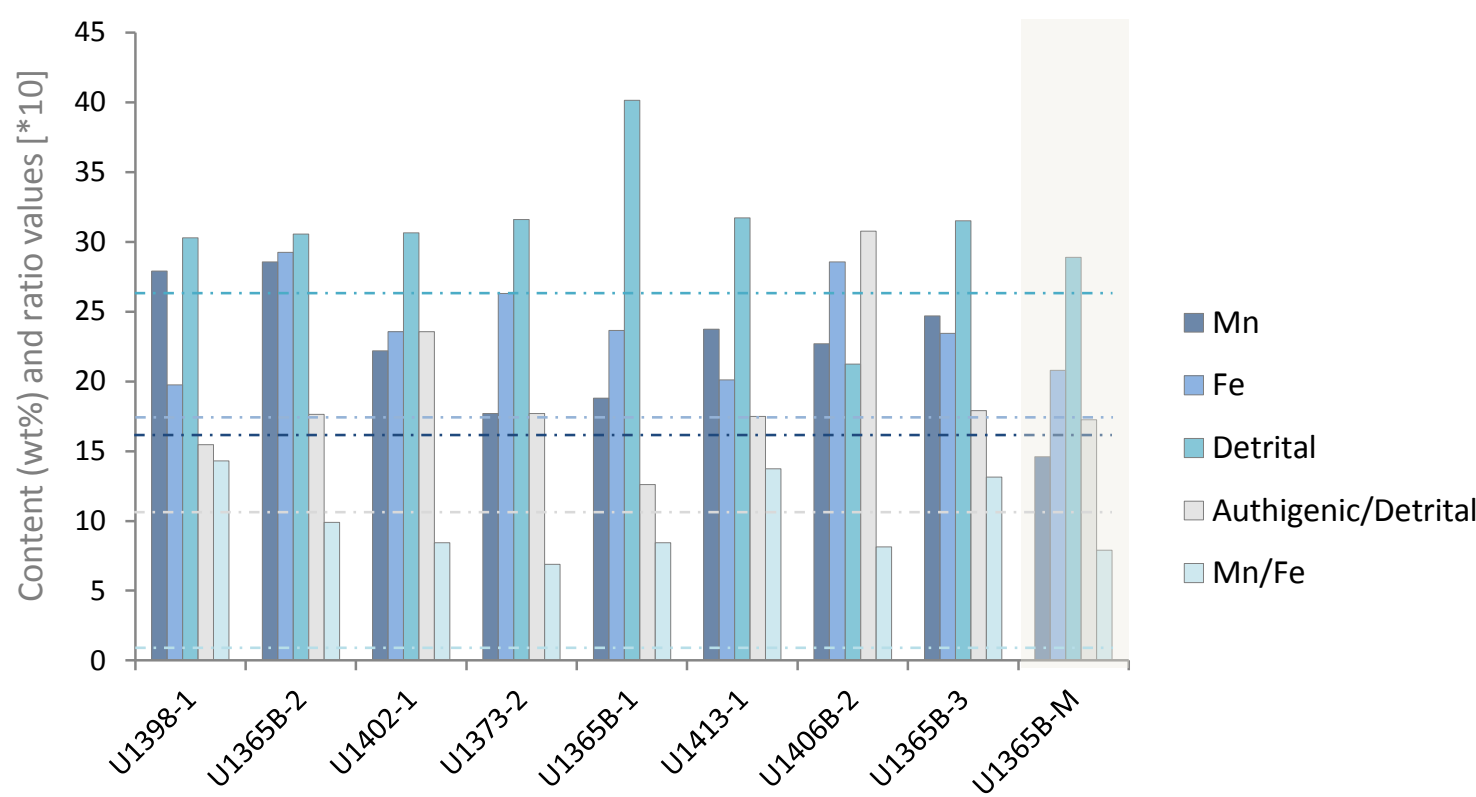

Cambell Nodule Field Samples

Figure 5.10 | Major element, authigenic \& detrital compositions of Campbell Nodules derived from Graham, et al. (2003a) 


\subsection{Minor \& Trace Element Chemistry}

Figure 5.11 illustrates variations in the concentration of the minor elements, each being representative of the associated elements within that group: nickel [Group 1], cobalt [Group 2], copper [Group 3], cerium [Group 4], lead [Group 4] and barium [associated with Group 6]. However group 5 elements are represented by Fe, and thus been described in the previous section. Elements are displayed as time-depth series, with concentrations plotted versus depth and the depth profile visible, to link physical and chemical archives.

Overall, $\mathrm{Ba}, \mathrm{Pb}$ and $\mathrm{Ce}$ display high concentrations in zone 1 and rapidly decline over Zones $2 \mathrm{i}$ and 2 ii to mid-way between zone 2 iii, where concentrations reach a low at c. 61 $\mathrm{mm}(9.80 \mathrm{Ma})$. From 9.8 to c. $6.3 \mathrm{Ma}$ concentrations rise to a broad peak for $\mathrm{Pb}$ spanning zone 3, with concentrations peaking at $8.4 \mathrm{Ma}$ for $\mathrm{Ce}$ and $\mathrm{Ba}$. $\mathrm{Ce}$ and $\mathrm{Ba}$ then continue to decline in concentrations to zone 4 before rising to a peak at $3 \mathrm{Ma}$ and rapidly declining in concentration thereafter.

As for $\mathrm{Co}, \mathrm{Cu}$ and $\mathrm{Ni}$, their concentrations profiles are very different. $\mathrm{Ni}$ displays extremely low concentrations from 13 to $3 \mathrm{Ma}($ c. $12 \mathrm{~mm}$ ) when concentrations spike 8fold in concentration. From $3-0 \mathrm{Ma} \mathrm{Cu}$ also displays this trend. However, from 13 to 3 $\mathrm{Ma}$ the $\mathrm{Cu}$ profile bears similarity to percentage detrital (Figure 5.6). Co concentrations generally show three trends: (1) a Co-poor zone (12.7 to 7.4 Ma) - characterised by low Co concentrations between 2400 and $4000 \mathrm{ppm}$ with an average, (2) a transition zone (7.4 to $6.3 \mathrm{Ma}$ ) - where Co concentrations and Co-fluxes rise from 3000 to $6200 \mathrm{ppm}$ in association with a lowering in the growth rate and; (3) a Co-rich zone (6.3 to $0.1 \mathrm{Ma})$ with $~ 6000$ to 4000 ppm Co.

Interestingly, Co-Cu-Ni decrease at c. $25 \mathrm{~mm}$, corresponding to the $6 \mathrm{Ma}$ time marker after which growth rates decline. However, from c. $4 \mathrm{Ma}, \mathrm{Ni}$ and $\mathrm{Cu}$ synchronously increase, spiking at c. $1 \mathrm{Ma}$. Co on the other hand decreases, cyclically fluctuating every c. 1 $\mathrm{Ma}$. Conversely, $\mathrm{Ba}, \mathrm{Pb}$ and $\mathrm{Ce}$ increase part way through zone 4, reaching a third peak at c. $3 \mathrm{Ma}$ and declining roughly thereafter. The similarity of these element profiles (and the slight deviations), supports their being within the same or proximate clusters (Figure 5.8). 


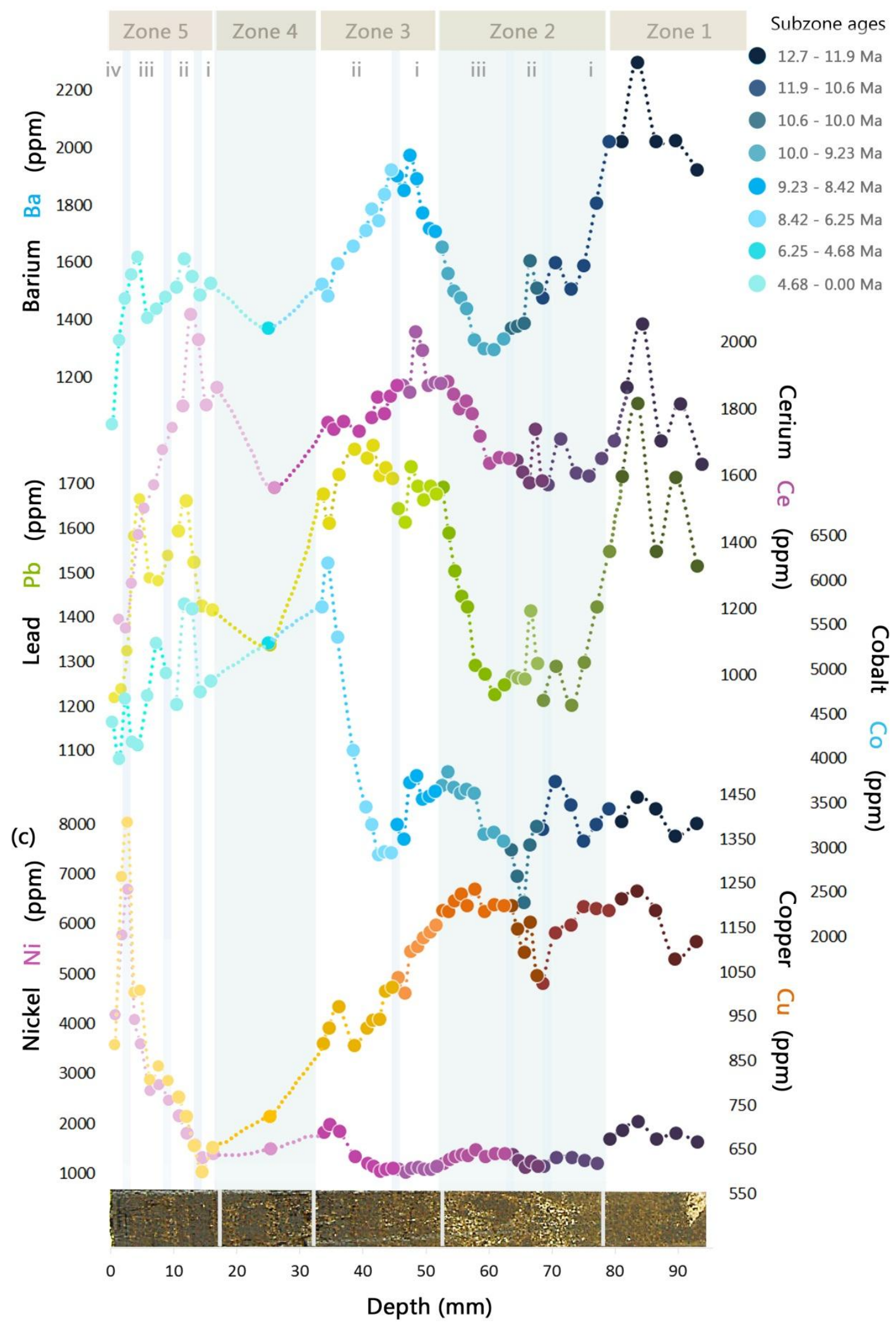

Figure 5.11 | Minor element depth-time series for U1365B-M. The depth-time profiles are presented for the major elements and represent the general trends exhibited by the lesser enriched elements of that group. Key subzone ages are colour coded for barium and cobalt, and thus provide a time-series for the other elements. 


\subsection{Lead Isotope Chemistry}

$\mathrm{Pb}$ isotopic compositions of ${ }^{206} \mathrm{~Pb} /{ }^{204} \mathrm{~Pb},{ }^{207} \mathrm{~Pb} /{ }^{204} \mathrm{~Pb}$ and ${ }^{208} \mathrm{~Pb} /{ }^{204} \mathrm{~Pb}$ range from 18.80 to $18.95 \pm 0.001$ (Figure 5.12(a)), 15.64 to $15.67 \pm 0.001$ (Figure 5.12(b)) and 38.81 to 39.06 \pm 0.003 (Figure 5.12 (c)), respectively. These values agree well with $\mathrm{Pb}$ isotopic data gathered from nearby crusts and nodules (Abouchami \& Goldstein, 1995; Baker, et al., 2001; Ulfbeck, et al., 2001; van de Flierdt, et al., 2004)

The lead isotope seawater record shows two distinct trends in $\mathrm{Pb}$ compositions that have occurred in the past $13 \mathrm{Ma}$. The first trend, from the core to c. $65 \mathrm{~mm}(12.7-10 \mathrm{Ma})$, shows a shift from relatively unradiogenic values in Zone $1\left({ }^{206} \mathrm{~Pb} /{ }^{204} \mathrm{~Pb}=18.82\right.$, ${ }^{207} \mathrm{~Pb} /{ }^{204} \mathrm{~Pb}=15.66$ and $\left.{ }^{208} \mathrm{~Pb} /{ }^{204} \mathrm{~Pb}=38.86\right)$ toward the most radiogenic values record by the nodule in Zone 2 ii $\left({ }^{206} \mathrm{~Pb} /{ }^{204} \mathrm{~Pb}=18.95,{ }^{207} \mathrm{~Pb} /{ }^{204} \mathrm{~Pb}=15.67\right.$ and $\left.{ }^{208} \mathrm{~Pb} /{ }^{204} \mathrm{~Pb}=39.06\right)$. This trend is then reversed from $10 \mathrm{Ma}$ to present, with values progressively decreasing toward the most unradiogenic compositions of the outer crust, Zone $\operatorname{5iv}\left({ }^{206} \mathrm{~Pb} /{ }^{204} \mathrm{~Pb}=18.80\right.$, ${ }^{207} \mathrm{~Pb} /{ }^{204} \mathrm{~Pb}=15.65$ and $\left.{ }^{208} \mathrm{~Pb} /{ }^{204} \mathrm{~Pb}=38.83\right)$. These values are intermediate between present day NPDW and LCDW.

From a depth of $95 \mathrm{~mm}(12.7 \mathrm{Ma})$ to c. $65 \mathrm{~mm}(10 \mathrm{Ma}){ }^{207} \mathrm{~Pb} /{ }^{204} \mathrm{~Pb}$ display greater variability compared to the smooth trends exhibited by ${ }^{206} \mathrm{~Pb} /{ }^{204} \mathrm{~Pb}$ and ${ }^{208} \mathrm{~Pb} /{ }^{204} \mathrm{~Pb}$, with the local maximum at $10 \mathrm{Ma}$ illustrated by a spike in ${ }^{207} \mathrm{~Pb} /{ }^{204} \mathrm{~Pb}$. Between Zone $2 \mathrm{ii}$ and Zone $3 \mathrm{i}$ $(10-8.4 \mathrm{Ma})$ ratios decrease to a minimum $\left({ }^{206} \mathrm{~Pb} /{ }^{204} \mathrm{~Pb}=18.82,{ }^{207} \mathrm{~Pb} /{ }^{204} \mathrm{~Pb}=15.65\right.$ and ${ }^{208} \mathrm{~Pb} /{ }^{204} \mathrm{~Pb}=38.81$ ), reaching the most unradiogenic values for ${ }^{208} \mathrm{~Pb} /{ }^{204} \mathrm{~Pb}$ and displaying $\mathrm{a}$ large spike in ${ }^{207} \mathrm{~Pb} /{ }^{204} \mathrm{~Pb}$. Across Zone 3ii values appear to show a regular variability and continue to rise toward Zone 4 were ${ }^{206} \mathrm{~Pb} /{ }^{204} \mathrm{~Pb}$ and ${ }^{207} \mathrm{~Pb} /{ }^{204} \mathrm{~Pb}$ trends (on either side of zone 4) indicate a gradual decrease in values toward a minimum at Zone $5 \mathrm{i}$ (c. $4 \mathrm{Ma}$ ). $\mathrm{Pb}$ isotopic ratios increase again across Zone 5ii from $4-3 \mathrm{Ma}$ with ${ }^{208} \mathrm{~Pb} /{ }^{204} \mathrm{~Pb}$ displaying a systematic increase in values, peaking at c. $2.5 \mathrm{Ma}$ in Zone 5 iii. ${ }^{206} \mathrm{~Pb} /{ }^{204} \mathrm{~Pb}$ and ${ }^{207} \mathrm{~Pb} /{ }^{204} \mathrm{~Pb}$ ratios display an earlier peak at the end of Zone 5ii (c. 3 Ma). Across Zone 5iii, from c. 2.5 to $1 \mathrm{Ma}, \mathrm{Pb}$ ratios decrease to the most unradiogenic values recorded by $\mathrm{U} 1365 \mathrm{~B}-\mathrm{M}$, similar to the minimum at $8.4 \mathrm{Ma}$ (Zone $3 \mathrm{i})$. Within the last $2-3 \mathrm{~mm}$, Zone $5 \mathrm{iv}(<1 \mathrm{Ma})$, $\mathrm{Pb}$ isotopic compositions display an increase toward more radiogenic values in the order ${ }^{206} \mathrm{~Pb} /{ }^{204} \mathrm{~Pb}<{ }^{208} \mathrm{~Pb} /{ }^{204} \mathrm{~Pb}<{ }^{207} \mathrm{~Pb} /{ }^{204} \mathrm{~Pb}$. 


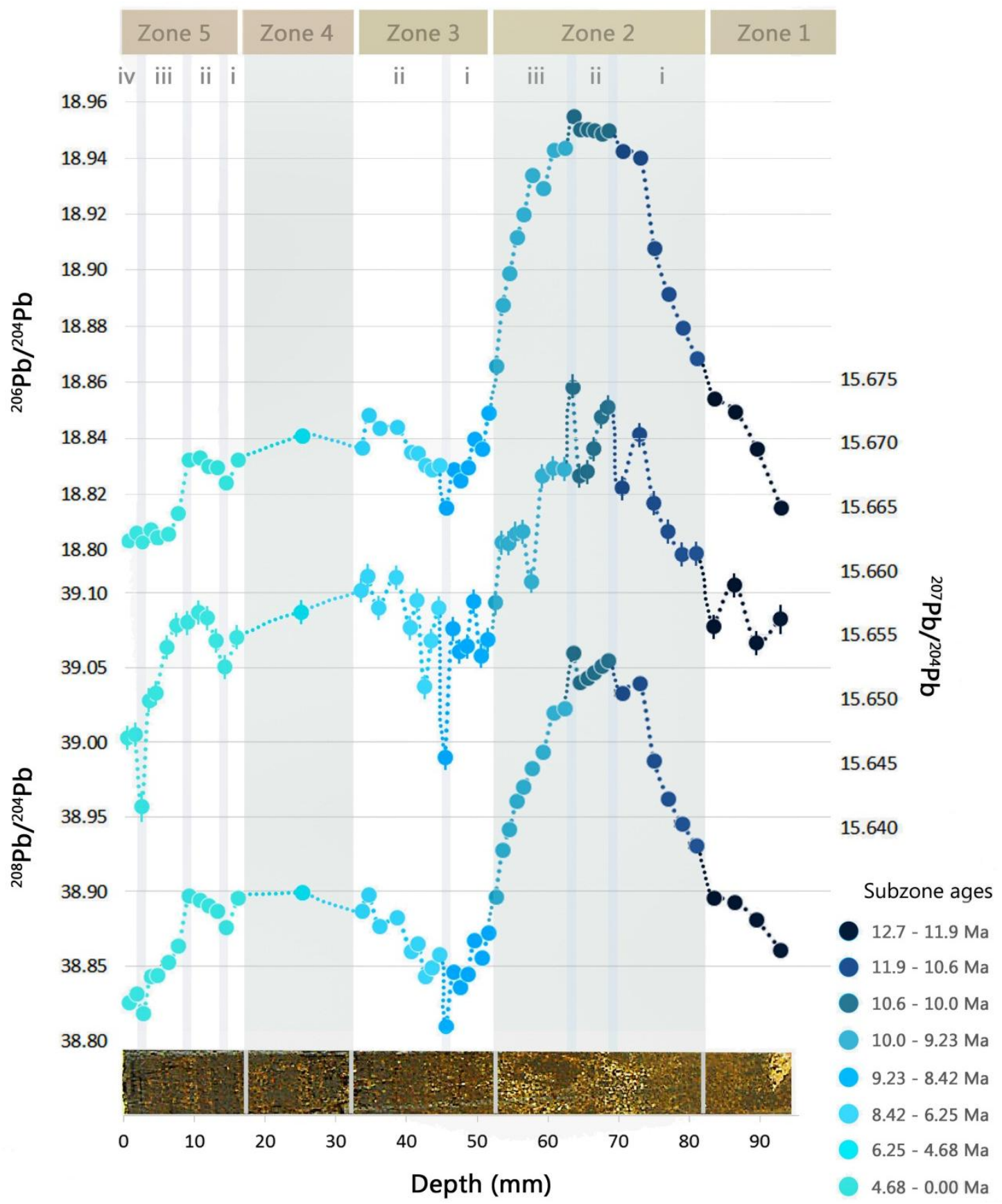

Figure 5.12 | Paleo-seawater Pb isotopic compositions for the 13 Ma growth history of U1365B-M. ${ }^{208} \mathrm{~Pb} /{ }^{204} \mathrm{~Pb},{ }^{207} \mathrm{~Pb} /{ }^{204} \mathrm{~Pb}$ and ${ }^{206} \mathrm{~Pb} /{ }^{204} \mathrm{~Pb}$ are plotted for the depth profile of U1365B-M. Each zone, defined by changes in nodule texture, is colour coded and the timeframes of each zone defined, with progressively younger deposits becoming lighter in colour. Error bars are illustrated when larger than the data point. 
$\mathrm{Pb}-\mathrm{Pb}$ ratios display a quasi-cyclic character with changes in composition roughly corresponding to the $2.1 \mathrm{Ma}$ eccentricity cycle. The huge monotonic shift in ${ }^{206} \mathrm{~Pb} /{ }^{204} \mathrm{~Pb}$ from $18.82(12.7 \mathrm{Ma})$ to $18.96(10 \mathrm{Ma})$, with an increase to more radiogenic values of 0.14 , and in ${ }^{208} \mathrm{~Pb} /{ }^{204} \mathrm{~Pb}(0.2)$, is accompanied by only small variations in ${ }^{207} \mathrm{~Pb} /{ }^{204} \mathrm{~Pb}(0.018)$.

The 13 Ma seawater record illustrated in Figure 5.12, presents well-defined changes in composition with time and provides one of the first long-term $\mathrm{Pb}$ isotopic characterisation of the ACC-DWBC from the vicinity of the Campbell Nodule Field. An initial study was conducted by Baker et al. (2001) and Ulfbeck, et al. (2001) who obtained in situ Pb isotopic compositions for a profile across U1365B-2 (Figure 5.13) using laser ablation MC-ICPMS. Unfortunately, $\mathrm{Pb}$ isotopic profiles could not be matched to an accurate chronology. Figure 5.13 presents the ${ }^{207} \mathrm{~Pb} /{ }^{206} \mathrm{~Pb}$ isotopic profile of $\mathrm{U} 1365 \mathrm{~B}-2$ with the ${ }^{207} \mathrm{~Pb} /{ }^{206} \mathrm{~Pb}$ isotopic compositions of U1365B-M. The isotopic profile of U1365B-2 has been matched to the ${ }^{10} \mathrm{Be} /{ }^{9} \mathrm{Be}$ chronology of U1365B-M. It is clear from Figure 5.13 that both FMNs record coherent changes in $\mathrm{Pb}$ isotope compositions. Additionally, the high resolution bulk ${ }^{207} \mathrm{~Pb} /{ }^{206} \mathrm{~Pb}$ ratios reveal four distinct spikes in the $\mathrm{Pb}$ record that our authigenic micosampling technique was unable to detect, which occur at approximately: 6.7 Ma, 3.9 Ma, 1.2 Ma and 0.3 Ma. Lead isotope variations with time, in both U1365B-2 and U1365B-M occur gradually and systematically with time.

\section{$\mathrm{Pb}-\mathrm{Pb}$ mixing Plots}

The $\mathrm{Pb}$ isotopic variations over time in $\mathrm{U} 1365 \mathrm{~B}-\mathrm{M}$, display well defined linear arrays in $\mathrm{Pb}-\mathrm{Pb}$ space. Based on ${ }^{207} \mathrm{~Pb} /{ }^{204} \mathrm{~Pb}$ vs ${ }^{206} \mathrm{~Pb} /{ }^{204} \mathrm{~Pb}$ (Figure 5.14), data points generally fall along a long-term mixing array, with dissolved $\mathrm{Pb}$ from at least four different sources resulting in short-term isotopic excursions. Three excursions are identifiable and occur at: (i) $9.5 \mathrm{Ma}$ (toward unradiogenic ${ }^{207} \mathrm{~Pb} /{ }^{204} \mathrm{~Pb}$ and more radiogenic ${ }^{206} \mathrm{~Pb} /{ }^{204} \mathrm{~Pb}$ ); (ii) $8.4 \mathrm{Ma}$ (toward more unradiogenic compositions) and; (iii) from $1.7 \mathrm{Ma}$ to present (toward unradiogenic ${ }^{207} \mathrm{~Pb} /{ }^{204} \mathrm{~Pb}$ with fairly constant ${ }^{206} \mathrm{~Pb} /{ }^{04} \mathrm{~Pb}$ ). In addition there is a complex mixing zone of different $\mathrm{Pb}$ sources with no discernible isotopic arrays (i.e., mixing lines) for Zones 1, 3, 4 and 5i-ii. For ${ }^{208} \mathrm{~Pb} /{ }^{204} \mathrm{~Pb}$ versus ${ }^{206} \mathrm{~Pb} /{ }^{204} \mathrm{~Pb}$ well-defined sub-parallel arrays can be distinguished for each textural zone, corresponding to different periods of time. These distinct arrays exclude a simple two source mixing model for the isotopic evolution 


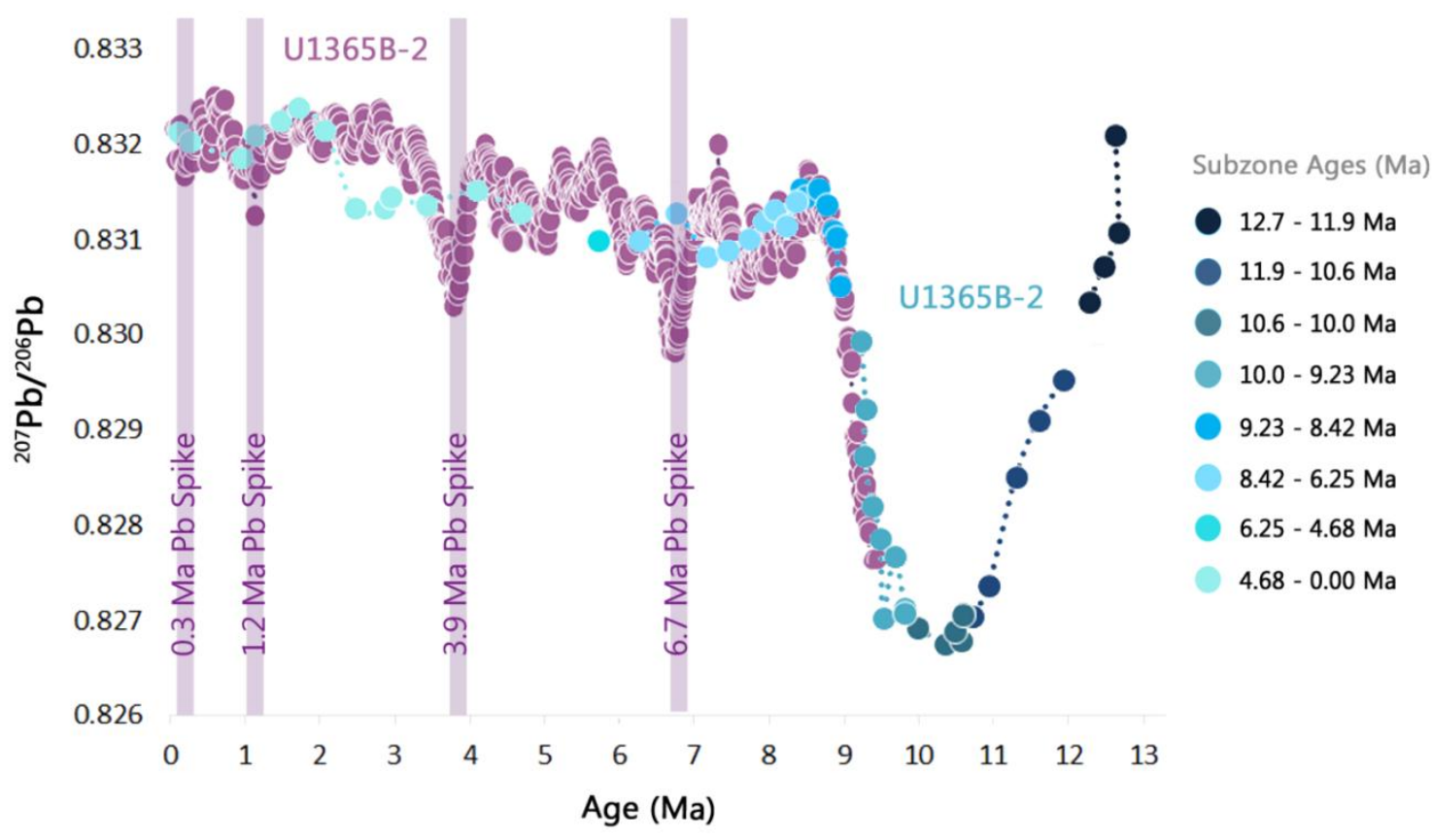

Figure 5.13 | Paleo-seawater $\mathrm{Pb}$ isotopic compositions for $\mathrm{U} 1365 \mathrm{~B}-2$ and $\mathrm{U} 1365 \mathrm{~B}-\mathrm{M}{ }^{207} \mathrm{~Pb} /{ }^{206} \mathrm{~Pb}$ ratios of U1365B-M and U1365B-2 (Baker, et al., 2001) are plotted for the ${ }^{10} \mathrm{Be} /{ }^{9} \mathrm{Be}$ derived chronology of U1365B-M. Each zone, defined by changes in nodule texture, is colour coded and the timeframes of each zone defined, with progressively younger deposits becoming lighter in colour. Purple bars emphasise the isotopic excursions in the Pb record of U1365B-2 at c. 6.7 Ma and 3.9 Ma.

of $\mathrm{Pb}$ in Lower Circumpolar Deep Water, but point to the involvement of (at least) four different sources. Between Zone $1(12.7-11.9 \mathrm{Ma})$ and Zone $2 \mathrm{i}(11.9-10.6 \mathrm{Ma})$ there is a shift toward higher ${ }^{208} \mathrm{~Pb} /{ }^{204} \mathrm{~Pb}$ ratios for a given ${ }^{206} \mathrm{~Pb} /{ }^{204} \mathrm{~Pb}$. Zone $2 \mathrm{i}(11.9-10.6 \mathrm{Ma})$ and Zone 2iii $(10.0$ - 9.23 Ma) have mixing arrays that run parallel. Thus, the dissolved $\mathrm{Pb}$ recorded in these nodule textures shared a common source of uranogenic lead $\left({ }^{206} \mathrm{~Pb} /{ }^{204} \mathrm{~Pb}\right)$ but varied in thorogenic lead $\left({ }^{208} \mathrm{~Pb} /{ }^{204} \mathrm{~Pb}\right)$, with Zone $2 \mathrm{i}$ composed of more radiogenic ${ }^{208} \mathrm{~Pb} /{ }^{204} \mathrm{~Pb}$ than Zone 2iii. For Zone $2 \mathrm{i}$ the radiogenic end-member becomes an increasingly dominant source of $\mathrm{Pb}$. At Zone $2 \mathrm{ii}(10.6-10 \mathrm{Ma})$ the radiogenic endmember consistently contributes a dominant source of lead for c. 600,000 years before reaching a turning point at $10 \mathrm{Ma}$. Beyond the turning point the unradiogenic source with lower ${ }^{208} \mathrm{~Pb} /{ }^{204} \mathrm{~Pb}$ becomes progressively more dominant and continues through Zone $3 \mathrm{i}$ $(9.23-8.42 \mathrm{Ma})$. At $8.4 \mathrm{Ma}$ a second turning point occurs, with Zone $3 \mathrm{ii}(8.42-6.25 \mathrm{Ma})$ displaying an increased source of radiogenic $\mathrm{Pb}$. The mixing arrays of Zone 4 (6.25 - 4.68 $\mathrm{Ma})$ and Zone 5i-ii (4.68 - 1.70 Ma) fall roughly along the same mixing lines of Zone 1 and 
Zone $2 \mathrm{i}$ indicating a return to similar environmental conditions, in terms of $\mathrm{Pb}$ isotope source end-members, with the exception that within this portion of the nodule (Zones 1, 4, 5i-ii) the unradiogenic end-member forms a dominant source of $\mathrm{Pb}$. A distinct change in $\mathrm{Pb}$ compositions occurs within Zone 5iii-iv (1.7 Ma to present) falling along an array that is almost perpendicular to those of the other nodule zones. This indicates a clear change in the end-member sources of $\mathrm{Pb}$ with an increasing contribution from a $\mathrm{Pb}$ source with $\mathrm{a}$ fairly consistent ${ }^{206} \mathrm{~Pb} /{ }^{204} \mathrm{~Pb}$ but variable ${ }^{207} \mathrm{~Pb} /{ }^{204} \mathrm{~Pb}$ and ${ }^{208} \mathrm{~Pb} /{ }^{204} \mathrm{~Pb}$.

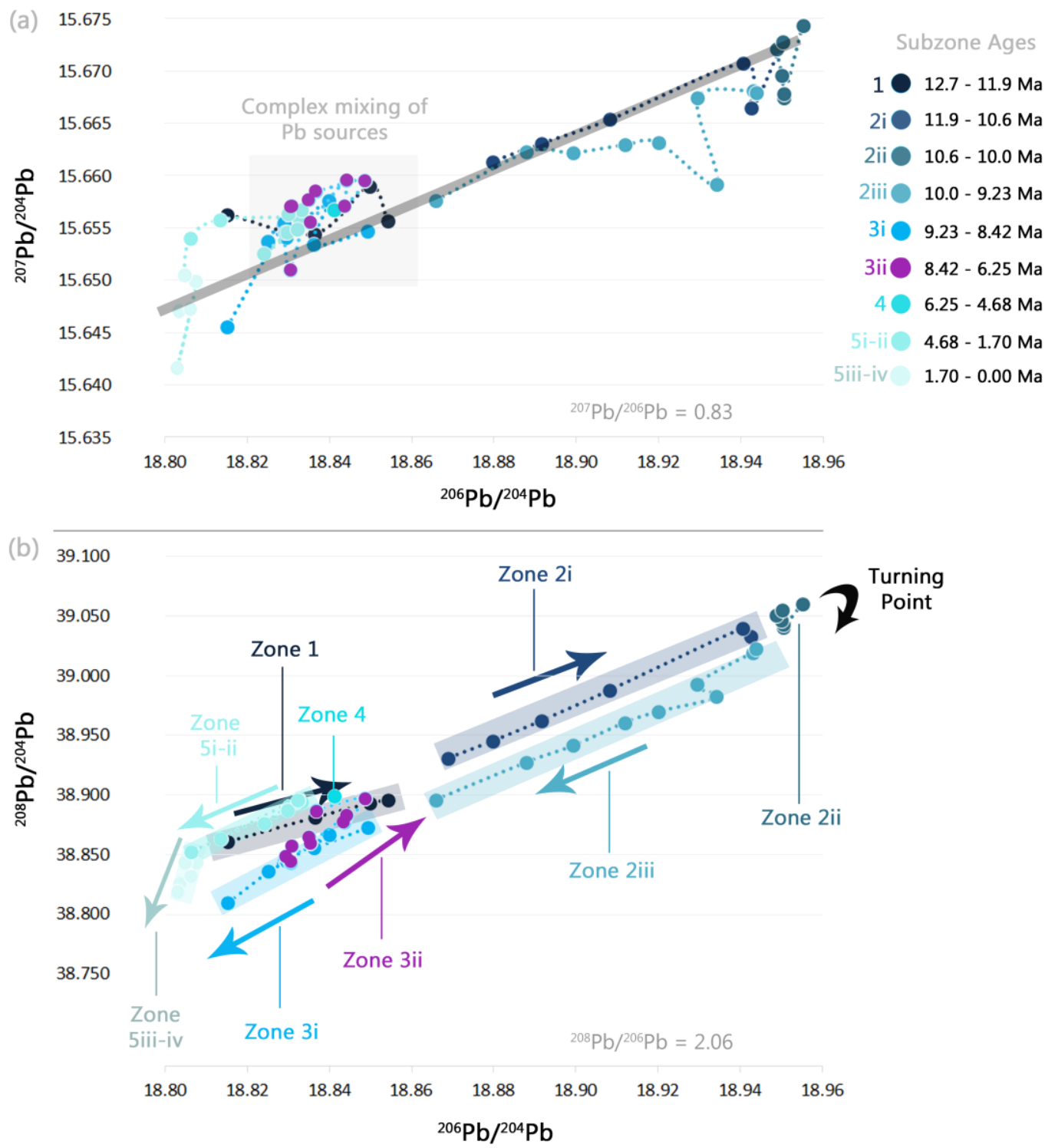

Figure 5.14 | Pb-Pb mixing plots of U1365B-M Three-isotope plots of (a) ${ }^{207} \mathrm{~Pb} /{ }^{204} \mathrm{~Pb}$ vs. ${ }^{206} \mathrm{~Pb} /{ }^{204} \mathrm{~Pb}$ and $(\mathrm{b}){ }^{208} \mathrm{~Pb} / 204 \mathrm{~Pb}$ vs. ${ }^{206} \mathrm{~Pb} /{ }^{204} \mathrm{~Pb}$. 


\section{Chapter}

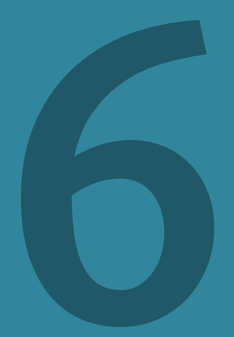

Discusses the links between physical and geochemical signals recorded within U1365B-M with local and global oceanic and climatic events that have occurred over the last $13 \mathrm{Ma}$

\section{Discussion}

\section{Unravelling 13 Million Years of Deep Ocean}
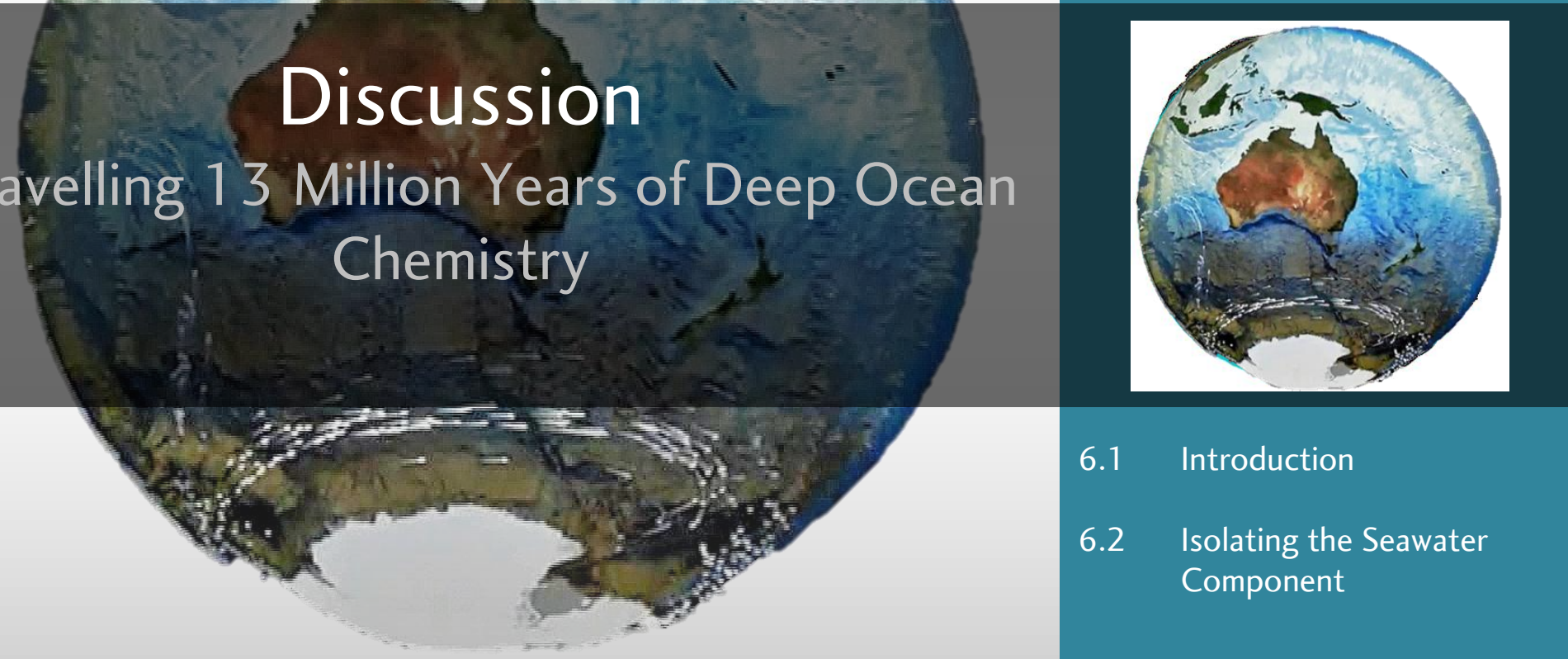

6.1 Introduction

6.2 Isolating the Seawater Component

6.3 Revising \& Utilising the Chronological Framework
6.4 Unravelling the Physical Archives
6.5 Unravelling the Chemical Archives

6.6 Unravelling the Late Neogene Evolution of the PDWBC 


\subsection{Introduction}

Abyssal ocean currents develop unique physical and chemical properties, based on their geographic location of formation, circulation pathways, and the biogeochemical cycling of elements and their isotopes between different water masses (Goldstein \& Hemming, 2003). These distinct physiochemical properties enable water fingerprinting, the ability to identify and trace water masses as they circulate the globe, in their relentless attempt to redistribute the Earths heat, salt and biogeochemical agents (Glasby, 2000; Frank, 2002; Goldstein \& Hemming, 2003). Over geological time, the chemical fingerprint of water masses has evolved in response to changing climatic regimes and tectonic events (Cronin, 2010). Hydrogenous FMNs incorporate a record of these chemical fingerprints from the abyssal water masses in which they grow, as they accrete each successive growth layer from the elements and compounds available within ambient deep waters (Mangini, et al., 1991; Eisenhauer, et al., 1992; Banakar, et al., 1993; Glasby 2000). Due to the exceptionally slow growth rate of these abyssal archives, FMNs provide insights on the chemical history of the deep ocean over millions of years. Such changes in FMN geochemistry have been linked to the development and demise of polar ice sheets (e.g., von Blanckenburg \& Nägler, 2001; Frank, et al., 2002; Xu, et al., 2006; Crocket, et al., 2013) and the opening and closing of ocean gateways (e.g., Burton, et al., 1997, 1999; Frank, et al., 1999, 2006; Chen, et al., 2013).

Since FMN U1365B-M began to grow from waters of the Pacific DWBC, some thirteen million years ago, the face of the earth has undergone extraordinary changes in oceancontinent geometry, global ice volume, climate, and thus, the structure, circulation and chemistry of the global ocean (see Table 1.1). Due to the location of U1365B-M below the combined flow of the ACC and PDWBC, on its transit from the Southern Ocean in to the greater Pacific, this large FMN has the potential to record such global events due to the effective mixing of all major water masses within the ACC (Carter, et al., 2009; van Sebille, et al., 2013). In addition to recording changes in the lateral advection of water masses to the nodule growth site, FMN geochemistry is also controlled by the vertical flux of material through the water column (Banakar, et al., 1997; Verlaan, et al., 2004; Perrit \& Watkeys, 2007; Banakar, 2010). Local environmental controls on element fluxes such as, paleoproductivity and redox conditions can be inferred from the application of proxies 
previously utilised in the literature for a variety of sedimentary archives (see Tribovillard, et al., 2006; Chapter 3). Paleoproductivity of surface waters and the redox state of the deep ocean exert strong controls on the position of the CCD and OMZ, which in turn control the delivery of Fe and Mn, respectively, to the deep ocean (Verlaan, et al., 2004; Perrit \& Watkeys, 2007; Chapter 3). In light of the capacity of FMNs to store a record of local and global environmental change (see Figure 3.7), the main aim of this thesis was to extract and examine the authigenic component of a 13 Myr old hydrogenous FMN, that has precipitated from waters of the PDWBC, for its multi-elemental and lead isotopic chemistry, to determine how the chemical oceanography of this current has evolved in response to climatic (development and demise of the polar ice sheets) and tectonic (opening and closing of ocean gateways) events of the late Neogene. In the knowledge that these climatic-tectonic perturbations ultimately control: oceanic circulation pathways and export of various water masses to the Southern Ocean, bottom water production, current speeds and the degree of oceanic mixing and stratification, in addition to controls on the degree of continental weathering and erosion, the supply of bio-available elements for surface water biological activity and the redox state of the deep ocean - all of which are encoded in the chemical fingerprint of the PDWBC and archived within the physiochemical properties of mega nodule U1365B-M.

Five objectives were designed to address the aim of the thesis: (1) isolating the seawater record, established a technique to extract and analyse the pure seawater (authigenic) fraction of U1365B-M and record the proportion of detrital minerals; (2) revising \& utilising the chronological framework, provided an accurate age model consistent with the most recent applications of beryllium dating; (3) unravelling the physical archives, described significant changes in texture, accretion rates, detrital and authigenic minerals; (4) unravelling the chemical archives, described significant changes in element concentration and $\mathrm{Pb}$ isotope compositions, and; (5) reconstructing the late Neogene evolution of the PDWBC, is a summation of the findings from the physical and chemical archives of U1365B-M. This Chapter discusses implications of each objective in turn, with the last objective providing a summary of the cumulative information gathered from each of the previous objectives, with attempts made to relate these results to climatic-oceanictectonic events reported for the late Neogene, addressing the broad aim of the thesis. 


\subsection{Isolating the Seawater Record}

The objective was to develop an experimental procedure that could successfully isolate and analyse the pristine record of seawater chemistry and to determine the proportion of entrapped detrital minerals in FMN U1365B-M to assess implications of this data for nodule genesis and the chemical evolution of the PDWBC over the late Neogene.

Traditionally, FMNs and crusts have been discussed based on bulk chemical composition. This approach derives isotopic and elemental data that represent an average of both authigenic and detrital sediments (Wu, 2010). As such, bulk analyses do not represent a pristine record of seawater chemistry. The presence of detrital material serves to dilute element signals of the authigenic fraction (such as $\mathrm{Co}, \mathrm{Ce}, \mathrm{Cu}$ ), enrich concentrations of primarily land derived elements (such as $\mathrm{Hf}, \mathrm{Zr}, \mathrm{HREE}$ ) and combine the differing isotopic histories of the two nodule components (Gutjahr, et al., 2007; Crocket, et al., 2013). Consequently, bulk digestion methods are inappropriate for discussions on nodule genesis and paleoceanography (Koschinsky \& Hein, 2003). Alternatively, sequential leaching procedures have been developed to analyse element concentrations and associations within various authigenic and detrital mineral phases (Chester \& Hughes, 1967; Förstner \& Soffers, 1981; Koschinsky \& Halbach, 1995; Koschinsky \& Hein, 2003). Such, sequential leaching methods are prone to problems of incomplete selectivity for discrete mineral phases and variable reproducibility, which can limit successful interpretations of the results (e.g., Wolf, 1981; Tipping et al., 1985; Kersten \& Förstner, 1989; Koschinsky \& Hein, 2003). Furthermore, the utilisation of sequential leaching for general discussions on element associations, can be made successfully from analyses of authigenic minerals in their entirety (e.g., Graham, et al., 2003; van de Flierdt, et al., 2003; Gutjahr, et al., 2007; Chandnini, et al., 2011), eliminating the need to analyse individual authigenic phases. Selective and bulk chemical analyses generally require multiple acid digestions, involving large volumes of various acids and a wide variety of acid combinations. This increases the risk of contamination, precipitation losses and spectral interferences, especially if the reagent to sample ratio is large, which is almost always the case (Axelsson, et al., 2002). 
Additionally, these methods commonly require sample sizes of more than $100 \mathrm{mg}$. This limits the degree of micro-sampling and hence decreases the spatial resolution of samples and ultimately, the paleoceanographic record. Consequently, an analytical technique was required that could successfully isolate the seawater (authigenic) record and obtain accurate (element concentration) and precise (element distribution) data for as many elements as possible, using limited sample material and few (high grade) reagents (see Section 4.2; Appendix B). The wet chemistry technique developed for this thesis utilised the classic application of $\mathrm{HCl}$ acid in sample digestion and liberation of $\mathrm{HCl}$-soluble authigenic minerals from HCl-insoluble detrital minerals (Arrhenius, 1963; Mero, 1965; Graham, et al., 2003a; Koschinsky \& Hein, 2003). As authigenic and detrital mineral solubility in $\mathrm{HCl}$ is dependent upon many parameters (e.g. molarity \& volume of $\mathrm{HCl}$ ), experiments were conducted to determine acid leaching procedures and optimised with respect to the volume and concentration of the $\mathrm{HCl}$ leaching reagent, reaction time, temperature, and use of an ultra-sonic bath for sample agitation (Appendix B). The developed technique is illustrated for minor and trace element chemistry in Figure 4.3.

The two-stage digestion procedure incorporated room temperature and ultra-sonic bath-assisted digestion. Use of the latter has the advantage of shortening the digestion time and, aside from the initial transfer of $\mathrm{HCl}$ onto the samples, was straight forward. Each stage of the experimental procedure is also characterised by an easily identifiable colour change (Figure 4.3), signifying the completion of each chemical reaction. This method of sample preparation in combination with the well-established analytical techniques of ICPMS (major, minor and trace element concentrations) and MC-ICP-MS (Pb isotope compositions), provided quantitative information on 33 elements and ${ }^{208} \mathrm{~Pb} /{ }^{204} \mathrm{~Pb}$, ${ }^{207} \mathrm{~Pb} /{ }^{204} \mathrm{~Pb},{ }^{206} \mathrm{~Pb} /{ }^{204} \mathrm{~Pb}$ compositions. Furthermore, the range of elements and isotopes analysed could be further expanded, constrained only by the availability of single and multi-element reference solutions, modifications of sample preparation for various isotopic separation procedures and the capabilities of the available ICP-MS and MC-ICPMS. In addition to optimising sample digestion, experiments were also conducted to assess analyte recovery, volatilisation losses, formation of insoluble species and spectral interferences, all of which were concluded to be insignificant (Appendix B). 
The technique was developed using Certified Reference Material (CRM) NOD-P1. Data were assessed in terms of reproducibility and how close the average of these repeated measurements were to those previously reported. A well referenced bulk chemical method (Axelsson, et al., 2002) was used due to the lack of an equally well referenced selective digestion method, performed on the authigenic fraction. Geochemical compositions were generally accurate to within $\pm 10 \%$ of values reported, with all results falling well within the range of published data (cf. Axelsson, et al., 2002). However, Ce, Co, Cu, Zr, Gd and Lu concentrations were higher for the method developed in this thesis, when compared to concentrations derived by Inductively Coupled Plasma Double Focusing Sector Field Mass Spectrometry (ICP-SFMS) on bulk samples reported by Axelsson, et al. (2002). Discrepancies in the concentrations of these elements are most likely related to the different digestion procedures, highlighting the dilution effects of the detrital fraction on authigenic element concentration data. Conversely, V, Fe, Mn, Ni, Zn, Hf, Bi and Th were lower in concentration compared to values reported by Axelsson, et al. (2002). The latter may result from element contributions of the detrital fraction in the bulk data set of Axelsson, et al. (2002), increasing the concentration of these elements in comparison to the authigenic data set of U1365B-M (this thesis), or a consequence of applying different mass spectrometric methods (ICP-SFMS; Axelsson, et al., 2002). A recent study confirmed that significant discrepancies are in fact produced by using different analytical instrumentation (Kriete, 2011). However, the findings of Kriete (2011) concluded that the methods applied in this thesis (ICP-MS, collision/reaction cell, sample digestion, dilution and the use of internal standards), were the most efficient approach in analysing complex FMN samples.

On a final note, Flanagan \& Gottfried (1980) reported a certain degree of sample heterogeneity of NOD-P-1 reference material and variations in multi-element concentrations of other nodule CRMs are common (Axelsson, et al., 2002; Kriete, 2011). This highlights the complexity of the Fe-Mn oxyhydroxide matrix (and the intricately interwoven fine-grained aluminosilicates), which clearly pose a challenge in analytical chemistry. Despite these challenges, the developed separation technique, successfully isolates both the seawater (authigenic) and land (detrital) derived nodule fractions, providing a simple procedure for complete multi-elemental and $\mathrm{Pb}$ isotopic analysis of the isolated seawater fraction. 


\subsection{Revising \& Utilising the Chronological Framework}

The objective was to provide a revised chronological framework for the crust to core depth profile of U1365B-M, so that significant physiochemical changes in the nodule could be linked to our present knowledge on the coeval evolution of the ACC-PDWBC. A sub-goal was to assess how accurately cobalt chronometers could derive similar nodule age models.

In order to use the elemental and $\mathrm{Pb}$ isotopic data stored within the growth rings of FMN U1365B-M, as a record of paleoceanographic change, a geochronological framework was essential. Moreover, the growth rates of FMNs provide critical insights into the processes which govern their formation. The most precise growth rate estimates for FMNs on $>10^{6}$ year timescales have been obtained using beryllium isotope dating (e.g. Nagai, et al.,2000). Beyond 10-15 Ma, ${ }^{10} \mathrm{Be} /{ }^{9} \mathrm{Be}$ dating becomes inaccurate and few viable alternatives are presently available (see Section 3.1). Co concentration profiles referenced to ${ }^{10} \mathrm{Be} /{ }^{9} \mathrm{Be}$ growth rates are the most widely applied method for extending chronologies beyond beryllium dating, however, the accuracy of these age models has recently been brought into question. Large discrepancies were identified by Nielsen, et al. (2011), between their new age derived by osmium and thallium isotopes (c. $6.5 \mathrm{Ma}$ ), and that previously derived by Co-flux modelling (c. $15 \mathrm{Ma}$ ), for a well-studied crust from the Indian Ocean (109D-C). High resolution sampling and the unpublished ${ }^{10} \mathrm{Be} /{ }^{9} \mathrm{Be}$ dating of U1365B-M (Ditchburn \& Graham, 2006b), provided an opportunity to assess the accuracy of both beryllium and cobalt chronologies.

\section{Beryllium Cosmochronology}

Beryllium dating was initially conducted in 2003, on a suite of FMNs collected from the Campbell Nodule Field (Graham, et al., 2003b; Ditchburn \& Graham, 2003). U1365B-M was found to be the largest and oldest nodule recovered, presenting great potential for paleoceanographic study. As such, sampling (see Ditchburn \& Graham, 2006a) and dating (see Ditchburn \& Graham, 2006b) were repeated at a higher resolution in 2006. Nodule chronologies were developed using the ${ }^{10} \mathrm{Be}$ half-life of $1.51 \mathrm{Ma}$ (Bhat, et al., 1978), which was modified to $1.39 \mathrm{Ma}$ in 2010 (Chmeleff et al., 2010; Korschinek et al., 2010). Consequently, age models of the original study and the new chronology of U1365B-M 
required updating to this new value. Age models can be updated by either substituting the ${ }^{10} \mathrm{Be}$ half-life $\left({ }^{10} \mathrm{Be} t \frac{1}{2}=1.51 \mathrm{Ma}\right.$ for $\left.{ }^{10} \mathrm{Be} t \frac{1}{2}=1.39 \mathrm{Ma}\right)$ in the age equation or by updating AMS measurements (see Section 4.3). In this case, both approaches yield the same results. The latter approach was adopted and employed to update the Southwest Pacific Ocean 'initial' ${ }^{10} \mathrm{Be} /{ }^{9} \mathrm{Be}$ ratio and age models of the selected FMNs. For U1365B-M the revised chronology provided a late mid Miocene age (c. $12.7 \pm 0.2 \mathrm{Ma})$ for the initiation of nodule formation. Using the revised chronology, average growth rates were determined to be 5.9 $\mathrm{mm} / \mathrm{Ma}$. Growth rates have long been used as a preliminary tool in classifying the different modes of FMN formation: (i) hydrogenetic (0.5-15 mm/Ma); (ii) hydrothermal (> 20-100 $\mathrm{mm} / \mathrm{Ma}$ ), and; (iii) suboxic diagenesis (168-200 mm/Ma), and (iv) oxic diagenesis (12-50 $\mathrm{mm} / \mathrm{Ma}$ ) (Mero, 1965; Glasby, 2000). The slow accretion rates of U1365B-M indicate a hydrogenetic origin. This is in stark contrast to the accumulation of deep-sea sediments in the region which range from $8-95 \mathrm{~cm} / \mathrm{Ma}$ (Graham, et al., 2004). Thus, the presence of U1365B-M at the sediment-water interface, accreting material over the last $13 \mathrm{Ma}$, presents a paradox of how this mega nodule has remained unburied. This problem is apparent for all FMNs growing at the sediment-water interface over any substantial length of time, and has resulted in challenges to the validity of radioactive dating and the assumptions made when calculating ages and growth rates (see Glasby, 1977; Somayajulu, 2000).

As such, three models currently exist to explain the observed decay curve in radionuclide depth profiles: (i) a growth model, (ii) a diffusion model and a (iii) growthdiffusion model (see Somayajulu, 2000). The first is the most widely accepted model that has gained continued support from a growing body of literature on the use of beryllium dating and the concordance of these results with those of different isotopic systems e.g. ${ }^{230} \mathrm{Th}$ and ${ }^{231} \mathrm{~Pa}$ (Segl, et al., 1984; Banakar \& Borole, 1991; Frank, et al., 1999). A growth model was applied in explaining the ${ }^{10} \mathrm{Be} /{ }^{9} \mathrm{Be}$ profile of U1365B-M (see Graham, et al., 2003b). The accuracy of calculated ages and growth rates depends on this choice of model and its inherent assumptions. The growth model functions under four principle assumptions (see Somayajulu, 2000), that are summarised in Table 6.1. Tests were performed to assess the validity of each assumption (Figure $6.1 \mathrm{a}-\mathbf{d}$ ). Firstly, the assumption that U1365B-M has remained a closed system and thus has experienced no 
post depositional isotopic exchange, is investigated by looking at the relationship between the concentration of ${ }^{9} \mathrm{Be}$ and the amount of detrital material incorporated into each sample (Figure 6.1 a).

\begin{tabular}{|c|c|c|c|c|}
\hline Method & Model & & Assumption & Test for validity \\
\hline \multirow{4}{*}{ 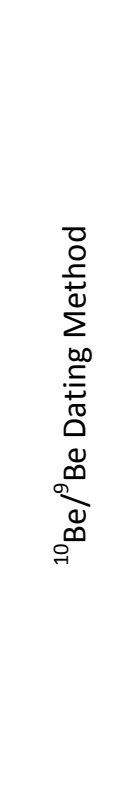 } & \multirow{4}{*}{$\begin{array}{l}\overline{0} \\
\frac{0}{0} \\
\sum^{0} \\
\overline{1} \\
3 \\
0 \\
0 \\
0\end{array}$} & 1 & $\begin{array}{l}\text { No post-depositional isotopic } \\
\text { exchange has occurred as FMNs } \\
\text { behave as closed systems }\end{array}$ & $\begin{array}{l}\text { No positive correlation should occur between } \\
\text { continentally derived }{ }^{9} \mathrm{Be}(\mathrm{ppm}) \text { and detrital } \\
\text { material (\%) }\end{array}$ \\
\hline & & 2 & $\begin{array}{l}{ }^{10} \mathrm{Be} \text { and }{ }^{9} \mathrm{Be} \text { isotopes are scavenged } \\
\text { equally into FMNs }\end{array}$ & $\begin{array}{l}\text { Decay corrected }{ }^{10} \mathrm{Be} p p m\left({ }^{10} \mathrm{Be}_{\mathrm{DC}}\right) \text { and }{ }^{9} \mathrm{Be} \\
\text { ppm should exhibit a near perfect positive } \\
\text { correlation }\end{array}$ \\
\hline & & 3 & $\begin{array}{l}\text { The initial }{ }^{10} \mathrm{Be} /{ }^{9} \mathrm{Be} \text { ratio has } \\
\text { remained constant and is equal to } \\
\text { the present day seawater value }\end{array}$ & $\begin{array}{l}{ }^{10} \mathrm{Be} /{ }^{9} \mathrm{Be} \text { ratios restored to their original values } \\
\text { should be within } \pm 1.5 \times 10^{-7} \text { of the } \\
{ }^{10} \mathrm{Be} /{ }^{P} \mathrm{Be}_{\text {SWPO }}\end{array}$ \\
\hline & & 4 & $\begin{array}{l}\text { FMN growth rates are slow enough } \\
\text { so that }{ }^{10} \mathrm{Be} \text { is easily measured }\end{array}$ & $\begin{array}{l}\text { The decay curve of }{ }^{10} \mathrm{Be} \text { atoms should clearly } \\
\text { show a reduction to half its original value } \\
\text { within } \sim 1.4 \mathrm{Ma} \text { for at least four half-lives }\end{array}$ \\
\hline
\end{tabular}

Table 6.1 | Assumptions of the growth model for beryllium dating details on the assumptions, and tests for their validity, were derived from Somayajulu (2000) and Graham, et al. (2003b).

Trapped within the mineral lattices of detrital grains are variable concentrations of ${ }^{9} \mathrm{Be}$ (Graham, et al., 2004; Lebatard, et al., 2010). Thus, there is the potential that the detrital (non-dissolved) fraction of ${ }^{9} \mathrm{Be}$ may be released from entrapped aluminosilicates causing an apparent increase in authigenic (dissolved) ${ }^{9} \mathrm{Be}$. This could decrease the ${ }^{10} \mathrm{Be} /{ }^{9} \mathrm{Be}$ ratio and affect the 'true' age of samples. If post-depositional isotopic exchange had taken place then a significant positive correlation (Pearson's $\mathrm{r}^{2}=>0.7$ ) would be evident between ${ }^{9} \mathrm{~B}$ $(\mathrm{ppm})$ and the percentage of detrital material. Figure 6.1 (a) illustrates that no significant correlation $\left(r^{2}=0.3\right)$ exists between the two variables and thus it is assumed that no significant isotopic exchange has taken place. The two parameters actually display a negative correlation for three sections of the nodule from approximately: (i) 13 to $9 \mathrm{Ma}$ $\left(\mathrm{r}^{2}=-0.7\right)$; (ii) 7 to $3 \mathrm{Ma}\left(\mathrm{r}^{2}=-0.6\right)$ and; (iii) 1 to $0 \mathrm{Ma}$ (Figure $\left.6.1(\mathrm{a})\right)$. 

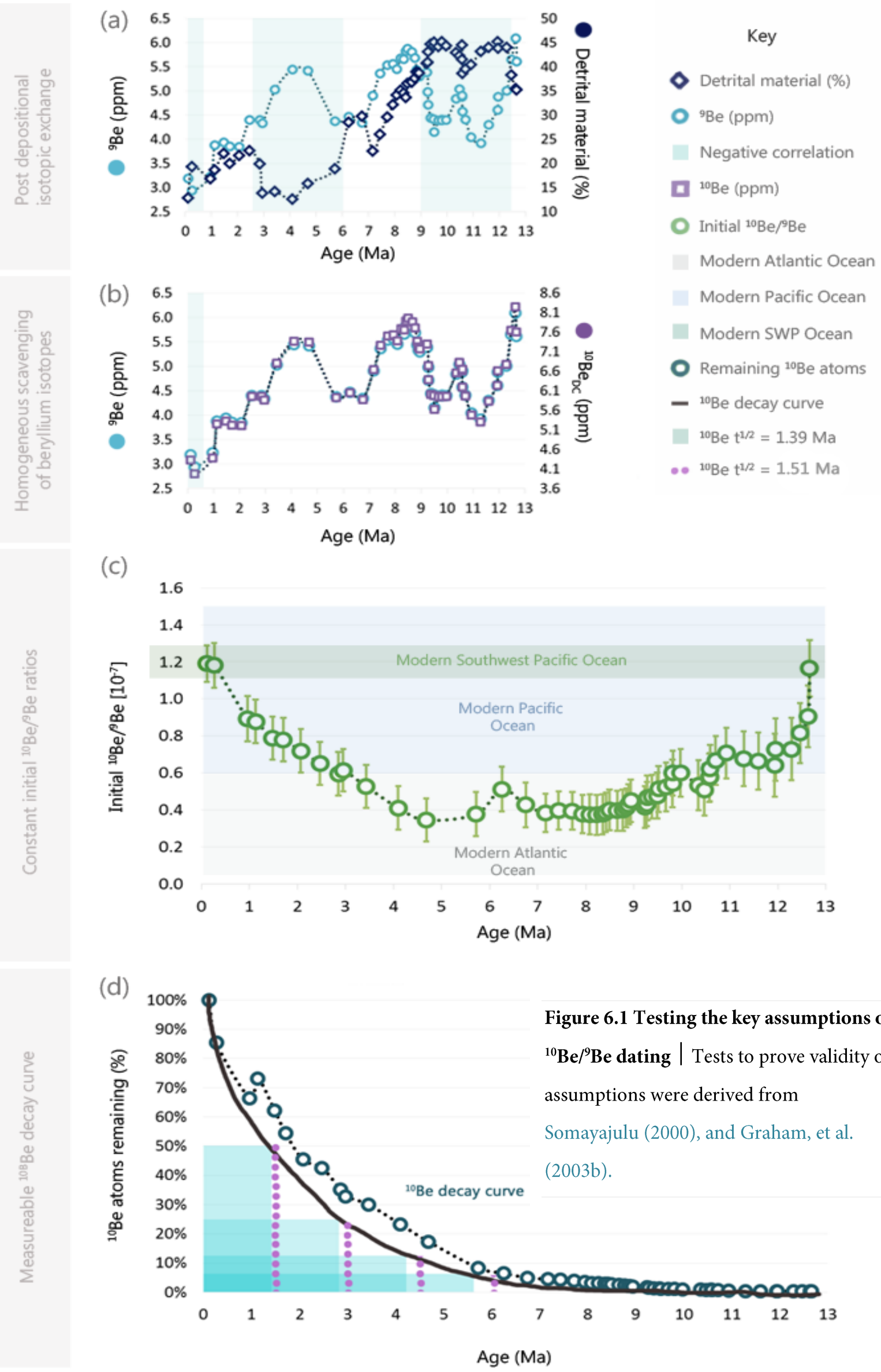
The second assumption is that ${ }^{10} \mathrm{Be}$ and ${ }^{9} \mathrm{Be}$ are equally scavenged from the water column, so that the isotopes of beryllium are incorporated into FMNs at a constant isotopic ratio. Figure 6.1 (b) is a plot of ${ }^{9} \mathrm{Be}$ and decay corrected ${ }^{10} \mathrm{Be}\left({ }^{10} \mathrm{Be} \mathrm{DC}\right)$ concentrations with age. Except for the small excursion exhibited by the last three sample points, beryllium isotopes appear to be incorporated into U1365B-M at a near constant 1:1 isotopic ratio, similar to the updated initial SWPO ${ }^{10} \mathrm{Be} /{ }^{9} \mathrm{Be}$ ratio of $1.22 \times 10^{-7}$. It can therefore be assumed that the ${ }^{10} \mathrm{Be} /{ }^{9} \mathrm{Be}$ ratio recorded in the authigenic fraction of U1365B$\mathrm{M}$ is representative of the soluble Be present in the deep ocean at the time of deposition. The third assumption is that initial ${ }^{10} \mathrm{Be} /{ }^{9} \mathrm{Be}$ ratios $\left(\mathrm{N}^{0}=1.22 \pm 0.03\left[10^{-7}\right]\right)$ have remained constant from initiation to cessation of nodule growth (Somayajulu, 2000; Graham, et al., 2003). As a first order assessment of this assumption, the correspondence observed in Figure 6.1 (b), suggests that it is a sufficiently good approximation for a valid chronology and rates of growth to be obtained by this method. A more detailed assessment involves back-calculating the initial ${ }^{10} \mathrm{Be} /{ }^{9} \mathrm{Be}$ ratios at the time of FMN growth (Figure $\left.6.1(\mathrm{c})\right)($ see Willenbring \& von Blanckenburg, 2010). Back-calculated paleo-SWPO ${ }^{10} \mathrm{Be} /{ }^{9} \mathrm{Be}$ ratios are on average ${ }^{10} \mathrm{Be} /{ }^{9} \mathrm{Be}=0.6 \times 10^{-7} \pm 0.02$, which is lower than the SWPO paleo-ocean value of ${ }^{10} \mathrm{Be} /{ }^{9} \mathrm{Be}=1.22 \times 10^{-7} \pm 0.02$. Despite these differences values are consistent with ranges previously reported from FMNs, crusts and sediment cores from the Pacific Ocean (e.g., Ling, et al., 1997; von Blanckenburg \& Igel, 1999; Willenbring \& von Blanckenburg, 2010). According to Ling et al. (1997) and Willenbring \& von Blanckenburg (2010), if the difference between the lowest and highest paleo-SWPO ${ }^{10} \mathrm{Be} /{ }^{9} \mathrm{Be}$ ratios are within $1.5 \times 10^{-7}$ then they have remained constant. This indicates that the ${ }^{10} \mathrm{Be} /{ }^{9} \mathrm{Be}$ ratio has remained relatively constant throughout the past $13 \mathrm{Ma}$.

The fourth assumption is that nodule growth rates are slow with respect to beryllium decay, so that the decay of ${ }^{10} \mathrm{Be}$ is easily measurable. Figure 6.1 (d) illustrates the percentage of ${ }^{10} \mathrm{Be}$ remaining after a series of half-lives $\left({ }^{10} \mathrm{Be} \mathrm{t}^{1 / 2}=1.39\right.$ in blue boxes and ${ }^{10} \mathrm{Be}$ $\mathrm{t}^{1 / 2}=1.51$ purple lines) and indicates that this assumption is also valid. Thus, the assumptions of the growth model hold true for the application of beryllium dating and provide a robust late mid Miocene through recent (12.7 - $0 \mathrm{Ma})$ chronological framework for U1365B-M and additionally, revised age models for FMNs selected from the Campbell Nodule Field (Appendix C). Furthermore, through application of a growth model, the for 
disjointed ${ }^{10} \mathrm{Be} /{ }^{9} \mathrm{Be}$ profile correlates with a change in texture (see Figure 5.3, 5.4 and Table 5.3) these 'time markers' are inferred to represent a significant change in the way U1365B$\mathrm{M}$ has accreted material, reflecting an equally significant change in the circulation, flow and(or) chemical properties of the ACC-PDWBC. Significant changes in the growth rate history of U1365B-M were reported at $13,10,7.4$ to 6.3 , c. 6, 3, 1, and $0.3 \mathrm{Ma}$, bearing strong correlations with the timings of key climatic, tectonic and oceanic events that are proposed to have caused significant changes in the structure and flow of the global ocean (Table 6.3), discussed further in Section 6.4.

\section{Cobalt Chronometry}

Established ${ }^{10} \mathrm{Be}$ age-model and growth rates were used to assess the accuracy of three different Co chronometers and how successfully Co concentration profiles, referenced to beryllium derived growth rates, provide an accurate chronology for U1365B-M (Appendix C). The assumptions of cobalt chronometry and tests to validate are listed in Table 6.2.

\section{Method Model}

1 The flux rate of Co to the oceans and FMNs is constant with time at $~ 3.0 \mu \mathrm{g} \mathrm{cm}{ }^{2} \mathrm{ky}$

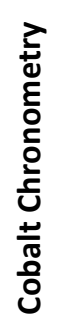

2 Co is incorporated into vernadite at a constant rate

3 Co concentrations vary only as a function of growth rate, with slow rates leading to higher concentrations and vice versa.

\section{Test for validity}

Calculations of Co flux rates should yield constant $\left(\mu \mathrm{g} / \mathrm{cm}^{2} \mathrm{kyr}\right)$ values $( \pm 10 \%)$

Co contents should positively correlate (> $r=7$ ) with $\mathrm{Mn}$ and the authigenic growth rate of FMNs

Co contents should display a near perfect negative correlation $(r=-1)$ with growth rates

Table 6.2 Assumptions of cobalt chronometry key assumptions in applying Co-chronometers. Tests for their validity were derived from Puteanus \& Halbach (1988) and Frank, et al. (1999).

To test the first assumption, the flux of Co into U1365B-M was calculated using the flux rate equation of Halbach, et al. (1984). The average Co-flux rate, derived using the total growth rate, is $2.5 \mu \mathrm{g} / \mathrm{cm}^{2} \mathrm{ky}$, which is roughly midway between rates calculated for Co-rich 
seamount crusts of the Central Pacific $\left(3.0 \mu \mathrm{g} \mathrm{cm}{ }^{2} \mathrm{ky}\right.$; Halbach et al., 1984) and those of Co-poor crusts of the Atlantic, Indian and Pacific Oceans $\left(1.9 \mu \mathrm{g} \mathrm{cm}{ }^{2} \mathrm{ky}\right.$; Frank et al., 1999), consistent with the chemical profile of Co displaying both Co-rich and Co-poor concentrations in U1365B-M (Figure 5.10 \& 6.2). Evident from Figure 6.2 is that the Coflux was not constant over time, ranging from $3.9 \mu \mathrm{g} / \mathrm{cm}^{2} \mathrm{ky}$ at $6.8 \mathrm{Ma}$ (end of Zone 3ii) to $1.5 \mu \mathrm{g} / \mathrm{cm}^{2} \mathrm{ky}$ at c. $1 \mathrm{Ma}$ (end of Zone 5iv), displaying a significant peak at $6.3-6.7 \mathrm{Ma}$ in association with a rapid reduction in growth rate, supporting the third assumption. Halbach \& Puteanus (1984) indicate that Co-flux rates are constant over one order of magnitude of growth rate and thus these results would support a constant Co flux. However, for nodules exhibiting large changes in growth rate (e.g. Segl, et al., 1989; Mangini, et al., 1990) application of any general algorithms (such as the three assessed here) will not account for the effect a change in growth rate has on Co concentration and thus derive erroneous results. The second and third assumptions illustrated in Figure 6.2 show that $\mathrm{Co}$ and $\mathrm{Mn}$ concentrations share a significant positive correlation (Pearson's $\mathrm{r}^{2}=$ 0.7), indicating that $\mathrm{Co}$ is associated with $\mathrm{Mn}$ and may therefore be adsorbed onto vernadite $\left(\delta \mathrm{MnO}_{2}\right)$. However, relationships of Co with the authigenic growth rate are scattered (Pearson's $\mathrm{r}^{2}=0.03$ ) and display stronger negative correlations with the total and detrital growth rates (Pearson's $r^{2}=0.7$ ). Thus, it appears that the presence of detrital material plays a role in altering authigenic Co concentrations. This association may be related to the authigenic growth rate of FMNs which are reduced when detrital fluxes are high (Banakar, et al., 2000). High detrital entrapment within U1365B-M, results in chaotic mottled microstructures which grade from mottled to cuspate to columnar with decreasing detrital content and increasing authigenic growth rates and Mn concentration.

To conclude, the assumptions of beryllium cosmochronometry have proved valid, supporting the view that this method is reliable in its ability to produce accurate $( \pm 15 \%$ of values determined in 2003; Graham, et al., 2003b), and precise (within $\pm 0.1 \mathrm{Ma}$ for each sample; Ditchburn \& Graham, 2006) age model data, and in providing valuable and detailed information about the growth history of FMNs from the New Zealand sector of the Southern Ocean. However, the application of cobalt chronometry does not seem a reliable alternative for providing age estimates for FMNs, supported the findings of Nielsen, et al., (2011). 


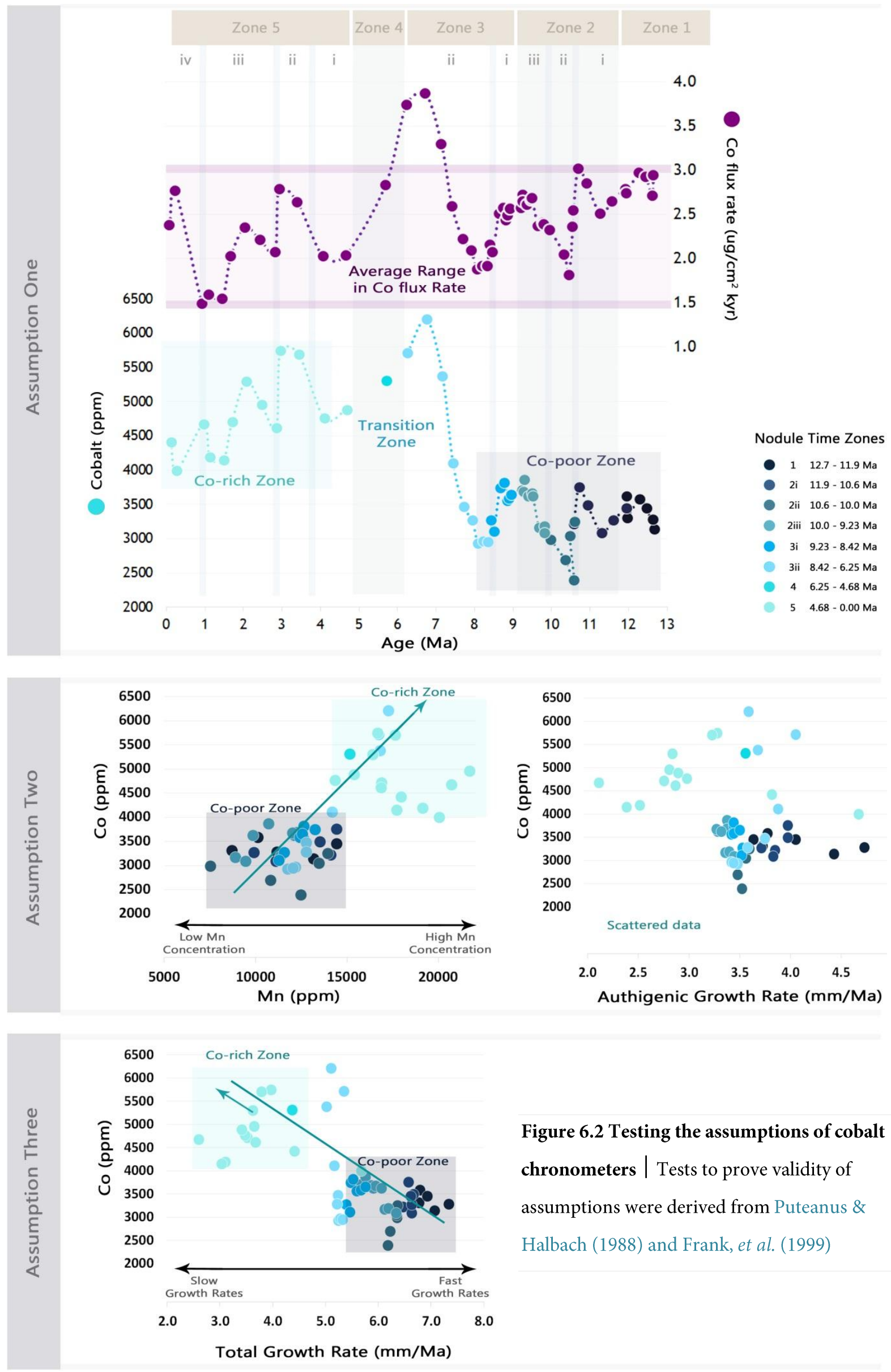




\subsection{Unravelling the Physical Archives}

The objective was to use the revised chronology of FMN U1365B-M to identify and assign ages to, significant changes in macroscopic texture, microscopic growth structures and proportions of detrital and authigenic minerals.

The majority of studies utilising FMNs as archives of past oceanographic change, do so through the study of changing isotopic compositions, namely $\mathrm{Hf}, \mathrm{Nd}$ and $\mathrm{Pb}$ (e.g. Abouchami, et al., 1999; van de Flierdt, et al., 2004, Frank, et al., 2008) and more recently Mo, Tl, and Fe isotopes (see Koschinsky \& Hein, 2013). In comparison, few studies utilise the physical archives of FMNs, despite their successful application in identifying significant changes in the structure, flow, and chemistry of past oceans (e.g. Banakar, et al., 1993, Xu, et al., 2006). Several researchers have shown from stratigraphic analysis of macroscopic nodule textures, that there are certain periods within the late Neogene when the pattern of nodule accretion changed coevally with global changes in deep water circulation (Halbach \& Puteanus, 1984; Segl, et al., 1984, 1989; Glasby, 1986; Mangini, et al., 1990; Xu, et al., 2006; Zhang, et al., 2013), summarised in Table 6.3. Segl, et al. (1989) referred to these visible changes in texture as 'time markers' and found them to occur in nodules throughout the world oceans.

In addition to macroscopic changes, the importance of microstructures and their application in interpreting the paleoceanographic evolution of FMNs have been recognised and categorised since the publication of Sorem \& Foster (1972). However, there are contrasting theories as to their paleoceanographic significance and their application has been relatively rare (see Segl, et al., 1989; Mangini, et al., 1990; Hein, et al., 1992; Banakar, et al., 1993; Wang, et al., 2011; Zhang, et al., 2013). Additionally, proportions of authigenic and detrital minerals have been used to provide a first order assessment of the building blocks available for nodule formation. High authigenic components indicates an increase in Fe-Mn precipitation, potentially associated with increased inputs of Fe and(or) Mn, increased ocean oxygen, and increased current speeds, maintaining low sedimentation rates with the reverse assumed for low percentages. The proportion of detrital material has been utilised as a proxy of continental weathering history and indication of abyssal current velocity (e.g. Mangini, et al., 1990; Banakar, et al., 2003; Wright, et al., 2005). Therefore, 


\begin{tabular}{|c|c|c|}
\hline $\begin{array}{l}\text { Age } \\
\text { (Ma) }\end{array}$ & Physical Archive 'Time Markers' & Oceanographic Event \\
\hline $1.7-1$ & $\begin{array}{l}\text { Definable mm-scale banding of the } \\
\text { outermost layers ( } 3-6 \mathrm{~mm} \text { ) of FMNs }\end{array}$ & $\begin{array}{l}\text { Beginning of mid-Pleistocene oscillations of global } \\
\text { ice volume }\end{array}$ \\
\hline $3.5-3$ & $\begin{array}{l}\text { Bands of higher detritus have been noted } \\
\text { at } 3 \mathrm{Ma} \text {, with decreased authigenics [weak } \\
\text { banding of FMNs from c. } 6 \mathrm{Ma} \text { now } \\
\text { developed into cyclical banding] } \\
\text { microstructures grade from columnar to } \\
\text { laminated }\end{array}$ & $\begin{array}{l}\text { Initiation of Northern Hemisphere glaciation, } \\
\text { world-wide sedimentary hiatus } 3.7-3.1 \mathrm{Ma} \text { (Keller } \\
\text { \& Barron, 1983), change in ocean circulation to } \\
\text { shallow glacial seas, present day circulation achieved } \\
\text { c. } 3 \mathrm{Ma}\end{array}$ \\
\hline $5-3$ & $\begin{array}{l}\text { Increased authigenic component, pulse of } \\
\text { faster growth rates, large cuspate } \\
\text { microstructures [inner and central banded } \\
\text { zone] }\end{array}$ & $\begin{array}{l}\text { Warm mid Pliocene temperatures, shoaling and } \\
\text { closure of the Panama Isthmus, }\end{array}$ \\
\hline 6.3 & $\begin{array}{l}\text { Major change in structure from more } \\
\text { uniform textures of high detrital content } \\
\text { to a banded structure, coincide with } \\
\text { significant decrease in growth rates, and } \\
\text { increase in } \mathrm{Mn}, \mathrm{Ni}, \mathrm{Cu} \text { [marks the horizon } \\
\text { between compact and crumbly zones of } \\
\text { U1365B-M] }\end{array}$ & $\begin{array}{l}\text { Shift in }{ }^{813} \mathrm{C} \text { in benthic foraminifera, beginning of } \\
\text { modern bottom water circulation, drop in the CCD } \\
\text { in the Central Pacific, potentially marking the onset } \\
\text { of modern NADW production }\end{array}$ \\
\hline $8-6$ & $\begin{array}{l}\text { Decreasing silicate content [spans the } \\
\text { outer compact zone] }\end{array}$ & $\begin{array}{l}\text { An overall cooling of the oceans, increase in abyssal } \\
\text { current strength, increase in the fertility of the } \\
\text { oceans, lowering of sea level, drying up of the } \\
\text { Mediterranean, shoaling of the isthmus of Panama, } \\
\text { significantly increased input of cold oxic SCW to } \\
\text { Study area and deepening of CCD (Haywood, et al., } \\
2004 \text { ) }\end{array}$ \\
\hline 10 & $\begin{array}{l}\text { Minimum in } \mathrm{Mn} \text {, [time marker between } \\
\text { central and outer iris - significant change } \\
\text { in } \mathrm{Pb} \text { isotopic compositions] }\end{array}$ & $\begin{array}{l}\text { A maximum extent reached in Antarctic ice sheet } \\
\text { development, closure of the Indonesian Gateway, } \\
\text { spin up of the ACC due to enhanced atmospheric } \\
\text { circulation and colder climates. From } 8 \text { to } 10 \mathrm{Ma} \text {, } \\
\text { stronger PCW export to the Southern Ocean, } \\
\text { reported in FMNs and crusts (van de Flierdt, et al., } \\
\text { 2004) }\end{array}$ \\
\hline $13-12$ & $\begin{array}{l}\text { Uniform textures, high silicates, chaotic } \\
\text { mottled microstructures, indicate fast } \\
\text { abyssal currents and seafloor scouring }\end{array}$ & $\begin{array}{l}\text { Build-up of the east Antarctic Ice Sheet, rapid global } \\
\text { cooling, onset of AABW production and ventilation } \\
\text { of the deep ocean, fast abyssal currents, raising of the } \\
\text { CCD in the Pacific }\end{array}$ \\
\hline
\end{tabular}


Table 6.3 | Global time markers recorded in FMNs of the global ocean \& U1365B-M. See also Table 1.1 for additional climatic and tectonic events coeval with FMN time markers. Information for FMN time markers are compiled from; Halbach \& Puteanus, 1984; Segl, et al., 1984, 1989; Glasby, 1986; Mangini, et al., 1990; Banakar, et al., 1993; Xu, et al., 2006 and oceanographic events summarised from above references in addition to Kennett \& von der Borch (1986) and Cronin (2010).

identifying changes in texture and the nature of nodule layers can provide a powerful tool for distinguishing significant changes in the chemical oceanography of the PDWBC. Here, macro- and microstructures and detrital proportions are used as a proxy for significant changes in the paleoenvironment of deposition and paleo-current strength. The internal structure of U1365B-M (and Campbell Nodules) was studied via cross-sectional cuts through the nodule and BSE images, which had not previously been discussed in any detail (see Graham, et al., 2003a). The revised age model of U1365B-M was superimposed along the depth profile of BSE images to facilitate discussion on the paleoceanographic implications of the various microstructures. Although, this was not a perfect match, as the BSE imaging and age model were developed along two different nodule radii however, they do provide a good indication of microstructures that have formed over the nodules growth history.

\section{Paleo-environment of Deposition}

Significant changes in the underlying authigenic chemistry of U1365B-M and thus, by proxy, the PDWBC, are expected to be reflected in the emergent physical properties of the deposited FMN layers (Banerjee, et al., 1999; Pulyaeva \& Hein, 2010). Stratigraphic analysis and of U1365B-M, revealed five distinct concentric zones: (1) core zone [12.7 to $11.9 \mathrm{Ma}$ ]; (2) iris zone [11.6 to $8.9 \mathrm{Ma}$ ]; (3) compact zone [8.9 to $5.7 \mathrm{Ma}$ ] terminating in a visible erosional hiatus; (4) crumbly zone [5.7 to $4.7 \mathrm{Ma}$, and; (5) banded zone [4.7 to present] (also referred to as Zone 1-5; Figure $5.3 \& 5.4$ ), which were named after their dominant textural appearance and interpreted as reflecting significant changes in PDWBC chemistry. The discrimination based on the five-zone morphology is confirmed by corresponding changes in microstructures (Figure 5.5) and chemical composition (Section 5.4), the timing and nature of each zone are also consistent with those previously reported for a range of FMNs and FMCs from: the Southwest Pacific (von Stackelberg, et al., 1984; Segl, et al., 1989; Mangini, et al., 1991); the Greater Pacific (e.g., Segl, et al., 1989; 
DeCarlo \& Fraley, 1992; McMurtry, et al., 1994; van de Flierdt, et al., 2004; Xu, et al., 2006; Chen, et al., 2013); the Indian Ocean (e.g., Banakar, et al., 1993, 1997; Banerjee, et al., 1999; Banakar \& Hein, 2000; Rajani, et al., 2005), and; the Atlantic Ocean (e.g., Segl, et al., 1989; Koschinsky, et al., 1996; Frank, et al., 1999, 2002, 2006; von Blanckenburg \& Nägler, 2001), reflecting underlying changes in the chemical composition of these archives in response to the evolving chemical fingerprint of these various water masses over the late Neogene. Each of the accretionary zones indicate periods of relatively continuous Fe-Mn precipitation over the 12.7 Myr growth history of U1365B-M, and are separated by hiatuses of c. 40 kyrs duration, when Fe-Mn precipitation was prevented by unfavourable conditions, related to the redox state of the ocean, paleoproductivity or a restricted supply of Fe and(or) Mn (Banakar, et al., 1997; Glasby, 2000). Equally, the surface of U1365B-M may have been buried by sediment and later exhumed. Additionally, these zone boundaries may have resulted from the erosion of previously deposited layers (as indicated by the erosional hiatus between zones 3 and 4) (Glasby, et al., 1985; Segl., et al., 1989). These hiatuses or 'time markers', are also associated with changes in nodule growth rates and thus the mechanism of nodule accretion (Figure 5.1; Table 5.2), and represent comparatively rapid changes to the depositional environment of the PDWBC. These time markers of change were used to further divide the five zone morphology into a series of subzones, and closely correlate with those compiled in Table 6.3 and are illustrated in Figure 6.3 (note the erosional hiatus cutting through layers of the Compact Zone that must have occurred prior to the deposition of the crumbly zone c. $6.3 \mathrm{Ma}$ ).

Correlation of the time-markers, reported for U1365B-M, with those recorded for FMNs and crusts from each of the major ocean basins (references above), indicate that U1365B-M has preserved the chemical response of the PDWBC to long-term global oceanographic events as noted previously (e.g., Segl, et al., 1989; Banerjee, et al., 1999). Additionally the correlation of these abyssal archives, over the millennial growth history FMNs and crusts, indicates that there are strong telecommunications between these deposits, suggesting that climatic and tectonic processes that alter deep ocean chemistry, are effectively translated through the medium of the deep-ocean to various FMN (and deep oceanic crust) growth sites. Thus, the classic principle of marker beds 'stratigraphic units of the same age and of such distinctive composition and appearance that despite their 


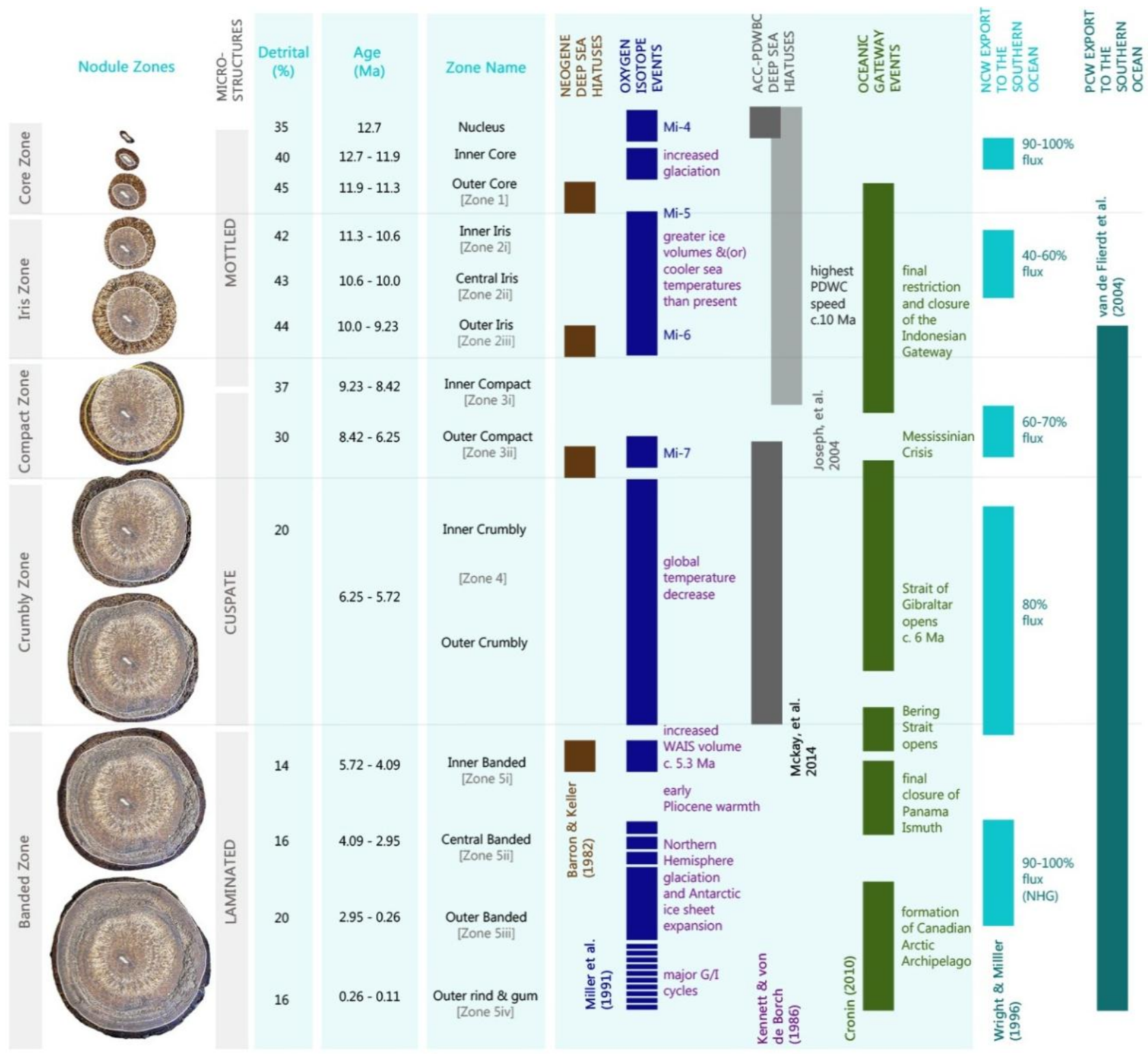

Figure 6.3 Physical archives of FMN U1365B-M and key climatic-oceanic-tectonic events over the late Neogene. See also Table 1.1 for additional climatic and tectonic events coeval with FMN time markers. Information for FMN time markers are compiled from the references cited, which are colour coded in accordance with the parameter being illustrated.

presence in separate geographic locations there is no doubt about their being of equivalent age and of common origin' (Boggs, 2000), may be applicable to FMNs and crusts, as suggested by previous authors (e.g., Banerjee, et al., 1999; Segl, et al., 1989; Xu, et al., 2006), and deserve further investigation as these conditions suggest that the deep sea depositional environment has remained relatively uniform over a wide area for millions of years and that these long periods of relative 'quiescence' are separated by rapid changes to the depositional environment. 


\section{Paleo-current Strength}

The strength or speed of the PDWBC over the late Neogene is expected to have changed in response to G/I cycles, with cooler climatic periods enhancing polar-equator temperature gradients, promoting faster wind speeds, and thus resulting in a 'spin-up' of the ACCPDWBC system, in addition to encouraging AABW formation (Zachos, et al., 2001; Lear, et al., 2003; Cronin, et al., 2010). Periods of intensified bottom current speeds are commonly identified in the sedimentary record as deep sea hiatuses in association with these colder climatic periods (Barron \& Keller, 1982; 1989; Joseph, et al., 2004; Hayward, et al., 2004; McKay, et al., in press). Figure 6.4 illustrates the percentage of detrital minerals (remaining as the insoluble residue after acid digestion of U1365B-M samples) in association with global (Barron \& Keller, 1987), conjoined ACC-PDWBC (McKay, et al., in press) and solely PDWBC flow (Joseph, et al., 2004), in addition to potential continental sources of the detrital fraction. Incorporation of large quantities of detrital grains (20 $45 \%$ ) occur at: 12 to $11 \mathrm{Ma}, 10.5$ to $9.5 \mathrm{Ma}, 7$ to $6 \mathrm{Ma}$ (correlating with a reoccurrence of mottled structures) and from 3 to $1 \mathrm{Ma}$. With the lowest proportions (c. 10\%) reported at 4 $\mathrm{Ma}$ (correlating with cuspate microstructures), and at $0.1 \mathrm{Ma}$ (correlating with laminated structures).

The overall decline in detrital incorporation of U1365B-M does not correlate with increased uplift rates of the Southern Alps from c. 10 and $5 \mathrm{Ma}$, or intra-plate volcanism of the Campbell Plateau, despite Chang, et al. (2003) reporting the occurrence of volcanic nuclei for those nodules studied in close proximity to Antipodes Island. However, pulses of high detrital incorporation do coincide with the timings of enhanced ACC-PDWBC velocities reported by McKay, et al. (in press) and phases of strong PDWBC flow reported by Joseph, et al. (2004) until c. 6 Ma. The increase in detrital incorporation (but still appreciable low c. $10-20 \%$ ) from c. $3 \mathrm{Ma}$, could be a consequence of the global and oceanic change associated with Northern Hemisphere Glaciation (Glasby, 1987; Mangini, et al., 1990; Frank, et al., 2002) and(or) advance of the Ross Ice Shelf and polynya-style deep water mixing in the Ross Sea between 3.3 and 2.5 Ma (McKay, et al., 2012), or could equally reflect opening of Macquarie Ridge Seaway to current flows of the ACC-PDWBC and inception of the Solander Trough (Shuur, et al., 1998; Carter \& McCave, 1997). 
In light of the above, the high percentage of detrital minerals present in the core zone (35-35\%) between c. 12 - $10 \mathrm{Ma}$ and the pulse from 20 - 30\% between 7 and $6 \mathrm{Ma}$, could be associated with sediment scouring of the seafloor, due to increased bottom current velocities. Mangini, et al. (1990) noted similar occurrences of detrital grains between c. 13 to $6 \mathrm{Ma}$, in a proximal FMN 143GB. They interpreted increased detrital inclusions as reflecting the onset of various stages of AABW production and 'spin-up' of the ACCPDWBC in association with Antarctic ice sheet development. Furthermore, the gradation from; mottled to cuspate to columnar to laminated microstructures, seen in U1365B-M (Figure 6.4), was also noted by Mangini, et al. (1990) and, in the order listed, has been associated with decreasing bottom current speeds (Sorem \& Fewkes, 1972, 1977; Banerjee, et al., 1999; Pulyaeva \& Hein, 2010; see also Figure 3.6). Moreover, seafloor photographs of the Campbell Nodule Field, taken during sample collection in 2003, revealed significant scour marks in the seafloor (see Chang, et al., 2003). It is therefore probable that the detrital component of U1365B-M indicates phases of increased PDWBC speeds over the late Neogene.

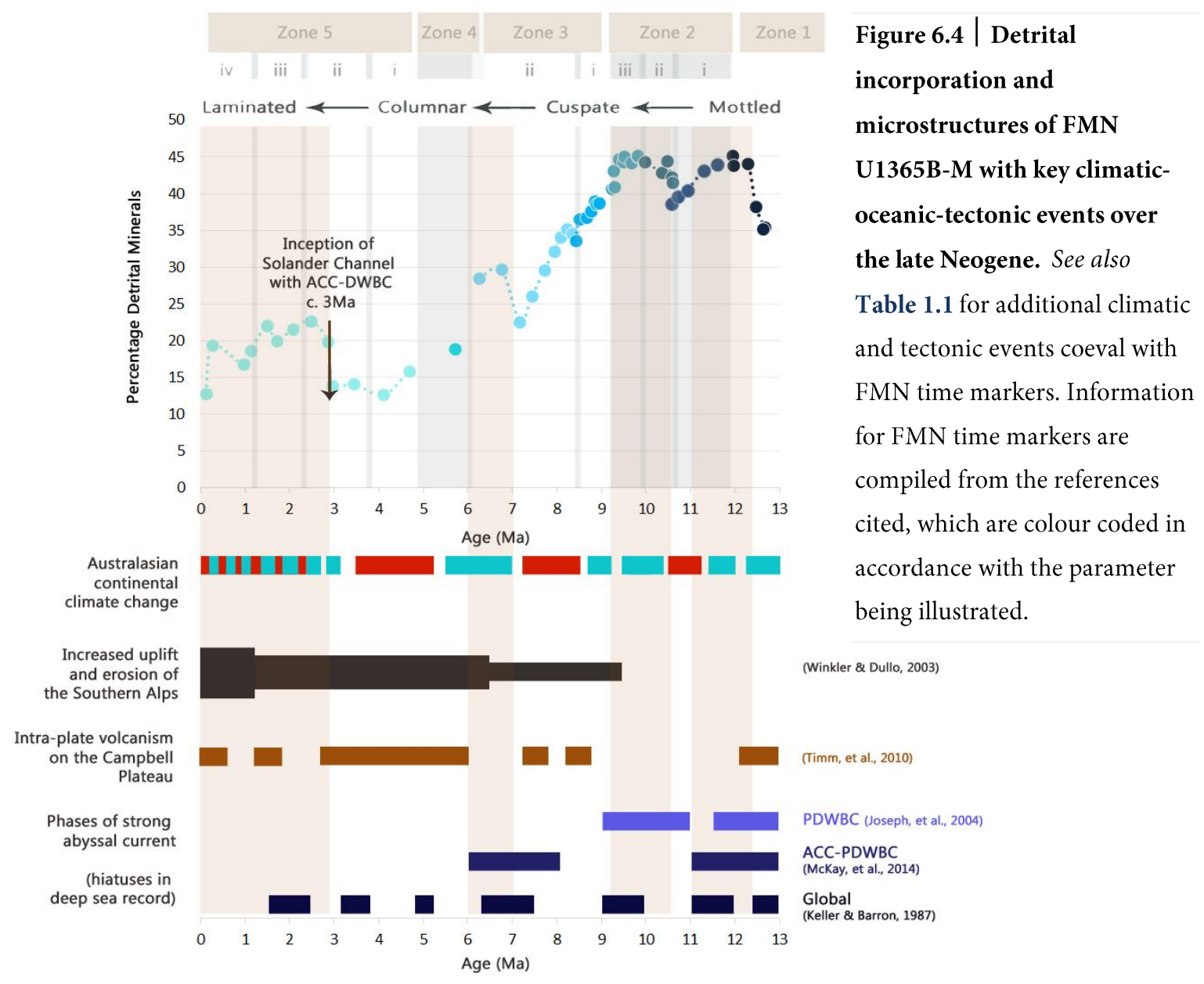




\subsection{Unravelling the Chemical Archives}

Objective four was to use the revised chronology of FMN U1365B-M to identify and assign ages to, significant changes in the elemental and lead isotopic compositions of the authigenic seawater record, and to identify inter-archival and inter-elemental correlations.

Since their discovery, the chemistry of FMNs has been widely documented, principally as bulk chemical data, and less so as the products of sequential leaching techniques (e.g., Chandnini, et al., 2012). Despite wide documentation of chemical content and element associations, discussion on the application of FMN geochemistry as proxies to elicit information on past environments is rare. The majority of information utilised here on element proxies is derived from a variety of sedimentary archives (e.g., Tribovillard, et al., 2006; Sheldon \& Tabor, 2009; Soua, 2011). However, attempts were made to ensure that these proxies were applicable to Fe-Mn deposits. Due to the large data set on element chemistry, the initial task was to identify the general trends in element concentration and composition across the various zones of U1365B-M, followed by identifying element groups or element associations based on cluster and correlation analyses. Following the identification of element groups representative elements were selected and element distributions were investigated further. Here, elements are investigated based on their previous application as proxies of past changes in the depositional environment and are discussed in terms of: (1) paleoprecipitation and element associations; (2) paleo-source; (3) paleoproductivity; (4) paleo-redox, and; (5) paleo-circulation. In Section 6.6 these proxies are then discussed in more detail in regards to their paleoceanographic implications for determining how the chemical fingerprint of the PDWBC, has evolved in response to well documented climatic and tectonic events of the Late Neogene.

Connecting the physical archives of FMNs with the underlying geochemistry, the physical properties are important for the sequestration of elements from ocean water, as this process largely depends on the bulk density of the nodule (mean $1.3 \mathrm{~g} \mathrm{~cm}^{-3}$ dry bulk; U1365B-M $1.9 \mathrm{~g} \mathrm{~cm}^{-3}$ dry bulk; Chang, et al., 2003), its porosity (mean 60\%), and the extremely high specific surface area (mean $325 \mathrm{~m}^{2} \mathrm{~g}^{-1}$; Hein, et al., 2000) characteristic of FMNs and crusts (Hein \& Koschinsky 2013). These properties, combined with their 
incredibly slow growth rates of 1-10 mm Myr (U1365B-M; $5.4 \mathrm{~mm} / \mathrm{Ma}$ ) and surface charges on colloidal $\mathrm{Mn}$ (strong negative charge) and $\mathrm{Fe}$ (weak positive charge) oxyhydroxide phases (see Figure 3.2), determine surface redox conditions of the FMN, and allow for the adsorption, replacement (element substitution e.g. $\mathrm{Mn}^{2+} \leftrightarrows \mathrm{Co}^{2+}$ ) and coprecipitation reactions that scavenge and secure tracer elements from seawater into Fe-Mn mineral lattices (Koschinsky \& Hein, 2003; Hein \& Koschinsky 2013). The chemical composition of FMNs is thus dependant on Fe-Mn precipitation and the chemical composition of ambient seawater. Variations recorded in FMN geochemistry on global, regional, local, inter-nodule and intra-nodule scales, are therefore a reflection of changes in seawater chemistry due to alterations in the biogeochemical cycling of elements, principally Fe and Mn (Hein \& Koschinsky, 2013).

\section{Paleoprecipitation and Element Associations}

The hydrogenous precipitation of Fe-Mn oxyhydroxides, acquire significant quantities of elements (e.g. $\mathrm{Co}, \mathrm{Ni}, \mathrm{Ba}, \mathrm{Pb}, \mathrm{Ce}$ ) from seawater, to the extent that seawater concentrations of some elements, such as $\mathrm{Ce}$, are controlled by their incorporation into these oxyhydroxide minerals (e.g., Goldberg et al., 1963; Piper, 1974). The mechanisms of tracer element sequestration by $\mathrm{Fe}$ oxyhydroxides and $\mathrm{Mn}$ oxides can, to a first-order approximation, be determined through calculations of the Pearson's product-moment correlation coefficient $\mathrm{r}^{2}$ values, for various pairs of elements, and hierarchal cluster analyses (HCA), to determine inter-element relationships and the association of tracer elements with each major mineral phase (Li, 1982; Wen, et al., 1997; Koschinsky \& Hein, 2003). Application of Pearson's $r^{2}$ and HCA on the multi-element concentration data for the authigenic fraction of U1365B-M, revealed three clusters of geochemically similar elements (Figure 6.5). The first cluster was subdivided into two groups of geochemically similar elements and the third cluster was divided into three, providing a total of six element groups, that generally displayed $>70 \%$ geochemical similarity in their time-series profiles (Figure 6.5). Information gathered on element speciation in seawater (see Table 3.2), and the most common compounds that form (i.e., carbonates), are annotated on Figure 6.5 and illustrate how, in general, the charge of the dissolved species appears to be especially important for the adsorption of these elements by Fe-Mn oxyhydroxides from 


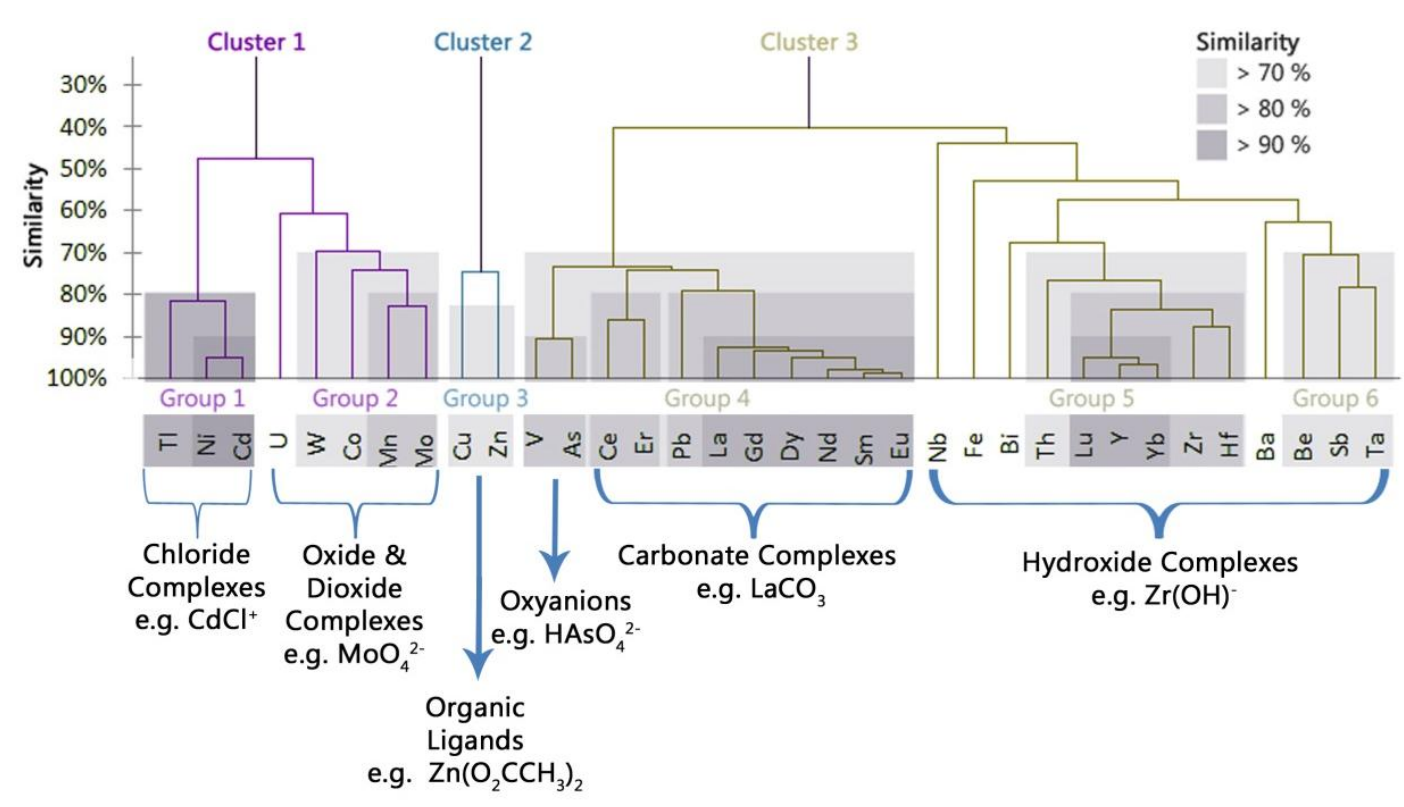

Figure 6.5 $\mid$ Hierarchal cluster analysis and element speciation in seawater The results from performing HCA on the multi-element geochemistry of U1365B-M are presented, in addition to the shaded groups of elements displaying 70, 80 and $80 \%$ similarities in their chemical profiles. An example of chemical time-series for cluster 1 elements $(\mathrm{Mo})$, cluster $2(\mathrm{Cu})$ and cluster $3(\mathrm{Ce})$ are shown. Additionally each of the six groups has their dominant seawater complex/speciation annotated.

seawater, as each group can be associated with a common ligand, supported by previous findings (e.g., Li, 1981; Wen, et al., 1997; Koschinsky \& Halbach, 1995; Koschinsky \& Hein, 2003). The three clusters in Figure 6.5 most likely reflect the dominant mineral phase that scavenged the displayed selection of elements from seawater. Correlation coefficients in the literature for various pairs of elements based on FMN geochemistry (on the basis of bulk or acid leachate chemical composition data) show that sequestered elements are generally associated with one or more of four phases: $\mathrm{Mn}$-oxide (Co, Mn, Mo, $\mathrm{Ni}, \mathrm{Cu}, \mathrm{Zn}, \mathrm{Tl}, \mathrm{Ce}$ ); Fe-oxyhydroxide (Fe, Zr, Hf, Nb, Ta, Bi, Th, U, V, As, Ce, Pb, YREE, Cd, Mo, W); biogenic (Fe, Cu, Ni, Zn, Ba, Ce), and; detrital (Si, Al, Fe) (e.g., Cronan, 1977; Calvert \& Price, 1977; Li, 1982; Wen, et al., 1997; Koschinsky \& Hein, 2003). Additionally, it is commonly reported that elements, including YREEs, $\mathrm{Cu}, \mathrm{Zn}, \mathrm{V}$ and $\mathrm{As}$, can partition between Fe and Mn phases (Li, 1982; Wen, et al., 1997; Koschinsky \& Hein, 2003). Furthermore, as $\mathrm{Fe}$ is the most widely distributed element, having been found associated with the Fe-oxide phase, the detrital phase (due to its concentration in minerals such as 
pyroxene, amphibole, smectite and spinel), and the biogenic phase (due to its utilisation as a vital nutrient for marine organisms), those elements strongly associated with Fe can also display greater geochemical variability and thus, statistically, can seem to not correlate with a specific mineral phase or group of elements such as $\mathrm{U}, \mathrm{W}, \mathrm{Nb}, \mathrm{Bi}$, and $\mathrm{Ba}$ (Koschinsky \& Hein, 2003), illustrated in Figure 6.5 as those elements with generally $<60 \%$ geochemical similarity. Additionally, the position of $\mathrm{Ba}$ in the HCA may be due to its associated with another major mineral phase, i.e., reviews on the behaviour of $\mathrm{Ba}$ (incl. $\mathrm{Ni}$, $\mathrm{Cd}, \mathrm{Cu}, \mathrm{Zn})$ in seawater revealed nutrient-like distributions, indicating strong biological constraints on its oceanic concentration (Bruland, 1983; Whitfield \& Turner, 1987; Li, 1982).

In light of the above cluster 1 likely reflects elements sequestered by $\mathrm{MnO}_{2}$, cluster 2 , elements associated with the biogenic phase, due to controls on the distribution of organic ligands (see Bruland, 1989), and; cluster 3, reflects elements sequestered by FeOOH. In regards to the latter, groups 4 to 6 most likely reflect scavenging by: group 4, mixed Fe-Mn oxyhydroxide colloids/minerals (becoming progressively more dominated by $\mathrm{FeOOH}$ scavenging from $\mathrm{V}$ to $\mathrm{Eu}$ ); group 5 (Th to $\mathrm{Hf}$ ), the pure Fe-oxyhydroxide phase (cf. Koschinsky \& Hein, 2003), and; group 6, associated with the background seawater signal derived from detrital Fe-oxyhydroxides. The reported element speciations in seawater and element association observed in the authigenic fraction of U1365B-M, are consistent with those previously reported (Li, 1981; Wen, et al., 1997; Koschinsky \& Halbach, 1995; Koschinsky \& Hein, 2003), and are explained by the simple sorption model of Koschinsky \& Hein (2003) who related element associations to the inorganic speciation of elements in seawater, whereby free and weakly complexed cations, such as $\mathrm{Co}, \mathrm{Ni}$ and $\mathrm{Tl}$, are adsorbed preferentially on the negatively charged surface of $\mathrm{MnO}_{2}$, whereas neutral or anion complexes bind with the FeOOH phase (see Figure 3.2).

To assess the over-all scavenging of these elements from the water column by Fe-Mn minerals over the growth history of U1365B-M, and long-term chemical trends, the sum of the concentration for each element analysed (excluding Fe and $\mathrm{Mn}$ ) are displayed in Figure 6.6 in addition to the total growth rate, $\mathrm{Mn} / \mathrm{Fe}$, a representative element from each element group and the percentage of incorporated detrital minerals. 


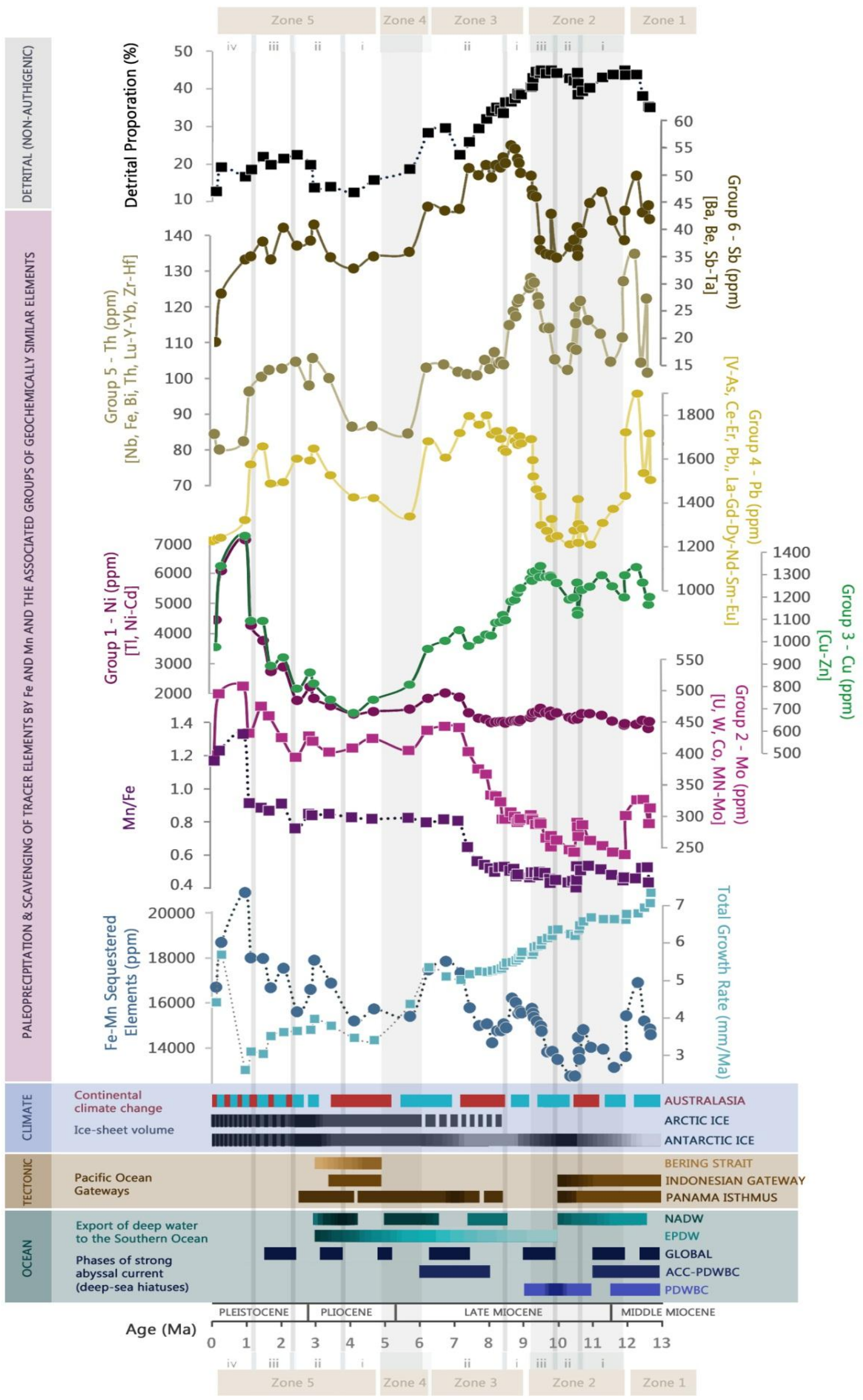


Figure 6.6 | Geochemically similar element groups of U1365B-M The six groups identified by cluster and correlation analyses are illustrated by a representative element for each group, and the associated elements assigned to each group are listed in the axis label. Groups 1 and 2 associated with cluster one $(\mathrm{Mn})$ are colour coded in hues of purple-pink in addition to the $\mathrm{Mn} / \mathrm{Fe}$ profile. Group 3 associated with cluster two are green, and groups 4-6 associated with cluster 3 are progressively darker shades of brown, indicating the increased correlation (or partial correlation) of these elements with the percentage of detrital material incorporated into U1365B-M growth structures. The scavenging capacity of Fe-Mn oxyhydroxides are illustrated by the sum of the total concentration of all elements analysed (excluding Fe-Mn) and are illustrated in dark blue with the total growth rate in light blue. At the base of the Figure are the key climate-tectonic-ocean events of the Late Neogene.

Long-term chemical trends

The chemical profile representing the total budget of sequestered elements for the growth history of U1365B-M (dark blue; Figure 6.n) display a general increase from c. 10 Ma to present, consistent with decreasing growth rates, which allow additional time for the sequestration of elements from seawater (Halbach \& Puteanus, 1984). Superimposed on this long-term trend are periods of enhanced chemical scavenging: 12.7 to $12.3 \mathrm{Ma}$ [0.4 Myr duration]; 11.6 to 10.7 [c. 1 Myr duration]; 10.5 to 8.6 [2 Myrs]; 8 to 7.2 [1.3 Myrs] and maintained at a high scavenging capacity (c. $18000 \mathrm{ppm}$ ) for one million years from 7.2 to $6.3 \mathrm{Ma} ; 4$ to $3 \mathrm{Ma}$ [1 Myrs]; 2.5 to 2 [0.5 Myrs], and; 1.7 to $1 \mathrm{Ma}$ [0.7 Myrs duration].

These periods of enhanced precipitation roughly correlate with cooler climatic regimes reported for the region, and the intervening periods of reduced chemical scavenging with relatively warmer climates (Hall, et al., 2001, 2002, 2003; Hayward, et al., 2004; Joseph, et al., 2004; Crundwell, et al., 2008; Naish, et al., 2009), such as the sharp decline in precipitation (from 14,000 to $13,000 \mathrm{ppm}$ ), between 10.7 and $10.5 \mathrm{Ma}$, identified as a transient warming episode by Holbourn et al. (2012) in association with peak insolation during an eccentricity maximum (100 and $400 \mathrm{kyrs}$ ). And additionally, the period of sustained low precipitation (c. $16000 \mathrm{ppm}$ ) from 5 to 4 Ma during the Mid Pliocene Warm Period (MPWP), when average global temperatures were $2-3{ }^{\circ} \mathrm{C}$ higher than present and global sea-levels rose by c. $20-25 \mathrm{~m}$ in response to the greatly reduced Greenland and West Antarctic Ice Sheets (McKay, et al., 2012). These glacial (interglacial) enhanced (decreased) scavenging has been previously noted (e.g., Glasby, 2000; van de Flierdt, et al., 2004; Xu, et al., 2006; González, et al., 2012) and associated with increased (decreased) 
deep sea ventilation through enhanced (reduced) bottom water production, as can be seen in Figure 6.6, with phases of greater chemical scavenging correlating with periods of enhanced ACC-PDWBC speeds. High current speeds are reported to impede sediment deposition and remove any sediment covering the surfaces of FMNs (re-establishing precipitation) that may have been deposited during phases of reduced current velocity (Glasby, 1985; Glasby, 2000; González, et al., 2012).

Most notable in Figure 6.6 is that the element groups of U1365B-M displays distinct trends for each nodule zone and subzone. With the exception of zone 3ii and 5ii which appear to display an additional change in chemistry (unaccompanied by a change in the physical archive) at 7.2 and c. $3 \mathrm{Ma}$ respectively. The mangophile elements of group 2, (consisting of $\mathrm{U}, \mathrm{W}, \mathrm{Co}, \mathrm{Mn}$ and Mo) display close similarity to the $\mathrm{Mn} / \mathrm{Fe}$ profile, with zone 1 of group 2 elements displaying a short pulse in content and during zone 2, a distinct 'W' with a peak in content at c. 10.8 Ma, before the sharp decline between 10.7 to 10.5 Ma. From 10.5 (zone 2ii) to mid-way between zone 3ii, at $7.2 \mathrm{Ma}$, mangophile elements generally double in their concentration and are maintained at this level of enrichment for a million years, from 7.2 to 6.3 Ma. Concentrations then decrease slightly around $6 \mathrm{Ma}$ (e.g., Mo - 436 to $400 \mathrm{ppm}$ ) and are then maintained about this concentration throughout the Pliocene until the mid-Pleistocene at 2.5 Ma. From 2.5 to $1 \mathrm{Ma}$, mangophile elements near double in concentration once more to a broad peak between c. 1 and $0.3 \mathrm{Ma}$.

Group 2 elements $(\mathrm{Ni}, \mathrm{Cd}, \mathrm{Tl})$ show the same variations in element concentrations at a variable magnitude and differ from group two elements during the mid-Pliocene at c. 4 $\mathrm{Ma}$, when element concentrations that had been previously maintained at low concentrations (e.g., $\mathrm{Ni}$ - at c. $2000 \mathrm{ppm}$ ) increase three-fold from 4 to $1 \mathrm{Ma}$, over the transition from a warm Pliocene to a cold Pleistocene ocean. The group three elements, $\mathrm{Cu}$ and $\mathrm{Zn}$, predominantly suggested to be associated by biological activity due to their complexation with organic ligands (Li, 1982; Hein, et al., 1992; Wen, et al., 1997; Koschinsky \& Hein, 2003; Little, et al., 2014), are strongly associated with group one elements from $4 \mathrm{Ma}$ to present. The $4 \mathrm{Ma}$ time marker is a pivotal point for these elements, marking the point in time when general long-term chemical trends are reversed. Prior to 4 Ma, group 3 elements closely approximate the profile for the percentage of incorporated detrital grains for U1365B-M. This association may be correlative or causal, in the case of 
the latter a potential explanation could be the association of enhanced biological activity in oceanic surface waters in association with the delivery of aeolian fluxes and supply of bioavailable elements (Martin, 1990; Jickells \& Spokes, 2001; Jickells, et al., 2005; Raiswell, et al., 2008).

The cluster three elements associated with $\mathrm{FeOOH}$, are distinctly different to the mangophile and biogenic element groups. Group 5 elements (Nb, Fe, Bi, Th, Lu, Y, Yb, Zr, and Hf) display the greatest similarity to groups 1-3 due to the distinct ' $W$ ' in the shape of the chemical profile across zone two. However, for group 1 and 2 element concentrations of this zone are low (e.g., the lowest concentrations for Mo are reported at c. 10.5 and 12 Ma; c. $245 \mathrm{ppm}$ ), whereas for group 5 elements, this is where the highest concentration are recorded (consistent with the highest concentrations of Fe c. $25 \%$ ) and they decline thereafter in a series of steps from 9.3 to $8.5 \mathrm{Ma}$, (separated by a period of relative stability 9.5 to $6 \mathrm{Ma}$ ), 6.3 to $5.7 \mathrm{Ma}$, (a period of relative stability from 5.7 to $4 \mathrm{Ma}$ ), and then display a reversal in trends - similar to group 3 elements - whereby concentrations increase between 4 and $3 \mathrm{Ma}$, in association with the relatively warmer climates of the Pliocene (Haywood, et al., 2009) and are roughly maintained 3 to $1 \mathrm{Ma}$, as Northern hemisphere glaciation established permanent ice in the Arctic over this period (Cronin, 2010; O'Reagen, et al., 2011), and then rapidly decrease thereafter. Groups 4 and 6 show very similar profiles to the group 5, with only slight variations, such as the sharp decrease in concentrations of group 4 elements c. 12 to $11 \mathrm{Ma}$, and the strong association of group 6 elements with percentage detrital incorporation from 8.5 Ma.

Thus, the cold Miocene ocean is characterised by higher concentrations of groups 3-6 (the FeOOH cluster) with groups 1-2 displaying low concentrations. A significant change in ocean chemistry occurs between c.10 to $7 \mathrm{Ma}$, where groups 1, 2, and 4 increase, but groups 3, 5, 6 decrease. Group 3 displays a reversal in long-term chemical trends at $4 \mathrm{Ma}$. However, groups 4-6 display a reversal in chemical trends 2 Myrs earlier at 6 Ma. All element groups display an increase in concentration during the mid-Pliocene warm period (c. 4 to $3 \mathrm{Ma}$ ). The final significant shift in over-all chemistry occurs for the group 1-3 elements where concentrations increase significantly from 4 to $1 \mathrm{Ma}$. These changes in the direction of chemical trends during growth of U1365b-M for the various groups of elements (geochemically similar and thus controlled by similar processes in the marine 
environment) probably reflect variations in oceanographic conditions. Wen et al. (1997) proposed that element concentrations generally reflect local environmental influences on the supply of said elements. The elements composing the Fe-Mn minerals of U1365B-M, may be sourced from local (sediment-water interface), regional (New Zealand) or global (PDWBC and mixing within the ACC) sources (e.g., Glasby, 2000).

\section{Paleosource}

On a regional scale, elements may be derived from the surrounding New Zealand landmass via riverine, aeolian and volcanic processes, contributing to the background seawater chemistry (hydrogenous), in addition to supplying a flux of detrital minerals to the deep sea. Paleo-seawater lead isotopes are often employed to identify regional source contributions from various continental (and MORB) provinces (e.g. Chen, et al., 2013; van de Flierdt, et al., 2003). The provenance of $\mathrm{Pb}$ may be of regional crustal sources or mixed advected $\mathrm{Pb}$ signals (Frank, 2002; van de Flierdt, et al., 2003). However, due to the relatively short oceanic residence time of $\mathrm{Pb}$ (50 - 100 years; Henderson \& Maier-Reimer, 2002), it is usually assumed that isotopic variations would reflect local contributions from the nearest landmass, in this case, New Zealand.

\section{Riverine sources}

The influence of riverine sources on the $\mathrm{Pb}$ budget of seawater is, in general, disputed and poorly understood. On one hand, the magnitude of the flux of particulate matter from rivers entering the oceans is enormous (Milliman \& Meade, 1983; Milliman \& Syvitski, 1992; Syvitski, et al., 2003) and considered the principle mechanism by which oceanic waters and marine sediments derive their geochemical compositions (Carey, et al., 2002). On the other hand, the fraction of dissolved or particulate $\mathrm{Pb}$ that escapes beyond nearcoastal traps is assumed to be minor. Few geochemical data exist from these sedimentproducing environments and so the actual contributions are poorly constrained (e.g. Turekian, 1977; Duce, et al., 1991). In the case of New Zealand's South Island, sediments are transferred from the continental shelf to the abyssal seafloor along deep submarine channels (Carter, et al., 1996). The most southerly conduit, and most likely source of terrigenous sediments to the CNF, is the Solander Channel however, the Solander Channel 
was a prograding fan complex for most of U1365B-M growth history and therefore, it is unlikely that riverine sources present a dominant source of elements to the $\mathrm{CNF} . \mathrm{Pb}$ isotope compositions of Torlesse schists and Kermadec-Hikuarangi margin sediments are illustrated as a grey field in Figure 6.7. The field forms an array that is parallel to $\mathrm{Pb}$ compositions recorded in U1365B-M, but with lower ${ }^{208} \mathrm{~Pb} /{ }^{204} \mathrm{~Pb}$ and ${ }^{207} \mathrm{~Pb} /{ }^{204} \mathrm{~Pb}$ ratios at any given ${ }^{206} \mathrm{~Pb} /{ }^{204} \mathrm{~Pb}$. If New Zealand sediments had contributed a dominant source of $\mathrm{Pb}$ to U1365B-M, then the well-defined mixing arrays (Figure 6.7) would lie somewhat perpendicular to their current position, indicating New Zealand sediments as a potential mixing end-member. However, the $\mathrm{Pb}-\mathrm{Pb}$ mixing array from 1.7 to $0 \mathrm{Ma}$, plots perpendicular, between that of relatively unradiogenic seawater $\mathrm{Pb}$ (Zone 1; 12.7-11.9 Ma) and the Torlesse Metasediments Field for New Zealand sediments. This would be consistent with the increased rates of physical and chemical weathering characteristic of GI cycles of the Pleistocene.

\section{Aeolian sources}

Recently, it has been proposed that $\mathrm{Pb}$ loosely bound to aeolian silicate dust has exerted the principal control on the seawater $\mathrm{Pb}$ isotopic signature for water masses, especially for remote oceanographic regions such as the North Central Pacific (Jones, et al., 2000; Pettke, et al., 2002; Erhardt, et al., 2013). New Zealand has the second most extensive loess deposits in the Southern Hemisphere (second only to Argentina; Berger, et al., 2002), with sequences on the South Island up to $18 \mathrm{~m}$ thick (Berger, et al., 2002), thus making it a potentially important source of $\mathrm{Pb}$ in U1365B-M. Dust records for the Southwest Pacific are essentially lacking and few data exist for estimating contributions of the New Zealand (South Island) loess fields to the aeolian flux to the South Pacific region (see Rea, 1994). However, quaternary ice-core dust records from Antarctica suggest wide dispersal and circulation of mineral dusts from Australia and New Zealand (Delmonte, et al., 2004; Grousset \& Biscaye, 2005; Revel-Rolland, et al., 2006). These observations were also confirmed from a late Miocene dust record extracted from Marlin Rise sediments (MV0502-01JC) in the Southwest Equatorial Pacific (Stancin, et al., 2008). In addition to the Torlesse and Kermadec-Hikuarangi margin sediments, plotted in Figure 6.7 is a field representing the $\mathrm{Pb}$ isotopic composition of Australian-New Zealand loess derived from Stancin, et al. (2008). This field overlaps the $\mathrm{Pb}$ isotope excursion at 9.5 Ma and exhibits an 

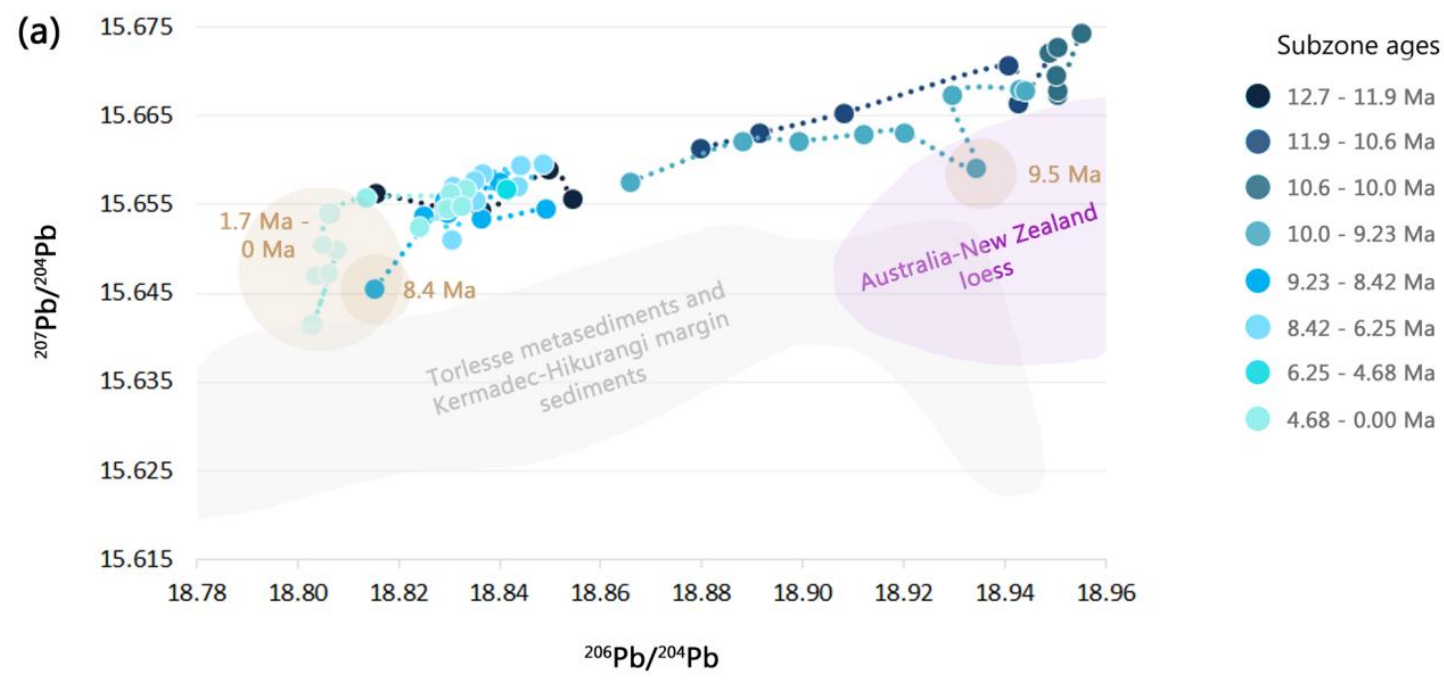

(b) 39.100

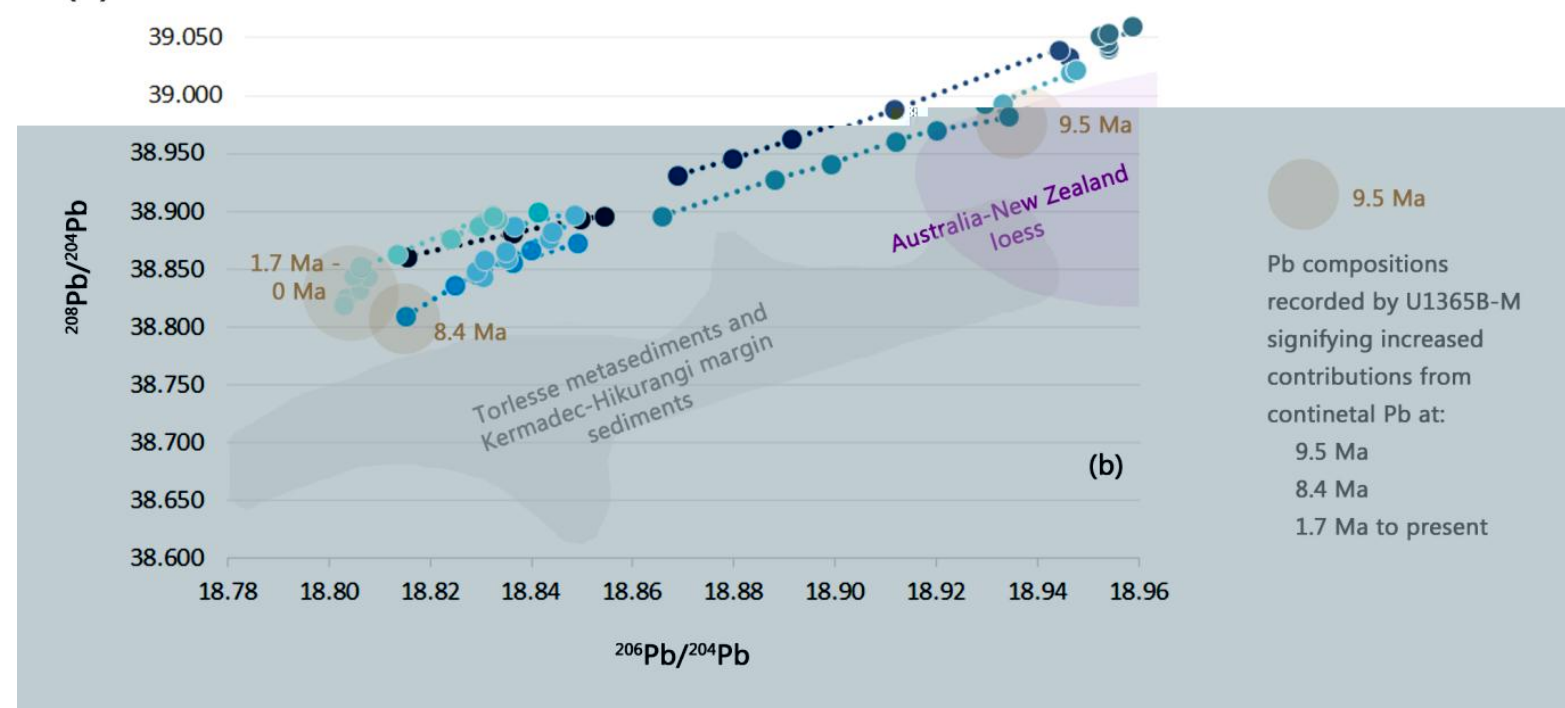

Figure 6.7 | Pb-Pb mixing plots of U1365B-M and regional, riverine, aeolian, sources of $\mathrm{Pb}$ from

New Zealand. Three-isotope plots of (a) ${ }^{207} \mathrm{~Pb} /{ }^{204} \mathrm{~Pb}$ vs. ${ }^{206} \mathrm{~Pb} /{ }^{204} \mathrm{~Pb}$ and $(\mathrm{b}){ }^{208} \mathrm{~Pb} /{ }^{204} \mathrm{~Pb}$ vs. ${ }^{206} \mathrm{~Pb} /{ }^{204} \mathrm{~Pb}$

extremely comparable $\mathrm{Pb}$ isotopic composition ${ }^{206} \mathrm{~Pb} /{ }^{204} \mathrm{~Pb}=18.937,{ }^{207} \mathrm{~Pb} /{ }^{204} \mathrm{~Pb}=15.659$ ${ }^{208} \mathrm{~Pb} /{ }^{204} \mathrm{~Pb}=38.955$ (Stancin, et al., 2008) to that recorded in $\mathrm{U} 1365 \mathrm{~B}-\mathrm{M}{ }^{206} \mathrm{~Pb} /{ }^{204} \mathrm{~Pb}=$ $18.934,{ }^{207} \mathrm{~Pb} /{ }^{204} \mathrm{~Pb}=15.659{ }^{208} \mathrm{~Pb} /{ }^{204} \mathrm{~Pb}=38.982$. Thus, an aeolian source of $\mathrm{Pb}$ is the most likely cause for the excursion at $9.5 \mathrm{Ma}$, and shift to lower ${ }^{208} \mathrm{~Pb} /{ }^{204} \mathrm{~Pb}$ and ${ }^{207} \mathrm{~Pb} /{ }^{204} \mathrm{~Pb}$ values for any given ${ }^{206} \mathrm{~Pb} /{ }^{204} \mathrm{~Pb}$, from $\mathrm{c}$. 10 to $8.4 \mathrm{Ma}$ indicating increased aeolian contributions to the deep sea during this period. In support of this, Stein \& Robert (1985) noted an increase in the flux of New Zealand derived iolite on the Lord Howe Rise starting at c. $9 \mathrm{Ma}$ and suggested that late Cenozoic cooling was responsible for the increased flux of loess. 
Furthermore, at 9.5 Ma U1365B-M records an increased flux of detrital sediments and large detrital grains are visible in the BSE profile (Figure 5.5). This coincides with an increase in aeolian grain size recorded for both Marlin Rise sediments (Stancin, et al., 2008) and ODP Leg 92 in the Southeast Pacific (Rea and Bloomstein, 1986) and potentially supports the findings of Rea \& Bloomstein (1986) for a more energetic atmospheric circulation commencing at about $10 \mathrm{Ma}$, coincident with ice build-up on Antarctica and a subsequent decrease in sea level.

\section{Volcanic sources}

Hot spot volcanism began to penetrate the Campbell Plateau in the Middle Miocene (c. 19 - $12 \mathrm{Ma}$ ) associated with volcanism of the Ross and Carnley Volcanoes of the Auckland Islands, from then onward the following volcanic events took place: (i) a Late Miocene shift in the locus of volcanism to Campbell Island, ${ }^{40} \mathrm{Ar} /{ }^{39} \mathrm{Ar}$ dated by Hoernle, et al. (2006) at c. $7.5 \mathrm{Ma}$, falling within the $\mathrm{Kr} / \mathrm{Ar}$ range of 6.5 - $8.5 \mathrm{Ma}$ (Adams, et al., 1979); (ii) Chatham Island volcanism resumed between c. 6 and $2.6 \mathrm{Ma}$; (iii) volcanism on Pukaki Rise occurred between 3.3 and 3.7 Ma; (iv) Solander Island, became active during the early Pleistocene (c. 1.4 Ma) and; (v) the Antipodes Islands emerged in the late Pleistocene (0.5 0.25 Ma; Cullen, 1969). The isotopic excursions at 8.4 Ma (U1365B-M) and 7.5 Ma (U1365B-2) coincide with the timing of volcanic activity on Campbell Island. Additionally, spikes in ${ }^{207} \mathrm{~Pb} /{ }^{206} \mathrm{~Pb}$ recorded in U1365B-2 at c. $0.3 \mathrm{Ma}, 1.2 \mathrm{Ma}$ and $4 \mathrm{Ma}$ occur about the timing of volcanism on: the Antipodes Islands, Solander Island, and Pukaki Rise, respectively (Figure 5.13). It is clear from the proceedings of the RV Tangeroa, that volcanic detritus plays an important role in the formation of nodules, with many having nucleated around volcanic debris and some of the highest density nodule facies occur immediately south of the Antipodes Islands (Chang, et al., 2003; Wright, et al., 2005). Plotted in Figure 6.8 (a) are ${ }^{207} \mathrm{~Pb} /{ }^{204} \mathrm{~Pb}$ vs. ${ }^{206} \mathrm{~Pb} /{ }^{204} \mathrm{~Pb}$ ratios for $\mathrm{U} 1365 \mathrm{~B}-\mathrm{M}$, Australian-New Zealand loess, the Subantarctic Islands and other proximal volcanic samples. In $\mathrm{Pb}-\mathrm{Pb}$ space compositions of the Subantarctic Islands encompass a far broader range of compositions than U1365B-M and form a sub-parallel array at higher ${ }^{206} \mathrm{~Pb} /{ }^{204} \mathrm{~Pb}$ for a given ${ }^{207} \mathrm{~Pb} /{ }^{204} \mathrm{~Pb}$ ratio. 

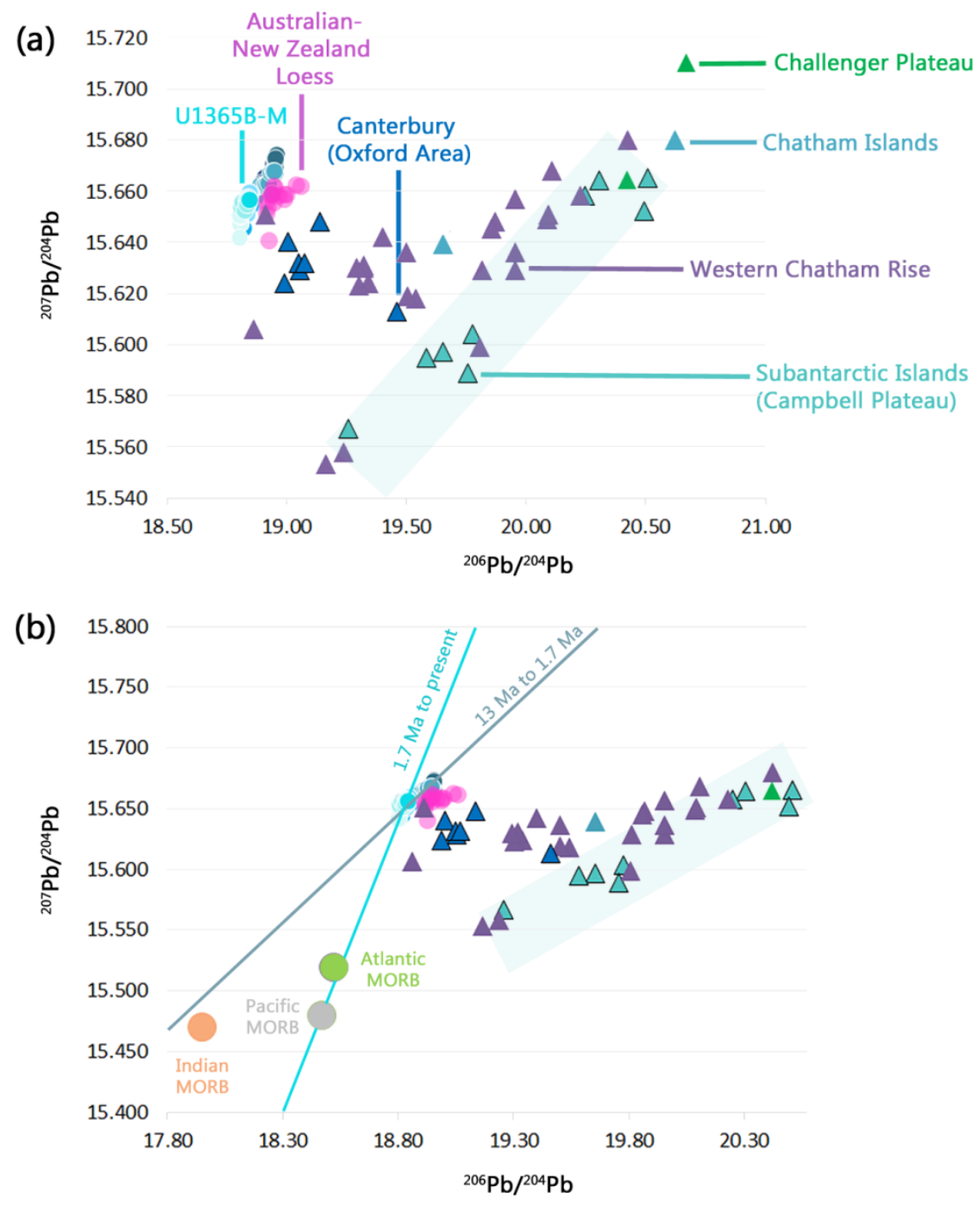

Figure 6.8 $\mathrm{Pb}-\mathrm{Pb}$ mixing plots of U1365B-M and local or advected volcanic sources Three-isotope plots of (a) ${ }^{207} \mathrm{~Pb} /{ }^{204} \mathrm{~Pb}$ vs. ${ }^{206} \mathrm{~Pb} /{ }^{204} \mathrm{~Pb}$ and $(\mathrm{b}){ }^{208} \mathrm{~Pb} /{ }^{204} \mathrm{~Pb}$ vs. ${ }^{206} \mathrm{~Pb} /{ }^{204} \mathrm{~Pb}$. Data derived from Timm, et al., (2010) for (a) and (b) with MORB values taken from Christiansen, et al (1997).

In addition to local volcanic sources, hydrothermal $\mathrm{Pb}$ derived from advected Mid-Ocean Ridge Basalts (MORB) may also contribute to the Pb budget of the ACC-DWBC. Pacific MORB is known to be transported considerable distances $(\sim 1000 \mathrm{~km})$ in particles carried by hydrothermal plumes (Barrett, et al., 1987) however the degree to which $\mathrm{Pb}$ is dissolved and transported within general ocean circulation is unclear. In figure 5.n the average $\mathrm{Pb}$ composition of Atlantic, Indian and Pacific Ocean MORBs are plotted in addition to the components of Figure 6.8 (b). From c. $13 \mathrm{Ma}$ to $1.7 \mathrm{Ma} \mathrm{Pb}$ compositions (on average) sit along a mixing array that trends toward Indian MORB compositions, as is commonly 
observed for Indian FMNs and crusts (e.g. Vlastélic, et al., 2001). In contrast, from 1.7 Ma to present the average $\mathrm{Pb}-\mathrm{Pb}$ mixing array sits between Atlantic and Pacific MORB, as is commonly observed for Pacific FMNs and crusts (e.g. Christensen, et al., 1997). The fact that FMNs and crusts show $\mathrm{Pb}$ compositions that generally trend toward their respective MORB compositions indicates that MORB-derived $\mathrm{Pb}$ may be contributing a dissolved component to seawater. Thus, the respective MORBs present a potential end-member source of $\mathrm{Pb}$ in U1365B-M. Additionally, these results indicate that Indian MORB may have played a more significant role from 13-1.7 Ma, and Atlantic-Pacific MORB from 1.7 Ma to present.

In terms of the evolution of $\mathrm{Pb}$ isotope ratios, $\mathrm{MORB}$ contributions only go part way to explain the $\mathrm{Pb}$ signature of $\mathrm{U} 1365 \mathrm{~B}-\mathrm{M}$. One important point is that ${ }^{207} \mathrm{~Pb} /{ }^{204} \mathrm{~Pb}$ compositions are on average $>15.6$. To derive this radiogenic composition requires $\mathrm{Pb}$ derived from the erosion of uranium rich (and thorium rich) upper crustal rocks (van de Flierdt, et al., 2004). Hence, a proportion of the $\mathrm{Pb}$ must be derived from old continental material. As the Pacific Ocean is surrounded by young Circum-Pacific Arcs (including New Zealand; Chen, et al., 2013), old continental material must be advected to the nodule growth site from further afield via ocean currents. Hence, it is reasonable to assume that the two dominant end-members of $\mathrm{Pb}$ are: (i) hydrothermal and/or recycled lead of volcanic origin and (ii) erosion-averaged crustal lead.

As the arrays of U1365B-M trend toward different MORB compositions for different time slices, this suggests that $\mathrm{Pb}$ derived from Indian, Atlantic and Pacific MORB (or their respective water masses), is mixed and transported within the ACC at varying degrees for specific periods of time. Thus, the $\mathrm{Pb}$ isotopic compositions of U1365B-M likely reflect fluxes in the export of NADW (18.9 to $\left.>19.0{ }^{206} \mathrm{~Pb} /{ }^{204} \mathrm{~Pb}\right)$, IODW $\left(18.9-18.7{ }^{206} \mathrm{~Pb} /{ }^{204} \mathrm{~Pb}\right.$ ) and NPDW (18.7 to $\left.<18.6{ }^{206} \mathrm{~Pb} /{ }^{204} \mathrm{~Pb}\right)$ to the Southern Ocean from the late Middle Miocene to the Quaternary (13 to $1.7 \mathrm{Ma}){ }^{206} \mathrm{~Pb} /{ }^{204} \mathrm{~Pb}$ values; Abouchami \& Goldstein, 1995; Frank, et al., 2002). To ascertain potential Pb sources advected from NADW, NPDW and IODW the isotopic distributions of: (1) Atlantic river sediments, (2) the southernmost Circum-Pacific Arcs and; (3) High Himalayan gneisses, are illustrated in Figure 6.9. 


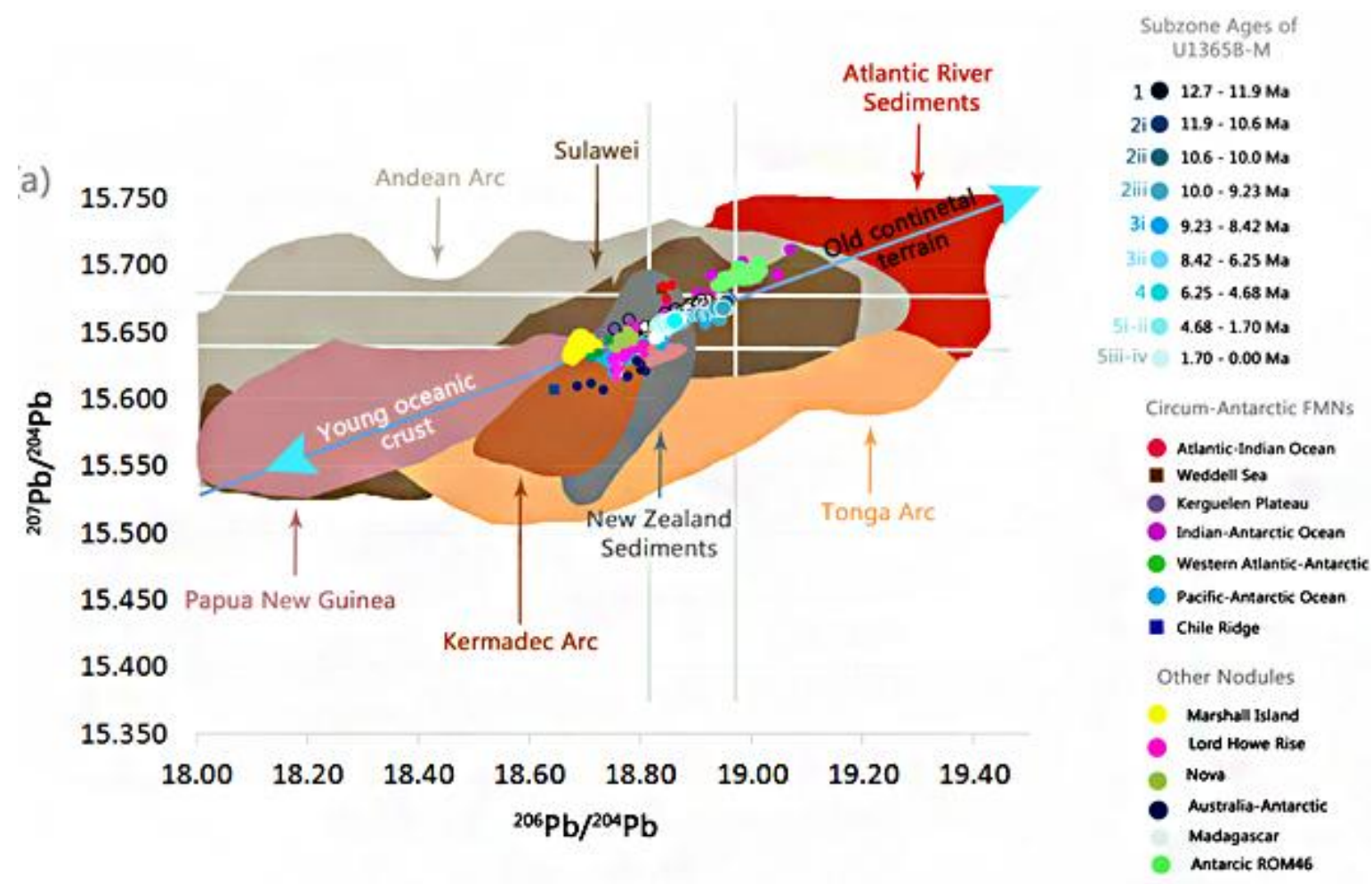

Figure 6.9 $\mathrm{Pb}-\mathrm{Pb}$ mixing plots of U1365B-M and global provenance Comparison of $\mathrm{Pb}$ isotope signatures recorded by U1365B-M, circum-antarctic FMNs and FMNs from the Southwest Pacific and Atlantic Oceans with those of potential source rocks of Circum Antarctic Arcs and Atlantic river sediments in ${ }^{207} \mathrm{~Pb} /{ }^{204} \mathrm{~Pb}$ vs. ${ }^{206} \mathrm{~Pb} /{ }^{204} \mathrm{~Pb}$ space. A Himalayan source has been excluded based on the detailed assessment of $\mathrm{Pb}$ sources in the Indian Ocean by Vlastélic, et al. (2001) who could not trace the erosion protects of the Ganges-Brahmaputra into the Southern Indian Ocean. The fields representing potential source rocks were constructed using the GEOROC geochemical database.

Overall, the $\mathrm{Pb}$ isotopic compositions of the different arcs and sediments each show a wide range of compositions and largely overlap. Thus, it is not possible to distinguish elemental $\mathrm{Pb}$ contributions from each provenance based on their $\mathrm{Pb}$ isotopic signatures. However, of all the potential source terrains, Himalayan gneisses, Andean Arc and Atlantic sediments are characterised by high ${ }^{207} \mathrm{~Pb} /{ }^{204} \mathrm{~Pb}$, whereas the Northwest Pacific arcs generally have lower ${ }^{207} \mathrm{~Pb} /{ }^{204} \mathrm{~Pb}$. So a broad assumption can be made that the $\mathrm{Pb}$ signal advected in the PDWBC is a composite of old continental weathering products derived from NADW-IODW and eroded material from young Circum-Pacific Arcs from NPDW.

This assumption is supported by findings of Abouchami \& Goldstein (1995), who studied $\mathrm{Pb}$ isotopic composition of a suite of circumpolar FMNs. They noted that FMNs in the eastern Atlantic had highly radiogenic $\mathrm{Pb}$ signals that become stronger into the Indian sector of the Southern Ocean (interpreted to reflect NADW) and reported the most 
unradiogenic signatures in the eastern Pacific Ocean (Figure 6.10). Using the $\mathrm{Pb}$ provenance fields of Figure 6.9, this could reflect the introduction of Andean and Atlantic sediments are characterised by high ${ }^{207} \mathrm{~Pb} /{ }^{204} \mathrm{~Pb}$, whereas the Northwest Pacific arcs generally have lower ${ }^{207} \mathrm{~Pb} /{ }^{204} \mathrm{~Pb}$. So a broad assumption can be made that the $\mathrm{Pb}$ signal advected in the PDWBC is a composite of old continental weathering products derived from NADW-IODW and eroded material from young Circum-Pacific Arcs from NPDW.

This assumption is supported by findings of Abouchami \& Goldstein (1995), who studied $\mathrm{Pb}$ isotopic composition of a suite of circumpolar FMNs. They noted that FMNs in the eastern Atlantic had highly radiogenic $\mathrm{Pb}$ signals that become stronger into the Indian sector of the Southern Ocean (interpreted to reflect NADW) and reported the most unradiogenic signatures in the eastern Pacific Ocean (Figure 6.8). Using the $\mathrm{Pb}$ provenance fields of Figure 6.7, this could reflect the introduction of Andean and Atlantic weathering products via NADW and the increasingly radiogenic signature may reflect contributions from Himalayan erosional products via IODW, as the ACC approaches the Ganges \& Bengal fan complex. Additionally, the progressively unradiogenic signature eastward across the Pacific Ocean, may reflect contributions from young Circum-Pacific Arc volcanism and the East Pacific Rise.

The inability to be any more specific on the provenance of $\mathrm{Pb}$ to the oceans confirms the original findings of Chow \& Patterson (1959), who stated that "the oceans serve as collecting and mixing reservoirs for leads... derived from vast land areas... [reflecting] large continental segments". Thus, modern water masses can be identified based on their geographically constrained 'crustal average' $\mathrm{Pb}$ compositions. Isotopic ratios from the outer layers of U1365B-M are representative of present day PDWBC $\ell L D C W\left({ }^{206} \mathrm{~Pb} /{ }^{204} \mathrm{~Pb}\right.$ $=18.8$ ) and fall between those of radiogenic NADW (e.g. ${ }^{206} \mathrm{~Pb} /{ }^{204} \mathrm{~Pb}=19.3$; Frank, et al., 2002) and unradiogenic NPDW (e.g. ${ }^{206} \mathrm{~Pb} /{ }^{204} \mathrm{~Pb}=18.5$; van de Flierdt, et al., 2003), with IODW sharing a comparable $\mathrm{Pb}$ signature. Thus, variations in the composition of $\ell \mathrm{LDCW}$ $\mathrm{Pb}$ over the past $13 \mathrm{Ma}$ most likely record fluxes in the export of NADW and NPDW to the ACC-PDWBC. The water mass mixing history of the PDWBC, over the growth history of $\mathrm{U} 1365 \mathrm{~B}-\mathrm{M}$, is discussed in relation to Paleocirculation proxies. 


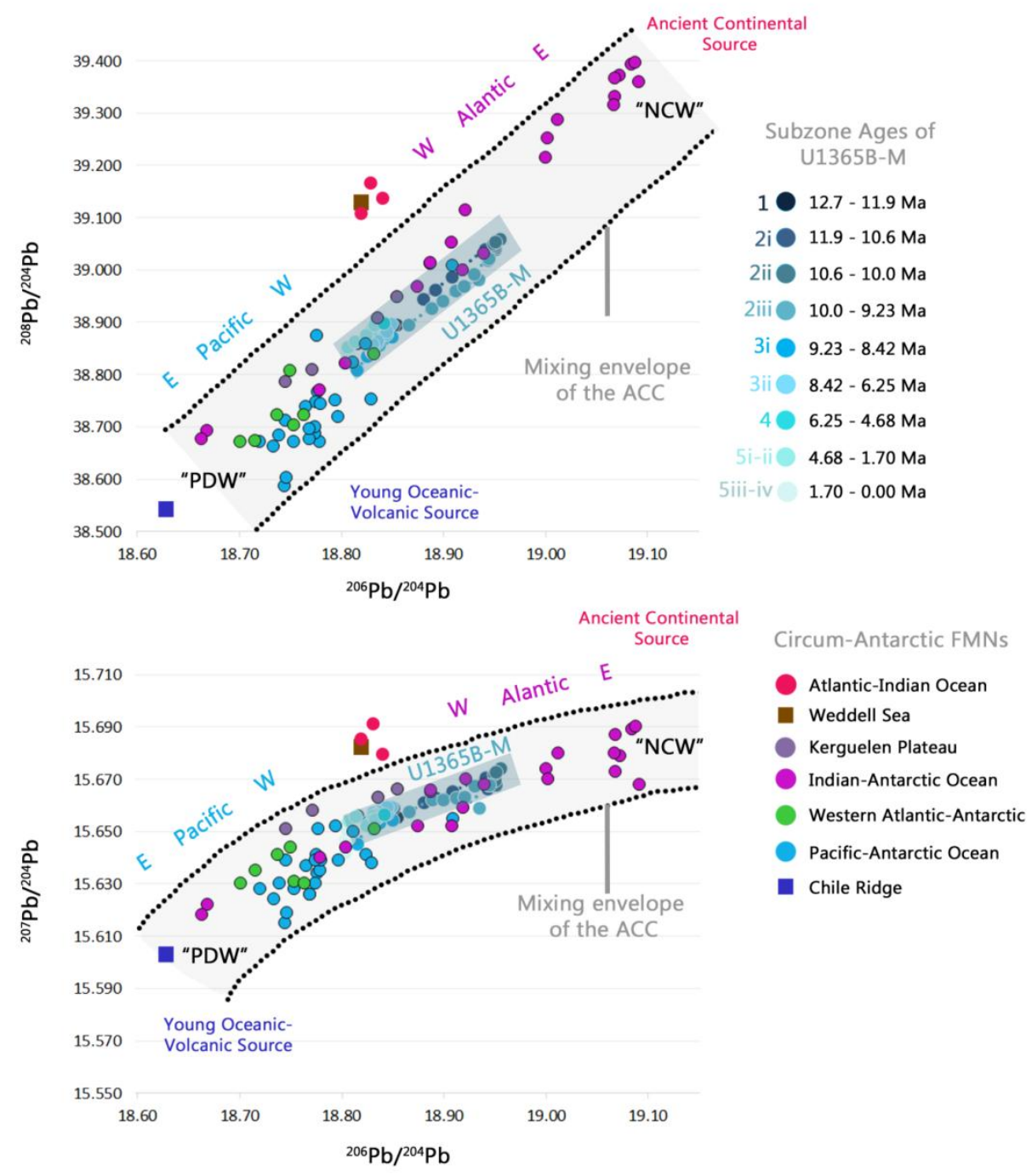

Figure 6.10 $\mathrm{Pb}-\mathrm{Pb}$ mixing plots of U1365B-M and surface scrapings of Circum-Antarctic FMNs Comparison of $\mathrm{Pb}$ isotope signatures recorded by $\mathrm{U} 1365 \mathrm{~B}-\mathrm{M}$, with circum-antarctic nodules (Abouchami \& Goldstein, 1995)

In addition to the delivery of regional sourced elements vertically through the water column and elements supplied to the nodule growth site by lateral advection (as indicated by $\mathrm{Pb}$ isotopic compositions), FMN geochemistry and thus the physical and chemical archives are also strongly controlled by variable element sources at the sediment-water interface. Here, FMN geochemistry is generally controlled by the ratio of hydrogenetic to diagenetic components and whether the diagenetic component results from oxic or suboxic diagenesis, with the boundary generally defined as $5 \mu \mathrm{M}$ oxygen concentration (Dymond, et al., 1984; Glasby, 2000). Additionally, FMNs in proximity to hydrothermal vents derive their elements from vent fluids (Chen \& Owen, 1989; Glasby, 2000). Figure 
6.11 presents a ternary plot of $\mathrm{Fe}-\mathrm{Mn}-(\mathrm{Co}+\mathrm{Ni}+\mathrm{Cu})$, commonly used to determine the relative contributions of hydrothermal, diagenetic, and hydrogenous element sources (e.g., Bonatti, et al., 1976; Halbach, et al., 1981; Hein, et al., 1994). U1365B-M samples plot within the hydrogenous end-member field (Figure 6.n; grey field).

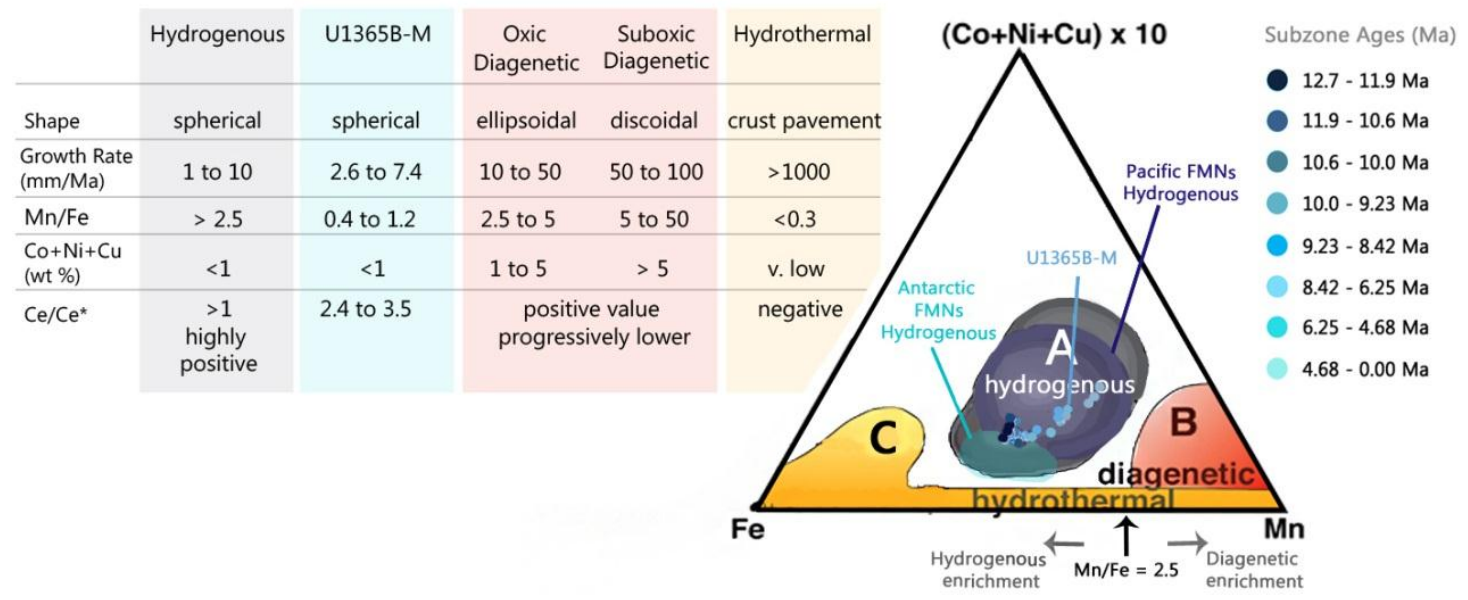

Figure 6.11 $\mid$ Mode of FMN U1365B-M formation. A ternary plot of $\mathrm{Fe}-\mathrm{Mn}-(\mathrm{Co}+\mathrm{Ni}+\mathrm{Cu})$, developed by Bonatti, et al. (1972; 1976) and modified by Halbach, et al. (1981) to incorporate the Mn/Fe ratio as an indicator of hydrogenetic and diagenetic contributions (black and grey arrows), a commonly used method in identifying proximal sources. The three-end member fields of: (a) hydrogenous (grey); (b) diagenetic (red), and; c) hydrothermal (yellow) modes of formation, were adopted from Hein, et al. (1994). Additional fields were constructed from Antarctic FMNs (turquoise; Ohta, et al., 1999) and Pacific FMNs (purple; Calvert \& Price, 1977; Halbach, et al., 1981; Dymond, et al., 1984; Calvert, et al., 1987; Guo \& Sun, 1992; Graham, et al., 2003a). A colour coded table, according to the colours assigned to each end-member field and U1365B-M, list the characteristic features of each dominant mode of formation (see Glasby, 2000).

The plotted parameters display three distinct clusters for the growth history of U1365BM: (1) the older section of the nodule, zones 1 to 3 ii (12.7 to c. $8 \mathrm{Ma})$, are characterised by low $\mathrm{Mn} / \mathrm{Fe}$ values (0.5) and $\mathrm{Co}+\mathrm{Ni}+\mathrm{Cu} \times 10$ (c. $5 \mathrm{wt} \%$ ) which are more comparable with present day Antarctic hydrogenous FMNs (Ohata, et al., 1999; Figure 6.11; turquoise field); (2) the mid-section of the nodule, zones 3ii to 5iii (c. 8 to $1 \mathrm{Ma}$ ), are characterised by elevated $\mathrm{Mn} / \mathrm{Fe}$ values (c. 0.8 ) and $\mathrm{Co}+\mathrm{Ni}+\mathrm{Cu}$ x 10 (c. 8 wt\%) which are more closely related to values reported for Pacific hydrogenous FMNs (Calvert \& Price, 1977; Halbach, et al., 1981; Dymond, et al., 1984; Calvert, et al., 1987; Guo \& Sun, 1992; Graham, et al., 2003a), and; (3) the youngest section of the nodule, zones 5iii to 5iv (c. 1 Ma to present), are 
characterised by the highest $\mathrm{Mn} / \mathrm{Fe}$ values (c. 1.2) and $\mathrm{Co}+\mathrm{Ni}+\mathrm{Cu} \times 10$ (c. 11 wt\%) measured for U1365B-M, although high values, these samples remain within the field of hydrogenous precipitation, thus, from 12.7 to c. $8 \mathrm{Ma}$ U1365B-M displays $\mathrm{Mn} / \mathrm{Fe}$ and $\mathrm{Co}+\mathrm{Ni}+\mathrm{Cu}$ contents comparable to present day Antarctic FMNs. However, from c. $8 \mathrm{Ma}$ onward U1365B-M is more comparable with Pacific FMNs. Additional physiochemical parameters used for discerning the mode of nodule formation are presented in Figure 6.11 and provide further evidence for U1365B-M having acquired its geochemical composition from the direct precipitation of elements from seawater. Furthermore, these geochemical parameters are lower, by a factor of five, to those listed for FMNs characterised by oxic diagenesis.

Despite physical (e.g., spherical shape) and chemical (e.g., $\mathrm{Mn} / \mathrm{Fe}$ ) characteristics of U1365B-M, attesting to a hydrogenous mode of formation, Aplin \& Cronan (1985) argued that no nodules resting on or in marine sediments can be considered entirely hydrogenous. Moreover, Jung \& Lee (1999) suggested that the vast majority of FMNs grow episodically under the influence of oxic diagenesis, when elements such as Mn (and its associated transition elements e.g., $\mathrm{Cu}, \mathrm{Ni}$ and $\mathrm{Zn}$ ) become re-mobilised within reducing pore fluids and enriched within FMNs during intermittent periods of faster abyssal currents, capable of reworking seafloor sediments. To assess the degree to which oxic and suboxic diagenesis may have contributed remobilised elements to U1365B-M, the data for $\mathrm{Mn} / \mathrm{Fe}$ and $\mathrm{Ni}+\mathrm{Cu}$ (wt \%) are compared with FMNs (hydrogenous and diagenetic) from the ClarionClipperton Fracture Zone (blue upper curve; Figure 6.12(a)) and Peru Basin (red lower curve; Figure 6.12(a)). Evident in Figure 6.12 (a) \& (b), is that oxic diagenesis has contributed comparatively little remobilised elements to U1365B-M, which is positioned within the hydrogenous region of the graph (with $\mathrm{Mn} / \mathrm{Fe}$ values of about unity). Additionally, the oxygen concentration of the PDWBC must have remained $>5 \mu \mathrm{M}$ for the growth history of U1365B-M, as the data points plots to the far left of the turning point on the hyperbolic regression curve, suggested by Halbach, et al. (1981) as indicating the onset of suboxic diagenesis. However, the three clusters identified in Figure 6.5 (also see Figure 6.6), do display a stepped increase in $\mathrm{Mn} / \mathrm{Fe}$ values (Figure 6.12(c)) and $\mathrm{Co}-\mathrm{Ni}-\mathrm{Cu}$ contents, which are indicative of increased contributions from diagenetically remobilised elements (e.g., Mn, Ni, Cu; Halbach, et al., 1981; Glasby, 2000). 
(a)

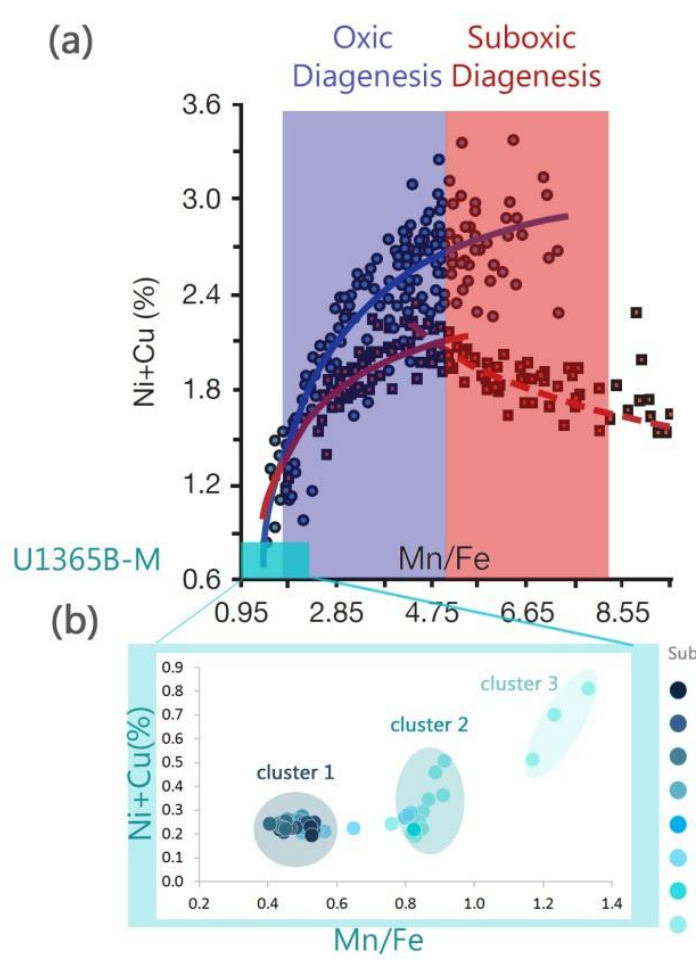

(b) (c)

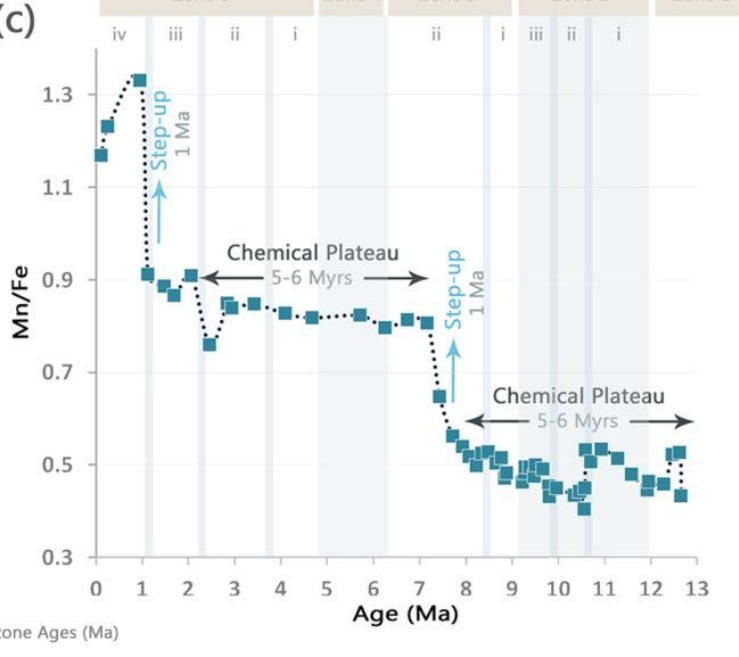

Figure 6.12 $\mid$ Contributions from oxic and suboxic diagenesis. (a) Hyperbolic regression curves of $\mathrm{Ni}+\mathrm{Cu}$ against $\mathrm{Mn} / \mathrm{Fe}$ for FMNs from the clarion-Clipperton Fracture Zone region (upper curve; blue) and Peru Basin (lower curve; red) (after Halbach, et al., 1981) with a Mn/Fe value of 5 indicating the transition between oxic and suboxic diagenesis. (b) $\mathrm{Ni}+\mathrm{Cu}$ against $\mathrm{Mn} / \mathrm{Fe}$ for FMN U1365B-M indicating the three clusters identified in the $\mathrm{Fe}-\mathrm{Mn}(\mathrm{Co}+\mathrm{Ni}+\mathrm{Cu}$ x10) ternary diagram. (c) $\mathrm{Mn} / \mathrm{Fe}$ against age, illustrating 5-6 Myr periods of relatively constant $\mathrm{Mn} / \mathrm{Fe}$ values (clusters 1-3) separated by transitions to higher $\mathrm{Mn} / \mathrm{Fe}$ values from c. $8 \mathrm{Ma}$ to $7 \mathrm{Ma}$ and c. 2 to $1 \mathrm{Ma}$.

\section{Paleoproductivity}

The observed decrease in $\mathrm{Ni}$ and $\mathrm{Cu}$ contents at $\mathrm{Mn} / \mathrm{Fe}$ values $>5$, has been suggested, since the initial work of Halbach, et al., (1981), to be related to biological activity in ocean waters above FMN growth sites. Halbach, et al., (1981) found that FMNs that fall within the suboxic zone of Figure 6.12 where those collected from below the equatorial zone of high biological activity. Here, Halbach, et al. proposed decomposing organic matter results in a decrease of the redox potential within the uppermost part of the underlying sediment column, which promotes the mobilisation of $\mathrm{Mn}^{2+}$ hence FMNs from this region grow faster and are enriched in $\mathrm{Mn}$ whilst depleted in $\mathrm{Ni}$ and $\mathrm{Cu}$. The hydrogenous nature of U1365B-M may thus be related to the low biological productivity of the surface waters of the Southwest Pacific basin, in comparison to the Clarion-Clipperton Fracture Zone and 
Peru Basin (Glasby, 2000). In regards to the supply of $\mathrm{Mn}$ and $\mathrm{Fe}$ oxyhydroxides to U1365B-M (Figure 6.12(c)), primary productivity is considered the principal regional environmental control (Halbach \& Puteanus, 1984; Verlaan, et al., 2004): (a) through controls on the 'rain' to the seafloor of biogenic detritus, and thus diagenetic enrichment (e.g., $\mathrm{Mn}$ ) or depletion (e.g., $\mathrm{Ni}, \mathrm{Cu}$ ) of certain elements (see above); (b) through position of the Carbonate Compensation Depth (CCD; 4200 - 4500 m, Southwest Pacific; Verlaan, et al., 2004) below which, the dissolution of carbonate plankton tests form the primary control on the delivery of Fe, and; (c) through physiochemical controls on depth of the Oxygen Minimum Zone (OMZ; UCDW c. 1500-2500 m; Hayward, et al., 2004), which forms the primary control on the delivery of $\mathrm{Mn}$ to the deep ocean. Additional controls involve abyssal current speeds and corrosiveness (Hein, et al., 1992).

The search for chemical proxies of biological activity, persevered in deep-sea sediments, has continued for many years. Concentrations of organic carbon, calcium carbonate and opal have collectively and individually been used to infer past changes in biological productivity (e.g., Farrell, et al., 1995; Diester-Hass \& Ness, 2004; Diester-Hass, et al., 2004; Hayward, et al., 2004; Kuhn, et al., 2004). These studies have revealed two major paleoceanographic events of global extent for the Late Neogene: a carbonate crash event sharp depression in carbonate concentrations related to strong dissolution events between 12 and $9 \mathrm{Ma}$ (11 to $7 \mathrm{Ma}$ for the Southwest Pacific east of New Zealand; Hayward, et al., 2004) and biogenic bloom event - an increase in marine biological productivity between 7 and $4 \mathrm{Ma}$ (7 to $6 \mathrm{Ma}$ for the Southwest Pacific east of New Zealand; Hayward, et al., 2004). Alternative chemical tracers such as Ba (e.g., Dymond, et al., 1992; Pfeifer, et al., 2001), Cd/Ca (Jarvis, et al., 1994; Henderson, 2002) and Th/Ba (e.g., Fagel, et al., 1997), have been increasingly explored as proxies of paleoproductivity. However, there has been limited application of these proxies for unravelling past productivity changes from FMN geochemistry.

In the case of $\mathrm{Ba}$, the formation of authigenic barite in surface water has been related to bio-induced processes and high barium concentrations have been observed in seafloor sediments underlying regions of high biological activity (e.g., Dymond, 1986; Gingele \& 
Dahmke, 1994; see also Tribovillard, et al., 2006). The use of authigenic $\mathrm{Ba}\left(\mathrm{Ba}_{\text {excess }}\right)$ as a paleoproductivity proxy has the underlying assumption that changes in $\mathrm{Ba}_{\text {excess }}$ are directly and predicable related to productivity. However, as many studies have eluded, Ba may be contained within many different mineral phases, some of which are biologically associated (e.g., carbonates, organic matter, barite) and others which may not be directly or primarily related to biological activity (such as ferromanganese oxyhydroxides and terrestrial material) (Dehairs, et al., 1980; Dymond, et al., 1992; Gingele and Dahmke, 1994; Schroeder, et al., 1997; McManus, et al., 1998; Rutten and de Lange, 2002; Gonneea \& Paytan, 2006). Thus, as Ba concentrations are strongly correlated with the Fe-oxide phase of U1365B-M, related to the background seawater signal derived from terrigenous fluxes (Figure 6.5), Ba concentrations are presented in Figure 6.13 (a) but not assessed alone as a paleoproductivity proxy. In addition to authigenic Ba concentrations, the association of high $\mathrm{Ba} / \mathrm{Th}$ values with high productivity, identified by Fagel, et al., (1997), was also applied to U1365B-M and illustrated in Figure 6.13 (b).

Utilising element associations of U1365B-M, as $\mathrm{Cu}$ and $\mathrm{Zn}$ where identified as being associated with the biogenic phase (and Wen, et al. (1997) emphasised the application of element ratios for identifying regional or basin-wide processes), $\mathrm{Zn} / \mathrm{Cu}$ values are also presented in Figure 6.13 (c) and considered as a proxy for the vertical flux of organic ligands, as $\mathrm{Zn}$ is more weakly complexed in comparison to $\mathrm{Cu}$, intuition dictates that an increase in $\mathrm{Zn} / \mathrm{Cu}$ indicates increased availability of organic ligands (e.g., Coale \& Bruland, 1988; Bruland, 1989; Little, et al., 2014). Furthermore, Ba/Cu values are presented (Figure 6.13(d)), as increased concentrations of these elements are reported in the literature to be associated with surface water productivity (principally Ba; e.g., Dymond, et al., 1992) and organic decomposition on the seafloor (principally Cu; e.g., Halbach, et al., 1981). Additionally, a $\mathrm{Mn} /(\mathrm{Ni}+\mathrm{Cu})$ has been calculated to represent the relationship identified by Halbach, et al., 1981 whereby, high biological activity results in increased abundance of $\mathrm{Mn}$ and decreased $\mathrm{Ni}+\mathrm{Cu}$ contents (Figure 6.13(e)) (generally in FMNs with $\mathrm{Mn} / \mathrm{Fe}>5$ ). 


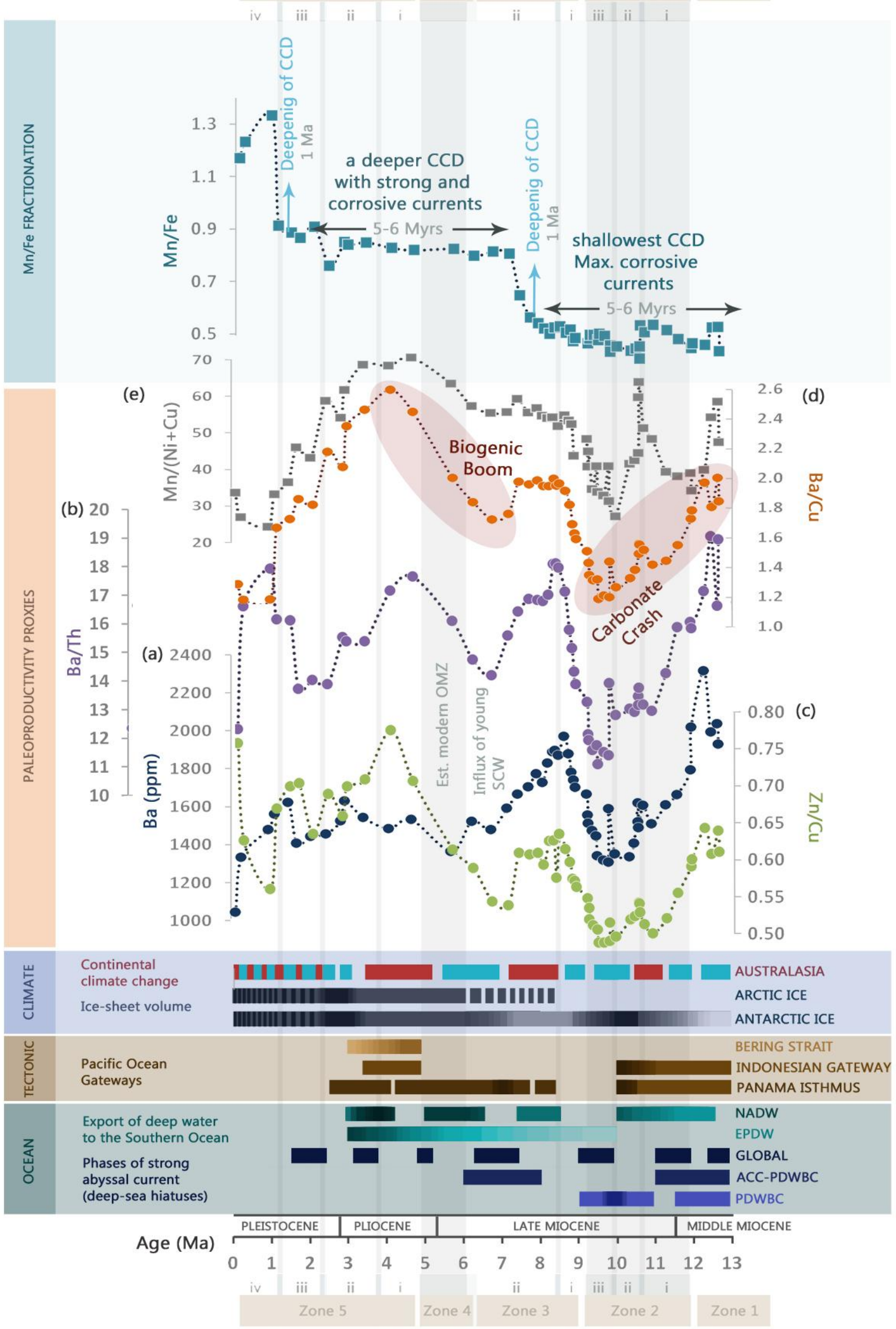


Figure 6.13 | Paleoproductivity proxies of U1365B-M as record of relative changes in biological activity throughout the late Neogene (a) displays the paleoredox proxy of authigenic $\mathrm{Ba}$, reported to be associated with inorganic minerals produced as a by-product of high biological activity, (b) $\mathrm{Ba} / \mathrm{Th}$ utilising the relationship identified by Fagel, et al., (1997) with high values associated with high biological activity, (c) $\mathrm{Zn} / \mathrm{Cu}$, utilising the element associations identified in Figure 6.5 and published suggestions of these elements increasing in concentration in association with an increased flux of organic ligands through the water column (e.g., Little, et al., 2014), (d) $\mathrm{Ba} / \mathrm{Cu}$, , utilising the element associations and reports of their associations in the literature, (e) $\mathrm{Mn} /(\mathrm{Ni} / \mathrm{Cu}$ ) to indicate the relationship between the release of these elements via oxic diagenesis to the background seawater chemistry with high values recorded in response to increased productivity and subsequent decomposition at the sediment-water interface, and the $\mathrm{Mn} / \mathrm{Fe}$ ratio illustrating $\mathrm{Fe}-\mathrm{Mn}$ fractionation in association with changes in the depth of the CCD, in addition to annotations from regional changes in biological activity, depth of the CCD and establishment of the OMZ (Hayward, et al., 2004). At the base of the Figure key climate-tectonic-ocean events of the Late Neogene are illustrated.

The aforementioned geochemical parameters, plotted in Figure 6.13 as $\mathrm{Mn} / \mathrm{Fe}$ values and paleoproductivity proxies, show good correlation with biological events previously reported for the region (Southwest Pacific, east of New Zealand) from benthic foraminifera proxies of late Neogene paleoceanography (Hayward, et al., 2004; annotated on Figure 6.13), and further afield. Firstly in regards to the fractionation of Fe-Mn oxyhydroxides $(\mathrm{Mn} / \mathrm{Fe}$; Figure 6.13(a)), the chemical plateau signifying stable $\mathrm{Mn}$ and Fe delivery to U1365B-M, at a relatively constant and low ratio (c. 0.5 ), from 12.7 to $8.4 \mathrm{Ma}$ (zone 1 to 3ii), indicate a high Fe flux (c. 22 wt \%) as a result of significant dissolution of calcareous tests (Halbach, et al., 1984; Glasby, et al., 2000; Hein \& Koschinsky 2013). This is consistent with reports of maximum corrosive abyssal currents for the study area (Joseph, et al., 2004; McKay, et al., 2014) and the shallowest CCD and lysocline for the New Zealand region (Hayward, et al., 2004; 11 - 7 Ma), for South of Tasmania (Diester-Haass \& Nees, 2004; 11 - 9.6 Ma), for the Central Pacific (van Andel, et al., 1975; Halbach, et al., 1984; 11 - $6 \mathrm{Ma}$ ), equatorial Pacific (Farrell, et al., 1995; 12 - $9 \mathrm{Ma}$ ) and Southeast Atlantic Ocean (Diester-Haass \& Nees, et al., 2004; 9 - $7 \mathrm{Ma}$ ). These authors note that during this period, paleoproductivity proxies display a significant 'carbonate crash' in response to rapid development of Antarctic ice-sheets and onset of corrosive AABW formation over this period and thus this carbonate crash also correlates with global Neogene Hiatus NH5 (10 to 9 Ma; Barron \& Keller, 1989) and Miocene oxygen isotope excursion Mi6 (Miller, et al., 1991). From zones 1 to the termination of zone 2, all paleoproductivity proxies indicate 
a reduction in biological productivity with some of the lowest values being reached between 10 and $9.5 \mathrm{Ma}$ (e.g., Ba decreases by c. 1000 ppm between 12.7 and $9.5 \mathrm{Ma}$ ). This is highly comparable with the carbonate crash event reported for South of Tasmania (10 to 9.6 Ma; Diester-Haass \& Nees, 2004). A rapid but short-term rise in paleoproductivity is illustrated most clearly in the $\mathrm{Mn} /(\mathrm{Ni}+\mathrm{Cu})$ curve at 11.6 to 10.6 correlating with a period of relative climatic warmth (Kennett \& von der Borch, 1986; Cronin, 2010).

Returning to the $\mathrm{Mn} / \mathrm{Fe}$ time-series, from c. 8.4 to $7.2 \mathrm{Ma}$ (throughout zone 3ii), Fe concentrations decrease (22 to $19 \mathrm{wt} \%$; indicating reduced carbonate dissolution) and $\mathrm{Mn}$ is enriched ( 11 to $16 \mathrm{wt} \%$; indicating initial development of the OMZ). This $1 \mathrm{Myr}$ transition phase to a new stable, higher $\mathrm{Mn} / \mathrm{Fe}$ of c. 0.8 , is associated with increased AABW production and current speeds (Hayward, et al., 2004; McKay, et al., 2014) and a significant deepening of the CCD (and lysocline; Hayward, et al., 2004). At c. 7.2 Ma when $\mathrm{Mn} / \mathrm{Fe}$ values reach a new higher equilibrium, paleoproductivity proxies all show a decrease in values (to varying degrees), consistent with the reported influx of cool AABW, before increasing from $\mathrm{c}$. 7 to a peak at about $4 \mathrm{Ma}$ consistent with warming climatic conditions and peaking during the Mid-Pliocene Climate Optimum (Kennett \& von der Borch, 1986; Cronin, 2010) (however this is not reflected in Ba ppm). The timing of this biogenic bloom is consistent with those reported for the New Zealand region (Hayward, et al., 2004; 7 - $6 \mathrm{Ma}$ ), for South of Tasmania (Diester-Haass \& Nees, 2004; 7 - 6.5 Ma), for the Central Pacific (van Andel, et al., 1975; Halbach, et al., 1984; 6 - 4 Ma), equatorial Pacific (Farrell, et al., 1995; 7 - 4 Ma) and Southeast Atlantic Ocean (Diester-Haass \& Nees, et al., 2004; 7 - $6 \mathrm{Ma}$ ). These researchers have associated this biogenic bloom with increased nutrient availability in the oceans associated with: (a) stratification of the Southern Ocean and establishment of the modern OMZ within UCDW (c. $1500-2600 \mathrm{~m}$ for the New Zealand region Hayward et al., 2004 and Southwest Pacific Ocean; Verlaan, et al., 2004); (b) NADW export to the Southern Ocean with properties comparable to present day and thus establishment of modern thermohaline circulation, inferred from world-wide decrease in $\delta 13 \mathrm{C}$ content of benthic foraminifera (Bender \& Keigwin, 1979; Kennett \& von der Borch, 1986; Cronin, 2010). From c. 6 - 7 to $1 \mathrm{Ma}$, the 5 - $6 \mathrm{Myr}$ period of stable $\mathrm{Mn} / \mathrm{Fe}$ values is associated with stable CCD and lysocline depths and relatively strong abyssal currents until c. 3 to $1 \mathrm{Ma}$ when, during late Pliocene cooling association with WAIS ice 
sheet expansion and northern hemisphere glaciation (Kennett \& von der Borch, 1986; Cronin, 2010; McKay, et al., 2012), the OMZ and CCD extended deeper (Hayward, et al., 2004). All proxies, except for $\mathrm{Zn} / \mathrm{Cu}$, generally show a corresponding decrease in productivity since c. $4 \mathrm{Ma}$ and especially since c. $1 \mathrm{Ma}$. The $6 \mathrm{Ma}$ time marker of significant oceanographic change was noted in the physical archives of U1365B-M by the presence of an erosional hiatus and significant change in texture between zones 3 and 4 . As noted in the previous section, this change in nodule accretion, from which point the growth rate of U1365B-M (and FMNs from the Pacific, Atlantic and Indian Oceans see Segl, et al., 1989) decreases from c. $6 \mathrm{~mm} / \mathrm{Ma}(12.7$ to c. $6 \mathrm{Ma}$ ) to $3.5 \mathrm{~mm} / \mathrm{Ma}$ (c. 6 to 1 $\mathrm{Ma})$. Additionally, this basin wide phenomenon is recorded in a change from mottled and cuspate microstructures into more structured columnar and laminated growth, inferred to reflect increased frequency and cyclical of G/I climatic changes (Glasby, et al., 1980; Segl, et al., 1989; Mangini, et al., 1990; Banakar, et al., 1997; Glasby, 2000). Loutit \& Keigwin (1982) and more recently Cronin (2010) give a summary of events that may be correlated with the corresponding ${ }^{813} \mathrm{C}$ shift at c. $6 \mathrm{Ma}$ : (1) an overall cooling of surface waters; (2) an increase in bottom water circulation speeds and ocean fertility; (3) lowering of sea-level; (4) isolation of the Mediterranean; (5) global deepening of the CCD; (6) establishment of modern thermohaline circulation, and; (7) shoaling of the Isthmus of Panama.

The establishment of the Southwest Pacific OMZ at c. $6 \mathrm{Ma}$, due to biological decomposition and consumption of $\mathrm{O}_{2}$ at mid-depths within the ocean (Dickens \& Owen, 1994), controls the delivery of Mn to the deep sea (Glasby, 2000). A series of investigation concerning the marine geochemistry of $\mathrm{Mn}$, has led to the concept of OMZ $\mathrm{Mn}$ redirection. This occurs when Mn oxyhydroxides re-dissolve upon entering the $\mathrm{OMZ}$ and the resulting $\mathrm{Mn}^{2+}$ is redirected by lateral advection or vertical diffusion processes toward more oxygenated environments (e.g., Klinkhammer \& Bender, 1980; Halbach \& Puteanus, 1984; Dickens \& Owen, 1993). In this case the underlying PDWBC. The downward flux of reducible $\mathrm{Mn}$ (and $\mathrm{Fe}$ ) is thus redirected through the $\mathrm{OMZ}$ via redox gradients to the more oxygen rich deep waters. Johnson et al., (1992) stated that the downward flux of $\mathrm{Mn}$ is proportional to the concentration of bottom water $\mathrm{O}_{2}$, thus in addition to biological controls, changes in the redox state of the PDWBC will also play a role in controlling the delivery of $\mathrm{Mn}$ (and Fe) to the Campbell Nodule Field. 


\section{Paleoredox}

Climatic controls on primary productivity, varying depths of the OMZ, CCD, large changes in sea level due to ice-sheet development and demise, changes in the export and production of water masses to and from the Southern Ocean, in addition to tectonic opening and closing of oceanic basins, have periodically led to relatively rapid shifts in the oxygenation of marine bottom waters (Kominz, 2001; Pattan \& Pearce, 2009; Cronin, 2010; Schijf, 2012). However, late Neogene changes in ocean $\mathrm{O}_{2}$ are not well documented. The distinct redox states that certain metals have under oxidising and reducing conditions (e.g., $\mathrm{As}^{5+}$ and $\left.\mathrm{As}^{3+}\right)$ can result in their differential adsorption onto settling Fe-Mn particles, which cause their concentration in FMNs (crusts and sediments) to rise and fall with the oxygenation of deep water at the time of deposition (Kominz, 2001; Cronin, 2010; Schijf, 2012). A particularly promising example is cerium (Ce), the only member of the YREE (yttrium and rare earth element) series that can be oxidized to $\mathrm{Ce}(\mathrm{IV})$ at the normal temperatures and pressures of seawater. Since the higher charge and smaller ionic radius of $\mathrm{Ce}(\mathrm{IV})$ make it more particle-reactive than its strictly trivalent REE neighbours, it is more strongly adsorbed on to Fe oxides, Mn oxides, and organic matter (Goldberg, et al., 1963; Elderfield, 1988; German, et al., 1995). Thus, in the presence of dissolved oxygen, cerium is oxidized to Ce (IV) and displays a positive Ce anomaly in YREE shale-normalised patterns of FMNs (German \& Elderfield, 1989; Karsten, et al., 1998; Glasby, 2000; Kato, et al., 2002) as illustrated for U1365B-M in Figure 6.14.

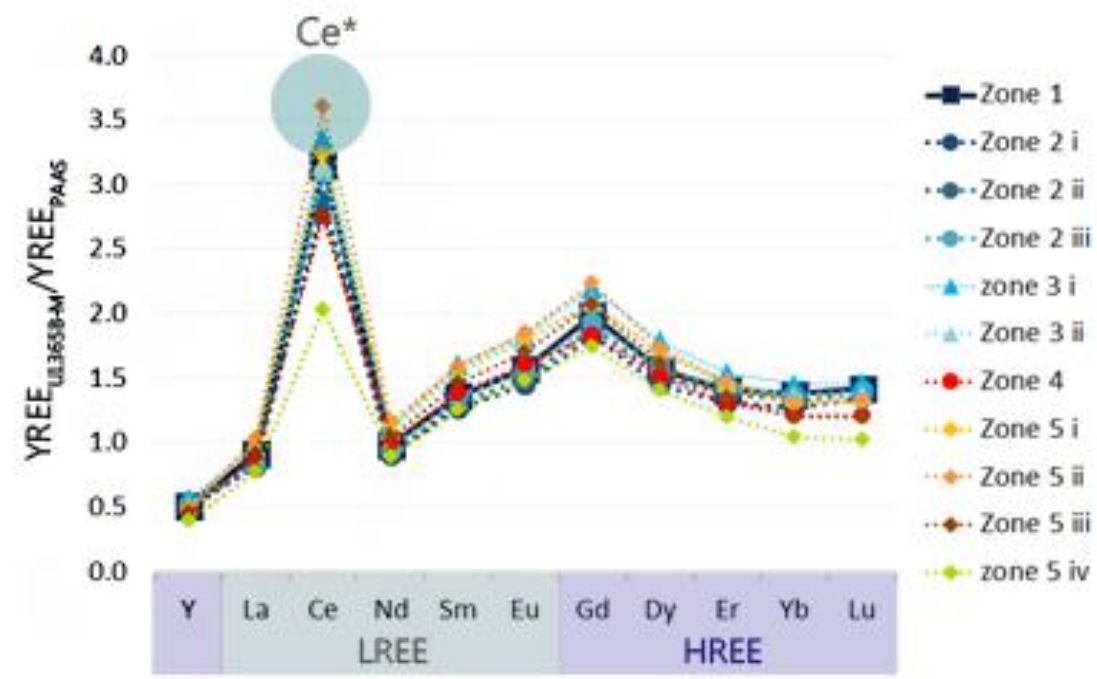

Figure 6.14 | Shale normalised YREE profile of U1365B-M. The Ce anomaly is identified by normalising YREE values to those of Post-Achaean Australian Sedimentary Rocks (PAAS) reported by McLennan (1989). 
Various studies have pointed out that $\mathrm{Ce} / \mathrm{Ce}^{\star}$ is subject to a number of caveats, particularly that the sedimentary Ce anomaly record, does not exclusively depend on the oxygenation of ambient seawater, for example: modifications by diagenetic remobilisation of Ce (e.g. Pattan, et al., 2005) and the oxidation of Ce by $\mathrm{MnO}_{2}$ scavenging rather than ocean oxygen (e.g. Takahashi, et al., 2000; Nakada, et al., 2013), compromise the legitimacy of $\mathrm{Ce}$ as a paleo-redox proxy. However, studies conducted on Ce adsorption in the natural environment, have found (especially for FMNs) Ce adsorbed to both $\mathrm{Fe}$ and $\mathrm{Mn}$ oxyhydroxides (e.g. Nath, et al., 1994; Bau \& Koschinsky 2006). Nath, et al., (1994) suggested that $\mathrm{Ce}$ is chemisorbed onto iron oxyhydroxides which are epitaxially intergrown with $\mathrm{MnO}_{2}$ (as illustrated for U1365B-M by Ce falling under group 4, inferred to be associated with mixed Mn-Fe oxyhydroxide minerals; Figure 6.5). Furthermore, Jiang et al. (2011) concluded from their studies that the positive Ce anomaly in hydrogenic ferromanganese crusts results from the oxidation of soluble $\mathrm{Ce}^{3+}$ to insoluble $\mathrm{Ce}^{4+}$ by the actively soluble oxygen of the abyssal current rather than by the oxidation on $\mathrm{MnO}_{2}$ minerals. Here, the redox history of the PDWBC is inferred from the Ce-anomaly $\left(\mathrm{Ce} / \mathrm{Ce}^{*}=2[\mathrm{Ce}]_{\mathrm{n}} /[\mathrm{La}]_{\mathrm{n}}+[\mathrm{Pr}]\right.$; were $\mathrm{Pr}$ has been substituted for $\left.\mathrm{Nd}\right)$ and compared to a number of other redox sensitive parameters to test its reliability. These include: $\mathrm{V} /(\mathrm{V}+\mathrm{Ni})$, $\mathrm{Ni} / \mathrm{Co}, \mathrm{U} / \mathrm{Th}$, illustrated in Figure 6.15 and $\mathrm{Th} / \mathrm{U}, \mathrm{Eu} / \mathrm{Eu}^{*}$ and $\mathrm{V} /(\mathrm{V}+\mathrm{Ni})$ time series illustrated in Figure 6.16. (see Jones \& Manning, 1994; Tribovillard, et al., 2006; Pattan \& Pearce, 2009; Soua, 2011).
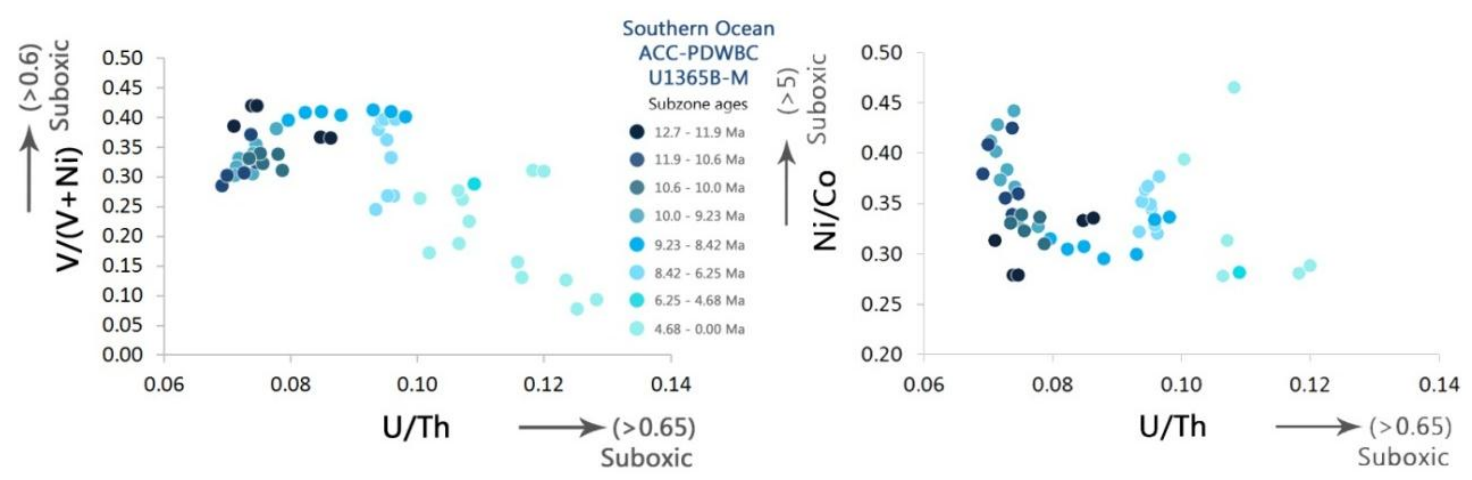

Figure 6.15 Paleoredox proxies of U1365B-M: V/(V+Ni), Ni/Co and U/Th (left) the paleoredox proxy of $\mathrm{V} /(\mathrm{V}+\mathrm{Ni}$ ) is plotted against that of $\mathrm{U} / \mathrm{Th}$ and (right) Ni/Co versus U/Th. The plotted parameters indicate highly oxic conditions of the PDWBC throughout the late Neogene as values remain below those annotated that are indicative of suboxic conditions. However, within the constraints of highly oxic conditions, ocean oxygen has decreased. 
In the marine system the depositional environment can be either oxic (high levels of dissolved oxygen), suboxic (low dissolved oxygen levels $\sim 1-2 \mathrm{ml} / \mathrm{l}$ ) or anoxic (absence of oxygen). Figure 6.15 illustrates that the geochemical parameters indicating suboxic conditions $\mathrm{V} /(\mathrm{V}+\mathrm{Ni})>0.6$ and $\mathrm{U} / \mathrm{Th}>0.65$ (Jones \& Manning, 1994) are far in excess of the plotted position of U1365B-M samples, indicating highly oxic conditions have prevailed throughout the growth history of U1365B-M and thus the past $12.7 \mathrm{Ma}$ for the PDWBC. However, as seen in Figure 6.16 within the constraints of a highly oxic PDWBC, the time-series of the paleoredox proxies indicate a long-term progressive reduction in ocean oxygen, consistent with long-term declining bottom water temperatures for the Atlantic and Pacific (Lear, et al., 2003; see also Billups \& Shrag, 2002) and benthic ${ }^{\delta 18} \mathrm{O}$ (Zachos, et al., 2001).

This apparent decline in ocean oxygen has occurred within three main steps (Figure 6.16).Using the $T h / U$ paleoredox proxy as representative of the redox proxies presented (noting that $\mathrm{V} /(\mathrm{V}+\mathrm{Ni})$ displays a time-series more comparable with declining bottom water temperatures reported for the west Atlantic and $\mathrm{Eu} / \mathrm{Eu}^{\star}$ generally display a mirrored profile to $\mathrm{Th} / \mathrm{U}$ and the $\mathrm{Ce} / \mathrm{Ce}^{\star}$ with increased values indicating periods of more reducing bottom waters) these three stages are: (1) the relatively high $\mathrm{Th} / \mathrm{U}$ values (14.5) that were maintained for c. $3.5 \mathrm{Myr}$ (from c. 13 to $9.5 \mathrm{Ma}$ ) rapidly decrease (Th/U - 14.5 to 10 ) over c. 1 Myrs from 9.5 to $8.4 \mathrm{Ma}$ across zone 3i; (2) relatively stable $\mathrm{Th} / \mathrm{U}$ values (c. 10) that were maintained for 2 Myrs from 8.4 to 6.3 Ma undergo further reduction (Th/U - 10 to 8) from 6.3 to $4 \mathrm{Ma}$, and; (3) from the Mid-Pliocene period c. 4 Ma to 2.5 Ma values return to higher $\mathrm{Th} / \mathrm{U}$ of c. 10 before undergoing a third decline in values from 10 to $<8$ from 2.5 to present. The three transition periods (between 9.5 and $8.4 \mathrm{Ma}, 6.3$ to $4 \mathrm{Ma}$ and from 2.5 $\mathrm{Ma}$ to present) to lower $\mathrm{O}_{2}$ contents correlate with inferred biological blooms in the previous section. Redox proxies thus indicate that over the climatic deterioration of the late Neogene, $\ell \mathrm{LCDW}$ of the PDWBC are characterised by progressively lower oxygen levels. Generally, during periods of enhanced glaciation and phases of high ACC-PDWBC flow (Joseph, et al., 2004; Hayward, et al., 2004; McKay, et al., in press), oxygen levels are maintained, indicated by consistent $\mathrm{Th} / \mathrm{U}$. The transition to lower ocean oxygen occurs between these phases of fast current activity, which are generally, characterised by 


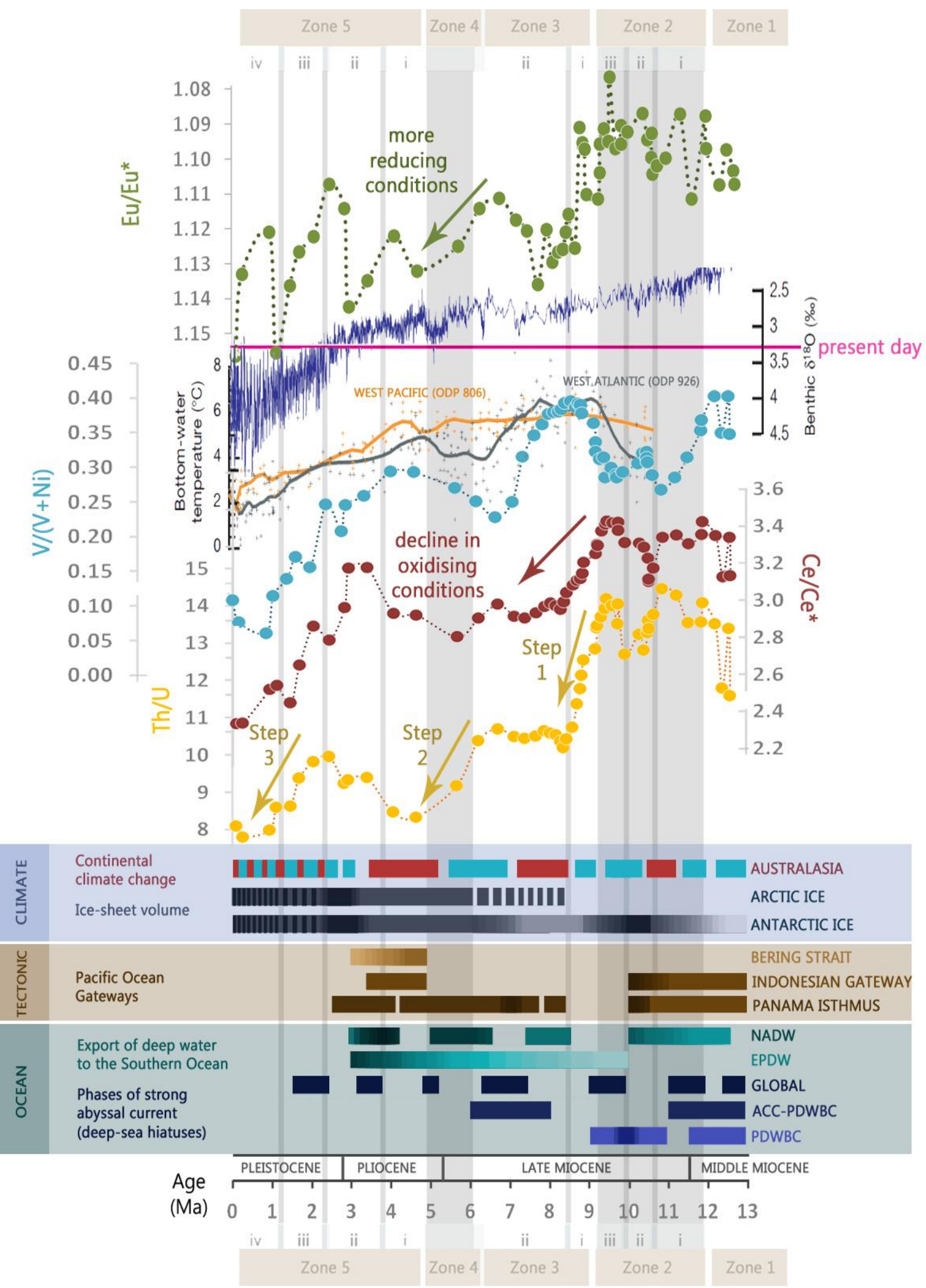

Figure 6.16 Time-series of paleoredox proxies of U1365B-M as a record of relative ocean oxygen contents throughout the late Neogene. From the bottom up the paleoredox proxies of $\mathrm{Th} / \mathrm{U}, \mathrm{Ce} / \mathrm{Ce}^{*}$, $\mathrm{V} /(\mathrm{V}+\mathrm{Ni})$, and $\mathrm{Eu}, \mathrm{Eu}^{*}$ are illustrated in addition to the benthic oxygen isotope curve of Zachos, et al. (2001) and bottom water temperatures for the west Pacific and Atlantic from Lear et al., (2003). 
relatively warmer climates (Joseph, et al., 2004; Naish, et al., 2007; Cronin, 2010; McKay, et al., in press), except for the mid Pliocene warm period were redox proxies indicate an increase in ocean oxygen in association with the warmer oceanic conditions.

Past inferences of paleo-oxygen levels are highly debated and focus on the question as to whether, during shallow glacial conditions: (a) ocean oxygen is lower, or (b) higher due to the increased capacity of the ocean for incorporating dissolved atmospheric gases (e.g., Broecker \& Peng, 1986; Francois, et al., 1997; Rutberg \& Peacock, 2006). Results that support low oxygen levels for shallow glacial oceans (e.g., Francois, et al., 1997) have been controversial, largely due to the association of high(reduced) oxygen levels with fast(slow) abyssal current speeds, the latter of which are known to have formed extensive deep sea hiatus's (e.g., Ganachaud \& Wunsch, 2000; Wunsch, 2003). The paleoredox proxies utilised here for U1365B-M, present a long-term decline in ocean oxygen for the PDWBC, consistent with late Neogene climate cooling. However, on millennial time-scales (c. 1-3 Myrs), paleoredox proxies indicate higher ocean $\mathrm{O}_{2}$ during peak glacial advances i.e., at $c$. $10 \mathrm{Ma}$ when Kennett \& von der Borch, (1986) and Cronin (2010) report Antarctic icesheet advance to volumes exceeding those of present-day, and from c. 3 to $2.7 \mathrm{Ma}$, during peak Northern Hemisphere Glaciation (NHG). These periods indicating short-term increases in ocean $\mathrm{O}_{2}$ are also coeval with phases of strong abyssal currents, generally considered to be well-oxygenated and having served to ventilate the deep-ocean since the Mid-Miocene Climate Transition c. 13 Ma (Cronin, 2010; Figure 6.16). Additionally, paleoredox proxies indicate low values during the Mid-Pliocene warm period, despite these low values showing an increase in ocean oxygen. Thus, paleoredox proxies also highlight the controversy associated with such proxies and thus the importance of abyssal current velocities and corrosiveness on the ventilation of the deep ocean, causing perturbations in the long-term trend of reduced oxygen content (see also Halbach \& Puteanus, 1984; Cronin, 2010). The amount of dissolved oxygen present in bottom waters at the time of deposition is, as alluded to above, a product of supply and biological consumption (Dickens \& Owen, 1994). An additional supply (or reduction) of ocean $\mathrm{O}_{2}$ to consider, is the variable export of water masses characterised by varying oxygen contents, to the Southern Ocean over the late Neogene i.e., present-day Pacific deep waters are at the end of the thermohaline circulation pathway and as such are depleted in ocean $\mathrm{O}_{2}$ (Schlosser, et al., 2001; Carter, et al., 2009; see also Chapter 2). 


\section{Paleocirculation}

Deciphering changes to past ocean circulation patterns is a vital prerequisite for decoding the chemical and physical archives of U1365B-M, as changes in water mass mixing and speed of the ACC-PDWBC encode information regarding climatic and tectonic conditions at the time of deposition. Late Neogene cryospheric development and oceanic gateway events can be inferred from changes in paleoseawater $\mathrm{Pb}$ (U1365B-M) (e.g., Chow \& Patterson, 1959; Abouchami \& Goldstein, 1995; von Blanckenburg, et al., 1996; Christiansen, et al., 1997; Reynolds, et al., 1995; Frank, et al., 1999; Vlastélic, et al., 2001; Henderson \& Maier-Reimer, 2002; van de Flierdt, et al., 2003; van de Flierdt, et al., 2004; Ling, et al., 2005; Frank, et al., 2006; Basak, et al., 2011; Chen, et al., 2012).

One of the most interesting results of the paleoseawater $\mathrm{Pb}$ record is that each textural zone, and their subtle subzone variations, displays unique $\mathrm{Pb}-\mathrm{Pb}$ mixing arrays in $\mathrm{Pb}-\mathrm{Pb}$ space (Figure 5.14 \& Figure 6.7). To recall, $\mathrm{Pb}-\mathrm{Pb}$ mixing arrays displayed five distinct features: (1) 13 to $10 \mathrm{Ma}$ (Zone 1 to Zone 2ii), a large progressive shift to more radiogenic values; (2) 10 to $8.4 \mathrm{Ma}$ (Zone 2ii to $3 \mathrm{i}$ ), a return to previously unradiogenic $\mathrm{Pb}$ values characteristic of Zone 1 but with a lower ${ }^{208} \mathrm{~Pb} /{ }^{204} \mathrm{~Pb}$ for a given ${ }^{206} \mathrm{~Pb} /{ }^{204} \mathrm{~Pb}$; (3) 8.4 to c. 6.3 $\mathrm{Ma}$ (Zone 3ii), a return to higher ${ }^{208} \mathrm{~Pb} /{ }^{204} \mathrm{~Pb}$ for a given ${ }^{206} \mathrm{~Pb} /{ }^{204} \mathrm{~Pb}$ with $\mathrm{Pb}$ values characteristic of Zone 1 ; (4) 6.3 to $1.7 \mathrm{Ma}$ (Zone 4, 5i-ii) maintenance of $\mathrm{Pb}-\mathrm{Pb}$ mixing that characterised Zone 1 but trending toward more unradiogenic values and; (5) $1.7 \mathrm{Ma}$ to present, a kink to lower ${ }^{208} \mathrm{~Pb} /{ }^{204} \mathrm{~Pb}$ ratios, inferred to represent $\mathrm{Pb}$ sourced from $\mathrm{New}$ Zealand (see Figure 5.14). As the majority of $\mathrm{Pb}$ compositions cluster within a relatively narrow range: $(\mathrm{a}){ }^{206} \mathrm{~Pb} /{ }^{204} \mathrm{~Pb}=18.80$ to 18.86 and $(\mathrm{b}){ }^{208} \mathrm{~Pb} /{ }^{204} \mathrm{~Pb}=38.8$ to 38.9 discussions on the paleoceanographic implications of this record are focused on the large isotopic changes that occur between 13 and 8.4 Ma.

Plotted in Figure 6.8 are the ${ }^{207} \mathrm{~Pb} / 204 \mathrm{~Pb}$ vs ${ }^{206} \mathrm{~Pb} /{ }^{204} \mathrm{~Pb}$ and ${ }^{208} \mathrm{~Pb} /{ }^{204} \mathrm{~Pb}$ vs ${ }^{206} \mathrm{~Pb} /{ }^{204} \mathrm{~Pb}$ compositions of U1365B-M in addition to those of Circum-Antarctic FMNs reported by Abouchami \& Goldstein (1995) and Vlastélic, et al. (2001). Pb isotope ratios of the India, Atlantic and Pacific Oceans show remarkably coherent data with the $\mathrm{Pb}-\mathrm{Pb}$ mixing arrays of U1365B-M, which lie directly between those of the Indian-Antarctic Ocean and Pacific, supporting the above assumption. According to the interpretations of Abouchami \& 
Goldstein (1995) the Indian-Antarctic seawater $\mathrm{Pb}$ composition is translated from NADW, and thus these data points reflect radiogenic NADW or "North Component Water" (NCW) when discussing water mass mixing throughout the late Neogene. In contrast, $\mathrm{Pb}$ compositions of the Chili Ridge FMN represent the most non-radiogenic end-member of "Pacific Component Water" (PCW). NCW and PCW define the two end-member compositions recorded in the ACC with intermediate compositions falling within a 'mixing envelope' between the two end-members. From the position of paleoseawater $\mathrm{Pb}$ compositions (U1365B-M) within this mixing envelop it appears that from 12.7 to $10 \mathrm{Ma}$ NCW export to Southern Ocean increased reaching a peak at this time. From 10 to $8.4 \mathrm{Ma}$ either there was a reduction in the export of NCW or NCW export was maintained while PCW became increasingly important over this period. From 8.4 to 6.3 $\mathrm{Ma} \mathrm{Pb}$ compositions become more radiogenic indicating a renewed flux of NCW or reduction in PCW export.

From 6.4 Ma to 1.7 Ma, compositions become more unradiogenic, reaching their present day values mid-way between NCW and PCW. The quaternary record (1.7 to $0 \mathrm{Ma}$ ) has been inferred to reflect New Zealand terrigenous fluxes. The time slices that are proposed to reflect increased NCW export to the Southern Ocean, 12.7 - $10 \mathrm{Ma}$ and 8.4 6.3 Ma, are strikingly similar to those proposed by Wright \& Miller (1996). Based on their study of mantle plume activity beneath the Greenland-Scotland Ridge, Wright \& Miller identified periods of time when this oceanic gateway was closed and NCW export to the Southern Ocean was restricted (13 $\mathrm{Ma}, 9 \mathrm{Ma}$, and $7 \mathrm{Ma}$ ) and illustrated that once mantle plume activity had subsided, the flux of NCW then resumed (12.5-9.6 Ma, 8.5 - 7.6 Ma). Wright \& Miller suggested that periods of restricted NCW flux were typically associated with cooler climates and enhanced NCW flux with periods of relative warmth, which is consistent with the occurrence of global deep sea hiatus's and climatic state illustrated in Figure 6.3 (and at the base of paleoprecipitation, paleoproductivity and paleoredox Figures). The coeval changes in the $\mathrm{Pb}$ composition of U1365B-M with those of NCW fluxes may therefore record Arctic gateway events and their controls on the export of NCW to the Southern Ocean. Additional support for the increasingly 'Pacific' Pb signal from $10 \mathrm{Ma}$ to present, has been presented by van de Flierdt et al. (2004). van de Flierdt et al. studied FMCs that roughly tracks the northward flow of the PCDW into the greater Pacific Ocean. The ${ }^{208} \mathrm{~Pb} /{ }^{204} \mathrm{~Pb}$ timeseries are illustrated in Figure 6.17 in addition to those 
of U1365B-M. For crusts Tasman and Nova the timeseries data are comparable, the slight offset in ages are most likely due to the $1.5 \mathrm{Ma}$ half-life used for their beryllium chronological framework. These data demonstrate a continuous northward dilution of €LCDW with overlying Pacific deep water, leading to progressively more Pacific like compositions. Additionally, the time-series of Tasman and Nova show no record of the significant shift to more radiogenic values between 13 to $10 \mathrm{Ma}$, as recorded by Zones 1 and $2 \mathrm{i}$ in $\mathrm{U} 1365 \mathrm{~B}-\mathrm{M}$. The records of these crusts were already recording more radiogenic $\mathrm{Pb}$ signals or, were illustrating stable $\mathrm{Pb}$ signals, until $10 \mathrm{Ma}$ when all three archives record a peak in $\mathrm{Pb}$ isotopic compositions. Thus, the $\mathrm{Pb}$ isotopic composition of the PDWBC was not translated to these crusts until this peak. Suggesting that until this time, the flux of NADW to the Southern Ocean was not strong enough to be traced north of the ACC and potentially records the onset of NADW formation from 12.7 to $10 \mathrm{Ma}$.

The progressive reduction in $\mathrm{Pb}$ isotope ratios, from $10 \mathrm{Ma}$ onwards was inferred by van de Flierdt et al. (2004) to have been driven by closure of the Indonesian Gateway and subsequent reorganisation of ocean circulation due to the restriction of deep water exchange between the Pacific and Indian Oceans. The timing of gateway closure has been proposed from the tectonic history of the region to range from 15.5 to $7.5 \mathrm{Ma}$ (e.g. Linthout, et al., 1997; Lawver \& Gahagan, 2003; Cronan, 2010). Thus, the drop in $\mathrm{Pb}$ signals from $10 \mathrm{Ma}$ to $8.4 \mathrm{Ma}$ may reflect the progressive closure of this gateway. In this respect, the $\mathrm{Pb}-\mathrm{Pb}$ mixing array and timeseries of Zone 5i-5iii (c. 5 to $1.7 \mathrm{Ma}$ ), which shows an increasing contribution of 'Pacific $\mathrm{Pb}$ ' to the present day ratios, could also record a shift in the location of Indonesian Throughflow. Cane \& Molnar (2001) proposed that between 5 and $3 \mathrm{Ma}$, south equatorial Pacific water flowed westward into the Indian Ocean at a more southerly position. Thus, the $\mathrm{Pb}-\mathrm{Pb}$ mixing array may record this gradual change in location with the continued shoaling of the Indonesian archipelago.

An alternative explanation for the $\mathrm{Pb}$ isotope record of $\mathrm{U} 1365-\mathrm{M}$ comes from the relatively new application of $\mathrm{Pb}$ isotopes for providing information on the timing and nature of ice sheet development and demise (Foster \& Vance, 2006; Crocket, et al., 2013). Crocket et al. (2013) associate increases in the radiogenic $\mathrm{Pb}$ (and to a lesser extent $\mathrm{Pb}$ concentration) as times when ice sheets where active at the marine margin. In this respect, the increase in $\mathrm{Pb}$ compositions from 13 to $10 \mathrm{Ma}$ could reflect ice-sheet development, 

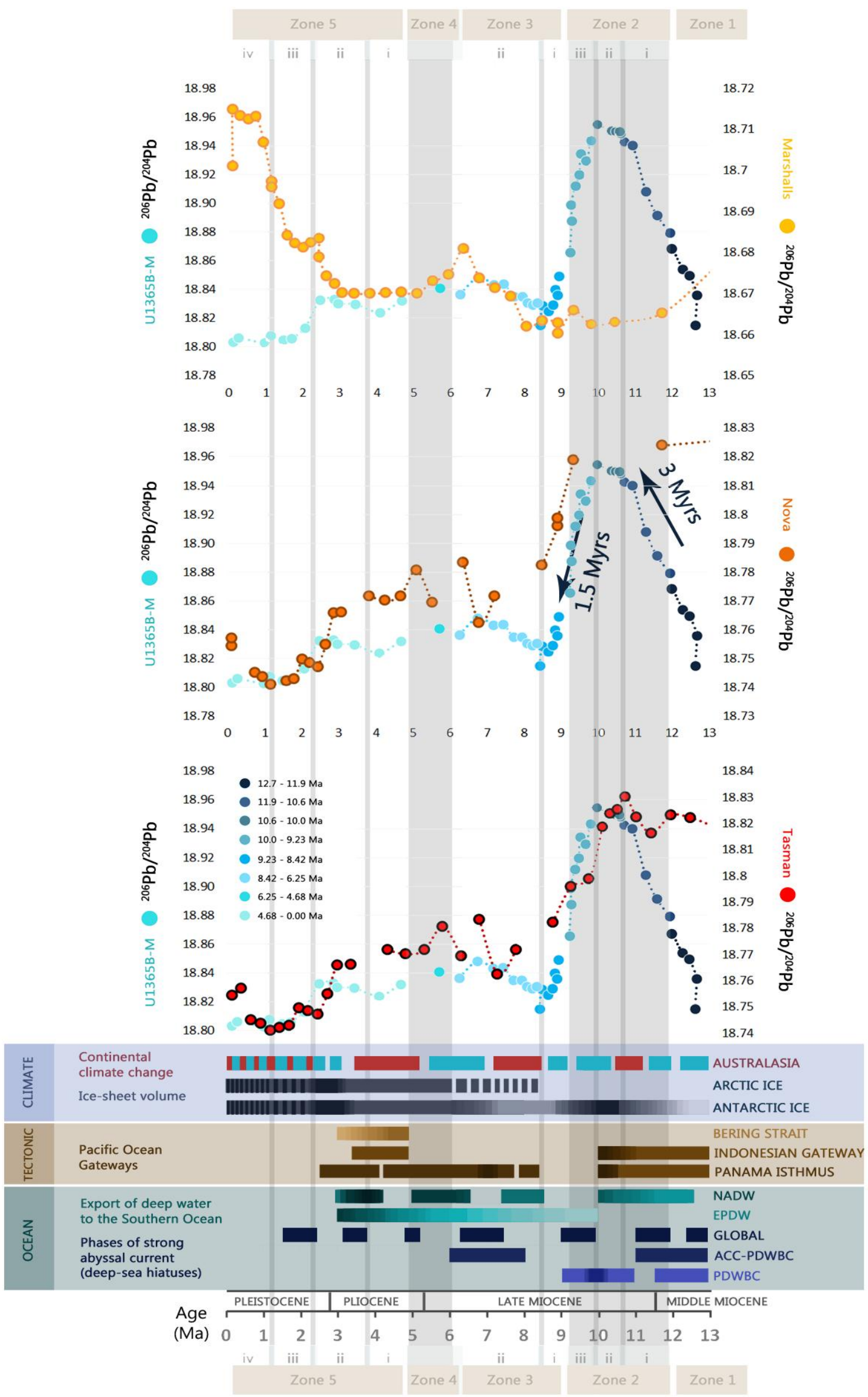
Figure 6.17 | Tracing the PDWBC from the Southern Ocean into the Equatorial Pacific over the late Neogene A Comparison of the ${ }^{206} \mathrm{~Pb} /{ }^{204} \mathrm{~Pb}$ timeseries recorded by U1365B-M, with Southwest Pacific Nodules, (bottom) crust Tasman, (middle) crust Nova and (top) crust Marshall, illustrated in the map (right) from van de Flierdt et al. (2004)

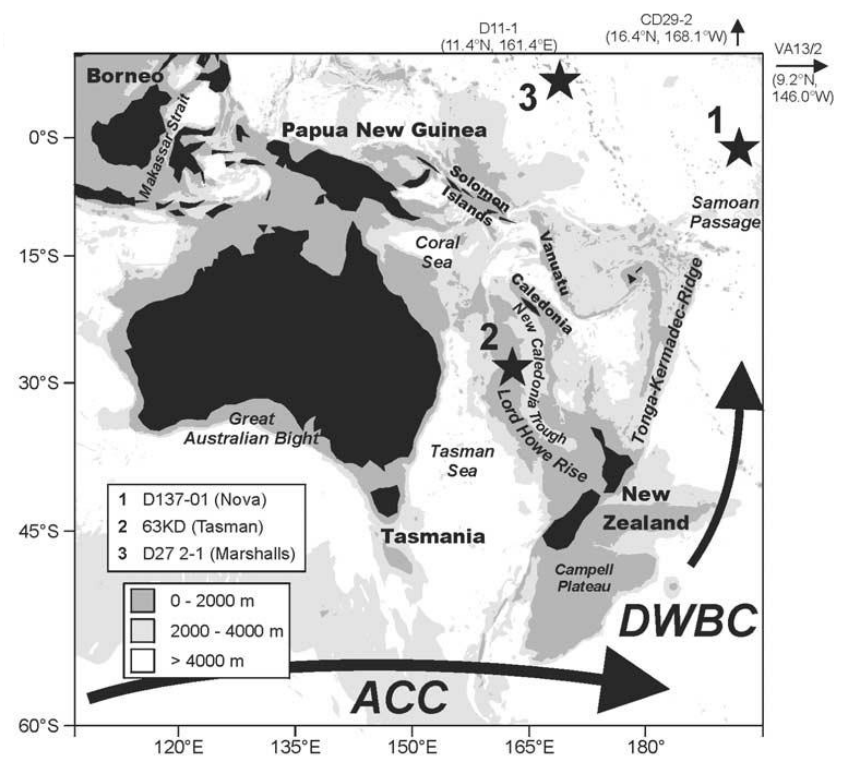

peaking in extent at $10 \mathrm{Ma}$, and from 10 to $8.4 \mathrm{Ma}$ seeing a return to the original glacial state prior to this expansion, with these 'factory settings' being roughly maintained since 8.4 $\mathrm{Ma}$ (illustrated by $\mathrm{Pb}-\mathrm{Pb}$ mixing arrays that fall within the cluster of relatively unradiogenic values). Additionally, this would indicate that Antarctic ice-sheet progressively built-up over c. 3 Myrs, and were restored from this excess volume within half the time taken to establish the large ice-sheets, within c. 1.5 Myrs (Figure 6.17).

Antarctic development of both the west and eastern ice sheets are well documented between 13-10 Ma (e.g. Haywood, et al., 2009), and greater ice volumes and(or) cooler temperatures than modern day have been proposed. Furthermore, evidence for a peak in ice sheet development being reached by $10 \mathrm{Ma}$ can be inferred from the occurrence and extent of deep-sea hiatus's (Joseph, et al., 2004). The drop in Pb isotopic compositions from 10 to $8.4 \mathrm{Ma}$, roughly corresponds to reports of a relatively warmer climatic period, but still characterised by cold conditions and ice sheet development. Similarly, the rise to more radiogenic $\mathrm{Pb}$ composition from 8.4 to $6.3 \mathrm{Ma}$ coincides with a late Miocene terminal event that has been inferred from a $\delta 13 \mathrm{C}$ shift in foraminifera to represent a global change in circulation and significant production of AABW (Segl, et al., 1989; Mangini, et al., 1990; Glasby, 2000). This culmination at 6.3 Ma is marked by an erosional hiatus and significant change in texture of U1365B-M and represents a time marker that has been observed in FMNs from each of the major ocean basins (Segl, et al., 1989). The three potential explanations (water mass mixing, tectonic and climatic events) for the 
observed $\mathrm{Pb}$ isotopic evolution of the ACC-PDWBC illustrate the complexity of climatetectonic dynamics on global paleoceanography. To decode the $\mathrm{Pb}$ record would require additional evidence from the use of other isotopic and elemental systems.

One type of candidate elements are the high-field strength elements zirconium $(\mathrm{Zr})$, hafnium (Hf), niobium ( $\mathrm{Nb}$ ) and tantalum (Ta). This group of elements consist of the geochemical twins, Zr-Hf and Nb-Ta (Goldschmidt, 1937; Firdaus et al., 2011; Frank, 2011). Within each pair their similar geochemical behaviour means that their relative abundance in the oceans should not be significantly affected (or equally affected) by biogeochemical cycling of these HFSE. As such, twin ratios $\mathrm{Zr} / \mathrm{Hf}$ and $\mathrm{Nb} / \mathrm{Ta}$ are expected to develop characteristic values for different regions of the oceans, reflecting their input sources, similar to Pb isotopes (Firdaus et al., 2011; Frank, 2011). Godfrey, et al. (1996) and Firdaus, et al. $(2008,2011)$ noted $\mathrm{Zr} / \mathrm{Hf}$ ratios display interoceanic fractionation, with values increasing with water depth and time along the deep ocean conveyor, from Atlantic deep water to Pacific deep water, with Firdaus et al., (2011) having measured the dissolved concentration of these HFSE in the Pacific Ocean, along two meridional transects (Figure 6.18(a)) and found that individual water masses displayed distinctive $\mathrm{Zr} / \mathrm{Hf}$ values, with old NPDW displaying the highest $\mathrm{Zr} / \mathrm{Hf}$ values (c. $500 \mathrm{pmol} / \mathrm{kg}$ ), and that $\mathrm{Nb} / \mathrm{Ta}$ values were more uniformly distributed for the deep Pacific Ocean, generally ranging between 50 and 60 (Figure 6.18(b)). Thus, the temporal record of these ratios in individual layers of FMNs and crusts could serve as a new proxy for changes in ocean circulation (Frank, 2011), and is applied here for the first time (based on publications to date) as a paleocirculation proxy.

The Zr/Hf measured for U1365B-M (Figure 6.18(c)), form a compatible AABWLCDW ( $(\mathrm{LCDW}$ ) end member for the $\mathrm{Zr} / \mathrm{Hf}$ values of Pacific water masses (Figure 6.18(b)), with $\mathrm{Zr} / \mathrm{Hf}$ values (in $\mathrm{pmol} / \mathrm{kg}$ ) ranging from 70 to 130 , indicating young $\mathrm{LCDW}$. The $\mathrm{Zr} / \mathrm{Hf}$ values are lower than those recorded along the Pacific seawater transects and $\mathrm{Nb} / \mathrm{Ta}$ values are higher for U1365B-M. This may be consistent with the fact that the Campbell Nodule Field is located further to the southwest and within the main flow of the ACC-PDWC, in comparison to the transects. 


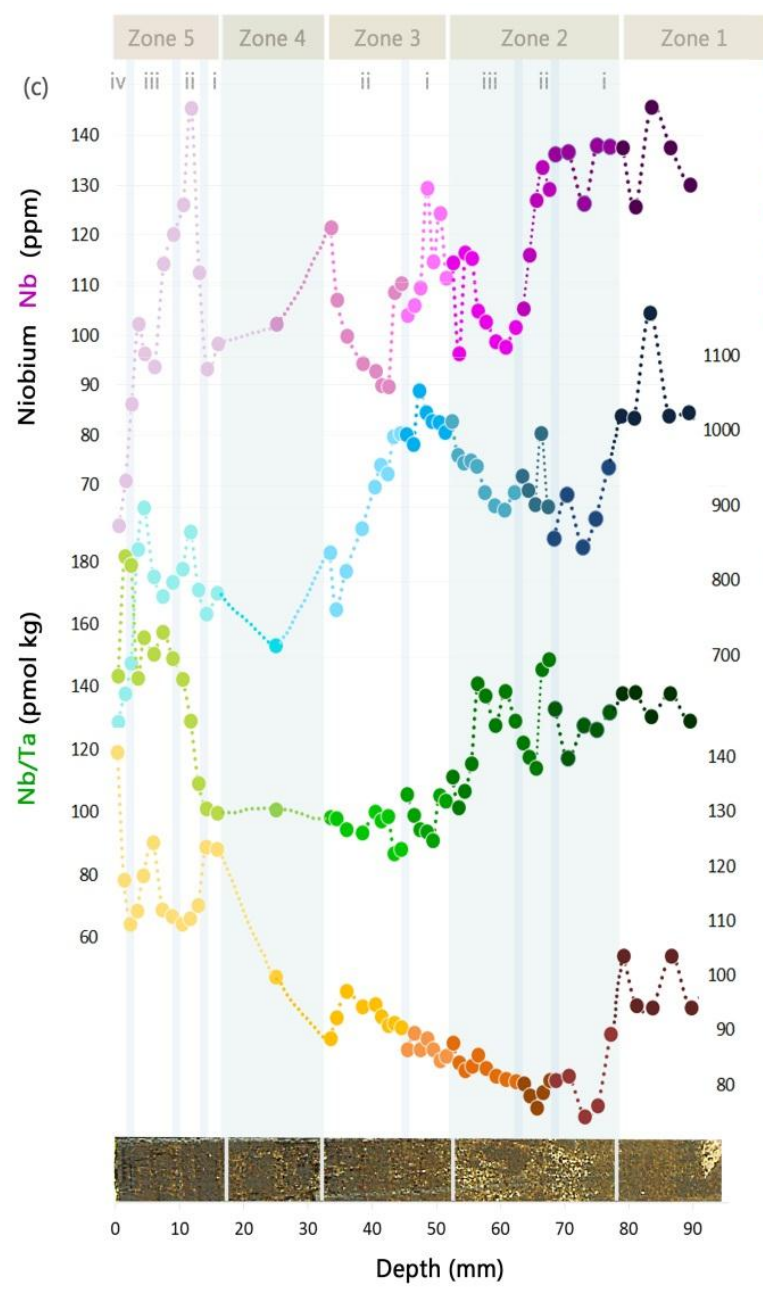

Subzone ages

$12.7-11.9 \mathrm{Ma}$

$11.9-10.6 \mathrm{Ma}$

$10.6-10.0 \mathrm{Ma}$

$10.0-9.23 \mathrm{Ma}$

$9.23-8.42 \mathrm{Ma}$

$8.42-6.25 \mathrm{Ma}$

$6.25-4.68 \mathrm{Ma}$

$4.68-0.00 \mathrm{Ma}$

송

$\stackrel{ }{ᄀ}$

ㅎํํ

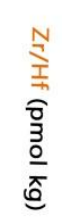

꼴

(b)

(a)
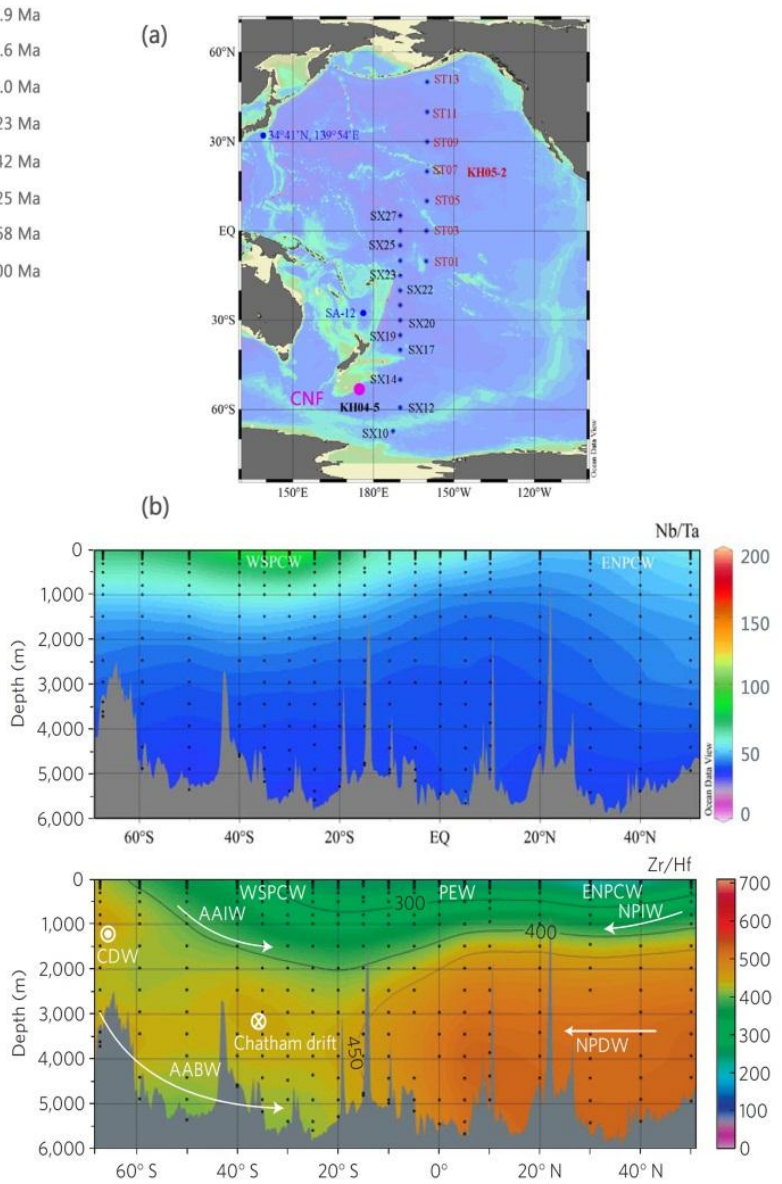

Figure 6.18 | Depth-time-series of HFSE paleocirculation proxies of U1365B-M as a record of water mass mixing throughout the late Neogene (a) displays the Pacific transect along which Firdaus, et al. (2011) collected HFSE data from a variety of Pacific waters from surface to deep masses, (b) indicates the results of Firdaus, et al. (2011) and the characteristic Nb/Ta and $\mathrm{Zr} / \mathrm{Hf}$ values for Pacific water masses, and (c) indicates $\mathrm{Nb}$ and $\mathrm{Zr}$ concentrations (each being representative of the element pair) and $\mathrm{Nb} / \mathrm{Ta}$, $\mathrm{Zr} / \mathrm{Hf}$ (in pmol $\mathrm{kg}$ for comparisons with values present by Firdaus for seawater) depth-timeseries for U1365B-M, re-stressing the link between the chemical and physical archives.

The application of $\mathrm{Zr} / \mathrm{Hf}$ and $\mathrm{Nb} / \mathrm{Ta}$ ratios as paleoceanographic tools requires that the $\mathrm{Zr} / \mathrm{Hf}$ and $\mathrm{Nb} / \mathrm{Ta}$ ratios in FMNs reflect the respective ratio of ambient seawater (Schmidt, et al., 2014). The few published data sets for $\mathrm{Zr}-\mathrm{Hf}$ and $\mathrm{Nb}-\mathrm{Ta}$ distributions in bulk FeMn crusts (Bau, 1996; Baturin and Dubinchuk, 2011; Hein et al., 2012) display superchondritic $\mathrm{Zr} / \mathrm{Hf}$ and $\mathrm{Nb} / \mathrm{Ta}$ values (deviating from values calculated from continental crust), however, a comprehensive investigation in terms of water mass characteristics is 
still lacking. One of the first studies to remedy this fact, Schmidt, et al. (2014), analysed a suit of Pacific and Atlantic FMCs and found that $\mathrm{Zr} / \mathrm{Hf}$ and $\mathrm{Nb} / \mathrm{Ta}$ values from bulk analyses were significantly lower and higher, respectively, (consistent with the lower $[\mathrm{Zr} / \mathrm{Hf}]$ and higher $[\mathrm{Nb} / \mathrm{Ta}]$ values reported for $\mathrm{U} 1365 \mathrm{~B}-\mathrm{M})$ than the ratios derived from modern Atlantic deep waters (Godfrey, et al., 1996, 2009) and Pacific deep waters (Firdaus, et al., 2011). Schmidt, et al. found that FMCs from Atlantic deep waters were characterised by lower $\mathrm{Zr} / \mathrm{Hf}$, values (consistent with the lower $\mathrm{Zr} / \mathrm{Hf}$ values of NADW [85-100 ppm; Godfrey, et al., 1996, 2009] from which they have grown), when compared to FMCs that have sequestered Zr and Hf from Pacific deep water [200-250 ppm; Firdaus, et al., 2011] and associated this with the significantly higher Hf concentrations found in the Atlantic Ocean due to the surrounding continental landmasses. Schmidt, et al. thus concluded that the $\mathrm{Zr} / \mathrm{Hf}$ signature in FMCs (and FMNs) reflects variations in regional seawater on a basin wide scale.

Presented in Figure 6.19 are the HFSE measurements for U1365B-M in Nb/Ta versus $\mathrm{Zr} / \mathrm{Hf}$ space. U1365B-M data has been superimposed upon the findings of Schmidt et al., 2014 for HFSE ratios of FMCs from the Pacific and Atlantic Ocean (Figure 6.19(a)) and the findings of Firdaus, et al. (2011) for HFSE ratios in water masses of the Pacific Ocean (Figure 6.19(b); see also Figure 6.18). Evident in Figure 6.19(a), is that from c. 10 to $6 \mathrm{Ma}$ U1365B-M HFSE ratios display values that are most similar to those reported for Atlantic FMCs, with $\mathrm{Zr}$-Hf ratios varying little (bordering c. 50) whilst $\mathrm{Nb} / \mathrm{Ta}$ display greater variability (c. 35 to 90 ). HFSE ratios from c. 12.7 to $10 \mathrm{Ma}$ display a tight cluster with $\mathrm{Zr} / \mathrm{Hf}$ 50-60] and $\mathrm{Nb} / \mathrm{Ta}$ [50-60] values in between those reported for Atlantic and Pacific FMCs. From $6 \mathrm{Ma}$ onward there appears to be a significant change in HFSE chemistry, with a shift to a new higher $\mathrm{Zr} / \mathrm{Hf}$ range (bordering c. 60). From $6 \mathrm{Ma}$ to present HFSE ratios are more similar to those reported for Pacific FMCs plotting within and close to the SCP (Southern Central Pacific) and NCP (North Central Pacific) FMCs. In Figure 6.19(b), U1365B-M plots between the continental chondritic values and those reported for the various water masses of the Pacific, illustrating the interplay of the two sources from HFSE to the nodule growth site. Between both Figures it is evident that Pacific waters (namely equatorial) appear to play a dominant role in FMN geochemistry from c. 6 Ma onward. 

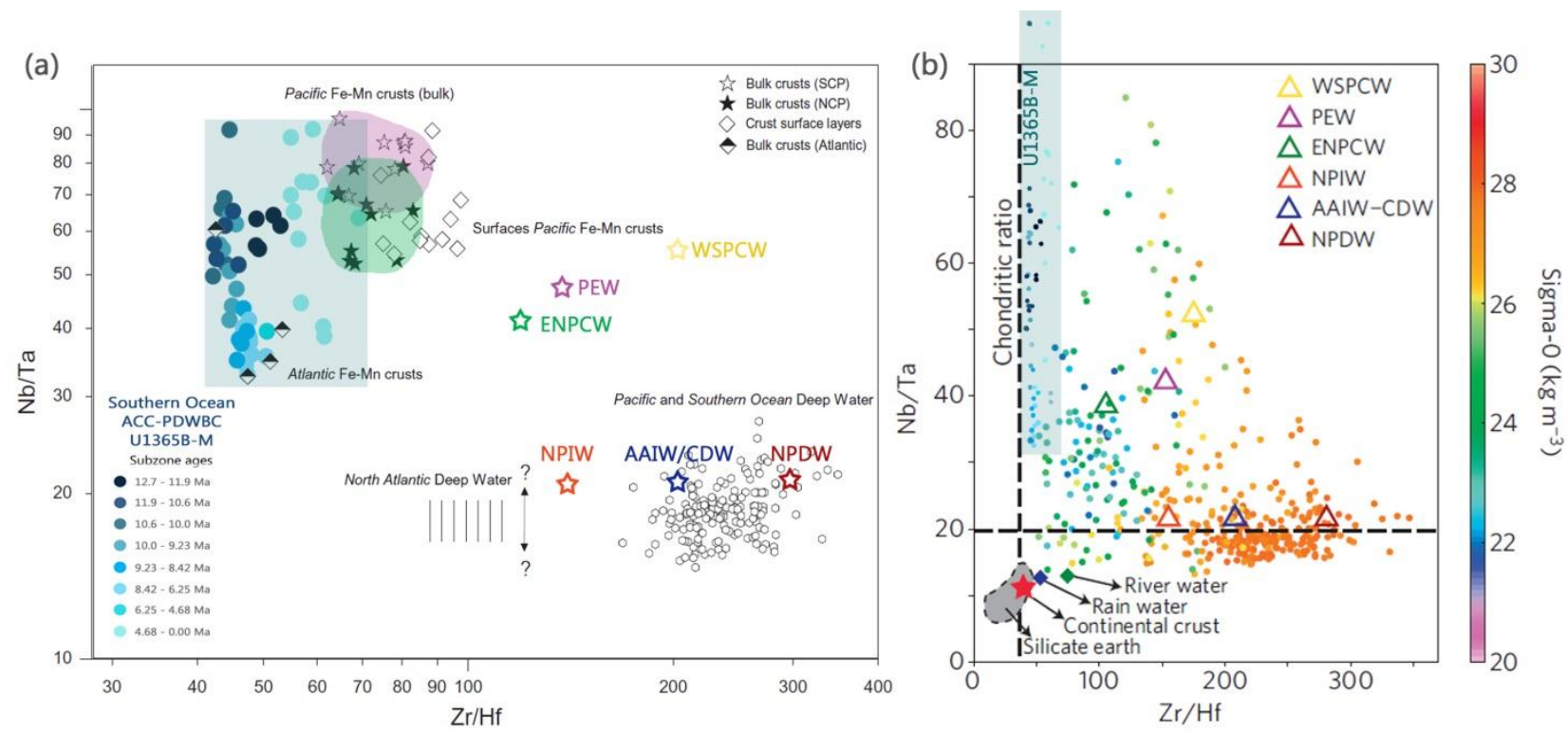

Figure 6.19 | HFSE paleocirculation proxies of U1365B-M as a record of water mass mixing throughout the late Neogene (a) displays the results of Nb/Ta versus $\mathrm{Zr} / \mathrm{Hf}$ for U1365B-M, illustrated in blue, superimposed upon the results of Schmidt, et al. (2014) with $\mathrm{Nb} / \mathrm{Ta}$ and $\mathrm{Zr} / \mathrm{Hf}$ of Pacific water masses illustrated with coloured stars and the corresponding nodule geochemistry derived from growing within these waters is coloured in the same colour, e.g. green for ENPCW. (b) displays the results of $\mathrm{Nb} / \mathrm{Ta}$ versus $\mathrm{Zr} / \mathrm{Hf}$ for U1365B-M, illustrated in blue, superimposed upon the results of Firdaus, et al. (2011)

Using Figure 6.18(b) and Figure 6.19(a-b) as a reference for present day $\mathrm{Zr} / \mathrm{Hf}$ values of Pacific and Atlantic water masses, the $\mathrm{Zr} / \mathrm{Hf}$ values for the growth history of U1365B-M would indicate AABW/LCDW ( $\ell \mathrm{LCDW}$ ) composed of an admixture of Pacific and Atlantic deep waters, with $\mathrm{Zr} / \mathrm{Hf}$ values not too dissimilar to present day FMCs from the central Pacific Ocean, c. 12.7 Myrs ago, after which the $\mathrm{Zr} / \mathrm{Hf}$ then decrease from $12.5 \mathrm{Ma}$ to $10.9 \mathrm{Ma}(\mathrm{Zr} / \mathrm{Hf}$ - 53 to 42 ; from zone 1 to zone $2 \mathrm{ii})$, indicating an influx of younger North Component Water (NCW; proto-NADW), consistent with the results from radiogenic $\mathrm{Pb}$ isotopic compositions. From 10.9 to $7.2 \mathrm{Ma}$ (zone 2ii to mid-way between zone $3 \mathrm{ii}) \mathrm{Zr} / \mathrm{Hf}$ ratios steadily increase from 42 to 51, indicating a progressively stronger influx of Pacific Component Water (PCW; proto-NPDW, EPDW). This would be consistent with the predictions of van de Flierdt, et al. (2004) of an increased export of Equatorial Pacific Deep Water (EPDW) to the region since closure of the Indonesian gateway c. $10 \mathrm{Ma}$ (Figure 6.n). Zr/Hf values then decrease again at $6.3 \mathrm{Ma}(\mathrm{Zr} / \mathrm{Hf}-47)$, 
consistent with reports from Wright, et al. (1996) of an increased flux of NCW or establishment of present day NADW, during this climatically cooler period c. 6 Ma. From c. 6 to $5 \mathrm{Ma} \mathrm{Zr/Hf}$ ratios rapidly increase (47 to 61) and remain high during the warmer climatic regimes of the Pliocene, from 5 to $4 \mathrm{Ma}$, indicative of increased PCW fluxes or establishment of a more vigorous Pacific circulation, as suggested by Cane and Molnar (2001; see also Molnar \& Cane, 2002; Molnar 2008) as a consequence of further restriction of the Indonesian gateway (cf. Frank, et al., 2008). From 4 to $2.5 \mathrm{Ma} \mathrm{Zr} / \mathrm{Hf}$ values decrease (c. 60 to 55), consistent with the timing for the onset of significant NHG (Cronin, et al., 2010), before displaying c. 1 Myr oscillations between periods of higher $\mathrm{Zr} / \mathrm{Hf}$ values (at 1.7 Ma [61] and 0.1 Ma [67]) and those of lower values (at $1 \mathrm{Ma}$ [55]), likely reflecting the increased tempo of G-I cycles characteristic of the Pleistocene epoch (Glasby, 1985; Segl, et al., 1989; Banakar, et al., 1997; Naish, et al., 2009). These short-term, variations are superimposed upon a long-term trend of increasing $\mathrm{Zr}$-Hf values since c. $10 \mathrm{Ma}$. This, as with the evidence from $\mathrm{Pb}$ isotopic compositions, would indicate decreased export of NADW to the nodule growth site since c. $10 \mathrm{Ma}$ (Figure 6.17), contradicting the findings of Frank, et al. (2002) who determined a steady flux of NADW to the Atlantic sector of the Southern Ocean until c. 3 Ma. Conversely, $\mathrm{Nb} / \mathrm{Ta}$ (and $\mathrm{Zr} / \mathrm{Ta}, \mathrm{Hf} / \mathrm{Ta}$ ) do not appear to reflect water mass mixing, rather the $\mathrm{Nb} / \mathrm{Ta}$ timeseries bears close resemblance to group 3 elements $(\mathrm{Cu}-\mathrm{Zn}$; Figure 6.5). Thus, the distribution and concentration of $\mathrm{Nb}$ and more so $\mathrm{Ta}$ in the ocean are probably controlled by a passive involvement in biogeochemical cycles and other non-biogenic particles such as re-suspended silicate particles (see Godfrey, et al., 1996; Rickli, et al., 2009), resulting in complex scavenging processes (see also Orians \& Merrin, 2003; Godfrey, et al., 2009). As this is the first time $\mathrm{Zr} / \mathrm{Hf}$ and $\mathrm{Nb} / \mathrm{Ta}$ have been applied as paleoceanographic proxies of past water mass mixing, there is a lack in any published comparative data. However, the application of $\mathrm{Zr} / \mathrm{Hf}$ values as a water mass tracer looks very promising. In contrast, the potential processes of what the $\mathrm{Nb} / \mathrm{Ta}$ profiles present a more complex puzzle, the deciphering of which is beyond the scope of this thesis.

In contrast to the relatively new application of HFSE, YREE have been extensively studied and applied in paleoceanographic investigations (e.g., Glasby, 1973; Glasby, et al., 1987; Karsten, et al., 1998; Lacan \& Jeandel, 2001; Nozaki \& Alibo, 2002; Hongo, et al., 
2006). Yttrium and the Rare Earth Elements (YREEs) are an extremely coherent group in terms of chemical behaviour and have been intensively investigated in the field of marine geochemistry to elucidate particulate scavenging processes, seawater oxygen content and to characterise water masses (see Byrne \& Scholkovitz, 1996; Nozaki, 2001). Although a coherent group, there are subtle differences in YREE chemistry, resulting from ionic contraction across the period and redox effects. YREE are generally subdivided into two groups based on atomic weight: the Light Rare Earth Elements (LREE; lanthanum [La] samarium [Sm]), and; the Heavy Rare Earth Elements (HREE; yttrium [Y], gadolinium [Gd] - lutetium [Lu]) (Nozaki \& Alibo, 2003). Differences in atomic mass cause variations in the stability constants of REE complexes in seawater e.g., YREE-carbonate complexes that form (see Table 3.2) are increasingly more stable from LREE to HREE (Glasby, 1972; Nozaki \& Alibo, 2003). Thus, LREE are preferentially removed from seawater to take part in scavenging processes (like Th), whereas HREE show a greater tendency to complex with seawater ligands and remain in solution (like $\mathrm{U}$ ) and are largely governed by horizontal processes of ocean circulation (see Byrne \& Scholkovitz, 1996; Nozaki, 2001; Nozaki \& Alibo, 2003). It has been proposed that the HREE/LREE fractionation of dissolved REE in seawater results from continuous scavenging of dissolved LREEs from deep water over the mixing time of the oceans, resulting in the observation that seawater becomes progressively more HREE enriched with age (Goldberg, et al., 1963; Elderfield, 1988; German, et al., 1995). Thus for FMNs, scavenging from successively older waters, it would be expected that HREE would become less enriched in the nodule as LREE are preferentially scavenging from the seawater.

The HREE/LREE profile (Figure 6.20) shows a striking resemblance to $\mathrm{Pb}-\mathrm{Pb}$ isotopic time series, displaying a large and broad peak from $11-10 \mathrm{Ma}$ (HREE/LREE 0.28 to > 0.30 ) and from 10 to $4 \mathrm{Ma}$ (and then decreases from c. 0.3 to 0.25 and then continues to rise again from 4 to $1 \mathrm{Ma}$ ). The HREE/LREE values could therefore support the findings of $\mathrm{Pb}$ and $\mathrm{Zr} / \mathrm{Hf}$, indicating that from $10 \mathrm{Ma}$ to $\mathrm{c}$. $4 \mathrm{Ma}$ the PDWBC is receiving an increasing flux of Pacific component waters, potentially in association with the shoaling and closure of the Central American Gateway, rather than (or in conjunctions with) oceanic restrictions associated with the Indonesian gateway (Figure 6.20). 


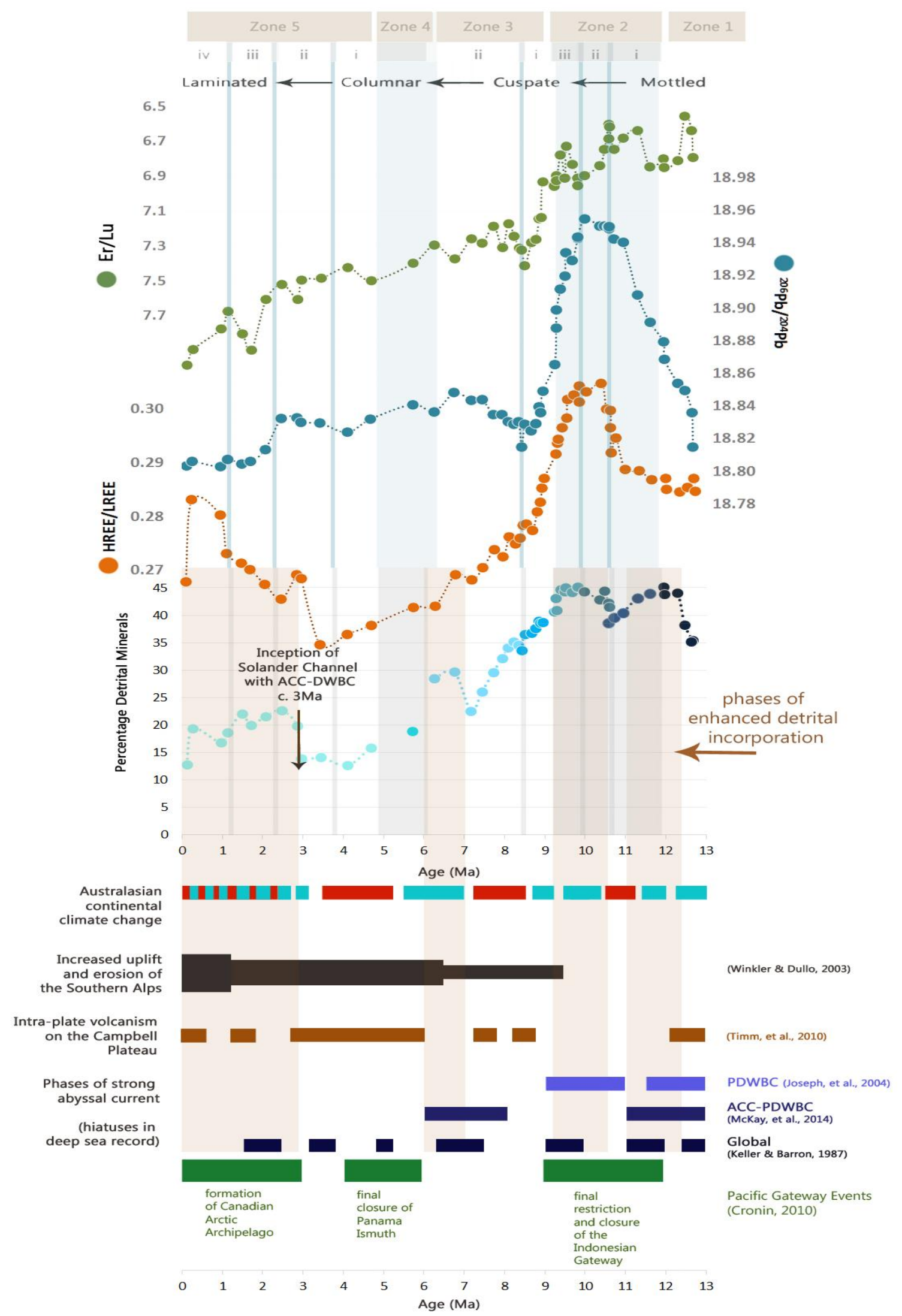

Figure 6.20 | Time-series of paleocirculation proxies of U1365B-M as a record of water mass mixing throughout the late Neogene illustrating HREE/LREE, ${ }^{206} \mathrm{~Pb} /{ }^{204} \mathrm{~Pb}$ compositions, $\mathrm{Er} / \mathrm{Lu}$, and detrital (\%) as a paleospeed proxy (peach phases) in addition to climate-ocean-tectonic events c. $13 \mathrm{Ma}$ 
Figure 6.20 (and Figure 6.21) also depicts variation in $\mathrm{Er} / \mathrm{Lu}$ values over the $12.7 \mathrm{Ma}$ growth history of U1365B-M. Previous use of these ratios have been used to show that high values (>9) are characteristic of subtropical Pacific Equatorial Water (PEW) and low values $(<8)$ of Subantarctic Upper Water (Hongo, et al., 2006). According to Hongo et al. (2006) latitudinal variations in the Er- $\mathrm{Yb}$-Lu ratios of surface waters are caused by differences in the variable sources of YREEs. However, $\mathrm{Er} / \mathrm{Lu}$ (and $\mathrm{Er} / \mathrm{Yb}$ which display the same profile) has been shown to be constant in deep waters $(>2000 \mathrm{~m}$ ) of the: Atlantic (Bertram \& Elderfield, 1993); Southern Ocean (German, et al., 1995), and; North Pacific (Nozaki, et al., 1999). In light of these findings, the progressive increase in $\mathrm{Er} / \mathrm{Lu}$ values (6.5 to 8) from $\mathrm{c}$. $12 \mathrm{Ma}$ to present could be interpreted as reflecting increased export of Pacific Equatorial Waters (or more broadly Pacific component waters) to the Southern Ocean since c. 12 Ma. van de Flierdt et al. (2004) proposed that the subsequent reorganisation of ocean circulation patterns in the Southwest Pacific, due to closure of the Indonesian Gateway, marked the onset of the present day South Equatorial Current, the deeper parts of which, van de Flierdt et al. propose to be deflected southward along the eastern coast of Australia to currently supply equatorial Pacific waters to the ACC. If this interpretation holds true, the chemical data for U1365B-M may reflect the progressive shoaling of the Indonesian Gateway, and thus increased export of SEC to the Southern Ocean, translated to the PDBWC through water mass mixing within the ACC on its eastward transit to the nodule growth site.

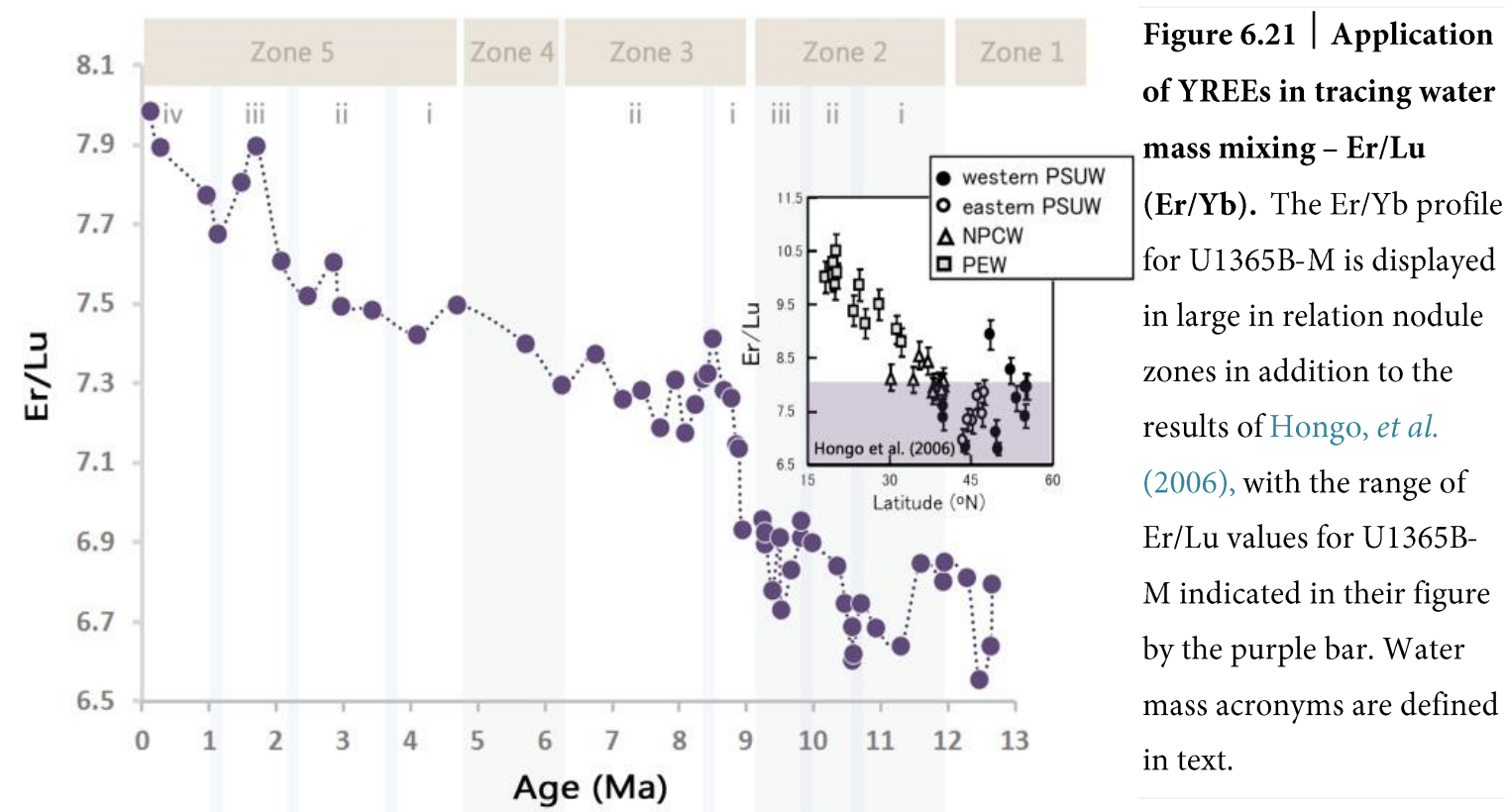




\subsection{Unravelling the Late Neogene Evolution of the PDWBC}

Objective five was to recover the paleoenvironments recorded in the physical and chemical archives of U1365B-M and to describe the paleoceanographic history of each distinguishable zone, as each zone is characterised by a change in the mode of nodule formation in response to a significant change in the chemical fingerprint of the PDWBC, ultimately reflecting climatic-oceanic-tectonic perturbations of the late Neogene.

A stratigraphic analysis of the physical archives shows that there were certain periods within the late Neogene when FMN U1365B-M changed its pattern of accretion (see Figure 6.3). The corresponding horizons are visible to the unaided eye as five major zones of accretion. The boundaries between zones (and subzones) and their chemical archives, correspond to key climatic and tectonic events of local and global extent, suggesting that U1365B-Ms growth history has recorded the late Neogene evolution of the ACC-DWBC. However, evident from the previous sections, and attempts made to associate physical and chemical changes in U1365B-M with synchronous climatic and tectonic events, is that there is an amazing congruence of seemingly unrelated (and related) events, reported in the literature, in relation to climatic \& cryospheric, oceanic gateway \& oceanic water mass changes, in addition to many conflicting lines of evidence. Thus, with such a broad thesis aim:

How the oceanographic properties of the deep ocean have changed in response to the Late

Neogene evolution of the oceans, climate and cryosphere, as recorded within a large hydrogenous FMN at the New Zealand oceanic gateway.

and large geochemical data set (largely neglected in the literature, i.e., the application of element concentrations and element ratios, from FMNs, as proxies of paleoproductivity, redox, and circulation; see Chapter 3), it is near impossible to state a causal link between changes in the physiochemical archives of U1365B-M with distinct climatic-tectonicoceanic events of the Late Neogene. And thus, attempts are made to make broad and general statements regarding correlations of FMN archives with the aforementioned events, in relation to the chemical history of the PDWBC. 


\section{Zone 1 [12.7 to $11.9 \mathrm{Ma}$ ]: How have oceanographic properties of the PDWBC changed} in response to the onset of the cold late mid-Miocene Ocean?

U1365B-M began to form 12.7 Myrs ago, upon the abyssal sediments of the mobile Campbell skin drift, abutting the steep continental slopes of the Campbell Plateau where this bathymetric feature forces the ACC-PDWBC to impinge along its margin. The initiation of growth resulted from a shift in deep ocean conditions to accommodate Fe-Mn precipitation (Chang, et al., 2003; Graham et al., 2003a; Graham, et al., 2003b; Wright, et al., 2005). The timing of the initiation of FMN growth is paleo-environmentally significant within the New Zealand sector of the Southern Ocean, marking the transition from phosphorite to ferromanganese deposition (Glasby \& Summerhayes, 1979; Hall et al., 2003; Graham, et al., 2004) in association with the transition from warm conditions of the mid Miocene climate optimum to the cooler conditions of the late mid-Miocene (c. 15 to 13 Ma; Woodruff \& Savin, 1991; Flower \& Kennett, 1995; see also Zachos, et al., 2001).

In relation to the mid Miocene increase in benthic ${ }^{\delta 18} \mathrm{O}$ values of $1-1.3 \%$ (Shackleton \& Kennett, 1975; Billups \& Shrag, 2002), significant ice-sheet development (e.g., Hayward, et al., 2009; Naish, et al., 2009), spin-up of ACC-PDWBC in in association with strengthen wind fields (Hall, et al., 2003; Joseph, et al., 2004; Pollard \& DeConto, 2009), stepwise decrease in SST of 6-7 ${ }^{\circ} \mathrm{C}$ (e.g., Shevenell, et al., 2004) and a reduction in atmospheric $\mathrm{CO}_{2}$ concentrations from $\sim 500$ ppmv to 300 ppmv (Kushner, et al., 2008; 0'Reagn, et al., 2011), oceanographic properties of the PDWBC evolved toward: (1) more vigorous current flows, indicated in the physical archives of U1365B-M by the accretion of this zone synchronous with the occurrence of deep sea hiatuses of regional and global extent (Barron \& Keller, 1989; Hall, et al., 2003; Joseph, et al., 2004; Figure 6.3), by the high percentage $(40 \%)$ of incorporated detrital grains, inferred by some authors to result from sediment scouring of the sea floor by high velocity abyssal currents (e.g., Mangini, et al., 1991; Banakar, et al., 1993; Glasby 2000), and by the occurrence of mottled growth structures suggested, to reflect high current velocities (Sorem \& Fewkes, 1977; Banakar \& Tarakian, 1991); (2) well-oxygenated conditions, reported by Glasby (2000) as a prerequisite for the onset of Fe-Mn precipitation during the mid-Miocene, and associated by many authors to the production of well-oxygenated AABW during this time (e.g., 
Glasby \& Summerhayes, 1979; Kennett, 1985; Banakar \& Hein, 2000; Hall, et al., 2003), are evidenced in the chemical archives of U1365B-M through the application of the paleoredox proxies with the following displaying some of the highest values for the growth history of $\mathrm{U} 1365 \mathrm{~B}-\mathrm{M}-\mathrm{V} /(\mathrm{V}+\mathrm{Ni}$ ) (at 0.4$), \mathrm{Ce} / \mathrm{Ce}^{\star}$ (increasing from 3 to 3.2 ) and $\mathrm{Th} / \mathrm{U}$ ( from 12 to 14 ), additionally $\mathrm{Eu} / \mathrm{Eu}^{\star}$, indicative of reducing conditions, are at their lowest values (c. 1.1) during this phase of accretion (Figure 6.14), and; (3) strongly corrosive currents, indicated by high marine carbonate dissolution, consistent with reports of maximum corrosive abyssal currents for the study area (Joseph, et al., 2004; McKay, et al., in press) and shallowest CCD and lysocline for the New Zealand region (Hayward, et al., 2004; $11-7 \mathrm{Ma}$ ), for South of Tasmania (Diester-Haass \& Nees, 2004; 11 - 9.6 Ma), for the Central Pacific (van Andel, et al., 1975; Halbach, et al., 1984; 11 - 6 Ma), equatorial Pacific (Farrell, et al., 1995; 12 - 9 Ma) and Southeast Atlantic Ocean (Diester-Haass \& Nees, et al., 2004; $9-7 \mathrm{Ma}$ ), evidenced in U1365B-M a decrease in all paleoproductivity proxies (e.g., Ba/Th decreases from 19 to 16; Figure 6.13).

Furthermore, the late mid-Miocene has been suggested by some authors, as marking the onset of NADW, that exhibit physical and chemical characteristics comparable to present day, between $\sim 13$ Ma (e.g., Cramer, et al., 2009) and 12 Ma (e.g., Poore, et al., 2006), which approximate well with the suggestion of Wright and Miller (1996) for the increased flux of NCW to the Southern Ocean at this time. Prior to this date $\delta 13 \mathrm{C}$ values support small inter-basin gradients and pointed toward a common Southern source of deep water until 12.5 Ma (Poore, et al., 2006; Cramer, et al., 2009; Butzin, et al., 2011). The paleocirculation proxies of U1365B-M (Figure 6.17 to 6.21), such as the shift toward more radiogenic $\mathrm{Pb}$ isotopic compositions $(206 \mathrm{~Pb} / 204 \mathrm{~Pb}-18.80$ to 18.96; Figure 6.17), decrease in $\mathrm{Zr} / \mathrm{Hf}$ values (100 to 80; Figure 6.18-6.19), slight increase in HREE/LREE (Figure 6.20) and low $\mathrm{Er} / \mathrm{Lu}$ (6.5-6.9; Figure 6.20), and additionally, back calculated initial ${ }^{10} \mathrm{Be} /{ }^{9} \mathrm{Be}$ values decrease over zone 1 from 1.2, characteristic of modern pacific values to 0.6 (Ling, et al., 1991), to values characteristic of Atlantic values (0.6) (Willenbring \& von Blanckenburg, 2010; see Figure 6.1), thus these proxies appear to support this claim as the chemistry of the PDWBC becomes more 'Atlantic' over this growth phase. 


\section{Zone 2 and Zone 3i [11.9 Ma to 8.4 Ma]: Late Miocene cooling, Antarctic Ice sheet expansion and closure of the Indonesian gateway}

During this second phase of nodule accretion, according to the composite ${ }^{\delta 18} \mathrm{O}$ curve of Zachos et al. (2001), mean ${ }^{818} \mathrm{O}$ values continued to rise gently throughout the late Miocene to the early Pliocene (c. $6 \mathrm{Ma}$ ), with the re-establishment of major ice sheets on Antarctica by $10 \mathrm{Ma}$ (Kennett \& von der Borch, 1986; Cronin, 2010). The response of the PDWBC to Antarctic ice sheet advance and further cooling of the global climate, sees a continuation and strengthening of the paleoceanographic conditions determined for the core zone with: (1) more vigorous current flows, indicated in the physical archives of U1365B-M by the synchronous accretion with global and regional deep sea hiatuses (Barron \& Keller, 1989; Hall, et al., 2003; Joseph, et al., 2004; Figure 6.3), with Joseph, et al. (2004) reporting the strongest phase of PDWBC speeds at $10 \mathrm{Ma}$, correlating with highest percentages (45\%) of incorporated detrital grains, and chaotic mottled growth structures; (2) conversely to zone 1, a reduction in oxygenated conditions, are evidenced in the chemical archives of U1365B-M (e.g., Th/U display a sharp reduction in values from c. 9.5 to 8.4 Ma consistent with global cooling and Mi-6 (c. 9.6 - 10 Ma; Miller, et al., 1991; see Figure 6.14)), and; (3) strongly corrosive currents, indicated by the 'carbonate crash event' recorded by paleoproductivity proxies in U1365B-M (e.g., Ba/Th decreases from 20 to 10; Figure 6.13) and correlate with similar reports in the Southwest and Greater Pacific (van Andel, et al., 1975; Halbach, et al., 1984; Farrell, et al., 1995; Hayward, et al., 2004; DiesterHaass \& Nees, 2004). Additionally, the shift to lower ${ }^{208} \mathrm{~Pb} /{ }^{204} \mathrm{~Pb}$ and ${ }^{207} \mathrm{~Pb} /{ }^{204} \mathrm{~Pb}$ values for any given ${ }^{206} \mathrm{~Pb} /{ }^{204} \mathrm{~Pb}$, from c. 10 to $8.4 \mathrm{Ma}$ (see Figure 6.7) indicates increased aeolian contributions to the deep sea during this period consistent with suggestions of increased aeolian dust fluxes as a result of energetic atmospheric circulation commencing at about 10 $\mathrm{Ma}$, coincident with ice build-up on Antarctica and a subsequent decrease in sea level (Stein \& Robert, 1985; Rea \& Bloomstein, 1986; Stancin, et al., 2008).

In terms of paleocirculation proxies, namely the monoisotopic shift in $\mathrm{Pb}$ isotopes to more radiogenic values from 11.9 to $10 \mathrm{Ma}$ and a return to less radiogenic values from 10 to $8.4 \mathrm{Ma}$ (also mimicked in the HREE/LREE profile; Figure 6.20). The first shift is taken to reflect one (or more) of four potential processes; (1) an increase in the export of NADW 
to the Southern Ocean, consistent with the assumptions outlined in zone 1, and also suggested by Frank, et al. (2002) and van de Flierdt, et al. (2004); (2) progressive erosion and transport of ancient continental material to the Southern Ocean, as a result of icesheet development on Antarctica and/or increased aridity of Patagonia-Australia-New Zealand (e.g., Frank, et al., 2008; von Blanckenburg, et al., 2010), and; (3) gradual and progressive closure of the Indonesian gateway to deep water exchange between the Indian and Pacific Ocean, resulting in a stronger NADW signal within the PDWBC until closure of the gateway c. $10 \mathrm{Ma}$ triggered a more effective Pacific to Southern Ocean circulation, in addition to the effects of a shoaling Central American Seaway (Cane \& Molnar 2001; Molnar \& cane, 2002; van de Flierdt, et al., 2004; Molnar, 2008). The second shift (10 to 8.4 Ma; extending into zone $3 \mathrm{i}$ ) has been inferred to reflect an increased contribution of NPDW into the Southern Ocean as a consequence of: (1) closure of the Indonesian gateway at $10 \mathrm{Ma}$; (2) build-up of ice on Antarctica and progressive development of the ACC, and; (3) a more vigorous Pacific circulation and or reduction in the export of NADW to the Southern Ocean (Frank, et al. 2002; van de Flierdt, et al., 2004).

Alternatively, $\mathrm{Pb}$ isotopic compositions have also been recently applied to discern the demise and retreat of ice sheets (e.g., von Blanckenburg and Nägler, 2001; Crocket, et al., 2013) with highly radiogenic $\mathrm{Pb}$ isotopic compositions associated with maximum ice-sheet activity (and increased solute fluxes e.g., of HREE to the deep ocean due to continental liberation). It is tempting to relate this radiogenic feature of the $\mathrm{Pb}$ isotope curve, to the gradual and persistent long-term build-up of Antarctic ice sheets over c. 3 Myrs, reaching their maximum threshold at $10 \mathrm{Ma}$ (associated with $\max .{ }^{206} \mathrm{~Pb} /{ }^{204} \mathrm{~Pb} 18.955$ ), and, in association with $3-4^{\circ} \mathrm{C}$ warming of deep Southern Ocean temperatures from 10 to $8.5 \mathrm{Ma}$ (Billups \& Shrag, 2002), ice sheet activity then progressively decreased from 10 to $8.4 \mathrm{Ma}$, over 1.5 Myrs, in the half-time it would have taken to reach maximum ice sheet activity. In this regard, if the isotopic $\mathrm{Pb}$ record does indeed reflect ice sheet dynamics, then the more radiogenic values from c. 13 to $10 \mathrm{Ma}$ would indicate significant ice sheet advance followed by a relatively rapid retreat from 10 to $8 \mathrm{Ma}$, and has since remained relatively stable since. 
The third zone appears to be a period of transition and exhibits distinct changes in both chemical and physical archives. Texturally, the zone is more compact and Mn rich (c. 13 wt \%) than previous zones with lower detrital occlusions (c. 30\%) and is subdivided into (1) Zone 3ii, 9.2 to 8.4 Ma and (2) Zone 3i, 8.4 to $6.3 \mathrm{Ma}$. Across zone 3i Pb isotope values continue to decline to a minimum value at c. $8.4 \mathrm{Ma}$ whilst $\mathrm{Mn} / \mathrm{Fe}$ ratios remain constant (c. 0.4), detrital grains systematically decrease to a minimum at c. $7 \mathrm{Ma}$ and minor elements indicate an increasingly hydrogenous mode of formation. Zone 3ii marks one of two transition periods in the $\mathrm{Mn} / \mathrm{Fe}$ ratio whereby values rapidly double from c. 0.4 to 0.8 from 6-7 Ma, establishing a new equilibrium state. This interpreted as reflecting the fraction of Mn and Fe in association with deepening of the CCD (Hayward, et al., 2004). Mangophile elements (group 1 and 2) such as $\mathrm{Co}, \mathrm{Mo}, \mathrm{Ni}, \mathrm{Cd}, \mathrm{Tl}$, illustrate an increase in concentration across this subzone, with minor elements such as Co illustrating the steepest changes in concentration (see Figure 6.6). Changes in subzone chemistry coincide with the occurrence of regional hiatus's from $8-6 \mathrm{Ma}$ as a result of a more vigorous ACC (Hall, et al., 2003; R. Carter, et al., 2004; McKay, et al., 2014). Across the entire zone, redox indicators suggest fairly constant ocean oxygen levels (see Th/U profile in Figure 6.16), counterintuitive to what would be expected during climatic cooling period and enhanced AABW-LCDW (Kennett, 1975; Glasby 2000) in association with the onset near modern circulation patterns (Bender \& Keigwin, 1979; Mangini, et al., 2000).

\section{Zone 4 [6.3 to 4.7 Ma]: Establishing modern thermohaline circulation}

The forth zone marks a period of major change in both physical and chemical archives. Rates of nodule accretion are halved (see Figure 6.6), despite a moderate pulse of detrital grain occlusion. Microstructures grade from large columnar structures into a more laminated zone (see Figure 5.5), which correspond to a seemingly rapid decrease (of varying degrees) in element and $\mathrm{Pb}$ isotopic content to more consistent values within the laminations (see Table F.2). Redox proxies such as $\mathrm{Ce} / \mathrm{Ce}^{\star}$ and $\mathrm{Th} / \mathrm{U}$, all indicate a less oxidising ocean than present. However, the $\mathrm{Mn} / \mathrm{Fe}$ ratio appears to have remained constant across this zone. These changes in macro- and micro-structures have been observed within crusts (Mangini, et al., 1991; van de Flierdt, et al., 2004, 2006) and nodules 
(Segl, et al., 1979; Glasby, et al., 2000; Frank et al., 2002, 2008) worldwide. The occurrence of this zone has been attributed to a change in global circulation and roughly correlates with the terminal Miocene $\delta^{13} \mathrm{C}$ shift in foraminifera at 6.2 Ma (Bender \& Graham, 1981; Kennett \& von der Borch, 1986; Glasby, 2000). The change in ocean/nodule chemistry is most likely a response to a series of events: expansion of the west Antarctic ice sheet (Kennett \& von der Borch, 1986) and overall cooling of surface waters, formation of the Ross Ice Shelf (Hodell \& Kennett, 1986), expansion of sea ice and the northward migration of circumpolar fronts to their present position. These climatic conditions have been associated with an increase in AABW production and which resulted in wide spread erosion and hiatus formation beneath the ACC (Barron \& Keller, 1983; McKay, et al., 2014), the associated lowering of the glacial ocean (Haq, et al., 1987; Diester-Haass, 1988; Glasby, 2000), isolation and drying up of the Mediterranean, shoaling of the isthmus of Panama, an increase in biogenic silica removal in the Southern Ocean high productivity zone (Loutit \& Keigwin, 1982; Segl, et al., 1989; Frank, et al., 2002; O’Reagen, 2011).

\section{Zone 5 [4.7 to $0.1 \mathrm{Ma}$ ]: From the warm Pliocene to the cold Pleistocene}

This final growth phase of FMN U1365B-M is subdivided into four subzones based on microstructures and element distribution characteristics: (1) zone 5i [4.7-4.1 Ma]; (2) zone 5ii [4.1 to c. $3.0 \mathrm{Ma}$ ]; (3) zone 5 iii [c. 3.0 to $1.0 \mathrm{Ma}$ ], and; (4) zone 5iv [1.0 to 0.1 Ma]. The first two subzones reflect the accretion of U1365B-M from the PDWBC during the warm Pliocene epoch [4.7 to 3.0 Ma] and the last two subzones, during the cooler climates of the Pleistocene. Nodule accretion from 4.7 to $3.0 \mathrm{Ma}$, during zones $5 \mathrm{i}$ and 5ii, represent a two million year summary of PDWBC chemistry, with each sample having been deposited over c. 500 kyrs, reflecting the overall slower accretion rates of these subzones (c. $3.7 \mathrm{~mm} / \mathrm{Ma}$ ). These zones are characterised by semi-laminated microstructures, however there is a reappearance of relatively large cuspate structures, with low detrital incorporations [c. $14 \%]$, indicative of a warmer and slower PDWBC, consistent with reports of a $2{ }^{\circ} \mathrm{C}$ warming of the deep ocean (e.g., Hodell \& Venz, 1992; Billups \& Shrag, 2002) and a lack of any significant deep sea hiatuses (Joseph, et al., 2004; McKay, et al.,2014). Furthermore, redox proxies such as $\mathrm{Ce} / \mathrm{Ce}^{\star}$, indicate an increase in relative $\mathrm{O}_{2}$ contents of the ocean from low levels in zone 4 (c. 2.8) to a peak between c. 3.5 to $3 \mathrm{Ma}$ with the theory of 
increased (decreased) inter-glacial (glacial) ocean oxygen, (also supported by the progressive decrease in paleoredox proxies throughout the Late Neogene, in parallel with the benthic ${ }^{\delta 18} \mathrm{O}$ isotope curve; Figure 6.16), with the peak in ocean oxygen recorded by U1365B-M consistent with the warmest phase of the Mid-Pliocene Warm Period (Miller \& Fairbanks, 1991; Billups \& Shrag, 2002; O’Reagan, 2011; McKay, et al., 2012). The findings of increased PDWBC ventilation during the Pliocene are also supported by Zhang, et al., (2012), who proposed intensified and a poleward shift of the Antarctic wind field, led to the increased ventilation and reduced stratification of the Southern Ocean during the Pliocene. Overall, the Pliocene Ocean was characterised by temperatures $\sim 3{ }^{\circ} \mathrm{C}$ higher than present (Haywood, et al., 2000, 2009; Dowsett, et al., 2009; Naish, et al., 2009; Fillippelli \& Flores, 2009), with 30\% higher $\mathrm{CO}_{2}$ concentrations (Kürschner, et al., 1996; Raymo, et al., 1996) and global temperatures comparable to those predicted for the end of this century (Haywood \& Valdes, 2004). The Pacific Ocean is suggested to have been characterised by a 'permanent' El Niño state (Ravelo, et al., 2004; Wara, et al., 2005; Dowsett, et al., 2009), with reduced east-west pressure gradients affecting wind-regimes and heat distribution. This atmospheric state is suggested to have resulted in a deepening of the thermocline and reduction of upwelling intensities in the Pacific Ocean (Cane \& Molnar, 2001; Molnar \& Cane, 2002; Molnar, 2008).

During this phase of accretion Fe-Mn scavenging of tracer elements remains low (c. 16,000 ppm; Figure 6.6) until c. $4 \mathrm{Ma}$ when values rise from c. 16,000 to $18,000 \mathrm{ppm}$ just prior to the onset of cooler Pleistocene climates at c. 3 Ma. Additionally, each of the element groups show a significant shift from decreasing trends toward lower concentrations during the early Pliocene (e.g., group $3 \mathrm{Cu}-\mathrm{Ni}$; Fig), or for groups 1 \& 2 , concentrations maintained at low levels, up until $4 \mathrm{Ma}$, when all of the elements analysed increase in concentration to a peak at c. $3 \mathrm{Ma}$ (e.g., $\mathrm{Pb}$ - from $70 \mathrm{ppm}$ at $4 \mathrm{Ma}$ to $80 \mathrm{ppm}$ at $3 \mathrm{Ma}$ ). It is tempting to relate this chemical shift to oceanic gateway events of the Pliocene, namely the final closure of the Central American Seaway, due to the progressive rise of the Isthmus of Panama around this time (Burton, et al., 1997; Molnar, 2008; Cronin, 2010). Closure of the Central American Seaway is reported to have effectively terminated PacificAtlantic Ocean communications, diverting deep and surface waters further into the North Atlantic Ocean, strengthening the Gulf Stream and North Atlantic Current, thereby 
enhancing heat transport from the tropics and increasing North Atlantic temperatures (Fillippelli \& Flores, 2009). Several authors (Raymo, et al., 1996; Haywood, et al., 2009; Dowsett, et al., 2009) suggested intensification of the Atlantic Meridional Overturning Circulation (AMOC) during this warm Pliocene interval. The paleocirculation proxies of $\mathrm{Pb}$ isotopic compositions, display a slight increase toward more radiogenic values over this period, and the new application of HFSE ratio $\mathrm{Zr} / \mathrm{Hf}$, display a decrease in values from 4 to $3 \mathrm{Ma}$ (61 to 55). These chemical signals could be indicative of increased export of NADW to the Southern Ocean during this warm Pliocene interval, as interpreted by Frank, et al., (2002). However, concurrent with the final closure of the Central American Seaway, Cane \& Molnar (2001) proposed that between 5 and $3 \mathrm{Ma}$, south equatorial Pacific waters, flowing westward into the Indian Ocean, shifted from at a more southern position, to its more northern location of present, with the continued rise of the Indonesian Archipelago. These authors propose that prior to this shift (and the termination of the permanent El Niño state) Indonesian Through flow was much stronger at its more southerly position, than present day. Thus, paleocirculation proxies, could equally reflect a reduced export of Pacific waters to the ACC-PDWBC, resulting in the reduction of $\mathrm{Zr} / \mathrm{Hf}$ values and seemingly more radiogenic $\mathrm{Pb}$ values due to the reduction of less radiogenic signals being exported to and mixed within the ACC. However, Er/Lu values indicate progressively stronger Pacific Equatorial Water signal throughout the growth history of U1365B-M.

In relation to paleoproductivity proxies and $\mathrm{Mn} / \mathrm{Fe}$ values, indicative of local vertical fluxes through the PDWBC to U1365B-M, the Pliocene is characterised by stable $\mathrm{Mn} / \mathrm{Fe}$ values of 0.8 from 4.7 to c. $3 \mathrm{Ma}$, when $\mathrm{Mn} / \mathrm{Fe}$ values undergo significant changes over the Pleistocene. This indicates no significant change in the CCD and (or) OMZ during this period. The biogenic bloom in the early Pliocene, (continuing from the initiation of the bloom in Late Miocene; zone 3ii), are also recorded in the sedimentary sequences deposited between 5.3 and 3.3 Ma recovered offshore Adélie Land, East Antarctica (Cook, et al., 2013; in addition to the referenced authors in the previous section) and reveal increased productivity in Southern Ocean surface waters, associated with the elevated ACC surface water temperatures. However, U1365B-M records a decrease in the relative biological productivity of the waters in this region from $\mathrm{Ba} / \mathrm{Cu}$ and $\mathrm{Mn} / \mathrm{Ni}+\mathrm{Cu}$ proxies (see Figure 6.13), which continue to decline from $4 \mathrm{Ma}$, throughout the Pleistocene (Hayward, et al., 2004). 
The warmth of the early Pliocene was succeeded by the late Pliocene climate transition (LPCT), which consists of a series of ${ }^{818} \mathrm{O}$ enrichment events that record the onset and progressive intensification of Northern Hemisphere Glaciation (NHG) between 3.5 and 2.4 Ma, were it is estimated that, at maximum glacial extent, $30 \%$ of the Earth's surface was covered by ice (Mattiessen, et al., 2009). During this latter phase of nodule accretion, the macroscopic architecture is characterised by distinct millimetre scale bands and microstructures are finely laminated, a characteristic found of almost all FMNs and crusts (e.g., Glasby, 1985; Segl, et al., 1989; Banakar, et al., 1993, 1997; Xu, et al., 2006), and thought to reflect the orbitally paced waxing and waning of ice-sheets throughout the Pleistocene (Clark \& Pollard, 1998; Zachos, et al., 2001; Cronin, et al., 2010). The banded structures of this zone alternate between darker red-brown layers and grey aluminosilicate rich layers. Over all, the incorporation of detrital material increases from the previous subzone (c. $14 \%$ to $20 \%)$.

However total growth rates continue to progressively slow from $3.7 \mathrm{~mm} / \mathrm{Ma}$ at c. $3 \mathrm{Ma}$ to $2.6 \mathrm{~mm} / \mathrm{Ma}$ at $2.5 \mathrm{Ma}$, coeval with the development of NHG to its maximum extent (Ravelo, et al., 2004; Marlow, et al., 2000) and similar advance of the Western Antarctic Ice Sheet (Naish, et al., 2009; McKay, et al., 2012; Hambrey \& Davis 2013), with a growth spurt from 1 to $0.3 \mathrm{Ma}$ from 2.6 to $5.7 \mathrm{~mm} / \mathrm{Ma}$ from 1 to $0.3 \mathrm{Ma}$. This rise in detrital grain incorporation during the Pleistocene could be associated with a resurgence of AABWLCDW production and thus increased seafloor scouring, however, based on the $\mathrm{Pb}$ isotopic shift at c. 1.7 $\mathrm{Ma}$ that indicates increased contributions from the New Zealandia continent, the increase in detrital incorporation could also be associated with inception of the Solander Channel c. $3 \mathrm{Ma}$, when the creation of a tectonic seaway through Macquarie Ridge in the Pleistocene-Pliocene allowed the ACC to enter the Solander Trough, effectively eroding the Solander Fan complex (Shuur, et al., 1998).

Group 1, 2 and 3 elements display a rise in element concentrations over the Pleistocene to a maximum at $1 \mathrm{Ma}$, after which they rapidly decline (e.g. Ni increases from c. 2000 at c. $3 \mathrm{Ma}$ to $7000 \mathrm{ppm}$ at $1 \mathrm{Ma}$ ). The $\mathrm{Mn} / \mathrm{Fe}$ values however maintain values at $0.8 \mathrm{Ma}$ until c. 1 $\mathrm{Ma}$, when values increase from 0.8 to 1.4 , consistent with the timing of CCD deepening within the region (Hayward, et al., 2009). 
Groups 4-6 however, display a peak in concentration at $3 \mathrm{Ma}$ and their concentrations are roughly maintained at this level of enrichment (e.g., $\mathrm{Sb}$ - increases from 80 to $100 \mathrm{ppm}$ from 4 to $3 \mathrm{Ma}$, and remains at c. $100 \mathrm{ppm}$ ) until $1 \mathrm{Ma}$, when the concentration of groups 4-6 rapidly decrease (e.g., Sb decreases from $100 \mathrm{ppm}$ to $80 \mathrm{ppm}$ over this interval).

These variations in geochemistry are most likely related to changes in bottom water production, export of water masses to the Southern Ocean, and general re-organising of thermohaline circulation over this cooler Pleistocene period. At this time, the closure of the Panama (to all water exchanges) and Indonesia (to deep and bottom water exchanges) corridors in the tropics was complete (Mikolajewicz \& Crowley, 1997; Haug \& Tiedemann, 1998; Haug, et al., 2001; Cane \& Molnar, 2001), and are proposed to have aided in the reorganisation of the oceanic and atmospheric system (Philander \& Fedorov, 2003). A progressive reduction in sea-surface temperature occurred at the same time that upwelling of the equatorial Pacific and the eastern ocean basin coastal regions intensified (Ravelo, et al., 2004; Marlow, et al., 2000). The enhanced coastal upwelling caused a general aridification of proximal landmasses to the east due to lowered water vapour content above cold upwelling zones (e.g., Cane \& Molnar, 2001; Molnar 2008). Glacial-interglacial cyclicity linked to the build-up and retreat of the Northern Hemisphere ice sheet, as well a strong variability in atmospheric $\mathrm{CO}_{2}$, became characteristic features of the Earth's climate system at this time (Tiedemann et al., 1994).

Productivity proxies are not in agreement over this period except for the decline in values to c. 1.5 Ma (see Figure 6.13). Paleoredox proxies display a continued decrease in ocean oxygen as the oceans continued to cool (see Figure 6.16). Paleocirculation proxies show a decrease from $3 \mathrm{Ma}$ onwards to less radiogenic $\mathrm{Pb}$ values consistent with the findings of Frank, et al. 2002 of a reduced export of NADW during the Pleistocene as the AMOC is reduced to its shallow glacial mode of circulation (Figure 6.20). 


\section{Chapter}

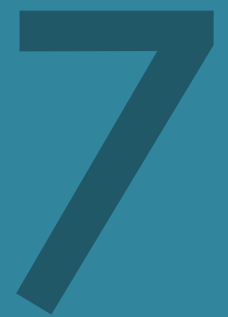

Summarises the key findings from each of the five objectives, addressing the thesis aim, followed by comments on future research challenges

\section{Conclusions}

\section{Key findings \& future challenges}

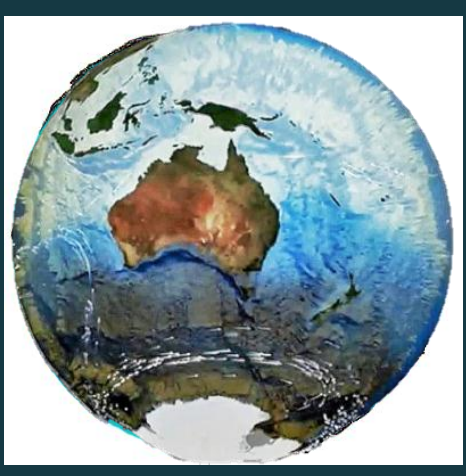

7.1 Key Findings

7.2 Future Challenges 


\subsection{Key Findings}

At any one time, the Pacific Deep Western Boundary Current holds a record of the prevailing climatic and tectonic conditions within its physical and chemical properties, as it is these external and internal earth processes that determine the delivery of elements to deep ocean via controls upon: the weathering, mass wasting and erosion of the surrounding continents and subsequent transport to the oceans via riverine, aeolian and glacial processes; from volcanic eruptions, rifts and hydrothermal vents; to a constant rain of cosmogenic particles; in addition to gaseous exchanges with the overlying atmosphere (e.g., $\mathrm{O}_{2}, \mathrm{CO}_{2}$ ), and the settling of dead organic debris to the seafloor. These chemical signals are translated through the oceanic medium to deep sea FMNs, as they sequester these elements over millions of years from abyssal ocean currents into their successive

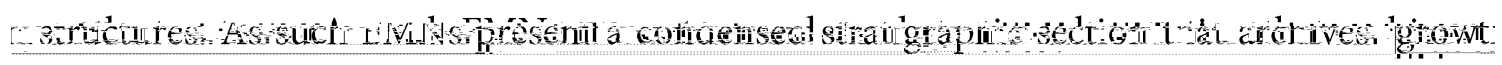
the climatic-oceanic-tectonic conditions of the surrounding environment during accretion. Unravelling the physical and chemical properties of a large hydrogenous nodule, accreted from waters of the PDWBC, in order to determine its chemical history, was the main aim of this thesis.

In order to determine the paleoenvironments recorded in U1365B-M: (1) a separation technique was developed to isolate the seawater component; (2) the age model established for the U1365B-M (and selection of the Campbell Nodule Field) was revised and utilised to provide an up-to-date chronology, total, authigenic and detrital growth rates, and to determine distinctly different phases of accretion (nodule zones) preliminarily based on growth rate changes; (3) the physical archives - macrostructures, microstructures, detrital and authigenic components where assessed; (4) the chemical archives - major, minor, trace and $\mathrm{Pb}$ isotopic compositions were analysed, and (5) previously reported changes in the late Neogene evolution of the oceans and climate (on a local, regional and global scale) where associated with key changes identified from the application of 1-4 above. These five pre-requisites for paleoenvironmental reconstruction constituted the objectives of the thesis. The key conclusions derived from applying each of the five objectives are summarised in the following sections. 


\section{Objective 1: Isolating the seawater component}

The new wet chemistry technique successfully isolates both the seawater (authigenic) and land (detrital) derived nodule fractions, offering an alternative to bulk chemical analyses and eliminating the need for complicated sequential leaching procedures. The technique provides a simple, unified approach to complete multi-elemental and $\mathrm{Pb}$ isotopic analysis of the isolated seawater fraction, with the potential to expand upon elemental and isotopic analyses and to perform similar investigations on the detrital nodule component.

\section{Objective 2: Revising \& utilising the chronological framework}

Beryllium dating performed on U1365B-M was updated to provide a late mid Miocene through recent chronology for U1365B-M (12.7 Ma to present), and found that Co chronometers were not reliable in their ability to reproduce a comparable chronology or growth rates. The application of a growth model to beryllium dating, enabled the identification of key points in time in which U1365B-M changed its mode of accretion and were used to divide the chronology into a series of time zones based on associated changes in texture. Total, authigenic and detrital growth rates were calculated from the revised age model providing insights in to the hydrogenous mode of nodule accretion, and most noticeably, the significant decrease in growth rates c. $6 \mathrm{Ma}$ associated with the onset of present day thermohaline circulation.

\section{Objective 3: Unravelling the physical archives}

Stratigraphic analysis of U1365B-M revealed five major changes in internal structure: (1) core zone (12.7 to $11.9 \mathrm{Ma}$ ), (2) iris zone (11.9 to 9.2 Ma), (3) compact zone (9.2 to 6.3 $\mathrm{Ma})$, (4) crumbly zone (6.3 to $4.7 \mathrm{Ma}$ ) and a banded zone (4.7 to $0 \mathrm{Ma})$. These time zones coincide with those previously reported for other FMNs and crusts from the CircumAntarctic, Pacific and Indian Oceans. As such U1365B-M has apparently preserved the signatures of long-term oceanographic events with considerable consistency on a global scale. Each zone represents a different mode of nodule accretion in response to a change in the depositional environment and display characteristic trends in their microstructures, proportions of authigenics and detritals in addition to their chemical content. In general, 
microstructures grade from mottled to cuspate to columnar to laminated as detrital material declines from 45 to $20 \%$ and authigenic precipitates increase and the chemical content mimics this trend by becoming progressively more cyclical in chemical variations as the nodule becomes progressively more banded with the onset of Pliocene-Pleistocene G-I cycles. Further evidence that each subzone was accreted in a different environment of deposition comes from $\mathrm{Pb}-\mathrm{Pb}$ mixing arrays, which display unique end-member $\mathrm{Pb}$ sources for each time zone identified.

\section{Paleoenvironment of deposition}

U1365B-M records five distinctly different physiochemical fingerprints for U1365B-M over its growth history associated with: [1] Core zone, declining temperatures of the late mid Miocene (12.7 to $11.9 \mathrm{Ma}$ ); [2] Iris zone, maximum Antarctic ice-sheet activity, aeolian fluxes and PDWBC speeds (11.9 to 9.2 Ma); [3] Compact zone, progressive cooling of the late Miocene and a transitional ocean (9.2 to $6.3 \mathrm{Ma}$ ), [4] Crumbly zone, establishment of modern thermohaline circulation (6.3 to $4.7 \mathrm{Ma}$ ), and; [5] Banded zone, from the warm Pliocene to cool Pleistocene ocean (4.7 to $0 \mathrm{Ma}$ ).

\section{Paleocurrent speeds}

Strength of the PDWBC, based on detrital incorporation associated with seafloor scouring of these powerful currents, indicates a long-term decrease in current speeds, with phases of more vigorous current activity occurring at [12.5 to 11.5], [10.5 to 9], [7 to 6], and [3 Ma onward] closely correlating with local (13 to 10 and 8 to $6 \mathrm{Ma}$ ) and global (Neogene hiatuses NH3 to 9).

\section{Objective 4: Unravelling the chemical archives}

The large geochemical data base of U1365B-M as assessed in terms of paleoprecipitation and element associations or deposition of Fe-Mn precipitates and the mechanisms involved in the sequestration of tracer elements from seawater; paleosource, on a global, regional and proximal scale; the novel application of paleoproductivity and redox proxies in addition to proxies concerning paleocirculation, the latter of which may also reflect icesheet dynamics over the late Neogene. 


\section{Paleoprecipitation \& element associations}

The geochemical suite of elements analysed fall into three main clusters, elements associated with $\mathrm{Mn}$, a biogenic phase and Fe, respectively. With the mangophile elements forming group $1(\mathrm{Ni}, \mathrm{Cd}, \mathrm{Tl})$ and group 2 (U, W, Co, Mn, Mo); biogenic elements for group $3(\mathrm{Cu}-\mathrm{Zn})$, and $\mathrm{FeOOH}$ associated elements forming group 4 (V, As, Ce, Er, Pb, La, $\mathrm{Gd}, \mathrm{Dy}, \mathrm{Nd}, \mathrm{Sm}, \mathrm{Eu}$ ), inferred to be associated with epitaxiallly interwoven $\mathrm{Mn}$ and $\mathrm{Fe}$ minerals, group $5(\mathrm{Nb}, \mathrm{Fe}, \mathrm{Bi}$, Th, $\mathrm{Lu}, \mathrm{Y}, \mathrm{Yb}, \mathrm{Zr}, \mathrm{Hf})$ thought to be associated with pure $\mathrm{FeOOH}$ colloids precipitated from seawater and group $6(\mathrm{Ba}, \mathrm{Sb}, \mathrm{Ta})$ thought to be associated with the background detrital contributions to seawater due to the closer approximation of these chemical profiles with that of the detrital \% incorporation. Elements are grouped in U1365B-M according their speciation in seawater, with $\mathrm{Ni}, \mathrm{Cd}, \mathrm{Tl}$ forming chloride complexes, the YREE forming hydroxide complexes, $\mathrm{Cu}$ and $\mathrm{Zn}$ forming organic bound ligands, $\mathrm{Mn}, \mathrm{Mo}, \mathrm{Co}, \mathrm{U}$, and $\mathrm{W}$ forming oxide complexes and so forth. Those elements displaying similarities of less than $70 \%$ have been inferred to be associated with more than one dominate speciation in seawater and thus are associated with various groups of elements. These findings are similar to those previously reported from sequential leaching techniques and thus provide additional support for the technique developed here in analysing Fe-Mn deposits.

\section{Paleosource}

U1365B-M is a hydrogenous FMN, having derived its geochemical composition from the direct precipitation of elements from the PDWBC, with little to no diagenetic or hydrothermal contributions. Any hydrothermal and diagenetic contributions have thus become part of the general background seawater chemistry of the PDWBC. Thus, no significant suboxic or oxic release of interstitial waters have contributed elements diagenetically to U1365B-M indicating that the oxygen concentration of the PDWBC must have remained $>5 \mu \mathrm{M}$ (boundary between oxic and suboxic conditions). Additional physiochemical parameters such as: spherical shape; smooth surface texture; slow growth rates c. $5.7 \mathrm{~mm} / \mathrm{Ma}$; average $\mathrm{Mn} / \mathrm{Fe}$ values of close to unity; low $\mathrm{Co}+\mathrm{Ni}+\mathrm{Cu}$ contents $(<1$ wt \%); high positive $\mathrm{Ce} / \mathrm{Ce}^{*}$ anomalies (>1), and; all U1365B-M samples plotting within the hydrogenous end-member field on the $\mathrm{Fe}-\mathrm{Mn}(\mathrm{Co}+\mathrm{Ni}+\mathrm{Cu} \times 10)$ ternary diagram, all attest to a hydrogenous mode of formation for the duration of the nodules 12.7 Ma growth 
history of U1365B-M. From 12.7 to c. 8 Ma U1365B-M displays Mn/Fe and $\mathrm{Co}+\mathrm{Ni}+\mathrm{Cu}$ contents comparable to present day Antarctic FMNs. However, from c. 8 Ma onward U1365B-M is more comparable with Pacific FMNs, which would be consistent with results from the chemical archives indicating increasing contributions of Pacific waters to the PDWBC. On a regional scale the PDWBC is unlikely to have received riverine sourced elements due to the location of the nodule field within a sediment derived region of the deep ocean, in addition to the inactivity of the Solander Trough until c. 1.7 Ma (according to $\mathrm{Pb}$ isotopic compositions, when Southern Alps-Solander Trough-PDWBC connections were established. During the phase of maximum ice-sheet expansion, $\mathrm{Pb}$ isotope may indicate increased aeolian fluxes to the deep ocean in association with reduced sea-levels, and aridification during this climatically cool period, as reported by other authors for the southwest and greater Pacific.

With the sample resolution used in our method of FMN analysis it is difficult to associate short lived local volcanic events with the $\mathrm{Pb}$ isotopic record. However, it appears that MORB is a potential mixing end-member of $\mathrm{Pb}$ within the PDWBC, in addition to crustal averages of NADW preserving ancient continentally soured $\mathrm{Pb}$ and NPDW preserving a record of young volcanic arc derived $\mathrm{Pb}$. The results of $\mathrm{Pb}-\mathrm{Pb}$ mixing arrays indicate the Indian-Atlantic MORB was a potential $\mathrm{Pb}$ end-member of the mixing arrays from 13 to $1.7 \mathrm{Ma}$ followed by an association with Pacific MORB thereafter.

\section{Paleoproductivity}

Previously reported proxies of authigenic $\mathrm{Ba}$ concentrations and $\mathrm{Ba} / \mathrm{Th}$ values were applied to U1365B-M in addition to proxies developed based on inter-element associations and relationships of certain elements to biological productivity reported in the literature and are: $\mathrm{Zn} / \mathrm{Cu}, \mathrm{Ba} / \mathrm{Cu}$ and $\mathrm{Mn} /(\mathrm{Ni}+\mathrm{Cu})$. All proxies appear to correlate well with previously reported biogenic bloom events c. 7 to $4 \mathrm{Ma}$ and carbonate crash events c. 12 to $9 \mathrm{Ma}$ of the late Neogene and indicate more specifically high productivity between c. 13 to $12 \mathrm{Ma}$, c. $10.6 \mathrm{Ma}$, c. 9.5 to $8 \mathrm{Ma}$, and 7 to $4 \mathrm{Ma}$, generally in associations with warmer climatic regimes and low biological activity between c. 12 to $11 \mathrm{Ma}, 10.6$ to c. $9.5 \mathrm{Ma}, 8$ to 7 Ma from $4 \mathrm{Ma}$ to present, generally in association with colder climatic regimes and(or) enhanced periods of fast corrosive currents. The Mn/Fe time-series for U1365B-M appears 
to reflect the step-wise deepening of the CCD in the region indicating as of yet undetermined long-term controls due to the cyclical nature of the $\mathrm{Mn} / \mathrm{Fe}$ curve displaying periods of $5-6$ Myrs of chemical stability and rapid 1 Myr transitions (at c. 7 and $1 \mathrm{Ma}$ ) to new equilibrium states where the fractionation of $\mathrm{Mn}$ and Fe are constant.

\section{Paleoredox}

Paleoredox proxies $\mathrm{V} /(\mathrm{V}+\mathrm{Ni}), \mathrm{Ni} / \mathrm{Co}$ and $\mathrm{U} / \mathrm{Th}$ indicate that $\mathrm{U} 1365 \mathrm{~B}-\mathrm{M}$ has precipitated from a highly oxic PDWBC throughout its $12.7 \mathrm{Ma}$ growth history. However, within this oxic marine environment, the time-series of $\mathrm{Th} / \mathrm{U}, \mathrm{Ce} / \mathrm{Ce}{ }^{\star}, \mathrm{Eu} / \mathrm{Eu}^{\star}$ and $\mathrm{V} /(\mathrm{V}+\mathrm{Ni})$ indicate a long-term progressive reduction in ocean oxygen, consistent with long-term declining bottom water temperatures for the Atlantic and Pacific. The apparent decline in ocean oxygen occurred in three main steps between 9.5 and $8.4 \mathrm{Ma}, 6.3$ to $4 \mathrm{Ma}$ and from $2.5 \mathrm{Ma}$ to present. These transition phases to lower $\mathrm{O}_{2}$ are synchronous with inferences of biological blooms recorded in the paleoproductivity proxies. Paleoredox proxies show short-term (c. 1- 3 Myrs) perturbations in long-term trends with higher ocean $\mathrm{O}_{2}$ occurring during peak glacial advances (e.g. at 10 and $3 \mathrm{Ma}$ ) consistent with deep-sea hiatuses inferred to record phases of increased bottom water velocities that are welloxygenated and serve to ventilate the deep ocean. Paleoredox proxies thus highlight the importance of abyssal current velocities and corrosiveness on the ventilation of the deep ocean, causing perturbations in the long-term trend of reduced oxygen content.

\section{Paleocirculation}

The application of $\mathrm{Pb}$ isotopes could not be used to discern a global provenance from 13 to $1.7 \mathrm{Ma}$ as the isotopic compositions of the potential source arcs and sediments, each show a wide range of compositions and largely overlap. However, $\mathrm{Pb}$ compositions of U1365B-M are mid-way between unradiogenic young Pacific arc leads and radiogenic old continental terrains. The unique lead signature recorded by U1365B-M was thus determined to be derived from advected $\mathrm{Pb}$ dissolved in $\mathrm{LLCDW}$ of the ACC-PDWC. This is counter intuitive to the short residence of $\mathrm{Pb}$ (c. $50 \mathrm{yrs}$ in the Southern Ocean) however this 'Sr'-like behaviour is commonly reported in the application of $\mathrm{Pb}$ isotopes in FMNs and crust studies. From 1.7 $\mathrm{Ma}$ to present $\mathrm{Pb}$ compositions are obscured from the inundation of local sources. 
For U1365B-M $>$ PDWBC $\mathrm{Pb}$ isotopic compositions either reflect varying export of Pacific and North Atlantic deep waters over the late Neogene and (or) Antarctic ice sheet activity. From 13 to $10 \mathrm{Ma}$ the shift to more radiogenic $\mathrm{Pb}$ values (characteristic of present day NADW) may reflect increased export of NADW and(or) spin-up of the ACC (as supported by the correlation of detrital mineral proportions and the occurrence of deep sea hiatuses) consist with a period of well-documented ice sheet development on Antarctica, and thus could equally reflect the systematic and progressive long-term buildup (3 Myrs) of the Antarctic ice-sheet to maximum extents at c. $10 \mathrm{Ma}$, and progressive but faster demise of these excessive ice-sheet until 'factory settings are restored c. $8 \mathrm{Ma}$ ). The HREE/LREE profile may also reflect such trends, due to the peaks in values at c. $10 \mathrm{Ma}$ associated excessive maximum ice sheet activity of Antarctica and equally with rapidly increasing values c. 3 to $1 \mathrm{Ma}$ associated excessive maximum ice sheet activity of the Northern Hemisphere. Alternatively, from 10 - $8 \mathrm{Ma}$, the return to more non-radiogenic values (characteristic of present day NPDW $\mathrm{Pb}$ compositions) is consistent with the findings of van de Flierdt et al. who interpret this to reflect increased export of Equatorial Pacific Deep Water (to their nodule growth site) due to closure of the Indonesian Gateway to deep water exchange at c. $10 \mathrm{Ma}$ and the resulting reorganisation of ocean currents thereafter, which are also supported by $\mathrm{Er} / \mathrm{Lu}$ and $\mathrm{Er} / \mathrm{Yb}$ values which indicate a progressively strong Pacific fingerprint within the PDWBC over the growth history of the nodule. The HFSE ratio $\mathrm{Zr} / \mathrm{Hf}$, presents a promise in their application as water mass tracers. The $\mathrm{Zr} / \mathrm{Hf}$ of U1365B-M fits in well with the predicted values for AABW-LCDW of $<300$. The $\mathrm{Zr} / \mathrm{Hf}$ time-series displays more Pacific-like values from c. $10 \mathrm{Ma}$ to presentday and appear to compliment the results of the more robust application of $\mathrm{Pb}$ isotopes.

\section{Objective 5: Unravelling the late Neogene evolution of the PDWBC}

From a revision and assessment of beryllium cosmochronometry, analysis of macro- and micro- growth structures, authigenic and detrital nodule components and growth rates, analysis of major, minor and trace element chemistry and $\mathrm{Pb}$ isotopic analysis, in addition to the application of multiple paleosource, paleocirculation proxies and novel application of paleoproductivity and redox, five major accretion periods and corresponding paleoenvironments can be ascertained for the late Neogene evolution of the PDWBC. 


\section{Phase 1: The late mid-Miocene PDWBC}

The first period of nodule growth is a faster accretionary period, distinguished by its calcareous shell fragment at the core, surrounded by dark red-brown Fe-Mn precipitates, and white-grey aluminosilicates and characterised by mottled microstructures due to high detrital incorporation. The physical and chemical archives of U1365B-M indicate that the PDWBC, during this phase of globally depressed atmospheric and oceanic temperatures, was characterised by the most oxygen rich conditions of the late Neogene. Current strengths were powerful enough to scour seafloor sediments, proximal to U1365B-M, and to carve out significant Neogene hiatuses surrounding the Southern Ocean (in association with combined ACC-PDWBC flow) and further north in the sub-tropical Pacific (where the PDWBC flows on solo into the Greater Pacific). Paleoproductivity proxies indicate the beginning of a carbonate crash event in association with significant carbonate dissolution due to a shallow CCD. As such, Fe contents (and group 4 to 6 elements) are high, whilst the Mn contents (and group 1-2 elements) are of low enrichment. Paleocirculation proxies suggest the PDWBC transmits a strong NADW signal throughout this interval or, in the case of $\mathrm{Pb}$, (and potentially HREE/LREE values) records systemically more radiogenic $\mathrm{Pb}$ in response to increased ice-sheet activity.

\section{Phase 2: The late Miocene PDWBC}

The paleoceanographic conditions of the PDWBC established during the late midMiocene are strengthened over this second phase of accretion, distinguished by the lighter zone textures, in association with highest detrital incorporation percentages. Current speeds appear to increase and remain well-ventilated, dissolution of marine carbonates progresses, and the shift toward more radiogenic $\mathrm{Pb}$ isotopic compositions (and HREE/LREE) progresses, reaching a maximum at $10 \mathrm{Ma}$ synchronous with records of maximum Antarctic ice-sheet expansion, and continuous export of NADW into the Southern Ocean. The excursion toward radiogenic $\mathrm{Pb}$ values has been associated with further restriction of the Indonesian seaway to bottom and deep water circulation between the Pacific and Indian Oceans in addition to a phase of shoaling of the Panama Isthmus, leading to the increased divergence of warm tropic waters into the North Atlantic and strengthening of the 'NADW' fingerprint being exported to the Southern Ocean and incorporated into the PDWBC through effective mixing within the greatly sped-up ACC 
at this time. Additionally, the shift in $\mathrm{Pb}$ isotopic compositions in $\mathrm{Pb}-\mathrm{Pb}$ space, indicate the PDWBC receives an increased aeolian flux in association with the colder, drier climate and shallow glacial ocean.

\section{Phase 3: The terminal late Miocene PDWBC}

This phase of FMN growth is a slowing accretionary period, displaying reductions in detrital components and as such, microstructures grade from mottled to cuspate, as $\mathrm{Mn}$ and mangophile elements increase in concentration. This phase of accretion is characterised by a three-fold (zone 3i \& 3ii and mid-way in 3ii) evolution of PDWBC chemistry: (1) From [10 to $8.4 \mathrm{Ma}$ ] the PDWBC is in a transitional state, bottom water temperatures are reported to be higher and ocean oxygen (redox proxies) is significantly reduced as surface water productivity increases (productivity proxies). The large excursion to more radiogenic $\mathrm{Pb}$ is systematically and gradually reduced to those characteristic of the PDWBC before the excursion occurred, potentially in response to: (a) closure of the Indonesian gateway and the resulting re-organisation and strengthening of Pacific circulation, strongly indicated by paleocirculation proxies which record an increasing 'equatorial Pacific' like signal from $10 \mathrm{Ma}$ onward; (b) reduced spin up of the ACC during this period of relatively warmer conditions and thus a reduced NADW signal, indicated by the lack of regional hiatuses and declining detrital incorporation; (c) reduction of Antarctic ice-sheet activity after reaching a critical threshold at $10 \mathrm{Ma}$; (2) From [8 to $7 \mathrm{Ma}$ ] the CCD deepens, indicated by an increase in the $\mathrm{Mn} / \mathrm{Fe}$ value as Fe delivery to the deep ocean is reduced due to decreased carbonate dissolution, and; (3) [7 - $6 \mathrm{Ma}$ ] when both detrital proportions and authigenic element concentrations increase potentially in response to a fresh influx of young AABW into the PDWBC as sheets are proposed to have increased once more, maintaining stable Ocean oxygen levels.

\section{Phase 4: The Miocene-Pliocene PDWBC}

This fourth phase of growth is a slower accretionary period, marking the transition from previously higher accretion rates to those that are greatly reduced and the previously mottled and cuspate microstructures of the previous zones become continuously laminated and structured from this point forward. This phase of growth signifies a change in PDWBC chemistry, associated with the onset of modern thermohaline circulation, recorded in U1365B-M by transition from Atlantic to Pacific like Zr-Hf values, declining 
ocean oxygen as bottom waters become progressively frigid, and a biological boom in surface water productivity in response to: expansion of the west Antarctic ice sheet cooler, drier climates and enhanced AABW production.

\section{Phase 5: The Pliocene-Pleistocene PDWBC}

The final phase of growth is the slowest accretionary period over which with microstructures become progressively more laminated on a finer micro-millimetre scale, indicative of strong PDWBC currents facilitating the accretion of a more compact and pure ferromanganese zone, displaying high concentrations of $\mathrm{Mn}$ (and associated elements, including group 3- $\mathrm{Cu} \& \mathrm{Zn}$ ) and reductions in $\mathrm{Fe}$ (and associated elements). During the warm Pliocene [4.7 Ma to $3 \mathrm{Ma}$ ], a slight return of cuspate microstructures, reduction of detrital grains, and increase in the redox proxies over this interval, indicate a slower, warmer an increasingly ventilated Pliocene PDWBC. Significant reversals in longterm chemical trends occur at c. $4 \mathrm{Ma}$, most noticeable in the group 3 and HREE/LREE profiles, potentially recording the chemical response of the PDWBC to final closure of the Central American Seaway, and(or) the coeval shift and weakening of Indonesian Throughflow from a more southerly position to its more northern position of present, accompanied by a weakening of this flow. The transition from a warm Pliocene to a cold Pleistocene PDWBC is marked by cyclical spurts of increased Fe-Mn scavenging of tracer elements to greater levels of enrichment, which generally rise to their highest concentrations at $3 \mathrm{Ma}$ (especially groups 4-6) and $1 \mathrm{Ma}$ (especially groups 1-3), the latter of which is associated with the final shift in $\mathrm{Mn} / \mathrm{Fe}$ values to double that of the terminal Miocene, indicating a further deepening of the CCD and thus decrease in PDWBC corrosivity. Productivity proxies are not in agreement over this period except for the decline in values to c. 1.5 Ma. Paleoredox proxies display a continued decrease in ocean oxygen as the oceans continued to cool and Paleocirculation proxies show a decrease from $3 \mathrm{Ma}$ onwards to less radiogenic $\mathrm{Pb}$ values consistent with a reduced export of NADW during the Pleistocene as the AMOC is reduced to its shallow glacial mode of circulation. 


\subsection{Future Challenges}

With the enormous volume of publications on FMNs, FMCs and more recently Fe-Mn oxyhydroxide fractions of deep-sea sediments, it would be beneficial for any future studies if the results derived from the physical and chemical archives of these deposits were made available in one place, via the world wide web or any other medium, so that a comprehensive and critical assessment can made of all the data gathered. Furthermore, although a grand task, a critical review and summation of the key conclusions made from these studies in light of all chemical, geological, biological and physical factors that influence the formation and enrichment of ferromanganese both presently and in the geological past, would provide an invaluable reference for future research.

As FMNs and crusts are basically condensed stratigraphic sections, it would be intriguing to see them treated as such, with the principles of stratigraphy and crosscorrelation applied between different deposits in various parts of nodule fields, the regional basin and global ocean. Additionally, the identification of key 'time markers' in FMNs, when the texture and growth rate of these deposits changed synchronously on a global scale, was presented in the 1980s, and, aside from 'one line comments' in some publications, little work has been done to explore this concept of marker beds within FMNs and to compile and correlate these time markers recorded in the literature, despite the wealth of information on deep ocean processes that could come from doing so. Equally, although isotopic studies provide a more constrained review of the various processes being investigated, there needs to be further investigations conducted on explaining variations in element associations, concentrations and ratios, and their application as proxies of source, redox, productivity, incongruent weathering, ice sheet dynamics and so forth. The large geochemical data base gathered here, presents the potential for further investigation of the elemental chemistry of FMNs and their potential application as proxies of past oceanic conditions.

On a final note, the method developed and applied in this thesis could be improved by incorporating an additional radiometric dating method i.e. ${ }^{230} \mathrm{Th} /{ }^{232} \mathrm{Th}$, which can provide detailed age models for the past c. 3 kyrs. In doing so, both a long-term (13 to $0 \mathrm{Ma}$ ) and 
short-term (c. 3 - 0 kyrs) assessment of FMN archives would enable a more complete paleoenvironmental reconstruction over the late Neogene and provide insight into late Pleistocene G-I cycles. Furthermore, selected 'crust to core' depth profiles could be sampled using both the micro-sampling and wet chemistry methods of authigenic beryllium dating (Section 4.n) and bulk in situ laser ablation ICP-MS methods. Microsampling (1-2 mm) yields a resolution of c. 200,000 kyrs, whilst laser ablation profiles (3050 microns) would represent a temporal resolution of c. 10 kyrs. Authigenic geochemical data from the micro-sampling technique can be used to calculate dilution effects of detritus present in the bulk LA-ICP-MS profiles. The dilution effects can then be corrected for to provide an authigenic record. Both dating methods can be manipulated to provide a detailed and comprehensive age model for both micro-sampling and laser ablated chemical data, thus providing a much higher resolution record of past ocean chemistry. 


\section{References}

Abouchami, W. \& Galer, S., 1998. The provinciality of Pb isotopes in Pacific Fe-Mn deposits. Mineralogical Magazine, 62A(August), pp. 1-1712.

Abouchami, W., Galer, S. \& Koschinsky, A., 1999. Pb and Nd isotopes in NE Atlantic FeMn crusts: Proxies for trace metal paleosources and paleocean circulation. Geochimica et Cosmochimica Acta, 63(10), pp. 1489-1505.

Abouchami, W. \& Goldstein, S., 1995. A lead isotopic study of circum-antarctic manganese nodules. Geochimica et Cosmochimica Acta, 59(9), pp. 1809 - 1820.

Abouchami, W. et al., 1997. Secular changes of lead and neodymium in central Pacific seawater recorded by a Fe-Mn crust. Geochimica et Cosmochimica Acta, 61(18), pp. 39573974.

Achurra, L. et al., 2009. Manganese nodules in the Miocene Bahía Inglesa Formation, northcentral Chile: Petrography, geochemistry, genesis and palaeoceanographic significance. Sedimentary Geology, 217(1-4), pp. 128-139.

Adams, C., 1980. New K-Ar age data for South Island lamprophyre dyke swarms in the Buller-S. Westland and Haast-Wanaka areas. Geological Society of New Zealand Conference, Christchurch, Nov 24-27, Programme and abstracts, Volume 14.

Adams, C. J., 1981. Migration of late Cenozoic volcanism in the South Island of New Zealand and the Campbell Plateau. Nature, Volume 294, pp. 153-155.

Aja, S., Wood, S. \& Williams-Jones, A., 1995. Applied Geochemistry. The aqueous geochemistry of Zr and the solubility of some Zr-bearing minerals, 10(6), pp. 603-620.

Albarède, F. \& Beard, B., 2004. Analytical methods for non-traditional isotopes. In: C. Johnson, B. Beard \& F. Albarède, eds. Geochemistry of non-traditional isotopes. Washington, D.C.: Mineralogical Society of America, pp. 113-152.

Alibo, D. S. \& Noazaki, Y., 1999. Rare earth elements in seawater: Particle association, shalenormalization, and Ce oxidation. Geochimica et Cosmochimica Acta, 63(3-4), pp. 363-372. 
Anderson, J. B. et al., 2011. Progressive Cenozoic cooling and the demise of Antarctica's last refugium. Proceedings of the National Academy of Sciences of the United States of America, 108(28), pp. 11356-11360.

Anderson, J. \& Wellner, J., 2011. Tectonic, Climatic, and Cryospheric Evolution of the Antarctic Peninsula. Washington, D.C., Geopress: American Geophysical Union: Special Publications Series.

Aplin, A. \& Cronan, D., 1985. Ferromanganese oxide deposits from the Central Pacific Ocean, II. Nodules and associated sediments. Geochimica et Cosmochimica Acta, 49(2), pp. 437-451.

Arrhenius, G., 1963. Pelagic sediments. In: M. Hill, ed. The Sea: Ideas and observations on progress in the study of the seas. New York: John Wiley, pp. 655-727.

Axelsson, M., Rodushkin, I., Ingri, J. \& Öhlander, B., 2002. Multi-elemental analysis of Mn-Fe nodules by ICP-MS: optimisation of analytical method. The Analyst, 127(1), pp. 7682.

Baines, P. \& Condie, S., 1985. Observations and modelling of Antarctic downslope flows: A review. In: S. S. Jacobs \& R. F. Weiss, eds. Ocean, ice, and atmosphere: Interactions at the Antarctic continental margin. Washington, D. C., American Geophysical Union: Antarctic Research Series, pp. 29-49.

Baker, E. \& German, C. R., 2004. On the global distribution of hydrothermal vent fields. In: C. R. German, J. Lin \& L. M. Parson, eds. Mid-Ocean Ridges. Washington, D. C., American Geophysical Union: Geophysical Monograph Series, pp. 245-266.

Baker, J. A., Peate, D., Waight, T. \& Meyzen, C., 2004. Pb isotopic analysis of standards and samples using a ${ }^{207} \mathrm{~Pb}-{ }^{204} \mathrm{~Pb}$ double spike and thallium to correct for mass bias with a doublefocusing MC-ICP-MS. Chemical Geology, 211(3-4), pp. 275 - 303.

Baker, J. A., Waight, T. E., Graham, I. J. \& Wright, I. C., 2001. High resolution Pb isotopic profiles of Fe-Mn nodules (19-0 Ma) from the Deep Western Boundary Current, Southern Pacific. American Geophysical Union: Fall Meeting: Abstract, 82(47), pp. OS31C-0438.

Banakar, V. K., 2010. Deep-sea ferromanganese deposits and their resource potentials for India. Journal of the Indian Institute of Science, 90(4), pp. 535-541.

Banakar, V. K. \& Borole, D., 1991. Depth profiles of ${ }^{230}$ Th excess, transition metals and mineralogy of ferromanganese crusts of the Central Indian basin and implications for palaeoceanographic influence on crust genesist genesis. Chemical Geology, 94(1), pp. 33 - 44. 
Banakar, V. K. et al., 2003. Himalayan sedimentary pulses recorded by silicate detritus within a ferromanganese crust from the Central Indian Ocean. Earth and Planetary Science Letters, 205(3-4), pp. 337-348.

Banakar, V. K. \& Hein, J. R., 2000. Growth response of a deep-water ferromanganese crust to evolution of the Neogene Indian Ocean. Marine Geology, 162(2-4), pp. 529-540.

Banakar, V. K., Nair, R., Parthiban, G. \& J., P., 2000. Oceanic ferromanganese deposits: Future resources and past-ocean recorders. Indian Mineralogist, 34(2), pp. 41-56.

Banakar, V. K., Nair, R., Tarkian, M. \& Haake, B., 1993. Neogene oceanographic variations recorded in manganese nodules from the Somali Basin. Marine Geology, 110(3-4), pp. 393402.

Banakar, V. K., Pattan, J. N. \& Mudholkar, A. V., 1997. Palaeoceanographic conditions during the formation of a ferromanganese crust from the Afanasiy-Nikitin seamount, North Central Indian Ocean: Geochemical evidence. Marine Geology, 136(3-4), pp. 299-315.

Banakar, V. K. \& Tarkian, M., 1991. Genesis and growth of internal microstructures of manganese nodule. Indian Journal of Marine Sciences, 20(3), pp. 20-24.

Banerjee, R., 2000. A documentation on burrows in hard substrates of ferromanganese crusts and associated soft sediments from the Central Indian Ocean. Current Science, 79(4), p. 517521.

Banerjee, R., Gupta, S., Miura, H. \& Borole, D., 2010. A 400 ka supra-Milankovitch cycle in the $\mathrm{Na}, \mathrm{Mg}, \mathrm{Pb}, \mathrm{Ni}$, and Co records of a ferromanganese crust from the Vityaz fracture zone, central Indian ridge. Climate of the Past Discussions, 6(4), pp. 1311-1335.

Banerjee, R. \& Miura, H., 2001. Distribution pattern and morphochemical relationships of manganese nodules from the Central Indian Basin. Geo-Marine Letters, 21(1), pp. 34-41.

Banerjee, R. et al., 1999. Petrogenesis of ferromanganese nodules from east of the Chagos Archipelago, Central Indian Basin, Indian Ocean. Marine Geology, 157(3-4), pp. 145-158.

Banner, J. L., 2004. Radiogenic isotopes: Systematics and applications to earth surface processes and chemical stratigraphy. Earth-Science Reviews, 65(3-4), pp. 141-194.

Barker, P. \& Thomas, E., 2004. Origin, signature and palaeoclimatic influence of the Antarctic Circumpolar Current. Earth-Science Reviews, 66(1-2), pp. 143-162.

Barrett, T., Taylor, P. N. \& Lugowski, J., 1987. Metalliferous sediments from DSDP leg 92, the East Pacific rise transect. Geochimica et Cosmochimica Acta, 51(9), pp. 2241-2253. 
Barron, J. \& Keller, G., 1983. Paleoceanographic implications of Miocene deep-sea hiatuses. Geological Society of America Bulltetin, 94(5), pp. 590 - 613.

Barth, M. G., McDonough, W. F. \& Rudnick, R. L., 2000. Tracking the budget of $\mathrm{Nb}$ and $\mathrm{Ta}$ in the continental crust. Chemical Geoogy, 165(3-4), pp. 197-213.

Basak, C., Martin, E. E. \& Kamenov, G. D., 2011. Seawater Pb isotopes extracted from Cenozoic marine sediments. Chemical Geology, 286(3-4), pp. 94-108.

Baturin, G. N., 1988. The Geochemistry of Manganese and Manganese Nodules in the Ocean. Dordrecht, Netherlands: Springer: Sedimentology and Petroleum Geology Series.

Baturin, G. N. \& Dubinchuk, V. T., 2010. On the composition of ferromanganese nodules of the Indian Ocean. Doklady Earth Sciences, 434(1), pp. 1179-1183.

Baturin, G. N. \& Dubinchuk, V. T., 2011. Mineralogy and chemistry of ferromanganese crusts from the Atlantic Ocean. Geochemistry International, 49(6), pp. 578-593.

Baturin, G. N. \& Savenko, V. S., 1989. Growth rates of deep-water iron-manganese nodules. Oceanology, 29(3), pp. 334-342.

Bau, M., 1996. Controls on the fractionation of isovalent trace elements in magmatic and aqueous systems: evidence from $\mathrm{Y} / \mathrm{Ho}, \mathrm{Zr} / \mathrm{Hf}$, and lanthanide tetrad effect. Contributions to Mineralogy and Petrology, 123(3), pp. 323-333.

Bau, M. \& Koschinsky, A., 2006. Hafnium and neodymium isotopes in seawater and in ferromanganese crusts: The "element perspective". Earth and Planetary Science Letters, 241(34), pp. 952-961.

Bayon, G. et al., 2004. Sedimentary Fe-Mn oxyhydroxides as paleoceanographic archives and the role of aeolian flux in regulating oceanic dissolved REE. Earth and Planetary Science Letters, 224(3-4), pp. 477-492.

Bayon, G. et al., 2006. The control of weathering processes on riverine and seawater hafnium isotope ratios. Geology, 34(6), pp. 433-436.

Bender, M. L., 1982. Trace elements and ocean chemistry. Nature, Volume 296, pp. 203-204.

Bender, M. L. \& Graham, D., 1981. On Late Miocene Abyssal Hydrography. Marine Micropaleontology, 6(5-6), pp. 451-464.

Bender, M. L. \& Keigwin, L., 1979. Speculations about the Upper Miocene change in abyssal Pacific dissolved bicarbonate 813C. Earth and Planetary Science Letters, 1979(2), pp. 383-393. 
Bender, M. L., Klinkhammer, G. P. \& Spencer, D. W., 1977. Manganese in seawater and the marine manganese balance. Deep Sea Research, 24(9), pp. 799-812.

Berger, G., Pillans, B., Bruce, J. \& McIntosh, P., 2002. Luminescence chronology of loesspaleosol sequences from southern South Island, New Zealand. Quaternary Science Reviews, 21(16-17), pp. 1899-1913.

Bhat, S., Krishnaswamy, S., Lal, D. \& Somayajulu, B., 1973. Radiometric and trace element studies of ferromanganese nodules. Symposium on Hydrochemistry and Biogeochemistry, VI: Hydro-geochemistry, 6(1), pp. 443 - 462.

Billups, K. \& Schrag, D., 2002. Paleotemperatures and ice volume of the past $27 \mathrm{Myr}$ revisited with paired $\mathrm{Mg} / \mathrm{Ca}$ and ${ }^{18} \mathrm{O} /{ }^{16} \mathrm{O}$ measurements on benthic foraminifera. Paleoceanography, 17(1), pp. 3-1-3-11.

Bischcoff, J. C., Piper, D. Z. \& Leong, K., 1981. The aluminosilicate fraction of North Pacific manganese nodules. Geochimica et Cosmochimica Acta, 45(11), pp. 2047-2049.

Bloomstein, M. \& Rea, D., 1986. Post-middle Oligocene eolian deposition from the trade winds of the southeast Pacific.. In: M. Leinen, D. K. Rea \& K. Becker, eds. Deep Sea Drilling Project Volume XCII: Part III Biostratigraphy \& Sedimentology. Washington, D.C.: United States of America Government Printing Office, p. 331 - 340.

Bogdanov, Y. A. et al., 1995. Composition of ferromanganese crusts and nodules at northwestern Pacific guyots and geologic and paleoceanographic considerations. In: J. A. Haggerty, I. Premoli Silva, F. Rack \& M. K. McNutt, eds. Proceedings of the Ocean Drilling Program: Scientific Results, 144. College Station, Texas: Ocean Drilling Program, pp. 745-768.

Boggs, S. J., 2011. Principles of Sedimentology and Stratigraphy. Fifth ed. New York: Prentice Hall.

Boiteau, R., Greaves, M. \& Elderfield, H., 2012. Authigenic uranium in foraminiferal coatings: A proxy for ocean redox chemistry. Paleoceanography, 27(3), p. PA3227.

Bollhöfer, A. et al., 1996. Thorium and uranium isotopes in a manganese nodule from the Peru basin determined by alpha spectrometry and thermal ionization mass spectrometry (TIMS): Are manganese supply and growth related to climate? Geologische Rundschau, 85(3), pp. 577-585.

Boltenkov, B. S., 2012. Mechanisms of formation of deep-sea ferromanganese nodules: Mathematical modeling and experimental results. Geochemistry International, 50(2), pp. 125132. 
Bolton, B. R., Bogi, J. \& Cronan, D. S., 1992. Geochemistry and Mineralogy of Ferromanganese Nodules from the Kiribati Region of the Eastern Central Pacific Basin. In: B. H. Keating \& B. R. Bolton, eds. Geology and Offshore Mineral Resources of the Central Pacific Basin: Circum-Pacific Council for Energy and Mineral Resources Earth Science Series: Volme 14. New York: Springer-Verlag, pp. 247-260.

Bolton, B. R., Exon, N. F., Ostwald, J. \& Kundrass, H., 1988. Geochemistry of ferromanganese crusts and nodules from the South Tasman Rise, southeast of Australia. Marine Geology, 84(1-2), pp. 53-80.

Bonatti, E., Kraemer, T. \& Rydell, H., 1972. Classification and genesis of submarine ironmanganese deposits. In: D. R. Horn, ed. Ferromanganese Deposits of the Ocean floor. Washington, D.C.: Arden House, pp. 149 - 165.

Bonatti, E. \& Nayudu, R., 1965. The origin of manganese nodules on the ocean floor. American Journal of Science, 263(1), pp. 17-39.

Bonatti, E., Zerbi, M., Kay, R. \& Rydell, H., 1976. Metalliferous deposits from the Apennine ophiolites: Mesozoic equivalents of modern deposits from oceanic spreading centers. Geological Society of America Bulletin, 87(1), pp. 83-94.

Bostock, H. et al., 2013. A review of the Australian-New Zealand sector of the Southern Ocean over the last $30 \mathrm{ka}$ (Aus-INTIMATE project). Quaternary Science Reviews, 74(3-4), pp. 35-57.

Bourles, D., Raisbeck, G. M. \& Yiou, F., $1989 .{ }^{10} \mathrm{Be}$ and ${ }^{9} \mathrm{Be}$ in marine sediments and their potential for dating. Geochimica et Cosmochimica Acta, 53(2), pp. 443 - 452.

Boyd, P. W. \& Ellwood, M. J., 2010. The biogeochemical cycle of iron in the ocean. Nature Geoscience, Volume 3, pp. 675-682.

Boyer, D. \& Guala, J., 1978. Model of the Antarctic Circumpolar Current in the vicinity of the Macquarie Ridge. In: D. E. Hayes, ed. Antarctica Oceanology II: The Australian-New Zealand Sector. Washington, D. C., American Geophysical Union: Antarctic Research Series, pp. 79 - 94.

Boyle, E. A., Sclater, F. R. \& Edmond, J. M., 1977. The distribution of dissolved copper in the Pacific. Earth and Planetary Science Letters, 37(1), pp. 38-54.

Brix, H. \& Gerdes, R., 2003. North Atlantic Deep Water and Antarctic Bottom Water: Their interaction and influence on the variability of the global ocean circulation. Journal of Geophysical Research, 108(C2), pp. 1-17. 
Broecker, W. S., 1971. A kinetic model for the chemical composition of sea water. Quaternary Research, 1(2), pp. 188-207.

Broecker, W. S., 1982a. Glacial to interglacial changes in ocean chemistry. Progress in Oceanography, 11(2), pp. 151-197.

Broecker, W. S., 1982b. Ocean chemistry during glacial time. Geochimica et Cosmochimica Acta, 46(10), pp. 1689-1705.

Broecker, W. S. \& Denton, G. H., 1990. The role of ocean-atmosphere reorganizations in glacial cycles. Quaternary Science Reviews, 9(4), pp. 305-341.

Broecker, W. S. et al., 1998. How much deep water is formed in the Southern Ocean? Journal of Geophysical Research, 103(C8), pp. 15833-15843.

Broecker, W. S. \& Peng, T.-H., 1982. Tracers in the Sea. New York: Eldigio Press, Palisades.

Brown, E. T. et al., 1992. Continental inputs of beryllium to the oceans. Earth and Planetary Science Letters, 114(1), pp. 101-111.

Bruland, K. W., 1980. Oceanographic distributions of cadmium, zinc, nickel, and copper in the North Pacific. Earth and Planetary Science Letters, 47(2), pp. 176-198.

Bruland, K. W., 1983. Trace elements in sea-water. In: J. P. Riley \& R. Chester, eds. Chemical Oceanography. London: Academic Press, pp. 157-220.

Bruland, K. W. \& Franks., R. P., 1983. Mn, Ni, Cu, $\mathrm{Zn}$ and Cd in the western North Atlantic. In: C. S. Wong, et al. eds. Trace Metals in Seawater: NATO Conference Series Volume 9. New York: Springer, pp. 395-414.

Bruland, K. W., Orians, K. J. \& Cowen, J. P., 1994. Reactive trace metals in the stratified central North Pacific. Geochimica et Cosmochimica Acta, 58(15), pp. 3171-3182.

Bryden, H. L. \& Heath, R. A., 1985. Energetic eddies at the Northern edge of the Antarctic circumpolar current in the Southwest Pacific. Progress in Oceanography, Volume 14, pp. 6587.

Burns, R. G. \& Burns, V. M., 1979. Manganese oxides. In: R. G. Burns, ed. Marine Minerals: Reviews in Mineralogy. Washington, D.C., Mineralogical Society of America, pp. 1-46.

Burns, V. M. \& Burns, R. G., 1977. Mineralogy. In: G. P. Glasby, ed. Marine Manganese Deposits. Amsterdam: Elsevier Oceanography Series, 15, pp. 185-248. 
Burton, J., Statham, P. \& Elderfield, H., 1988. Trace metals as tracers in the ocean. Philosophical Transactions of the Royal Society of London: Series A, Mathematical and Physical Sciences, 325(1583), pp. 127-145.

Burton, K. W. et al., 1999. Osmium isotope variations in the oceans recorded by Fe-Mn crusts. Earth and Planetary Science Letters, 171(1), pp. 185-197.

Burton, K. W., Ling, H.-F. \& O’Nions, R. K., 1997. Closure of the Central American Isthmus and its effect on deep-water formation in the North Atlantic. Nature, Volume 386, pp. 382-385.

Butzin, M., Lohmann, G. \& Bickert, T., 2011. Miocene ocean circulation inferred from marine carbon cycle modeling combined with benthic isotope records. Paleoceanography, 26(1), p. PA1203.

Bu, W. R., Shi, X. F., Peng, J. T. \& Qi, L., 2003. Geochemical characteristics of seamount ferromanganese nodules from mid-Pacific Ocean. Chinese Science Bulletin, 48(1), pp. 98-105.

Byrne, R. H. \& Kim, K.-H., 1990. Rare earth element scavenging in seawater. Geochimica et Cosmochimica Acta, 54(10), pp. 2645-2656.

Byrne, R. H. \& Sholkovitz, E. R., 1996. Marine chemistry and geochemistry of the lanthanides. In: K. A. J. Gschneidner, J. G. Bunzli \& V. K. Pecharsky, eds. Handbook on the Physics and Chemistry of Rare Earth Elements. Amsterdam: Elsevier, pp. 497-593.

Calvert, S. E., 1987. Oceanographic controls on the accumulation of organic matter in marine sediments. In: J. Brooks \& A. J. Fleet, eds. Marine Petroleum Source Rocks. London: Geological Society of London: Special Publications: No. 26, pp. 137-151.

Calvert, S. E. \& Pedersen, T. F., 2007. Elemental proxies for paleoclimatic and paleoceanographic variability in marine sediments: interpretation and application. In: C. Hillaire-Marcel \& A. de Vernal, eds. Proxies in Late Cenozoic paleoceanography. Amsterdam: Elsevier, pp. 567-643.

Calvert, S. E. \& Price, N., 1977. Geochemical variation in ferromanganese nodules and associated sediments from the Pacific Ocean. Marine Chemistry, 5(1), pp. 43-74.

Campbell, H. \& Hutching, G., 2007. In Search of Ancient New Zealand. Rosedale, Northshore, New Zealand: Institute of Geological and Nuclear Sciences Limited \& Pengiun Group (NZ).

Cane, M. A. \& Molnar, P., 2001. Closing of the Indonesian seaway as a precursor to east African aridification around 3-4 million years ago. Nature, Volume 411, pp. 157-162. 
Carey, A. et al., 2002. Trace metal fluxes to the ocean: The importance of high-standing oceanic islands. Geophysical Research Letters, 29(23), pp. 1-4.

Carter, L., 1989. New occurrences of manganese nodules in the South-western Pacific Basin, east of New Zealand. New Zealand Journal of Marine and Freshwater Research, 23(2), pp. 247253.

Carter, L., 2008. Ocean Crossroads. In: I. J. Graham, ed. A continent on the Move: New Zealand Geoscience at the dawn of the 21st Century. Wellington, New Zealand: Craig Potton Publishing: Geological Society New Zealand: GNS Science, pp. 207-211.

Carter, L., Carter, R. M. \& McCave, I. N., 2004. Evolution of the sedimentary system beneath the deep Pacific inflow off eastern New Zealand. Marine Geology, 205(1-4), pp. 9-27.

Carter, L. \& McCave, I., 1997. The sedimentary regime beneath the Deep Western Boundary Current inflow to the Southwest Pacific Ocean. Journal of Sedimentary Research, 67(6), pp. 1005-1017.

Carter, L., McCave, I. \& Williams, M., 2009. Circulation and water masses of the Southern Ocean: a review. In: F. Florindo \& M. Siegert, eds. Antarctic Climate Evolution. Amsterdam: Elsevier: Developments in Earth and Environmental Sciences Series, pp. 85-114.

Carter, L. \& Mitchell, J., 1987. Late Quaternary sediment pathways through the deep ocean, east of New Zealand. Paleoceanography, 2(4), pp. 409-422.

Carter, L. \& Wilkin, J., 1999. Abyssal circulation around New Zealand-a comparison between observations and a global circulation model. Marine Geology, 159(1-4), pp. 221-239.

Carter, R., Carter, L. \& McCave, I., 1996. Current controlled sediment deposition from the shelf to the deep ocean: The Cenozoic evolution of circulation through the SW pacific gateway. Geologische Rundschau, 85(3), pp. 438 - 451.

Carter, R., McCave, I. \& Carter, L., 2004. Leg 181 synthesis: fronts, flows, drifts, volcanoes, and the evolution of the southwestern gateway to the Pacific Ocean, eastern New Zealand. In: C. Richter, ed. Proceedings of the Ocean Drilling Program, Scientific Results: Southwest Pacific Gateways Sites 1119-1125. College Station, Texas: Ocean Drilling Program, pp. 1-111.

Chabaux, F., Cohen, A. S., O’Nions, R. K. \& Hein, J. R., 1995. ${ }^{238} \mathrm{U}-{ }^{234} \mathrm{U}-{ }^{230}$ Th chronometry of Fe-Mn crusts: Growth processes and recovery of thorium isotopic ratios of seawater. Geochimica et Cosmochimica Acta, 59(3), pp. 633-638. 
Chabaux, F., O'Nions, R. K., Cohen, A. S. \& Hein, J. R., 1997. ${ }^{238} \mathrm{U}_{-}{ }^{234} \mathrm{U}^{2}{ }^{230}$ Th disequilibrium in hydrogenous oceanic Fe-Mn crusts: Palaeoceanographic record or diagenetic alteration? Geochimica et Cosmochimica Acta, 61(17), pp. 3619 - 3632.

Chandnani, M. et al., 2012. Compositional variation recorded in deep-sea ferromanganese deposits of the Central Indian Ocean. Current Science, 103(5), pp. 540-546.

Chang, S-W. et al., 2003. Ferromanganese nodules in the vicinity of Bollons Seamount SE of the Campbell Plateau, SW Pacific Ocean: Part 1: Distribution and external morphology. Institute of Geological and Nuclear Sciences: Science Report, Volume 13, pp. 1-41.

Chapin, T. P., Johnson, K. S. \& Coale, K. H., 1991. Rapid determination of manganese in seawater by flow injection analysis with chemiluminescence detection. Analytica Chimica Acta, 249(2), p. 469-478.

Chen, R. C. \& Owen, R. M., 1989. The hydrothermal component in ferromanganese nodules from the southeast Pacific Ocean. Geochimica et Cosmochimica Acta, 53(6), pp. 1299-1305.

Chen, T-Y. et al., 2013. Lead isotope provinciality of central North Pacific Deep Water over the Cenozoic. Geochemistry, Geophysics, Geosystems, 14(5), pp. 1523-1537.

Chester, R., 2003. Marine geochemistry. Sixth ed. Oxford: Blackwell Science.

Chester, R., 2003. Unscrambling the sediment-forming chemical signals. In: R. Chester, ed. Marine Geochemistry. Oxford: Blackwell Science, pp. 594-659.

Chester, R. \& Hughes, M. J., 1967. A chemical technique for the separation of ferromanganese minerals, carbonate minerals and adsorbed trace elements from pelagic sediments. Chemical Geology, Volume 2, pp. 249-262.

Chester, R. \& Jickells, T., 2012. Marine Geochemistry. Third ed. Chichester, United Kingdom: John Wiley \& Sons, Ltd.

Chmeleff, J., von Blanckenburg, F., Kossert, K. \& Jackob, D., 2010. Determination of the 10Be half-life by multicollector ICP-MS and liquid scintillation counting. Nuclear Instruments and Methods in Physics Research Section B: Beam Interactions with Materials and Atoms Articles, 268(2), pp. 192-199.

Chow, T. \& Patterson, C., 1959. Lead isotopes in manganese nodules. Geochimica et Cosmochimica Acta, 17(1-2), pp. 21-31.

Christensen, J. N. et al., 1997. Climate and Ocean Dynamics and the Lead Isotopic Records in Pacific Ferromanganese Crusts. Science, 277(5328), pp. 913-918. 
Ciesielski, P. F., Ledbetter, M. T. \& Ellwood, B. B., 1982. The development of antarctic glaciation and the Neogene paleoenvironment of the Maurice Ewing Bank. Marine Geology, 46(1-2), pp. 1-51.

Clarke, A., Church, J. \& Gould, J. J., 2001. Ocean processes and climate phenomena. In: G. Siedler, J. Church, J. J. Gould \& W. J. Gould, eds. Ocean circulation \& climate observation and modeling of the global ocean. San Diego: Academic Press, pp. 11-30.

Claude, C. \& Hamelin, B., 2007. Isotopic Tracers of Water Masses and Deep Currents. In: C. Hillaire-Marcel \& A. De Vernal, eds. Proxies in Late Cenozoic Paleoceanography. Amsterdam: Elsevier: Developments in Marine Geology, pp. 645-679.

Collins, L. S. et al., 1996. The late Miocene Panama isthmian strait. Geology, Volume 24, pp. 687-690.

Cook, P. C. et al., 2013. Dynamic behaviour of the East Antarctic ice sheet during Pliocene warmth. Nature Geoscience, Volume 6, pp. 765-769.

Cramer, B. S. et al., 2009. Ocean overturning since the Late Cretaceous: Inferences from a new benthic foraminiferal isotope compilation. Paleoceanography, 24(4), p. PA4216.

Crocket, K. C. et al., 2013. A Pb isotope tracer of ocean-ice sheet interaction: the record from the NE Atlantic during the Last Glacial/Interglacial cycle. Quaternary Science Reviews, Volume 82, pp. 133-144.

Cronan, D., 1992. Marine Minerals in Exclusive Economic Zones. London: Springer.

Cronan, D., 1997. Some controls on the geochemical variability of manganese nodules. In: K. Nicholson, J. R. Hein \& B. Buhn, eds. Manganese Mineralization: Geochemistry and mineralogy of terrestrial and marine deposits. London: Geological Society of London, pp. 139151.

Cronan, D. \& Moorby, S. A., 1981. Manganese nodules and other ferromanganese oxide deposits from the Indian Ocean. Journal of the Geological Society of London, 138(5), pp. 527 539.

Cronan, D. S., 1977. Deep-sea nodules: distribution and geochemistry. In: G. P. Glasby, ed. Marine Manganese Deposits. New York: Elsevier: Oceanography Series, 15, pp. 11-44.

Cronan, D. S. \& Hodkinson, R. A., 1994. Element supply to surface manganese nodules along the Aitutaki-Jarvis Transect, South Pacific. Journal of the Geological Society of London, 151(2), pp. 391-401. 
Cronin, T., 2010. Paleoclimates: Understanding climate change past and present. New York: Columbia University Press.

Crundwell, M., Scott, G., Naish, T. \& Carter, L., 2008. Glacial-interglacial ocean climate variability from planktonic foraminifera during the Mid-Pleistocene transition in the temperate Southwest Pacific, ODP Site 1123. Palaeogeography, Palaeoclimatology, Palaeoecology, 260(1-2), pp. 202-229.

Cullen, D. J., 1969. Quaternary volcanism at the Antipodes Islands: its bearing on the structural interpretation of the southwest Pacific. Journal of Geophysical Research, 74(17), pp. 4213-4220.

Daly, K. L. et al., 2001. Hydrographic structure and distributions of nutrients and particulate and dissolved carbon in the Pacific sector of the Southern Ocean. Journal of Geophysical Research, 106(7), pp. 7107-7124.

Dams, R., Goossens, J. \& Moens, L., 1995. Spectral and non-spectral interferences in inductively coupled plasma mass-spectrometry. Microchimica Acta, 1995(3-4), pp. 277-286.

Damuth, J. E., 1980. Use of high-frequency $(3.5-12 \mathrm{kHz})$ echograms in the study of nearbottom processes in the deep sea: a review. Marine Geology, 38(1-3), pp. 51-75.

David, K. et al., 2001. The Hf isotope composition of global seawater and the evolution of Hf isotopes in the deep Pacific Ocean from Fe-Mn crusts. Chemical Geology, 178(1-4), pp. 23-42.

De Baar, H. W., Bacon, M. P., Brewer, P. G. \& Bruland, K. W., 1985. Rare earth elements in the Pacific and Atlantic Oceans. Geochimica et Cosmochimica Acta, 49(9), pp. 1943-1959.

DeCarlo, E. H., 1991. Paleoceanographic implications of the rare earth element variabiliy within a Fe-Mn crust from the central Pacific Ocean. Marine Geology, 98(2-4), pp. 449-467.

DeCarlo, E. H. \& Fraley, C. M., 1992. Chemistry and Mineralogy of Ferromanganese Deposits from the Equatorial Pacific Ocean. In: B. H. Keating \& B. R. Bolton, eds. Geology and Offshore Mineral Resources of the Central Pacific Basin: Circum-Pacific Council for Energy and Mineral Resources Earth Science Series Volume 14. New York: Springer-Verlag, pp. 225-245.

DeCarlo, E. H., McMurtry, G. M. \& Kim, K. H., 1987. Geochemistry of ferromanganese crusts from the Hawaiian Archipelago-I. Northern survey areas. Deep Sea Research Part A. Oceanographic Research Papers, 34(3), pp. 441-467.

Dehairs, F., Chesselet, R. \& Jedwab, J., 1980. Discrete suspended particles of barite and the barium cycle in the open ocean. Earth and Planetary Science Letters, 49(2), pp. 528-550. 
Delmonte, B. et al., 2004. Comparing the Epica and Vostok dust records during the last 220,000 years: stratigraphical correlation and provenance in glacial periods. Earth-Science Reviews, 66(1-2), pp. 63- 87.

Derry, L. A. \& France-Lanord, C., 1996. Neogene Himalayan weathering history and river 87Sr/86Sr: impact on the marine Sr record. Earth and Planetary Science Letters, 142(1-2), pp. 59-74.

Diester-Haass, L., 1988. Sea level changes, carbonate dissolution and history of the Benguela Current in the Oligocene-Miocene off Southwest Africa (DSDP Site 362, Leg 40). Marine Geology, 79(3-4), pp. 213-242.

Diester-Haass, L. \& Nees, S., 2004. Late Neogene History of Paleoproductivity and Ice Rafting South of Tasmania. In: N. F. Exon, J. P. Kennett \& M. J. Malone, eds. The Cenozoic Southern Ocean: Tectonics, Sedimentation, and Climate Change Between Australia and Antarctica. Washington, D. C.: American Geophysical Union: Geophysical Monograph Series, pp. 253-272.

Ding, X. et al., 2009. The relationship between the growth process of the ferromanganese crusts in the pacific seamount and Cenozoic ocean evolvement. Science in China Series D: Earth Sciences, 52(8), pp. 1091 - 1103.

Ditchburn, R. G. \& Graham, I. J., 2003. Preparation Procedures for the 10Be Analysis of Marine Deposits. Institute of Geological and Nuclear Sciences: Science Report, Volume 10, pp. $1-15$.

Ditchburn, R. G. \& Graham, I. J., 2006a. High resolution re-sampling of mega nodule U1365B-M: New sampling stratergy. Institute of Geological and Nuclear Sciences:

Miscellaneous - Unpublished Word document, pp. 1-4.

Ditchburn, R. G. \& Graham, I. J., 2006b. Re-dating of mega nodule U1365B-M along new sampling transect using 10Be/9Be dating methods. Institute of Geological and Nuclear Sciences: Miscellaneous - Unpublished data, Issue Excel Workbook.

Dowsett, H. J. \& Robinson, M. M., 2009. Mid-Pliocene equatorial Pacific sea surface temperature reconstruction: A multi-proxy perspective. Philosophical Transactions of the Royal Society of London: Series A Mathematics, Physical \& Engineering Sciences, Volume 367, pp. 109-125.

Duce, R. \& Tindale, N., 1991. Atmospheric transport and deposition of mineral dust to the ocean: implications for research needs. Limnology and Oceanography, 36(8), pp. 1715 -1726. 
Duque-Caro, H., 1990. Neogene stratigraphy, paleoceanography and paleobiology in northwest South America and the evolution of the Panama Seaway. Palaeogeography Paleoclimate Palaeoecology, 77(2), pp. 203-234.

Dutta, R. K., Sideras-Haddad, E. \& Connell, S. H., 2001. Distribution of various components in a hydrogenous ferromanganese nodule and an Afanasiy Nikitin Seamount crust from Indian Ocean - Ageological study using micro-PIXE. Nuclear Instruments and Methods in Physics Research B, 181(3), pp. 545-550.

Dymond, J. et al., 1984. Ferromanganese nodules from MANOP Sites H, S, and R-Control of mineralogical and chemical composition by multiple accretionary processes. Geochimica et Cosmochimica Acta, 48(5), pp. 931 - 949.

Dymond, J., Suess, E. \& Lyle, M., 1992. Barium in Deep-Sea Sediment: A Geochemical Proxy for Paleoproductivity. Paleoceanography, 7(2), pp. 163-181.

Edwards, K. J. et al., 2011. Ultra-diffuse hydrothermal venting supports Fe-oxidizing bacteria and massive umber deposition at $5000 \mathrm{~m}$ off Hawaii. The ISME Journal: Multidisciplinary Journal of Microbial Ecology, 5(11), pp. 1748-1758.

Eisenhauer, A., Gögen, K., Pernicka, E. \& Mangini, A., 1992. Climatic influences on the growth rates of Mn crusts during Late Quaternary. Earth Planetary Science Letters, 109(1-2), pp. 25-36.

Elderfield, H., 1977. The form of manganese and iron in marine sediments. In: G. P. Glasby, ed. Marine Manganese Deposits. Amsterdam: Elsevier Oceanography Series, 15, pp. 269-290.

Elderfield, H., 1988. The oceanic chemistry of the rare-earth elements. Philosophical Transactions of the Royal Society of London: Mathematical, Physical \& Engineering Sciences, 325(1583), pp. 105-126.

Elderfield, H. \& Greaves, M. J., 1982. The rare earth elements in seawater. Nature, Volume 296, pp. 214-219.

Elderfield, H., Hawkesworth, C. J., Greaves, M. J. \& Caalvert, S. E., 1981. Rare-earth element geochemistry of oceanic ferromanganese nodules and associated sediments. Geochimica et Cosnochimica, 45(4), pp. 513-528.

Eldrett, J. S. et al., 2007. Continental ice in Greenland during the Eocene and Oligocene. Nature, Volume 446, pp. 176-179. 
Ellwood, M. J., Kelly, M., Neil, H. \& Nodder, S. D., 2005. Reconstruction of paleoparticulate organic carbon fluxes for the Campbell Plateau region of southern New Zealand using the zinc content of sponge spicules. Paleoceanography, 20(3), p. PA3010.

Ennyu, A. \& Arthur, M. A., 2004. Early to Middle Miocene Paleoceanography in the Southern High Latitudes off Tasmania. In: N. F. Exon, J. P. Kennett \& M. J. Malone, eds. The Cenozoic Southern Ocean: Tectonics, Sedimentation, and Climate Change Between Australia and Antarctica. Washington, D. C., American Geophysical Union: Geophysical Monograph Series, pp. 215-233.

Erhardt, A. et al., 2013. Characterizing the $\mathrm{Pb}$ isotopic contribution of dust to seawater. Mineralogical Magazine, 77(5), p. 1045.

Exon, N. F., Kennett, J. P. \& Malone, M. J., 2004. The Cenozoic Southern Ocean: Tectonics, Sedimentation and Climate Change between Australia and Antarctica. Washington, D. C.: American Geophysical Union: Geophysical Monograph Series.

Fagel, N., André, L. \& Debrabant, P., 1997. Multiple seawater-derived geochemical signatures in Indian oceanic pelagic clays. Geochimica et Cosmochimica Acta, 61(5), pp. 9891008.

Fahrbach, E., 2013. Stromy and icy seas. In: D. W. H. Walton, ed. Antarctica: Global science from a frozen continent. New York: Cambridge University Press, pp. 137-160.

Farrell, J. W. et al., 1995. Late Neogene sedimentation patterns in the eastern equatorial Pacific Ocean. In: N. G. Mayer, T. R. Janecek, A. Palmer-Julson \& T. H. van Andel, eds. Proceeding of Ocean Drilling Program Scientific Results. College Station, Texas: Ocean Drilling Program, pp. 717-756.

Faure, G., 1977. Principles of Isotope Geology. Second Edition ed. New York: John Wiley \& Sons.

Fenn, C., Martin, E. \& Basak, C., 2013. Seawater and Detrital Marine Pb Isotopes as Monitors of Antarctic Weathering Following Ice Sheet Initiation. University of Florida: Journal of Undergraduate Research, 14(2), pp. 1-7.

Fillippelli, G. M. \& Flores, J.-A., 2009. From the warm Pliocene to the cold Pleistocene: A tale of two oceans. Geology, 37(10), pp. 959-960.

Firdaus, M. L., Minami, T., Norisuye, K. \& Sohrin, Y., 2011. Strong elemental fractionation of Zr-Hf and Nb-Ta across the Pacific Ocean. Nature Geoscience, Volume 4, pp. 227-230. 
Firdaus, M. L. et al., 2008. Dissolved and labile particulate Zr, Hf, Nb, Ta, Mo and W in the western North Pacific Ocean. Journal of Oceanography, 64(2), pp. 247-257.

Flanagan, F. J. \& Gottfried, D., 1980. USGS Rock Standards, III: Manganese-Nodule Reference Samples USGS-Nod-A-1 and USGS-Nod-P-1. United States of America Geological Survey Professional Paper, Volume 1155, p. 39.

Flegal, A. R. \& Patterson, C. C., 1985. Thallium concentrations in seawater. Marine Chemistry, 15(4), pp. 327-331.

Florindo, F. \& Siegert, M., 2009. Antarctic Climate Evolution. First Edition ed. Oxford: Elsevier: Developments in Earth and Environmental Sciences Series.

Flower, B. P. \& Kennett, J. P., 1993. Middle Miocene ocean-climate transition: Highresolution oxygen and carbon isotopic records from Deep Sea Drilling Project Site 588A, southwest Pacific. Paleoceanography, 8(6), pp. 811-843.

Flower, B. P. \& Kennett, J. P., 1995. Middle Miocene deepwater paleoceanography in the southwest Pacific: Relations with East Antarctic Ice Sheet development. Paleoceanography, 10(6), pp. 1095 - 1112.

Förstner, U. \& Stoffers, P., 1981. Chemical fractionation of transition elements in Pacific pelagic sediments. Geochimica et Cosmochimica Acta, 45(7), pp. 1141-1146.

Foster, G., Vance, D. \& Prytulak, J., 2007. No change in the neodymium isotope composition of deep water exported from the North Atlantic on glacial-interglacial time scales. Geology, Volume 35, pp. 37-40.

Foster, T. \& Carmack, E., 1976. Frontal zone mixing and Antarctic Bottom Water formation in the southern Weddell Sea. Deep Sea Research and Oceanographic Abstracts, 23(4), pp. 301317.

Frakes, L. A. \& Moreton, D. L. E., 1990. Manganese Nodule Provinces of the Southern Ocean. In: J. F. Splettstoesser \& Dreschhoff, eds. Mineral Resources Potential of Antarctica. Washington, D. C., American Geophysical Union: Antarctic Research Series, pp. 217-221.

Francois, R. et al., 1997. Contribution of Southern Ocean surface-water stratification to low atmospheric $\mathrm{CO}_{2}$ concentrations during the last glacial period. Nature, Volume 389, pp. 929935.

Frank, M., 2002. Radiogenic Isotopes: Tracers of Past Ocean Circulation and Erosional Input. Reviews of Geophysics, 40(1), pp. 1-38. 
Frank, M., 2011. Oceanography: chemical twins, seperated. Nature Geoscience, Volume 4, pp. 220-221.

Frank, M. et al., 2008. Beryllium isotopes in central Arctic Ocean sediments over the past 12.3 million years: Stratigraphic and paleoclimatic implications. Paleoceanography, 23(1), p. PA1S02.

Frank, M. \& O’Nions, R. K., 1998. Sources of Pb for Indian Ocean ferromanganese crusts: A record of Himalayan erosion? Earth and Planetary Science Letters, 158(3-4), pp. 121-130.

Frank, M., O'Nions, R., Hein, J. \& Banakar, V., 1999a. 60 Myr records of major elements and $\mathrm{Pb}-\mathrm{Nd}$ isotopes from hydrogenous ferromanganese crusts: reconstruction of seawater paleochemistry. Geochimica et Cosmochimica Acta, 63(11-12), pp. 1689-1708.

Frank, M., Reynolds, B. C. \& O’Nions, R. K., 1999b. Nd and Pb isotopes in Atlantic and Pacific water masses before and after closure of the Panama gateway. Geology, 27(12), pp. 1147-1150.

Frank, M. et al., 2002. North Atlantic Deep Water export to the Southern Ocean over the past $14 \mathrm{Myr}$ : Evidence from $\mathrm{Nd}$ and $\mathrm{Pb}$ isotopes in ferromanganese crusts. Paleoceanography, 17(2), pp. 1-9.

Frank, M. et al., 2006. $\mathrm{Nd}$ and $\mathrm{Pb}$ isotope evolution of deep water masses in the eastern Indian Ocean during the past 33 Myr. Chemical Geology, 226(3-4), pp. 264-279.

Friedrich, G., Glasby, G. P., Thijssen, T. \& Plüger, W. L., 1983. Morphological and geochemical characteristics of manganese nodules collected from three areas on an equatorial Pacific transect by R.V. Sonne. Marine Mining, Volume 4, pp. 167-253.

Fukamachi, Y. et al., 2010. Strong export of Antarctic Bottom Water east of the Kerguelen plateau. Nature Geoscience, Volume 3, pp. 327-331.

Galarraga, F. et al., 2008. V/Ni ratio as a parameter in palaeoenvironmental characterisation of nonmature medium-crude oils from several Latin American basins. Journal of Petroleum Science and Engineering, 213(4), pp. 9-14.

Galer, S. \& Abouchami, W., 1998. Practical application of lead triple spiking for correction of instrumental mass discrimination,. Mineral. Mag., Volume 62A, p. $491-492$.

Gall, L. et al., 2013. Nickel isotopic compositions of ferromanganese crusts and the constancy of deep ocean inputs and continental weathering effects over the Cenozoic. Earth and Planetary Science Letters, Volume 375, p. 148 - 155. 
Ganachaud, A. \& Wunsch, C., 2000. Improved estimates of global ocean circulation, heat transport and mixing from hydrographic data. Nature, Volume 408, pp. 453-456.

Garabato, A. C. N., Stevens, D. P., Watson, A. J. \& Roether, W., 2007. Short-circuiting of the overturning circulation in the Antarctic Circumpolar Current. Nature, Volume 447, pp. 194-197.

Garcia-Solsona, E. et al., 2014. Rare earth elements and Nd isotopes tracing water mass mixing and particle-seawater interactions in the SE Atlantic. Geochimica et Cosmochimica Acta, Volume 125, pp. 351-372.

German, C. et al., 1995. Dissolved rare earth elements in the Southern Ocean: Ce oxidation and the influence of hydrography. Geochim. Cosmochim.Acta, Volume 59, p. $1551-1558$.

German, C. R. \& Elderfield, H., 1990. Application of the Ce anomaly as a paleoredox indicator: The ground rules. Paleoceanography, 5(5), pp. 823-833.

Ghosh, A. \& Mukhopadhyay, R., 2000. Mineral Wealth of the Ocean. Rotterdam: AA Balkema.

Gille, S., Metzger, J. \& Tokmakian, R., 2004. Seafloor Topography and Ocean Circulation. Oceanography, 17(1), pp. 47-54.

Gingele, F. \& Dahmke, A., 1994. Discrete barite particles and barium as tracers of paleoproductivity in south Atlantic sediments. Paleoceanography, 9(1), pp. 151-168.

Glasby, G. P., 1974. Mechanism of incorporation of manganese and associated trace elements in marine manganese nodules. Oceanography and Marine Biology: An Annual Review, Volume 12, p. 11-40.

Glasby, G. P., 1976. Manganese nodules in the South Pacific: A review. New Zealand Journal of Geology and Geophysics, 19(5), pp. 707-736.

Glasby, G. P., 1977a. Marine Manganese Deposits. Amsterdam: Elsevier Oceanography Series, 15.

Glasby, G. P., 1977b. Why manganese nodules remain at the sediment-water interface. New Zealand Journal of Science: Royal Society of New Zealand: Wellington, 20(2), pp. 187 - 190.

Glasby, G. P., 1978. Deep-sea manganese nodules in the stratigraphic record: Evidence from DSDP cores. Marine Geology, 28(1-2), pp. 51 - 64.

Glasby, G. P., 1980. A review of three important recent publications on manganese nodules. Chemical Geology, Volume 31, pp. 347-361. 
Glasby, G. P., 1984. Manganese in the marine environment. Oceanography and Marine Biology: An Annual Review, Volume 22, pp. 169-194.

Glasby, G. P., 1985. Hiatuses in manganese nodule growth: Relation to bottom current activity? Geo-Marine Letters, 5(4), pp. 247-252.

Glasby, G. P., 1988. Manganese deposition through geological time: Dominance of the PostEocene environment. Ore Geology Reviews, 4(1-2), pp. 135-144.

Glasby, G. P., 2000. Manganese: Predominant role of nodules and crusts. In: H. D. Schulz \& M. Zabel, eds. Marine Geochemistry. New York: Springer, pp. 335-372.

Glasby, G. P., Cullen, D. J., Kunzendorf, H. \& Stuben, D., 1991. Marine manganese crusts around New Zealand: A preliminary assessment. New Zealand Oceanographic Institute: DSIR Marine and Freshwater: Miscellaneous Publication: Map, 106(1), pp. 1-25.

Glasby, G. P. et al., 1982. Distribution, morphology, and geochemistry of manganese nodules from the Valdivia 13/2 area, equatorial North Pacific. Pacific Science, 36(2), pp. 241-263.

Glasby, G. P. et al., 1987. The distribution of rare earth and minor elements in manganese nodules and sediments from the equatorial and S.W. Pacific. Lithos, 20(2), pp. 97 - 113.

Glasby, G. P., Hunt, J. L., Rankin, P. C. \& Darwin, J. H., 1979. Major element analyses of marine sediments from the southwest Pacific. New Zealand Soil Bureau Scientific Report, Volume 36, pp. 1 - 127.

Glasby, G. P., Meylan, M. A., Margolis, S. V. \& Bäcker, H., 1980. Manganese deposits of the Southwestern Pacific Basin. In: I. M. Varentsov \& G. Y. Grasselly, eds. Geology and geochemistry of manganese. Budapest: Hungarian Academy of Sciences, p. 137-183.

Glasby, G. P. et al., 1982. Manganese nodule formation in the Pacific Ocean: a general theory. Geo-Marine Letters, 2(1-2), pp. 47-53.

Glasby, G. P. \& Summerhayes, C. P., 1975. Sequential deposition of authigenic marine minerals around New Zealand: Palaeoenvironmental significance. New Zealand Journal of Geology and Geophysics, 18(3), pp. 477 - 490.

Glasby, G. P. \& Thijssen, T., 1982. Control of the mineralogy and composition of marine manganese nodules by the supply of divalent transition metal ions. Neues Jahrbuch für Mineralogie Abhandlungen, Volume 145, pp. 291-307.

Glasby, G. P. \& Wright, I. C., 1990. Marine mineral potential in New Zealand's exclusive economic zone. Marine Mining, 9(2), pp. 403-427. 
Godfrey, L. V. et al., 2009. Hafnium and neodymium isotope variations in NE Atlantic seawater. Geochemistry, Geophysics, Geosystems, 10(8), p. Q08015.

Godfrey, L. V. et al., 1997. The Hf isotopic composition of ferromanganese nodules and crusts and hydrothermal manganese deposits: Implications for seawater Hf. Earth and Planetary Science Letters, 151(1-2), pp. 91-105.

Godfrey, L. V., White, W. M. \& Salters, V. J. M., 1996. Dissolved zirconium and hafnium distributions across a shelf break in the northeastern atlantic ocean. Geochimica et Cosmochimica Acta, 60(21), pp. 3995-4006.

Goldberg, E., 1974. Marine manganese minerals. In: Oceanography: the last frontier. Washington: Voice of America, pp. 75 - 91.

Goldberg, E. \& Bruland, K., 1974. Radioactive geochronologies. In: In The Sea. New York: Wiley-Interscience, pp. 451 - 489.

Goldberg, E. D., 1954. Marine Geochemistry 1. Chemical Scavengers of the Sea. The Journal of Geology, 62(3), pp. 249-265.

Goldschmidt, V. M., 1937. The principles of distribution of chemical elements in minerals and rocks. Journal of the Chemical Society, Volume The seventh Hugo Müller Lecture, delivered before the Chemical Society on March 17th, 1937, pp. 655-673.

Goldstein, S. \& Hemming, S., 2003. Long-lived Isotopic Tracers in Oceanography, Paleoceanography, and Ice-sheet Dynamics. In: H. Elderfield, H. D. Holland \& K. K. Turekian, eds. Treatise on Geochemistry. New York: Elsevier, pp. 453 - 489.

Gonneea, M. E. \& Paytan, A., 2006. Phase associations of barium in marine sediments. Marine Chemistry, Volume 100, pp. 124-135.

González, F. J. et al., 2012. Ferromanganese nodules and micro-hardgrounds associated with the Cadiz Contourite Channel (NE Atlantic): Palaeoenvironmental records of fluid venting and bottom currents. Chemical Geology, Volume 310-311, pp. 56-78.

González, F. J. et al., 2010. Internal features, mineralogy and geochemistry of ferromanganese nodules from the Gulf of Cadiz: The role of the Mediterranean Outflow Water undercurrent. Journal of Marine Systems, 80(3-4), pp. 203-218.

Gordon, A., 1972. On the Interaction of the Antarctic Circumpolar Current and the Macquarie Ridge. In: D. E. Hayes, ed. Antarctica Oceanology II: The Australian-New Zealand SectorAntarctic Oceanology II: The Australian-New Zealand Sector. Washington, D. C.: American Geophysical Union: Antarctic Research Series, pp. 71 - 78. 
Gordon, A. L., 1975. An Antarctic oceanographic section along 170 E. Deep Sea Research, 22(3), pp. 357-377.

Graham, I. et al., 2003a. Ferromanganese nodules in the vicinity of Bollons Seamount SE of the Campbell Plateau, SW Pacific Ocean: Part 2: Petrology and chemsitry. Institute of Geological and Nuclear Sciences: Science Report, Volume 14, pp. 1-70.

Graham, I. J., Carter, R. M., Ditchburn, R. G. \& Zondervan, A., 2004. Chronostratigraphy of ODP 181, Site 1121 sediment core (Southwest Pacifc Ocean), using ${ }^{10} \mathrm{Be} /{ }^{9} \mathrm{Be}$ dating of entrapped ferromanganese nodules. Marine Geology, 205(1-4), pp. 227-247.

Graham, I. J. et al., 2003b. Ferromanganese nodules in the vicinity of Bollons Seamount SE of the Campbell Plateau, SW Pacific: Part 3: Beryllium isotope dating. Institute of Geological and Nuclear Sciences: Science Report, Volume 15, pp. 1-40.

Graham, I. J., Glasby, G. P. \& Churchman, G. J., 1997. Provenance of the detrital component of deep-sea sediments from the SW Pacific Ocean based on mineralogy, geochemistry and Sr isotopic composition. Marine Geology, 140(1-2), pp. 75-96.

Graham, I. J. \& Wright, I. C., 2006. The Campbell Ferromanganese nodule field in the southern part of New Zealand's Exclusive Economic Zone. In: A. Christie \& R. Brathwaite, eds. Geology and exploration of New Zealand mineral deposits. Parkville, Victoria, Australia: Australasian Institute of Mining and Metallurgy: Monograph Series 25, pp. 339-347.

Graham, I. J. \& Wright, I. C., 2008. Future Bounty. In: I. J. Graham, ed. A Continent on the Move: New Zealand Geoscience into the 21st Century. Wellington, New Zealand: Craig Potton Publishing:Geological Society New Zealand:GNS Science, pp. 296-297.

Greaves, M. J., Rudnicki, M. \& Elderfield, H., 1991. Rare earth elements in the Mediterranean Sea and mixing in the Mediterranean outflow. Earth and Planetary Science Letters, 103(1-4), pp. 169-181.

Griffiths, G. A. \& Glasby, G. P., 1985. Input of river derived sediment to the New Zealand continental shelf. Estuarine, Coastal and Shelf Science, 21(6), pp. 773-787.

Grousset, F. E. \& Biscaye, P. E., 2005. Tracing dust sources and transport patterns using Sr, $\mathrm{Nd}$ and $\mathrm{Pb}$ isotopes. Chemical Geology, 222(3-4), pp. 149-167.

Guichard, F., Reyss, J.-L. \& Yokoyama, Y., 1978. Growth rate of manganese nodule measured with 10Be and 26 Al. Nature, Volume 272, pp. 155-156.

Gutjahr, M. et al., 2007. Reliable extraction of a deepwater trace metal isotope signal from Fe-Mnoxyhydroxide coatings of marine sediments.. Chemical Geology, p. 351-370. 
Halbach, P., 1986. Processes controlling the heavy metal distribution in pacific ferromanganese nodules and crusts. Geologische Rundschau, 75(1), pp. 235-247.

Halbach, P. \& Fellerer, R., 1980. The metallic minerals of the Pacific Seafloor. GeoJournal, 4(5), pp. 407-422.

Halbach, P., Friedrich, G. \& von Stackelberg, U., 1988. The Manganese nodule belt of the Pacific Ocean: Geological environment, nodule formation, and mining aspects. Stutgart: Enke Verlag.

Halbach, P. \& Ozkara, M., 1979. Morphological and geochemical classification of deep-sea ferromanganese nodules and its genetical interpretation. In: C. Lalou, ed. La Genèse des Nodules de Manganèse. Paris: Colloques internationaux Centre national de la recherche scientifique , pp. 77-88.

Halbach, P., Ozkara, M. \& Hense, J., 1975. The influence of metal content on the physical and mineralogical properties of pelagic manganese nodules.. Mineralium Deposita, 10(4), p. $397-411$.

Halbach, P. \& Puteanus, D., 1984. The influence of the carbonate dissolution rate on the growth and composition of Co-rich ferromanganese crusts from Central Pacific seamount areas. Earth and Planetary Science Letters, 68(1), pp. 73 - 87.

Halbach, P. \& Puteanus, D., 1988. Morphology and composition of manganese nodules. In: P. Halbach, G. Friedrich \& U. von Stackelberg, eds. The Manganese Nodule Belt of the Pacifc Ocean: Geological Environment, Nodule Formation, and Mining Aspects. Stuttgart: Enke Verlag, pp. 17-69.

Halbach, P., Scherhag, C., Hebisch, U. \& Marchig, V., 1980. Regional variations in Mn, Cu, and Co of ferromanganese nodules from a basin in the Southeast Pacific. Marine Geology, 38(4), pp. M1-M9.

Halbach, P., Scherhag, C., Hebisch, U. \& Marchig, V., 1981. Geochemical and mineralogical control of different genetic types of deep-sea nodules from the Pacific Ocean. Mineralium Deposita, Volume 16, pp. 59-84.

Halbach, P., Segl, M., Puteanus, D. \& Mangini, A., 1983. Co-fluxes and growth rates in ferromanganese deposits from central Pacific seamount areas. Nature, Volume 304, pp. 716 719.

Hall, I. R., Carter, L. \& Harris, S. E., 2002. Major depositional events under the deep Pacific inflow. Geology, 30(6), pp. 487-490. 
Hall, I. R. et al., 2001. Intensified deep Pacific inflow and ventilation in Pleistocene glacial times. Nature, Volume 412, pp. 809-812.

Hall, I. R. et al., 2003. Paleocurrent reconstruction of the deep Pacific inflow during the middle Miocene: Reflections of East Antarctic Ice Sheet growth. Paleoceanography, 18(2), pp. $1-11$.

Hambrey, M. J. \& Davis, B. J., 2013. Antarctic Earth-Surface Processes and Palaeoenvironments in context. Geological Society of London Special Publications, Volume 381, pp. 1-5.

Hamon, N., Sepulchre, P., Lefebvre, V. \& Ramstein, G., 2013. The role of eastern Tethys seaway closure in the Middle Miocene Climatic Transition (ca. $14 \mathrm{Ma}$ ). Climate of the Past, Volume 9, pp. 2687-2702.

Han, X. et al., 2003. Rhythmic growth of Pacific ferromanganese nodules and their Milankovitch climatic origin. Earth and Planetary Science Letters, 211(1-2), pp. 143-157.

Han, X., Qiu, Z., Ma, Q. \& Qian, J., 2009. High-resolution dating of Co-rich crusts: A comparative study using the methods of orbital pacing and 230Thex/232Th dating. Science in China Series D: Earth Sciences, 52(4), pp. 484 - 488.

Haq, B., Hardenbol, J. \& Vail, P., 1987. Chronology of fluctuating sea levels since the Triassic.. Science, Volume 235, p. 1156 - 1167.

Harada, K. et al., 1976. Biostratigraphy of some marine manganese nodules. Nature, Volume 260, pp. 770-771.

Hartmann, M. et al., 1989. The manganese nodules of the Kane Gap (East Atlantic). Indicators of sedimentation erosion changes. Geologische Rundschau, 78(3), pp. 943-958.

Hassold, N. J. C. et al., 2006. Late Miocene to Pleistocene paleoceanographic records from the Feni and Gardar Drifts: Pliocene reduction in abyssal flow. Palaeogeography, Palaeoclimatology, Palaeoecology, 236(3-4), pp. 290-301.

Hassold, N. J. C., Rea, D. K., van der Pluijm, B. A. \& Parés, J. M., 2009. A physical record of the Antarctic Circumpolar Current: Late Miocene to recent slowing of abyssal circulation. Palaeogeography, Palaeoclimatology, Palaeoecology, 275(1-4), pp. 28-36.

Hastings, D. \& Emerson, M., 1986. Oxidation of manganese by spores of a marine bacillus: Kinetics and thermodynamic considerations. Geochimica et Cosmochimica Acta, 50(8), pp. 1819-1824. 
Haug G. H. \& Tiedemann, R., 1998. Effect of the formation of the Isthmus of Panama on Atlantic Ocean thermohaline circulation. Nature, Volume 393, pp. 673-676.

Hayward, B. W., Grenfell, H. R., Carter, R. \& Hayward, J. J., 2004. Benthic foraminiferal proxy evidence for the Neogene palaeoceanographic history of the Southwest Pacific, east of New Zealand. Marine Geology, 205(1-4), pp. 147-184.

Haywood, A. M., Valdes, P. J. \& Peck, V. L., 2007. A permanent El Niño-like state during the Pliocene? Paleoceanography, 22(1), p. PA1213.

Haywood, A. M. et al., 2009. Chapter 10: Middle Miocene to Pliocene history of Antarctica and the Southern Ocean. In: Developments in Earth and Environmental Sciences: Antarctic Climate Evolution. Amsterdam: Elsevier, pp. 401-463.

Hay, W., Soeding, E., DeConto, R. M. \& Wold, C. N., 2002. The Late Cenozoic uplift climate change paradox. International Journal of Earth Sciences, 91(5), pp. 746-774.

Hein, J., 2001. Cobalt-rich ferromanganese crusts: global distribution, composition, origin and research activities. In: ISA, ed. Minerals other than polymetallic nodules of the International Seabed Area.. Kingston, Jamaica: Workshop Report, pp. 188-272.

Hein, J. R., Banakar, V., Rajani, R. \& Chodankar, A., 2007. Platinum group elements and gold in ferromanganese crusts from Afanasiy-Nikitin seamount, equatorial Indian Ocean: Sources and fractionation. Journal of Earth System Science, 116(1), pp. 3 - 13.

Hein, J. R. et al., 1992. Variations in the fine-scale composition of a central Pacific ferromanganese crust: Paleoceanographic implications. Paleoceanography, 7(1), pp. 63-77.

Hein, J. R. et al., 2012. Copper-nickel-rich, amalgamated ferromanganese crust-nodule deposits from Shatsky Rise, NW Pacific. Geochemistry, Geophysics, Geosystems, 13(10), p. Q10022.

Hein, J. R. et al., 1993. Two Major Cenozoic Episodes of Phosphogenesis Recorded in Equatorial Pacific Seamount Deposits. Paleoceanography, 8(8), pp. 293-311.

Hein, J. R. et al., 1994. Composition and origin of hydrothermal ironstones from central Pacific seamounts. Geochimica et Cosmochimica Acta, 58(1), p. 179 - 189.

Hein, J. R. \& Koschinsky, A., 2013. Deep-ocean ferromanganese crusts and nodules. In: S. Scott, ed. Treatise on Geochemistry. Amsterdam: Elsevier, pp. 273-289.

Hein, J. R. et al., 1997. Iron and manganese oxide mineralization in the Pacific. In: K. Nicholson, J. Hein, B. Bühn \& S. Dasgupta, eds. Manganese Mineralization: Geochemistry and 
Mineralogy of Terrestrial and Marine Deposits. London: Geological Society of London: Special Publication, p. $123-138$.

Hein, J. R., Mizell, K., Koschinsky, A. \& Conrad, T., 2013. Deep-ocean mineral deposits as a source of critical metals for high- and green-technology applications: Comparison with landbased resources. Ore Geology Reviews, Volume 51, pp. 1 - 14.

Henderson, G. \& Maier-Reimer, E., 2002. Advection and removal of $210 \mathrm{~Pb}$ and stable $\mathrm{Pb}$ isotopes in the oceans: A GCM study. Geochim.Cosmochim.Acta, Volume 66, pp. 257 - 272.

Heye, D., 1978. The internal micro-structure of manganese nodules and their relationship to the growth rate. Marine Geology, 26(3-4), p. M59-M66.

Hlawatsch, S. et al., 2002. Trace metal fluxes to ferromanganese nodules from the western Baltic Sea as a record for long-term environmental changes. Chemical Geology, 182(2-4), pp. 697-709.

Hlawatsch, S. et al., 2003. Fast-growing, shallow-water ferro-manganese nodules fromthewestern Baltic Sea: origin and modes of trace element incorporation. Marine Geology, 182(3-4), pp. 373-387.

Hodell, D. \& Kennett, J., 1986. Late Miocene-early Plioccne stratigraLate Miocene-Early Pliocene stratigraphy and paleoceanography of the South Atlantic and southwest Pacific oceans: A syphy and paleoceanography of the South Atlantic and Southwest Pacific Oceans: a synthesis.. Paleoceanography, 1(3), pp. 285 - 311.

Hodkinson, R. \& Cronan, D., 1991. Regional and depth variability in the composition of cobalt-rich ferro-manganese crusts from the SOPAC area and adjacent parts of the central equatorial Pacific. Marine Geology, Volume 98, p. 1991.

Hoernle, K. et al., 2006. Cenozoic intraplate volcanism on New Zealand: upwelling induced by lithospheric removal.. Earth and Planetary Science Letters, Volume 248, p. 335 - 352.

Holbourn, A. et al., 2012. Middle to late Miocene stepwise climate cooling: Evidence from a high-resolution deep water isotope curve spanning 8 million years. Paleoceanography, 28(4), pp. 688-699.

Holbourn, A., Kuhnt, W., Frank, M. \& Haley, B., 2013. Changes in Pacific Ocean circulation following the Miocene onset of permanent Antarctic ice cover. Earth and Planetary Science Letters, 365(1), pp. 38-50. 
Holbourn, A., Kuhnt, W., Schulz, M. \& Erienkeuser, H., 2005. Impacts of orbital forcing and atmospheric carbon dioxide on Miocene ice-sheet expansion. Nature, Volume 438, pp. 483-487.

Holland, H. \& Turekian, K., 2003. Long-lived isotopic tracers in oceanography, paleoceanography, and ice-sheet dynamics. In: Treatise on Geochemistry, Volume 6. s.l.:Elsevier, pp. 453-489.

Hollister, C. D. \& Nowell, A. R. M., 1991. HEBBLE epilogue. Marine Geology, 99(3-4), pp. 445-460.

Hongo, Y., Obata, H., Alibo, D. S. \& Nozaki, Y., 2006. Spatial variations of rare earth elements in north pacific surface water. Journal of Oceanography, 62(4), pp. 441-455.

Hotinski, R. M. \& Toggweiler, J. R., 2003. Impact of a Tethyan circumglobal passage on ocean heat transport and "equable" climates. Paleoceanography, 18(1), p. 1007.

Huag, G. H. \& Tiedemann, R., 1998. Effect of the formation of the Isthmus of Panama on Atlantic Ocean thermohaline circulation. Nature, Volume 393, pp. 673-676.

Hughes, C. W. \& Ash, E. R., 2001. Eddy forcing of the mean flow in the Southern Ocean. Journal of Geophysical Research, 106(C2), pp. 2713-2722.

Igel, H. \& von Blanckenburg, F., 1999. Lateral mixing and advection of reactive isotopes in ocean basins: Numerical modeling. Geochem. Geophys. Geosys., Volume 1.

Ingram, B. L., Hein, J. R. \& Farmer, G. L., 1990. Age determinations and growth rates of Pacific ferromanganese deposits using strontium isotopes. Geochimica et Cosmochimica Acta, 54(6), pp. 1709-1721.

International World Ocean Circulation Experiment Office, 2007. WOCE Atlas Volume 2: The Pacific Ocean: P14 Bibliography and Related Links. [Online] Available at: http://www-pord.ucsd.edu/whp atlas/pacific/p14/info/bibliog.htm [Accessed 31 September 2010].

Ito, T., Usui, A., Kajiwara, Y. \& Nakano, T., 1998. Strontium isotopic compositions and paleoceanographic implication of fossil manganese nodules in DSDP/ODP cores, Leg 1-126. Geochimica et Cosmochimica Acta, 62(9), pp. 1545-1554.

Jaccard, S. L. \& Galbraith, E. D., 2012. Large climate-driven changes of oceanic oxygen concentrations during the last deglaciation. Nature Geoscience, Volume 5, pp. 151-156.

Jacobs, S., Giulivi, C. \& Mele, P., 2002. Freshening of the Ross Sea during the late 20th century. Science, 297(5580), pp. 386-389. 
Jacobs, S. S., 2004. Bottom water production and its links with the thermohaline circulation. Antarctic Science, 16(4), pp. 427-437.

Janecek, T. \& Rea, D., 1983. Eolian deposition in the northeast Pacifc Ocean: Cenozoic history of atmospheric circulation. Geol.Soc.Am.Bull, Volume 94, pp. 730 - 738.

Jauhari, P. \& Pattan, J. N., 2000. Ferromanganese nodules fromthe Central Indian Ocean Basin. In: D. S. Cronan, ed. Handbook of Marine Mineral Deposits: CRC Marine Science. Boca Raton, Flordia: CRC Press, pp. 171-195.

Jickells, T. D. et al., 2005. Global iron connections between desert dust, ocean biogeochemistry, and climate. Science, Volume 308, pp. 67-73.

Jickells, T. D. \& Spokes, L. J., 2001. Atmospheric inputs to the ocean. In: D. R. Turner \& K. A. Hunter, eds. The Biogeochemistry of Iron in Seawater. New York: Wiley, pp. 85-121.

Johnson, K. S., Coale, K. H., Berelson, W. M. \& Gordon, R. M., 1996. On the formation of the manganese maximum in the oxygen minimum. Geochimica et Cosmochimica Acta, 60(8), pp. 1291-1299.

Johnson, K. S., Gordon, R. M. \& Coale., K. H., 1997. What controls dissolved iron concentrations in the world ocean? Marine Chemistry, 57(3-4), pp. 137-161.

Jones, B. \& Manning, D., 1994. Composition of geochemical indices used for the interpretation of paleoredox conditions in ancient mudstones. Chemical Geology, Volume 111 , pp. $111-129$.

Jones, E., Halliday, A., Rea, D. \& Owen, R., 2000. Eolian inputs of lead to the North Pacifc. Geochimica et Cosmochimica Acta, Volume 64, pp. 1405 - 1416.

Joseph, L., Rea, D. \& van der Pluijm, B., 2004. Neogene history of the Deep Western Boundary Current at Rekohu Sediment Drift, Southwest Pacifc (ODP Site 1124). Marine Geology, 205(1-4), pp. 85 - 206.

Joshima, M. \& Usui, A., 1998. Magnetostratigraphy of hydrogenetic manganese crusts from Northwestern Pacific seamounts. Marine Geology, 146(1-4), pp. 53-62.

Jung, H. \& Lee, C., 1999. Growth of diagenetic ferromanganese nodules in an oxic deep-sea sedimentary environment, northeast equatorial Pacific. Marine Geology, Volume 157, p. 127 144.

Karas, C., Nürnberg, D., Tiedemann, R. \& Garbe-Schönberg, D., 2011. Pliocene climate change of the Southwest Pacific and the impact of ocean gateways. Earth and Planetary Science Letters, 301(1-2), pp. 117-124. 
Kasten, S. et al., 1998. Rare earth elements in manganese nodules from the South Atlantic Ocean as indicators of oceanic bottom water flow. Marine Geology, Volume 146, pp. 33 - 52.

Kato, Y. et al., 2002. Geochemistry of Late Permian Triassic pelagic cherts from southwest Japan: implications for an oceanic redox change. Chemical Oceanography, Volume 182, pp. $15-34$.

Keller, G. \& Barron, J., 1987. Paleodepth distribution of Neogene deep-sea hiatuses. Paleoceanography, Volume 2, pp. 697 - 713.

Kennett, J. P., 1977. Cenozoic evolution of Antarctic glaciation, the Circum-Antarctic Ocean, and their impact on global Paleoceanography. Journal of Geophysical Research, 82(27), pp. 3843-3860.

Kennett, J. P., 1995. A review of polar climate evolution during the Neogene based on the marine sedimentary record. In: E. S. Vrba, G. H. Denton, T. C. Partridge \& L. H. Burckle, eds. Paleoclimate and Evolution. New Haven: Yale University Press, pp. 49-64.

Kennett, J. P. et al., 1975. Cenozoic paleoceanography in the Southwest Pacific Ocean, Antarctic glaciation, and the development of the Circum-Antarctic Current. In: Initial Reports of the Deep Sea Drilling Program. Washington, D. C.: United States of America Government Prinitiing Office, pp. 1155-1169.

Kennett, J. P. \& von der Borch, C., 1986. Southwest Pacific Cenozoic paleoceanography. In: J. P. Kennett \& C. von der Borch, eds. Initial Reports of the Deep Sea Drilling Project Leg 90. Washington, D. C.: United States Government Printing Office, pp. 1493 - 1517.

Kennett, J. P. \& Watkins, N. D., 1978. Regional Sedimentary Disconformities and Upper Cenozoic Changes in Bottom Water Velocities Between Australasia and Antarctica. In: D. E. Hayes, ed. Antarctica Oceanology II: The Australian-New Zealand Sector. Washington, D. C.: American Geophysical Union: Antarctic Research Series, pp. 273-294.

Kersten, M. \& Frostner, U., 1989. Speciation of trace elements in sediments.. In: Trace Element Speciation: Analytical Methods and Problems. Boca Raton: CRC Press, p. 245 - 309.

Kim, S-J. \& Crowley, T. J., 2000. Increased Pliocene North Atlantic Deep Water: Cause or consequence of Pliocene warming?. Paleoceanography, 15(4), pp. 451-455.

Klemm, V. et al., 2008. Seawater osmium isotope evidence for a middle Miocene flood basalt event in ferromanganese crust records. Earth and Planetary Science Letters, 273(1-2), pp. 175183. 
Klemm, V.et al., 2005. Osmium isotope stratigraphy of a marine ferromanganese crust. Earth and Planetary Science Letters, 238(1-2), pp. 42-48.

Klinkhammer, G. P. \& Palmer, M. R., 1991. Uranium in the oceans: Where it goes and why. Geochimica et Cosmochimica Acta, 55(7), pp. 1799-1806.

Knoop, A., Owen, R. M. \& Morgan, C. L., 1998. Regional variability in in ferromanganese nodule composition: northeastern tropical Pacifc Ocean. Marine Geology, 147(1-4), pp. 1-12.

Knorr, G. \& Lohmann, G., 2014. Climate warming during Antarctic ice sheet expansion at the Middle Miocene transition. Nature Geoscience, Volume 7, pp. 376-381.

Korschinek, G. et al., 2010. A new value for the half-life of 10Be by Heavy-Ion Elastic Recoil Detection and liquid scintillation counting. Nuclear Instruments and Methods in Physics Research Section B: Beam Interactions with Materials and Atoms Articles, 268(2), pp. 187-191.

Koschinsky, A. \& Halbach, P., 1995. Sequential leaching of marine ferromanganese precipitates: Genetic implications. Geochimica et Cosmochimica Acta, 59(24), pp. 5113-5132.

Koschinsky, A., Halbach, P., Hein, J. \& Mangini, A., 1996. Ferromanganese crusts as indicators for paleoceanographic events in the NE Atlantic. Geologische Rundschau, 85(3), pp. 567-576.

Koschinsky, A. \& Hein, J., 2003. Uptake of elements from seawater by ferromanganese crusts: solid-phase associations and seawater speciation. Marine Geology, 198(3-4), pp. 331351.

Koschinsky, A., Stascheit, A., Bau, M. \& Halbach, P., 1997. Effects of phosphatization on the geochemical and mineralogical composition of marine ferromanganese crusts. Geochimica et Cosmochimica Acta, 61(19), pp. 4079 - 4094.

Kriete, C., 2011. An evaluation of the inter-method discrepancies in ferromanganese nodule proficiency test geopt23a. Geostandards and Geoanalytical Research, Volume 35, p. 319 - 340.

Krishnaswami, S. et al., $1982 .{ }^{10} \mathrm{Be}$ and Th isotopes in manganese nodules and adjacent sediments: Nodule growth histories and nuclide behavior. Earth and Planetary Science Letters, 59(2), pp. 217-234.

Kuhnt, W. et al., 2004. Neogene History of the Indonesian Throughflow. In: P. P. Clift, W. Kuhnt, P. Wang \& D. Hayes, eds. Continent-Ocean Interactions Within East Asian Marginal Seas. Washington, D. C.: American Geophysical Union: Geophysical Monograph Series , pp. 299-320. 
Kunze, E. \& Smith, S. G. L., 2004. The Role of Small-Scale Topography in Turbulent Mixing of the Global Ocean. Oceanography, 17(1), pp. 55-64.

Kunzendorf, H., Pluger, W. L. \& Friedrich, G. H., 1983. Uranium in pacific deep-sea sediments and manganese nodules. Journal of Geochemical Exploration, 19(1-3), pp. 147-162.

Kürschner W. M. et al., 1996. Oak leaves as biosensors of Late Neogene and Early Pleistocene paleoatmospheric $\mathrm{CO}_{2}$ concentrations. Marine Micropaleontology, Volume 27, pp. 299-312.

Kurzweil, F., Gutjahr, M., Vance, D. \& Keigwin, L., 2010. Authigenic Pb isotopes from the Laurentian Fan: Changes in chemical weathering and patterns of North American freshwater runoff during the last deglaciation. Earth and Planetary Science Letters, 299(3-4), pp. 458-465.

Kusakabe, M. \& Ku, T-L., 1984. Incorporation of Be isotopes and other trace metals into marine ferromanganese deposits. Geochimica et Cosmochimica Acta, 48(11), pp. 2187-2193.

Kusakabe, M. et al., 1987. Distribution of ${ }^{10} \mathrm{Be}$ and ${ }^{9} \mathrm{Be}$ in the Pacific Ocean. Earth and Planetary Science Letters, 82(3-4,), pp. 231-240.

Ku, T. L., 1977. Rates of accretion. In: G. P. Glasby, ed. Marine Manganese Deposits. Amsterdam: Elsevier Oceanography Series, 15, pp. 249-267.

Ku, T. L. et al., 1982. Constancy of oceanic deposition of 10Be as recorded in manganese crusts. Nature, Volume 299, pp. 240-242.

Kylandera, M., Klaminder, J., Bindler, R. \& Weiss, D., 2010. Natural lead isotope variations in the atmosphere. Earth and Planetary Science Letters, Volume 290, pp. 44 - 53.

Lacan, F. \& Jeandel, C., 2001. Tracing Papua New Guinea imprint on the central Equatorial Pacific Ocean using neodymium isotopic compositions and rare earth element patterns. Earth and Planetary Science Letters, 186(3-4), pp. 497-512.

Lawver, L. A. \& Gahagan, L. M., 2003. Evolution of Cenozoic seaways in the circumAntarctic region. Palaeogeography, Palaeoclimatology, Palaeoecology, 198(1-2), pp. 11-37.

Lawver, L. A., Gahagan, L. M. \& Coffin, M. F., 1992. The development of paleoseaways around Antarctica. In: J. P. Kennett \& D. A. Warnke, eds. The Antarctic Paleoenvironment: A Perspective on Global Change. Washington, D. C.: American Geophysical Union: Antarctic Research Series, pp. 7-30.

Lear, C. H., Elderfield, H. \& Wilson, P. A., 2000. Cenozoic Deep-Sea Temperatures and Global Ice Volumes from Mg/Ca in Benthic Foraminiferal Calcite. Science, 287(5451), pp. 269-272. 
Lear, C. H., Rosenthal, Y. \& Wright, J. D., 2003. The closing of a seaway: ocean water masses and global climate change. Earth and Planetary Science Letters, 210(3-4), pp. 425-436.

Lebatard, A. et al., 2010. Application of the authigenic 10Be/9Be dating method to continental sediments:Reconstruction of the Mio-Pleistocene sedimentary sequence in the early hominid fossiliferous areas of the northern Chad Basin. Earth and Planetary Science Letters, 297(1-2), pp. 57-70.

Leclaire, L., 1974. Late Cretaceous and Cenozoic pelagic deposits-paleoenvironments and paleoceanography of the Central Western Indian ocean. Init. Rep. (DSDP), Volume 25, pp. $481-515$.

Leduc, G. et al., 2006. Authigenic ${ }^{10} \mathrm{Be} /{ }^{9} \mathrm{Be}$ signature of the Laschamp excursion:A tool for global synchronisation of paleoclimatic archives. Earth and Planetary Science Letters, 245(12), pp. 19-28.

Levin, H., 2013. The Sedimentary Archives. In: H. Levin, ed. The Earth Through Time. Tenth ed. New York: Wiley, pp. 85-124.

Lewis, A. et al., 2007. Major middle Miocene global climate change: evidence from East Antarctica and the Transantarctic Mountains. Geological Society of America, Volume 119, p. $1449-1461$.

Ling, H. F. et al., 1997. Evolution of $\mathrm{Nd}$ and $\mathrm{Pb}$ isotopes in Central Pacific seawater from ferromanganese crusts. Earth and Planetary Science Letters, 146(1-2), pp. 1-12.

Ling, H.-F.et al., 2005. Differing controls over the Cenozoic $\mathrm{Pb}$ and $\mathrm{Nd}$ isotope evolution of deepwater in the central North Pacific Ocean. Earth and Planetary Science Letters, 232(3-4), pp. 3-4.

Linthout, K., Helmers, H. \& Sopaheluwakan, J., 1997. Late Miocene obduction and microplate migration around the southern Banda Sea and the closure of the Indonesian Seaway. Tectonophysics, Volume 281, p. 17 - 30.

Little, S. H., Vance, D., Walker-Brown, C. \& Landing, W. M., 2014. The oceanic mass balance of copper and zinc isotopes, investigated by analysis of their inputs, and outputs to ferromanganese oxide sediments. Geochimica et Cosmochimica Acta, Volume 125, pp. 673693.

Li, Y.-H., 1982. Interelement relationship in abyssal Pacific ferromanganese nodules and associated pelagic sediments. Geochimica et Cosmochimica Acta, 46(6), pp. 1053-1060. 
Li, Y.-H., 1991. Distribution patterns of the elements in the ocean: a synthesis. Geochimica et Cosmochimica Acta, 55(11), pp. 3223-3240.

Li, Y.-H. \& Schoonmaker, J. E., 2006. Chemical composition and minerology of marine sediments. In: F. T. Mackenzie, ed. Treatise on Geochemistry: Sediments, Diagenesis and Sedimentary Rocks. Oxford: Elsevier, pp. 1-36.

Loutit, T. \& Keigwin, L., 1982. Stable isotopic evidence for latest Miocenesea-level fall in the Mediterranean region. Nature, Volume 300, pp. 163 - 166.

Lozier, S., 2012. Overturning in the North Atlantic. Annual Review of Marine Science, Volume 4, pp. 291-315.

Lutfi, M., Minami, T., Norisuye, K. \& Sohrin, Y., 2011. Strong elemental fractionation of Zr-Hf and Nb-Ta across the Pacific Ocean. Nature Geoscience, Volume 4, pp. 227 - 230.

Lyle, M. et al., 2008. Pacific Ocean and Cenozoic evolution of climate. Reviews of Geophysics, 46(2), p. RG2002.

Mangini, A., Eisenhaue, A. \& Walter, P., 1990. Response of manganese in the ocean to the climatic cycles in the Quaternary. Paleoceanography, 5(5), pp. 811 - 821.

Mangini, A., Eisenhauer, A. \& Walter, P., 1991. A spike of $\mathrm{CO}_{2}$ in the atmosphere at glacialinterglacial boundaries induced by rapid deposition of manganese in the oceans. Tellus Series B: Chemical and Physical Meteorology, 43(2), pp. 97-105.

Mangini, A. et al., 2000. Similar glacial and interglacial export bioproductivity in the Atlantic sector of the Southern Ocean: Multiproxy evidence and implications for glacial atmospheric $\mathrm{CO}_{2}$. Paleoceanography, Volume 15, p. $642-658$.

Mangini, A., Jung, M. \& Laukenmann, S., 2001. What do we learn from peaks of uranium and of manganese in deep sea sediments? Marine Geology, 177(1-2), pp. 63-78.

Mangini, A. et al., 1990. Element accumulation rates in and growth histories of manganese nodules from the southwestern Pacific Basin. Marine Geology, 94(1-2), pp. 97-107.

Mangini, A. et al., 1986. Diffusion and supply rates of ${ }^{10} \mathrm{Be}$ and ${ }^{230} \mathrm{Th}$ radioisotopes in two manganese encrustations from the South China Sea. Geochimica et Cosmochimica Acta, 50(1), pp. 149 - 156.

Manheim, F., 1986. Marine cobalt resources. Science, 232(4750), pp. 600 - 608.

Manhein, F. \& Lane-Bostwick, C., 1988. Cobalt in ferromanganese crusts as monitor of hydrothermal discharge on the Pacific sea floor. Nature, Volume 335, pp. 59 - 62. 
Manighetti, B., 2001. Lessons of the Past: Ocean circulation: the planet's great heat engine. National Institute of Water and Atmospheric Research: Water \& Atmosphere Series, 9(4), pp. $12-14$

Marchig, V., Von Stackelberg, U., Hufnagel, H. \& Durn, G., 2001. Compositional changes of surface sediments and variability of manganese nodules in the Peru Basin. Deep-sea Research. Part 2. Topical Studies in Oceanography, 48(17-18), pp. 3523-3547.

Marchitto, T. M., 2007. Physical and Chemical Proxies in Quaternary Paleoceanography: Nutrient Proxies. In: S. A. Elias, ed. Reference Module in Earth Systems and Environmental Sciences: Encyclopedia of Quaternary Science (Second Edition). Amsterdam: Elsevier, pp. 899906.

Margolis, S. V., 1973. Manganese deposits encountered during Deep Sea Drilling Project, Leg 29, in subantarctic waters. In: M. Morganstein, ed. The Origin and Distribution of Manganese Nodules in the Pacific and Prospects for Exploration. Honolulu, Hawaii: An international Symposium organised by the Valdiva Manganese Exploration Group and the Hawaii Institute of Geophysics, pp. 1-175.

Margolis, S. V., 1975. Manganese deposits encountered during Deep Sea Drilling Project, Leg 29, in subantarctic waters. In: Initial Reports of the Deep Sea Drilling Project. Washington, D. C., United States Government Printing Office, pp. 1083-1091.

Marshall, J. \& Speer, K., 2012. Closure of the meridional overturning circulation through Southern Ocean upwelling. Nature Geoscience, Volume 5, pp. 171-180.

Marshall, K., 1979. Biogeochemistry of manganese minerals. In: Biogeochemical Cycling of Mineral-Forming Elements. Amsterdam: Elsevier, pp. 253 - 286.

Martin, J. H., 1990. Glacial-interglacial $\mathrm{CO}_{2}$ change: The Iron Hypothesis. Paleoceanography, 5(1), pp. 1-13.

Mattiessen, J., Knies, J., Vogt, C. \& Stein, R., 2009. Pliocene palaeoceanography of the Arctic Ocean and subarctic seas. Philosophical Transactions of the Royal Society A, 367(1886), pp. 21-48.

McCave, I. \& Carter, L., 1997. Recent sedimentation beneath the Deep Western Boundary Current off northern New Zealand. Deep Sea Research Part I: Oceanographic Research Papers, 44(7), pp. 1203-1237.

McCave, I. N., Carter, L., Carter, R. M. \& Hayward, B. W., 2004. Cenozoic oceanographic evolution of the SW Pacific gateway: introduction. Marine Geology, 205(1-4), pp. 1-7. 
McCave, I. N., Carter, L. \& Hall, I. R., 2008. Glacial-interglacial changes in water mass structure and flow in the SW Pacific Ocean. Quaternary Science Reviews, 27(19-20), pp. 18861908.

McHague, L. R. \& Damon, P. E., 1991. The global beryllium 10 cycle. Reviews of Geophysics, 29(2), pp. 141-158.

McKay, R. et al., 2012. Antarctic and Southern Ocean influences on Late Pliocene global cooling. Proceedings of the National Academy of Sciences, 109(17), pp. 6423 - 6428.

McKelvey, B. \& Orians, K. J., 1993. Dissolved zirconium in the North Pacific Ocean. Geochimica et Cosmochimica Acta, 57(15), pp. 3801-3805.

McLennan, S. M., 1989. Rare earth elements in sedimentary rocks: influence of provenance and sedimentary processes. Geochemistry and Mineralogy of Rare Earth Elements. In: B. R. Lipin \& G. H. McKays, eds. Review in Mineralogy, Volume 21. Washington, D. C.: Mineralogical Society of America, pp. 169-200.

McManus, J., 1998. Geochemistry of barium marine sediments: implications for its use as a paleoproxy.. Geochimic et Cosmochimica Acta, 62(21-22), pp. 3453-3473.

McMurtry, G. M., 2001. Deep-Sea Sediment: Authigenic Deposits. In: J. Steele, S. Thorpe \& K. Turekian, eds. Encyclopedia of Ocean Sciences. London: Academic Press, pp. 201-212.

McMurtry, G. M. et al., 1994. Cenozoic accumulation history of a Pacific ferromanganese crust. Earth and Planetary Science Letters, 125(1-4), pp. 105-118.

Measures, C. et al., 1996. The distribution of 10Be and 9Be in the South Atlantic. Deep Sea Res, Volume 43, pp. 987 - 1009.

Meinen, C. S., Piola, A. R., Perez, R. C. \& Garzoli, S. L., 2012. Deep Western Boundary Current transport variability in the South Atlantic: preliminary results from a pilot array at $34.5^{\circ}$ S. Ocean Science, Volume 8, pp. 1041-1054.

Mero, J., Arrhenius, G. \& Korkisch, J., 1964. Origin of oceanic manganese nodules. Science, Volume 144, pp. 170 - 173.

Mero, J. L., 1965. The Mineral Resources of the Sea. Amsterdam: Elsevier Oceanography Series.

Meylan, M. A., Bäcker, H. \& Glasby, G. P., 1975. Manganese nodule investigations in the Southwestern Pacific Basin. New Zealand Oceanographic Institute Field Report, 4(1), pp. 1-24. 
Middleton, R., Brown, L., Dezfouly-Arjomandy, B. \& Klein, J., 1993. On ${ }^{10}$ Be standards and the half-life of ${ }^{10} \mathrm{Be}$. Nuclear Instruments and Methods in Physics Research Section B: Beam Interactions with Materials and Atoms, 82(3), pp. 399-403.

Mikolajewicz U. et al., 1997. Response of a coupled ocean/energy balance model to restricted flow through the central American isthmus. Paleoceanography, Volume 12, pp. 429-441.

Miller, K. G., Fairbanks, R. G. \& Mountain, G. S., 1987. Tertiary oxygen isotope synthesis, sea level, and continental margin erosion. Paleoceanography, 2(1), pp. 1-19.

Miller, K. G., Wright, J. D. \& Fairbanks, R. G., 1991. Unlocking the Ice House: OligoceneMiocene Oxygen Isotopes, Eustasy and Margin Erosion. Journal of Geophysical Research, 96(B4), pp. 6829-684891.

Miller, K. G. et al., 2009. Climate threshold at the Eocene-Oligocene transition: Antarctic ice sheet influence on ocean circulation. In: C. Koeberl \& A. Montanari, eds. The late Eocene earth - hothouse, icehouse, and impacts. Boulder, Colorado: Geological Society of America Special Papers, pp. 149-168.

Millero, F. J., 2010. History of the Equation of State of Seawater. Oceanography, 23(3), pp. 18-33.

Milliman, J. \& Meade, R., 1983. Worldwide delivery of river sediment to the oceans. Journal of Geology, Volume 91, p. 1 - 21.

Milliman, J. \& Syvitski, J., 1992. Geomorphic/tectonic control of sediment discharge to the ocean: the importance of small mountainous rivers. Journal of Geology, Volume 100, p. 525 544.

Mills, R. A., Wells., D. M. \& Roberts, S., 2001. Genesis of ferromanganese crusts from the TAG hydrothermal field. Chemical Geology, 176(1-4), pp. 283-293.

Molnar, P., 2008. Closing of the Central American Seaway and the Ice Age: A critical review. Paleoceanography, 23(2), p. PA2201.

Molnar, P. \& Cane, M. A., 2002. El Niño's tropical climate and teleconnections as a blueprint for pre-Ice Age climates. Paleoceanography, 17(2), pp. 11-1 - 11-11.

Moorby, S. \& Cronan, D., 1981. The distribution of elements between co-existing phases in some marine ferromanganese deposits. Geochimica et Cosmochimica Acta, 45(10), pp. 18551878. 
Morris, M., Stanton, B. \& Neil, H., 2001. Subantarctic oceanography around New Zealand: Preliminary results from an ongoing survey. New Zealand Journal of Marine and Freshwater Research, 35(3), pp. 499-519.

Morrow, R. et al., 1992. Eddy momentum flux and its contribution to the Southern Ocean momentum balance. Nature, Volume 357, p. 482 - 484.

Mukhopadhyay, R., Ghosh, A. \& Iyer, S., 2008. Ferromanganese Deposits. In: M. Hale, ed. The Indian Ocean nodule field: Geology and resource potential. Amsterdam: Elsevier: Handbook of Exploration and Environmental Geochemistry Series, pp. 155-225.

Mukhopadhyay, R. \& Ghosh, A. K., 2010. Dynamics of formation of ferromanganese nodules in the Indian Ocean. Journal of Asian Earth Sciences, 37(4), pp. 394-398.

Mukhopadhyay, R., Iyer, S. D. \& Ghosh, A. K., 2003. The Indian Ocean Nodule Field: petrotectonic evolution and ferromanganese deposits. Earth-Science Reviews, 60(1-2), pp. 67130.

Murray, J. \& Renard, A., 1891. Deep Sea Deposits, Report on the Scientific Results of the Voyage of H.M.S. Challenger During the Years 1872-1876. Edinburgh: Great Britain Challenger Office.

Murray, J. W. \& Brewer, P. G., 1977. Mechanisms of removal of manganese, iron and other trace metals from sea water. In: G. P. Glasby, ed. Marine Manganese Deposits. Amsterdam: Elsevier Oceanography Series, 15, pp. 291-325.

Nagai, H., Tada, W. \& Kobayashi, T., 2000. Production of 7Be and 10Be in the atmosphere.. Nuclear Instruments and Methods in Physics Research, Volume 172, pp. 796 - 801.

Naish, T. et al., 2009. Obliquity-paced Pliocene West Antarctic ice sheet oscillations. Nature, Volume 458, pp. 322-328.

Nakada, R., Takahashi, Y. \& Tanimizu, M., 2013. Isotopic and speciation study on cerium during its solid-water distribution with implication for Ce stable isotope as a paleo-redox proxy. Geochimica et Cosmochimica Acta, Volume 103, pp. 49-62.

Nath, B. N. et al., 1994. Cerium anomaly variations in ferromanganese nodules and crusts from the Indian Ocean. Marine Geology, Volume 120, pp. 385-400.

Nayak, B., Das, S. K. \& Munda, P., 2013. Biogenic signature and ultra microfossils in ferromanganese nodules of the Central Indian Ocean Basin. Journal of Asian Earth Sciences, 73(5), pp. 296-305. 
Nelson, C. S. \& Cooke, P. J., 2001. History of oceanic front development in the New Zealand sector of the Southern Ocean during the Cenozoic-a synthesis. New Zealand Journal of Geology and Geophysics, 44(4), pp. 535-553.

Nielsen, S. et al., 2011. New age for ferromanganese crust 109D-C and implications for isotopic records of lead, neodymium, hafnium, and thallium in the Pliocene Indian Ocean. Paleoceanography, 26(2), p. PA2213.

Nishiizumi, K. et al., 2007. Absolute calibration of 10Be AMS standards. Nuclear Instruments and Methods in Physics Research Section B: Beam Interactions with Materials and Atoms, 258(2), pp. 403-413.

Nozaki, Y. \& Alibo, D. A., 2003. Dissolved rare earth elements in the Southern Ocean, southwest of Australia: Unique patterns compared to the South Atlantic data. Geochemical Journal, 37(1), pp. 47-62.

O’Regan, M., Williams, C. J., Frey, K. E. \& Jakobsson, M., 2011. A synthesis of the longterm. Oceanography, 24(3), pp. 66-80.

Oda, H. et al., 2011. Ultrafine-scale magnetostratigraphy of marine ferromanganese crust. Geology, 39(3), pp. 227-230.

Ohta, A., Naito, K., Okuda, Y. \& Kawabe, I., 1999. Geochemical characteristics of Antarctic deep-sea ferromanganese nodules from highly oxic deep-sea water. J. Earth Planet. Sci. Nagoya Univ., Volume 46, p. 1 - 13.

Ollister, C. \& Nowell, A., 1991. Hebble epilogue. Mar. Geol., Volume 99, pp. 445 - 460.

Orians, K. J. \& Merrin, C. L., 2001. Encyclopedia of Ocean Sciences. Academic, Volume 4, pp. 2387-2399.

Orpin, A. et al., 2008. New Zealand's diverse seafloor sediments. Wellington, New Zealand: National Institute of Water and Atmospheric Research: NIWA Chart Miscellaneous Series 86.

Orsi, A. H., 2010. Oceanography: Recycling bottom waters. Nature Geoscience, Volume 3, pp. 307-309.

Orsi, A. H., Johnson, G. C. \& Bullister, J. L., 1999. Circulation, mixing, and production of Antarctic Bottom Water. Progress in Oceanography, 43(1), pp. 55-109.

Orsi, A. H., Nowlin, W. D. \& Whitworth III, T., 1993. On the circulation and stratification of the Weddell Gyre. Deep Sea Research Part I: Oceanographic Research Papers, 40(1), pp. 169203. 
Orsi, A. H., Whitworth III, T. \& Nowlin, W., 1995. On the meridional extent and fronts of the Antarctic Circumpolar Current. Deep Sea Research Part I: Oceanographic Research Papers, 42(5), pp. 641-673.

Osborne, A. H. et al., 2014. The seawater neodymium and lead isotope record of the final stages of Central American Seaway closure. Paleoceanography, 29(7), pp. 715-729.

Padro, P. C., Perez, F. F., Velo, A. \& Gilcoto, M., 2012. Water masses distribution in the Southern Ocean: Improvement of an extended OMP (eOMP) analysis. Progress in Oceanography, Volume 103, pp. 92-105.

Pattan, J. N. \& Pearce, N. G., 2009. Bottom water oxygenation history in southeastern Arabian Sea during the past 140 ka: Results from redox-sensitive elements. Palaeogeography, Palaeoclimatology, Palaeoecology, 280(3-4), pp. 396 - 405.

Pattan, J. N., Pearce, N. G. \& Mislankar, P. G., 2005. Constraints in using Cerium-anomaly of bulk sediments as an indicator of paleo bottom water redox environment: A case study from the Central Indian Ocean Basin. Chemical Geology, 221(3-4), pp. 260-278.

Pattan, J. N. et al., 2001. Ferromanganese Nodules and their Associated Sediments from the Central Indian Ocean Basin: Rare Earth Element Geochemistry. Marine Georesources \& Geotechnology, 19(3), pp. 155-165.

Pedersen, T. F., Pickering, M., Vogel, J. S. \& Southon, S. N., 1988. The response of benthic foraminifera to productivity cycles in the eastern equatorial Pacifc: Faunal and geochemical constraints on glacial bottom water oxygen levels. Paleoceanography, 3(2), pp. 157-168.

Perritt, S. \& Watkeys, M. K., 2007. The effect of environmental controls on the metal content in ferromanganese crusts and nodules from the Mozambique Ridge and in the Mozambique Basin, southwestern Indian Ocean. South African Journal of Geology, 110(2-3), pp. 295-310.

Pettke, T. \& Halliday, A., 2002. Cenozoic evolution of Asian climate and sources of Pacific seawater $\mathrm{Pb}$ and $\mathrm{Nd}$ derived from eolian dust of sediment core LL44-GPC3.

Paleoceanography, Volume 17, pp. 1 - 13.

Pfeifer, K., Kasten, S., Hensen, C. \& Schulz, H. D., 2001. Reconstruction of primary productivity from the barium contents in surface sediments of the South Atlantic Ocean. Marine Geology, 177(1-2), pp. 13-24.

Pichoki, C. \& Hoffert, M., 1987. Characteristics of Co-rich ferromanganese nodules and crusts sampled in French Polynesia. Marine Geology, 77(1-2), pp. 109-119. 
Piper, D. Z., 1974. Rare earth elements in ferromanganese nodules and other marine phases. Geochimica et Cosmochimica Acta, 38(7), p. 1007-1022.

Piper, D. Z., Swint, T. R., Sullivan, L. G. \& McCoy, F. W., 1985. Manganese nodules, seafloor sediment, and sedimentation rates of the Circum-Pacific region. Tulsa, Oklahoma: CircumPacific Council for Energy and Mineral Resources: American Association of Petroleum Geologists: Circum-Pacific Map Project.

Piper, D. Z. \& Williamson, M. E., 1977. Composition of Pacific Ocean ferromanganese nodules. Marine Geology, 23(4), pp. 285-303.

Pollard, D. \& DeConto, R. M., 2009. Modelling West Antarctic ice sheet growth and collapse through the past five million years. Nature, Volume 458.5n $329+332$.

Poore, H. R. et al., 2006. Neogene overflow of Northern Component Water at the Greenland-Scotland Ridge. Geochemistry, Geophysics, Geosystems, 7(6), pp. 1-24.

Post, J., 1999. Mangenese oxide minerals: crystal structures and economic and environmental significance. Proceedings of the National Academy of Sciences of the United States of America, 96(7), pp. 3447-3454.

Pourret, O. \& Davranche, M., 2013. Rare earth element sorption onto hydrous manganese oxide: A modeling study. Journal of Colloid and Interface Science, Volume 395, pp. 18-23.

Pulyaeva, I. A. \& Hein, J. R., 2010. Paleoceanographic Conditions During the Formation of Fe-Mn Crusts from the Pacific Ocean: Biostratigraphic and Compositional Evidence. In: Toward the Sustainable Development of Marine Minerals: Geological, Technological, and Economic Aspects. Gelendzhik, Russia: Under Water Mining Institute, pp. 1 - 11.

Puteanus, D. \& Halbach, P., 1988. Correlation of Co concentration and growth rate - A method for age determination of ferromanganese crusts. Chemical Geology, 69(1-2), pp. 73 85 .

Raab, W., 1972. Physical and chemical features of the Pacific deep sea manganese nodules and their implications to the genesis of nodules. In: D. R. Horn, ed. Ferromanaganese Deposits on the Ocean Floor. Washington, D.C.: The Office for the International Decade of Ocean Exploration, National Science Foundation, pp. 31-50.

Raab, W. \& Meylan, M., 1977. Morphology. In: Glasby, ed. Marine Manganese Deposits. Amsterdam: Elsevier Oceanography Series, 15, pp. 109-146. 
Rack, F. R., 1993. A geologic perspective on the Miocene evolution of the Antarctic Circumpolar Current system. Tectonophysics: Geological Perspetives on Global Change, 222(13), pp. 397-415.

Raisbeck, G. et al., 1979. ${ }^{10} \mathrm{Be}$ concentration and residence time in the ocean surface layer. Earth and Planetary Science Letters, 43(2), pp. 237-240.

Raisbeck, G. et al., 1981. Cosmogenic ${ }^{10} \mathrm{Be} /{ }^{7} \mathrm{Be}$ as a probe of atmospheric transport processes.. Geophysical Research Letters , 8(9), p. 1015 - 1018.

Raiswell, R., Benning, L. G., Tranter, M. \& Tulaczyk, S., 2008. Bioavailable iron in the Southern Ocean: the significance of the iceberg conveyor belt. Geochemical Transactions, 7(9).

Raiswell, R. \& Canfield, D. E., 2012. The Iron Biogeochemical Cycle Past and Present. Geochemcial Perspectives, Volume 1, pp. 1-220.

Rajani, R. P. et al., 2005. Compositional variation and genesis of ferromanganese crusts of the Afanasiy-Nikitin Seamount, Equatorial Indian Ocean. Journal of Earth System Science, 114(1), pp. 51-61.

Ravelo, A.C., et al., 2004. Regional climate shifts caused by gradual global cooling in the Pliocene Epoch. Nature, Volume 429, pp. 263-267.

Rawson, M. D. \& Ryan, W. F., 1978. Ocean Floor Sediments and Polymatallic Nodule Maps. New York: LDGO Columbia University.

Raymo, M.E., Grant, B., Horowitz, M. \& Grey H. R., 1996. Mid-Pliocene warmth: Stronger greenhouse and stronger conveyor. Marine Micropaleontology, Volume 27, pp. 313-326.

Raymo, M., Hodell, D. \& Jensen, E., 1992. Response of deep ocean circulation to initiation of Northern Hemisphere glaciation. Paleoceanography, 7(5), pp. 645-672.

Rea, D., 1994. The paleoclimatic record provided by eolian deposition in the deep sea: The geologic history of wind. Rev.Geophys, Volume 32, pp. 159 - 195.

Rehkämper, M. \& Nielsen, S., 2004. The mass balance of dissolved thallium in the oceans. Marine Chemistry, Volume 85, pp. 125 - 139.

Revel-Rolland, M. et al., 2006. Eastern Australia: a possible source of dust in East Antarctica interglacial ice.. Earth Planet. Sci. Lett., Volume 249, p. 1 - 13.

Reynolds, B., Frank, M. \& O’Nions, R., 1999. Nd- and Pb-isotope time series from Atlantic ferromanganese crusts: implications for changes in provenance and paleocirculation over the last 8 Myr. Earth and Planetary Science Letters, Volume 173, pp. 381 - 396. 
Reyss, J., Marchig, V. \& Ku, T., 1982. Rapid growth of a deep-sea manganese nodule. Nature, Volume 295, pp. 401-403.

Rickli, J., Frank, M. \& Halliday, A. N., 2009. The hafnium-neodymium isotopic of Atlantic seawater. Earth and Planetary Sciences, Volume 280, pp. 118-127.

Rintoul, S., Hughes, C. \& Olbers, D., 2001. The Antarctic Circumpolar Current system. In: G. Siedler, J. Church \& J. Gould, eds. Ocean Circulation and Climate: Observing and Modelling the Global Ocean. New York: Elsevier, pp. 271-302.

Rintoul, S., Meredith, M., Schofield, O. \& Newman, L., 2012. The Southern Ocean observing system. Oceanography, 25(3), pp. 68-69.

Rintoul, S. R., 2009. Antarctic Circumpolar Current. In: J. H. Steele, ed. Encyclopedia of Ocean Sciences. 2nd ed. Oxford: Academic Press, pp. 178-190.

Rintoul, S. R., 2011. The Southern Ocean in the Earth System. In: P. A. Berkman, M. A. Lang, D. W. H. Walton \& O. R. Young, eds. Science Diplomacy: Antarctica, Science and the Governance of International Spaces. Washington D.C.: Smithsonian Institution Scholarly Press, pp. 175-187.

Robert, C., Stein, R. \& Acquaviva, M., 1985. Cenozoic evolution and significance of clay associations in the New Zealand region of the South Pacific . In: Init.Repts.DSDP. Washington: U.S.Govt.Printing Office, pp. 1225 - 1238.

Robinson, L. \& van de Flierdt, T., 2009. Southern Ocean evidence for reduced export of North Atlantic Deep Water during Heinrich event 1. Geology, 37(3), pp. 195-198.

Rohling, E. J. et al., 2014. Sea-level and deep-sea-temperature variability over the past 5.3 million years. Nature, Volume 508, pp. 477-482.

Rue, E. L. \& Bruland, K. W., 1995. Complexation of iron(III) by natural organic ligands in the Central North Pacific as determined by a new competitive ligand equilibration/adsorptive cathodic stripping voltammetric method. Marine Chemistry, 50(1-4), pp. 117-138.

Russell, J., Stouffer, R. \& Dixon, K., 2006. Intercomparison of the Southern Ocean Circulations in IPCC Coupled Model Control Simulations. Journal of Climate, 19(18), pp. 4560-4575.

Rutberg, R., Hemming, S. \& Goldstein, S., 2000. Reduced North Atlantic Deep Water flux to the glacial Southern Ocean inferred from neodymium isotope ratios. Nature, 405(6789), pp. 935-938. 
Sageman, B. \& Lyons, T., 2003. Geochemistry of fine-grained sediments and sedimentary rocks. . In: Treatise on Geochemistry. . Oxford: Elsevier-Pergamon, pp. 115 - 158.

Sañudo-Wilhelmy, S. A. et al., 2002. Trace metal distributions off the Antarctic peninsula in the Weddell Sea. Marine Chemistry, 77(2-3), pp. 157-170.

Sarmiento, J. L. \& Gruber, N., 2006. Ocean Biogeochemical Dynamics. Princeton, New Jersey: Princeton University Press.

Schaule, B. K. \& Patterson, C. C., 1981. Lead Concentrations in the Northeast Pacific Evidence for Global Anthropogenic Perturbations. Earth and Planetary Science Letters, 54(1), pp. 97-116.

Schlitzer, R., 2002. Interactive analysis and visualization of geoscience data with Ocean Data View. Computers \& Geosciences, 28(10), pp. 1211-1218.

Schlosser, P. et al., 2001. Transformation and age of water masses. In: G. Siedler, J. Church \& J. Gould, eds. Ocean circulation and climate: Observing and Modelling the Global Ocean. New York: Elsevier, pp. 431-452.

Schmidt, K., Bau, M., Hein, J. R. \& Koschinsky, A., 2014. Fractionation of the geochemical twins $\mathrm{Zr}-\mathrm{Hf}$ and $\mathrm{Nb}-\mathrm{Ta}$ during scavenging from seawater by hydrogenetic ferromanganese crusts. Geochimica et Cosmochimica Acta, 140(10), pp. 468-487.

Schmittner, A., Chiang, J. \& Hemming, S., 2007. Introduction: the ocean's meridional overturning circulation. In: A. Schmittner, J. Chiang \& S. Hemming, eds. Ocean Circulation: mechanisms and impacts - past and future changes of meridional overturning. Washington, D.C.: American Geophysical Union: Geophysical Monograph Series , pp. 1 - 4.

Schroeder, J.et al., 1997. Barium in equatorial Pacific carbonate sediment: terrigenous, oxide, and biogenic associations. Paleoceanography, 12(1), pp. 125-146.

Schuur, C. et al., 1998. Sedimentary regimes at the Macquarie Ridge Complex: Interaction of Southern Ocean circulation and plate boundary bathymetry. Paleoceanography, 13(6), p. 646 -670 .

Segl, M. et al., 1984. ${ }^{10} \mathrm{Be}$-dating of a manganese crust from Central North Pacific and implications for ocean paleocirculation. Nature, 309(7), pp. 540-544.

Segl, M. et al., 1989. Growth rate variations of manganese nodules and crusts induced by paleoceanographic events. Paleoceanography, 4(5), pp. 511-530.

Shackleton, N. \& Kennett, J. P., 1975. Paleotemperature history of the Cenozoic and the initiation of Antarctic glaciation: Oxygen and carbon isotope analyses in DSDP sites 277, 279, 
and 281. In: J. P. Kennett \& R. E. Houtz, eds. Initial Reports of the Depp Sea Drilling Program. Washington, D. C.: United States of America Government Printing Office, pp. 743-755.

Sharma, P. et al., 1987. Transport of ${ }^{10} \mathrm{Be}$ and ${ }^{9} \mathrm{Be}$ in the ocean. Earth and Planetary Science Letters, 86(1), pp. 69-76.

Sharma, P. \& Somayajulu, B. L. K., 1982. ${ }^{10}$ Be dating of large manganese nodules from world oceans. Earth and Planetary Science Letters, 59(2), pp. 235-244.

Sheldon, N. D. \& Tabor, N. J., 2009. Quantitative paleoenvironmental and paleoclimatic reconstruction using paleosols. Earth-Science Reviews, 95(1-2), pp. 1-52.

Shevenell, A. E. \& Bohaty, S. M., 2012. Southern exposure: New paleoclimate insights from Southern Ocean and Antarctic margin sediments. Oceanography, 25(3), pp. 106-117.

Shevenell, A. E., Kennett, J. P. \& Lea, D. W., 2008. Middle Miocene ice sheet dynamics, deep-sea temperatures, and carbon cycling: A Southern Ocean perspective. Geochemistry, Geophysics, Geosystems, Volume 9.

Shirah, G. et al., 2009. Thermohaline circulation animation: Goddard Space Flight Center Scientific Visualisation Studio. In: Blue Marble: Next Generation Data. s.l.:National Aeronautics and Space Administration (NASA), p. Animation Number (3658).

Sholkovitz, E. R., 1989. Artifacts associated with the chemical leaching of sediments for rareearth elements. Chemical Geology, 77(1), pp. 47-51.

Shulz, H. D. \& Zabel, M., 2006. Marine Geochemistry. Second ed. Hidelberg, Germany: Springer-Verlag.

Smith, D., 1995. Manganese Nodule, NOD-P-1. United States Geological Survey, pp. 1 - 3.

Sohrin, Y.et al., 1998. Dissolved niobium and tantalum in the North Pacific. Geophysical Research Letters, 25(7), pp. 999-1002.

Sokolov, S. \& Rintoul, S., 2009. Circumpolar structure and distribution of the Antarctic Circumpolar Current fronts: 1. Mean circumpolar paths. Journal of Geophysical Research: Oceans, 114(C11), p. C11018.

Somayajulu, B. L. K., 2000. Growth rates of oceanic manganese nodules: Implications to their genesis, palaeo-earth environment and resource potential. Current Science, Volume 78, pp. 300-308.

Sorem, R. \& Fewkes, R., 1977. Internal Characteristics. In: G. P. Glasby, ed. Marine Manganese Deposits. Amsterdam: Elsevier Oceanography Series, 15, pp. 147-184. 
Sorem, R. \& Foster, A., 1972. Marine manganese nodules: importance of structural analysis. International Geological Congress, 24th Montreal, 24(8), pp. 192 - 200.

Sorem, R. K., 1967. Manganese nodules; nature and significance of internal structure. Economic Geology, Volume 62, pp. 141 - 147.

Sorem, R. K., 1973. Manganese nodules as indiactors of long-term variations in seafloor environment. In: M. Morgenstein, ed. The Origin and Distribution of Manganese Nodules in the Pacific and Prospects for Exploration. Honolulu, Hawaii: A syposium organised by the Valdivia Manganese Exploration Group and the Hawaii Institute of Geophysics , pp. 151-164.

Soua, M., 2011. Productivity and bottom water redox conditions at the CenomanianTuronian Oceanic Anoxic Event in the southern Tethyan margin, Tunisia. Revue méditerranéenne de l'environnement, Volume 4, pp. 653 - 664.

Stancin, A. et al., 2008. Miocene to recent eolian dust record from the Southwest Pacific Ocean at $40^{\circ}$ S latitude. Science Direct, Volume 261, pp. 218 - 233.

Stanton, B. R. \& Morris, M. Y., 2004. Direct velocity measurements in the Subantarctic Front and over Campbell Plateau, southeast of New Zealand. Journal of Geophysical Research: Oceans , 109(C1), p. C01028.

Stein, R. \& Robert, C., 1985. Siliciclastic sediments at sites 588, 590 and 591: Neogene and Paleogene evolution in the southwest Pacific and Australian climate. Initial Reports of the Deep SeaDrilling Project, Volume 90, pp. 1437-1454.

Stickley, C., Carter, L., McCave, I. \& Weaver, P., 2001. Lower Circumpolar Deep Water Flow Through the SW Pacific Gateway for the Last $190 \mathrm{Ky}$ : Evidence from Antarctic Diatoms. In: D. Seidov, B. J. Haupt \& M. Maslin, eds. The Oceans and Rapid Climate Change: Past, Present, and Future. Washington, D. C.: American Geophysical Union, pp. 101-116.

Summerhayes, C. P., 1967. Manganese nodules from the South-Western Pacific. New Zealand Journal of Geology and Geophysics, 10(6), pp. 1372-1381.

Syvitski, J., Peckham, S., Hilberman, R. \& Mulder, T., 2003. Predicting the terrestrial flux of sediment to the global ocean: a planetary perspective. Science Direct, Volume 162, pp. 5 - 24.

Takahashi, Y. et al., 2007. Chemical and structural control of the partitioning of Co, Ce, and $\mathrm{Pb}$ in marine ferromanganese oxides. Geochimica et Cosmochimica Acta, 71(4), pp. 984-1008.

Takematsu, N., Sato., Y. \& Kato, Y. S., 1993. Factors regulating the distribution of elements in marine sediments predicted by a simulation model. Journal of Oceanography, 49(4), pp. 425-441. 
Talley, L. D., Pickard, G. L., Emery, W. J. \& Swift, J. H., 2011. Typical Distributions of Water Characteristics. In: L. D. Talley, G. L. Pickard, W. J. Emery \& J. H. Swift, eds. Descriptive Physical Oceanography: An Introduction. Sixth ed. New York: Elsevier, pp. 67-110.

Taylor, S. R. \& McLennan, S. M., 1985. The Continental Crust: Its Composition and Evolution. Oxford: Blackwell.

Tessier, A., Campbell, P. \& Bisson, M., 1979. Sequential extraction procedure for the speciation of particulate trace metals.. Anal. Chem., Volume 51, p. $844-850$.

Thompson, B. et al., 2012. A model study of the first ventilated regime of the Arctic Ocean during the early Miocene. Polar Research, 31(10859), pp. 1-19.

Thurman, H. V. \& Trujilo, A. P., 2004. Introductory Oceanography. Tenth ed. New Jersey: Prentice Hall.

Tian, J. et al., 2009. Reorganization of Pacific Deep Waters linked to middle Miocene Antartica cryosphere expansion: A perspective from the South China Sea. Palaeogeography, Palaeoclimatology, Palaeoecology, 284(3-4), pp. 375 - 382.

Tiedemann R., Sarnthein M. \& N.J., S., 1994. Astronomic timescale for the Pliocene Atlantic $\delta^{18} \mathrm{O}$ and dust flux records of Ocean Drilling Program site 659. Paleoceanography, Volume 9, pp. 619-638.

Timm, C. et al., 2010. Temporal and geochemical evolution of the Cenozoic intraplate volcanism of Zealandia. Earth-Science Reviews, 98(1-2), pp. 38 - 64.

Tipping, E. et al., 1985. Artefacts in the use of selective chemical extraction to determine distributions of metals between manganese and iron. Anal. Chem., Volume 57, p. $1944-$ 1946.

Toggweiler, J. R. \& Samuels, B., 1995. Effect of sea ice on the salinity of Antarctic Bottom Waters. Journal of Physical Oceanography, 25(9), p. 1980-1997.

Trefil, J., 2001. The Encyclopedia of Science and Technology. London: Routledge.

Tribovillard, N., Alegeo, T., Lyons, T. \& Riboulleau, A., 2006. Trace metals as paleoredox and paleoproductivity proxies: An update. Chemical Geology: Isotope Geoscience sectioN, 232(1-2), pp. 12-32.

Tully, B. J. \& Heidelberg, J. F., 2013. Microbial communities associated with ferromanganese nodules and the surrounding sediments. Frontiers in Microbiology, 4(2), pp. 161-174. 
Turekian, K., 1977. Trace elements in the ocean. In: Oceanography: the last frontier. s.l.:Voice of America, pp. 91 - 106.

Turekian, K. K. \& Bacon, M. P., 2003. Geochronometry of Marine Deposits. In: H.

Elderfield, H. H. Holland \& K. K. Turekian, eds. Treatise on Geochemistry: Volume 6 The Oceans and Marine Geochemistry. Amsterdam: Elsevier, pp. 321-341.

Turekian, K. K. et al., 1979. The measurement of ${ }^{10} \mathrm{Be}$ in manganese nodules using a tandem Van De Graaff accelerator. Geophysical Research Letters, 6(5), pp. 417-420.

Ulfbeck, D. G., J. A. Baker, I. J. Graham \& Wright, I. C., 2001. Hf isotopic Isotopic Profiles of Fe-Mn Nodules (19-0 Ma) from the Deep Western Boundary Current, Southern Pacific. EOS Transactions: American Geophysical Union: Fall Meeting: Abstract, 82(47), pp. OS31C0439 .

Usui, A., Nishimura, A. \& Mita, N., 1993. Composition and growth history of surficial and buried manganese nodules in the Penrhyn Basin, Southwestern Pacific. Marine Geology, 114(1-2), pp. 133-153.

Usui, A. \& Someya, M., 1997. Distribution and composition of marine hydrogenetic and hydrothermal manganese deposits in the north-western Pacific. In: K. Nicholson, J. R. Hein, B. Buhn \& S. Dasgupta, eds. Manganese mineralisation: geochemistry and mineraology of terrestrial and marine deposits. London: The Geological Society of London, pp. 177-198.

Vallelonga, P. et al., 2010. Lead isotopic compositions in the EPICA Dome C ice core and Southern Hemisphere Potential Source Areas. Quaternary Science Reviews, 29(1-2), pp. 247255.

Valsangkar, A. \& Khadgc, N., 1989. Size analyses and geochemistry of ferromanganese noduels from the Central Indian Ocean Basin. Marine Mining, Volume 8, pp. 325 - 347.

van de Flierdt, T. et al., 2003. Lead isotopes in North Pacific deep water - implications for past changes in input sources and circulation patterns. Earth and Planetary Science Letters, 209(1-2), pp. 149-164.

van de Flierdt, T. et al., 2004. Deep and bottom water export from the Southern Ocean to the Pacific over the past 38 million years. Paleoceanography, 19(1), p. PA1020.

van de Flierdt, T. et al., 2007. Global neodymium-hafnium isotope systematics-revisited. Earth and Planetary Science Letters, 259(3-4), pp. 432-441. 
van de Flierdt, T., Hemming, S., Goldstein, S. \& Abouchami, W., 2006. Radiogenic isotope fingerprint of Wilkes Land-Adelie Coast Bottom Water in the circum-Antarctic Ocean. Geophysical Research Letters, 33(12), p. L12606.

van Dongen, B. E., Ashton, N. J., Pattrick, R. A. D. \& Hudson-Edwards, 2014. The formation of ferromanganese nodules in the southwest Indian Ocean; an abiotic process. Mineralogical Magazine, 78(4), pp. 941-955.

van Sebille, E. et al., 2013. Abyssal connections of Antarctic Bottom Water in a Southern Ocean State Estimate. Geophysical Research Letters, 40(10), pp. 2177-2182.

Verducci, M. et al., 2009. The Middle Miocene climatic transition in the Southern Ocean: Evidence of paleoclimatic and hydrographic changes at Kerguelen plateau from planktonic foraminifers and stable isotopes. Palaeogeography, Palaeoclimatology, Palaeoecology, 280(3-4), pp. 371-386.

Verlaan, P., Cronan, D. \& Morgan, C., 2004. A comparative analysis of compositional variations in and between marine ferromanganese nodules and crusts in the South Pacific and their environmental controls. Progress in Oceanography, 63(3), pp. 125-158.

Vineesh, T. C. et al., 2009. Manganese nodule morphology as indicators for oceanic processes in the Central Indian Basin. International Geology Review, 51(1), pp. 27-44.

Vlaste'lic, I., Abouchami, W., Galer, S. J. G. \& Hofmann, A. W., 2001. Geographic control on $\mathrm{Pb}$ isotope distribution and sources in Indian Ocean Fe-Mn deposits. Geochimica et Cosmochimica Acta, 65(23), pp. 4303-4319.

von Blanckenburg, F. et al., 1999. Lateral mixing and advection of reactive isotope tracers in ocean basins: Observations and mechanisms,. Earth and Planetary Science Letters, Volume 169 , p. $113-128$.

von Blanckenburg, F., Bouchez, J. \& Wittmann, H., 2012. Earth surface erosion and weathering from the $10 \mathrm{Be}$ (meteoric)/9Be ratio. Earth and Planetary Science Letters, Volume 351-352, pp. 295-305.

von Blanckenburg, F. \& Nägler, T. F., 2001. Weathering versus circulation-controlled changes in radiogenic isotope tracer composition of the Labrador Sea and North Atlantic Deep Water. Paleoceanography, 16(4), pp. 424-434.

von Blanckenburg, F., O'Nions, R. \& Hein, J., 1996. Distribution and sources of preanthropogenic lead isotopes in deep ocean water from Fe-Mn crusts. Geochimica et Cosmochimica Acta, 60(24), pp. 4957-4963. 
von Blanckenburg, F. et al., 1996. Global distribution of beryllium isotopes in deep ocean water as derived from Fe-Mn crusts. Earth and Planetary Science Letters, 141(1-4), pp. 213226.

von Stackelberg, U., 1984. Significance of benthic organisms for the growth and movement of manganese nodules, Equatorial North Pacific. Geo-Marine Letters, 4(1), pp. 37 - 42.

von Stackelberg, U., 1997. Growth history of manganese nodules and crust of the Peru Basin. In: K. Nicholson, J. Hein, B. Bühn \& S. Dasgupta, eds. Manganese Mineralization: Geochemistry and Mineralogy of Terrestrial and Marine Deposits. London: Geological Society of London: Special Publication, pp. 153-176.

von Stackelberg, U., 2000. Manganese nodules of the Peru Basin. In: Handbook of Marine Mineral Deposits. Boca Raton: CRC Press, p. $197-238$.

von Stackelberg, U., Kunzendorf, H., Marchig, V. \& Gwozdz, R., 1984. Growth history of a large ferromanganese crust from the Equatorial North Pacific Nodule Belt. Geologisches Jahrbuch, Volume 75, pp. 213-235.

VonderHaar, D., Mahoney, J. \& McMurtry, G., 1995. An evaluation of strontium isotopic dating of ferromanganese oxides in a marine hydrogenous ferromanganese crust. Geochimica et Cosmochimica Acta, 59(20), p. 4267-4277.

Walcott, R., 1998. Modes of oblique compression: Late Cenozoic tectonics of the South Island of New Zealand. Rev. Geophys., Volume 36, pp. 1 - 26.

Walton, D. W. H., 2013. Antarctica: Global Science from a Frozen Continent. New York: Cambridge University Press.

Wang, X. \& Müller, W., 2009. Marine biominerals: perspectives and challenges for polymetallic nodules and crusts.. Biotechnol, 27(2), pp. 375 - 383.

Wang, X. et al., 2012. From nanoparticles via microtemplates and milliparticles to deep-sea nodules: biogenically driven mineral formation. Frontiers of Material Science, 6(2), p. 97 115.

Wang, X., Wiens, M. \& Divekar, M., 2010. Isolation and characterization of a Mn(II)oxidising Bacillus strain from the Suberites domuncula. Marine Drugs, 9(1), p. 1 - 28.

Warren, B. A., 1971. Antarctic deep water contribution to the world ocean. In: L. O. Quam, ed. Research in the Antarctic. Washington, D. C.: American Association for the Advancement of Science, pp. 631-643. 
Warren, B. A., 1973. Transpacific hydrographic sections at latitudes $43^{\circ} \mathrm{S}$ and $28^{\circ} \mathrm{S}$ : the SCORPIO expedition-II. deep water. Deep Sea Research and Oceanographic Abstracts, 20(1), pp. 9-38.

Warren, B. A., 1981. Deep circulation of the world ocean. In: B. Warren \& C. Wunsch, eds. Evolution of physical oceanography. Cambridge, MA: MIT Press, pp. 6 - 41.

Watkins, N. \& Kennett, J., 1977. Erosion of Deep-Sea Sediments in the Southern Ocean Between Longitudes $70^{\circ} \mathrm{E}$ and $190^{\circ} \mathrm{E}$ and Contrasts in Manganese Nodule Development. Developments in Sedimentology, 23(1), pp. 103 - 111.

Weber, M. et al., 2000. Variability of surface sediments in the Peru basin: dependence on water depth, productivity, bottom water flow, and seafloor topography. Marine Geology, 163(1-4), pp. 169 - 184.

Weedon, G. \& Hall, I. R., 2004. Neogene palaeoceanography of Chatham Rise (Southwest Pacific) based on sediment geochemistry. Marine Geology, 205(1-4), pp. 207-225.

Weijer, W. et al., 2012. The Southern Ocean and its climate in CCSM4. Journal of Climate, 25(8), pp. 2652-2675.

Weiner, E. R., 2012. Applications of Environmental Aquatic Chemistry: A Practical Guide, Third Edition. Boca Raton, Florida: CRC Press.

Wen, X., De Carlo, E. H. \& Li, Y.-H., 1997. Interelement relationships in ferromanganese crusts from the central Pacific ocean: Their implications for crust genesis. Marine Geology, 136(3-4), pp. $277-297$.

Whitworth III, T. et al., 1985. Water masses and mixing near the Antarctic Slope Front. In: S. S. Jacobs \& R. F. Weiss, eds. Ocean, Ice, and Atmosphere: Interactions at the Antarctic Continental Margin. Washington, D. C.: American Geophysical Union:Antarctic Research Series, pp. 1-27.

Whitworth III, T. \& Peterson, R., 1985. Volume transport of the Antarctic Circumpolar Current from bottom pressure measurements. Journal of Physical Oceanography, 15(6), pp. 810-816.

Whitworth III, T. et al., 1999. On the deep western-boundary current in the Southwest Pacific Basin. Progress in Oceanography, 43(1), pp. 1-54.

Willenbring, J. \& von Blanckenburg, F., 2010. Long-term stability of global erosion rates and weathering during late-Cenozoic cooling. Nature, Volume 465, pp. 211 - 214. 
Williams, P., 1991. Tectonic geomorphology, uplift rates and geomorphic response in New Zealand.. Catena, Volume 18, p. 439 - 452.

Winkler, A. \& Dullo, W., 2003. Eocene to Pleistocene sedimentation patterns on Chatham Rise, New Zealand.. In: R. Carter, I. McCave \& L. Carter, eds. Proceedings of Ocean Drilling Programe Scientific Results 181 . College Station, Texas: Ocean Drilling Programe, pp. (CDROM and http:odp.tamu.edu/publications/181IR).

Winter, B. et al., 1997. Geochemical constraints on the formation of Late Cenozoic ferromanganese nodules from the Central Arctic Ocean. Marine Geology, Volume 138, pp. 149-169.

Wise, S. W. J., 2000. The Antarctic Ice Sheet: Rise and Demise?. Journal of Land Use \& Environmental Law, Volume 15, pp. 383-412.

Wolf, K. H., 1981. Handbook of Strata-Bound and Stratiform Ore Deposits. Amsterdam: Elsevier.

Woodruff, F. \& Savin, S., 1991. Mid-Miocene isotope stratigraphy in the deep-sea: high resolution correlations, paleoclimatic cycles, and sediment preservation.. Paleoceanography, Volume 6, p. 755 - 806.

Woodruff, F. \& Savin, S. M., 1989. Miocene deepwater oceanography. Paleoceanography, 4(1), pp. 87-140.

Wright, I. C. et al., 2005. Occurrence and physical setting of ferromanganese nodules beneath the Deep Western Boundary Current, Southwest Pacific Ocean. New Zealand Journal of Geology and Geophysics, 48(1), pp. 27-41.

Wright, J. D., Miller, K. G. \& Fairbanks, R. G., 1991. Evolution of Modern Deepwater Circulation: Evidence from the Late Miocene Southern Ocean. Paleoceanography, 6(2), pp. $275-290$.

Wright, J. \& Miller, K., 1996. Control of North Atlantic Deep Water circulation by the Greenland-Scotland Ridge. Paleoceanography, 11(2), pp. 157-170.

Wu, J. et al., 2010. Isotopic evidence for the source of lead in the North Pacific abyssal water. Geochim. Cosmochim. Acta, Volume 74, p. 4629 - 4638.

Wunsch, 2003. Determining paleoceanographic circulations, with emphasis on the Last Glacial Maximum. Quaternary Science Reviews, Volume 22, pp. 371-385. 
Xu, Z., Li, A., Jiang, F. \& Li, T., 2006. Paleoenvironments recorded in a new-type ferromanganese crust from the East Philippine Sea. Journal of China University of Geosciences, $17(1)$, p. $34-42$.

Yli-Hemminkia, P., Jørgensena, K. S. \& Lehtoranta, J., 2014. Iron-Manganese Concretions Sustaining Microbial Life in the Baltic Sea: The Structure of the Bacterial Community and Enrichments in Metal-Oxidizing Conditions. Geomicrobiology Journal , 31(4), pp. 263-275.

Zachos, J., Breza, J. \& Wise, S., 1992. Early Oligocene ice-sheet expansion on Antarctica: Stable isotope and sedimentological evidence from Kerguelen Plateau, southern Indian Ocean. Geology, 20(6), pp. 569-573.

Zachos, J. et al., 2001. Trends, Rhythms, and Aberrations in Global Climate $65 \mathrm{Ma}$ to Present. Science, 292(5517), pp. 686 - 693.

Zhang, J., Amakawa, H. \& Nozaki, Y., 1994. The comparative behaviors of yttrium and lanthanides in the seawater of the North Pacific. Geophysical Research Letters, 21(24), p. 2677 -2680 .

Zhang, J. \& Nozaki, Y., 1996. Rare earth elements and yttrium in seawater: ICP-MS determinations in the East Caroline, Coral Sea, and South Fiji basins of the western South Pacific Ocean. Geochimica et Cosmochimica Acta, 60(23), p. 4631 - 4644.

Zhang, J. \& Nozaki, Y., 1998. Behavior of rare earth elements in seawater at the ocean margin: a study along the slopes of the Sagami and Nankai troughs near Japan. Geochimica et Cosmochimica Acta, 62(8), p. 1307 - 1317.

Zhang, Z. et al., 2013. Growth of a polymetallic nodule from the northwestern continental margin of the South China Sea and its response to changes in the paleoceanographical environment of the Late Cenozoic. Science China Earth Sciences, 56(3), pp. 453-463.

Zhang, Z., Nisancioglu, K. H. \& Ninnemann, U. S., 2012. Increased ventilation of Antarctic deep water during the warm mid-Pliocene. Nature Communications, 4(1499), pp. 1-6.

Zhao, Y., Vance, D., Abouchami, W. \& de Baar, H. J. W., 2014. Biogeochemical cycling of zinc and its isotopes in the Southern Ocean. Geochimica et Cosmochimica Acta, Volume 125, pp. 653-672.

Zhou, L. \& Kyte, F., 1992. Sedimentation history of the south Pacific pelagic clay province over the last 85 million years inferred from the geochemistry of Deep Sea Drilling Project Hole 596. Paleoceanography, Volume 7, p. $441-465$. 


\section{Appendix}

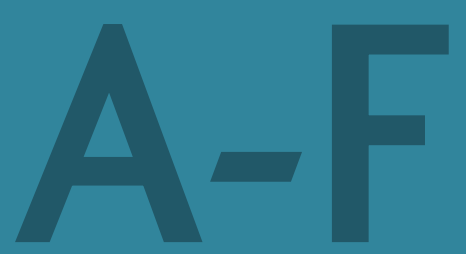

Appendices A-F are available on the accompanying

\section{CD-ROM}

\section{Appendices}

Available on accompanying CD-ROM
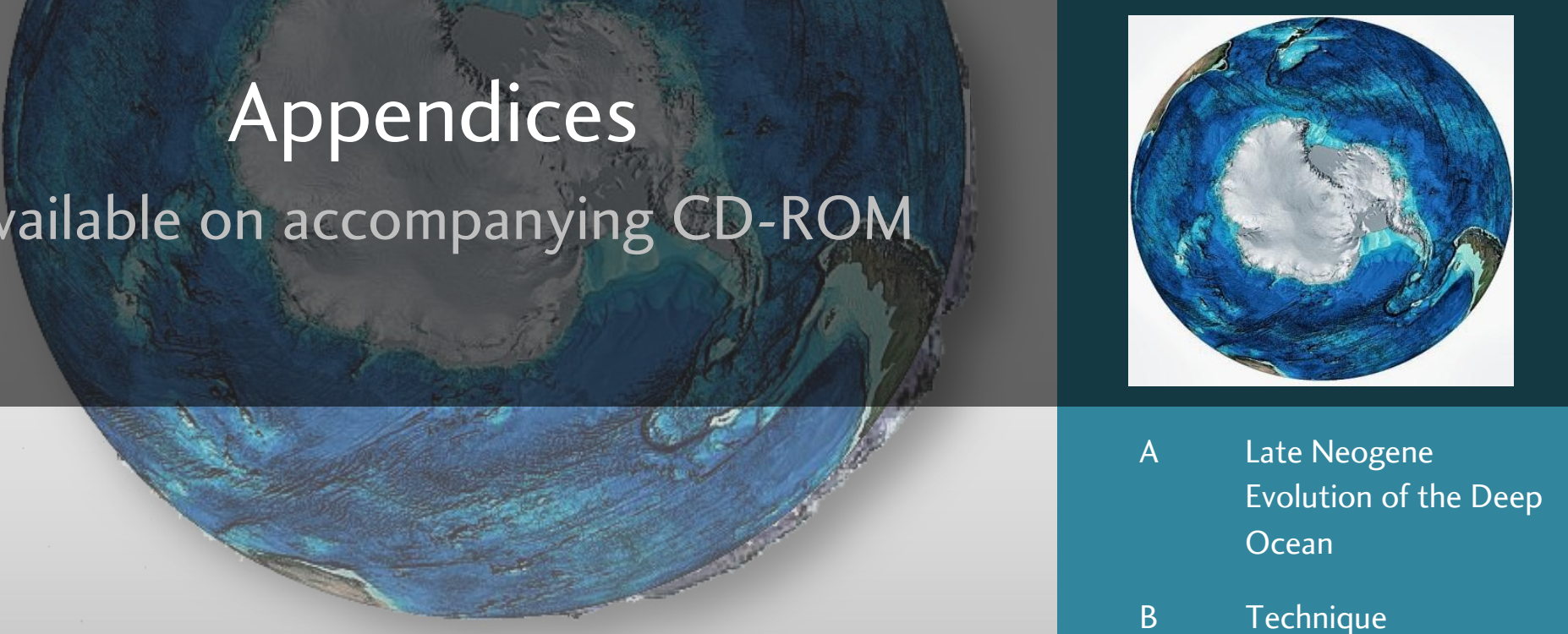

A Late Neogene Evolution of the Deep Ocean

B Technique

Development

C Beryllium and Cobalt Chronologies \& Growth Rates

L Lead Isotope
Chemistry

E Multi-Element Chemistry

F $\quad$ Multi-Element \& Lead Isotope Chemistry of FMN U1365B-M 
